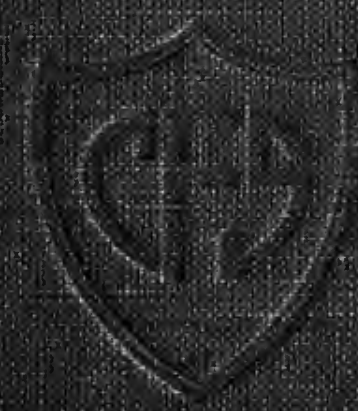




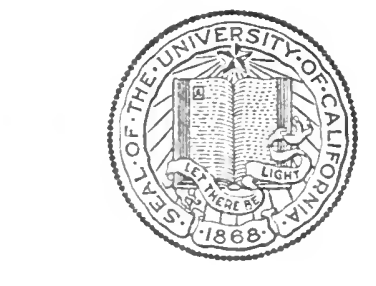

\section{UNIVERSITY \\ OF CALIFORNIA \\ LOS ANGELES}

SCHOOL OF LAW

LIBRARY

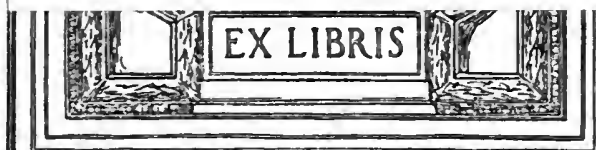

Adler Iibrary

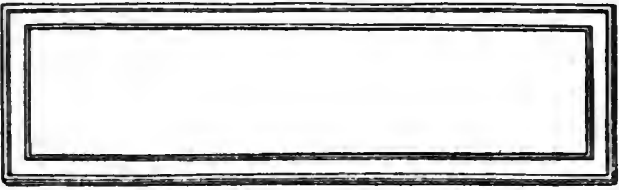





\section{Digitized by the Internet Archive in 2007 with funding from Microsoft Corporation}


CRIMINAL JUSTICE IN

CLEVELAND 


\title{
THE CLEVELAND FOUNDATION
}

\author{
COMMITTEE \\ J. D. Williamson, Chairman \\ Thomas L. Johnson \\ Malcolm L. McBride \\ W. H. Prescott \\ Belle Sherwin \\ Leonard P. Ayres, Secretary \\ James R. Garfield, Counsel \\ Raymond Moley, Director \\ THE SURVEY OF CRIMINAL JUSTICE \\ $\left.\begin{array}{l}\text { Roscoe Pound } \\ \text { Felix Frankfurter }\end{array}\right\}$ Directors \\ Amos Burt Thompson, Chairman of the \\ Advisory Committee
}



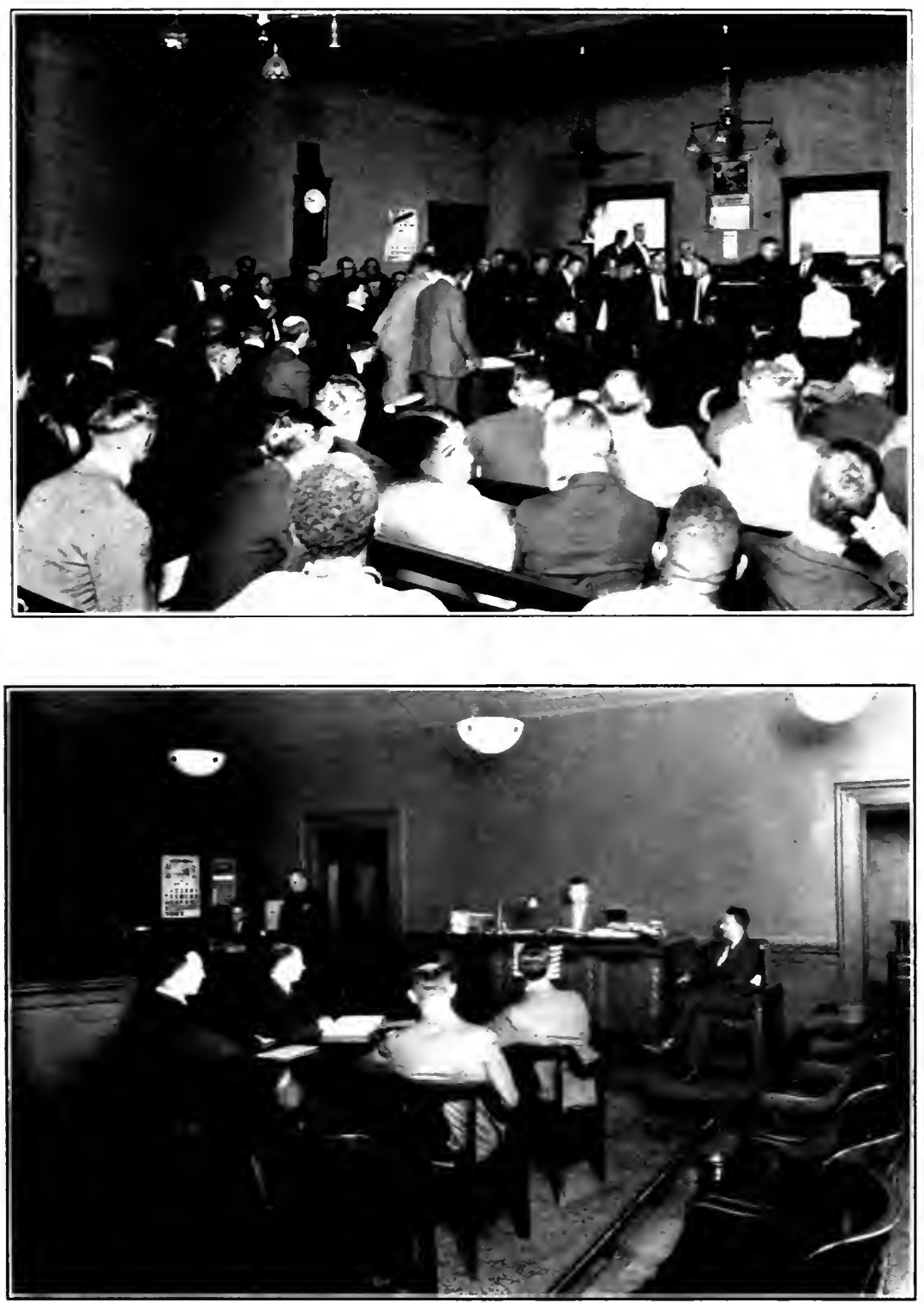

Contrast the order and dignity of the civil division of the Municipal Cont with the confusion of the criminal division or "police court." "The upper picture is a fashlight of a Monday morning arowd in the criminal division. 


\title{
CRIMINAL JUSTICE IN CLEVELAND
}

\author{
REPORTS OF
}

THE CLEVELAND FOUNDATION SURVEY OF THE ADMINISTRATION OF CRIMINAL JUSTICE IN CLEVELAND, OHIO

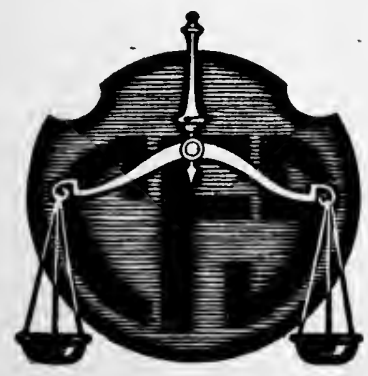

\section{By}

RAYMond FosDick

Reginald Heber Smith and Herbert B. Ehrmann

Alfred Bettman and Howard F. Burns BuRdette G. LEwis

Dr. Herman M. Aduer

Albert M. Kales

M. K. Wisehart

Feuix Frankfurter and Roscoe Pound

DIRECTED AND EDITED BY

ROSCOE POUND and FELIX FRANKFURTER

THE CLEVELAND FOUNDATION

CLEVELAND, OHIO 


\section{$\frac{-1}{1}$ \\ $C 5995$ c \\ 1922}

Coprriati, 1922, BY

The Cleveland Foundation

PRINTED IN THE CNITED gTATES

OF AMEUICA BY

WM. F. FEIL CO., PRINTERS

PHILADELPHIA

ü 


\section{PREFACE}

7 HIS book embodies the results of a scientific study of the present system of criminal justice in Cleveland, Ohio. The inquiry had two aims: first, to render an accounting of the functioning of this system, to the fullest extent that social institutions are as yet adapted to statistical appraisal; and, second, to trace to their controlling sources whatever defects in the system the inquiry disclosed. The Cleveland Foundation thus adds another to its series of fundamental studies of Cleveland's social life. Thus far this series has consisted of studies of the educational and recreational needs of the city and the city's response to these needs. The present study is, perhaps, the outcome of an even more fundamental effort at self-criticism.

For some time previous to this survey Cleveland had been restive under a growing feeling of insecurity of life and property. The fifth largest city in the country entertained a wide-spread conviction of its failure in the most primitive function of government. In the spring of 1920 this feeling was brought to a head. An atrocious and sordid crime, implicating the chief judge of the city's municipal courts, stirred to action dormant civic pride. With rare self-restraint and self-knowledge the leaders of the community realized that the city had the feeling, but not the understanding, for action. They had the insight to realize that this sensational case was but symptomatic of deeper causes. In a word, a problem in social sanitation and social engineering was presented. Therefore, in the winter of 1920 , a number of civic organizations, headed by the Cleveland Bar Association, requested the Cleveland Foundation to undertake a survey of the administration of criminal justice in Cleveland.

Doubtless, to a considerable extent, the survey proved what was already suspected by many and known to a few. The point is that the survey proved it. Instead of speculation, we have demonstration. Now, one ventures to say, there is no possible excuse for a citizen of Cleveland not knowing the shortcomings of the system, and the indispensable conditions for their correction. The system is judged not by the occasional dramatic case, but by its normal, humdrum operations. 
In order to ascertain how law functions as a daily instrument of the city's life a quantitative basis for judgment is essential. ${ }^{3}$

On the other hand, early in the investigation it became plain that the system of criminal justice had some of its roots deep in the whole social and spiritual life of the city. The sources of opinion and of education and the very social ideals of the community all bear their important share in that manifestation of its social life which we call criminal justice. Here we are confronted with a choice of social standards which cannot be statistically established. But here, too, we must work in the light of experience, and with that objective habit of mind which we call the scientific spirit.

The nation-wide response to "Main Street" indicates that every town, whether large or small, is in part a Gopher Prairie. These surface uniformities of our American cities must not be allowed to obscure their diversities. For every little Main Street, as every big Main Street, is also unique. And this uniqueness is significant, or must be made significant, if American life is to have distinction and depth. It is necessary to emphasize this truth in applying the Cleveland survey to other cities. Specific impulses gave birth to this survey; it was conditioned by the specific problems presented by Cleveland-its traditions, its rate of growth, its racial composition, its politics, its press, its bar. Not only was the study thus defined by the environment out of which it grew and in which it was moving, but in some aspects this was a pioneer study and had to improvise its own technique and procedure. These local limitations and empiric efforts debar blind imitation of this survey by other communities. In any city a survey of its administration of criminal justice must grow out of its own needs and be guided by its own individuality.

Nevertheless, the most outstanding features of criminal justice in Cleveland, namely, the practical breakdown of criminal machinery, has its parallel in other cities. The deep-seated causes for this conditionrooted, as they are, in modern industrialism and in the prevalent standards of the community, which turn into a menace the early American machinery and methods of law enforcement-will be found in other cities throughout the country, as the survey found them in Cleveland. In view of the fact that the problem and its causes are common to many

1 Therefore special attention is directed to the statistical basis of this study. The statistical method is set forth in an appendix by Professor C. E. Gehlke, of Western Reserve University. To his resourcefulness and talent for adapting statistical methods to a new field of social inquiry the working out of the technique here used is largely due. 
American cities, it may be pertinent to summarize the broad principles upon which the Cleveland survey was planned and executed.

1. Impersonal Aims.-From the outset it was insisted that presentday machinery and methods are largely the heritage of conditions which have fundamentally changed. The problem is more comprehensive and its elements more manifold than the good-man-bad-man explanation of political phenomena assumes. Personalities, of course, play their part, but a relatively small part. The task is that of diagnosing the causes of a system whose origins must be traced back to social, economic, and political conditions distant in time and different from the present, and whose consequences cannot be understood apart from the civic standards and economic preoccupations of today. "Head-hunting" was from the first disavowed. The search for causes rather than for victims had repeatedly to be insisted upon as the only aim of the survey, for blame of someone in office, or of the "boss" behind the scenes, is the natural, uncritical desire of people and of the press, which stimulates that desire. A personal victim for a complex community failure satisfies the sense of the dramatic, at the same time that it affords the luxury of vicarious punishment. But where the whole system of criminal justice has broken down under the weight imposed upon it by in' dustrial urban life, the trail of authentic and thorough diagnosis must not be diverted from essential causes to occasional officials who exploit these causes.

2. Scientific and Professional Direction.-To resist effectively the local demand for "head-hunting" requires disinterested, scientific direction of the survey. In Cleveland the survey was in the hands of men whose professional interest is the scientific administration of justice adapted to modern industrial conditions. Theirs was the final authority and theirs the responsibility. Only thus can it be insured that relevant factors are neither avoided nor their analysis withheld, nor, on the other hand, exploited to serve any interest other than truth-finding.

3. Non-Resident Investigators.-A disinterested and impersonal investigation also means that the investigators in charge of different divisions of the inquiry must be non-residents. Only thus can the subtle and often unconscious forces of fear and favor be wholly avoided. The Cleveland investigators were wholly indifferent to all Cleveland personalia. Neither past entanglements nor future embarrassments influenced in the slightest the scope of the inquiry or its thorough pursuit.

4. Local Advisory Coopperation.-While outsiders must direct and investigate, they must work with the forces of the community. Wholly apart from the necessity of full and easy access to the local material, 
it is indispensable to check up and interpret the record data, the statistical material, by intimate city traditions. Such a survey deals with social phenomena, and statistics are, in part, meaningless without human illumination. From the start the Cleveland investigation was greatly aided by an advisory committee representative of the manifold interests of the city. This survey could not have been made without the unstinted devotion, the civic influence, the professional equipment of $\mathrm{Mr}$. Amos Burt Thompson, the Chairman of the Advisory Committee. But such a committee must be strictly advisory. It cannot be too often repeated that the responsibility for the scope of such an inquiry and for its results must rest solely with the directors of the survey. Not the least of Mr. Thompson's services was his fastidious loyalty to this principle.

5. Indifference to "Quick Results."-Since the aim of such a study is strictly scientific, all exigent considerations, such as specific quick results or the effect on a forthcoming election, are irrelevant and destructive. The effort must be wholly concentrated on accurate investigation, significant interpretation, and fruitful suggestion. Of course, at bottom all such surveys are successful to the extent that they serve as means for the education of the community; and the press is undoubtedly the most important single instrument of civic education. But this consideration comes into play after the survey is completed, not while it proceeds. The newspapers must not be fed with hopes or hints. Nor must the progress of the inquiry be influenced in the slightest by the impatience, or the indifference, or the criticism of the press. If the survey finally produces a searching diagnosis, the newspapers will not be able, nor will they want, to neglect it.

6. Checks Against Inaccuracy.-There ought to be no question as to the accuracy of the facts upon which judgments or recommendations are based. The material for opinion ought to be indisputable. Therefore, before the results of the survey were published, they were thoroughly thrashed out with the Advisory Committee, and then submitted for comment to the officials administering the respective departments under investigation. ${ }^{1}$ There is thus furnished an authentic and agreed analysis of the facts, leaving for discussion the relatively narrow field of the inferences that flow from the facts and the changes which they suggest.

These, briefly, were the general principles which guided the planning and the execution of the Cleveland survey, always bearing in mind that

1 Except where the officials themselves preferred not to consider the findings. [ viii] 
the dominant factors were the scientific aim and the disinterested, professional devotion of the investigators. Thus far the work is that of outsiders-and there is little they can do beyond. The rest is with the community-but the rest is everything. First comes publication of the results of the survey through public meetings, pamphlets, press, and book; and then a sustained educational campaign to translate the results of the inquiry into a new civic outlook-a deeper understanding of the exactions of democracy, and of the fashioning of machinery and methods adequate to modern needs and equipped for self-appraisal.

A community which expects quick results or panaceas is doomed to disappointment. So much of our "reform" effort does not stay "put" because the aim is to "put things over." The complexities of an industrial democracy cannot be solved by the psychology of advertising. The starting-point of reform is the education of the public to the necessity of a sustained interest. The conditions disclosed by this survey-and the recent Massachusetts revelations show that no community can throw the first stone-can be rectified only if the community is aroused to the necessary persistent, unostentatious, detailed effort. That will come if the community cares-or if only a small part of it cares hard enough. At best, however, the task is one in which time is a necessary element and continuity of effort indispensable.

An investigation like the Cleveland survey is, of course, dependent upon the willing and effective coöperation of a host of individuals, official and private, and of many organizations. Where help has been so wide-spread and so generous it would be invidious to single out a few for special mention. This survey represents a collective effort of the community, and to the community grateful acknowledgment is made.

Felix Frankfurter. 


\section{TABLE OF CONTENTS}

Preface, by Feuix Frankfurter

PAGE

List of Tableg

List of Diagrams

$\mathrm{xxV}$

List of ILLUSTRATIONS

xxvii

\section{PART I.-POLICE ADMINISTRATION}

CHAPTER

By Raymond B. Fosdick

I. The Problem

PAGE

II. Present Conditions

III. The Organization of the Force

Scope of the Police Survey 11

The Problem of Administration 12

The Machinery of Police Administration in Cleveland 12

$\begin{array}{ll}\text { Recommendations } & 16\end{array}$

IV. Provision of Personnel-Its Selection and Training 24

Previous Occupation $\quad 24$

Age of Appointees $\quad 26$

Turnover in the Patrol Force $\quad 28$

Civil Service as a Source of Recruits 33

Police Training School 34

V. Promotion $\quad 36$

The System of Promotion 36

Limitations and Defects of the System 38

Recommendations $\quad 42$

VI. Discrpuins $\quad 45$

Record of Formal Disciplinary Actions $\quad 47$

Appeals $\quad 49$

Recommendations 53

VII. Uniform Patrol Service $\quad 55$

Number of Policemen Needed $\quad 57$

Methods of Patrol $\quad 59$

Patrol Booths $\quad 61$

Precinct Stations $\quad 62$

$\begin{array}{ll}\text { Recommendations } & 63\end{array}$

VIII. The Detective Bureau $\quad 64$

Poor Quality of Detectives $\quad 66$

Poor Work of Detective Bureau $\quad 69$

Inadequate Supervision of Detective Work $\quad 70$

$\begin{array}{ll}\text { Recommendations } & 71\end{array}$ 
IX. Special Service Division $\quad \mathbf{7 5}$

Other Crime Prevention Units Needed $\quad 77$

$\begin{array}{lr}\text { X. The Secretarial Division } & 81\end{array}$

\section{PART II.-PROSECUTION}

By Alfred Bettuan, assisted by Howard F. Burns

I. The Place of Prosecution in Criminal Jugtice 85

Some Fundamental Assumptions $\quad 85$

The System in Outline $\quad 86$

Prime Importance of Municipal Court and Prosecutor $\quad 87$

II. Case Mortality $\quad 89$

The Story Told by Statistics $\quad 89$

The Mortality Tables 91

What Becomes of the Felony Cases 93

III. The Municipal Court in Operation 97

Large Number of Cases; Unclassified Dockets; Excessive Speed 110

Negative Part Played by Prosecutor 114

No Stenographic Reports-Opportunities for Perjury 116

IV. The Municipal Prosecutor's Office 117

$\begin{array}{ll}\text { History } & 117\end{array}$

Office Organization 118

Laxity in Custody of Affidavits $\quad 119$

Record System $\quad 120$

Personnel 132

V. Operation of the Municipal Prosecutor's Office 135

The Affidavit $\quad 135$

Sifting of Cases $\quad 136$

County Prosecutor Does Not Participate in Early Stages of Case 138

Cases in Appellate Courts $\quad 139$

Statistics of Results of Cases $\quad 140$

Dispositions Without Trial $\quad 142$

"No Papers" or "No-papering" 143

Nolles 144

Acceptance of Pleas of Lesser Offense $\quad 149$

Suspension of Sentences $\quad 150$

Mitigation of Sentences 153

The Bail Bond $\quad 154$

Hours of Work; Private Practice 156

VI. The County Prosecutor's Ofrice 159

History 159

Criminal Court in Operation $\quad 160$

Office Organization $\quad 163$

Record System $\quad 164$

Personnel 165

ViI. Operation of the County Prosecutor's Office 169

Preparation of Cases $\quad 169$

Assignment of Cases $\quad 175$

The Grand Jury 175 
Statistics of Results of Cases

"No-billed" Cases

Nolles and Acceptances of Pleas of Lesser Offenses 180

Suspension of Sentences

The Bail Bond

Forfeited Bonds

Cases in the Appellate Court

VIII. The Federal Court and United States Attorney 188

Comparison is Possible 188

IX. The Lessons and the Remedies 192

General Considerations 192

The Municipal Prosecutors 194

The County Prosecutor 197

Municipal Court Procedure 198

The Segregation of Trials or Calendars 199

Arrest and Summons 202

Stenographic Report of Testimony 203

General Aspect of the Trials 204

Record Systems in Municipal Court and Prosecutor's Office 205

Disposition of Cases by the Prosecutor Himself 205

Conciliation by the Prosecutor 206

"No Papers" 207

Nolles $\quad 207$

"No Bills" 207

Acceptance of Lesser Pleas 208

Suspension and Mitigation of Sentences 208

The Preparation of Cases 208

The Grand Jury 210

Simplification of the Bail Bond System $\quad 212$

The Place Where Criminal Justice is Administered 213

Salaries, Terms, and Selection of Personnel 214

X. The Bar and the Community 216

The Bar $\quad 216$

Criminal Practice and the Bar 218

The Duty and Responsibility of the Bar 219

The Community 222

\section{PART III.-THE CRIMINAL COURTS}

By Reginald Heber Smith and Herbert B. Ehrmany

I. The Fundamental Trouble

II. Structure of the Present System 231

III. The Srstem in Practice 233

Influences Evoked by Arrests 233

The Professional Criminal Lawyer 233

Too Many Steps in the Procedure of Justice 234

How the System is "Worked" for Weak Spots 238

What Steps may be Eliminated 246

Results of Unified Court in Detroit 248 
IV. The Bench and its Backgrodnd 251

Importance of the Bench $\quad 251$

$\begin{array}{ll}\text { Personnel } & 251\end{array}$

Recent Changes in the Election Laws 253

Apparent Effects of these Changes $\quad 254$

$\begin{array}{ll}\text { The Underlying Cause for Dissatisfaction } & 259\end{array}$

$\begin{array}{ll}\text { Importance of the Petty Politician } & 261\end{array}$

The Influence of Groups $\quad 263$

1. Racial and Religious Appeal 263

2. Labor Organizations $\quad 264$

3. Bar Association and the Civic League 265

$\begin{array}{ll}\text { Publicity } & 268\end{array}$

1. Self-Advertisement $\quad \cdot \quad 269$

2. Exploitation of the Police Court 271

3. Character of the News $\quad 273$

4. Campaign Funds $\quad 273$

$\begin{array}{ll}\text { Recommendations } & \mathbf{2 7 3}\end{array}$

1. Appointed and Elected Judges 274

2. The Use of Vacancies $\quad 276$

3. Selection in the Usual Course 276

4. Joint Committee on the Judiciary 277

V. Tae Municipal Court $\quad 278$

$\begin{array}{ll}\text { Physical Conditions } & 278\end{array}$

$\begin{array}{lr}\text { Decorum } & 279\end{array}$

Separate Sessions Recommended $\quad 280$

Shifting Cases from One Judge to Another $\quad 280$

Scant Attention to Individual Cases $\quad 282$

Bad Effects of Many Continuances $\quad 282$

The "Motion in Mitigation" 285

The "Police Court Ring" 286

Bail Bonds $\quad 290$

The Clerk's Office $\quad 292$

Recommendations 295

VI. The Common Pleas Court $\quad 297$

History and Jurisdiction $\quad 297$

$\begin{array}{ll}\text { Physical Conditions } & 297\end{array}$

$\begin{array}{ll}\text { Decorum } & 298\end{array}$

Terms of the Court 298

Lack of an Executive Head $\quad 299$

"Loafing Judges" 299

Fluctuating Policies $\quad 303$

Inability to Use Personnel to Best Advantage 304

$\begin{array}{ll}\text { Assigned Counsel } & \mathbf{3 1 0}\end{array}$

Bail Bonds $\quad 313$

The Clerk's Office $\quad 314$

The Assignment Commissioner $\quad 315$

$\begin{array}{ll}\text { Recommendations } & 316\end{array}$ 
VII. The Court of Appeals

History and Jurisdiction $\quad 317$

$\begin{array}{ll}\text { Dispatch of Business } & 318\end{array}$

Results of Appealed Cases $\quad 318$

Failure of Clerk's Office to Act Promptly $\quad 319$

Bail Bonds Pending Error $\quad 320$

$\begin{array}{ll}\text { Recommendations } & 320\end{array}$

VIII. Sugpenden Sentences, "Nolles," and Pleas of Guilty to Lesser OFFense

Police and Prosecutors not Best Advisers to the Court 323

Public Clamor Followed

323

Cases "Paroled" in January, 1917

Paroling in the Dark 326

"Nolling" Cases 328

Recommendations $\quad 329$

1. Preliminary Suggestions $\quad 329$

2. An Adequate Probation Department 330

3. A Central Bureau of Information 331

IX. Motions for New Trial 332

$\begin{array}{ll}\text { Frequency } & 332\end{array}$

Analysis of Results 333

Clear Policy Recommended $\quad 336$

X. Perudry 337

Meaning of the McGannon Trial 337

Laxness in Punishing Offenses Against Justice 338

$\begin{array}{ll}\text { Recommendations } & 339\end{array}$

XI. JURIES $\quad 340$

General Dissatisfaction $\quad 340$

History $\quad 340$

The Present System $\quad 341$

$\begin{array}{ll}\text { Weaknesses } & 343\end{array}$

First Examination of Jurors $\quad 344$

Second Examination of Jurors 348

Occupation of Jurors $\quad 349$

Haven of the Unemployed $\quad 352$

Recommendations 353

XII. SUMmary of Recommendations

Organization and System $\quad 354$

Personnel: Elections $\quad 356$

The Defects and Evils in the Present System 357

Disrespect for Law $\quad 357$

Evils in Organization $\quad 359$

Personnel: Politics 362

Suggestions and Recommendations 363

As to Personnel $\quad 364$

As to Organization $\quad 366$

Civic Responsibility $\quad 371$ 
PART IV.-CORRECTIONAL AND PENAL TREATMENT

CHAPTER

By BurdetTe G. Lewis

I. Penal Institutions for Adults

PAGE

The Department of Public Welfare

375

Recommendations

375

The City Jail and Central Police Headquarters

Recommendations

The Warrensville Workhouse $\quad 380$

Recommendations $\quad 385$

The County Jail 386

Recommendations $\quad 388$

II. Correctional Agencies for Minors 389

The Juvenile Court $\quad 389$

Administrative Shortcomings $\quad 395$

Investigations $\quad 396$

General Criticism $\quad 397$

Summary of Recommendations $\quad 398$

The Detention Home $\quad 400$

Recommendations $\quad 403$

The Boys' School $\quad 403$

Recommendations $\quad 405$

The Cleveland Boys' Farm at Hudson $\quad 406$

Recommendations $\quad 409$

The Girls' Home at Warrensville $\quad 409$

Recommendations $\quad 410$

III. Probation 4412

Recommendations $\quad 420$

IV. Paroles, Commutations, and Pardons 422

Administration 423

Recommendations 430

V. The Proposed New Criminal Court, County Jail, and Police HeadQUARTERs BUILDing 431

Recommendations $\quad 434$

\section{PART V.-MEDICAL SCIENCE AND CRIMINAL JUSTICE}

By Herman M. Adeer, M.D.

I. Psychiatry and Crime

II. Juvenile Behavior Problems 441

The Need for Mental Health Stations 441

The Juvenile Behavior Problem in the Schools 443

Recommendations $\quad 444$

The Juvenile Behavior Problem in the Courts 445

Recommendations $\quad 446$

III. The Adult Criminal $\quad 447$

Progress of Mental Examination $\quad 447$

The Nature of Mental Examinations 448 
Criminal Detection by the Police

1. Departmental Health Work

2. Public Health Problems

3. Examination of Suspects and Prisoners

Recommendations

457

Crime Detection by the Coroner's Office

1. Relation to Police

463

2. Relation to Courts

464

3. Relation to Prosecutors

465

4. Relation to the Bar

465

5. Relation to the Medical Profession

465

6. Administrative Relations

465

7. Equipment

466

8. Death Records

467

9. Cost of Administration 468

10. The Remedy

468

Recommendations

473

Prosecution

474

Adjudication

474

1. Municipal Court

474

2. Common Pleas Court

475

3. Probate Court

476

Recommendations

IV. Prevention

Early Detection of Special Cases

Public Information and Education

Research

483

Training of Workers and Experts

484

Recommendations

\section{PART VI.-LEGAL EDUCATION IN CLEVELAND}

By Albert M. Kales

State Requirements and Local Facilities

The Law School of Western Reserve University

The Cleveland Law School

Faculty and Curriculum

The John Marghall Law School

Faculty and Curriculum

Hours of Teaching in Law Schools in Cleveland 


\section{PART VII.-NEWSPAPERS AND CRIMINAL JUSTICE}

CHAPTER

By M. K. Wiserart

I. Stgmary

PAGE

515

517

518

520

521

525

527

528

528

533

540

544

544

544

548

551

\section{PART VIII.-CRIMINAL JUSTICE AND THE AMERICAN CITY} By Roscoe Pound

I. The Nature of the Problem

Men, Machinery, and Environment

The Function of Law

Difficulties Involved in the Administration of Justice

II. Inherent Difficulties

Dissatisfaction with the Administration of Justice

Inherent Difficulties in All Justice According to Law

1. Mechanical Operation of Legal Rules

2. Difference in Rate of Progress Between Law and Public Opinion

3. Popular Underestimation of the Difficulties in Administering Justice

4. Popular Impatience of Restraint

5. Inherent Limitations on Effective Legal Action

1. Public Desire for Vengeance

2. A Condition of Internal Opposition in Criminal Law Due to Historical Causes

3. The Close Connection of Criminal Law and Administration with Politics

4. The Inherent Unreliability of Evidence in Criminal Cases

5. The Wider Scope for Administrative Discretion Required in Criminal Law

6. Inherent Inadequacy of Penal Methods

7. The Tendency to Put Too Great a Burden on the Criminal Law 
Prevalence of Dissatisfaction with Criminal Law and Its Administration

New Demands Upon Law

1. The Problem of Enforcement

2. The Demand for Concrete Justice

3. The Demand for Individualization

Changed Ideas as to the End of Criminal Law

1. The Passing of the Retributive Theory

2. Increased Regard for Human Personality

3. New Developments in Psychology and Psychopathology

The Present Condition of Criminal Law

Conditions for Which American Criminal Law and Procedure Were Shaped

The Administration of Criminal Justice in the First Half of the Nineteenth Century

1. The Criminals and Conditions of Crime

2. Administrative Machinery .

592

3. English Criminal Law at the Revolution

4. English Criminal Procedure at the Revolution

5. The System of Courts at the Revolution

6. The Bench at the Revolution and in the Nineteenth Century

7. The Bar At and After the Revolution

8. Penal Treatment at the End of the Eighteenth Century

1. Reshaping of the Substantive Criminal Law

2. Organization of the Administration of Justice 607

i. Unification of Courts 607

ii. Organization of the Prosecuting System 608

iii. Organization of Administrative Agencies 608

3. Adequate Provision for Petty Prosecutions 609

4. Preventive Methods

5. Justice in Family Relations

610

6. Unshackling of Administration 611

State and City

612

V. Local AND Temporary Difficulties $\quad 613$

Exceptionally Rapid Growth $\quad 613$

Instability of the Industrial Population $\quad 613$

Post-War Conditions $\quad 614$

VI. Police

IX. The Bar

$\begin{array}{ll}\text { X. Penal Treatment and Correctional Institutions } & 643 \\ \text { XI. The Utilizing of Medical Science } & 646\end{array}$

XII. General Conclusions 


\section{APPENDICES}

APPENDIX

I. The History of the Survey, by Raymond Moley

II. The Statistical Material and Methods of the Survey, by C. E. Gehlke

III. The Norwood Bill

IV. Pardons in Ohio, a Study of the Pardoning Power as Exercised by the Governor of Ohio, Applying to the State Penitentiary, by the Ohio Institute for Public Efficiency

V. Report of Intelligence Survey of the Cleveland Police Department, by E. K. Wickman

VI. Intelligence Survey of the Cleveland Workhouse, by E. K. Wickman

VII. Text of the Massachusetts Medical Examiner Law

VIII. Text of the New York Medical Examiner Law

IX. Bibliography, by Edward B. Adams 


\section{LIST OF TABLES}

\section{PART I.-POLICE ADMINISTRATION}

TABLE

1. Number of Appointments and Resignations of Men Appointed in Years 1914, $1916,1918,1919,1920$

2. Combined Record of Appointments, Resignations, and Dismissals

3. Median Scores and Range of Scores of Police Divisions

4. Distribution of Intelligence Ratings

5. Summary of Distribution of Intelligence Ratings

\section{PART II.-PROSECUTION}

1. Mortality Table of City Misdemeanor Cases, 1919-1920 91

2. Mortality Table of State Misdemeanor Cases, 1919-1920 93

3. Mortality Table of Felony Cases, 1919

4. Prosecutions for Perjury and Subornation of Perjury

5. Comparison of Growth of Population, Number of Arrests, Number and Salaries of "Police Court" Prosecutors, 1863 to 1920

6. Outcome of Cases Carried to the Court of Appeals, 1919 and 1920; Classified According to the Filing of Briefs

7. City Cases, Municipal Court, 1919-20; Disposition of Cases Classified by Charges

8. State Cases, Municipal Court, 1919-20; Disposition of Cases Classified by Charges

9. State Examinations, Municipal Court, 1919-20; Disposition of Cases Classified by Charges

10. State Cases Classified by Charges and by Dispositions and Degree of Suspension of Sentences

11. City Cases Classified by Charges and by Dispositions and Degree of Suspension of Sentences

12. Sentences Classified by Types and by Degree of Suspension, State Cases 152

13. Sentences Classified by Types and by Degree of Suspension, City Cases 153

14. Number and Outcome of Suits upon Forfeited Bonds

15. Comparison of Growth of the Population and Number of Arrests, with the Number and Salaries of the County Prosecutor's Staff, 1863-1921

16. All Indicted Cases, Common Pleas Court, 1919, Classified by the Prosecutor in Charge and by the Disposition

17. Average Number of Days Used in Disposing of Cases Originating in the Several Courts, Common Pleas Court, 1919 
1S. Cases in the Common Pleas Court, 1919, Classified by Disposition and by the Number of Days (A) from Arrest to Disposition, (B) from Indictment to Disposition, and (C) from Arrest to Indictment, Grouped According to the Origin of the Cases

19. Accumulation of Work in Common Pleas Court During Summer Vacations, 1916-1920

20. Number of Grand Jurors Appointed by Presiding Judge from Sources Other than the Original Panel

21. Number of Original Panel and Judge Selections (25 Men in Panel for Each Term)

22. All Cases in the Common Pleas Court, 1919, Classified by Dispositions and Types of Offenses

23A. Common Pleas Court, 1919; Sentences Classified by Type and by Execution and Suspension

23B. Common Pleas Court, 1919; Sentences Classified by Type and by Execution and Suspension; Percentages

24A. Cornmon Pleas Court, 1921; Sentences Classified by Type and by Execution and Suspension

24B. Common Pleas Court, 1921; Sentences Classified by Type and by Execution and Suspension; Percentages

25. Summary of Cases on the "Complaint Docket" of the United States District Attorney for Year Ending June 30, 1920

Exaibit A.-Police Blotter

Exribit B.-Prosecutor's Docket

Exнiвiт C.-Assignment of Cases, Tuesday, May 24, 1921

Exнгвiт D.-Docket-Room 2

Eхнгвгт E.-Judge's Docket, Vol. 50-Room 1

ExhibIT F.-Continuation Docket

Expibit G.-Journal and Execution Docket

\section{PART III.-THE CRIMINAL COURTS}

1. Disposition of Felony Cases Begun in $\mathbf{1 9 1 9}$

2. Disposition of Felony Cases, 1914-1920, from the Records of the Division of Police

3. Dispositions of Cases of 27 Political Lawyers Compared with Dispositions of all Other Cases Begun in 1919 in the Common Pleas Court

4. Sentences and Suspension of Sentences of the Cases of 27 Political Lawyers Compared with the Sentences of all Other Cases Begun in 1919

5. The Detroit Court; Police Record of Four Major Crimes of Professional Nature

6. Results of Unified Criminal Court in Detroit

7. Age on Election or Appointment, Common Pleas Court

8. Opportunity for Private Practice, Common Pleas Court

9. Total Years of Experience, Common Pleas Court 
12. Comparison of Number of Civil and Criminal Cases per Judge, Municipal Court, 1919

13. Average Number of Days Between Arrest and Sentence, Municipal Court

Cases, 1919-20, Classified by Disposition and by Type of Case

14. Cases of Liquor Law Violation Arraigned in January, 1921

15. Persons Arrested from January 1, 1918, to December 14, 1918, Released on

Bail Bonds Signed by .......... and Represented by ........ and ..........Attorneys

16. Disposition of Cases of 125 Known Criminals

17. Average Time per Case by Classes of Disposition

18. Disposition of Cases Classified by Judges Hearing Them

19. Cases Classified by Kinds of Sentences, Suspension, and Judges Hearing Them

20. Rank of Judges by Percentages of Specified Dispositions in Cases Tried by Them

21. Summary of Ranks of Each Judge in the Seven Disposition Classes of Table 20

22. Cases Classified by Disposition and by Counsel Appointed, not Appointed, or Unknown

23. Sentences Classified by Executed and Suspended Sentence and by Counsel Appointed and not Appointed

24. Motions for New Trial, by Judges

25. Disposition of $41 \mathrm{New}$ Trials Granted in $\mathbf{1 9 1 9}$

26. Reasons for Failure to Qualify of 6,520 Persons Called for Jury Service, Classified by Typical Residential Sections

27. Results of Second Examination of Jurors, Classified by Wards and Other Political Subdivisions

28. Summary by Selected Residential Districts of the Numbers of Jurors Called,

Qualified, and Served
29. Reasons for Excusing Persons from Jury Service, January Term, 1921 (Records for 65 Jurors Missing)

29. Reasons for Excusing Persons from Jury Service, January Term, 1921 (Rec-

30. The Occupations of Jurors, April 18-May 18, 1921, as Reported by Them, by Groups of Related Vocations

\section{PART IV.-CORRECTIONAL AND PENAL TREATMENT}

1. Commitments of Boys

2. Intelligence Survey of Cleveland Boys' Farm

3. Analysis of Sentences Terminated During the Months of January, February, and March, 1920, Classified by the Kind of Sentences Imposed by the Court

4. Analysis of Sentences Terminated During the Months of July, August, and September, 1920, Classified by the Kind of Sentence Imposed by the Court

5. Analysis of Sentences in 258 Cases, Expiring During the Months of January, February, and March, 1920, by Length of Sentence and by the Manner in which the Sentence was Terminated 
6. Analysis of Sentences in 293 Cases, Expiring During the Months of January, February, and March, 1920, by Length of Sentence and by the Manner in which Sentence was Terminated

7. Summary of the Manner in which 626 and 696 Prisoners were Released from the Workhouse During Stated Periods in 1920

8. Pardons and Commutations by the Governor of Ohio, 1915 to 1918

\section{PART VI.-LEGAL EDUCATION}

1. Comparative Study of Hours of Teaching in Law Schools

PART VII.-NEWSPAPERS AND CRIMINAL JUSTICE

1. Number of Felonies, by Weeks, Compared to News Space

\section{APPENDIX IV.-PARDONS IN OHIO}

1. Average Daily Population of the Ohio Penitentiary and Number of Releases Therefrom by Executive Pardon or Commutation by Fiscal Years Ending June 30, 1900, to 1921 Inclusive

2. Number of Official Actions Taken, January 11, 1915, to January 10, 1921, Classified by Principal Offenses and Kind of Action

3. Releases, January 11,1915, to January 10, 1921, Classified by Sentences and Average Time Served

4. Disposition of First and Second-Degree Murderers Committed During Ten Years, January 1, 1900, to December 31, 1909. Compiled as of November $15,1921$.

\section{APPENDIX V.-REPORT OF INTELLIGENCE SURVEY OF THE CLEVELAND POLICE DEPARTMENT}

1. Intelligence Distribution of Patrolmen by Date of Entry into the Department 690

\section{APPENDIX VI.-INTELLIGENCE SURVEY OF THE CLEVELAND WORKHOUSE}

1. Distribution of Intelligence Ratings in the Workhouse 


\section{LIST OF DIAGRAMS}

\section{PART II.-PROSECUTION}

DIAGRAM

1. What happened to each 100 state misdemeanor cases in the Municipal Court, 1919-1920

2. What happened to each 100 cases of violations of city ordinances in the $\mathrm{Mu}$ nicipal Court, 1919-1920

3. What happened to each 100 felony cases beginning in the Municipal Courts, 1919

4. How each 100 sentenced defendants pleaded

\section{PART III.-THE CRIMINAL COURTS}

1. The disposition of each 1,000 cases of felony arrests

2. The path of justice

3. Comparison of severity in sentencing with decreasing tendency to bring cases to sentence; felony cases, Common Pleas Court, 1914-20

4. Comparison of decline of "bench paroling" with the increase of allowing "nolle prosequi"

5. The legal career of judges of the Common Pleas Court, 1885 to the present, with respect to their ages and their public and private services

6. The legal career of judges of the Municipal Court, 1911 to the present, with respect to their ages and their public and private services

7. Comparison of number of cases filed during the month with the number on the list ready for trial at the beginning of the month; Municipal Court, January 1, 1919, to August 1, 1921

8. Comparison of the number of cases filed during the term of court with the number of cases on list pending at the opening of the term, January, 1919, to April, 1921

\section{PART IV.-CORRECTIONAL AND PENAL TREATMENT}

1. How the sentences of 626 prisoners received at the Workhouse during January, February, and March, 1920, were terminated

2. How the sentences of 696 prisoners received at the Workhouse during July, August, and September, 1920, were terminated

\section{APPENDIX IV.-PARDONS IN OHIO}

A STUDY OF THE PARDONING POWER AS EXERCISED BY THE GOVERNOR OF OHIO, APPLYING TO THE STATE PENITENTIARY

1. Comparison of Numbers of Releases Granted from Year to Year 


\section{APPENDIX V.-REPORT OF INTELLIGENCE SURVEY OF THE CLEVELAND POLICE DEPARTMENT}

DIAGRAM

1. Intelligence ratings of divisions of Cleveland police department

2. Median scores, Cleveland police department

3. Range of scores between first and third quartiles of Cleveland police department. (The median scores are indicated by the cross lines.)

\section{APPENDIX VI.-INTELLIGENCE SURVEY OF THE CLEVELAND WORKHOUSE}

1. Comparison of intelligence distributions of Cleveland Workhouse and United States Draft Army

2. Comparison of intelligence ratings, Warrensville Workhouse, with United States Draft Army 


\section{LIST OF ILLUSTRATIONS}

Contrast the order and dignity of the civil division of the Municipal Court with the confusion of the criminal division or "police court." The upper picture is a flashlight of a Monday morning crowd in the criminal division.

Frontispiece

The police training school, inadequately equipped but well conducted. The upper picture shows the lecture room; the lower, physical drill.

Monday morning in the office of the chief prosecutor of Municipal Court. Masses of visitors jam the corridors and little rooms, each person waiting for the prosecutor whom he or she has, by accident or design, chosen.

Central police station. This building contains police headquarters, first precinct station, chief's office, records, city jail, a court room, and prosecutors', clerks', and probation offices.

The "Old Court House" on the Public Square. This building houses two criminal court rooms, clerk's office, juvenile court, a branch of the public library, a law school, and a few county offices. A bridge connects it with the county jail.

Page from the conviction book, January, 1917, term of Common Pleas Court, showing the number of paroles.

Page from the conviction book, September, 1920, term of Common Pleas Court, showing the relatively small number of paroles.

The yard at Warrensville workhouse.

Training the eye and the hand at Cleveland's farm school for boys, Hudson, $0 . \quad 385$

Typical floor plans of cell blocks, Westchester County Penitentiary and Workhouse, White Plains, N. Y.

General view, Westchester County Penitentiary and Workhouse.

Outside cell block, typical floor plan, showing middle corridor and steel work, Westchester County Penitentiary and Workhouse.

Typical cell, Westchester County Penitentiary and Workhouse, showing equipment and outside window. 
1

1

1

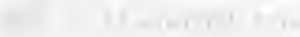

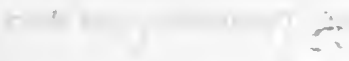

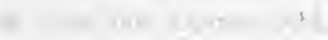

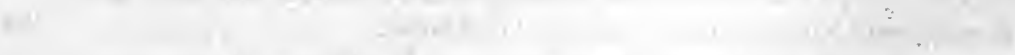

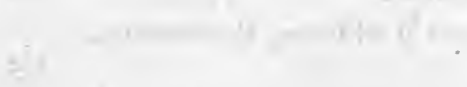




\section{PART I POLICE ADMINISTRATION \\ BY \\ RAYMOND B. FOSDICK}




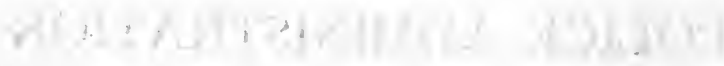

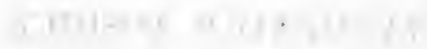

2

$\checkmark$ 


\section{POLICE ADMINISTRATION}

\section{CHAPTER I}

\section{THE PROBLEM}

$\mathrm{A}^{\mathrm{c}}$

CURSORY examination of the problem of crime in Cleveland produces some startling facts. For the year 1920 Cleveland, with

approximately 800,000 population, had six times as many murders as London, with $8,000,000$ population. For every robbery or assault with intent to rob committed during this same period in London there were 17 such crimes committed in Cleveland. Cleveland had as many murders during the first three months of the present year as London had during all of 1920. Liverpool is about one and one-half times larger than Cleveland, and yet in 1919 Cleveland reported 31 robberies for each one reported in Liverpool, and three times the number of murders and manslaughters. Practically the same ratio holds between Cleveland and Glasgow. There are more robberies and assaults to rob in Cleveland every year than in all England, Scotland, and Wales put together. In 1919 there were 2,327 automobiles stolen in Cleveland; in London there were 290; in Liverpool, 10.

Comparisons of this kind between Cleveland, on the one hand, and European cities, on the other, could be almost indefinitely extended. There is no gainsaying the fact that crime in Cleveland far exceeds, in point of volume, the crime of European cities of equal or larger size. And yet, compared with other American cities, Cleveland's record does not show to any special disadvantage. For the first quarter of 1921 there were four more murders committed in Detroit than in Cleveland, and nearly twice as many automobiles stolen in Detroit. During the first three months of 1921 St. Louis had 481 robberies, while Cleveland had 272; for the same period complaints of burglary and housebreaking in St. Louis numbered 1,106, as compared to 565 such complaints in Cleveland. For this same period the number of murders in Buffalo, a much smaller city, equaled those in Cleveland, and burglaries, housebreakings, and larcenies were almost as numerous. In 1919 Chicago, more than three times the size of Cleveland, had 293 murders and manslaughters, 
compared with Cleveland's 55, so that the ratio was easily two to one in Cleveland's favor; the 1920 statistics of the two cities show an even better proportion for Cleveland.

On the other side of the scale, for the first three months of the present year Cleveland had more than twice the number of robberies and assaults to rob that Detroit had, and a similar large proportion of burglaries and housebreakings. During this period there were 296 automobiles stolen in St. Louis, as against 446 in Cleveland. Cleveland is approximately three times larger than Toledo, and yet in 1920 Cleveland had 87 murders, while Toledo had only 11.

Another basis of comparison is between the crime statistics of Cleveland in 1921 and Cleveland in former years. For the first six months of 1921, the period in which this survey was carried on, the number of murders committed in Cleveland was 15. For the same period in 1920 the number of murders was 30 . Similarly, during this same period, there was a decrease of burglaries and larcenies from 573 in 1920 to 541 in 1921. On the other hand, robberies and assaults to rob increased, as between the two periods, from 454 to 534 , and the number of automobiles stolen increased from 1,156 to 1,238 . The following figures show the average number of complaints for the first quarter of each of the four years from 1917 to 1920 inclusive, classified according to four outstanding crimes:

Robbery and assault to rob

283

Burglary and larceny

418

Murder

17

Automobiles driven away

361

The following figures give the number of complaints of the same crimes for the first quarter of 1921 :

Robbery and assault to rob

Burglary and larceny

265

Murder

Automobiles driven away

446

Obviously, there has been some improvement within the last four years.

All in all, crime conditions are no more vicious in Cleveland than they are in other American cities. In point of volume of crime in relation to size of population Cleveland is neither much better nor much worse than the other municipalities of the United States. It is when we compare Cleveland with cities like London, Glasgow, Liverpool, or almost any other European municipality that ominous contrasts are obtained. In this respect, therefore, Cleveland's problem is the problem of America, 
for the same causes that are maintaining the high crime rate of Chicago, St. Louis, New York, Detroit, and San Francisco are operating here.

What are these causes? Here we can only hint at some of the deeper social and economic causes. The lack of homogeneity in our population and its increasing instability, the absence of settled habits and traditions of order, the breakdown of the administration of criminal law in the United States, and the many avenues by which offenders can escape punishment, our easy habit of passing laws which do not represent community standards or desires, our lack of cohesive industrial organization, our distrust of experts in the management of governmental enterprisesall these are undoubtedly contributing factors.

But there is another factor, still more potent: police machinery in the United States has not kept pace with modern demands. It has developed no effective technique to master the burden which modern social and industrial conditions impose. Clinging to old traditions, bound by old practices which business and industry long ago discarded, employing a personnel poorly adapted to its purposes, it grinds away on its perfunctory task without self-criticism, without imagination, and with little initiative.

From this general indictment the Cleveland police department cannot be excepted. 


\section{CHAPTER II}

\section{PRESENT CONDITIONS}

$\mathrm{T}$

HE present police department of Cleveland dates from 1866. In that year the force, consisting of a marshal and 44 watchmen, was reorganized on a semi-military basis, with a superintendent, captains, sergeants, detectives, and patrolmen. In the next forty years there followed many modifications of the scheme for administering the force; but few changes, other than increases in numbers, occurred in the internal organization. In 1907 the force totaled 614: a chief, one inspector, four captains, 27 lieutenants, 28 sergeants, 550 patrolmen, a secretary, surgeon, and detective sergeant. Of the 550 patrolmen, 20 were designated as detectives. At the beginning of 1921 the authorized force of regular police totaled 1,381, ${ }^{1}$ including-

1 chief

1 secretary

1 inspector

4 deputy inspectors

1 superintendent of criminal investigation

1 surgeon

1 veterinary surgeon

1 superintendent of civil investigation

1 superintendent of tailor shop

17 captains

53 lieutenants

99 sergeants

75 detectives

1,125 patrolmen

Since 1866 Cleveland has grown from a small town to the fifth city in the United States. It has grown not only in size, but in the heterogeneity of its population and in the complexity of its social and business life. From a town in which many people knew each other intimately and thus

1 Ordinance No. 52236 (Ordinances of 1920). The actual number of men employed has been below the authorized number. 
furnished a substantial degree of self-protection and aid to the police, Cleveland has become, like all other communities of its size in modern times, a city of strangers.

In contrast with this complex growth of the city the police department of 1921 is little more than a physical enlargement of the department of 1866. Other branches of the municipal government have made marked progress along lines of scientific development. The school system, public utilities, fire fighting, business offices-all these have taken on a new character compared with their prototypes of a generation ago. The police department has shown no such vitality-no such capacity to make itself over on a new and improved pattern, no willingness to reshape its methods to modern demands. Instead, it has hewn to the line of tradition, ventured almost nothing in experiment, and copied very little from the experience of other private and public organizations. Today the patrol force is distributed and managed exactly as it was twenty or thirty years ago. There is nothing new in the detective service save faces and a few meager records. Traffic regulation has been developed, but this modern necessity has been met only by draining the department's resources for coping with crime. No new practices have been employed for ferreting out and removing conditions that produce crime. Practically the same methods are employed for combating crime that were used when Cleveland was just a big neighborhood in which the police knew everybody.

Let us look a little further. The department has never had and does not have today the trained and intelligent leadership which European police forces have long enjoyed. Cleveland's directors of public safety and her chiefs of police come and go, apparently with scant appreciation by the public of the fact that transient administration is fatal to success in any complex technical enterprise. Moreover, the line of authority between the director of public safety and the chief of police is so vaguely drawn that effective administration would be impossible even under the best of conditions. Lacking in leadership, the department lacks, too, in the quality of its working personnel. Machinists, motormen, truckmen, and other manual workers-these are the sources from which Cleveland takes the men upon whom she imposes tasks requiring a high degree of intelligence and technical skill, besides a keen appreciation of social values.

Similarly, we find adherence to a rigid organization applying to the entire force, regardless of the great difference in types of work attempted by the various divisions of the service. We find the department acting as the eyes and ears of other city departments in reporting on the physical 
conditions of the city, promoting the safety of citizens in public places, arresting criminals, and preventing the commission of crimes, but using the same kind of man for all these tasks and clearing them through the same inelastic organization.

The department is trying heroically today to "catch up" in the apprehension of criminals and the prevention of crime. Its energies, however, are chiefly consumed in repairing damage that is not anticipated. Almost nothing is being done to find out the causes of crime, to learn the sources from which criminals are sprung, or to forestall their operations. The department takes no leading part in the study of criminals and their characteristics; it does not even avail itself of facilities for study and experiment that have been developed by schools, clinics, and other private and public organizations.

This lack of intelligence and imagination in Cleveland's police work is shown in the ragged character of the internal arrangements of the department. No private business whose affairs were carried on in such hit-ormiss fashion could escape bankruptcy. The record books of the department are poorly kept, sometimes showing erasures, changes, and additions. Nearly all reports made by patrolmen and detectives are written in pencil. There are no current consolidated reports showing summaries of operations, with comparative data for other periods which might be used for purposes of administrative control. Instead, there is a great mass of detailed matter passing over and lodging upon the chief's desk. On the other hand, not enough detailed material appears on the desks of commanding officers of the detective bureau, vice bureau, and precincts. Policemen are doing the work of clerks, and some, who might better have been employed as clerks, are doing the work of policemen. Most of the department's supervisory work is done on a memory basis, as in 1866 , without even any regular order for making and receiving the verbal summaries of current business. Every one, from the chief down, appears to be engaged with the interesting things of the moment. Study and analysis of persisting or recurring problems and of results in the aggregate are hardly known.

Inadequate equipment adds to this appearance of raggedness. No private business which has to show results could work with the department's equipment. The headquarters building is wholly inadequate. Workers in every division are cramped for space, with resulting confusion and chaos. If the record bureau facilities are contrasted with those of a private enterprise having an equal volume of business, the disadvantages under which the police are working will be readily seen. There are no typewriters in the precincts save those privately owned. Supervising 
inspectors do not have automobiles in which to cover the city. Members of the automobile recovery squad are frequently without a car, and must go on foot to search for stolen automobiles. The signal system is wholly inadequate for the ordinary needs of communicating with men doing field duty. No motor equipment is available for regular patrol duty.

A general picture of the police service in Cleveland gives the impression of a group of men, singularly free from scandal and vicious corruption, but working in a rut, without intelligence or constructive policy, on an unimaginative, perfunctory routine. As a matter of fact, this same indictment could be drawn against most of the police forces of America. The Cleveland department is no worse than many others; in some respects it is better. Official lethargy lies behind much that is distressing in this picture. There is another kind of lethargy, however, which cannot escape its share of the responsibility. It is the lethargy of public opinion, the community's easy habit of assuming that governmental machinery will somehow or other run itself, even in the face of meager equipment and inadequate funds. 


\section{CHAPTER III}

\section{THE ORGANIZATION OF THE FORCE}

$\mathrm{T}$ HE police service of Cleveland is organized as a division of the department of public safety. The department of which the police division forms a part is administered by a director appointed by the mayor and serving at his pleasure. The charter provides that "under the direction of the mayor the director of public safety shall be the executive head of the divisions of police and fire." The division of police is headed by a chief of police, who is appointed by the mayor, subject to civil service rules and regulations. The right to suspend the chief is lodged exclusively with the mayor. In case of such suspension, the charter provides that the mayor "shall forthwith certify the fact, together with the cause of such suspension, to the civil service commission, who within five days from the date of the receipt of such notice shall proceed to hear such charges and render judgment thereon, which judgment shall be final."'

The rank and file of the police service are appointed by the director of public safety. The chief of police has the exclusive right to suspend any officers or employees in the police division. In case of suspension the charter provides that a trial shall be held by the director, who is empowered to render judgment, "which judgment, if sustained, may be suspension, reduction in rank, or dismissal, and such judgment in the matter shall be final, except as otherwise hereinafter provided." The charter further provides that a member of the division of police may appeal to the civil service commission from the decision of the director of public safety within ten days after the date of suspension from duty, reduction in rank, or dismissal. In such appealed cases the civil service commission has the power to "affirm, disaffirm, or modify the judgment of the director of public safety, and its judgment in the matter shall be final."

All members of the professional force enter the department as patrolmen, after examinations conducted by the civil service commission. Promotions to the higher ranks, with the exception of the rank of chief of

${ }^{1}$ Cleveland City Charter, Sec. 107. 
police, are made as a result of competitive civil service examinations. In addition to these ranks of the professional police force there is a superintendent of criminal investigation (criminal identification), a surgeon, superintendent of civil investigation, veterinary surgeon, and superintendent of the tailor shop. Civilians are employed as matrons, chauffeurs, tailors, caretakers, janitresses, mechanics, and telephone operators.

The major part of the regular police personnel is distributed by types of work in four main divisions as follows: the uniformed patrol force, the division of traffic regulation, the detective division, and the vice squad. In addition to these main divisions are several small auxiliary units, such as the criminal identification bureau, information bureau, and record bureau, to which patrolmen and officers are assigned in the numbers required. Ranks and grades are not affected by assignment and transfer from one bureau or division to another, although some increase in salary is granted to sergeants who are detailed to the vice squad and to patrolmen assigned to serve regularly in the detective division.

For purposes of distributing the working force of the department geographically the city has been divided into 15 precincts, each having a precinct station house. The general administration of police affairs is carried on at police headquarters, which also includes the first precinct station, detective headquarters, vice squad, and all the special units.

\section{Scope of the Police Survey}

The subjects of study in this survey have been the relations between the civil service board, the public safety department, and the various police divisions and bureaus, the character of the supervision of police work in its many phases, the methods of procedure, the records and reports maintained for showing work accomplished, and the volume of crime dealt with.

In the main, appraisals of efficiency relate to methods of procedure and departmental organization viewed as an impersonal instrument of government. The relation of officials to one another and to their work in general has been looked at in the light of the office rather than of the individual. While this view of police administration has necessarily represented conditions prevailing during the period covered by the investigation, and is, therefore, an analysis of the practices and accomplishments of individuals who happened to be in office at that time, we have kept in mind throughout that it is methods rather than persons which form the permanent part of the organization, and it is the former, therefore, with which the larger purposes of the survey are concerned. Thus it has been the office of the chief of police, with its powers, duties, prac- 
tices, and accomplishments, rather than Chief Frank W. Smith, that has been the subject of investigation. The present personnel will, in due course, be separated entirely from police administration, and any appraisal of their efficiency as individuals will then be of no value. But the practices employed and policies laid down by the present personnel must necessarily form the basis for the development of the future.

\section{The Problem of Administration}

The task of the administration of police business in Cleveland consists in directing the daily activities of some 1,200 men. Keeping each of these men keyed up to his best is a problem in the management of human beings. Their work in turn consists in regulating human relations and thus promoting safety and good order in the community.

To achieve these ends in a city of the size of Cleveland a large organization with imposing equipment and record systems must be provided. It must be noted, however, that the ultimate end of this complex superstructure of organization is to be found in the acts of individual policemen, operating for the most part alone and initially unaided. The personnel of the department rarely moves in large units; the organization acts through individual members in performing the major part of the daily routine. The real police work is not done at headquarters or in stations, but on the beat.

Matters of organization, records, reports, and methods of procedure are merely convenient instruments to see that policemen are made available for duty and to provide some basis for estimating the effectiveness of these field forces. But police work itself, in its final analysis, is wholly personal. The sum of the generally isolated observations, investigations, and acts of individual policemen constitutes the primary police work of the department. The heart of the business of police administration, therefore, consists in training, stimulating, and directing men in the exercise of good judgment and initiative while on post or assignment in the field.

The work of a police department is, therefore, not readily reduced to well-defined standards of accomplishment. It involves such intangible and modifiable factors as good judgment, sympathy, patience, courage, and intelligence. Added to these there must be pride of profession, enthusiasm, and, above all, a spirit and willingness to take great pains in the prosecution of the work.

\section{The Machinery of Police Administration in Cleveland}

Let us see how well the administrative machinery of the Cleveland police department fulfils its task of administering these personal relations. 
Charter provisions covering the question of responsibility for the administration of police business are singularly confusing in terminology. The language is clear enough, however, to show that a deliberate attempt has been made to distribute specific powers between the director of public safety and the chief of police. Authority is apparently given to the chief by one provision of the charter, only to be taken away by another. Regarding general powers and duties in the department of public safety the charter reads: "Under the direction of the mayor the director of public safety shall be the executive head of the divisions of police and fire. He shall also be the chief administrative authority in all matters affecting the inspection and regulation of the erection, maintenance, repair, and occupancy of buildings." " Thus, with regard to the division of buildings, which is coördinate with the divisions of fire and police in the department of public safety, the charter specifies that the director shall be the administrative authority, while his responsibility with regard to the police and fire divisions would seem to be of a different kind. The distinction here made apparently implies that in the police and fire divisions, as distinguished from the division of buildings, the chiefs of the respective divisions are the administrative heads, with the director as a sort of over-lord. The charter does not specifically state that the chief of police is to be considered the administrative authority of the division of police, but the prescriptions relating to his appointment and removal by the mayor and not by the director, and the powers and duties ascribed to him, would seem to indicate that such was the intention.

Another section of the charter reads: "The chief of the division of police shall have exclusive control of the stationing and transfer of all patrolmen, and other officers and employees constituting the police force, under such rules and regulations as the director of public safety may prescribe. The director of public safety shall have the exclusive management and control of such other officers and employees as shall be employed in the administration of the affairs of the division."2 Here again we are confronted by an apparent conflict. Where does the authority of the chief leave off and that of the director of public safety begin? An inquiry along historical lines reveals that the probable intention of the framers of the charter was to charge the chief with responsibility for carrying on police enterprise proper, while the director was to have full responsibility in purely business matters, such as the purchase of supplies and equipment, repair and upkeep of property. If this be true, it must be pointed out that the intention was not well fortified by later provisions in the charter, wherein 
the chief-or administrative head of the "police force"-is shorn of all final authority in important matters governing the selection, promotion, and discipline of the police force.

Again, "The chiefs of the divisions of police and fire shall have the exclusive right to suspend any of the officers or employees in their respective division who may be under their management and control. * * * "This is no more than the ordinary authority attaching to the office of an administrative head of a department. In the next sentence, however, this language occurs: "If any officer or employeebe suspended, as herein provided, the chief of the division concerned shall forthwith in writing certify the fact, together with the cause for the suspension, to the director of public safety who, within five days from the receipt thereof, shall proceed to inquire into the cause of such suspension and render judgment thereon, which judgment, if the charge be sustained, may be suspension, reduction in rank, or dismissal, and such judgment in the matter shall be final, except as hereinafter provided."1

Thus it appears that the chief is given wide powers,-wider than in most cities where there is a non-professional administrative head, such as the director of public safety, between the mayor and the chief,-that he is charged with the initiation of authority in administration, that is, has "exclusive" control under ordinary circumstances, while the director's connection with the routine affairs of the police division is restricted to business matters or, as the charter vaguely calls it, "administration of the affairs of the division." Yet, when the real test of "exclusive" control appears, it is found that the director and not the chief has all the power. The director makes all of the really important decisions, as, for example, in the matter of preparing the budget for police service, making rules and regulations, conducting disciplinary trials, and making the selections for appointment and promotions from the civil service lists. The director, however, is not required, nor does he have an opportunity, to establish immediate and constant contact with the actual administrative processes of police work.

There is another odd arrangement in connection with the distribution of powers and the establishment of a line of responsibility between the two heads of the police service. The director, while depending on the chief to exercise "exclusive" control up to the point where the director himself makes the really important decisions, does not have direct control over the chief, but merely over the facilities with which the chief has to work. The chief is appointed by the mayor and not by the director.

${ }^{1}$ City Charter, Sec. 106. 
Likewise the mayor alone has "the exclusive right to suspend the chief of the division of police or fire for incompetence or any other just and reasonable cause." As a result, the chief is answerable to the director for his management of police work, but responsible to the mayor and not the director as far as his "incompetence" is concerned. Only confused notions respecting official responsibility can result from such a situation.

In the matter of disciplinary action, it should be pointed out here that there is another step in the scale of responsibility beyond the mayor and director. The municipal civil service commission alone has the power to pass on charges preferred against the chief of police, and it renders final judgment as well in all cases involving lower ranks which may be appealed to the commission from the judgment of the director. ${ }^{1}$

Under such a scheme of confused responsibility for police business as has been outlined above, to whom do the people at Cleveland actually look for results in policing the city? Who is held to account when a wave of robberies, burglaries, or automobile thefts occurs? Is it the director of public safety or the chief of police? Which of the two officials bears the final responsibility? The answer under the present charter is, neither. Whenever the question of efficiency is called up, the director can point to the chief and say: "There is the man who is running the department. I neither appoint him nor remove him; he is subject to civil service provisions. If he doesn't do the job satisfactorily, I am not to blame." A chief under the same conditions can reply by saying: "If I had the last word in matters of discipline, so as to weed out the unfit regardless of their political friends and influences, and keep all others on their toes; if I could make the rules and regulations governing the department and could select my men in accordance with my own standards of judgment, I could accomplish better results." The whole scheme is admirably suited to the favorite game of "passing the buck"-an especially useful game where public criticism is involved.

Moreover, the contention of each official, as suggested, would be absolutely correct so far as the charter goes. The director of public safety has wide general powers, but no specific contacts with the machinery he is controlling. The chief of police, on the other hand, is checked at a score of points where an administrator should have free initiative and complete authority. The chief's position at present is like that of a child driving a horse, while an adult sits beside him ready to grip the reins in front of his hands, whenever an important decision in the driving arises.

Naturally, under the present arrangement, the whole complexion of ad-

${ }_{1}^{1}$ This subject will be reviewed in some detail in a later section of this report. 
ministration changes with shifts in the offices of director and chief, and since neither officer is dependent on the other for appointment or continuance in office, such changes will be concurrent only by accident. Experience in the past has shown that with an aggressive type of man serving as chief the director will become a sort of fifth wheel whose exercise of his charter authority is likely at best to be a source of obstruction. With a less aggressive chief it is probable that the director will assume more influence in the disposition of members of the force than is intended in the charter, and more than he is fitted to assume by reason of the multiplicity of his duties and his remoteness from actual police operations. Unless the chief be especially aggressive, almost to the point of standing against the director, the suggestions of the latter, because of his superior position, will be tantamount to orders. The practice of a former director of suggesting the names of men whom he desired to have detailed to the detective bureau, and the famous Order $73,{ }^{1}$ are cases in point. With an aggressive chief of police, as at present, there is every opportunity of confusing the clear line of responsibility in a way which reacts against the chief as a penalty instead of reward for his attempted initiative.

\section{Recommendations}

1. The best escape from the difficulties inherent in the present scheme involves a complete overhauling of the whole administrative machinery. In the first place, there should be a direct line of responsibility, running from a single head down through the whole organization. There should be no such short circuits as now exist between the chief and mayor around the director, who is the chief's superior. Final authority, commensurate with responsibility, should be lodged exclusively with the single directing head. This single leader should be in immediate charge of directing the operations of the force.

2. To accomplish these ends it is recommended that the police service be disassociated from the department of public safety and established as an independent department, coördinate with the other combined divisions of the department of public safety, the finance department, or the department of public utilities.

From the police point of view, there is no good reason why the police service should be organically connected with the fire and buildings division. On the contrary, there are positive reasons why it should stand alone. Although both the police and fire divisions are established to

1 This order provided that the police were not to raid gambling houses or houses of ill fame without instructions from the director of public safety. 
secure public safety, their fields of work differ widely. The fact that the personnel of the two divisions is organized on a semi-military basis is not sufficient justification for their common administration. The problems of fire extinguishment are physically definable and the work of fire prevention is highly specialized and easily reduced to mechanical standards; the uniformed force of the fire division deals with material elementsi The police force deals largely with human relations; its problems are to a certain extent intangible. Firemen work in groups under the immediate direction of their superior officers; they respond to a fire in their properly assigned places and employ chemicals and other equipment as they are ordered by their officers in charge. The policeman's work is done largely on his own initiative, prompted by his own judgment.

Policies affecting fire administration relate almost entirely to the financial aspects of providing equipment and men that are necessary in the light of definitely known insurance rates and fire hazards. Policies of police administration involve social and moral needs which are far removed from such factors as the storage of inflammables, hose and water pressure, and building regulations. There is no divided opinion about the desirability of putting out fires; there is considerable room for division of opinion as to how much money the city should pay for the intangible returns of crime prevention to be achieved through an enlarged and better equipped police force, or even as to how far the police may go in curbing individual liberties in their efforts to prevent crime.

Thus, although these two forces are similarly organized, the objectives of their work are found to be wholly different and their methods of procedure widely dissimilar, while the values of their work are appraised on entirely different bases.

It may be contended that a combination of the police and fire divisions is necessary in order to assure active coöperation on the part of the police in looking for fires at night, assisting with rescue work, establishing fire lines, and enforcing the ordinances and regulations of the code of fire prevention and protection. These things the police must do, but a common administration of police and fire is not necessary to effect such coöperation. The duties of the police would remain the same if the two divisions were not connected by an overhead scheme of management. It is not reasonable to suppose that the police would neglect the performance of such specific duties merely because their directing head is not also the directing head of the fire force. One might as well expect them to neglect making arrests because the head of the police service is not also in charge of courts and prosecutions, or to fail to report broken 
manholes or leaking hydrants because their division is not organically connected with the departments of public utilities and public service.

A saving in the expenses of administration may result from combining police, fire, and buildings, and the practice may be defended on the ground of economy in small cities where these divisions are not large. In Cleveland, however, the savings in the overhead cost of administration are more than overbalanced by the loss in efficiency. Moreover, it is hardly possible to find a man with qualifications of expertness in the supervision of the technical matters of fire fighting and building regulation who qualifies also in understanding the human problems incident to policing.

It may be sufficient to point out that Cleveland is one of the few large cities in the United States which still combine the administration of the police department with that of other branches of the municipal system. In most other cities the police force was long ago established as a separate entity under independent management. The same is true of all European cities. There the police function is regarded as so important that no attempt is made to confuse its administration by bringing other public activities under its leadership. The time has come for Cleveland to recognize the same principle and to give to the police department the administrative position which the importance of its work demands.

3. The department of police should be in charge of a single civilian administrative head, to be known as the director of police. The director should be appointed by the mayor with full responsibility for administering the police service, and should have the exclusive right to name his own immediate assistants, including the chief ranking office of the uniformed force to correspond to the present chief of police. Such appointments should be terminated at the will of the director. It should be the director's duty to lay down a policy and program for police work, and to see that such policy is carried into effect by his subordinates. Under this arrangement the officer who develops the policies of police service will be subject to public reckoning, since his appointment and continuance in office depend on the mayor, who is subject to election. Undivided responsibility and authority would be reposed in a single officer at the head, and the line of responsibility and authority should continue downward direct and unbroken.

Such a director should be chosen from outside the professional ranks of the department, just as the director of public safety has always been chosen. The management of police business demands as able an administrator as can be obtained. Indeed, in a city like Cleveland, and in many cities of lesser size, the task of police administration is so great 
that the best man obtainable is none too good, and in an endeavor to find him, no search can be too thorough. That such a leader can be found in the ranks of a police force is in the highest degree improbable. The officer who has walked his "beat" as a patrolman, investigated crime as a detective, and managed the technical routine of station house activity as lieutenant or captain, is not fitted by this experience to administer the complex affairs of a large police department. The chances are rather that he is unfitted for the task. Lacking in administrative experience, with scant appreciation of the larger possibilities of his position, often indeed without imagination or resourcefulness, he has little chance of success, and it would be unwise and cruel to saddle him with the responsibility. If police management were merely a matter of assignments, promotions, and discipline; if it had to do only with the ordering of a well-defined routine, any capable man who himself had been through the mill might be well adapted to handle it.

But the task, particularly in large cities, is so much broader than routine, and involves activities of such vital consequence, that only a high order of creative intelligence can cope with it. The director must deal with community problems in the large. He must be familiar with the underlying social forces which are responsible for the need of police service. Constantly before him must be the conception of the department as an agency for the prevention of crime, and the consequent relation of his work to all activities, social, economic, and educational, operating to that end. He must be able to interpret public opinion, to be a community leader, and, above all, he must be qualified to inspire a great force of policemen. In addition he must have a thorough understanding of the principles of administration.

These qualifications are not readily found in the uniformed force, nor, indeed, are they easily found in any walk of life. For that reason the search for the right man should be broadcast, and no artificial barriers of politics or residence should be interposed. If the best man cannot be found in Cleveland, other sources should be examined. A residential qualification in such cases is as irrelevant as it would be if applied to the managing director of a railroad or to the head of a medical school or an experimental laboratory. In European cities there has been no thought of applying such a test for the reason that no one would care to limit so narrowly the field of choice. With the talent of Great Britain to draw from, for example, why should Liverpool or Birmingham insist that its chief constable be recruited from its own population? Or what would be gained if Stuttgart were barred from inviting an experienced deputy commissioner from Munich to join its staff as com- 
missioner, and had, instead, to employ some inferior man from its citizenship? This is the conception that governs the public service of European municipalities and to a great extent its application accounts for the difference in municipal administration here and abroad.

4. Once chosen because of his peculiar abilities, the director of police should be regarded as a permanent fixture. While the right of the mayor to remove him should remain unabridged, the exercise of that right for political causes or for reasons other than those relating to his efficiency should be checked by a public opinion strong enough to insist upon retaining a well-tried expert in an office as important as the directorship of police. A constantly shifting directorship of police can result in nothing but chaos. To gauge a well-trained administrator on the basis of his political faith is to introduce a factor as irrelevant and immaterial as his opinion on art or literature. When the right man is found for so highly developed a specialty, the city should cling to him as a business concern would cling to an indispensable employee. Only proved inefficiency or complete lack of sympathy with the police policies of the mayor should be sufficient cause for removal.

Here again we can find excellent example in the police departments not only of England and Scotland, but of France and Switzerland as well, to say nothing of several American cities where the principle of continuity in the police directorship has been followed with marked success. In Boston, Commissioner O'Meara served twelve years under four different administrations, both Democratic and Republican. The same situation today holds true in Milwaukee and in Berkeley, California, where over a long period of years the heads of the two police departments have served without interruption in spite of the kaleidoscopic changes in mayors and councils. Similarly, European cities always appoint their directors and commissioners of police as a board of directors selects a general manager or other official, not for a definitely established term, but on the basis of satisfactory work. Their task is to find men capable of serving indefinitely - men who have the ability and the willingness to devote a lifetime to the administrative problem. When such a man is found, there is no disposition to experiment with anybody else. No one would care to assume responsibility for jeopardizing an organization in which, as in all forms of business enterprise, continuity of administration is the best guarantee of effectiveness.

5. The director must have under him a chief executive officer who will serve as the superintendent or general manager of operations. Under such a scheme, what should be the relationship between the director and his chief subordinate? 
The director should have the task of laying down the general program and policy of policing, and of determining the financial needs of the department. He should represent the department in all its external contacts, such as with the appropriating body, the other departments of government, as well as the schools, churches, and welfare and civic agencies. He should determine, as a matter of policy, how much of the available resources of the department should be devoted to the regulation of traffic, as against the necessity, for example, of carrying on preventive work in connection with crime. In all the welter of laws and ordinances he should decide where police emphasis is to be placed.

Once the policy in such matters is determined, it should then fall to the chief line officer in charge of actual operations to see that these policies are carried into effect. If there were a question of establishing one-way streets, for example, or of rerouting street-cars, to facilitate the movement of traffic, the director would deal with the street railway company and the commercial interests affected by the proposed changes, making the decision in cases of conflict between the needs of the general public and the private interests involved. He would, in the first instance, depend on the recommendation of subordinate experts in the traffic regulation. When the policy is decided, he would turn to the chief executive officer to see that the police carry out the new policy.

In short, the director would determine how much and what type of police service is needed, and the chief professional officer would see that such service is carried out to the best of his ability with the men and equipment given him for the purpose. The one asks for certain results and the other manages the machinery used in getting the results.

A policy may be laid down by the administrative head, but the manner in which the routine work is executed gives color to the policy. Hence the head must have a superintendent or general manager of operations who understands his policies and has sufficient sympathy with their accomplishment to go about his work with the enthusiasm of conviction. Half-hearted execution practically amounts to obstruction. It is especially important, therefore, for the head of the police department to be able to choose the man in whom he has personal confidence. On no other basis can true leadership be developed.

6. For this reason the superintendent or the chief of police-whatever his title might be-as the immediate subordinate of the director, should not be chosen as a result of competitive civil service examinations. The objection will at once be made that the present scheme, wherein the office of chief of police is surrounded by the protection of civil service regulations, makes for continuity of administration in the leadership of 
the police, and that this continuity is the only protection against the ravages of politics. This assumes, in the first place, that continuity in this particular office is a guarantee of effective policing, and, in the second place, that Cleveland is hopelessly unregenerate in the matter of politics and inferior to other cities of a similar size. It is an open question how much is gained by an enforced continuity of service which is shorn of power by officers who are controlled by the fortunes of politics. Moreover, the non-political aspect of the chief's tenure in Cleveland-i. $e$, guarantee against removal on account of politics-is a singularly weak argument in its form when it is considered that the appointments to the office have been surrounded by all of the manœuvering known to politics. In the not remote past the custom has been privately to avow candidacies for appointment to the office of chief whenever a vacancy occurred, or when it was known that a vacancy was about to occur. Thus some of the higher officers in the department have approached business men of Cleveland, newspaper editors, and friends to secure their influence and aid in getting the appointment. Accordingly, newspapers and other interests have had their candidates, though perhaps not openly avowed, in much the same way as if the office were an elective one.

The truth of the matter is that civil service protection in high administrative police positions does not guard the community, certainly in Cleveland, against politics. Politics can get around any artificial system. On the other hand, with public opinion on the alert, politics can be kept in control without any system at all. In Boston and Detroit the incumbent superintendents of police, who are the professional heads of the police force,-corresponding in that relationship to the chief of police in Cleveland,-have held office throughout successive changes in the terms of the administrative heads. Yet these officials are not subject to civil service provisions of any sort. Their appointment and dismissal rest in the discretion of their superiors. The same is true in London and other European cities. Such a continuity of service, based on freedom of choice, has real meaning, but a continuity based on the inherent difficulties of removal through a civil service trial nullifies responsibility and stultifies the work of any administrator, however enterprising.

What every police force needs is leadership-one official to whom the community can say, "Thou art the man!" and who has power corresponding to his responsibility. We shall never solve the police problem in America until we give honest and effective leadership an opportunity to show what it can do. Some time or other we have to make a beginning of trusting our public officials. Checks and balances to curb and minimize possible abuses of power have gotten us nowhere. Complex 
systems to prevent bias and unfairness have brought nothing but confusion. It is time to take off a few of the yokes that have made public administration an impossible task, and put a new emphasis on positive qualities. The problem before us is not how to build up a structure that will circumvent the dishonest and incompetent official, but, after finding a competent and honest official, to surround him with conditions in which he can make himself effective.

Just as the community should, if necessary, go outside its own boundaries to get the best director possible, so the director should disregard all questions of residence in selecting his chief subordinate. Indeed, in view of the present demarcations in the police force in Cleveland, due largely to religious differences, such a step might be distinctly advisable. So long as there are in the department group-conscious Catholics and Masons, playing the part of the "ins" and the "outs," with discriminations practised by one group against the other as opportunity offers, just so long will it be difficult for a director to choose from the Cleveland force a chief who can command the unquestioned loyalty and support of his men. It will probably take the strong hand of an outsider, with no group to represent, with no old scores to settle, to put the final quietus to this factional nonsense. In any event the director, as the responsible head of his department, should be free to select his immediate subordinate on the basis of such qualifications as he himself determines. 


\section{CHAPTER IV}

\section{PROVISION OF PERSONNEL-ITS SELECTION AND TRAINING}

7 HE charter provides that the police force shall consist of a chief of police and "such officers, patrolmen, and other employees as may be provided by ordinance or resolution of the council."' In accordance with this provision, the city council determines what is known as the "authorized" number of police for each rank, from the rank of patrolman to inspector of police. The appointing authority is not compelled to recruit the force up to the authorized strength. He cannot, however, make appointments in excess of the number set by councilmanic action. The task of recruiting the force belongs to the civil service commission, original entrance to the department being by competitive examination. Actual appointments are made by the director of public safety from eligible lists certified by the civil service commission.

An analysis has been made of the original appointments to the department from 1914 up to and including the first two months of 1921, to determine the type of men who are drawn into police service. Particular attention has been given the appointments made in 1914 and 1921, since more nearly normal conditions prevailed in those years. The period between these two years presented unusual circumstances. Just prior to this country's entry into the war competition with industry seriously affected police recruiting, and from 1917 until after the completion of demobilization the scarcity of applicants made it difficult to keep up the authorized strength of the department. As a result, considerable modification of the standards governing entrance requirements was necessary. By 1921, however, conditions were normal in respect to the number of persons making application for police appointment.

\section{Previous Occupation}

A review of the occupational sources from which policemen are recruited shows that they are drawn from a wide range of civil employ- 
ments. Considering the occupations of the 56 men appointed during 1914 , it is found that, of the occupations engaged in prior to entering the police department, only six had furnished more than one representative. Machinists numbered six, carpenters three, shipping clerks, ship-builders, foremen (not further specified), railroad firemen, and street-car inspectors numbered two each. The remaining 37 came from as many occupations. ${ }^{1}$ An analysis of the previous occupations of the first 133 men appointed in 1921 shows that there were 14 occupations from which more than one recruit was drawn, accounting for 87 men altogether. Of these, 19 were machinists and machinists' helpers, 12 truck drivers, 10 chauffeurs, eight electricians and electrical workers, six carpenters, six from the plumbing trades, five clerks, etc. Forty-seven other occupations were listed, including a physical director, tree surgeon, barber, chef, sailor, musician, farmer, draftsman, chocolate maker, etc. Those who might be classified generally as manual workers numbered 111, or 83 per cent., and the miscellaneous non-manual occupations accounted for 22 appointees, or 17 per cent.

The previous experience of new policemen is, therefore, diversified, and offers almost no common factors which may be utilized in planning their training. With many of these men the choice of work is largely a hit-or-miss matter. Most of them finally settle upon policing without giving much thought to its significance or to its possibilities as a career. They think of it as a job giving steady employment and compensation equal to or better than what they were able to obtain in commercial fields.

This raw material, possessing every sort of occupational experience, must be molded into as great a degree of uniformity as possible. The recruits must first be converted into patrolmen as a sort of common denominator. When this has been done, the same men must be reconverted into detectives and special investigators, such as those attached to the vice squad. Some must give special attention to work with juveniles, and in the absence of women police, others are required to do work which should naturally fall to a division of women police.

The large proportion of men who are drawn from the various types of

1 The 37 occupations were as follows: assembler, ball-bearing inspector, boxmaker, brass finisher, brazing shifts, bricklayer, clerk, chauffeur, conductor (streetcar), driver, electric crane operator, engineer, foundryman, gateman, glazier, hotel clerk, houseman, inspector (street), inspector (factory), iron-worker, laborer, meterreader, mill worker, molder, mover, patternmaker, plate worker, presser, salesman, shoe clerk, stone assembler, trainman, tug fireman, tug despatcher, wire weaver woodworker. 
manual work is due to economic considerations and is not ascribable to any relation between police work and the manual occupations. While the physical demands of patrolling are considerable, the work does not in any sense involve skill or adaptability in the use of the hands. Physical prowess is required as a sort of incidental qualification, but mental alertness is the primary qualification. The routine manual occupations count for little as a basis of experience in making observations and exercising judgment in taking police action. Thus, men who have been trained to know how to do things are brought over into a new field, utterly foreign to their experience, where they are concerned with what to do.

Of course, the mere fact that a man has been a manual worker, often by force of accidental circumstance, does not mean that he cannot be the sort of brain worker that a policeman must be. Manual work need not be held to disqualify him. On the other hand, it in no way qualifies him for the more important phases of a policeman's task. The significant fact in Cleveland is that by far the largest percentage of its policemen are recruited from occupations whose character is as far removed from the character of police work as can be. Consequently there are bound to be many misfits, many instances of policemen whose total lack of qualifications for their work is altogether too obvious.

\section{Age of Appointees}

The ages at which men enter Cleveland's police service is also worthy of our consideration. According to present civil service regulations, 21 is the minimum and 35 the maximum age at which men may be eligible for appointment to the police force. Of the 56 men appointed in 1914, only one was aged below 25 and 55 were twenty-five years of age or over. Out of the 186 men appointed in 1920, there were 73, or 39 per cent., aged below twenty-five, and 113 , or 61 per cent., twenty-five or over. Similarly in 1921, of the first 134 men appointed, 55, or 41 per cent., were aged below twenty-five and the remaining 59 per cent. were twenty-five or over. ${ }^{1}$ Considering the more recent appointments, it is found that approximately one-fourth of the 1920 appointees were thirty years of age and over. Somewhat more than one-fourth of the first group of 1921 appointees were thirty or over. We believe that the maximum age for appointment to the patrol force should not exceed thirty years, and that a special effort should be made to recruit, as far as possible, men between the ages of twenty-one and twenty-five. It is said that men over twenty-five possess the advantage of maturity in their

1 The age of one appointee was not given: these figures and percentage calculations are for 133 men. 
fund of knowledge and that they are, on the whole, more reliable than "boys" between the ages of twenty-one and twenty-five. If the soundness of this position were to be fully admitted, it would be logical to conclude that the considerable number of men who have entered the department at an age below twenty-five have not been competent to do creditable police work. But this is not the fact. Indeed, it is only in a few isolated cases that criticisms of individual acts are laid to the youthfulness of policemen, and even then the criticism is made for want of a better reason.

Particular cases of failure to take proper police action are found to be due not so much to lack of maturity as to lack of experience in handling similar situations or faulty temperament. It is experience in the exercise of judgments required of policemen in the daily round that counts for most, and not the general maturity attaching to age. Nor is temperament a quality to be measured by age. True, the young man under twenty-five may become excited and lack self-composure in trying situations, and when such is the case, the criticism of incompetence is merited. The same may be true, however, of the man who is thirty. Higher police officials, whenever consulted on this point, agree that a man of twentyfive who has four years of actual police experience to his credit is almost invariably a better agent than the recruit of thirty or thirty-five who has had fewer years of experience.

On the other hand, there are distinct advantages to be had in recruiting the younger men to the service. In the first place, younger men are more readily trained and molded in response to the desires of the officers who direct them. Inspector Cahalane, who was, for a long time, in charge of the New York Police Training School, said: "Give me the boys in preference to the older men and I can more easily make policemen of them." In training men for the mounted service in New York, it has been found that the best results are achieved with men who have never ridden a horse. "They don't have to unlearn how to ride," said an officer in charge of the mounted squad. Men who know how to ride are accustomed to using the horse for the purpose of covering ground rapidly. Most mounted police work, however, is done with the horse in a walk or standing, and requires a different style of riding altogether. So it is with other types of police work. The fewer preconceived notions the police recruit has developed, the easier it is to train him in the peculiar requirements of police work generally. Mature men do not lend themselves to instruction and molding as readily as do the younger men, whose minds are more open and whose habits are less fixed.

It must be noted that the men who begin patrol work at an early age 
have much the best chance of maintaining physical fitness until the end of twenty or twenty-five years of continuous service. Over 80 per cent. of the men of any police force continue in actual field work without promotion. Entering as patrolmen, they remain as patrolmen to the end. The man who enters the force at the age of twenty-one may be expected to measure up to the rigorous demands of his work until he has reached the age of forty-six, whereas allowances will likely be required for the man who begins at thirty or thirty-five and continues to the age of fiftyfive or sixty. If for no other reason than to protect the city's investment in pension moneys allowed upon disability, there should be an effort to recruit the younger men in preference to the older ones. Field service in all hours and in all kinds of weather will much sooner bring disability to the man of fifty-five than to the man of forty-five.

The point that younger men are needed in the police department is strongly enforced by the experience of European cities. In London the minimum age for appointment to the force is twenty and the maximum twenty-seven. In Liverpool the minimum age is twenty-one and the maximum twenty-five. In Glasgow the maximum age is twenty-five, and in Manchester the maximum is twenty-eight. Paris has a maximum age of thirty, the higher limit being due to compulsory army service, which, under the old dispensation, took two years out of the young man's life.

\section{Turnover in the Patrol Force}

A further analysis of the histories of the men appointed during the years which we have been reviewing shows that the number of resignations during the first few years following appointment is excessive. Table 1 shows the record of voluntary separations from the service of men appointed in the given years.

The figures do not include the total number of separations. During this six-year period there were other resignations of men appointed in years prior to 1914 not included in the above calculation. These have not been included, as we are concerned only with showing the actual proportion of resignations for any one year's appointments. There are a few men dismissed from the department by order of the director of public safety who must be added to the voluntary resignations. The combined record of appointments, resignations, and dismissals for these years is given in Table 2 .

This is a high turnover of personnel for a service supposed to be professional in character, one that is made attractive by reason of its guarantee against periods of unemployment and by offering retirement on pension after twenty-five years of continuous service. Notwithstanding 


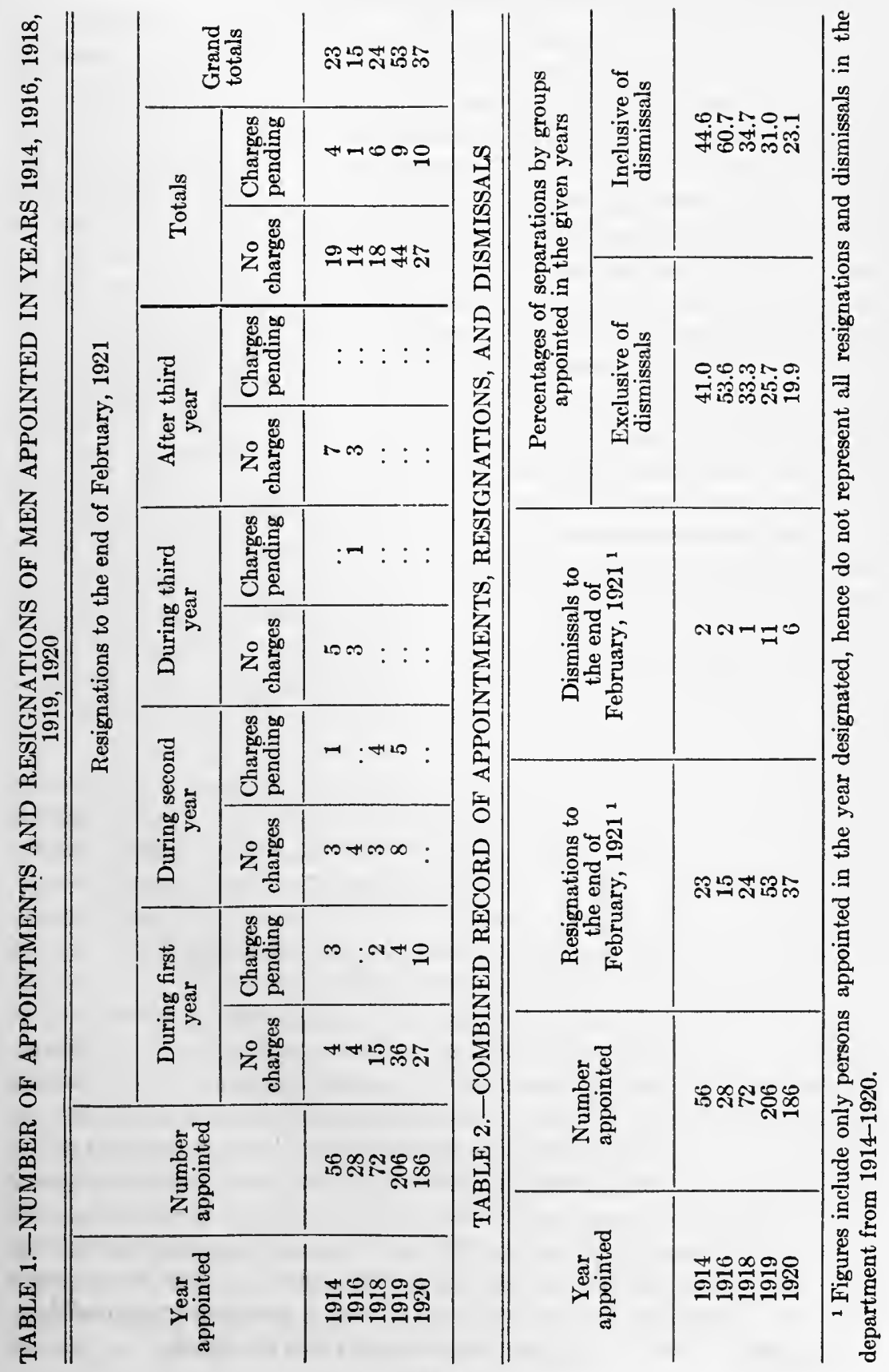


these factors making for permanency of tenure, it is found that of the men appointed in 1914, 1916, and 1918, no less than one in three appointed in any one year had left the department by the beginning of 1921 . Of the 1916 appointees, three out of every five resigned or were dismissed by 1921. Of the 1920 appointees, almost one-fourth of the number left the service for one cause or another within the first year of their appointment!

What are the causes of the large turnover of police personnel? In the first place, there may be cited the failure of a portion of the men to measure up to the demands of police work, resulting in dismissal or the initiation of disciplinary action causing voluntary resignation. Approximately one-sixth of the 1916 group left the service for these reasons. The same was true of nearly one-fourth of the 1914 and 1918 groups, and slightly less than one-third of the 1919 and 1920 appointees. Again, rates of pay given to policemen during the years under review have not been sufficient to hold the men in the department. By 1920 it is true that the increase in salary brought police pay into line with salaries paid in many commercial employments. Whatever the rates of pay, it is safe to say that the salary schedules of the Cleveland force have never been determined on the basis of their adequacy to hold the men in contentment once they were drawn into the department. Moreover, salary schedules have been devised with the view to getting a given quota of men and not to getting men having personal qualifications particularly useful in police work.

A less tangible reason for the impermanency of tenure is that no adequate consideration of the nature of police work is given by the individual before entering upon it. As has been pointed out before, police employment is more often than not considered merely as a job to satisfy immediate needs. The resignations show that many recruits do not approach police work with any serious notion of beginning at the bottom round of a distinctive profession and developing a life career.

The police department is burdened, therefore, with a good proportion of men out of each group appointed, who are soon going to be discontented or who have no serious intention of performing creditable work as a basis for a career as policemen. The fault cannot properly be laid at the door of the men who apply for appointment. It is the business of the municipality, as the employer, to make its selections with thoroughgoing care rather than to pass out jobs to a given number of men who happen to want the job at the time and who have certain simple qualifications of physique and education. Yet there is no conscious effort on the part either of the civil service commission-which is primarily responsibleor of police officials to influence recruiting in this direction. 
In this connection the practice in the London police department can well serve as a model. The utmost care is exercised by the London authorities in the selection of police recruits. Recruiting agents are constantly traveling from place to place in the country districts of England, and even in Scotland and Wales, looking for available men for the London force. They go about their business in workmanlike fashion, utilizing newspaper advertisements, and even bill-posters, and the greatest care is taken to weed out not only the unfit, from a physical and mental standpoint, but those who, in the judgment of the recruiting agents, give the impression that they are not looking upon the police service as a permanent profession.

In Cleveland, advertising for police recruits is of the most meager sort, consisting merely in a formal announcement in the papers that a competitive examination for entrance to the police department will be held on a date specified. For a while during the war some effort was made to use motion picture films to stimulate possible applicants, but this has been abandoned for the simple reason that there is now a sufficient number of applicants. The newspaper advertisement marks the end of the city's effort to attract men to the police service. Thereafter it is only a matter of measuring the men who present themselves. Whoever meets the requirements of residence, height, minimum and maximum weight and chest measurements, is entitled to continue in the examinations. These consist of a medical and physical examination as a qualifying test, and an educational examination, which is given to those who successfully pass the physical tests. The subjects of the examination, with the weights attaching to each one, are as follows: writing 1, spelling 1 , arithmetic 1 , practical questions 2 , oral examination 1, muscular strength 1, military or naval experience in recent war and honorable discharge 1. Applicants making a final average rate of 70 per cent. or over are placed on a list of those eligible for appointment.

The examinations involve minimum standards. The tests really determine how far above the passable minimum standards the applicants stand and are not adjusted to measure the full capacity of the more capable applicants. Another evidence of the fact that the examinations are designed to accommodate minimum or qualifying standards rather than to measure maximum capacities is shown by the practice of giving the same kind of examination-not the same questions, however-regardless of whether there are 50 applicants or 1,000. Types of examination are not adjusted to changes in the supply of men nor is there any modification made in response to the need for selecting special types of men in the light of the department's requirements. Indeed, there is no 
conversation between the officers of the civil service commission and of the police department on such matters.

As a result of the examinations applicants are divided roughly into two groups, the hopelessly unfit, who are promptly thrown out, and those who have made marks better than the minimum requirement. The latter are all retained on the eligible list, with certain technical limitations. The commission does not erect a scaling-wall which is heightened when applicants are many and which is made sufficiently difficult of scaling to measure the capacities of the superior competitors.

Finally, there is no effort, by either the civil service commission or the police department, to convey to prospective applicants any adequate notion of the prospects, demands, and possibilities of police service as a career. The men are taken as they come. If suitable men are not attracted, it is held to be regrettable. Standards of police work are then fashioned to fit the capacities of the men certified to the department by the civil service commission. There is never any attempt first to set the standards in accordance with the actual demands of constructive and improved methods of policing, and then through special efforts to get the kind of men who measure up to these standards.

While the police department exercises no initiative in going after the men it wants, it does have some opportunity of looking into such personal qualifications of the applicants as are not shown in the civil service examination. Under the present arrangement the civil service commission requires the police department to make a report on a character investigation of each applicant who has successfully passed the examinations. This investigation is conducted by the commanding officers of the precincts in which the applicants have their residence, and is a more complete investigation than is conducted in most cities. This is the police department's sole opportunity, although in a limited and purely negative way, to set its own standards.

With the civil service list established, the appointing authority has an opportunity to exercise some choice in making selections, under the provision of the law which permits him to choose one out of three who are certified by the civil service commission as eligible. This privilege is generally waived, and the policy is followed of appointing in one, two, three order from the list. However, the wisdom of this discretion allowed the appointing authority has been abundantly justified in other cities, and as long as recruits to the department continue to come through the channel of the civil service commission, the provision should be maintained. 


\section{Civil Service as a Source of Recruits}

As has been pointed out above, we are by no means satisfied with the way in which the civil service commission has discharged its obligations toward the police department. In spite of the fact that many of the commission's activities are prescribed by law in detailed fashion, its work has been too inelastic and stereotyped to obtain the best results. As a consequence, the department contains far too many men who are lacking in important qualifications necessary to a good policeman. It has been discouraging to examine the reports which the men are required to render in the course of their daily operations. Many of these reports show an utter lack of the ordinary intelligence demanded in making an observation the record of which becomes an official public document. A single illustrative example will suffice:

"First Precinct,

Nov. 16, 1920.

Lieut. Huge.

"Sir:

"About 11:15 Sergt. Harwood went to the rear of the building \& very shortly after that he came to the front again \& that, that time a yong lady coming east was entering the building and I stoped her asking the questions as I was instructed to, this yong lady refused to give her name \& the Sergt. interfered $\&$ said to this young lady to give me her name in which she did \& about 11:30 or 11:40 a man coming west made an atempt to enter the hotel \& this was Mr. - we three stood there up till the time he left was about 12:05 a.m. \& in the meantime about 11:50 another man came while the three of us were talking, this man I dont know his name \& came there with a machine to my knowledge, \& all of this time when Mr. — came, up till the time he left the sergt was still in the front of the — House, this is far as I can remember \& about 12:15 or 12:20 A.M. I was ordered by Sergt Harwood to go to the rear of the building \& tell the man in the rear to come to the front and that time this third man was still there.

"Respectfully,

"Patrolman."

However, we believe that as far as appointments to the force are concerned, the civil service commission can probably be more wisely employed than the police department itself. Generally speaking, civil service commissions, not only in Cleveland, but elsewhere, have done a great deal to raise the standards of eligibility in police appointments and to eliminate the unfit. Moreover, they relieve the police administrator of a vast burden of detail. The latter's whole concern is to secure raw recruits who can be turned into honest and intelligent policemen, and 
any plan or machinery which will produce this material upon demand adds to the effectiveness of his administration. Arthur Woods, former police commissioner of New York, who cannot be charged with being overfriendly to civil service, defines its application to the problem of police appointments as follows: "It is undoubtedly about as good a method as any other for picking out qualified candidates, for the men come from all walks of life, and seemingly from every profession, trade, and job there is. No comparative record could be obtained, nor could the judgment of employers fairly be used to distinguish between one man and another, since there might be a thousand different employers for a thousand applicants, and as many varying standards as employers."

If, therefore, civil service could be looked upon as machinery for furnishing raw material, and if the police executive had the unchallenged right to reject, after probation, any candidates who proved unsatisfactory, there would be little in this phase of activity which could interfere with the principle of responsible leadership. Cleveland's civil service system needs a thorough overhauling and a keener appreciation of the tasks and responsibilities of the police department for which it selects recruits.

\section{Police Training School}

The department is to be commended for its full-time training course of eight weeks for recruits. A lieutenant of police, enthusiastic and ambitious for its successful promotion, is in immediate charge. One reason for the school's firmly established position is to be found in Chief Smith's healthy interest in its welfare. To him is due the credit for its original establishment a few years ago-a noteworthy achievement in the department's history.

Considering the resources that are available, the school for recruits is well conducted. There is need for better equipment, especially for physical training and for a larger staff of instructors. There is room, too, for considerable development or rather evolution of the school. In the first place, it should be more than a school for recruits. Indeed, it should be the department's university, providing instruction for veterans and officers, and such specialists as detectives and men of the mounted service. The idea should be to have a school in which all ranks should constantly be "freshening up"-to use Colonel Woods' expression-in police technique. The purpose of such courses should be tokeep the officers from becoming "rusty," lest the recruits fresh from school be better versed in special subjects than their superiors. From time to time lectures might be given to members of various ranks by criminologists, 

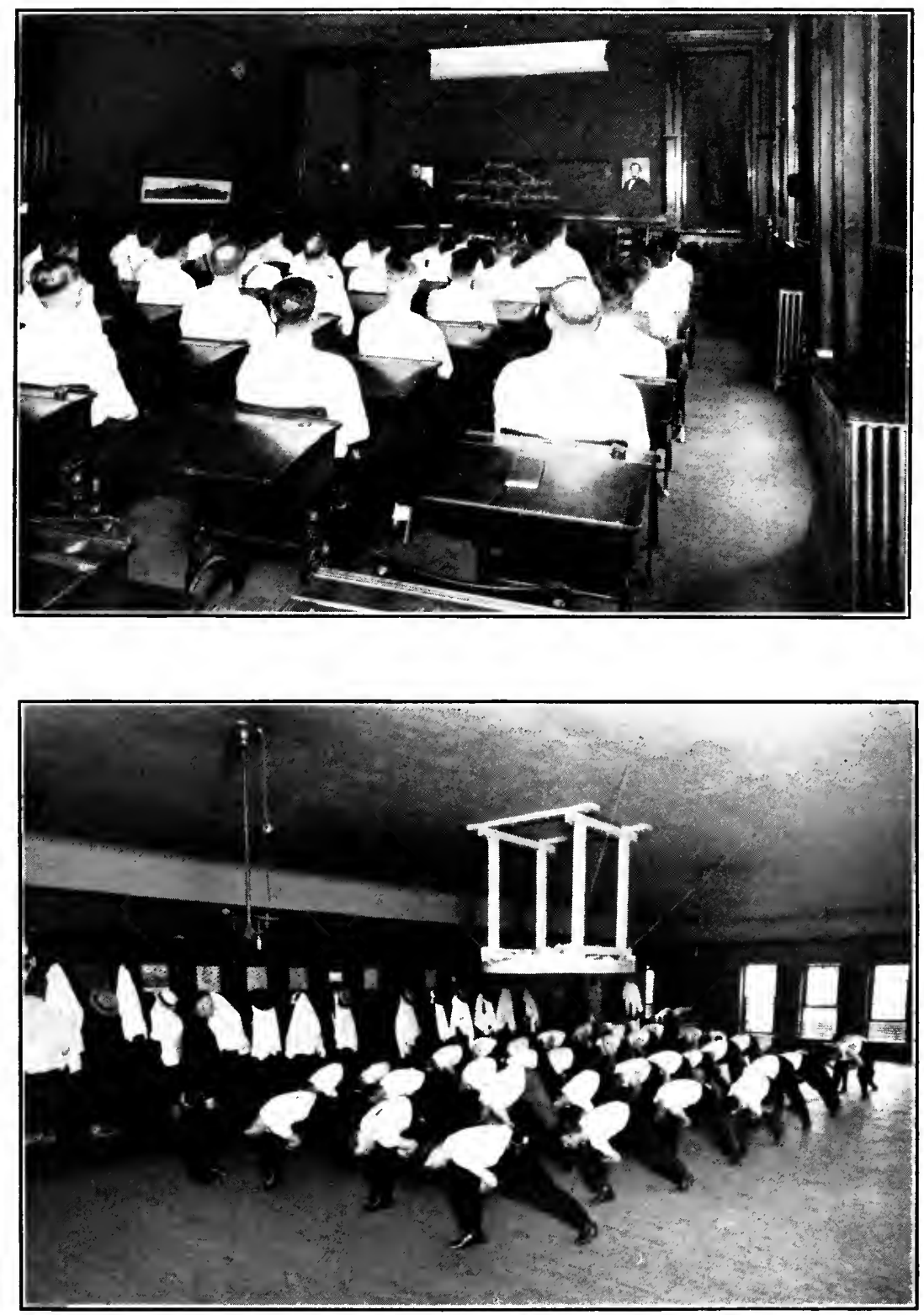

The police training school, inadequately equipped but well conducted. The upper picture shows the lecture room; the lower, physical drill 
lawyers, identification experts, and other specialists in fields related to police work. Such special phases of police activity as discipline, preparation of records, and the giving of bail might also be discussed in occasional courses. To this plan was due the splendid efficiency of the New York force under Commissioner Woods, and its wide adoption in such cities as London and Liverpool proves its worth.

We suggest, too, that the school be developed in such a way as to become the staff agency of the department, serving as a personnel service division. The school is primarily engaged in converting into policemen the raw material furnished by civil service lists. What better agency is there for passing efficiently on the quality and adaptability of this raw material? If the personality tests, such as were recommended by the chief in his last annual report, are to be conducted, or psychological tests of one sort or another are to be held, the training school is the proper agency for conducting them.

In other words, the school should be constantly engaged in studying the problems relating to personnel. When the classes are not in session, specialists attached to the school might devote their time to working out efficiency record systems and doing other research work in connection with tests and instructions. Industrial concerns recognize the value of the investment in personnel service departments. The police department of Cleveland has a large enough force to justify an investment in the same sort of work. 


\section{CHAPTER V}

\section{PROMOTION}

\section{The System of Promotion}

T HE selection of recruits is but the first step in the provision of police personnel. Filling the quotas of special divisions in the department and filling the higher posts through promotion are the next steps. Regular assignment to the detective bureau is generally considered as a promotion by reason of the increased compensation allowed, but it is not technically a promotion since detectives are only detailed to the detective bureau and the men so detailed continue in the rank held at the time of their assignment.

Promotions are governed entirely by the rules and regulations of the civil service commission. These regulations provide that all promotions in the uniformed force of the police department-excluding only civilian employees-"shall be from class to class, from the lowest class to the highest," within the force. Thus, promotion to any given rank in the department is restricted to the membership of the next lower rank, and it is, therefore, impossible to fill any post above the rank of patrolman by making appointments from outside the department.

All promotions are made as a result of competitive examinations conducted by the civil service commission. Eligible lists are furnished by the commission, and the director of public safety is obliged to make promotions from this list. Examinations given to applicants for promotion include the following subjects: "Writing, spelling, arithmetic, practical questions, as in the judgment of the commission pertain to the office to which said applicant seeks promotion; State laws and city ordinances pertaining to the duties of said office; rules and regulations of the department; seniority and record in the service of the applicant, and such other subjects or tests as the commission may prescribe."

A patrolman is not eligible to promotion to the rank of sergeant until after he has served three years as a patrolman. Sergeants and lieu-

1 Rule XVII, Sec. 5, of the Rules and Regulations of the Civil Service Commission of the city of Cleveland. 
tenants must have served two years in their respective ranks before they are eligible for promotion to the next higher rank. A patrolman who has served as many as five years in the department is entitled to a marking of 100 per cent. on seniority as one of the subjects of the promotional examination. If a patrolman has served as many as three years, but less than five, his marking in seniority is reduced 10 per cent. for each year less than five. In a similar way sergeants who are examined for promotion to the rank of lieutenant are entitled to a marking of 100 per cent. on seniority after the completion of seven years' service in the department, two years of which must have been served in the rank of sergeant, and a reduction of 10 per cent. in the seniority marking is made for each year less than the seven served in the department. Applicants for promotion to captaincy must have served ten years in the department to obtain a marking of 100 per cent. on seniority, and 10 per cent. is deducted for each year less than ten years served.

The "record" of an applicant for promotion, another factor counted in promotional examinations, is determined solely upon the basis of the applicant's disciplinary record in the department. Thus, if the record shows that the applicant has not been charged with a violation of the rules and regulations of the department within a period of five years immediately preceding the date of application for promotion, he is entitled to a marking of 100 per cent. on record. The regulations further provide that if the applicant "shall have been within such five years under charges for and found guilty of any offense specified in articles 1 to 12 inclusive, of Rule XIII, of the rules of the department, ${ }^{1}$ he shall have charged against him 20 per cent. (meaning 20 per cent. deduction from the record rating of 100 per cent.) for each of such charges; and for

1 Articles 1 to 12 inclusive, which are deemed specific cause for suspension from the department under charges, are as follows:

Art. 1. For intoxication while on duty or while in uniform.

Art. 2. For being a user of intoxicating liquor to excess.

Art. 3. For being engaged directly or indirectly as a vendor of intoxicating liquors.

Art. 4. For wilful disobedience of any order lawfully issued to him by a superior officer in the department.

Art. 5. For incompetency to perform the duties of his office.

Art. 6. For conviction of any crime or misdemeanor against the laws of the United States or the laws of the State of Ohio or for conviction of any violation of a lawful ordinance of the city of Cleveland.

Art. 7. For making known any proposed movement of the department to any person not a member of this department.

Art. 8. For unnecessary and unwarranted violence to a prisoner. 
conviction of any offense specified in articles 13 to 21 inclusive $^{1}$ of said rule XIII, he shall have charged against him ten (10) per cent. for each of such charges." 2

\section{Limitations and Defects of the System}

The practice of giving some credit for seniority is to be commended, and the markings for seniority ratings are reasonably scheduled. That portion of the examination which embraces the calculation of an applicant's "record" is a disguised attempt to permit the applicant's work and experience to have some weight in an examination looking to promotion. As a matter of fact, it is no more than a penalty schedulewholly negative in character. It is nothing short of absurd to imply that the present civil service examination for promotion in the police service gives any credit for meritorious work performed by members of the department who are being examined.

A mere absence of disciplinary charges indicates nothing as to the character of work done by the applicant for promotion, nor, indeed, whether much of any sort of work was done. Under the present scheme of record rating the mediocre man, if he avoid an open breach of the rules, as most of them can do without great effort, is placed on an equal footing, as far as record goes, with the energetic, able, and efficient officer who has also kept out of trouble. No attempt is made to give credit in a

Art. 9. For cowardice or lack of energy of such character as to amount either to incompetency or to gross neglect of duty.

Art. 10. For sleeping while on duty.

Art. 11. For wilfully or continually violating any of the rules or regulations of the department.

Art. 12. For habitually contracting debts which he is unable or unwilling to pay or for refusing or without reasonable excuse to discharge his lawful obligations.

1 Articles 13 to 21 inclusive of Rule XIII are also specific causes for suspension. They are as follows:

Art. 13. For intoxication while not on active duty.

Art. 14. For indecent, profane, or harsh language while on duty or in uniform.

Art. 15. For disrespect shown to a superior officer in the department.

Art. 16. For any neglect of duty.

Art. 17. For absence without leave.

Art. 18. For gossiping about the affairs of the department.

Art. 19. For conduct unbecoming an officer, patrolman, or a gentleman.

Art. 20. For conduct subversive to the good order and discipline of the department.

Art. 21. For neglecting to report his change of residence to the officer in charge of his precinct.

2 From rules and regulations of the civil service commission. 
positive way for valuable work performed. Instead of allowing the mere absence of wrongdoing the highest mark that is given for police "record," a clean disciplinary record should be rated as a normal median. Failure to measure up to the least that is expected of every member of the depart. ment-compliance with the rules-should apply as a subtraction in the shape of demerits from the median rating. But demerits should be only a part of a man's record. Provision should be made for showing the converse side of the record by taking into account the opposite of neglectfulness, disobedience, and the performance of improper police action. In other words, credit for meritorious work should be given in the form of an addition to the normal median rating. It is only in this way that a premium can be placed on accomplishing more than the avoidance of wrongdoing.

Considering the promotional examination as a whole, we believe it is not well adapted for the wise selection of men possessing qualities fitting them for the tasks which promotion imposes upon them; that, as far as the mere attainment of promotion is concerned, no adequate reward, hence no adequate stimulus, is given for the accomplishment of superior police work; that opportunities for preparation and for obtaining high marks in the examination are unequal; that an examination for a rank where no knowledge is given the applicant of what specific duty he may be assigned to perform-whether patrol, traffic, detective, or crime prevention duty-is an unsound practice; and finally that responsibility for the appraisal of the personnel assets of the department and utilization of those assets through promotion are too far removed from the official who is responsible for directing the men.

The present scheme of having an independent body apply the tests which determine eligibility for promotion was devised primarily as a protection against a possible display of favoritism in making promotions. The plan has met with success in so far as it has minimized political, social, and religious influences as factors in determining promotion. This, however, is a purely negative achievement. On the positive side there is little if anything to show that there is an advantage to be gained in turning over the matter of promotions to an outside body. The written examination and the seniority and disciplinary record fall short in measuring the qualifications most needed in superior officers, for example, integrity, executive ability, and a natural disposition to assume the initiative. These qualities are all important to men filling the higher posts in a police department, yet they are not reckoned with in the promotional examinations conducted by the civil service commission. Instead, facility in arithmetic and spelling and ability to answer certain 
commonplace practical questions are the measurements applied. The examination at present tests what an applicant knows. What he can do, what he has the spirit to do, and what he has done are significant considerations which are altogether neglected.

Judgment of fitness for promotion in work where initiative and zeal play so large a part must take into account the experience basis for determining differences between the hard workers and the lazy, between the thorough ones and the hasty or careless, between the backwardpulling, disgruntled dispositions and the enthusiastic, forward-looking men. Any method of selection which omits this test is inadequate and hence unfair to the men involved, and inimicable to the welfare of the department.

It is possible to cram for an examination, which is certain to be much like the examinations previously held for promotion to the same rank, and the applicants devote much time and thought in preparing for it. In this connection it is to be observed that the lieutenant, for example, who has an assignment in a quiet precinct or at some post which allows him considerable leisure, has the important advantage of time at his disposal during which he may prepare for an examination. In this way he may easily secure an advantage over a lieutenant who is energetically carrying on his work in a busy precinct and continuing it to such hours that he has neither energy nor time left for productive study. The latter man is building up an experience in the practical operation of the day's routine, but it stands him in no stead when he is called to compete in a promotional examination.

Under the civil service arrangement examinations for a given rank are held in advance of the actual need for making a promotion. The grades and standings on the eligible list for promotion to, and including the rank of captain of police, established as a result of the examination markings, remain in force for two years, although, after it has stood for one year, the commission has the right to abolish the list and hold another examination. Accordingly, the practical questions section of the examination must relate in a very general way to the requirements of the rank involved, for it is not known in what branch of the service the applicant will be employed. There is no opportunity, therefore, to weigh the specific needs of a given post of duty and pick a man then and there to fill it. This prevents the promotion of men within a single branch of specialized work, as in the vice bureau, detective bureau, or traffic squad. If, for example, it were determined that an additional captain of detectives was needed, the place would have to be filled either by transferring some captain from another branch of the service or by taking a man from 
the list of lieutenants eligible for promotion to the rank of captain. If a lieutenant of detectives does not happen to be in one, two, or three order on the list, then there is no opportunity to promote a man with detective experience. Most of the captains recently assigned to commands in the detective bureau have been taken directly from commands of the uniformed patrol service. Some had never had any detective experience. The same would be true in making a promotion in any other branch of specialized work.

Perhaps the most serious objection to the present methods of making promotions is that the choosing of men to fill the higher posts is so far removed from the directing head of police operations. An independent body determines who the subordinate leaders of police business shall be after tests which, as has been shown, do not consider the more important personal attributes with which only the police administrators alone can be acquainted. Actual choice, with a range of one out of three eligibles, is left to the director of public safety. The chief of police, acting as the administrative head of the department, has nothing to say about it except in cases where there is such happy accord between the director and chief that the director may ask the chief for his recommendations of choice. The net result is that there is no one exercising the practical police point of view in looking out for evidences of ability in individuals who indicate fitness for promotion to particular posts of duty. Where the administrative head has no concern about naming the men who shall be promoted, he will spend no time in making appraisals. He will simply take the men who are given him by the civil service commission and do the best he can.

This situation relieves the head of the department of what should be one of the most important of his tasks, if not the most important, namely, the intimate supervision of the work of his subordinates with a view to developing the maximum use of whatever special abilities may be discovered in them.

Stephen O'Meara, who for many years served creditably as police commissioner of Boston, defined the situation as follows: "No written examination can possibly disclose the qualities and habits which are of vital importance in a police officer of rank and can be known only to his superiors. Among them are judgment, coolness, moral as well as physical courage, executive ability, capacity for the command of men, sobriety, and other moral qualities, standing among his associates and in the community, powers of initiative, temper, integrity, energy, courtesy."1

${ }^{1}$ From a private memorandum. 
Theodore Roosevelt, in his Autobiography, expressed himself in similar vein. "I absolutely split off from the bulk of my professional civil service reform friends when they advocated written competitive examinations for promotion. In the police department I found these examinations a serious handicap in the way of getting the best men promoted, and never in any office did I find that the written competitive promotion examination did any good. The reason for a written competitive entrance examination is that it is impossible for the head of the office, or the candidate's prospective immediate superior, himself to know the average candidate or to test his ability. But when once in office, the best way to test any man's ability is by long experience in seeing him actually at work. His promotion should depend upon the judgment formed of him by his superiors."

\section{Recommendations}

It is recommended, therefore, that the matter of promotions be put squarely up to the director of police. He should be enabled to make use of the civil service commission as a staff or agency equipped to make certain limited measurements. But he should be allowed to place his own valuations on the tests made by the commission and make any other tests he may see fit in order to arrive at his decisions regarding promotions. Under such an arrangement the civil service commission might be asked to conduct examinations which would really amount to qualifying examinations based on certain minimum qualification standards. The police head could then add to these results the estimates of a candidate's worth, based on lines not covered by the civil service examination.

It is further recommended that there be established a board, to be known as a board of promotion, consisting of three to five members of the higher ranks in the department. It should be the duty of this board to make recommendations for promotion to the director of police after thorough investigation and examination or series of examinations as may seem necessary. The members of this board should be designated by the administrative head of the department to serve in such capacity at his pleasure. We do not wish to recommend in too specific detail what the composition of this board should be. If the principle be established, there may be many modifications in a scheme designed to carry it out. It is suggested, however, that in addition to the chief line officer of the uniformed force the head of the police training school, as the depart- 
ment's specialist in matters of personnel, be included in the membership of the board. Of course, it would be necessary to have the board composed only of members having a rank always equal to and generally higher than the rank to which promotion is to be considered. In the case of promotions in the detective service, the chief of detectives and possibly another detective officer should be included in the board's membership. For promotions to posts in the patrol service, officers of the uniformed force should be substituted for the detective officers. Similar substitutions should be made in designating the board's membership when considering promotion to other special branches of the service.

Preliminary to the examination made by the board of promotion, commanding officers of the various units in the department should be required to submit names of such members of their commands as are deemed worthy of consideration for promotion. These recommendations, together with such efficiency records of the candidates as may be available, should be reviewed by the board of promotions. Provision should be made for allowing any member of an eligible rank who may not be endorsed by his commanding officer to make application to the board to have his name considered for promotion. The board could establish weights for seniority and prepare a schedule of merits and demerits to apply in making its recommendations. There are no measurements now used by the civil service which could not be used by a board of promotion, but the board of promotion can employ measurements that are not and cannot be employed by an outside civil service commission.

Recommendations for promotion should be delivered by the board to the administrative head of the department, who should have unrestricted authority to accept or reject the board's recommendations.

We submit that the establishment of a board of promotion, composed of members of the professional force, whose duty it is to pass judgment on the quality of men as policemen and the quality of their work, will accomplish four highly desirable results: First, such a scheme would introduce expert appraisal of fitness for work with which the appraisers are themselves thoroughly familiar. Secondly, it would tend to stimulate a feeling of self-reliance in the police personnel and imbue the higher officers with a heightened sense of responsibility for promoting the best interest of their profession. Thirdly, it would be the first step in the direction of setting up machinery which would almost certainly evolve standards and means of measuring the efficiency of policemen. When all members of the force realize that what they do, as observed by their superiors who are competent to judge, alone counts for advancement, there will be a new tone in the whole department. Fourthly, a board of 
promotion would eliminate favoritism in making choices for promotion perhaps more thoroughly than does the civil service commission. Policemen will be the first to welcome an escape from outside interference. They do not need barriers to keep them from rushing to influences which they know have always worked for demoralization and the disrepute of their activity. They have in the past affected alignments with outside political interests only because those interests had connections with elected officers who determined appointments, promotions, and assignments to favored posts. But once the whole job of policing is left to the personnel responsible for it,--including, of course, a civilian administrative head,-without the introduction of outside connections that make for interference, the professional force will show that it has a natural pride in its work, that it desires a good name and an efficient department, more, indeed, than other persons whose standing and interests do not rise and fall with the standing of the police department.

Lest it be thought that this recommendation for a board of promotion is of too radical a character, attention is called to the fact that this same system is now and has been for many years in operation in Boston and other American cities, where it has worked with unqualified success. Similarly in London the non-competitive system of promotions is the method in vogue. There the civil service commission enters the situation only upon the invitation of the police commissioner, to assist the department in weeding out men whose lack of education makes them unfit for promotion, and the examination which it gives is merely to test the general educational capacity of the applicant. A second examination in the elements of police duty, both oral and written, is given by a board of police officials, and those who emerge from these two tests are eligible to promotion, although the commissioner, of course, makes his own choices from the list.

Some such system as this is necessary if our police departments are to be saved from lifelessness and dry rot. With promotions the result of real excellence in police work under the watchful eye of superiors, much of the present inertia would disappear. 


\section{CHAPTER VI}

\section{DISCIPLINE}

$\mathrm{T}$

YHE term discipline as here used includes both its narrower and broader meanings. Discipline in its narrow sense relates only to punishment administered for some violation of the rules and regulations or dereliction of duty. This punishment may take the form of a cancellation of vacation days, suspension without pay, demotion, or dismissal from the department. In its wider meaning the word discipline embraces the conduct and bearing of members of the force in the performance of their duty and the manner in which the force responds to the leadership of the various officers in charge of operations.

In its wider meaning, therefore, the discipline of a police force is of far-reaching significance. The essential basis of all good police work is the character and physical power of the individual men. As Arthur Woods says: "They must be strong of body, stout of soul-sturdy, two-fisted specimens, knowing how to hold themselves in restraint even under severe provocation, yet prompt and powerful to act with force and uncompromising vigor when only that will maintain order and protect the law-abiding." In other words, alertness, keenness, self-restraint, and vigor are the essential earmarks of a good police force.

It would be impossible to claim that these characteristics are particularly noticeable in Cleveland. We have observed a sufficient number of instances of laxity in police work to warrant the general conclusion that something is radically wrong with the standard of discipline. No effort was made to spy on the men for the purpose of detecting flaws in their conduct, but many casual observations were made of the men as they went about their work on the streets, in station houses, and at police headquarters. It was not at all uncommon to find two policemen talking together while on post duty, and carrying on long conservations with citizens while on post seems to be a habit. Some conversation with citizens is, of course, necessary, but reference is here made only to those conversations the manner of which clearly showed that the discussion was not confined to lines of police duty. These conversations occurred on posts covering the busiest streets as well as in the more quiet districts.

On one occasion the traffic cornerman at the intersection of Superior 
Avenue, N. E. and the Public Square was off duty from 11 A. M. until some time after 11.15 A.M. A gale was blowing at the time, so that there wassome danger to pedestrians in crossing the street, as automobiles and street cars were moving without any regulation. During all of this time the patrolman who was on post at the southwest corner of the post-office building was engaged in conversation with a citizen, with his back turned to what really amounted to an emergency situation on the uncovered traffic post a few feet away. Many patrolmen while on post duty were observed leaning against posts or buildings as if too tired to stand erect. The frequency with which needlessly prolonged conversation and other forms of idling occur reflects discredit on the work of patrol sergeants. Either the sergeants are not aware of what constitutes alert patrol, or they are too lenient in their supervision.

On the afternoon of February 21 a building in process of demolition at East Sixth Street and Superior Avenue, N. E., collapsed, killing and injuring several men. A large crowd gathering to view the rescue work necessitated a considerable detail of policemen to keep the crowd back, so as to allow firemen to work and to protect the people against the danger of the unsafe building walls. Crowds were allowed to gather on the sidewalks across Superior Avenue from the building, and no adequate measures were taken to keep open passageways on the crossing sidewalks. A patrolman was stationed at the southwest corner of Sixth and Superior. He was watching the firemen at work about the wrecked building with the same sort of preoccupation as that manifested by the crowd blocking the sidewalk. He was not doing as well as the crowd, in fact, for he was chewing tobacco and violating the law by expectorating continually in the street. A sergeant forced his way through the crowd and instructed this patrolman to clear a passageway. The patrolman made a grimace, as if in disapproval of having his attention called to the fact that he was supposed to be policing the crowd. $\mathrm{He}$ started a few citizens moving, but never properly cleared the passageway.

At the same place, on the day following, two other policemen, one a foot patrolman and the other a horse-mounted man, were observed while they were policing a crowd which had gathered to witness a parade of the Cleveland Grays. Both men were facing the parade, and as the flagbearers' detachment passed the policemen failed to salute the national emblem, in careless disregard of the instructions covering honors to be rendered by members of the force when in uniform and on duty.

One more example of slovenly attitude may be cited. A squad of nine men was observed at the $2.15 \mathrm{P}$. $\mathrm{\text {c}}$. roll call assembly in a precinct station. While the officer who was holding the roll call read the orders 
to this outgoing platoon, three of the men who were chewing tobacco stepped out of their line formation in order to expectorate. Another was seen whispering to the man standing in line beside him as the description of persons wanted and alarms giving information of all kinds was being read by the officer in charge. An attitude of this sort makes a joke of discipline. It makes the uniform a cheap pretense.

These instances have not been given in any captious spirit. It is submitted, however, that although these minor derelictions may be small in themselves, the very frequency of careless, slovenly, and inattentive actions indicates a general absence of good discipline. The whole force needs toning up. It needs to be infused with vigor and alertness. The men should be gotten onto their toes. The department's morale should be stiffened with the same spirit that Arthur Woods put into the New York force during his administration. This means discipline; it means the strict observance of the letter of the department's regulations; it means the exaction of a full measure of compliance with police duty. It brings with it no hardships. On the contrary, it promotes an esprit de corps that makes for the happiness and self-respect of the entire force.

\section{Record of Formal Disciplinary Actions}

An analysis was made of major cases of disciplinary action which had resulted in suspension from duty on the order of the chief of police and subsequent trial by the director of public safety. There were 64 members of the force tried during the year 1920. One member was tried twice during the year and two other members were charged with a second offense within the year and dismissed from the department, having signed after the first trial a resignation to be accepted by the director at his pleasure. Thus, there were 67 offenses subject to the trial judgment of the director committed by 64 persons during 1920 . In a number of cases more than one charge was preferred against a single offender. The nature of the charges preferred in the 67 trials is shown in the following tabulation:

Intoxication and drinking in uniform

Intoxicated while on duty

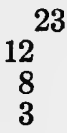

Intoxicated while off duty

Drinking in uniform while on duty

Neglect of duty (allowing prisoner to escape, not using due diligence, etc., etc.)

Off patrol (sleeping, sitting in stores, etc.)

Reporting late; failure to ring duty calls, etc.

Disobedience

Use of indecent language

Feigning sickness 
Shooting craps or running crap game

Interfering with an officer on duty

Miscellaneous

Beating horse; offering to permit the making of whisky in return for payment of money; refusing to pay street-car fare while not in uniform; abusing pool-room keeper, etc.

An examination of the previous record of the 64 men tried in 1920 shows that 25 of them had not been previously charged with offenses. The remaining 39 had been charged at one time or another with 99 offenses, as shown by the following tabulation:

Drinking and intoxicated

Off post

Neglect of duty

Late to roll call

Failure to ring duty calls

Indecent and abusive language

Disobedience

Failure to report to prosecute

Feigning sickness

Improper performance of duty

Miscellaneous

The results of the 67 trials held in 1920 were as follows: two members were reinstated without punishment, being found not guilty; in 38 trials some form of punishment was administered and the members retained in the department. Of the remaining 27 trials, 21 resulted in dismissal from the service of the persons tried, and six members resigned before the date for trial, while charges were pending against them. The nature of the punishment imposed in cases other than cases of dismissal is shown below:

Reprimanded, suspended four days, fined ten days' vacation and required to sign a resignation to take effect when accepted by the director

Reprimanded, suspended four to thirteen days, fined two to six days' vacation

Reprimanded, suspended four to six days' vacation

Suspended four to thirty-five days, fined four days' vacation to all vacation for a period of five months, and required to sign a resignation to take effect when accepted by the director

Suspended three to thirty days, fined one day's vacation to all vacation for nine weeks

Suspended five to forty-five days and demoted

Suspended nine to fourteen days

Fined three days' vacation to vacation for a period of one month, and required to sign a resignation

Considering the cases involving a charge of intoxication and drinking in uniform, it is found that out of 23 cases, only four resulted in dis- 
missal from the department. One resigned while charges were pending; eight received a sentence of suspension from duty for a definite period, fine of days off or vacation, and in addition were required to sign a resignation to be made effective at the pleasure of the director. The remaining 11 were suspended and fined days off or vacation. Since some punishment was levied in all cases, it would appear that proof of the charges was furnished to the director in each case.

The record for the first five months of 1921 is much like that of 1920 . Intoxication cases from January through May, 1921, numbered 11. The records show that in a majority of the cases the member accused was intoxicated or drinking while on active duty. These 11 trials resulted in the dismissal of four members. In the case of one member whose previous record showed charges of intoxication on several occasions, the penalty was suspension for five days, fine of two days' pay, and loss of the next four days off duty. In another case charging intoxication and being off post the punishment was suspension for ten days and fine of five days' pay. Intoxication is a very serious offense in police business. A policeman who has possession neither of his wits nor of his self-control is worse than useless. Indeed, it is nothing less than shocking for a policeman, with all the wide powers which his office implies, to be under the influence of liquor. A man who cannot resist the temptation to become intoxicated while on duty is not fit to wear the uniform, however insignificant the offense may appear, or however worthy the man may be for other employment.

The London police force long ago adopted the principle of making intoxication while on duty the occasion for immediate dismissal. No excuse is accepted. The same rule could wisely be adopted in Cleveland. Certainly the penalties imposed in Cleveland for intoxication by the civil service commission during 1920 were not sufficient to reduce the rate of offenses in 1921, nor will the punishments imposed in 1921 convey to the members of the force any adequate appreciation of the seriousness of their offense.

\section{ApPEALS}

The decision of the director of public safety is not final in the event that the member tried desires to appeal his case to the civil service commission. No case resulting in a punishment less than dismissal or demotion was appealed to the commission during 1920. However, in something more than half of the cases resulting in dismissal or demotion such an appeal was taken, and with much success. The civil service commission affirmed the judgment of the director in seven cases, but 
disaffirmed his ruling in six cases. Four patrolmen who had been dismissed from the service were reinstated, and two sergeants who had been demoted to the rank of patrolman were restored to the rank of sergeant by order of the civil service commission.

A brief résumé of the facts pertaining to the cases in which the commission disaffirmed the ruling of the director follows:

1. Patrolman — was dismissed after trial on the charge of refusing to arrest a woman who, he knew, had stolen a ring and of accepting custody of the ring. This patrolman's previous disciplinary record disclosed that he had been reported some 15 times-late, several times; off post, several times; having debts of long standing, slapping a newsboy, and failing in appearance to prosecute. He was reinstated by the civil service commission with a forfeiture of six weeks' salary. In other words, the civil service commission substituted its own judgment for the judgment of the director of public safety.

2. Patrolman — was dismissed after trial on a charge of having visited a known prostitute in a city hospital and interceding with an attending doctor on her behalf while in an intoxicated condition. Previous record shows charges of intoxication and ungentlemanly conduct. The civil service commission reinstated him in the service without penalty.

3. Patrolman — was dismissed on a charge of refusing to pay his street-car fare when not in full uniform. Doubtless this charge was viewed in the light of this patrolman's previous record, which follows: charged with undue use of blackjack; feigning sickness; twice failed to report to prosecute; received money for the performance of regular police duty; reporting late; making false report; using abusive language. He was reinstated by the civil service commission.

4. Patrolman — was dismissed after trial on a charge of failure to patrol and ring duty calls. His previous record shows: absence from post; late at roll call; feigning sickness; failed to charge another with violation of law; intoxicated; off patrol; failure to ring duty calls; drunk and picking fight; drinking; off patrol. The civil service commission reinstated him.

5. Sergeant — was suspended for six weeks and demoted to rank of patrolman as a result of charges of disobedience, leaving a post before he should, and failure to prefer charges against a patrolman. Restored by the civil service commission to rank of sergeant.

6. Sergeant — was suspended and demoted to rank of patrolman following charges of neglect of duty and unnecessary conversation with citizens. Restored by the civil service commission to rank of sergeant. 
Incidentally, one of the cases above cited affords striking illustration of the present chaotic conditions in the police department due to divided leadership. The chief of police evidently felt that a violation by a superior officer of the department's rule in regard to the holding of unnecessary conversation with a citizen gave evidence of such officer's unfitness to do supervisory work. Accordingly, the chief, in preferring charges, recommended demotion. There was no disputing the technical guilt of the officer, and the director ordered demotion in compliance with the chief's recommendation. However, in delivering formal notice of judgment the director completely vitiated his attempt to uphold the chief when he stated in the letter which was made public that he did not approve of the judgment which he himself had rendered. The following is an extract from the letter: "While there may be some doubt as to whether the mere conversing with citizens for this period of time, when supervising detail policemen, constitutes neglect of duty within the meaning of the rules and regulations of the police department and the city charter, I am satisfied that you were indiscreet in your conduct on this occasion, and I therefore have resolved all doubts against you in the interest of strict discipline in the police department. My finding is that you are guilty of violation of Article 16 of Rule 13, as charged. Such finding is made for disciplinary reasons upon the recommendation of the chief of police, although I believe the punishment is severe for the offense committed."

It is small wonder that the disciplined member in the case just cited appealed to the civil service commission and that the commission reversed the judgment of the director when he himself believed it too severe. We have here, therefore, one head of the department determining that satisfactory standards are not being met and demanding a penalty; another head interpreting the issue without having standards of his own; and a third body in no way responsible for administration overruling both.

The record of cases appealed to the civil service commission in 1921 is even worse than that for 1920. At the time the survey tabulation was made, four cases had been appealed to the commission. Three of these cases involved dismissal from the service and one demotion in rank. Two of the dismissed members were reinstated, and the officer demoted was restored to rank by order of the commission. In only one case out of four was the judgment of the director sustained.

Obviously, the civil service commission must make its decisions without any thought of the defendant's value as a reliable policeman. It must confine its considerations, as would a court of law, to the single 
charge at hand. From the police point of view the specific charge covering an offense may confirm a well-grounded distrust or lack of confidence in a certain policeman; the last charge may be the final proof of unfitness. The civil service commission, however, does not assume the point of view of the police official. Moreover, it brings no responsibility for achieving police results into its deliberations and measures offenses by standards which are bound to be more lenient than can reasonably be employed in police discipline. It views offenses as mistakes and transgressions that would not be so grave, perhaps, in other lines of work. It often appears to overlook the significance of such offenses in a policeman and the demand of good conduct and right morals which the policeman's peculiar tasks present.

So long as the civil service commission in Cleveland is permitted to impose its own standards of personal fitness for police work, good discipline in the department cannot be attained. Neither the chief of police nor the director can do away with the weak links in the department's chain under the present arrangement, whereby final authority in matters of discipline is given to an outside body having no connection with police work and no intimate appreciation of its problems.

It must be pointed out, moreover, that the difficulty of civil service usurpation extends far beyond the particular cases handled by the commission. Efforts on the part of the head of the police department to improve police discipline and standards of conduct are hindered in all of the border-line cases for the simple reason that fear of failure in being supported by the civil service commission makes for hesitation in initiating disciplinary action and for tolerance of much that it is desired to correct and improve. With the recent year's record of reinstatement of policemen whom the chief and director have adjudged to be unqualified for the performance of satisfactory police work, is it any wonder that the chief is hesitant in taking adequate measures to correct minor evidences of poor discipline? And what is the effect of a ruling by the civil service commission that while a policeman may be guilty of refusing to swear out a warrant as ordered by his superior officer, demotion in rank is too severe a penalty to be imposed? The obvious effect is that those members who are least valuable to the department can snap their fingers in the faces of their superiors and pay only so much allegiance and obedience to them as would be required by the civil service commission. 


\section{Recommendations}

The remedy for strengthening the morale and improving the discipline of the department lies in transferring final authority in matters of discipline from an uninformed, irresponsible, politically appointed civil service commission to a single responsible, expert administrative head of the police force. As far as its disciplinary functions are concerned, the civil service scheme has been fully tried in Cleveland, and we submit that it has been found wanting. It is recommended, therefore, that full powers of disciplinary action be vested in the director of the department of police, and that a trial board, composed of officers of the professional force, be designated by the director to try delinquent members and submit findings, with recommendations to him. The director should have the power to accept, reject, or modify the recommendations of the trial board.

We recognize that objection will be made in some quarters that if so much power is given to a single police head in matters of promotion and discipline, he will abuse it by interjecting elements of political favoritism, and that giving members of the police force a share in determining these matters is dangerous. This danger is admitted, but we shall never solve the police problem in America until we give honest and effective leadership an opportunity to show what it can do. There is no chance for progressive improvement in a police department if the hands of the responsible executive are tied in his dealings with his men. Here again we must turn to Boston for an example of a rational system. As we have seen, complaints against members of the force are heard by a special trial board of three captains appointed by the police commissioner. The commissioner, however, is always supreme. He can at any time change the personnel of the trial board, order a new trial, or set aside the recommendations of the board in regard to the punishment to be imposed. His word is final, and from it there is no appeal to a higher civil authority. On no other basis can responsibility be centered and a police force be rid of useless or dishonest employees. To divide responsibility with a civil service commission, a mayor, a court, or any other authority, is to sow the seed of demoralization and to make real success impossible for any administrator, no matter how able.

Briefly, we do not believe that large strides in the improvement of the police service can be accomplished in Cleveland under the general assumption that:

1. Cleveland can only have public servants who are politically minded and whose natural dishonesty must be checked and guarded against at all times. 
2. That members of the police force who do the work can never know their job as well as persons on the outside, for example, newspapermen and politicians, and that policemen have little or no natural respect for themselves or pride in the success of their work.

3 . That the public service is only worthy of mediocre men, and no attempt need to be made to get superior men.

4. That power and authority necessary to do a given job well cannot be entrusted to a public servant. 


\section{CHAPTER VII}

\section{UNIFORM PATROL SERVICE}

$\mathbf{P}$ OLICE operations will be discussed under four headings, representing four functions of a police department's work, viz., uniform patrol service, detective bureau operations, special activities, including crime prevention work, and the secretarial division.

Patrol by members of the Cleveland uniform force is a matter largely influenced by tradition. Little change in the method of distributing the patrol force or in supervising its operations has occurred within many years. Some improvements have recently been made in the reporting of work performed by the patrol force, although slight use is made of this information; for the most part it becomes merely a matter of record and is not employed for purposes of administrative control. While there have been substantially no changes in police patrol practices, or in the geographic distribution of the force by precincts, there have occurred many marked changes in conditions prevailing in Cleveland.

It is not unusual for a migration of population to occur which completely alters the police problem of a district. The influx of negroes, which has'occurred in the Eighth Precinct, presents a new police problem, and so does the mixture of races in the Third, Fifth, and Sixth Precincts, lying southeast of the business center of the city. The character of these areas has so changed in a short time as to alter completely the demands made upon the police department. Again, there have been instances of rapid change from good residential districts, with a permanent population, to boarding-house and furnished-room districts, accommodating a transient population. This has been true in the Fourth Precinct, which has become in recent years a much livelier district as far as calls upon the police service are concerned. Then, on the other hand, there are changes in certain limited districts which tend to reduce the need of police attention. Some areas change from populous residential districts to manufacturing or warehouse centers. The police problem is greatly altered in a given precinct, as in the case of a portion of the Fifth, for example, when several rows of tenement houses are torn down and a factory erected in their stead. 
Not only has the character of districts changed in the past twenty years, but changes in methods of transportation have altered the problem of police work. Years ago there was little traveling at night, and identification of those who did travel was comparatively easy, whereas now the number of people moving about after dark has increased a thousandfold. The use of the automobile alone has revolutionized the police problem. The movement of automobiles must be regulated to promote safety; they must be guarded from theft; and increasing vigilance is necessary because criminals make use of them in the commission of crimes.

Notwithstanding all of these changes in the objectives of policing, the means and methods of policing in Cleveland remain practically unaltered. There has been no modification of police arrangements to correspond with the kaleidoscopic changes brought about by shifting populations and new inventions. One gets the impression in Cleveland that police organization is merely a conventional arrangement, sanctioned by usage and traditions, but with little relation to needs or neighborhoods. It looks as if it had been wrenched from widely different surroundings and poorly fitted to its new environment. The admirable adaptation of means to end, of machinery to purposes, which one finds in many European departments, is conspicuously lacking. In brief, methods and organization are not fitted to new social and criminal conditions.

It is absurd to saddle on a single official the deficiencies due to so glaring a disparity between need and system. But the new system must be worked out and administered by a new head, capable of understanding the inadequacies of the antiquated existing system and sufficiently resourceful and commanding to afford Cleveland a police department adapted to its modern conditions.

A leadership of imagination and creative intelligence is urgently needed. Under such leadership one of the first steps in reorganization would undoubtedly be a restudying and recasting of the present patrol beat boundary lines. Many patrol beats have had the same boundaries for years. Indeed, most precinct stations do not have a beat map, and even the officers are often not familiar with the exact location of the patrol posts. When, after a thorough study of present conditions and present needs, the beats are revamped, they should be left open for future changes. A beat should not be reckoned as a permanently fixed area, but should be subject to readjustment at any time in the discretion of the captain of the precinct after approval by the chief of police. Patrol beats should be laid out in the light of the ordinary demands of 
each particular beat for police protection, the number of patrolmen available for duty, and the methods of patrol that may be in use or may be put into use.

In laying out patrol beats all information in regard to street blocks should be available. Such information is not now to be had in the police department. It is recommended that a card record description of every block within each precinct be prepared under the direction of the captain of the precinct, giving the following information:

Length of block

Kind of paving

Kind of traffic

General description of buildings

Kind of street lighting

Population statistics as to total number, nationality, number of families, permanent population, transient population

List of such important burglary risks as banks, jewelry-stores, warehouses, etc.

List of places to be inspected by the police, as pool-rooms, clubs, dance halls, cigar-stores with back rooms, pawn shops, etc.

There should then be a space for entering the crime record on the block description card, showing separately the number of complaints of misdemeanors and felonies and the number of arrests classified by misdemeanors and felonies. These card records of blocks should be kept up to date by the precinct commanders, and from them information should be obtained for the determination of patrol beat boundaries.

\section{Number of Policemen Needed}

Another matter which should be considered under a progressive leadership of the police is the number of policemen necessary for Cleveland. We cannot undertake to say in any confidence whether or not the police department needs more policemen. Certainly the crime rate in Cleveland affords plenty of opportunity for work by any additional men who might be appointed to the police force. Certainly, too, the addition of more men to the patrol force or to other branches of the service would show some returns in lessening the number of crime complaints and increasing the number of crimes solved. In this connection Detroit offers an illuminating experience. Complaints of robbery were steadily reduced for a period of four months, in which the police force was increased each month. An official bulletin of the Detroit Depart- 
ment discloses that in September, 1920, with a shortage of 198 men, there were 98 robberies committed, as against an average of 55 for September of the four preceding years. In October, with a shortage of 170 men, there were 74 robberies against an average of 61 for the previous four months of October. In November, with the shortage entirely made up, there were 55 robberies, against an average of 92 for the same month of the four preceding years, and in December, with the number of patrolmen brought up to 132 in excess of the regular quota by December 31 , there were 48 robberies, against an average of 93 for the same month of the previous four years.

A comparison of personnel quotas and police costs in Cleveland and Detroit shows clearly the superior resources possessed by the latter city. Approximately $\$ 4,500,000$ was appropriated for Detroit's police service during the fiscal year 1920-21, while the total estimated cost for police service in Cleveland for 1921 amounted to approximately $\$ 2,500,000$. The total authorized police force in Detroit for the year 1921-22 numbered 1,926, while the total authorized force in Cleveland for 1921 numbered 1,381 .

On the other hand, the fact has to be borne in mind that Detroit is larger than Cleveland by nearly 200,000. Nevertheless it is found that Cleveland has only 174 men per 100,000 population, while Detroit has 194.

Similarly, a comparison between Cleveland's police resources and those of St. Louis shows to the disadvantage of Cleveland. St. Louis is slightly smaller than Cleveland, yet the estimated expenditure for the police department in 1921 exceeded Cleveland's police cost by $\$ 500,000$. The total strength of the St. Louis force exceeded Cleveland's total force by more than 500 men. St. Louis has 250 men per 100,000 population.

The question of increasing the number of men is one of public policy, involving chiefly the amount of money that can be spared for police protection. That more policemen will mean an improvement in crime conditions is not to be debated. Whether the resulting reduction in crime is worth the additional money required of a tax- and debt-burdened city is a question with which we have no proper concern. The questions that confront us are these: Is the city of Cleveland getting all the return it should from the money now spent on patrol service? If not, where does inefficiency lie or where does failure to make the best use of resources appear? We believe greater returns could be had from the number of policemen employed at present-(1) by greatly extending the use of motor vehicles, and, in some cases, bicycles, in doing patrol work; (2) 
by reducing the number of daily assignments in the horse-mounted section of the traffic division; (3) by employing some of the men in a special service or crime prevention bureau. Whether these measures, which are discussed in later sections of the report, will of themselves, without adding to the force, achieve the desired results in reducing the volume of crime, is a question which only experience can solve.

\section{Methods of Patrol}

At the present time regular patrol work is done on foot. The men who are equipped with horses confine their attention almost entirely to the regulation of traffic and enforcement of traffic ordinances. Special units, known as reserve squadrons, consisting of a sergeant and three uniformed men, are attached to nine of the 15 precincts. These squadrons operate in what are called, in newspaper fashion, "high-powered automobiles." They are held in reserve at precinct station houses during the day to answer emergency alarms, but at night are used in a limited way for general circulating patrol.

The results achieved by the squadrons in 1920 point clearly to the value of extending the use of motor equipment for doing regular patrol work, thereby replacing many foot patrolmen. In the sections of outlying residential districts which have good paving, motor patrol service can take the place of foot patrolmen entirely. In congested districts, however, where large numbers of people are passing on the street, it will, of course, be necessary to have patrolmen doing duty on foot and covering comparatively small beats, so that they can keep their posts constantly under eye.

The use of automobiles for patrolling the streets is in line with the best development in police work. New York, Kansas City, Detroit, and many other cities have adopted the idea, with marked success. In April of 1918 the Detroit department placed over 150 Ford automobiles on the streets to patrol beats formerly covered by foot patrolmen. Each machine carries two policemen-one in plain clothes and one in uniform. During the first month of the operation of these machines felony complaints were reduced from 654 , reported in the previous month, to 528 ; in the second month there was a further decrease of 65 felony complaints over the previous month. "The innovation of the automobile as a preventive [of crime] has proven a great success," said an official of the Detroit department, "for two men can now do the work that formerly took four or five, and are able to do any kind of work with more success in residential districts than officers on foot."

Similarly other cities, such as St. Louis, Seattle, Los Angeles, and 
Louisville, are making small beginnings in the use of automobiles for patrolling beats. The hesitation of many departments in taking up the automobile for patrol purposes is due to the expense involved in the initial outlay and maintenance charges. On the other hand, if two men equipped with an automobile can do the work of five, or perhaps eight, men on foot, a reduction in the patrol force is possible, and the saving in salaries would more than offset the cost of providing the necessary motor equipment.

The motor equipment to be used in patrol work should consist in medium-sized passenger automobiles of good quality, with perhaps a few of the smaller and cheaper cars and motor-cycles equipped with side cars. The number of men attached to a car or motor-cycle need not exceed two; they may both be uniformed, or one uniformed and one in citizen's dress. There is no work performed in the non-congested areas by patrolmen on foot which cannot be carried on in an automobile or motor-cycle. When the need for a close investigation is seen, the patrolman simply stops his vehicle and proceeds to do his work as formerly. On the other hand, much work that can be carried on successfully by using a vehicle cannot be done by the foot patrolman.

There are many positive advantages to be secured from motorized patrol service. In the first place, a patrolman riding an automobile or motor-cycle can cover from 12 to 15 times as much ground as a man on foot. Realization of this advantage can be measured in one of two ways - either by reduction of the number of men employed in patrol or in making more frequent observation of a given territory. On the present basis of the distribution of patrolmen it would be possible to cover more territory with even fewer men.

Again, patrolmen riding in cars can carry considerable equipment; often urgently needed by them, but which it is not possible for a foot man to carry. Police cars should include, as their equipment, lanterns and other bracket materials for safeguarding dangerous places, fire extinguisher for use on grass fires, towing rope, heavy firearms, and a first-aid kit. These cars can at once be converted into emergency ambulances if an occasion demands, or they may serve the purpose of a patrol wagon in taking prisoners to headquarters or precinct stations, thus cutting down the need for the present number of patrol wagons used.

Moreover, the increasing use of automobiles by criminals makes it important that policemen be equally equipped. Observations of suspected persons keeping automobiles can be effected from an automobile in a way that cannot be done from on foot. Pursuit of a fleeing auto- 
mobile may be done only in another car. The greater possibilities of the unsuspected arrival of the police when equipped with an automobile is another advantage in dealing with criminal operations.

Finally, the use of motor equipment greatly promotes the physical fitness of policemen in covering large territories. In emergencies they can arrive at the scene of crime, disturbance, or accident more quickly and in better physical shape to do police duty. The protection which an automobile affords in severe weather is another item of great value to be reckoned in preserving the physical efficiency of the men.

In this connection attention must be called to an order of the Director of Public Safety, dated March 14, 1921, directing the chief to see that the use of the reserve squadrons be "limited to the investigation of such cases as are manifestly important." In partial explanation of what would not be "manifestly important," it was ordered that the squads do no work on crap-shooting complaints, street-corner loitering, etc. Quite apart from the fact that the director obviously overstepped his power as laid down by the charter in thus interfering with the functions of the chief, the order itself has little justification, and its results can only be to curtail the effectiveness of motor patrol. By using the squadrons in breaking up crap games and objectionable street loitering the number of serious complaints can undoubtedly be lessened, while the efficiency of the squadrons in important cases of murder or robbery will in no way be decreased.

\section{Patrol Booths}

As an essential part of the system of motor patrol, patrol booths should be erected in the outlying districts of the city. This is a system which has been thoroughly tested in many cities, notably New York and Detroit. The patrol booth is in effect a miniature police station. Its chief advantage lies in the fact that a policeman in a given territory is made immediately available to citizens and headquarters alike. A proper operation of the booth system requires that not less than two men, equipped with motor-cycle or automobile, be attached to a booth at the same time. One man remains at the booth while the other circulates through the district, returning periodically to the booth. In case the booth man is absent on an emergency call, the other remains at the booth until his return. By this arrangement a district is given the benefit of patrol-in point of fact the motor-cycle or automobile man gives better patrol service than the foot patrolman, and at the same time a policeman can be had at once in case of need. Citizens naturally have a greater feeling of security in knowing that they can get a policeman immediately than in knowing that a foot patrolman is somewhere in 
the district and that there is a chance that he is near enough to hear a call for help.

\section{Precinct Stations}

Precinct stations, numbering $\mathbf{1 5}$ at the present time, have been developed as necessary means for distributing the patrol force. The districts served by these stations vary considerably in size, and some, due to topographical peculiarities, are very irregularly laid out.

The precinct stations were established to meet the needs of the old type of patrol. When men are sent out on foot to cover their beats, it is, of course, necessary to assemble them by groups at a point near where they are to patrol. As the city grew in size it became impossible to send men from headquarters to the outlying beats, hence the need for precinct stations. This need can be reckoned in terms of yards and miles from the station house to the farthest removed post, and the time required to cover this distance. Obviously, when men proceed from the station to their beats in automobiles or motor-cycles, not as many stations will be required as under the present system of foot patrol.

It seems probable that, upon the introduction of motorized patrol, precinct lines could be reëstablished, so as to reduce the number of precincts from 15 to seven or eight, allowing two on the West Side and five or six in the eastern portion of the city. This calculation is but roughly made. It is based on the following suggestions for consolidations: combining the First, Second, and Third Precincts and the westerly tip of the Fourth into one precinct that will be housed in a new headquarters building; combining parts of the Fourth, Thirteenth, and Eleventh, to form a single precinct; providing one or possibly two stations to accommodate the needs of the southwest section of the city, beyond the limits of the Fifth and Sixth Precincts. One station should suffice for that territory lying north and east of Wade and Rockefeller Parks, since there is no chance for extension on the north, and any annexations on the east would present a new situation entirely, requiring complete rearrangement of station facilities. These suggestions would need further study, but they afford an illustration, at least, of the possibility of consolidation as a result of motorized patrol.

Combinations such as those suggested above will not only increase the efficiency of the force but will lessen the cost of police administration. Every precinct means additional overhead, both in record keeping and supervision. By combining two or more precincts into one this overhead can be reduced, thereby saving in expense and contributing to a greater uniformity in police practice. Officers now performing duplicate tasks of supervision could be freed for more productive work 
in other special divisions of the department. An examination of the station records and reports in the Tenth and Twelfth Precincts showed that there is a very small volume of work, and yet a full complement of officers is required to supervise approximately 35 men in each of these precincts. Seventy men, or even as many as 125, distributed over four platoons, can easily be managed in a single command and the clerical duties incident to the work of such a number of men can well be handled without addition to the number of men employed in clerical work in a single precinct. On the whole, discipline is likely to be better under the business-like aspects of a large unit than in the home-like atmosphere of small, quiet precincts.

Again, emphasis must be laid on the fact that these improvements and others of a similar nature can come only as the result of a sustained, intelligent leadership of the police. They cannot be successfully installed by law or ordinance, or by any other legislative short-cut. They must be thoughtfully matured over a period of years. They must be the result of careful planning, of fearless initiative, and wise guidance. This means a leadership of brains, free from unwarranted interference. More than anything else the Cleveland force needs such leadership today.

\section{RECOMMENDATIONS}

The patrol service should be reorganized so as to accommodate the changes which the use of motor equipment demands. It is recommended, therefore, that-

(1) Motor equipment be used in regular patrol work.

(2) Patrol booths be established.

(3) Police precincts be consolidated so as to reduce the number from 15 to seven or eight.

(4) Patrol beats be rearranged. 


\section{CHAPTER VIII}

\section{THE DETECTIVE BUREAU}

$\mathrm{T}$

THE detective bureau is the second major division of the police organization. It is a bureau of specialized operations, involving not only the solution of crimes which have occurred despite the preventive efforts of all other divisions, but the apprehension of the perpetrators who have escaped after the commission of crime. Work on the solution of murder and manslaughter cases requires considerable time, but the investigation of complaints involving loss of property is by far the largest part of the detective bureau's work. These complaints include robbery, burglary, housebreaking, grand larceny, frauds, and swindles.

The bureau is commanded by a deputy inspector of police, who is detailed by the chief of police to serve as inspector of detectives. Similarly, he may be transferred from the detective bureau at the pleasure of the chief. Two captains of police are detailed to serve as captains of detectives, assisting the inspector in command. These commanding officers are generally drawn from commands of the uniformed patrol force, instead of being taken from the detective bureau membership.

The present inspector of detectives served as a captain in command of the Third Police Precinct prior to being detailed to head the detective bureau. However, he had had some previous experience in detective work as a member of the old detective bureau. One of the two captains of detectives was previously in command of a precinct station, and later had charge of the police training school, from which he was transferred to the detective service. The other captain was originally a patrolman detailed to the detective bureau. Upon receiving his promotion to the rank of sergeant, he was transferred from the detective service to a precinct to supervise uniformed patrolmen, afterward going to the traffic division. Upon being promoted to the rank of lieutenant he was transferred to desk duty in a precinct. Later he was promoted to the rank of captain and placed in command of a precinct station. From this post he was transferred to the detective bureau.

From records of this sort it is easy to see that no attempt is made to develop detective commanders from detective personnel. The de- 
tective bureau in Cleveland is directed by men who have had no adequate training in the detective business, and whose promotion to leadership depended, in the first instance, on attaining a certain rank, and only secondarily on experience and fitness. Under the present system, if a patrolman, serving as a detective, obtains promotion to the rank of sergeant, he must leave detective work and take up uniformed patrol supervision merely because there is no rank of sergeant in the detective bureau. He must then continue in the uniformed patrol or traffic service until he has attained the rank of captain before he again becomes eligible for transfer to the detective service. The detectives who do not ascend through the uniformed ranks of sergeant and lieutenant to captain are barred from attaining a post of command in the detective bureau.

There are 81 patrolmen detailed to the detective bureau at the present time. They are assigned to various duties as follows:

4 assigned to desk duty

5 to office duty-clerical work

5 to the automobile squad

4 to the bureau of criminal identification

3 to the taxicab quad

2 to the pawnshop squad

1 to apartment house detail

1 to the hotel detail

1 to the bank detail

1 to the rooming-house detail

50 on general assignments

Of the 50 general men, five are carried on the detective bureau roll, but assigned outside of the bureau as follows: one as a clerk in the chief's office, one to the law department for investigation of civil action cases involving possible damages to the city, one in charge of the department's telephone exchange, one as a clerk in the office of director of public safety, and one to the mayor's office, serving as the mayor's bodyguard. These men are not doing detective work and there is no justification for carrying them as detectives.

All detectives are taken from the rank of patrolmen in the uniformed force. Detectives who have served in the bureau for ten years or more are paid a salary of $\$ 2,406.80$, which is slightly more than the salary paid to lieutenants of police in the uniformed force; those with less than ten years' service to their credit receive $\$ 2,288$, which is the same as the salary of a uniformed lieutenant. Detectives are selected by the chief of police. Whether he is permitted to exercise his own judgment without influence of any sort depends on the mayor and director. 
Detectives may be returned to duty in the uniformed force in the discretion of the chief of police and by his order. The privilege, however, is rarely used. The detective assignment is considered as a promotion, and loss of the assignment occurs only in such extreme cases as would result in demotion in rank in the uniformed force as a result of charges of incompetency.

\section{Poor Quality of Detectives}

The detective personnel is supposed to be the "cream" of the uniformed patrol force. The superior type of work demanded of detectives and the greater compensation which they receive would seem to require that they be the ablest patrolmen in the service. We doubt the truth of the presumption that the detective personnel in Cleveland is entitled to rank as a group having superior abilities. In the first place, there appears to be no adequate provision for selecting detectives on the basis of proved worth in doing the type of work required. No particular standards are followed. Not infrequently policemen are detailed to the detective bureau in recognition of daring and as a reward for the performance of some unusually good bit of work in the uniformed force, such as making an arrest at the scene of a major crime. Daring and quick wit are valuable assets to the detective, but their display in a single case does not warrant the conclusion that the men have other qualities of perception and aptitude needed in detective work. The point is that there is no regularly pursued practice of looking out for detective material or of trying men out in an apprenticeship assignment in the detective service.

Another consideration on which we base our conclusion that the detective personnel is not of the uniformly high caliber which should characterize a detective force is the low rating of the detective group in the United States Army Alpha Test. It is a singular and significant point that the detectives as a group made a lower average rating in this standard psychological test than any other group in the police service. The range of scores made by 10 different groups is shown in Table $3 .{ }^{1}$

1 This psychological examination was made in connection with the present survey. The method of marking is as follows:

Grade of

intelligence Explanation

A Very superior intelligence

B Superior intelligence

C+ High average intelligence

C Average intelligence

C- Low average intelligence

D Inferior intelligence

E Very inferior intelligence
Alpha score

135-212

$105-134$

75-104

45- 74

25- 44

$15-24$

0 - 14
Approximate mental age, years
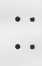

..

11-13

9-10.9

Below 9 
TABLE 3.-MEDIAN SCORES AND RANGE OF SCORES OF POLICE DIVISIONS

\begin{tabular}{l|c|c|c|c}
\hline \multirow{2}{*}{ Rank or division } & Median & \multicolumn{3}{|c}{ Range of scores of each division } \\
\cline { 3 - 5 } & & Low third & Middle third & High third \\
& & & & \\
\hline & $98 \mathrm{C}+$ & $50-75$ & $76-104$ & $105-154$ \\
Captains & $95 \mathrm{C}+$ & $36-81$ & $82-108$ & $109-165$ \\
Lieutenants & $99 \mathrm{C}+$ & $28-79$ & $79-109$ & $110-166$ \\
Sergeants & $75 \mathrm{C} \mp$ & $23-61$ & $64-84$ & $84-134$ \\
Vice squad & $59 \mathrm{C}$ & $23-50$ & $51-71$ & $72-131$ \\
Detectives & $63 \mathrm{C}$ & $25-56$ & $57-74$ & $77-138$ \\
Training school & $61 \mathrm{C}$ & $5-56$ & $56-74$ & $75-137$ \\
Traffic & $78 \mathrm{C}+$ & $22-59$ & $60-91$ & $92-155$ \\
Mounted & $67 \mathrm{C}$ & $19-64$ & $65-80$ & $83-150$ \\
Emergency & $67 \mathrm{C}$ & $6-52$ & $53-82$ & $82-170$ \\
Patrolmen & & & & \\
\hline
\end{tabular}

From this record it is seen that the average of scores made by 63 detectives is 8 points below the average of scores made by 759 patrolmen doing duty in uniform, 16 points below the average score of 26 vice bureau operatives who were chosen from the uniformed force in the same way that detectives are, and 36 points below the average made by 46 lieutenants who are rated on approximately the same salary schedule as detectives.

Another basis of scoring which shows the number attaining different group ratings is given in Tables 4 and 5 .

From this tabulation it is seen that no detective was rated in the $\mathbf{A}$ group, although all the other classes of the service had some percentage of their membership in this grouping. The percentage of detectives in the B group was less by one-half than that of any other class, and six to seven times smaller than the percentage of lieutenants, sergeants, and vice bureau operatives in the B group. Two detectives were in what is rated as the failure group, with a score of less than 25 , while no member of the lieutenants, sergeants, or vice bureau classes fell so low.

Of course the Alpha test is not a complete measurement of ability. As has been pointed out, the ratings are useful as measures of general intelligence, but they do not include measurements of personality and character traits such as initiative, leadership, bravery, honesty, etc. They are measures to indicate the speed and accuracy with which persons are able to deal successfully with new situations and problems. But the comparison, even on this limited basis, is highly significant. The "cream of the uniformed force" serving as detectives should not fall below the uniformed force in a test involving general information and ability to meet new situations quickly and accurately. 


\begin{tabular}{|c|c|c|}
\hline \multirow{2}{*}{ 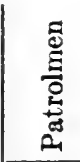 } & 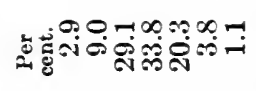 & 8 \\
\hline & 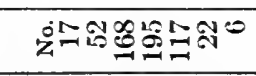 & 点 \\
\hline \multirow{2}{*}{ 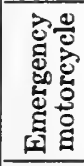 } & 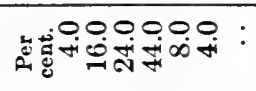 & $\stackrel{\circ}{8}$ \\
\hline & $\dot{z}^{\circ}+\pi 0 \Xi N-1$ & เ \\
\hline \multirow{2}{*}{ 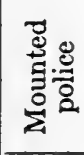 } & 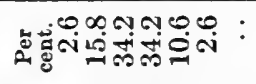 & : \\
\hline & 方ーのッッルー: & $\underset{\sim}{\infty}$ \\
\hline \multirow{2}{*}{ 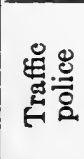 } & 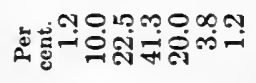 & $\ddot{8}$ \\
\hline & 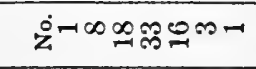 & $\infty$ \\
\hline \multirow{2}{*}{ 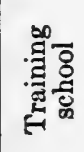 } & 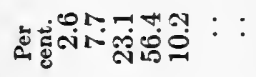 & $\stackrel{8}{8}$ \\
\hline & 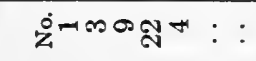 & 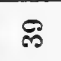 \\
\hline \multirow{2}{*}{ 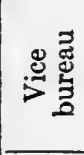 } & 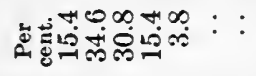 & $\ddot{8}$ \\
\hline & $\sin ^{2}+\infty \pi-$ & $\mathscr{N}$ \\
\hline \multirow{2}{*}{ ه্ّ } & 总 : : & $\stackrel{8}{8}$ \\
\hline & 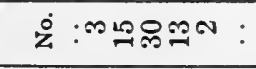 & 8 \\
\hline \multirow{2}{*}{ 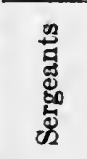 } & 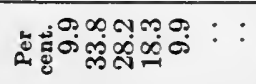 & $\stackrel{8}{0}$ \\
\hline & 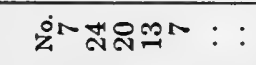 & $E$ \\
\hline \multirow{2}{*}{ 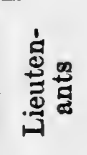 } & 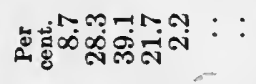 & : \\
\hline & 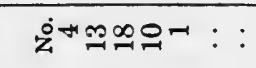 & gr \\
\hline \multirow{2}{*}{ 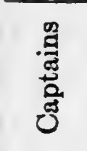 } & 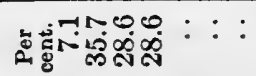 & $\stackrel{8}{8}$ \\
\hline & 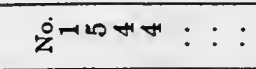 & \pm \\
\hline & 1 & \\
\hline
\end{tabular}

\begin{tabular}{|c|c|c|}
\hline 司密 & 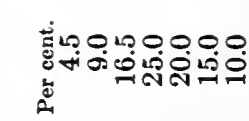 & : \\
\hline \multirow{2}{*}{ 惡 } & 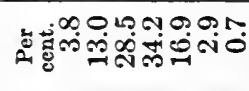 & $\stackrel{8}{8}$ \\
\hline & 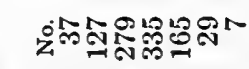 & 总 \\
\hline \multirow{2}{*}{ 之总 } & 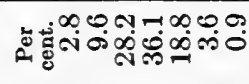 & $\stackrel{8}{8}$ \\
\hline & 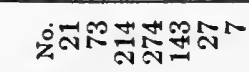 & 品 \\
\hline \multirow{2}{*}{ 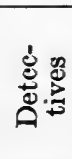 } & 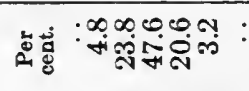 & $\stackrel{0}{8}$ \\
\hline & 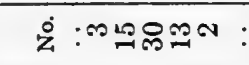 & $\because$ \\
\hline \multirow{2}{*}{ 电葛 } & 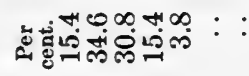 & : \\
\hline & $z+c$ & $\mathscr{2}$ \\
\hline \multirow{2}{*}{$\sum_{\text {电 }}$} & 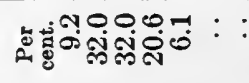 & $\stackrel{\circ}{\mathscr{8}}$ \\
\hline & ว่ำฟสำ & $\vec{a}$ \\
\hline & 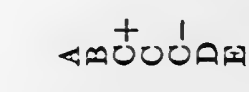 & \\
\hline
\end{tabular}




\section{Poor Work of Detective Bureau}

One does not have to resort to psychological tests to prove the ineffciency of the detective personnel or the general run-down condition of the whole bureau. A glance at the organization or an examination of the reports of the men easily sustains the point. With the exception of the criminal identification section, which is ably managed, the whole bureau seems to be run on a small-town pattern. Poor office arrangements no doubt contribute in some measure to the appearance of disorder and confusion generally evident in the bureau. Clerks, officers, detectives, witnesses, and citizens shuffle around in a large room, and there is no appearance of system or method in the hurly-burly of the day's routine. Supervision of operations is poor when it is employed at all, and the records are inadequate and carelessly prepared.

Lest this be thought too sweeping an indictment of the work of the bureau, it may be well to quote some of the reports of the detectives. During the month of January, 1921, Detectives Callahan and Cowles, working together, handled 16 cases of burglary and larceny. The following are their own complete reports of their activities on burglary cases during this period:

1. "Detective Cowles and I investigated this complaint we were unable to locate the men suspected will continue on same."

2. "Detective Cowles and I investigated this complaint we were unable to get any trace of the thief or property."

3. "Detective Cowles and I investigated this complaint was unable to locate the man suspected."

4. "Detective Callahan and myself investigated above report, interviewed $\mathrm{Mr}$. - also made inquiries in that vicinity, was unable to get any further information than original report."

5. "Detective Cowles and I investigated this complaint we were unable to learn anything on same."

6. "Detective Callahan and myself investigated above report, interviewed manager also made inquiries in that vicinity was unable to get any trace of the thief or thieves. They do not suspect any one."

7. "Detective Cowles and I investigated we were unable to get any trace of the thief or property."

8. "Detective Cowles and I investigated this complaint we were unable to learn anything on same."

9. "Detective Cowles and I investigated the complaint was unable to get any trace of the thief or property."

10. "Detective Cowles and I investigated this complaint we were unable to get any trace of the thief or property this job evidently was done by boys." 
11. "Detective Cowles and I investigated this complaint we were unable to learn anything on same."

12. "Det. Callahan and myself investigation above report. Interviewed Mr. — was unable to receive any further information or any trace of the Burglars."

13. "Det. Callahan and myself investigated above report, interviewed Mr. - Learned that the property stolen was insured for more than he valued it at. Satisfied this report is not Legidiment."

14. "Det. Callahan and myself investigated above report, interviewed Mr. - Also made inquires in that vicinity, was unable to get any trace of Burglars \& property. Will continue."

15. "Det. Callahan \& myself investigated above report was unable to give any description. Does not suspect any one."

16. "Detective Cowles and I investigated this complaint we were unable to learn anything on same."

The above represents a whole month's work of two detectives on burglary cases. Reports of this type could be instanced almost indefinitely. In many cases they seem to show that the detectives merely verified the fact that a crime had been committed, and beyond asking a question or two of the neighbors, made no attempt to solve the mystery. Under such circumstances the wonder is not that crimes occur in Cleveland, but that any perpetrators are ever arrested.

\section{Inadequate Supervision of Detective Work}

One of the significant causes of this situation just described is the lack of adequate supervision of detective operations. Apparently each detective determines for himself just how much he shall do on a given case and when he shall regard the case as closed. Of any adequate follow-up on individual cases, there is none. There is no administrative oversight to put enthusiasm and determination into the solution of individual crimes. The commanding officers of the detective bureau devote most of their time to important cases upon which newspaper comment is centered, and very little time to the less interesting task of management. Indeed, the rôle of detective officers is that of super-detective case workers rather than supervisors. The commanding officers lock their offices and go out into the field to assist in the investigation of murder cases, payroll robberies, and other important crimes. They have been accustomed also to make trips to other cities, sometimes as far away as California and New York, for the purpose of bringing to Cleveland fugitives held by the police in other jurisdictions. When the inspector of detectives makes such a trip, the detective bureau is managed by an assistant. This practice must be condemned without reserva- 
tion. Ordinary detectives can be assigned to make such journeys. It is far more important that detective commanders stay on the job and keep in constant touch with the mass of less spectacular cases where the scrutiny of immediate supervision is needed. Otherwise the minor cases will slip by almost unnoticed except for a perfunctory examination by the detectives assigned to them.

Briefly, the detective bureau needs administration badly. It is impossible to spend days in solving particular crimes and at the same time supervise the operations of 80 men who are working on hundreds of cases.

\section{Recommendations}

One approaches the subject of recommendations for the detective bureau almost with despair. The whole department needs overhauling; the methods of work require a complete shaking up; and much of the present personnel should be gotten rid of. However, the following recommendations are pertinent to our inquiry:

1. The director of police should be given the right to recruit detectives directly from civil life through original appointments. There is no good reason for restricting the selection of detectives so that none but members of the uniformed force are eligible. The uniformed patrol force may or may not have in sufficient number the sort of material that is demanded in detective work. The chances are that the patrol force does not have the best material available in the community. It is not here proposed that all members of the detective service be taken directly from civil life. When uniformed patrolmen are found to have the qualifications for detective work, they will be preferred because of their experience. But the department should not be compelled to limit its choice of detectives as at present.

Detective work requires some men of scientific training-men having the educational foundation that will permit them to develop scientific methods of operation. There are many principles of criminology, such as the examination of the physical evidence of crime, which can only be applied and developed by specially trained men. These men cannot be drawn exclusively from the uniformed patrol force for the reason that men having scientific training do not enter the patrol service. Aside from those with qualifications of this type there are men in private life specially trained in getting information and making investigations, who would be willing to enter the detective service at the rate of pay now given detectives, provided there were an opportunity for making a creditable career. But these men would not first serve an apprenticeship of walking beats as patrol watchmen. 
Detective bureaus are the weak spots in all police departments of this country, chiefly for the reason that the choice of detectives is limited to men who are recruited and trained as patrolmen. In this connection August Vollmer, head of the police department of Berkeley, California, asks the following pertinent questions: "Where is there a business concern that compels applicants for various vacancies in the organization to submit to the same physical and mental examination; where the janitor, clerk, salesman, engineer, department heads, superintendents, and managers are all compelled to answer the same questions, measure up to the same physical standards as to health, height, weight, age, and sex, and all commencing their employment at the same occupational level and at the same pay? Where is there a business concern that limits the selection of men for technical positions to employees holding inferior positions in the same establishment?" It is obvious that police departments are alone in their indefensible practices in such matters. If any real progress is to be made in detective bureau efficiency, it must come after the removal of senseless bars to getting men who have the intelligence and training needed to perform the special tasks that daily confront detectives.

2. Under any circumstances, some of the personnel of the detective bureau, perhaps a majority of it, would be recruited to the detective service from other branches of the police organization. The present method of such recruiting, however, should be changed. Instead of detailing patrolmen to become full-fledged detectives at once, there should first be an apprenticeship assignment. Members of other divisions of the service who show signs of special fitness for detective work-an ability to remember faces, a knowledge of local thieves and their habits, an ability to get accurate information and to make coherent reports - should be detailed to the detective bureau to serve as junior detectives. To require a period of apprenticeship does not constitute a discrimination against members of the force as compared with civilians who might be appointed to full detective rank. The civilians will also have had their period of tryout in some civil pursuit. As a matter of fact, the member of the police force has every advantage in securing the detective posts which do not necessarily demand scicntific training. The department affords the patrolman his qualifying experience, while the outsider has not such opportunity to develop it.

Members detailed to the detective bureau from other branches of the department should be classed as junior detectives for a period of possibly two years, during which time they should be tested and observed as candidates for appointment as senior detectives. During this period of apprenticeship members should receive the salary attaching to the 
rank from which they are detailed. If their detective work proves satisfactory, appointment to full detective rank may be made permanent. If, however, junior detectives do not show themselves to be adapted to detective work, they should be remanded to duty in uniform. This would not be considered such a hardship as at present, for the reason that there would be no loss in pay upon being remanded.

3. After qualifying in the period of apprenticeship or probation, as it might be called, appointment to full rank of detective should follow. Two years will not always suffice to prove a detective's ability, hence provision should also be made for remanding senior detectives to uniformed duty whenever they do not measure up to the bureau's demands. There are no soft places in detective service where the lazy or inefficient man may be shelved. "Deadwood" can perhaps be used in posts which involve routine duties and little initiative, but "deadwood" is a total loss in the detective bureau. A detective should either show continuous advancement through energetic work and the accumulation of experience or he should be put out of the detective service altogether.

Accordingly, it is proposed that, as continuance in the detective service presupposes fitness, automatic increases in salary should be given. A salary schedule should be devised which would allow some five or six increases, ranging from the lowest, approximately the salary paid to a uniformed sergeant, to a rate equaling that received by a uniformed captain of police. The schedule should be so arranged that the last increase should come about three years before the pension service retirement.

The advantages of granting salary increases to detectives without regard to changes in rank are twofold. In the first place, it would make the detective service a career of itself and would permit advancement entirely on the basis of meritorious work. In the second place, it would do away with the present situation, wherein detectives, to secure advances in rank, must compete in examinations designed to cover types of work other than those which they have been doing. It would also do away with the absurd practice of sending back to duty in the uniformed force a detective who receives promotion to the rank of sergeant, with its corresponding decrease in pay.

4. Promotion to posts of command in the detective bureau should be made from among members of the bureau, and not, as at present, from the uniformed force. The determining consideration to date has been the rank-captain and inspector-desired for commanding officers of the detective bureau. The qualification of experience has been entirely overlooked. What is wanted is not rank, but brains and ability. 
5. With well-trained men in the detective bureau, under competent leadership, constant attention would have to be given to the administrative problem. After all, running a detective bureau is like running any complicated business: it requires an intimacy with detail and continual follow-up, so that every individual feels the stimulus of the leadership. In this respect the Cleveland detective bureau is conspicuously lacking at the present time. What is needed is a man in charge who will live constantly with his cases and whose guiding principle will be that no case is settled until it is solved.

6. Members of the detective bureau should do only detective work. They should not be detailed as clerks, telephone operators, or to guard the person of the mayor. They should be technical men, well paid for their abilities, and not job-holders who can be assigned to any task. 


\section{CHAPTER IX}

\section{SPECIAL SERVICE DIVISION}

$\mathrm{T}$

HE third major function of police work, crime prevention, is poorly developed in the Cleveland department. Of course, some measure of crime prevention work is aimed at by the uniformed force and detective bureau as well, but we are here considering the distinctly constructive efforts to prevent crime-efforts that cannot be employed by the uniformed force, the members of which must necessarily devote most of their attention to patrolling streets in the capacity of watchmen. Detectives are kept busy for the most part with solving crimes that have not been prevented, although they do some preventive work. The development of a special unit engaged in preventive work need not relieve the members of either the uniformed force or the detective bureau of any feeling of responsibility for taking action looking toward crime prevention. The members of a special service division, however, should be freed from the duties of watchmen, and should not have their time fully occupied with the apprehension of criminals and solution of crimes already committed. Such a division should investigate conditions that are known to lead to the commission of crime and should become an expert agency in handling persons who show themselves disposed to delinquency.

Inasmuch as there are practically no special facilities in the Cleveland department for undertaking constructive action in preventive work, our survey was confined to the need for such a service. The vice squad or bureau, as now organized, is the nearest approach to a specialized crime prevention unit in the department. This squad is organized as an independent unit under the direct supervision of the chief of police. Two lieutenants of police are assigned by the chief to command the bureau. Members of the squad are patrolmen who are detailed by the chief in the same way that patrolmen are detailed as detectives. No provision is made for recruiting directly from civil life. Members of the squad devote considerable time to the investigation of complaints referred to the vice bureau by the chief. Some of these complaints come from citizens and others originate with the uniformed force. These 
complaints often relate to suspicious conditions which lead the complainants to believe that certain premises are being used for prostitution, gambling, sale of liquor, or illegal traffic in narcotics. Sometimes complaints are made against individuals, but in either case members of the vice squad must get new and additional evidence of a specific violation of law repeated some time after the violation referred to in the complaint. Thus, the vice bureau operatives are chiefly engaged in the investigation of general conditions. In their effort to develop specific charges of violation against individuals, much of their best work is done by way of anticipating the occurrence of new violations. The very investigations made by them often lead to an abandonment of activity on the part of the promoters of vice. In this respect the work of the vice squad takes on more of the aspect of crime prevention than does the work of other divisions. The vice bureau, therefore, may serve as a nucleus for building up a unit devoted to investigations of conditions and individuals with a view to forestalling criminal acts.

The attitude of police heads toward the vice bureau at present seems to be one of suspicion. The chief of police keeps in his office a complete record system, which provides a check on all complaints assigned to members of the vice bureau for investigation. Daily reports of the vice bureau's operations are submitted to the chief and the director. No other division of the police service submits such a report to the director. It was not disclosed what use, if any, the director makes of these reports. It is necessary to maintain a close check on the operatives who are subjected to such unusual temptations as are met with in combating prostitution, gambling, and traffic in liquor and drugs. But the chief should not be burdened with the details of checking 30 men in the vice bureau. Rather, he should depend on an officer of higher rank than now detailed to the vice bureau to do the checking and hold him responsible for general results as in other divisions of the service.

While complaints which are referred to the vice bureau cannot be thrown out without rendering a report of action taken thereon, it is cases that are supervised rather than the methods employed by operatives in working on the cases. An examination of the records maintained in the vice bureau discloses the fact that supervising officers do not keep adequate check on the cumulative operations of the men under their command. It would seem that too much reliance is placed on the automatic check which the mere submission of supplementary reports is supposed to afford. True, operatives are required to write up a summary of each day's work in books kept in the bureau for that purpose, and this enables the supervising officers to tell what was done by the 
men on the day's cases, provided the men are always faithful in recording all cases. It does not, however, afford a means of keeping tab on complaints which are a few days or a week old. As a matter of fact, supervision in the vice bureau, as in the detective bureau, is conducted on the memory basis, which is bound to be wholly inadequate in a large department. It is simply impossible for two commanding officers to remember the multitude of assignments given to some 30 men extending over a period of weeks and months. It would be a laborious task to find out, from the record now kept, how many cases or complaints A or B is working on at any given time, or to learn from their reports what progress has been made on the cases which they have under investigation. As a result, old cases become dead cases, and are readily lost to the view of supervising officers in the shuffie of each day's new business.

\section{Other Crime Prevention Units Needed}

As has been pointed out, the vice bureau should comprise but one section of the special service division, although it could well remain a more or less independent section. There is need for the immediate establishment of a woman's bureau, composed of not less than 10 police women. Cleveland is the only city of over a half million population that does not employ police women. The experience of such cities as London, New York, Detroit, St. Louis, Los Angeles, and Indianapolis has proved conclusively that women can perform police work of the highest order, often in a way that cannot be equaled by men. The Police Woman's Section should perform most of the duties now carried on by the Cleveland Woman's Protective Association, an organization privately financed and managed. Police women can do most effective crime prevention work in the inspection of dance halls, parks, movingpicture theaters, and other places of amusement. They can do good work in pre-delinquency cases with incorrigible girls and boys. They can also take under investigation the cases of adults who may possibly contribute to the delinquency of minors. The investigation of complaints of missing persons, which many times disclose runaway cases, can often be best handled by women. Women selected for this section of the crime prevention division should possess a strong sense of social service, and should have the training and outlook of the type of social worker employed by such private agencies as charity organizations, the Travelers' Aid Society, and the Woman's Protective Association.

At the present time dance halls are being supervised by a special unit known as the Dance Hall Inspection Bureau. This bureau is attached to the office of the director of public safety. The dance hall 
inspectors, numbering about 40 deputies or special police, are not members of the police department. They are paid fees by the proprietors of the dance halls which they inspect. A clerk-patrolman detailed to the director's office assigns the inspectors and keeps a record of dance hall permits. The dance hall inspection division should be abolished and the work taken over completely by the police department, for the inspection of public dance halls is a duty which cannot properly be delegated to unofficial observers whose salaries are paid by the people they inspect. Much of this work should naturally fall to the division of women police.

A unit of welfare officers is another much-needed section of the special service division. This unit may be composed of both men and women. It should be the duty of this division to investigate the bad home conditions that make for delinquency and cases of destitution coming to the attention of the police. Another fruitful field of crime prevention service that can be performed by a welfare unit is that of giving counsel and aid to persons who are turned out of hospitals and other institutions, and who are often unwelcome in their former homes. Experience in other cities shows that such persons easily drift into a life of crime. The same field of valuable service is found in dealing with criminals who are released from institutions and prisons and thrown on the community, often without opportunity for making a living in a fair and honest way. A welfare unit should keep in touch with opportunities of employment for these persons. By helpful coöperation a sort of protective supervision may be established looking toward the redemption of many who would otherwise gravitate to vice and crime. It is a fact that parents of wayward children, and many persons who are on the verge of desperate helplessness, will frequently turn for aid to a welfare division of the police service when they would not approach the police through the ordinary channels which carry with them the idea of repression and even hostility toward those in distress.

An excellent precedent of such a unit of welfare officers exists in the system which Commissioner Woods established in New York during his term of office. Carefully chosen officers were assigned to the busier precincts of the city to ferret out conditions which seemed to be leading people astray. This experiment did not have time to prove itself before Commissioner Woods left office, but it illustrates the new technique in police work for diminishing crime.

The fourth section of crime prevention service needed is a unit of juvenile officers. Complaints of juvenile delinquency should be referred to specially selected officers, who may be chosen because of their 
peculiar qualifications as experts in handling children's cases. This Juvenile Bureau or Section should coöperate actively with the Juvenile Court and make many of the investigations for the court which are now made by court probation officers. It is a police function, and the police department should not be relieved of responsibility for performing it. Juvenile officers should be distributed through the city by assignments to precincts, although general supervision of their work should be carried on by the special service division at headquarters. The work of juvenile officers attached to precincts in Chicago affords an excellent example of the value of such a division. The long-established juvenile bureaus in the Detroit and Los Angeles police departments likewise have proved the value of employing a special unit engaged in crime prevention among children.

All of the special activities mentioned above should be consolidated in a single division devoted to the more constructive features of crime prevention. One of the highest ranking officers in the service should be selected by the director of police to head this important division. His duty would be to survey general conditions in the city which indicate opportunity or need for corrective crime prevention measures. He should then see that the various sections of his division are well coordinated. Although the several fields of work are specialized, there is much opportunity for active coöperation. Thus, members of the vice bureau, in the course of their investigation of complaints of gambling and sex delinquencies, run across hangers-on and idlers against whom they may not proceed with formal charges, but who, nevertheless, may properly be investigated. Information regarding these border-line cases of delinquency should be handled by the Police Woman's Section, Welfare Section, or Juvenile Section, as the case may warrant. Similarly, the investigations conducted by the Police Woman's Division or Welfare officers will many times disclose conditions that should be investigated by the vice bureau. It is important that the common factors of a crime prevention program be recognized and that the agencies carrying out such a program be closely knit together. There should be a single head directing the development of a crime prevention program in its several aspects.

Members of the special service division who are not engaged on specific assignments should keep in constant touch with the breeding places of crime throughout the city. Insistent police surveillance of pool-rooms, cigar-stores having back rooms, hotels and lodging-houses, and the other places where there is customary idling will do much to prevent the commission of petty crimes on the spot and the hatching of 
crimes to be committed elsewhere. The young criminal is a gregarious being, and idling with bad associates is the primary requirement for sending him or her on the road to some criminal act.

It is not necessary for the police to wield a club or even to proceed with a warrant in many cases. They can, wholly within their legal rights, so interfere with idling that it may be largely broken up in public places. By sending a boy home or questioning an idler or by making many inquiries of the origin and intentions of idlers, the police can make idling uncomfortable instead of interesting and at times profitable. It requires groups of idlers to keep alive the contacts of the underworld, which show the way to traffic in drugs, liquor, and prostitution. Crimes ordinarily produced by these associations cannot flourish when the police are ever questioning and scrutinizing.

The importance of having a separate division recognized as the responsible agency in the department for the promotion of facilities for constructive efforts of crime prevention cannot be overestimated. When such a division is established, there will be a logical place for inaugurating new practices and experiments in social service and pre-delinquency activities, thus avoiding haphazard creation of a number of small new units which are likely to be poorly organized and inadequately supervised. Finally, the special service division should become the police department's liaison division between schools, hospitals, and private charitable and correctional institutions. Because of the character of its work, such a division could readily secure a degree of coöperation with other agencies of social service that is not now usually had by any other branch of the police department.

It must be admitted that this whole idea is new in police work in America, but its basic idea gives shape to the police work of the future. There is as much room for crime prevention in our communities as for fire prevention or the prevention of disease, and in this endeavor to limit the opportunities of crime and keep it from claiming its victims the police department must take the leading part. 


\section{CHAPTER $\mathrm{X}$}

\section{THE SECRETARIAL DIVISION}

$\mathbf{T}$

JHE work properly belonging to the office of a secretary of the police department is now scattered among several offices and divisions, with almost no coördination. There is a waste in men employed in the various tasks relating to record keeping, filing, and correspondence. Furthermore, the work that is being done is inadequate.

Personnel service records, payrolls, equipment, repair, and supply records are prepared and kept in the office of the director of public safety, and certain classes of permits, such as for dances and parades, are issued from that office. A detective and a patrolman are detailed there to care for a portion of the police work. Other clerks devote part of their time to clerical work which pertains to the administration of the fire department as well as police. All the correspondence and stenographic work of the police department is done in the office of the chief of police. One detective, two sergeants, and three patrolmen are detailed to do this work. Personnel records duplicating those kept in the director's office are also filed in the chief's office.

The bureau of records cares for the preparation and filing of pawnshop and lost property records, and all records relating to the license, ownership, and identification of automobiles. In this bureau also are filed all criminal complaints and copies of reports made by the various divisions of the department. Six patrolmen are detailed to serve as clerks in this bureau. There is no officer in command, the patrolmen severally assuming responsibility for the management of the bureau during the eight-hour period when they are on duty. The record bureau is cramped in a small room on the first floor of the police headquarters building. It is poorly ventilated and lighted by a single window opening on a court. Records are not protected from fire. The record bureau facilities of the police departments in Detroit, where the whole top floor of the headquarters building is given over to the record bureau, and in St. Louis, where an enormous well-lighted room is used for the record bureau, are in striking contrast to Cleveland's meager facilities.

A clear duplication of record keeping is found in an office known as 
the bureau of information, which has no organic relation to any clerical division and no particular place in the scheme of organization. Toree sergeants and three patrolmen are detailed to this office. Three additional men are attached to a telephone desk on another floor. These desk officers also belong to the bureau of information. A sergeant of police, known as the court sergeant, has an office adjoining the municipal court. This officer keeps a record of cases presented in court and also prepares statistics of daily crime complaints.

All of the offices mentioned above should be combined in a single division under the management of a secretary of the department. Civilian clerks and stenographers-most of them girls-should be employed to do the work in the place of policemen. Clerks trained and experienced in clerical duties can do the work better and at far less cost than at present. It is absurd to employ detectives and sergeants of police in activities of this kind.

The secretarial office should be organized in several sections, as, for example, the correspondence section, the filing section, the information desk, and the division of statistics. Combined in one bureau, all this work which is now scattered throughout the department could be coordinated in a way that would increase its effectiveness and greatly reduce its cost. 


\title{
PART II \\ PROSECUTION
}

\author{
BY \\ ALFRED BETTMAN \\ ASSISTED BY \\ HOWARD F. BURNS
}




\section{PROSECUTION}

\section{CHAPTER I}

\section{THE PLACE OF PROSECUTION IN CRIMINAL JUSTICE}

\section{Some Fundamental Assumptions}

7 HIS division deals with the work of the prosecuting attorneys in preparing, presenting, influencing, and controlling the case of and for the State or city. ${ }^{1}$ Naturally, it touches, on the one hand, the work of the police, and, on the other hand, the work of the courts. The police and courts are dealt with in other divisions of this survey, and an attempt will be made to avoid repetition, so far as possible.

This survey began during a somewhat sensational agitation regarding a "crime wave" in Cleveland. The people of the city seemed to believe there was something wrong with the administration of criminal justice in Cleveland, and blamed the inefficiency or even corruption of individuals engaged in that administration. Despite this atmospheric condition, this study has proceeded upon the theory that the facts of the situation are ascertainable and that conclusions should follow and not precede the facts. Facts have a reforming power of their own, and there are occasions when it is useful to gather statistics which prove the obvious.

This investigation was based upon certain fundamental assumptions. We are here dealing with the enforcement of the criminal law by means of the traditional methods of procedure, involving a case in the courts with a trial of the facts and law before judges and juries, with a lawyer on each side of the case, or, at least, each side entitled to be represented by a lawyer, the prosecuting attorney being the attorney for the State or city. In other words, the assumption is made that, though the treatment of the offender may be increasingly regarded as a problem in medical science or public hygiene, and the disposition of the offender increasingly determined by means of medical, psychologic, or similar examinations, still, for a long time to come, most cases will be treated as involving law enforcement and administration of justice, and the

1 Prosecutions for violation of State laws are brought in the name of the State of Ohio; those for the violation of eity penal ordinances in the name of the City of Cleveland. 
function of the prosecuting attorney will remain substantially as at present. In short, the scope of this report does not include a discussion of any question of abolishing the prosecutor: it seeks to appraise the success with which the prosecutor is performing the task assigned to him.

The American political and constitutional system will also be assumed. This study does not aim to go beyond practical suggestions for the improvement of the administration of justice which are easily available to Cleveland without any fundamental changes in either the political or social system or the treatment of crime.

\section{The System in Outhine}

Criminal justice in Cleveland is administered mainly in the Court of Common Pleas of Cuyahoga County and the Municipal Court of Cleveland. Prosecutions before grand juries and county courts are in charge of the prosecuting attorney of Cuyahoga County; those in the Municipal Court are conducted by the prosecuting attorney of the Municipal Court. The records show that about 10 per cent. of the county cases originate in the grand jury and these involve no work of the municipal prosecutor. No record is made of matters which are presented to the grand jury but in which no indictment is found, and these matters involve no official work on the part of the municipal prosecutor. About 4 or 5 per cent. of the cases reaching the county courts, and included in the statistics contained in this report concerning county cases, arise in territory within Cuyahoga County but outside of the city of Cleveland, and therefore beyond the jurisdiction of the Municipal Court or municipal prosecutor of the city of Cleveland. The remaining cases fall within the jurisdiction of the Municipal Court of Cleveland and are in charge of the municipal prosecutor of that city. The facts and statistics here set forth concerning that court and prosecutor relate to these cases.

Jurisdiction over the accused is obtained by arrest. The arrest may precede the making of the charge and the warrant of arrest, as, for instance, in the case of an arrest made by a police officer who is present at the commission of the offense and makes the arrest upon the basis of what he himself sees. Or the arrest may follow the affidavit setting forth the charge and the issuance of the warrant thereon. In either event the case is placed on the docket of the Municipal Court, where the case is either dropped or given a preliminary hearing or tried.

Basing the classification upon jurisdiction of the courts, the cases may be divided into three general classes: 
1. Charges of violation of a municipal law or ordinance; that is, municipal offenses, in which the trial of the case itself and the final sentence in the case take place exclusively in the Municipal Court.

2. Cases involving violation of State statutes of a minor degree, that is, state misdemeanors, where the Municipal Court is given the jurisdiction of a minor State court.

3. Violations of State law, where the offense involved is more serious and the sentence of imprisonment in the State penitentiary or other State penal institution is allowed-that is, state felonies. In these cases the Municipal Court acts as the court of preliminary examination to determine whether sufficient basis of fact exists for any further proceeding. The case, however, is not tried in the Municipal Court, but is tried by and judgment rendered by the Common Pleas Court.

All three classes, therefore, involve a hearing of a more or less final nature by the Municipal Court. In all proceedings in this court the State or city is represented by the prosecuting attorney of the Municipal Court. This official belongs to the department of law of the city of Cleveland, being appointed by the Director of Law, and, theoretically at least, his assistants are also appointed by the Director of Law. Consequently, in all cases the work of the municipal prosecutor chronologically precedes the work of the county prosecutor, and the hearing in the Municipal Court chronologically precedes the proceeding in any other court.

\section{Prime Importance of Municipal Court and Prosecutor}

In setting down the facts regarding the administration of criminal justice in Cleveland, therefore, the description of the work of the municipal prosecutor and Municipal Court naturally comes first in order. This order of precedence, however, is justified on deeper and more significant grounds than mere chronological sequence. For, though the public is not always conscious of it, the police court or criminal branch of the Municipal Court and the officials who conduct its work are the most important of all the tribunals and officials engaged in the administration of justice in any community, especially where, as in Cleveland, the municipal prosecutor has charge of the early stages of State cases. $\mathrm{He}$ has the function of deciding in the very beginning whether any criminal proceeding be brought at all, and in most cases, even where an arrest has been made, it is the municipal prosecutor who has the responsibility of sifting out at the start the cases which justify subjecting a person to the pains and penalties of prosecution. When we come to observe the mere volume of criminal cases in Cleveland and the bearing of that volume on the possibilities of efficient administration, we will 
realize the importance of the municipal prosecutor as a sifter of the material to go into the mill.

Moreover, the office of the municipal prosecutor and the Municipal Court are the points of contact with the administration of justice of the overwhelming majority of the inhabitants who come into any contact with courts and court officials. There the great bulk of the population receives its impressions regarding the speed, certainty, fairness, and incorruptibility of justice as administered. For law to be effective there must not only be justice, but also the appearance of justice-that truism requires no elaboration. As a deterrent of crime, the Municipal Court is more important than any other of our institutions with the possible exception of the police force.

The work of the municipal prosecutor may not end with the Municipal Court, for if the case, being a municipal or a state misdemeanor case, is tried by the Municipal Court and results in a judgment or conviction and sentence, the defendant may carry the case up on error to the Court of Appeals. Proceedings in error of this nature involve the same sort of questions as in civil cases-that is, the appellate court simply hears arguments upon questions of law and decides the case in the light of the arguments and the record of the hearing in the Municipal Court. Some cases may be carried to the Supreme Court of Ohio. The presentation of the city's or State's side of these appellate cases is in charge of the municipal prosecutor.

Where, however, the Municipal Court acts simply as a court of preliminary examination,-binding the defendant over to the grand jury,-then from that moment the charge of the State's case falls within the jurisdiction of the county prosecutor. It becomes the province of the latter official to present the case to the grand jury, and if the grand jury finds an indictment, to try the case before the trial court and jury. Cases which do not come up from the Municipal Court but are initiated in the grand jury are in charge of the county prosecutor from the beginning. He has the opportunity, within certain limitations, at any stage previous to the verdict of the trial jury, to drop those cases which he deems insufficiently proven to justify any further proceeding. Consequently, from the binding over of the accused to the grand jury or the initiation of the case there, the observation of facts and data will relate to the grand jury and the county courts and office of the prosecuting attorney of Cuyahoga County (which official, for purpose of abbreviation, we shall henceforth call "county prosecutor"). He is an elected official, and, theoretically at least, appoints his own assistants. 


\section{CHAPTER II}

\section{CASE MORTALITY}

\section{The Story Told By Statistics}

$\mathrm{N}$ ATURALLY the first questions for the survey are: What is the number of criminal prosecutions in Cleveland? What are the different stages through which they go? What are the different points at which they may be successful or lost or dropped or disappear? What are the different steps at which the capacity or incapacity, the honesty or corruption of the prosecutor, may play a part? What has actually been the result of the work of the offices of municipal and county prosecutors in Cleveland?

The answers to these questions have been sought objectively by means of a representative body of statistics. These tables of statistics will be permitted largely to tell their own story. In reading such statistics and drawing conclusions therefrom, we must necessarily formulate more or less consciously some standard or measure of efficiency and success. The acquittal of an innocent man obviously cannot be treated as a failure in the administration of criminal justice, however disappointed the prosecuting attorney may have been about losing the case. If at any stage of a case, and after thorough investigation, the prosecuting attorney becomes conscientiously convinced that there is no proof of crime, it is his duty to "nolle" the case. Such a "nolle" is not a failure in the administration of criminal justice. There may have been inefficiency somewhere along the line which resulted in the necessity of a "nolle," and acquittal may have been due to inefficiency in preparation of the case and not to the innocence of the accused. The more highly efficient the preparatory steps and preliminary stages, the less likely will be the necessity of trying cases against innocent men or ill-prepared cases against guilty ones. Consequently, a high percentage of cases which fail at various stages is an indication of something wrong in earlier stages. Statistics of the results of cases, therefore, while perhaps not capable of exact interpretation, do furnish significant indication of the efficiency of the system. 
For the purpose of answering these questions there have been gathered from the records of the Municipal Court all data shown by these records for the years 1919 and 1920. Owing to the enormous number of cases $(23,776$ cases on the docket in 1919 , and 26,579 in 1920), it was deemed impossible to tabulate all the cases for those two years. Consequently, every tenth case was taken, ${ }^{1}$ without any other basis of selection. These years are chosen because they were the last two full calendar years preceding the survey. In both of these years the political complexion of the office of the municipal prosecutor was Republican. To have included a Democratic administration of that office would have required going back as far as 1915 and an analysis of the records of the court for at least six years, a more extensive period than was deemed necessary for the study of existing conditions.

From the records of the Common Pleas Court were taken complete data, as disclosed by those records, regarding all criminal cases appearing in that court for the first time during the calendar year 1919. Too late for changing the tables, it was discovered that about 100 cases of 1920 had been included. As cases are not analyzed from the point of view of the date of their appearance in the court, this addition merely increases the volume of cases, and does not invalidate any conclusions. ${ }^{2}$ Included in the material collected about each case are: the facts about it in the examining courts; its history in the Common Pleas Court and the Court of Appeals down to April 1, 1921.

In 1919 and 1920 the county prosecutor's office was Democratic. Since January, 1921, it has been Republican, with a complete change of personnel. Naturally, there is a considerable proportion of cases which began in 1920 and have run over into 1921, so that these cases have been in charge of successive administrations of opposite politics and of entirely changed personnel. For this reason it was deemed advisable to choose 1919 as the year for analysis, as that is the last full year in which it is possible to trace the full history of the majority of a year's cases within a single administration.

1 The total number of cases appearing in our statistical study of the Municipal Court for 1919 and 1920 is somewhat less than one-tenth of the total cases $(50,355)$. This is due to the fact that the system of filing makes the number of "cases" less than the number of persons: 50,355 is the total number of persons handled by the court. The clerks who copied the data from the files were instructed to take every tenth "case" by the file numbers-hence the discrepancy.

2 The last of these extra cases was entered in the Common Pleas Court January $15,1920$. 


\section{The Mortality Tables}

We are calling certain of the results of these studies the "Mortality Tables," because they show the mortality of the cases at their various stages. Accompanying the tables are diagrams which show in a more easily comprehended manner the relative quantities of the more important types of dispositions. Table 1 gives the statistics concerning the results and dispositions of the city misdemeanor cases; Table 2 gives these statistics concerning the state misdemeanor cases-that is, State cases which are ultimately decided or final judgment therein rendered in the Municipal Court, though the case might have included appellate proceedings in an appellate court. Table 3 gives these statistics regarding state felony cases, showing the results thereof in the Municipal Court, before the grand jury, and in the Common Pleas Court, where felony cases are finally tried and where sentence is imposed.

TABLE 1.-MORTALITY TABLE OF CITY MISDEMEANOR CASES, 1919-1920

\begin{tabular}{|c|c|c|c|c|}
\hline & $\begin{array}{l}\text { Number } \\
\text { of cases }\end{array}$ & $\begin{array}{l}\text { Number } \\
\text { of cases } \\
\text { remaining }\end{array}$ & $\begin{array}{l}\text { Per cent. } \\
\text { of cases }\end{array}$ & $\begin{array}{l}\text { Per cent. } \\
\text { of cases } \\
\text { remaining }\end{array}$ \\
\hline $\begin{array}{l}\text { Total } \\
\text { Unknown disposition } \\
\text { Discharged } \\
\text { "No papers" } \\
\text { Nolle prosequi } \\
\text { Dismissed for want of prosecution } \\
\text { Other dispositions; no sentence } \\
\text { Found guilty; total } \\
\text { Plead guilty } \\
\quad \text { Plead not guilty } \\
\text { Plea unknown }\end{array}$ & $\begin{array}{r}1,832 \\
4 \\
232 \\
27 \\
141 \\
\because 8 \\
8 \\
(1,420) \\
813 \\
598 \\
9\end{array}$ & $\begin{array}{r}1,8 \ddot{2} \\
1,596 \\
1,569 \\
1,428 \\
1,4 \ddot{20} \\
6 \ddot{7} \\
9\end{array}$ & $\begin{array}{r}100.00 \\
0.22 \\
12.66 \\
1.47 \\
7.70 \\
0.44 \\
(77.51) \\
44.38 \\
32.64 \\
0.49\end{array}$ & $\begin{array}{r}99.78 \\
87.12 \\
85.65 \\
77.95 \\
77.51 \\
33.13 \\
0.49 \\
\ldots\end{array}$ \\
\hline
\end{tabular}

Execution, Suspension, and Mitigation of Sentences

\begin{tabular}{c|c|c}
\hline & Number & Per cent. \\
\hline Total found guilty & 1,420 & $\ldots$ \\
Sentence unknown & 8 & $\ldots$ \\
Sentence known $^{\text {Sentence executed }}$ & 1,412 & 100.00 \\
Sentence wholly suspended $^{\text {Sentence mitigated }}$ & 768 & 54.39 \\
& 386 & 27.34 \\
\hline
\end{tabular}

1 "Sentence executed," in this table and in the other tables in this report, means sentences which the trial court itself did not suspend or mitigate. It does not mean that the number of sentences indicated were necessarily carried out. The figures in these tables were taken from court records and have not taken into account any action of the executive authorities in the exercise of executive clemency, such as pardon or commutation, or of the acts of paroling prisoners from penal institutions. 

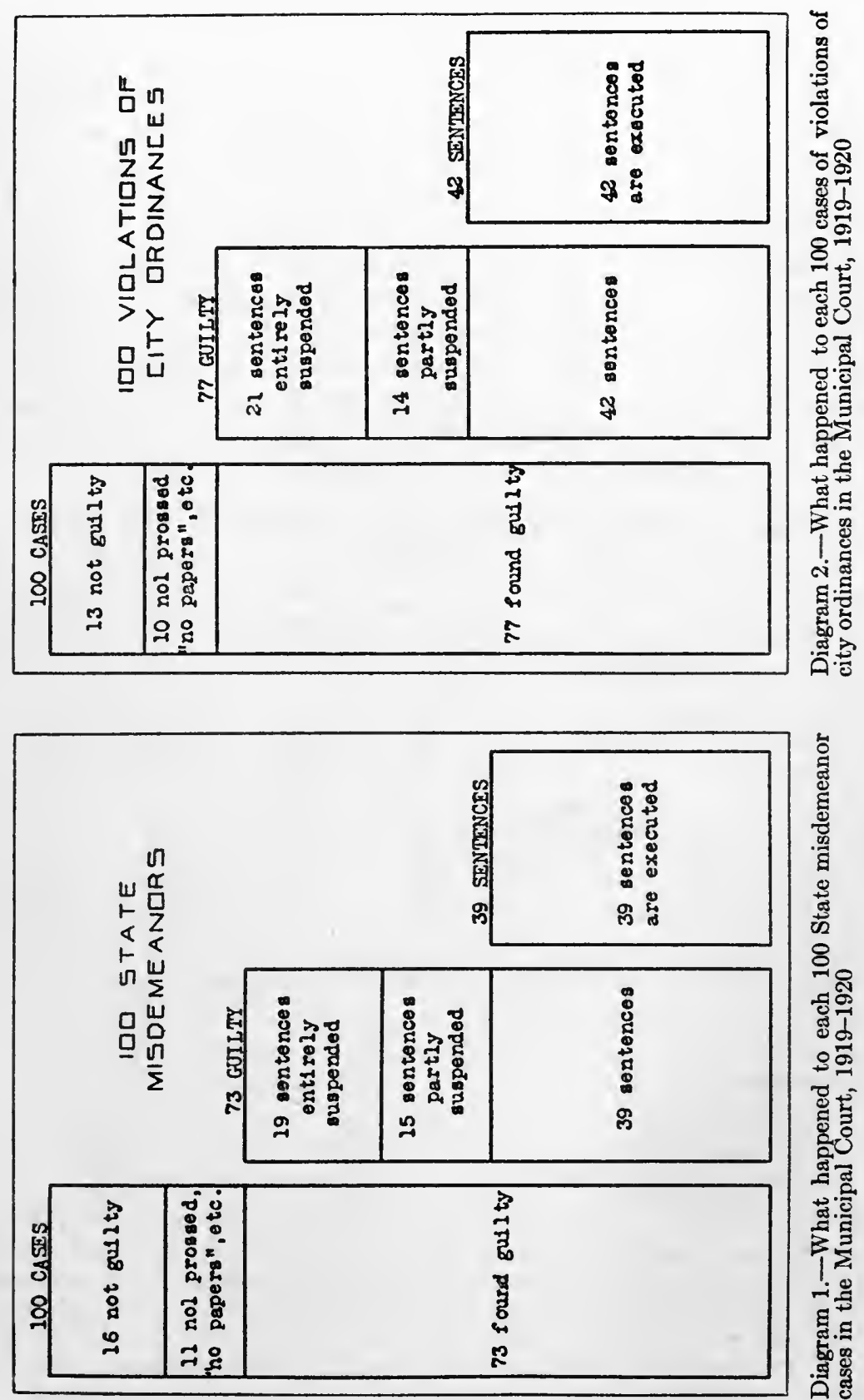
TABLE 2.-MORTALITY TABLE OF STATE MISDEMEANOR CASES, 1919-1920

\begin{tabular}{|c|c|c|c|c|}
\hline & $\begin{array}{l}\text { Number } \\
\text { of cases }\end{array}$ & $\begin{array}{l}\text { Number } \\
\text { of cases } \\
\text { remaining }\end{array}$ & $\begin{array}{l}\text { Per cent. } \\
\text { of cases }\end{array}$ & $\begin{array}{l}\text { Per cent. } \\
\text { of cases } \\
\text { remaining }\end{array}$ \\
\hline $\begin{array}{l}\text { Total } \\
\text { Unknown disposition } \\
\text { Discharged } \\
\text { "No papers" } \\
\text { Nolle prosequi } \\
\text { Dismissed for want of prosecution } \\
\text { Other dispositions; no sentence } \\
\text { Found guilty; total } \\
\text { Plead guilty } \\
\text { Plead not guilty } \\
\text { Plea unknown }\end{array}$ & $\begin{array}{c}1,953 \\
20 \\
308 \\
19 \\
89 \\
87 \\
8 \\
(1,422) \\
812 \\
577 \\
33\end{array}$ & $\begin{array}{r}1,933 \\
1,625 \\
1,606 \\
1,517 \\
1,430 \\
1,422 \\
610 \\
33 \\
\ldots\end{array}$ & $\begin{array}{r}100.00 \\
1.02 \\
15.77 \\
0.97 \\
4.57 \\
4.45 \\
0.41 \\
(72.81) \\
41.58 \\
29.54 \\
1.69\end{array}$ & $\begin{array}{r}98.98 \\
83.21 \\
82.24 \\
77.67 \\
73.22 \\
72.81 \\
31.23 \\
1.69 \\
\ldots\end{array}$ \\
\hline
\end{tabular}

Execution, Suspension, and Mitigation of Sentences

\begin{tabular}{l|r|r}
\hline & Number & Per cent. \\
\hline Total found guilty & 1,422 & 100.00 \\
Sentence unknown & 14 & 100.00 \\
Sentence known & 1,408 & 52.77 \\
Sentence executed & 743 & 26.42 \\
Sentence wholly suspended & 372 & 20.81 \\
Sentence mitigated & 293 & \\
\hline
\end{tabular}

\section{What Becomes of Felonx Cases}

Table 3 requires further explanation. That portion which is marked "A" is a tabulation of the disposition of felony cases in the Municipal Court, and is taken from the record book known as "Execution Docket" for the period approximately identical with the year 1919, which is the period for which the tabulations of results in the county court were made. The percentages are based on the whole number of felony cases in the Municipal Court in that period, namely, 3,927. That portion marked " $\mathrm{B}$ " is the analysis of results in the Common Pleas Court, as shown by an actual tracing of every case in that period. As the cases include those which originated in the grand jury and those which originated in magistrates' courts outside of Cleveland proper, the number is greater than the number of felony cases in the Municipal Court of Cleveland. Column 3 represents the percentage of each type of disposition based on all the cases in the county court, namely, 3,236. We cannot assume that the cases bound over in 1919 by the Municipal Court correspond with absolute identity with the bound-over cases 
which were disposed of by the county court in the same period. In view, however, of the fact that the bound-over cases constitute so predominant a proportion of the cases in the county court, it is fair to assume that the 2,901 bound-over cases received approximately the same percentage of dispositions as were found to have been received by all cases in the county court. The percentages, calculated on the basis

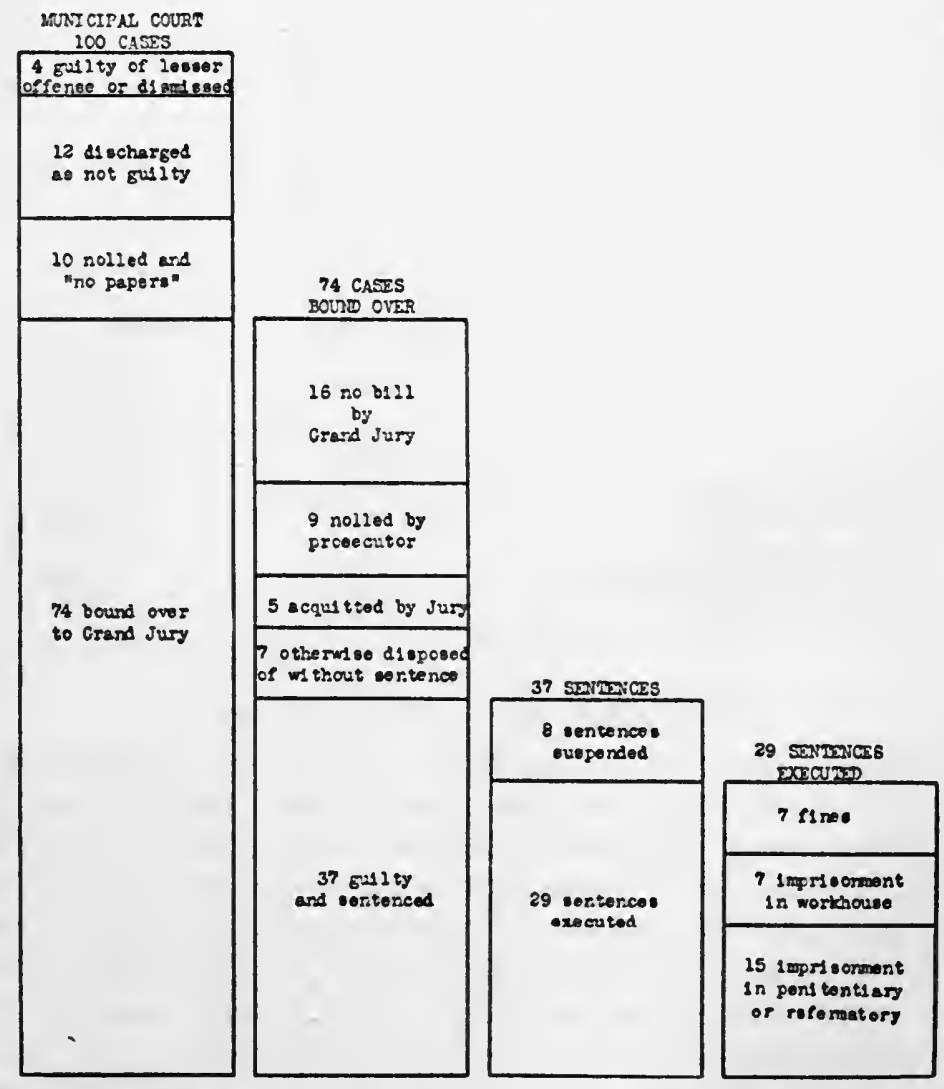

Diagram 3.-What happened to each 100 felony cases beginning in the Municipal Courts, 1919

of this assumption, are set forth in column 5 , each percentage being based on the whole number of cases originating in the Municipal Court. For instance, take the item "nolle prosequi on all counts." As shown in column 3, 12.33 per cent. of the cases received this disposition. As Part A shows, 73.87 per cent. of the felony cases in the Municipal Court are 


\begin{tabular}{|c|c|c|c|c|c|c|}
\hline 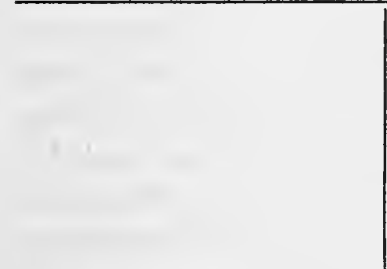 & $\begin{array}{l}\text { Num- } \\
\text { ber } \\
\text { of cases }\end{array}$ & $\begin{array}{c}2 \\
\text { Num- } \\
\text { ber } \\
\text { of cases } \\
\text { re- } \\
\text { main- } \\
\text { ing }\end{array}$ & \begin{tabular}{|c|}
3 \\
Per cent. \\
of cases \\
Common \\
Pleas \\
Court \\
base
\end{tabular} & \begin{tabular}{|c|}
4 \\
Per cent. \\
of cases \\
remain- \\
ing \\
Common \\
Pleas \\
Court \\
base
\end{tabular} & $\begin{array}{c}5 \\
\text { Per cent. } \\
\text { of cases } \\
\text { Muni- } \\
\text { cipal } \\
\text { Court } \\
\text { base }\end{array}$ & $\begin{array}{c}6 \\
\text { Per cent. } \\
\text { of cases } \\
\text { remain- } \\
\text { ing } \\
\text { Muni- } \\
\text { cipal } \\
\text { Court } \\
\text { base }\end{array}$ \\
\hline \\
\hline Tot & 3,927 & & $\cdots$ & $\cdots$ & 100.00 & 100.00 \\
\hline Discharged & 483 & 3,444 & . & . & 12.30 & 87.70 \\
\hline "No 1 & 70 & 3,374 & . & . & 1.78 & 85.92 \\
\hline Nolle prosequi & 312 & 3,062 & . & . & 7.95 & 77.97 \\
\hline $\begin{array}{l}\text { Dismussed for want or } \\
\text { prosecution }\end{array}$ & 57 & 3,005 & . & . & 1.45 & 76.52 \\
\hline sentence & 24 & 2,981 & .. & . & 0.61 & 75.91 \\
\hline Charge reduced; total & $(80)$ & & . & . & (2.04) & \\
\hline Plead guilty; sentenced & 45 & 2,936 & . & . & 1.15 & 74.76 \\
\hline $\begin{array}{l}\text { Plead not guilty; sen- } \\
\text { tenced }\end{array}$ & 18 & 2,918 & & . & 0.46 & 74.30 \\
\hline Plea unknown & 17 & 2,901 & . . & $\cdots$ & 0.43 & 73.87 \\
\hline \multirow{2}{*}{\multicolumn{7}{|c|}{ B. In the Common Pleas }} \\
\hline & & & & & & \\
\hline Total & 3,236 & 39 & 100.00 & 78.46 & 73.87 & 73.87 \\
\hline Nolle prosequi on all counts & 399 & 2,140 & 12.33 & 66.13 & 9.11 & 48.85 \\
\hline $\begin{array}{l}\text { trial is ordered } \\
\text { Nolle prosequi after jury }\end{array}$ & 13 & 2,127 & 0.40 & 65.73 & 0.30 & 48.55 \\
\hline disagreed & 6 & 2,121 & 0.19 & 65.54 & 0.14 & 48.41 \\
\hline ed first trial & 223 & 1,898 & 6.89 & 58.65 & 5.09 & 43.32 \\
\hline $\begin{array}{l}\text { Acquitted second trial } \\
\text { Nolle prosequi, convicted } \\
\text { or in prison on other }\end{array}$ & 5 & 1,893 & 0.15 & 58.50 & 0.11 & 43.21 \\
\hline $\begin{array}{l}\text { charges } \\
\text { Discharged on demurrer }\end{array}$ & $\begin{array}{r}84 \\
5\end{array}$ & $\begin{array}{l}1,809 \\
1,804\end{array}$ & $\begin{array}{l}2.60 \\
0.15\end{array}$ & $\begin{array}{l}55.90 \\
55.75\end{array}$ & 1.92 & $\begin{array}{l}41.29 \\
41.18\end{array}$ \\
\hline $\begin{array}{l}\text { Discharged on motion to } \\
\text { discharge }\end{array}$ & 10 & 1,794 & 0.31 & 55.44 & 0.23 & 40.95 \\
\hline $\begin{array}{l}\text { Discharged for want of } \\
\text { prosecution }\end{array}$ & 16 & 1,778 & 0.49 & 54.95 & 0.36 & 40.59 \\
\hline $\begin{array}{l}\text { Bail forfeited or never in } \\
\text { custody } \\
\text { Miscellaneous dispositions }\end{array}$ & 90 & 1,688 & 2.78 & 52.17 & 2.05 & 38.54 \\
\hline & 92 & 1,596 & 2.85 & 49.32 & 2.10 & 36.44 \\
\hline $\begin{array}{l}\text { Convicted of misdemeanor } \\
\text { Original plea guilty of les- }\end{array}$ & 74 & 1,522 & 2.29 & 47.03 & 1.69 & 34.75 \\
\hline $\begin{array}{l}\text { ser offense } \\
\text { Changed plea not guilty }\end{array}$ & 22 & 1,500 & 0.68 & 46.35 & 0.50 & 34.25 \\
\hline $\begin{array}{l}\text { to plea of gu } \\
\text { offense }\end{array}$ & 193 & 1,307 & 5.96 & 40.39 & 4.40 & 29.85 \\
\hline $\begin{array}{l}\text { Original plea guilty of } \\
\text { offense charged }\end{array}$ & 433 & 874 & 13.38 & 27.01 & 9.88 & 19.97 \\
\hline $\begin{array}{l}\text { Changed plea not guilty } \\
\text { to guilty of offense } \\
\text { charged }\end{array}$ & 550 & 324 & 17.00 & 10.01 & 12.56 & 7.41 \\
\hline Convicted of felony & 293 & 31 & 9.05 & 0.96 & 6.69 & 0.72 \\
\hline $\begin{array}{l}\text { Miscellaneous combina- } \\
\text { tions of pleas; sentenced }\end{array}$ & 17 & 14 & 0.53 & 0.43 & 0.39 & 0.33 \\
\hline $\begin{array}{l}\text { Other dispositions; sen- } \\
\text { tenced }\end{array}$ & 14 & $\cdots$ & 0.43 & . & 0.33 & . \\
\hline
\end{tabular}


bound over. If 12.33 per cent. of these are later "nolled," it follows that the percentage of all felony cases originating in the Municipal Court $(3,927)$ which are ultimately "nolled" by the county prosecutor after they are in his charge is 73.87 per cent. of 12.33 per cent., namely, 9.11 per cent.-which is the figure found in column 5 . The item "Miscellaneous dispositions resulting in no sentence" includes disposi-

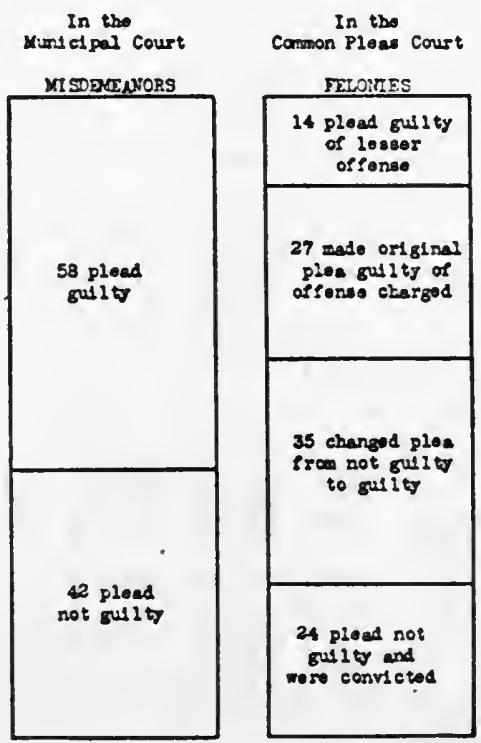

Diagram 4.-How each 100 sentenced defendants pleaded

tions such as abatement by death of defendant, commitment of defendant to a non-penal institution, dismissal of case on demurrer, etc., in which the case was neither tried nor dropped by the prosecutor.

Supplementing these tables and diagrams is Diagram 4. It shows the number of each kind of plea made by those sentenced. All the misdemeanor cases are lumped in one column, because the difference between city cases and State cases in respect to pleas is very slight. 


\section{CHAPTER III}

\section{THE MUNICIPAL COURT IN OPERATION}

\section{T}

JHE Municipal Court forms the stage upon which the municipal prosecutor plays his part. He can play this part well only if the settings permit. The orderliness and dignity or the disorderliness and slovenliness with which the court itself proceeds necessarily affect the prosecutor's work, and his work, in turn, reacts upon the court.

On March 23, 1921, the writer of this report watched one of the rooms of the Municipal Court in operation. There was no malice aforethought in the choice of room or day. Immediately after the visit the following memorandum of impressions was made:

"I spent the whole morning in this court-room, arriving promptly at 9.1 There was as yet no evidence that any court would be held that day, except the docket book lying open on the table and a few stragglers in the spectators' benches. It was fully 9.30 before the judge appeared and fully 9.45 before he got under way. By that time all the seats and aisles were filled with peoplepolicemen, defendants, lawyers, spectators. The atmosphere of the room was extremely sordid. It was a room about 40 feet square, walls painted in an ugly yellow, made still more ugly by accumulated soot, and no decorations of any kind whatever. Though I sat within 15 feet of the bench and witness-chair and strained my ears, I could seldom eatch a word of what was going on. From the beginning to end the whole proceeding seemed to me one calculated to impress the spectator with at least the suspicion that the main influence at work was not

${ }_{1}^{1}$ The rules of the Municipal Court of Cleveland on the subject of sessions of court provide:

"The sessions in the civil branch of this court shall be from 8 o'clock $A$. M. until 11 o'clock A. M., and from 12 o'clock M. until 3 o'clock P. M., central standard time, on each week-day, except Saturday, when the session shall be from 8 o'clock A. M. until 11 o'clock A. M., central standard time; and the sessions in the criminal branch of this court shall be from 7.30 o'clock A. M. until 11 o'clock A. M., and from 12.30 o'clock P. M. until 3 o'clock P. M., central standard time, on each week-day, except Saturday, when the session shall be from 7.30 o'clock A. M. until 11 o'clock A. M., central standard time." 
the evidence or judicial procedure as we know it, but either strange influences not audible in the court-room or things that were whispered into the ear of the judge.

"The cases are called by number, with only occasionally the name of a defendant also added. The witnesses are sworn by a form of oath which identifies every case under the expression 'pending case,' without reference to either the number or the names of the defendants. The prosecutor had no papers whatever. He lolled against the bench. For each case he was handed a copy of the affidavit and that is all he ever looked at. He took a glance at the paper to ascertain the nature of the case. He then mumbled something to the judge, whereupon the case was often announced as 'continued' or 'no-papered' or a light fine or sentence given. Other times he called the police officer or other chief prosecuting witness and mumbled some question which started the witness off, and generally that was the full extent of the participation of the prosecutor.

"In a few cases the attorney for the defense took part in the interrogation. Generally, however, he seemed to simply wander and stand around, mysteriously going in and out, sometimes approaching the bench, sometimes going to the benches and talking to somebody, and every once in a while somebody would go up and whisper something into the judge's ear. Seldom were all the witnesses sworn in any case actually called to the stand.

"While this mumbling and whispering were going on in the immediate vicinity of the bench, the main aisle leading in from the door into the court-room and to the bench was the scene of constant goings and comings. It was never quiet a second. Walking around, standing around in groups, moving around hither and thither, went on constantly. Not only was it impossible to hear what was going on in the trial, but it was generally impossible to see what was going on. One or two well-tried - -that is, by the defense--and well-fought--that is, by the defense-liquor cases were the only exceptions to the above picture."

In order that we might get the picture as seen by a more highly trained observer, an experienced newspaper reporter, but one whose work had not previously included a police court, was asked to observe these criminal rooms of the Municipal Court in action. He reported:

"On the morning and afternoon of April 8 and on the morning of April 9, I visited the court of Judge A in Room 2 of the Police Headquarters Building, and the court of Judge B in Room 1 of the same building, for the purpose of observing as closely as possible the details of the handling of cases.

"Judge A's court was by far the more objectionable. The environment is anything but conducive to respect for the law. The room itself is inexcusably dirty, dark, and noisy. From the four doors there is a constant stream of visitors, witnesses, court attendants, probation officers, and attorneys filing around the edges of the room.

"The confusion is enhanced by the way in which cases are conducted. The witness-stand is but a few feet from the seat of the judge, so that whatever 
questioning is going on is inaudible 10 feet away. Reporters who are 'covering' the court are forced to lean over the back of the witness-chair in order to hear. It is easy to see why newspapers often get court reports mixed up.

"At many times during the trying of cases there were as many as 40 persons gathered closely around the witness-stand or within 10 feet of the bench. This gathering was not confined to those persons taking part in the case under consideration, but consisted largely of attorneys waiting for their own cases to be called. There was no method of distinguishing prosecutors from witnesses or attorneys from prisoners.

"A large part of the day was taken up by conversations which went on in undertones between the judge and attorneys or prosecutors. These conversations had largely to do with pleas for continuance or excuses for the non-appearance of clients. If these conversations constitute part of the dispensing of justice, no one except the parties conversing could tell.

"The only case in which I was able to get any detail was that of a man named Fred Meyer, who, it seems, should have appeared in court to face a charge of violating the traffic ordinance. Apparently he had been summoned for the day before (Friday) and had not appeared. After questioning the attorney who represented Mr. Meyer, Judge A mentioned something about contempt. The attorney left the bench but returned a few minutes later and pleaded for a closing of the case, saying he would take the blame for the non-appearance of his client. The judge smiled and pronounced a sentence; I believe it was $\$ 10$ and costs.

"Non-appearances seemed to be in fashion at this court. In at least a dozen cases neither the accused nor the policemen nor detectives were present at first. The cases were called again and again, some of them being heard with part of the witnesses present, others apparently going by default. I did not hear the judge order a single person brought in or mention 'contempt' once. He may have done so, but if he did, it was in a whisper.

"Frequently Judge A was conversing with the clerk or some other person. and was not in a position to hear the evidence being brought out. At all times he was conducting cases in a spirit of complete boredom.

"Prosecution of cases was conspicuous chiefly by its absence. Nine-tenths of the questioning of witnesses was done by the attorneys for the defense. The prosecutor was present during part of some cases and absent during all of some. In not one case which I observed was he present at a complete trial. His chief function seemed to be to assist the bailiff in rounding up witnesses and in informing the judge of facts regarding the cases which the blotter did not show. This lack of prosecution was so obvious it was almost laughable.

"Swearing of witnesses was done in most cases, though not in all. I saw no attempt to manhandle or intimidate the foreigners who thronged the court. The treatment accorded them was courteous on the whole. In fact, a spirit of levity was reached in some of the cases. There was a total lack of dignity in all.

"Judge B's court was much more dignified, despite his habit of repeating 
the question-'how much money has the prisoner got?'- before pronouncing sentence. He asked this question mostly in cases where men had been given time in which to pay large fines and had been brought back for failure to make good. On being informed (correctly or otherwise) of the status of the prisoner's pocket-book, the judge then reduced the fine in practically every case.

"After one such case, in which the fine had been reduced from $\$ 300$ to $\$ 150$, the judge jokingly asked the attorney who had represented the prisoner how much he got out of the man. 'One hundred dollars,' said the attorney, and they both laughed.

"On the whole, Judge B's court was somewhat impressive. The court was more open as to conversation, and the judge attempted to impress on the prisoners the seriousness of their position. Judge A took no pains to say anything to the prisoners.

"There was less crowding around the bench and less conversation than in A's court. In both there was much delay in getting cases started because of missing witnesses."

A description was also requested from a capable Cleveland attorney sufficiently familiar with the Municipal Court to be able to interpret many things which might puzzle the lay spectator. He reported:

"To anyone who has seen the criminal branch of the Municipal Court, commonly called the police court, in operation, it is obvious that an observer can secure only the most superficial information unless he were to spend at least ten days continuously in that court. Confusion reigns supreme, and the tramping of witnesses and spectators back and forth across the court-room, together with the frequent rapping of the bailiff for order, are interruptions which are all too frequent, especially in view of the fact that the proceedings are usually conducted in very low tones. The usual number of spectators who apparently have no business in police court but who are always there and who are reputed to represent various lawyers appearing there, are to be found in both courtrooms every day.

"On Tuesday, April 26, at the morning sessions, the following incidents were noticeable: In Room 2, Judge A presiding, the court opened about 9.05 and immediately proceeded to hear cases, principally of traffic violations, without the presence of a prosecutor in the room. Most of these cases were disposed of very quickly by hearing the brief statement of the traffic officer and the defendant himself-fines usually running $\$ 5.00$ and costs. About 9.45 Prosecutor Novario entered and, after advising the court that two cases were 'nolled,' proceeded to conduct the prosecution. Throughout the proceedings there was considerable banter exchanged between the court and the prosecutor, usually with reference to liquor law violations, with such remarks as, 'What were you drinking, coal oil or gasoline?' 'Can you tell us where you got that stuff?' 'Must have been drinking a high explosive,' and other remarks of a similar nature. First question addressed to witnesses for either prosecution or defense was usually, 'What 
happened in this here case?' No trouble was taken to ask any of the witnesses their names or whether or not they had seen the incident. In other cases, involving traffic violations, the first question asked by the prosecutor was, 'What do you want to do, kill everybody in Cleveland?' and in other cases it was, 'What do you mean driving a million miles an hour on the street?' It was observed in this court-room that several witnesses testified without being sworn and to others the oath was administered in such a manner that they probably had not the slightest idea what proceeding was taking place.

"In Court-room No. 1, Judge B presiding, Prosecutor Russick was observed not to have asked any of the witnesses any questions until the latter part of the morning, when Case No. 37, Harry Wright, cited for contempt of court, came on and then there was an argument between Prosecutor Russick and Attorney Day on a motion in this case. At no other time during the proceeding did Prosecutor Russick question any of the witnesses, with the single exception of Case No. 59, which was heard about 11.15 A. M., and in this case the prosecutor questioned the first witness, who was an incompetent witness because of the fact that he had not witnessed the act itself. The examination of the other witnesses in this case was conducted by the court, and defendant eventually fined $\$ 50$ and costs. Prosecutor Russick then sat down at the trial table and proceeded to read a book, when Case No. 57 was called. This was a case in which Joseph Sklarski was arrested at the instance of his landlady, with whom he had boarded for one year, on the charge of assault. Neither the prosecuting witness nor the defendant spoke English, and the defendant was asked by an interpreter if he plead guilty or not guilty, without having the charge translated for his benefit. The interpreter then addressed the court as follows: 'Judge, he says that he pleads guilty but he wants a continuance to get a lawyer.' The court then made some inaudible remark, and in a louder voice told the interpreter to put the prosecuting witness on the stand. She then gave her testimony and the defendant was called to the stand. He testified, and without further testimony the court sentenced him to six months and $\$ 200$ fine and costs, and he was hurried out of the court-room in spite of the fact that he protested that he wanted a chance to get an attorney. Throughout the proceeding in this case the prosecutor sat at the trial table reading."

The next observer was an able Cleveland lawyer whose experience enabled him to know "who's who" in the police court. He was asked to observe especially the part played in the drama by the habitués of the court. He reported: (Except in the case of prosecutors, fictitious names are used.)

"To report everything that goes on in the criminal branch of the Municipal Court of Cleveland, generally referred to as the police court, is an impossibility for one man. To do so it would require the ability to see in all directions at the same time and to hear what was said in every part of the room, and in addition insight into the mental workings of any number of individuals who are present 
and who operate in such a manner as not to be discerned either by the sense of sight or hearing. This last type has in most instances got in its work outside of court hours and is present merely for the purpose of seeing that promises are fulfilled or to convince those for whom they are working that they have had some part in the accomplishment or services rendered.

"The following account is a rough sketch of observations made at the session of police court on Friday morning, April 22, 1921:

"I arrived at the Central Police Station about 8.45 and found the persons who are in attendance at the court beginning to assemble; a number were gathered around the bulletin board containing the names of about 150 defendants whose cases were on for hearing on that day. Some of the attorneys who had considerable practice in police court were busy interviewing witnesses and conferring with prosecutors and clerks. I noticed particularly Fred Smith ${ }^{1}$ conferring with Frank Brown, the last-named person not being an attorney, and to my knowledge has for six years been a runner for Thomas Jones, an attorney. Frank Brown still seemed to be at his regular business of interviewing witnesses and soliciting business for Thomas Jones. Also I saw present in the hallway leading from the clerk's office to the court-rooms Louis Napier, who is not an attorney and who is a brother of one of the prosecutors. I did not see him in conference with any individual during the whole morning, but during the first hour and a half of the session of the court he passed through the back of court-room No. 1 on his way to court-room No. 2 no less than half-dozen times, and I am advised by one who is in attendance at the court most every day that he is present every day.

"Frank Brown was also busy about the court-room practically all morning, either in Room 1 or Room 2, and conferred with Thomas Jones and Fred Smith on numerous occasions, and such conferences were apparently acquiesced in and unnoticed by the judges, prosecutors, and clerks. Frank Brown was also seen a number of times in the hallway leading to Court-room No. 1, and also in the hallway of Rooms 1 and 2 in conference with persons, but I was unable to hear what was said as the conversation was carried on in a very low tone.

"I have gone into details somewhat at length with regard to these two examples of police court hangers-on, and have referred to them merely as an example of a number of such persons who are present morning after morning in police court, but who are not attorneys and who apparently have no business there and who are not engaged in any regular occupation, but who somehow or other make their living out of such attendance.

"By 9 o'clock the seats in Room 1 were about two-thirds full of witnesses and defendants and those awaiting hearing, and upon the appearance of Judge B, the bailiff thumped three times on the desk with his gavel and called the court to order. This was followed by the clanging of the door of the bull pen where

${ }^{2}$ A lawyer practising habitually in this court and partner of Thomas Jones, a more prominent habitual practitioner in this court. 
the prisoners are kept. The court officer then led out into the court-room three defendants who were designated by numbers only, such as Cases 71, 72, and 73 . The clerk then read the charge in a monotone voice, and asked the question, 'How do you plead?' There was a nodding of heads by the defendants, all of whom pleaded guilty apparently. The judge then motioned to one of the defendants to take the stand, he asked him a few questions, and then said a few words to the other two parties. Finally he wrote something on the docket and the three men were led back into the bull pen. I should have stated that by this time William Gardner and Mr. Chester ${ }^{1}$ had seated themselves at the trial table, and Smith, Jones, and others had assembled and stood around the witness-chair listening to the testimony, but apparently having no other interest in the cases. Prosecutor Russick stood by the witness-chair up until intermission at 10.30, but only in one of the hearings took any part in the prosecution, the judge making all inquiry of witnesses and handling the cases without the assistance or interference of the prosecutor. I sat on the front bench in the court-room, where witnesses and spectators are seated, about 10 to 20 feet away from where the trial was going on, but was unable to hear anything that was said. I would have been unable to comprehend what was going on except for the fact that my experience there has enabled me to know by seeing just what is being done.

"Tramping was so continuous and so loud that persons seated in Courtroom No. 1, not being able to hear any of the proceedings, passed the time away talking with one another. This added to the general hubbub. Policemen waiting to testify as witnesses also felt at liberty to keep up a continuous conversation with whoever was sitting next to them, usually another policeman. During the session of the court from 9 to 10.30 the court, bailiffs, and prosecutors went ahead with their work regardless of the noise that was going on around them. At no time was anything said to bring order or to impress the assembled crowd as to the dignity of the whole proceeding.

"To give an example, the conduct of a specific case: Two negro girls were called before the clerk and charged with street soliciting. Jones was representing both of these women, and the two defendants, together with Prosecutor Russick and Attorney Jones, immediately gathered in front of the desk of the judge. A police officer took the stand and immediately about 18 persons gathered around the witness-stand and within a few feet of the witness and the defendants and leaned forward to catch what the police officer was saying. About half of these were attorneys. The prosecutor did not assist in the prosecution, except to ask the police officer to get off the stand. The judge then asked another police officer as to his testimony, and upon being advised that it was exactly like the officer who had testified, proceeded no further, and the State's side of the case was considered as complete. Jones apparently was satisfied with the State's side of this case. The judge then leaning over his desk spoke to the larger of the two defendants without having her take the witness-chair and inquired what

1 Two colored lawyers and politicians. 
she was doing down on Hamilton Avenue, completed the cross-examination himself, and also conducted the cross-examination of the other defendant, and the prosecutor apparently not resenting this assumption of his duties by the court, in fact, appearing to feel somewhat relieved that the judge saved him his additional labor. A probation officer then volunteered some information to the court regarding both of these defendants, and from a card indicated that one of the women was on parole and had violated her parole. The court gave the smaller of the women a sentence of thirty days, at which Jones protested very vigorously, and leaning over the desk assumed a confidential air with the judge and attempted to pour into his ear a story that would procure a lighter sentence for his client. The smaller of the two defendants was committed to jail and the other one given a suspended sentence.

"I omitted to mention the fact that City Councilmen Green, Walter, and Temple were present in court a great part of the morning. Councilman Green was seated at the table in Room No. 1 from about 9.30 to 10 , and was seen repeatedly 'kidding' a police officer who had a package under his arm, which officer I later learned was the prosecuting witness in a case against clients of Councilman Green, who were awaiting trial on the charge of larceny. He appeared to be making light of the charge, and repeatedly snatched at the bundle under the officer's arm, which seemed to contain a piece of men's wearing apparel, and at one time snatched the bundle from the officer's arm and threw it under the table, much to the amusement of the councilman's clients, who were sitting on the bench awaiting the calling of their case, which was the next one. This intimacy of the councilman with the policeman was typical of his conduct toward all of the officers of the court. When the case was called a continuance was granted, and the prisoners who were out on bail walked out of the court-room apparently satisfied with the services Councilman Green, who is also an attorney, had rendered them. The police officer who was ready to go ahead with the hearing acquiesced in the continuance.

"On Tuesday, April 26, I again visited the police court and found practically all of the persons mentioned in my previous report present in one or other of the court-rooms.

"There were three prosecutors in Court-room No. 2, namely, Prosecutors Novario, Russick, and Kreisberg, each of them appearing to be interested in the disposition of particular cases. I heard Prosecutor Novario ask for a 'nolle' in two cases-the nature of the offenses in such cases I was not able to find out.

"Prosecutors Russick and Kreisberg remained in the room perhaps ten or fifteen minutes, and then Prosecutor Russick returned to Room No. 1, where he was handling cases.

"This illustrates the practice of some attorneys in going to a prosecutor and requesting a 'nolle,' even though he is not the prosecutor handling cases in the court-room in which the 'nolle' is requested, and frequently 'nolles' are granted in a court-room without the knowledge of the prosecutor in charge of cases in that room. 
"A police sergeant was on duty this day, the same as on the Friday previous, as reported, preventing persons from loitering in the hallway leading from the court-room to the prosecutor's office. On two occasions he strode through this hallway crying in a loud voice to the persons there to move on; there were probably about two dozen standing there, and about half of them obeyed his orders. I have seen him perform this duty on about half a dozen different occasions and have noted that his orders were obeyed implicitly by newcomers, who dispersed at once, but were ignored by the regular attendants of the police court, the officer apparently being blind to their presence."

Another attorney was sent to observe the court on these same two days. He was not familiar with the "regulars" there, but was instructed to keep his eyes and ears on the trials, take notes and report all details observed by him. His report for April 22, 1921, follows:

"I reached the Municipal Court at 8.15 A. M. and found Room 2 entirely empty. In Room 1 there were five colored people waiting for the court to open, including three women, one man, and one child. There were six white women, all of whom looked to be of foreign extraction, and apparently all were engaged upon the same errand.

"There was already considerable activity in the clerk's office, and a group of several men and women were examining the docket on the bulletin board in the hall. At this time there were 125 cases on the docket for the day.

"Court was called to order at approximately 9 A. M. in both rooms: Judge A and Prosecutor Novario in Room 2, Judge B and Prosecutor Russick in Room 1.

"I went to Room 2, sitting about 10 feet from the witness-stand. During most of the time it was practically impossible to hear what was said.

"The following cases were called either by number or by name, and sometimes in both ways, but in many cases it was impossible for me to tell whether or not the defendant appeared or whether the court went on to some other case or what disposition was made of the particular case:

Case

No.

29,42

49 Pleaded guilty.

44,45

55 John Molnar.

57 Martin Gross and Sam Cunsolo, colored. I could not tell what disposition was made of this case, but the two men were locked up again.

51 Pleaded not guilty.

50 Arthur Phillips, pleaded guilty.

46 Joseph Tobias, pleaded guilty.

36 Pleaded guilty.

32 William Day, pleaded guilty. Five days and costs.

40 Anthony Paris, pleaded guilty.

49 Oscar Wagner. 
8 A stenographer was taking a record in this case, and in order to hear was obliged to sit on the table and write on the railing surrounding the witness-stand.

48 Pleaded guilty. Prosecutor Rosenberg handled this case, and perhaps the following one, and then retired in favor of John Novario. It was 9.40 .

47 John Vitski.

John Berry.

38 M. O. Gordon.

Joseph Rosen.

33 and 34 These were apparently two felony charges against the same defendant, and his' lawyer was not there. The judge told the defendant to get a move on and get a lawyer, and the case was apparently continued.

56 Martin Gross.

Charles Wo.

Max Herman.

J. W. Lolabias and John Burrs.

24 The defendant was charged with being a married man and representing himself as unmarried. The prosecuting witness stated that on the basis of his representation she had broken her engagement with some other man and that he had asked her to marry him. Two other women testified in support of the prosecuting witness.

18 Harry Burney. Councilman Green represented the defendant. A few minut es before this case was called Novario wandered a little way from the witnessstand, although a case was in progress, and held a whispered conversation with Finkel. When the case was called, Novario made some remark to the judge which I heard imperfectly, but I understood him to say, 'I understand that the prosecuting witness does not want to go on with this case.'

The case was dismissed for want of prosecution, I think.

23 Sam Ettinger. The charge was manslaughter in two cases arising out of an automobile accident at the corner of East 40 th Street and Superior Avenue, N. E. There was a number of witnesses, and Hart sat down at the trial table, as did also Novario, and it looked as though there might be something to suggest a trial. As soon as the witness began to testify, however, the attorney and prosecuting witness crowded around the witness-stand in the customary fashion. Attorney for defendant asked for a separation of the witnesses for the prosecution, which was allowed. The two principal prosecuting witnesses were a young man and his sister who were driving along Superior Avenue at the time of the accident. They both stated that the man at the filling station at the corner of East 40th Street and Superior Avenue had also seen the accident, but he was not there as a witness. I heard Prosecutor Novario ask the police officer whether or not the man from the filling station was there and he said not. I think that the defendant was not bound over. Prosecutor Novario paid very little attention to the prosecution or the witnesses. He stood around the witness-stand a great deal of the time and participated a little, but from time to time would wander off to talk to his brother or to Councilman Green or some other bystander, although the case was in progress and a witness testifying.

"At 10.30 I went into Room 1. The numbers of the cases called in Room 2 [ 106 ] 
given above are, of course, numbers from the cases on the docket in Room 2 , and not the numbers of the cases as they appear in the prosecutor's docket in Room 1 or upon the bulletin board in the hall. The following cases were called in Room 1 subsequent to 10.30 :

Case

No.

(?) This was a case against two defendants, apparently for stealing a dress or receiving it as stolen property. Councilman Green represented the defendants and they were apparently dismissed.

(?) The next case was ruled upon by the judge without any audible conversation. The defendant, so far as I could see, did not come on the stand, but his attorney and the prosecutor whispered to the judge and the judge simply waved his hand to the defendant, who was sitting in one of the benches, and the defendant and his attorney walked out. There was no way to tell what the name of the defendant, the number of the case, or the charge was.

93 and 95 Pleaded guilty.

77 Joe Bilski. It was a case of assault and battery, a man having struck his wife and she had a beautiful black eye. The defendant was represented by some attorney whom I do not know. The defense was that the defendant was trying to compel his oldest son to go to work, and in the course of the discussion picked up a shoe and threw it at him and the shoe, very unfortunately, struck the wife in the eye. The testimony was that the defendant and his wife had been married over twenty years and that they had three children, the oldest twenty-three and the youngest four. During the trial of the case Prosecutor Russick was walking around and talking to different people and paying no particular attention to the case. The evidence also showed that the defendant had not been working for the last ten months. The court sentenced the defendant to pay the costs and to serve four months in the workhouse.

49 and 50 These were two cases against the same doctor for failure to record a birth and failure to report diseased eyes. Judge B apparently expressed the opinion that he could fine the defendant $\$ 50$ and costs, and upon defendant's attorney protesting said, 'I will split the difference and give him $\$ 25$ and costs.'

1 Michael Mees.

25 James Slater.

31 Sam Schultz. I am not sure whether this case was continued to April 29 or whether it was this case which was tried and the court held that it was simply a civil matter and it was up to the defendant to sue and get the money. The facts in the case which the court decided were that the prosecuting witness had given the defendant certain goods, apparently dresses to sell, and the defendant had sold them on time. The defendant claimed that he had asked the approval of his employer before selling them on time and had tendered whatever he had received to his employer. The employer, the prosecuting witness, testified that he had not agreed to allow payment by installments and that the defendant had not tendered any payments to him. The court dismissed the case and held that it was simply a matter to be settled in a civil action.

32 Henry Neale. Passed to April 29.

(?) This case involved a dispute as to the ownership of a dog. Each of the parties 
had several witnesses and the court spent considerable time in hearing the case, and finally held it was merely a civil matter and must be settled in the civil courts.

39 and 40

52 This was a prosecution under the health ordinance for having a dirty bakery. The case had been continued from some time in February. The defendant was fined $\$ 2$ and costs.

78 Prosecution under the health ordinance for keeping a large pool of standing water in an empty lot. The court continued the case until May 6, and told the officer that he would have to have some positive proof that the pool of standing water jeopardized the health of the neighborhood before he would convict the defendant. The defendant had been warned several times to have the pool removed.

121 and 122 Case of assault and battery and contempt. At 11.30 the court in Room 1 took a recess.

24 Hoffmeyer. Case of assault and battery of a lodger upon his landlady. The story of the prosecuting witness was that the defendant had hit her and knocked her all the way downstairs. It was the defendant's contention that the landlady first struck the defendant, and that she was standing on a very narrow landing at the top of the stairs and in her excitement stepped off backward and fell downstairs. Attorney for the defendant tried to prove these facts, including the physical surroundings, size of the landing, and so forth, but Judge B said: 'That hasn't anything to do with the case-I was not even listening.'

Prosecutor Russick sat back at the table and merely watched the case as it was being tried. The court in Room 1 adjourned at 11.49 until 1.30.

"I went immediately into Room 2. Kreisberg was prosecuting and Russick had come into the room and was hanging around. The case was a felony charge against some one, and the prosecuting witness was a Chinaman named Shang Hai. At the close of the State's case the defendant started to prove an alibi, and Judge A said: 'If you are going to prove an alibi I won't hear it.' The defendant was bound over.

Case

No.

12 Max Golden. Assault and battery. Defendant was fined $\$ 10$ and costs.

9 Anton Wrabliski. Fined $\$ 100$ and costs. I did not hear the court say anything about suspending any of the sentence, but as the defendant was put back into the lock-up the officer yelled after him, 'You have to pay the costs.'

14 Walter Brown. Defendant was chauffeur for Mr. Lyon (?) and Mr. Lyon was present in court, standing in front of the judge. As the case was being tried the clerk of the court walked in, shook hands with Mr. Lyon, joked with him a little about the case, and walked out, stopping a minute to tell me what a fine fellow Mr. Lyon is. The defendant was fined $\$ 10$ and costs. The proceeding was apparently the first skirmish leading up to a civil case growing out of the injury to two automobiles.

60 Richard Weeden. 
"The following cases were called at the end of the session in Room 2, but the defendants did not appear:

Case

No.

Louis Oblitski, et al.

5 Louis Sapas.

6 Paul Borsick.

Morris Collin. Officer remarked that defendant owed $\$ 15$ and costs. Capias issued.

37 Joseph Rosen. Capias issued.

"Court adjourned in Room 2 for the day at 12.10. I returned to Room 1 shortly after 1.30 and found an assault and battery case in progress. There was no prosecutor present. The court, after listening to testimony about half an hour, dismissed the case and said it was a purely civil matter. As the defendant and prosecuting witnesses went out I noticed that they were the same six women who were waiting for the court to open when I arrived at 8.15 in the morning. The court adjourned at 2.15 for the day. One of the court officers, in checking up the entries for the day, inquired of Attorney $X$ to what date the Solomon case had been passed. $\mathrm{X}$ said until June 8 . The officer seemed to be a little doubtful of this, but concluded to take X's word for it and made the entry."

The report for the sessions of April 26 is quite similar. It contains the following notes concerning a prosecutor:

"Prosecutor Russick arrived in the room at 9.15 but, so far as I could see, during the entire morning did not participate in a single case to the extent of asking one question. A great deal of time he was talking to other people or sitting back at the table when the cases were going on. Most of the time, however, he was lolling upon the witness-stand and listening to what the witnesses had to say and the court's examination of the witnesses."

According to a fundamental principle of American justice, the accused is entitled to that impartiality and fairness of treatment which is presumed to be promoted by the fact that the judge and prosecutor perform their functions with the eyes and the ears of the public upon them. The above-described conditions in the Municipal Court fail to fulfill this fundamental requirement. The doors are open, but Argus himself could not see what is going on; and were the man who could hear the blade of grass growing on the mountainside to drop into the court-room, his exceptional aural capacity would only intensify for him the general din which suffocates the gentle mumblings and whisperings of the group on and around the bench.

These pictures of the court in operation show the danger that the individual who comes into the Municipal Court in one relationship or another would be more likely to feel that results are dependent upon 
favor or strange influences than upon a judgment of the court based exclusively on the dictates of law and justice.

\section{Large Number of Cases; Unclassified Dockets; Excessive SPEED}

It is interesting at this place to report what actually did occur in these two rooms of the court on the morning of April 22. The following is a list of the cases called as shown on the docket, with the nature of the charge and the disposition of the case:

\begin{tabular}{|c|c|c|}
\hline \multicolumn{3}{|c|}{ ApriL 22.-Court-Room No. 1} \\
\hline No. ${ }^{1}$ & Charge & Disposition \\
\hline 1 & Liquor law & Continued June 1. \\
\hline 2 & Liquor law & Original sentence. \\
\hline 7 & Liquor law & $\begin{array}{l}\$ 100 \text { and costs, "motion in mitigation" } \\
\text { April } 29 .\end{array}$ \\
\hline 12 & Liquor law & Original sentence. \\
\hline 13 & Liquor law & Continued April 29. \\
\hline 14 & Liquor law & Continued June 8. \\
\hline 19 & Assault and battery & Discharged. \\
\hline 20 & Assault and battery & Discharged. \\
\hline 23 & Assault and battery & Discharged for want of prosecution. \\
\hline 24 & Assault and battery & Costs. \\
\hline 25 & Defrauding innkeeper & Capias. \\
\hline 31 & Conversion & Discharged. \\
\hline 34 & Suspicious person & Costs and 30 days, suspended. \\
\hline 35 & Suspicious person & Costs and 30 days. \\
\hline 36 & Suspicious person & Bond forfeited capias. \\
\hline 37 & Suspicious person & Continued April 23. \\
\hline 38 & Suspicious person & Continued April 23. \\
\hline 39 & Grand larceny & Continued May 11. \\
\hline 40 & Grand larceny & Continued May 11. \\
\hline 42 & Conversion & $\$ 500$ and costs and 3 months. \\
\hline 46 & Health ordinance & Discharged. \\
\hline 47 & Destroying property & Discharged. \\
\hline 48 & Petit larceny & Discharged. \\
\hline 49 & Fail to report diseased eyes & Discharged. \\
\hline 50 & Fail to report birth & $\$ 25$ and costs. \\
\hline 51 & Assault and battery & Discharged for want of prosecution. \\
\hline 52 & Health ordinance & $\$ 2$ and costs. \\
\hline 53 & Health ordinance & Continued April 29. \\
\hline 54 & Suspicious person & Discharged. \\
\hline 55 & Suspicious person & Discharged. \\
\hline 56 & Pocketpicking & Error. \\
\hline
\end{tabular}

${ }^{1}$ As all the cases are first put on the docket in Room 1 and the Room 2 cases then transferred, the remaining Room 1 cases will not have consecutive numbers. 


\begin{tabular}{|c|c|c|}
\hline No. & Charge & Disposition \\
\hline 62 & Petit larceny & $\$ 50$ and costs and 30 days. \\
\hline 71 & Intoxication & Continued April 29. \\
\hline 72 & Intoxication & Costs. \\
\hline 73 & Intoxication & Continued April 29. \\
\hline 74 & Intoxication & Continued April 29. \\
\hline 75 & Intoxication & Costs. \\
\hline 76 & Assault and battery & Discharged. \\
\hline 77 & Assault and battery & Costs and 4 months. \\
\hline 78 & Health ordinance & Continued May 6. \\
\hline 79 & Petit larceny & Costs and 30 days. \\
\hline 80 & Common beggar & Costs and 15 days. \\
\hline 81 & Common beggar & Costs and 15 days. \\
\hline 82 & Common beggar & Discharged. \\
\hline 83 & Petit larceny & Continued April 29. \\
\hline 84 & Disturbance & Costs. \\
\hline 85 & Disturbance & Costs. \\
\hline 86 & Disturbance & Costs. \\
\hline 87 & Disturbance & $\$ 25$ and costs. \\
\hline 88 & Vagrancy & Discharged. \\
\hline 89 & Vagrancy & Discharged. \\
\hline 90 & Vagrancy & Costs and 15 days. \\
\hline 91 & Suspicious person & $\$ 10$ and costs. \\
\hline 92 & Suspicious person & Continued April 29. \\
\hline 93 & Suspicious person & Costs and 30 days, suspended. \\
\hline 94 & Suspicious person & Continued April 29. \\
\hline 95 & Suspicious person & Costs and 30 days, suspended. \\
\hline 96 & Suspicious person & Continued April 29. \\
\hline 119 & Liquor law & Continued April 30. \\
\hline 120 & Contempt & Discharged. \\
\hline 121 & Contempt & Discharged. \\
\hline 122 & Assault and battery & Discharged. \\
\hline 126 & Liquor law & Discharged. \\
\hline 127 & Liquor law & $\begin{array}{l}\$ 100 \text { and costs, "motion in mitigation" } \\
\text { April } 30 .\end{array}$ \\
\hline 128 & Liquor law & Continued April 29. \\
\hline 129 & Liquor law & Motion granted, $\$ 500$ of fine suspended. \\
\hline 130 & Liquor law & Continued April 29. \\
\hline 131 & Liquor law & April 28 continuance. \\
\hline 132 & Carrying concealed weapons & Bound over. \\
\hline 133 & Auto law & Continued April 26. \\
\hline
\end{tabular}

April 22.-Court-Room No. 2

No. Charge

1 Liquor law

2 Liquor law

3 Liquor law

4 Liquor law
Disposition

Continued to April 29.

$\$ 50$ of fine suspended.

Discharged.

Discharged. 
No.

5 Liquor law

6 Liquor law

7 Liquor law

8 Liquor law

9 Liquor law

10 Liquor law

11 Assault and battery

12 Assault and battery

13 Assault and battery

14 Traffic ordinance

15 Traffic ordinance

16 Traffic ordinance

17 Traffic ordinance

18 Obtaining money under false pretense

19 Dance-hall ordinance

20 License ordinance

21 Receiving stolen property

22 Manslaughter

23 Manslaughter

24 Misrepresentation by married man

25 Burglary

26 Liquor law

27 Liquor law

28 Liquor law

29 Liquor law

30 Traffic ordinance

31 Auto law ${ }^{1}$

32 Auto law

33 Auto law

34 Robbery

35 Auto law

36 Auto law

$37 \quad$ Traffic ordinance

38 Vehicle ordinance

39 Liquor law

40 Liquor law

41 Auto law

42 Auto law

43 Auto law

44 Auto law
Disposition

Motion granted, $\$ 50$ of fine suspended.

Original sentence.

Continued April 29.

$\$ 300$ and costs, "motion in mitigation" April 29.

Motion granted, fine suspended.

$\$ 200$ and costs, "motion in mitigation" May 6. $\$ 25$ and costs, "motion in mitigation" May 6.

$\$ 10$ and costs, "motion in mitigation" April 29.

Continued April 29.

$\$ 10$ and costs.

$\$ 15$ and costs.

Discharged.

Motion granted, fine suspended.

Discharged, want of prosecution.

Original sentence.

Capias ordered.

Continued April 29.

Discharged.

Discharged.

$\$ 25$ and costs, "motion in mitigation" April 30 .

Bound over.

$\$ 200$ and costs, "motion in mitigation" April 30.

$\$ 200$ and costs, "motion in mitigation" May 6. Bound over.

Continued April 29.

Capias.

$\$ 5$ and costs.

$\$ 5$ and costs.

Bound over.

Bound over.

$\$ 5$ and costs.

$\$ 5$ and costs.

Capias.

$\$ 5$ and costs, suspended.

$\$ 100$ and costs, "motion in mitigation"April 29. $\$ 100$ and costs, "motion in mitigation" May 6. Nolle.

April 29.

Continued May 5.

$\$ 30$ and costs, "motion in mitigation" April 25.

${ }^{1}$ Cases designated "auto law" include all degrees of cases relating to automobiles, from misdemeanors, such as driving without lights illuminating the license, to serious felonies, such as operating motor vehicle without consent of the owner. 
49 Auto law

50 Auto law

51 Traffic ordinance

52 Traffic ordinance

53 Traffic ordinance

54 Traffic ordinance

$55 \quad$ Traffic ordinance

56 Traffic ordinance

$57 \quad$ Shoot to wound

58 Contempt

59 Liquor law

60 Assault and battery

61 Liquor law

62 Traffic ordinance

\section{Disposition}

$\$ 25$ and costs.

$\$ 5$ and costs, "motion in mitigation" April 28.

$\$ 5$ and costs.

$\$ 5$ and costs, "motion in mitigation" April 29. $\$ 30$ and costs and 10 days. Days suspended,

"motion in mitigation" April 29.

$\$ 5$ and costs.

$\$ 15$ and costs.

$\$ 15$ and costs.

$\$ 5$ and costs.

$\$ 5$ and costs.

$\$ 15$ and costs.

$\$ 10$ and costs, "motion in mitigation" April 30.

$\$ 25$ and costs and 30 days.

Discharged.

Motion granted, $\$ 150$ of fine suspended.

$\$ 25$ and costs and 30 days suspended.

Continued May 6.

May 24 continuance.

Several interesting phenomena are disclosed by this table. There is especially the fact that all sorts of cases are indiscriminately lumped together on one morning's docket and called, heard, and decided without segregation of the trials of state from municipal cases, state felonies from state misdemeanors, crime cases from vice cases, grave cases from lesser ones. The cases are not called in the order in which they appear on the docket. Under the orders of the presiding judge of the court certain classes of cases are given precedence in the call, as, for instance, those in which the night duty policemen are witnesses, or cases of defendants who are in jail. Whether this order is fully adhered to is doubtful. Within any class of cases the order of call is largely in the control of the clerk in the room. In the answers to a questionnaire sent to members of the Cleveland bar, many lawyers complained of the delays to which they were subjected in having to wait for the cases to be called, and in many of the answers this was given as the reason why lawyers avoid practice in the criminal branch of the Municipal Court.

This list of cases shows some disposition in 71 cases in Room 1 in the course of two and three-fourths hours, making about two and onefourth minutes per case, and 62 cases in Room 2 in about three and onefourth hours, making about two and one-half minutes per case. These dockets of April 22 were by no means abnormally heavy. Almost always on Mondays, and very frequently on other days, the number of cases exceeds the number on that day. Of course, the judges show variations 
in the speed with which they dispose of cases, some taking more time than others. The time here noted of two and one-fourth and two and one-half minutes per case does, however, represent a fairly habitual and normal rate. Of course, not all of the cases involved a trial or hearing of evidence. Continuances involved no trial on that date, and in the list of cases disposed of were a number with pleas of guilty. But even these cases with pleas of guilty required, on the question of the amount of sentence, some inquiry into the facts concerning the offender and the facts of the offense.

By way of contrast, it is interesting to note the time given by this same Municipal Court to petty civil cases which fall within its jurisdiction. For instance, on this same date of April 22, 1921, the docket in Room 5 contained 18 items. Of these 18, 12 involved practically no hearing of evidence or argument on part of the court, being judgments by consent of parties or other matters summarily disposed of. Four related to motions. That left only six cases in which the court was called upon to determine questions of fact, and in one of these, involving the possession of real estate, the defendant failed to appear. One case was decided for the defendant. In the other five, judgments were rendered in the sums respectively of $\$ 76, \$ 99, \$ 400$, and $\$ 84$, sums less in amount, measured in mere dollars and cents, than were involved in many of the cases on the criminal docket. That represented a full day's work, morning and afternoon, of that one of the civil rooms which on that day had the largest docket and also the largest number of contested cases.

\section{Negative Part Played by Prosecutor}

The descriptions of the Municipal Court in operation disclose the negative part which the prosecutor plays in both the trial and the disposition of cases. With rare exceptions his part is as negative in the major offenses as in the lesser ones. Even more negative is his rôle as a source of influence in the general conduct of the proceedings. At no time did he ask that the group surrounding the bench be freed from those who had no business there. At no time did he ask that the aisles be cleared or the noise of moving feet and the chatter be suppressed. He seemed in fact the least influential person in the room.

A jury trial by its very nature compels orderliness and openness of procedure. Each side desires that the jury hear its witnesses. In trials before a judge without a jury, this restraining influence is absent, and both court and attorneys are apt, unless they make special effort 


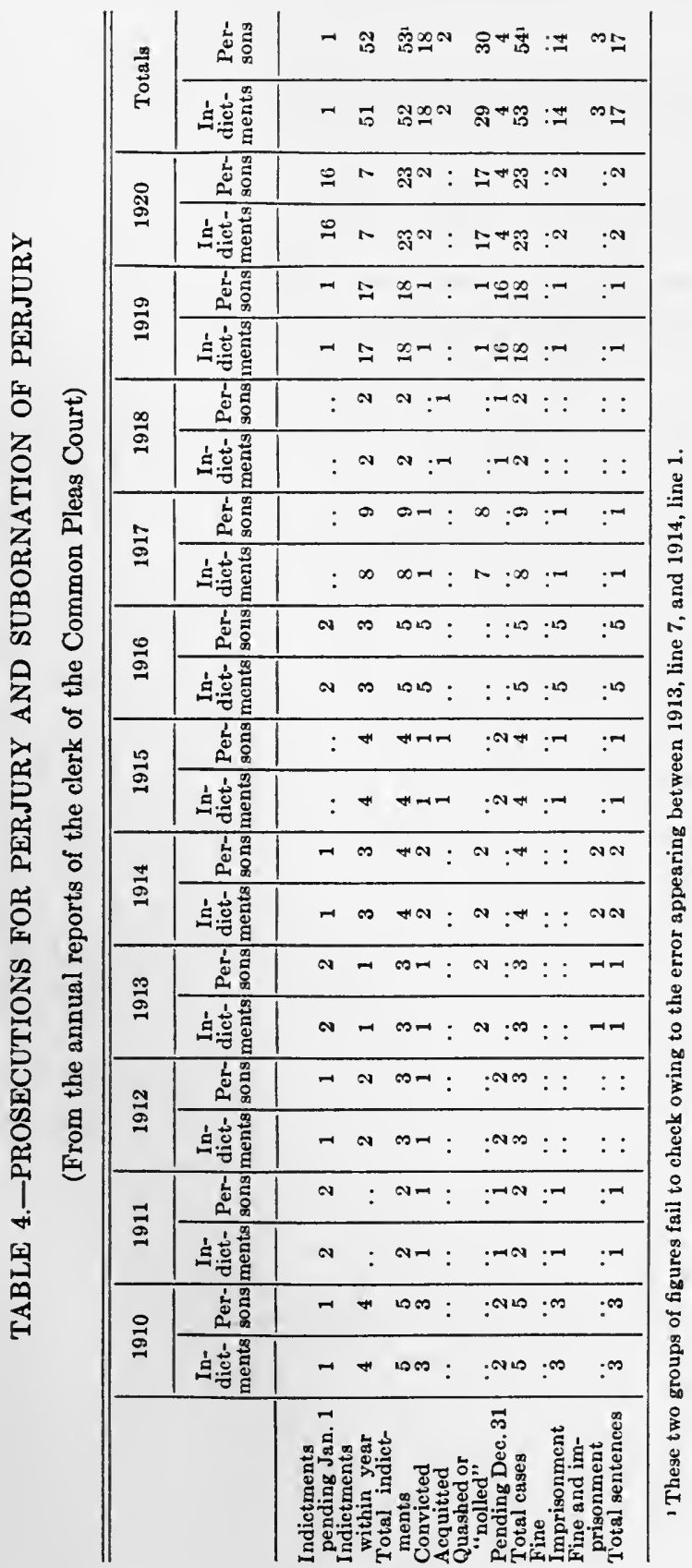


to guard against it, to let themselves drift into the habits which have been described in this chapter.

No Stenographic Reports-Opportunities for Peruury

Except where the defendant desires to have a record of the case, the testimony is not taken down stenographically or otherwise. The trials are ground out without attempt on the part of anybody, judge or prosecutor, to bring out all the facts in any case, and seldom is any witness permitted to complete his story. One of the judges of this court, in the course of an interview, stated in a casual manner, as though expressing something of no significance, that in preliminary hearings of felony cases, as soon as he hears something which, taken by itself, would justify passing the case on to the grand jury, he hears no more and binds the case over, and that he treats these hearings as nothing more than stepping-stones to the grand jury.

This absence of a stenographic report of the testimony, taken in connection with the whole atmosphere of the court, obviously produces opportunity, if not inducement, for perjury. The people of Cleveland are convinced that perjury has been prevalent in the trial of criminal cases, and the criminal court reporters of the newspapers affirm this beyond a shadow of doubt. In view of this general opinion, which surely has considerable basis in fact, it will be interesting to note the exceedingly small number of cases of prosecution for perjury and the even smaller number of successful prosecutions for perjury. Table 4 gives the statistics of all prosecutions for perjury and subornation of perjury for the years 1910 to 1920 inclusive, with the results thereof, as reported by the county clerk to the Secretary of State. 


\section{CHAPTER IV}

\section{THE MUNICIPAL PROSECUTOR'S OFFICE}

\section{HisTORY}

$\mathbf{I}$

N 1912 the criminal branch of the Municipal Court of Cleveland became the successor of the police court, which had been in operation since 1853. It also succeeded to the criminal jurisdiction of the justices of the peace functioning in Cleveland. Justices of the peace, with certain criminal jurisdiction, had existed in Cleveland on the territory which is now Cleveland since 1798. The municipal prosecutor is the successor of the prosecuting attorney of the police court, an office created in 1854. For more than a century this court and its predecessors have been the examining courts for state felonies and for almost seventy years have had general jurisdiction to try city and state misdemeanors. The nature of the jurisdiction has not changed, but with the growth of the community and the consequent growth of the number of arrests and offenses and the development of the criminal law, both State and municipal, the volume of work passing through this court and office has grown enormously. Table 5 gives the growth, as shown by statistics, to the extent obtainable, of the years $1863,1880,1890,1900,1910$, and 1920 , of the area and population of Cleveland, the number of arrests, the number and compensation of prosecutors, assistants, and office force.

TABLE 5.-COMPARISON OF GROWTH OF POPULATION, NUMBER OF ARRESTS, NUMBER AND SALARIES OF "POLICE COURT" PROSECUTORS, 1863 TO 1920

\begin{tabular}{|c|c|c|c|c|c|c|c|}
\hline $\begin{array}{l}\text { Area } \\
\text { square } \\
\text { miles }\end{array}$ & Year & $\begin{array}{c}\text { Population } \\
\text { of Cleve- } \\
\text { land }\end{array}$ & $\begin{array}{l}\text { Number } \\
\text { of ar- } \\
\text { rests in } \\
\text { Cleve- } \\
\text { land }\end{array}$ & $\begin{array}{c}\text { Number of } \\
\text { police or Mu- } \\
\text { nicipal Court } \\
\text { prosecutors } \\
\text { and assistants }\end{array}$ & $\begin{array}{c}\text { Size of } \\
\text { clerical } \\
\text { force }\end{array}$ & $\begin{array}{l}\text { Payroll } \\
\text { of office } \\
\text { exclu- } \\
\text { sive } \\
\text { of chief }\end{array}$ & $\begin{array}{l}\text { Salary } \\
\text { chief } \\
\text { prose- } \\
\text { cutor }\end{array}$ \\
\hline ・ & 1863 & $58,241^{1}$ & $\begin{array}{l}1,687 \\
7,432\end{array}$ & 1 & 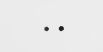 & & $\cdots$ \\
\hline 27.78 & $\begin{array}{l}1880 \\
1890\end{array}$ & $\begin{array}{l}160,140 \\
261,353\end{array}$ & $\begin{array}{l}7,432 \\
9,616\end{array}$ & $\begin{array}{l}1 \\
2\end{array}$ & .. & $\$ 1,600$ & $\$ 2,300$ \\
\hline 33.94 & 1900 & 381,768 & 19,923 & 4 & . & 5,300 & 3,000 \\
\hline 45.90 & 1910 & 560,663 & 7,185 & 4 & . & (10) & \\
\hline 56.65 & 1920 & 796,841 & $27,615^{2}$ & 6 & $\cdots$ & $\left\{\begin{array}{l}12,300 \\
15,300\end{array}\right\}$ & $\left\{\begin{array}{l}3,500 \\
4,000\end{array}\right\}$ \\
\hline
\end{tabular}

1 Taken from estimates of Chamber of Commerce. ₹79,897 warned and released. 
The large decline in the number of arrests in the year 1910 was the result of the so-called "golden-rule policy" of the then Chief of Police, Fred Kohler, who instituted a general régime of warning, advice, and persuasion, as distinguished from arrest and prosecution. The facts outstanding from this table are the continued absence of any clerical force despite the enormous increase in the volume of work, and the absence of any substantial increase in the salary of the chief prosecutor.

\section{Office Organization}

Reference has been made to the importance of the aspect of the place where the people of a city in general first come into contact with justice in operation. In a large percentage of cases complainants, accused, and witnesses have occasion to come to the prosecutor's office before going into the court-room. Furthermore, thousands of complaints which do not result in arrest are brought to the prosecutor's office and there aired, discussed, and disposed of. In fact, the municipal prosecutor estimates that he sifts out more cases than he permits to go into the mill. Thus this office is a point of contact for a larger number of individuals than any other spot in the city.

The force of the municipal prosecutor's office consists of the chief prosecutor and five assistants. ${ }^{1}$ The total office space consists of five small rooms, 7 by 9 feet in size-just enough for a desk and a chair, the number of rooms being one less than the number of prosecutors, so that two of the assistants occupy one of these cubby-holes. There are no clerks, no stenographers, and no messengers. The suite also contains a small room used as a combination of general waiting-room and the office of the telephone operator of the Municipal Court clerk and prosecutors. The telephone desk is railed off from the remainder of the room, leaving a space of 10 by 15 feet which serves both as a waiting-room and a conference room.

There is no office system nor organization whatsoever. Two assistants are assigned to the court-rooms for the trial work there, with others assigned specially to court work elsewhere, such as error cases in the Court of Appeals and jury cases. There is no distribution or specialization of work, whether of preparation or trial, according to classes of cases, importance of cases, or any other basis of classification. A visitor, whether he has a complaint or desires a prosecution instituted, a police officer who desires an affidavit made, or any other person on any other mission, chooses the particular member of the force to whom he will

${ }^{1}$ Since this report was written, a sixth assistant has been appointed. 


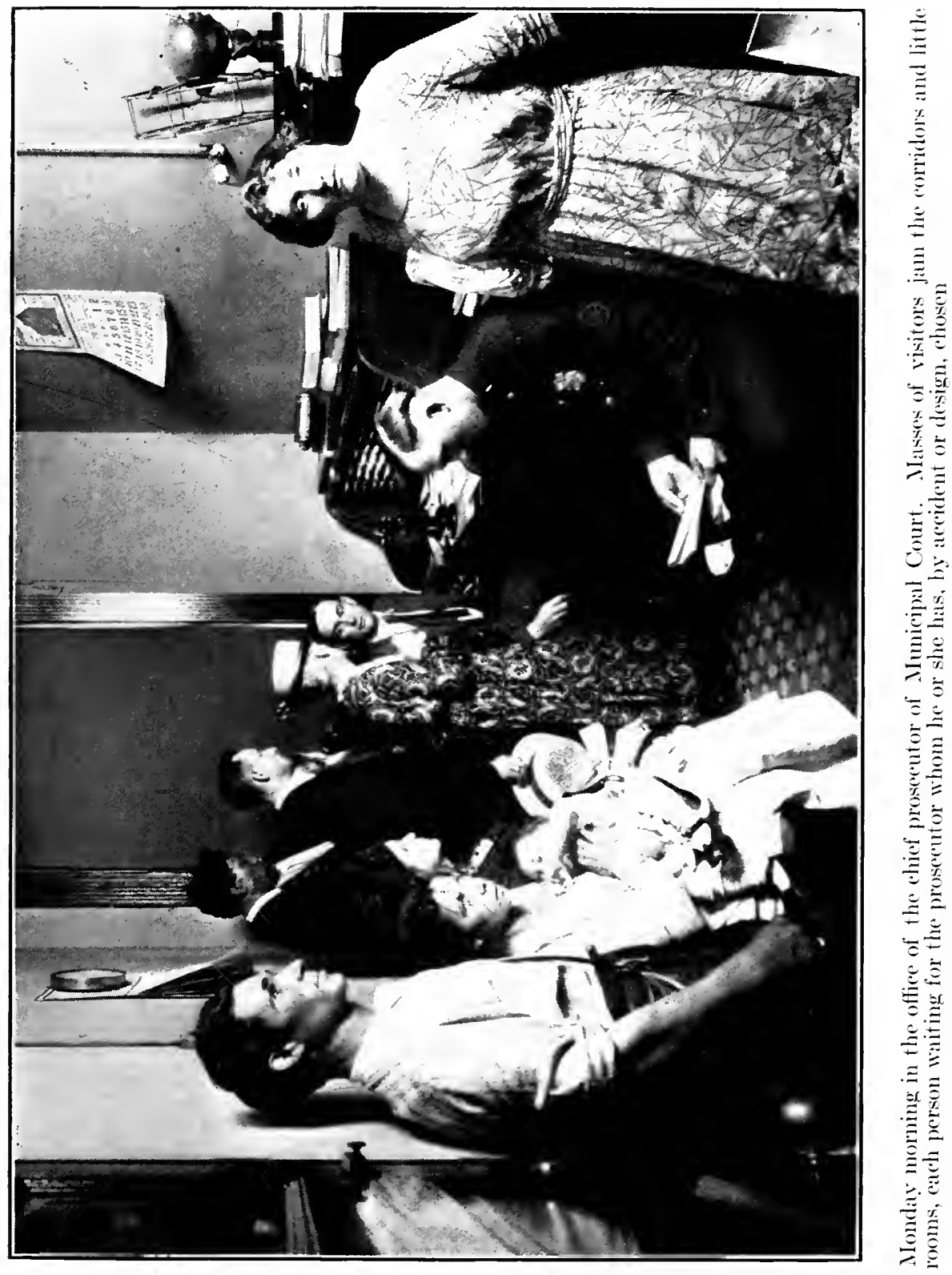


.

$-$ 
submit his business. At the busy hours of the day indiscriminate masses of applicants and visitors jam the offices and the adjacent hallways, each person waiting for the particular prosecutor whom he or she has, by design or accident, chosen.

There are no regular office rules laid down by the chief prosecutor regarding the submission to him of a particular type of problem. There are no detailed, clearly defined policies regarding continuance of cases, preparation of cases, the position to be taken by the office on difficult or doubtful questions of law, or any other recurring problem. Generally speaking, each assistant pursues his own policy or lack of policy, his own interpretation of the law, his own methods.

Edward.C. Stanton, who, previous to his election as county prosecutor, had been chief prosecutor of the Municipal Court, was asked why he had not disciplined one of his assistants in his old office for certain improper conduct. His answer was that he had no authority over the assistant prosecutors, that they were appointed just as he was and acted on their own responsibility in all cases. It was not clear whether he meant that the chief prosecutor and all the assistants were appointed by the Director of Law, whom the city charter designates as the appointing officer, or by the Republican "boss," who is popularly credited with the actual appointing power. As a matter of fact, the Director of Law devotes himself almost exclusively to the civil side of the work of the city's law department, and practically finds little time or energy for the administration of the criminal division. As things are at present, this latter division enjoys only slight executive control or direction.

\section{Laxity in Custody of Affidavits}

There is dangerous laxity in the care of the affidavits. On the basis of the information submitted by complainants or police officers, the prosecutors prepare the affidavits setting forth the charge. The warrant of arrest and all subsequent proceedings are based upon the affidavit. No further step in the prosecution of the case is possible without the affidavit. There is no office system whereby these affidavits are placed in charge of any official or attaché of the prosecutor's office. An affidavit remains in the hands of the particular prosecutor who prepared it until he finds it convenient to carry or send it to the office of the clerk of the Municipal Court. There it is placed in a box. The affidavits are used by the clerk as a basis for the drafting of warrants, and after having served as such they are placed in the files of the clerk's office. They are not sealed, and no copy is made for nor kept in the prosecutor's office. Obviously such a system or lack of system furnishes opportunities for 
the mysterious disappearance of affidavits, and such disappearances are said to take place occasionally.

\section{RECORD System}

The record system in any office or court with such a volume of work as in the Municipal Court of Cleveland is of vital importance. The records may be said to have two functions: they are instruments for promoting the efficiency of the work itself, and also are the means whereby the department head or the public can appraise the accomplishment of the office.

The municipal prosecutor's office has no records or files. There is no docket-no record of cases pending or past. Memoranda made by the individual prosecutor are kept or disposed of by him as he may please. There is no means within the office itself by which the chief prosecutor can ascertain the history or status of any case or check the work of an assistant.

For the records of the work of his office and of the status of cases in his charge the prosecutor is dependent upon the records of the Municipal Court itself. Consequently, the study of the effectiveness of the present system requires a detailed examination of the record system of the $\mathrm{Mu}-$ nicipal Court and the office of the Municipal Court clerk.

The first entry in any case takes place upon the arrest of the accused person. This is made upon the police blotter in the office of the clerk, a large book about two and one-half feet square. Exhibit A illustrates the nature of this entry. ${ }^{1}$

From this police blotter and the continuation docket which will be shortly described the court officer in the Division of Police makes up the "prosecutor's docket." This prosecutor's docket contains a full list of all the cases to be called in the two rooms of the court at the following court session, and contains all cases of arrest from 6 A. M. of one day to 6 A. M. of the following day, which is the day of the call in court. Exhibit $B$ is an illustration of the number of columns, the titles of columns, and the nature of the entries. The number in the first column (161, etc.) is the number or order of the case on that day's docket. The entries in the "Disposition of case" column are made after the case has been called and has received that day's disposition by the court.

About 7 in the morning this book is sent to Court-room No. 1. At that time it contains all that it will finally contain, except the notation

${ }_{1}^{1}$ The illustrations in this chapter are taken from the actual records, all notations retained as on the originals, with the exception of the names, which are fictitious. 


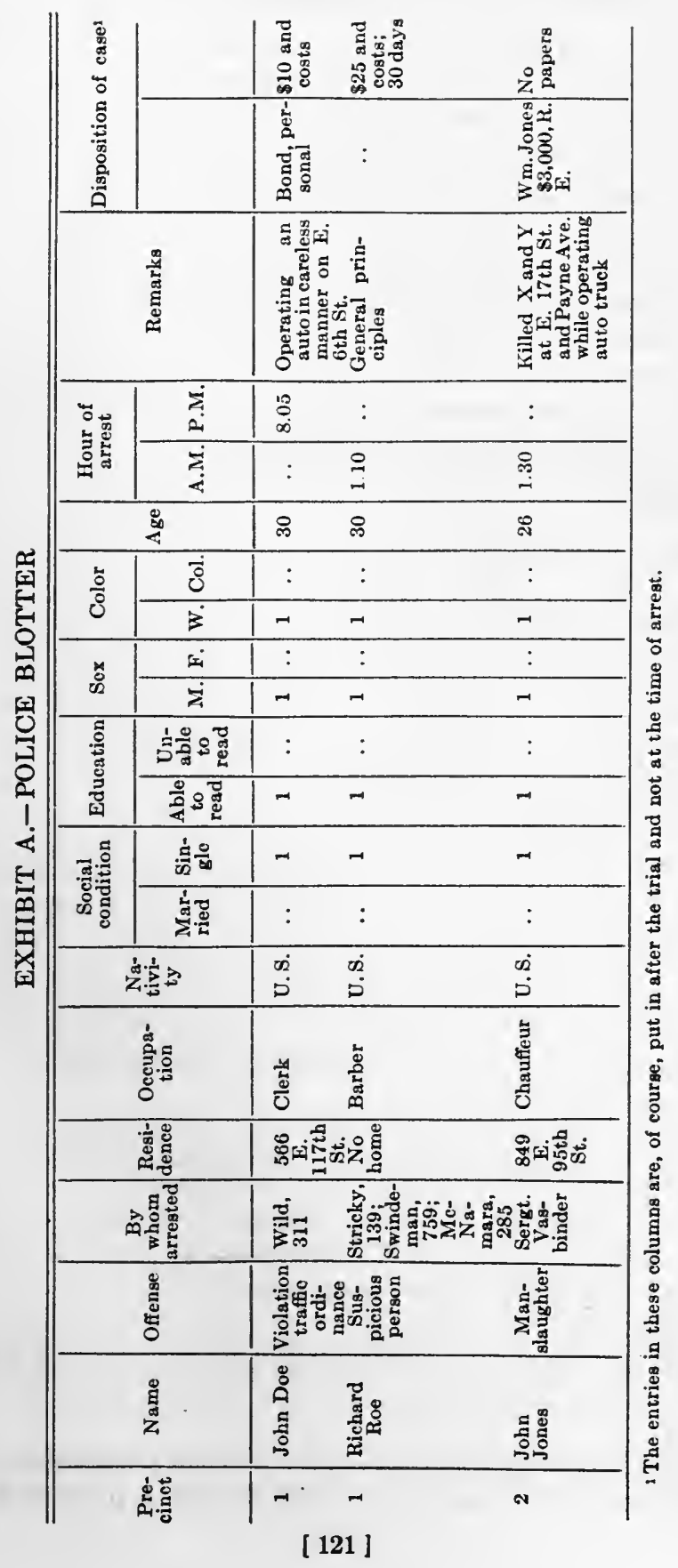


of the room to which the case is to be assigned and the disposition of the case. The column marked "Plea" is not used at all.

Then the clerk in Room No. 1 has the duty of distributing to Courtrooms Nos. 1 and 2 the cases on the prosecutor's docket. He does this - by assigning the traffic cases, the State examination cases, and most of the liquor cases to Room 2, and if there are not enough cases for Room 2, he throws in a few cases of other classes; or if the traffic, liquor, and State examination cases amount to more than one-half of the day's docket, he will assign some of them to Room 1 . If the case is assigned to Room No. 1, no notation is made on the docket, since the docket itself is in Room 1. If assigned to Room 2, as appears from Exhibit B, the clerk stamps thereon "Court-room No. 2."

EXHIBIT B.-PROSECUTOR'S DOCKET

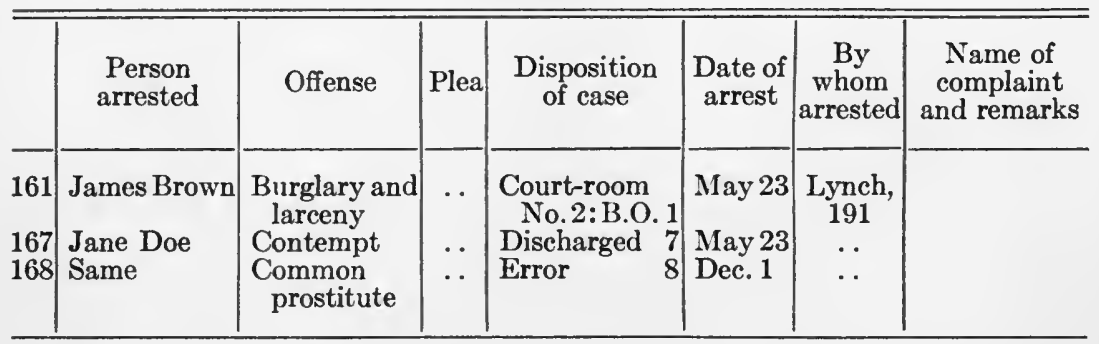

With the prosecutor's docket is sent up from the police department an assignment list of cases. This contains merely the numbers of the cases, the names of the defendants, and the charges. After the cases have been divided between the two rooms, "Room 1 " or "Room 2 " is rubber-stamped on this list, and the list is posted in the hallway outside the court-rooms. Exhibit $\mathrm{C}$ illustrates the set-up of this assignment list after it haș been so stamped.

EXHIBIT C.-ASSIGNMENT OF CASES, TUESDAY, MAY 24, 1921

\begin{tabular}{|c|c|c|c|}
\hline No. & Name & Charge & Court-room \\
\hline $\begin{array}{l}51 \\
52 \\
53 \\
54\end{array}$ & $\begin{array}{l}\text { Fred Miller } \\
\text { Anna Kinney } \\
\text { Mary Smith } \\
\text { Frank Butler }\end{array}$ & $\begin{array}{l}\text { Neglecting parent } \\
\text { Keeping house ill fame } \\
\text { Visiting house ill fame }\end{array}$ & $\begin{array}{c}\text { ․ } \\
\text { Court-room No. } 2 \\
\text { Court-room No. } 2\end{array}$ \\
\hline
\end{tabular}

The cases on the prosecutor's docket and on the assignment list are numbered consecutively each day, beginning with 1 , in the order in which 
they appear on the docket, which corresponds roughly to the order of the arrest. ${ }^{1}$

A docket for Room 2 is then made up from the assignments to that room on the prosecutor's docket, these cases in Room 2 being numbered from 1 up consecutively. Exhibit D is an illustration from a part of this Room 2 docket, the entries in the third column, of course, having been made in accordance with the disposition of the case on the morning indicated.

EXHIBIT D.-DOCKET-ROOM 2

Saturday, May 21, 1921

\begin{tabular}{l|l|l|l}
\hline \hline No. & \multicolumn{1}{|c|}{ Name } & \multicolumn{1}{|c}{ Offense } & \\
\cline { 3 - 4 } 30 & Aaron Rosenberg & Traffic ordinance & Cap. \\
31 & Pat Gray & Traffic ordinance & May 26 \\
32 & Dan White & Traffic ordinance & May 26 \\
33 & Aubrey Greene & Auto law & Cap. \\
34 & Mamie Biller & Common prostitute & 25 C. S. S. \\
35 & Same & Obtaining money by false & 25 C. 30 D. S. S. \\
36 & Harry Kane & pretenses & Obtaining money by false \\
37 & Leon Schmitt & 25 C. 30 D. S. S. ${ }^{2}$ \\
& & pretenses & \\
\hline
\end{tabular}

From the prosecutor's docket, a docket or calendar, called the "judge's docket," is made for the judges in each of the rooms. It gives the number of the case, the name of the defendant, and the charge. This docket is before the court during the entire session, and as each case is disposed of the judge writes opposite the defendant's name the particular disposition that has been made. Exhibit $\mathrm{E}$ is a copy of portions of the judge's docket in Room 1.

The file in each case consists of the affidavit, the warrant of arrest, the subpœnas for witnesses, the cost bill, and the bail bond, if any. The file for each case, with a pencil notation of its number for the day somewhere on the outside, is placed in the hands of the clerk in the particular room to which the case has been assigned. The cases have no numbers except the consecutive numbers $1,2,3$, etc., on the daily dockets as above described. As each case is ruled upon, the clerk notes the disposi-

${ }^{1}$ A case does not receive any number which belongs to it throughout its history, and by which it appears on the dockets and records of the court. After the case is completed, the file of the papers in the case receives a number.

2 "Cap." means capias issued; "May 26"-continued to May 26; "Dis."-discharged or dismissed; " 25 C. 30 D. S. S." - sentence of $\$ 25.00$ and costs and 30 days' imprisonment, sentence suspended. 
tion of it on the back of the affidavit, which acts as the wrapper for the file. At the close of the day's session the court officer in each room takes the judge's docket and copies therefrom the entries of disposition into the prosecutor's dockets in Room 1 and Room 2, as the case may be. Then these entries are recopied from the Room 2 docket into the original prosecutor's docket. Thus that day's prosecutor's docket contains entries of that day's disposition of all the cases docketed for the day.

EXHIBIT E.-JUDGE'S DOCKET, VOL. 50-ROOM 1

\begin{tabular}{|c|c|c|c|}
\hline 336 & \multicolumn{3}{|c|}{ September 30,1920} \\
\hline $\begin{array}{l}141 \\
142\end{array}$ & $\begin{array}{l}\text { James Robt. Henry Jackson } \\
\text { Michael Dowd }\end{array}$ & $\begin{array}{l}\text { Arson } \\
\text { Bastardy }\end{array}$ & $\begin{array}{l}\text { Court-room No. } 2 \\
\text { Court-room No. } 2\end{array}$ \\
\hline 356 & \multicolumn{3}{|c|}{ Tuesday, October 5, 1920} \\
\hline 21 & Lester W. Klein & Susp. person & $\begin{array}{l}\text { Nolle pros. (bound over } \\
\text { to grand jury) }\end{array}$ \\
\hline 22 & Ira Luff & Susp. person & $\begin{array}{l}\text { P.G. } 25 \text { and C. and } 30 \mathrm{D} \text {. } \\
\text { Sus. one year pro. }\end{array}$ \\
\hline 23 & Earl Brown & Susp. person & Con. Oct. 9 \\
\hline 24 & Arthur White & Susp. person & Nolle pros. (police dept.) \\
\hline 25 & Napeen T. Klopowsky & Assault and battery & $\begin{array}{l}\text { P.N.G. } 25 \text { and C. and } 30 \\
\text { D. Sus. one year prob. }\end{array}$ \\
\hline 26 & John Edwards & Assault and battery & Dis. want pros. \\
\hline 27 & Herman Keith & Assault and battery & Discharged \\
\hline 28 & Aug. Krinski & Assault and battery & Con. Oct. $20^{1}$ \\
\hline
\end{tabular}

A considerable number of the cases on the docket of any date are continued to some subsequent date. From these notations of continuances a "continuation docket" is made up, having a separate page for each day to which any of the cases has been continued. Exhibit F is an illustration of this continuation docket, showing the list of cases which have been continued to April 22, 1921. It does not show the day on which the case made its first appearance on the prosecutor's docket or court calendar, though, of course, that date was presumably the day of arrest or the day immediately following.

At the close of the day's session the file in each" case, with a notation thereon of the action of the court, is delivered to the journal clerk, who proceeds to make up what is called the "journal and execution dockets," which is the official record of the cases. Separate journal and execution dockets, identical in form, are kept for city and State cases. This docket

1 "P.G." means plea of guilty; "Sus." - suspended; "pro" or "prob."-probation; "con."-continued; "P.N.G."-plea not guilty; "Pros."-prosequi or prosecution. 
is illustrated by Exhibit G, containing parts on two dates of journal and execution docket No. 23 in State cases. The numbers 14567 and 14713 are the page or folio numbers of this docket.

\section{EXHIBIT F.-CONTINUATION DOCKET}

Friday, April 22, 1921

\begin{tabular}{l|l|l|l|l}
\hline \multicolumn{1}{c|}{ Name } & Charge & $\begin{array}{l}\text { Date of last } \\
\text { continuance }\end{array}$ & Date of arrest & Officer \\
\hline James Carpenter & Defrauding innkeeper & March 18 & March 9 & $\begin{array}{c}\text { Diskow- } \\
\text { sky Det. } \\
\text { Jones, } \\
\text { Michael Burke }\end{array}$ \\
\hline Violating liquor law & March 23 & December 10 & \\
\hline
\end{tabular}

A case travels on the name of the defendant-as, for instance, State of Ohio v. Leslie Stephens - until it is finally disposed of. The result of this is that, if there are three or four charges for the same crime against the same man, as is often the case, there is no possible way of telling which entry in the execution docket applies to which case, although the answer might possibly be traced by means of the pencil notations on the back of the affidavit. Each time a case appears in court it is entered upon a different page of the journal and execution docket, so that, if a case be continued 10 times, as is not infrequent, the entries regarding it will appear on 10 different pages of the journal and execution docket, and will frequently be distributed through two or three volumes of the book. At no one place on the records, with the exception of the pencil notations on the back of the affidavit, is it possible to find a full record of the history of any case.

As will be seen by an examination of Exhibit G, the journal and execution docket shows the date to which, but not the date from which, a case has been continued. To illustrate by the case of State of Ohio v. William Williams (Exhibit G), the entry shows that the case was continued to October 19. The fact that the journal records "Defendant in court-case continued," etc., shows that this was not the first appearance of the case, for on the first appearance there will always be the entry, "Affidavit fled-warrant issued," etc. There is, however, no way of telling from this page of the journal the original date on which the case appeared in court or the previous continuances, and the tracing of the full history of any case is often a work of considerable difficulty and expenditure of time. We can, of course, go to the index, and trace back therein the name of the defendant until we arrive at the first entry 
in the case. In a case which is pending for several months, involving many continuances or other steps, this tracing through the index is an arduous and lengthy task.

\section{EXHIBIT G.-JOURNAL AND EXECUTION DOCKET}

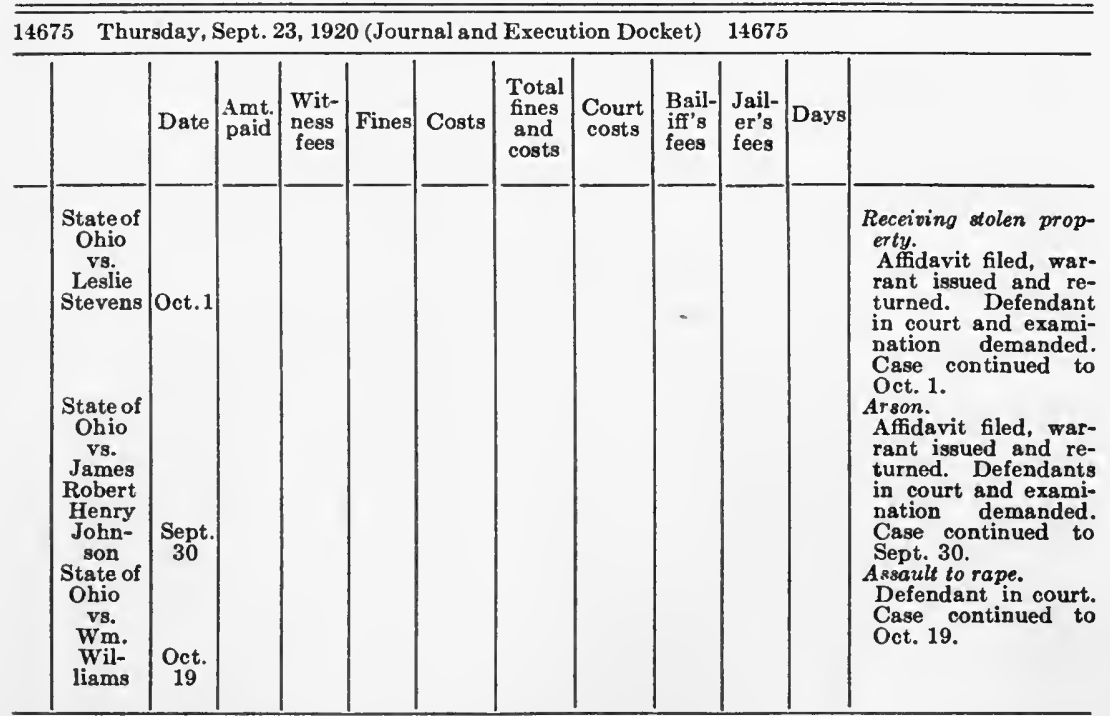

14713 Sept. 30,1920

\begin{tabular}{|c|c|c|c|c|c|c|c|}
\hline $\begin{array}{l}\text { 67,567 } \\
\text { Sttate of } \\
\text { Ohio } \\
\text { va. } \\
\text { James } \\
\text { Johnson } \\
\text { P. } \\
\text { Cologso } \\
\text { C. } \\
\text { Pagy } \\
\text { R. } \\
\text { Carran } \\
\text { E. } \\
\text { Carran } \\
\text { W. } \\
\text { Levy } \\
\text { L. } \\
\text { Levy }\end{array}$ & $\mid \begin{array}{l}\$ 2.00 \\
\$ 2.00 \\
\$ 2.00 \\
\$ 1.00 \\
\$ 1.00 \\
\$ 1.00\end{array}$ & $\$ 22.35$ & $\$ 22.35$ & $\$ 5.00$ & $\$ 8.35$ & $\$ 1.00$ & $\begin{array}{l}\text { State examination. } \\
\text { Arson. } \\
\text { Defendants in court. } \\
\text { Examination had and } \\
\text { he is required to fur- } \\
\text { nish bail in the sum } \\
\text { of } \$ 1,000 \text { for his per- } \\
\text { sonal appearance at } \\
\text { the present term of } \\
\text { the Court of Com- } \\
\text { mon Pleas of Cuya- } \\
\text { hoga County } \\
\text { And in default of } \\
\text { bail to be committed } \\
\text { to the jail of the } \\
\text { county aforesaid; } \\
\text { which was accord- } \\
\text { ingly done. }\end{array}$ \\
\hline
\end{tabular}

Separate indices are kept of State and city cases. Exhibit $\mathrm{H}$ is an exhibit of parts of pages 164 and 276 of Volume 6 of the Index of State Cases.

The index is not as helpful as its name might indicate. The index in the civil branch of the Municipal Court is extensively subdivided, both as to first and last names, which makes it comparatively simple to locate 
the case of any particular defendant. In the criminal branch, however, there is just one heading for all defendants whose names, we will say, begin with "T." To locate a particular man whose name begins with " $T$ " necessitates going over about 26 times as many names as would be necessary if the index were divided as in the civil branch. The tracing of the police court record of a man who has been before that court with some frequency would be a task of enormous difficulty and delay, and it is noteworthy that in the trial of the cases which were observed for this survey the police court record of the defendant was practically never produced or mentioned. ${ }^{1}$

EXHIBIT H.-PARTS OF PAGES 164 AND 276 OF VOL. 6, INDEX OF STATE CASES

\begin{tabular}{l|l|l|c}
\multicolumn{1}{c|}{ State } & Index & Vol. 6 \\
\hline \hline \multicolumn{1}{c|}{ Surname } & Christian name & Folio & 1920 date \\
\cline { 2 - 3 } Jackson & John & 14672 & Sept. 23 \\
Johnson & Henry & 1472 & Sept. 23 \\
Washington & Willie & 14675 & Sept. 24 \\
276 & & & Sept. 23 \\
Robert & James & 14675 & \\
\hline
\end{tabular}

In Exhibit H, in the case of Henry Johnson, the figures 14712 and 14675 , with the date, September 23 , indicate that the case originally appeared on the docket September 23, that the first entry in the case is recorded on folio 14675 of the journal and execution docket, and the last entry in the case on folio 14712 of that docket. That case, therefore, appeared twice on the court docket and there were two entries or orders. A large number of cases, however, have more numerous appearances and entries; and frequently, when the time arrives for indexing a later or trial entry, the clerk is unable to find the place where the case was previously recorded, and he proceeds to note the later entry at a different place in the index, with the result that the case is twice indexed, and, so far as the index itself indicates, there is no connection between the two entries.

Under this record system the case receives no number by which it is recorded and indexed, and its history is not recorded or indicated at any single part or place of any single record book. The cumbersomeness of

${ }^{1}$ One of the judges complained of the habitual failure of the prosecutor to bring this record to his attention. 
the system, both as a method of recording and as a means of tracing the history of a case, as well as the liability to error, is disclosed in the above illustrations.

Looking at Exhibit $\mathrm{H}$, we find on page 164 of the index a case against Henry Johnson with reference to folio 14675 of the journal and execution docket, and on page 276 a case against James Robert with reference to the same folio. Turning to this folio 14675, as shown on Exhibit G, we find the case of State of Ohio v. James Robert and Henry Johnson, with the following entry:

"Arson. Affidavit filed, warrant issued and returned. Defendants in court and examination demanded. Case continued to Sept. 30."

This same index, page 164, gives folio 14712 as the place where the final entry in the Henry Johnson cases is recorded. A thorough examination of folio 14712, however, disclosed no mention whatever of any Henry Johnson case. The list of names on the prosecutor's docket for September 30 was then searched, but without finding any Henry Johnson or any James Robert. The list of arson cases on the docket of that day was then traced, and disclosed a charge against James Johnson, which, as appears from Exhibit G, was recorded on folio 14713 of the journal and execution docket. So a case which, upon the official record of the court, on September 23 with two defendants, James Robert and Henry Johnson, terminated on that record with one defendant bearing the combination name of James Johnson. In an effort to solve the mystery, the original files were examined. This affidavit is not quite clear as to whether it charges one or two persons with the offense. But the warrant of arrest was made for the arrest of two persons, resulting, however, according to the return of the warrant, in the arrest of one person, James Robert Henry Johnson.

While engaged in examining the journal and execution docket (city cases) for a purpose unrelated to this matter of the record system, the following entry under date of January 19, 1921, was noted:

"Blanche Jackson, soliciting for immoral act, motion in mitigation granted, sentence suspended, twelve months' probation."

We were immediately impressed by the fact that this entry did not disclose when the case began or what sentence was originally imposed or when the sentence was originally imposed.

It occurred to us that this might be a fair case in which to ascertain the time and energy involved in tracing the record history of a case, and it was chosen for that purpose.

The first step necessary to trace the case back from the entry of 
January 19,1921 , was to look back through the pages of the name index under the letter "J," beginning with January 19, 1921. This required looking through all names in six columns, each containing about 50 names written in a rather illegible hand. The name Blanche Jackson was finally found under date of August 23, 1920, with reference to folio 8894. The next step necessary was the examination of the city journal and execution dockets, to ascertain the volume in which folio 8894 or the records of August 23, 1920, might be found. After handling several of these volumes, Volume 14 was discovered to be the desired one, and on folio or page 8894 , together with another entry and six or eight other cases, was found the following entry:

"Stella Brown, Blanche Jackson, soliciting for immoral act, affidavit filed, warrant issued, defendants in court, case continued to date set opposite respective names."

After the name of each defendant was the date, "September 14." It was then necessary to turn over about 100 pages of this volume until arriving at the pages dated September 14. The next necessary step was to look carefully through the four large pages devoted to that date, with six to 10 cases on each page, until the names of Stella Brown and Blanche Jackson might be discovered. The entry opposite their names: "defendants in court, case continued to September 15." September 15 being the next day, it was comparatively easy to discover the pages devoted to that day, and on the fifth or sixth subsequent page was found the entry:

"Defendants in court and plead guilty, hearing is had, and each is sentenced to thirty days and to pay the costs. Days suspended, one year probation, motion in mitigation filed, case continued to September 18."

Turning over some 10 or 15 pages, the four pages devoted to September 18 were found, on one of which the entry for Stella Brown showed that she had paid the costs, whereas the entry relating to Blanche Jackson was found on an entirely different page and read: "Case continued to September 24." To find the pages devoted to September 24 required the turning over of 20 to 30 intervening pages. Six pages were given to September 24, and the entry "Blanche Jackson, continued to September 30 ," was found by a careful examination of these six pages. Twenty to 30 pages again intervened between these two dates of September 24 and September 30, and on one of four "September 30 " pages was the Blanche Jackson entry: "Affidavit filed, warrant issued, defendant in court, case continued to October 15." This is the form of entry usually used at 
the very beginning of a case, and its use at this stage of the Jackson case must have been an error. To reach the pages devoted to October 15 required the turning over of 50 to 70 intervening pages, and on one of the October 15 pages was found the entry: "Continued to November 12." Turning to the back of Volume 14 in hand, it was disclosed that it did not reach November 12, and therefore Volume 15 had to be found and examined. On about the fourth page occurred the entry: "Blanche Jackson continued to November 27." Turning over the 60 to 75 intervening pages and examining the four pages relating to November 27 was found the entry: "Blanche Jackson, continued to December 17." Similarly turning over from 60 to 75 pages intervening and looking through the four pages devoted to December 17 was found the entry: "Blanche Jackson, continued to January 12." Similarly turning over about 100 intervening pages and looking through the five pages given to January 12, the following entry appeared: "Blanche Jackson, continued to January 19." Turning over the 20 to 30 intervening pages and examining the four pages of January 19 was found the entry which had first attracted our attention and which at the time of the examination was the last entry of the case, namely:

"Blanche Jackson, motion in mitigation granted, sentence suspended, twelve months' probation, case no. 44672."

The time and difficulties involved in searching the history of a case cannot be fully realized from reading a mere statement such as the above. To be understood they need to be experienced. If the offense happens to be a State rather than a city case, there are eight or 10 pages of the journal and execution docket for every date, as compared with four or five pages in city cases. If the case happens to be one of a type of frequent occurrence, such as violation of liquor law, traffic ordinance, or being a suspicious person, a particular name which is being traced will often be found in a column containing 8, 10, or 20 names, all grouped under one case involving the same offense. On one page of the journal and execution docket defendant's name will be found in one group, and on another page in the midst of an entirely different group, and on another page entirely alone.

As has been stated above, the clerk in the court-room notes each disposition or order on the back of the affidavit, and consequently one might think that the history of the case can be most easily discovered from these pencil memoranda on the back of the affidavit. However, those memoranda do not constitute the official or authentic record. 
'They are in pencil, and written upon a document open to access and examination by anyone.

In the Blanche Jackson case we did not stop with the journal and execution docket. That docket showed that on September 15, 1920, defendant was sentenced to thirty days and to pay the costs and that the days were suspended. There followed a number of appearances in court and continuances, and it seems strange that so much trouble should have been taken to avoid the payment of $\$ 2.80$ costs. The file of original papers was, therefore, examined, and the affidavit contained the pencil notation: "Costs and thirty days, m.m. 9/18." This notation did not say that the sentence of imprisonment had been suspended, and therein differed quite vitally from the entry on the record. To explain this discrepancy, the judge's docket or calendar for September 15 was examined. This involved obtaining and looking through four volumes of calendars for Room 1 to find September 15. This was necessary because there is no indication on the back of any volume as to the period covered by it, and the docket or calendar books in Room 1 are used only on alternate days, so that September 14 docket or calendar would be in one volume and September 15 in another. When this calendar for September 15 was found, it disclosed that the case had been assigned to Room 2, and the handling of two volumes of the court calendar for Room 2 was necessary to locate the September 15 entries. These calendar books are not alternate in Room No. 2 as in Room No. 1. The entry was finally found, reading: "39 Blanche Jackson, soliciting for immoral act, jury waived, G. C. and 30 days m.m. September 18-40 Stella Brown, soliciting for immoral act, G. C. and 30 days, days suspended one year, m.m. Sept. 18": which, being interpreted, means that the sentence of Stella Brown as to days was suspended, whereas the sentence of Blanche Jackson was not. So the record of the case on the record of the court, namely, the journal and execution docket, differs from the actual judgment of the court as disclosed on the judge's docket.

Another point to note is that neither the files nor the records give the name of the particular prosecutor who tried the case nor the name of the defendant's attorney. The chief prosecutor may remember in a general way the assistant who had charge of cases called in any one of the court-rooms at a designated period. But even these designations are not strictly adhered to, and the files and records themselves give little assistance to the chief prosecutor, the court, or the public in investigating the efficiency of the work of any member of the force or in locating responsibility in individual cases under examination. In contested cases there is great need for communication with the defendant's attorney, and 
in any study of the administration of justice there will arise occasion when it becomes important to know the names of specific defendant's attorneys.

In the civil branch of the Municipal Court, 28,463 cases were docketed in 1920-more, therefore, than in the criminal branch. Every one of these civil cases had its space on the records in which every step in the case, including names of attorneys on both sides, was recorded: another indication of the relative solicitude shown for the administration of civil and criminal justice.

\section{Personnel}

The man on the street, in his rough and ready appraisal of any institution, is apt to interpret it exclusively in terms of the ability and character of the persons conducting it. Things go well because $A$ is honest or capable, or go badly because $\mathrm{A}$ is corrupt or inefficient. This is a superficial view. The system of organization, the traditions of the office or institution, community factors or forces, need to be analyzed and their effects pointed out. Undoubtedly the character and competence of the men composing the prosecutor's office are important factors in the result of its work. In truth, the competence and honesty of the individuals in the office are at the same time an operating cause of the standards attained and an effect of other conditions and factors in the situation. The inadequacy of the men themselves, if such inadequacy exists, would be a fact of the situation, just as the inadequacy of any other facility engaged in the administration of justice in Cleveland. Able and scrupulous men sometimes produce splendid results with poor facilities, and, more important, they will often improve the facilities.

The municipal prosecutor's office has been Republican since January 1, 1916, the present being the third successive administration of that political complexion. The table on page 133 gives the names of the members of this office through four city administrations, with political affiliations, the period of service, age at commencement of service, years at the bar at commencement of service.

In most human affairs there is no sharp dividing line between fact and opinion; and this matter of the character and ability of an official lies in the twilight zone. The subject is delicate; dogmatic statements, based on impressions, must be avoided. Conversations were held with many Cleveland lawyers, practically all of whom seemed to agree that, taking the office by and large, the caliber of members of this office is not 
proportionate to the positions they occupy. In a questionnaire sent to all the members of the bar was the following request:

"Kindly state anything that occurs to you, in as great detail as possible, concerning the administration of criminal justice in Cleveland, its merits and defects. Please include your opinion as to the caliber of judges and prosecuting attorneys and defendants' attorneys in criminal cases and methods of trial."

MEMBERS OF MUNICIPAL PROSECUTOR'S OFFICE

\begin{tabular}{|c|c|c|c|c|}
\hline Name & Time of service & $\begin{array}{l}\text { Age at } \\
\text { com- } \\
\text { mence- } \\
\text { ment of } \\
\text { service }\end{array}$ & $\begin{array}{l}\text { Date } \\
\text { ad- } \\
\text { mitted } \\
\text { to bar }\end{array}$ & $\begin{array}{c}\text { Years } \\
\text { admitted } \\
\text { to bar } \\
\text { at com- } \\
\text { mence- } \\
\text { ment of } \\
\text { service }\end{array}$ \\
\hline \multicolumn{5}{|l|}{ DEMOCRATIC } \\
\hline Frank S. Day & Jan., 1912 to 1916 & 30 & 1907 & $41 / 2$ \\
\hline James G. Reyant & Jan., 1914, to Dec., 1916 & 34 & 1903 & $101 / 2$ \\
\hline Francis W. Poulson & Jan., 1914 , to Dec., 1916 & 24 & 1910 & $31 / 2$ \\
\hline Samuel W. Silbert & Jan., 1914 , to Dec., 1916 & 33 & 1907 & $61 / 2$ \\
\hline \multicolumn{5}{|l|}{ REPUBLICAN } \\
\hline James L. Lind (chief) & Jan., 1916, to Dec., 1919 & $\begin{array}{l}27 \\
29\end{array}$ & 1912 & $31 / 2$ \\
\hline Herman E. Kohen & Jan., 1916, to Jan., 1917 & 25 & 1914 & $\begin{array}{l}02 / 2 \\
11 / 2\end{array}$ \\
\hline Edward Stanton & Jan., 1916, to Dec., 1919 & 32 & 1913 & $21 / 2$ \\
\hline Edward Stanton (chief) & Jan. 1920 , to Dec., 1920 & 36 & 1913 & $61 \%$ \\
\hline E. J. Russick & Jan., 1916, to & 28 & 1913 & $31 / 2$ \\
\hline V. A. Marco & May, 1916, to Oct., 1916 & & 1912 & \\
\hline Fred A. Irvine & Oct., 1916, to Sept., 1917 & 25 & 1914 & \\
\hline W. D. Cole & Sept., 1917, to Feb., 1918 & 31 & 1912 & \\
\hline Nathan C. Beckerman & Dec., 1917, to Dec., 1919 & 31 & 1910 & $71 / 2$ \\
\hline Joseph Nuccio & Feb., 1918, to Sept., 1919 & 31 & 1917 & $1 / 2$ \\
\hline John J. Sexton & Apr., 1918, to Dec., 1920 & 42 & 1915 & $21 / 2$ \\
\hline $\begin{array}{l}\text { John Novario } \\
\text { K J }\end{array}$ & Sept., 1919, to & 24 & 1917 & \\
\hline Sam Rosenberg & $\begin{array}{l}\text { Feb., } 1920 \text {, to } \\
\text { Dec., } 1919 \text {, to }\end{array}$ & $\begin{array}{l}26 \\
26\end{array}$ & $\begin{array}{l}1916 \\
1917\end{array}$ & $31 / 2$ \\
\hline Oscar Bell (chief) & Jan., 1921, to & 41 & 1913 & $71 / 2$ \\
\hline Michael L. Sammon & Jan., 1921, to & 45 & 1919 & $11 / 2$ \\
\hline
\end{tabular}

There were about 100 specific responses to that part of this question which related to the prosecutors, and all of these with only two exceptions declared these officers to be lacking in requisite ability. Neither the question nor the answers differentiated between municipal and county officers. General opinion was expressed that the men in the prosecutor's offices are chosen for political reasons, and many asserted that in such choices the community suffers from the practice of deliberately giving the large racial or national groups of the community, such as the Poles, other Slavs, Jews, Italians, and Irish, representation in the presecutor's 
offices. There can be no doubt there exists a lack of public confidence in the freedom of the office from political and other influences operating to bring fear or favor into the administration of the law.

In order to obtain an estimate which could not be considered as biased by partisan considerations, confidential opinions were obtained from a leading Democratic lawyer and a leading Republican lawyer, both of whom are active in their party organizations and personally acquainted with all the members of the prosecutor's office. The opinions of these two men were startlingly identical. Each pointed out the same one or at most two members of the office as able and the rest as not sufficiently experienced or capable for the work.

With the office and the Municipal Court conducted as at present, except for an occasional jury trial or argument in an appellate court, the prosecutors do not have, or at least do not take, the opportunity to demonstrate their ability either as trial lawyers or prosecuting attorneys. It can be fairly stated as an unquestionable fact that they have not aggressively attempted to improve and reform the administration of justice in Cleveland, but have permitted themselves to drift with the currents, political and otherwise, in which they found themselves. Everybody consulted considered present Chief Prosecutor Bell to be an honest man and an official with the best of intentions. But whether he has the executive talents and driving power necessary to steer the ship in such rapid and swirling waters still remains to be demonstrated.

The present salary scale of the office is as follows:

Chief prosecutor......................\$4,000

First assistant. ................... 3,500

Second assistant..................... 3,100

Three remaining assistants. . . . . . . . . 2,900 


\section{CHAPTER V}

\section{OPERATION OF THE MUNICIPAL PROSECUTOR'S OFFICE}

\section{The Afridavit}

$\mathbf{P}$ ROCEEDINGS looking to a criminal prosecution are instituted either by police or by the injured person. This injured person corresponds to the private prosecutor in the English criminal practice, and is in most cases the chief prosecuting witness if the case comes to a trial.

Proceedings instituted by the police officer are of two classes: those in which an arrest has been made prior to issuance of any affidavit or warrant, and those in which no arrest has been made at the time the police officer takes the matter up with the prosecutor. The former class consists generally of cases in which the police officer has caught the offender in the act of the offense, such as an arrest for violation of traffic regulations or the arrest of a drunken man for intoxication. Often when the information at hand does not point to a definite charge, but the police officer has reason to be suspicious of someone he sees lurking about or in following a clue, he suspects the arrested person of being a participant in or having knowledge concerning the commission of the crime under investigation, the suspected person is arrested by the police officer as a "suspicious person."

In all cases, whether instituted by the police or by others, policemen or prosecuting witnesses come to the prosecutor's office for an affidavit. This is the first pleading or formal beginning of the criminal prosecution. Where the case is brought into the office by a police officer, an affidavit is almost invariably issued if the facts recounted by the officer show the commission of a crime, and, with a few exceptions, the only question considered by the prosecutor is the nature of the charge to be made. In most cases there is little doubt about the nature of the charge, and the prosecutor's part at this stage of the case consists of hardly more than the mechanical process of picking out from one of the compartments of his desk the form containing the charge of the particular offense involved and filling it in with the name of the person charged and the date. In fact, even this slight mechanical detail is performed in a large number of 
cases by the police officer himself, leaving the prosecutor nothing to do but to affix his name. In fact, by reason of the rush, confusion, and congestion in which the work is done, the prosecutor learns or hears the facts only when the policeman himself has some doubt as to the nature of the charge or the sufficiency of the facts and, on his own initiative, presents his doubt to the prosecutor.

\section{Siftivg of Cases}

Where the moving party is the injured person or prosecuting witness, the case is not a major felony, and there are no reasons pressing for the immediate arrest of the accused, the prosecutor follows the practice of issuing a summons calling upon the defendant to appear at his office at a designated time. This summons has no standing in law. Because of the dignity of the form used and the fact that it is served by a uniformed policeman, it generally has the effect of bringing in the prospective defendant. The complaining party is told to return at the same time, and the accused is then subjected to an informal examination, the purpose of which is to ascertain whether the facts show an offense sufficiently serious to warrant prosecution, and also incidentally to get information about the case. The prosecutor, by this practice, holds a sort of informal court of conciliation wherein he soothes the anger of the prosecuting witness in matters which do not justify a prosecution. Thus a certain amount of "sifting out" of charges takes place before they become cases.

The present prosecutor estimates that more cases are thus disposed of without prosecution than are placed upon the court dockets. A former member of the office estimates that a case, whether dropped or prosecuted, receives, on the average, three minutes' attention in the office. The estimate is liberal.

Complainants frequently desire to use the prosecution or threat of prosecution for purposes of collecting a claim or debt and have little interest in criminal proceedings except as it may serve this purpose. A danger arises, therefore, that in this preliminary and unofficial court of conciliation the prosecutor will permit himself to be used to further this purpose, and even a danger that, through inadvertence or favoritism, he will permit himself to use his position to aid in the collection of doubtful or trumped-up claims. ${ }^{1}$

${ }^{1}$ An actual case occurred in 1919 which jllustrates this evil: One Knox (the names used are fictitious) was an expressman. One day in July, 1919, a man and a woman came to his place of business and left an order with his colored helper to 
The extent of this evil is difficult to discover. The present chief prosecutor, feeling that some step toward decreasing the practice was advisable, ordered that these office summons be personally signed in longhand by the assistants issuing them, and not, as theretofore, by means of a stamp. Reliance must, however, be placed upon the caliber and character of the prosecutors themselves as well as the office record or reporting system. Some preliminary sifting out of the cases is necessary, and it would be unwise to issue an affidavit in every case in which one is sought and thereby add to the already excessive number of cases.

Resuming the description of the work of the prosecutor in the preparation of affidavits:

When he fails to allay the prosecuting spirit of the prosecuting witness and considers that there is sufficient proof of an offense, he issues the affidavit. It is in this class of cases that the prosecutor actually obtains some information about the case. Generally speaking, however, there is no particular book, paper, or file on which he puts down what he has learned. There is no system whereby he transmits this information to the trial prosecutor-that is, to the one who will

move a trunk from a given address to another given address. The next day they again dropped in and changed the destination address. The helper called for the trunk, found the lock broken, both straps broken, and one strap tied with a little cotton string. The trunk was successively taken to the designated destinations, at both of which it was refused, and then returned to Knox's premises, to be kept there until the owner might call for it and claim it. About two weeks later the woman who had left the order originally came to claim the trunk. She acknowledged that the lock and straps had been broken at the time the order was originally given. In order to identify her as the owner, Knox asked her a number of questions concerning the contents of the trunk, which she seemed to answer correctly. On examining the contents herself, she exclaimed that two shirt-waists and two pillow-tops were missing, and on being asked the value of the missing articles said, "\$75." She denied that she had ever given Knox or his helper orders to take her trunk. The next event was a telephone call to Knox from an attorney, Henry Frith, who in a very bulldozing and insulting manner ordered Knox to find and surrender the missing articles. Knox, of course, stated he knew nothing about them. Suit was thereupon brought against him in the Municipal Court for $\$ 314$. Then, late in November, over three months after the woman's alleged discovery that there were articles missing from the trunk, a police officer left a summons ordering Knox to call at the prosecutor's office the following day. In the room of one of the assistant prosecutors to whom he was directed, and whose name he did not know, he found this assistant prosecutor, the woman, and Attorney Frith. He was informed that unless he settled immediately he would be arrested. Refusing to pay anything, he was arrested on the charge of receiving stolen property. When the trials were held, both the civil and criminal cases were immediately dismissed, for there was not an iota of evidence against Knox. 
try the case. The information ceases to function at this point and, in fact, can hardly be called information for trial, since it is rather scanty at best and it does not reach the trial prosecutor. Practically speaking, therefore, the trial prosecutor has no information about the cases which he tries and has made no preparation for them, and we have seen the negative part which he plays in the actual trial. He may act as a starter for the police or other prosecuting witnesses, but he has no idea of what they will say.

\section{County Prosecutor Does Not Participate in Early Stages of Case}

A most important fact to note at this point is that the county prosecutor's office plays no part either in the preparation of the affidavit, the determination whether there shall be a charge made or what the charge shall be, the ascertainment of the facts upon which the affidavit is based, or the preparation for trial at the preliminary hearing. Though a large percentage of the cases are State cases, there is no system of coöperation or coördination whereby the county prosecutor, who may have the charge of and responsibility for the later and final stages of the case, gets in touch with it in time to mold its preparation. Except in sensational cases which are exploited by the newspapers at early stages, there is no coördination between the police department and the county prosecutor. Except as he reads about the cases in the newspapers, he never hears of them until they have been sent by the Municipal Court to the grand jury.

There seems to be no lack of willingness on the part of the police department to coöperate with the municipal prosecutor's office, and when the prosecutor requests service from the police department in the nature of preparation for the trial, such as the detection of facts, the ascertainment of names of witnesses, and the like, such assistance is promptly forthcoming. Such assistance is seldom requested, however, except in the comparatively few cases in which the public is aroused or the police officer who has made the arrest or is investigating the case has sufficient imagination and energy to realize the problems involved and to bring them to the attention of the prosecutor.

The up-to-dateness, adequacy, and expertness of the methods of criminal investigation in use in Cleveland are matters which fall more appropriately within the police division of this survey, but there is nothing to indicate that the prosecutors are in any degree equipped by education, experience, or interest to lead and educate the police department in this respect.

Except in its activity as an informal court of conciliation, the part [ 138 ] 
played by the municipal prosecutor's office prior to trial is largely the preparation of the affidavits, and, as above stated, except in a relatively small percentage of the cases, this preparation is a rather mechanical affair. Of the other cases, that is, those in which the preparation of the affidavit has involved the exercise of judgment and a knowledge of law, there is no practical way of ascertaining, with a fair degree of statistical accuracy, the percentage in which the prosecutor has exercised this judgment and discretion with efficiency. The present county prosecutor, when asked to explain the considerable percentage of cases "no-billed" and "nolled" by him, charged the municipal prosecutor's office with carelessness in the preparation of the affidavits. This resulted, he said, in a large number of inaccurate charges; that is, of affidavits in which the offense charged did not correspond to the provable facts.

Taking all the cases into account, therefore, while the affidavit is correct in a great percentage of all cases, there are indications that, in the small percentage of cases in which special skill is required, avoidable mistakes occur. Naturally, the percentage of these errors relative to total number of cases is less significant and important than is the class of cases in which these errors occur; and a few miscarriages of justice by reason of an error in the charge, in cases of importance or cases which have attracted public interest, is very damaging to the prestige of the administration of criminal justice and, therefore, to its effectiveness as a deterrent of crime.

\section{Cases in Appellate Courts}

The municipal prosecutor's duties also include the presentation of the side of the city or State in the hearings by the appellate courts of proceedings to reverse the judgments of the Municipal Court in criminal cases. Thorough preparation of this work is of prime importance. It is in these cases that an important part of the criminal law is interpreted and established. Furthermore, professional criminals, who know the ropes, are more apt than other types of defendants to carry cases up, and the effectiveness of law enforcement is especially important in their eases. And, as defendants with large financial means are more able to appeal cases than those of lesser means, it is highly important that this advantage be offset and minimized to the greatest extent consonant with justice.

A study was made of the relative number of cases in the Court of Appeals in which the municipal prosecutor filed or failed to file briefs, the study covering a period of two years-1919 and 1920 . The results are shown in Table 6. This record shows that the prosecutor filed a 
brief in only two of the 43 completed cases. It is noteworthy that he had filed no brief in any of the 13 cases in which the judgment of conviction was reversed, that is, in which he lost the case before the appellate court. In judging this record, the fact should be kept in mind that the prosecutor has had no stenographic assistance.

TABLE 6.-OUTCOME OF CASES CARRIED TO THE COURT OF APPEALS, 1919 AND 1920; CLASSIFIED ACCORDING TO THE FILING OF BRIEFS

\begin{tabular}{|c|c|c|c|c|}
\hline $\begin{array}{l}\text { Final disposition of case by } \\
\text { Court of Appeals }\end{array}$ & $\begin{array}{l}\text { No brief } \\
\text { filed by } \\
\text { either } \\
\text { side }\end{array}$ & $\begin{array}{l}\text { Brief by } \\
\text { plaintiff- } \\
\text { in-error } \\
\text { only }\end{array}$ & $\begin{array}{l}\text { Brief by } \\
\text { both plain- } \\
\text { tiff-in-error } \\
\text { and prose- } \\
\text { cutor }\end{array}$ & Total \\
\hline $\begin{array}{l}\text { Judgment affirmed } \\
\text { Judgment reversed } \\
\text { Dismissed at costs of plaintiff-in- } \\
\text { error } \\
\text { Dismissed for want of preparation }\end{array}$ & $\begin{array}{l}1 \\
3 \\
1 \\
7\end{array}$ & $\begin{array}{r}17 \\
10 \\
1 \\
1\end{array}$ & $\begin{array}{l}2 \\
\cdots \\
\cdots\end{array}$ & $\begin{array}{r}20 \\
13 \\
2 \\
8\end{array}$ \\
\hline Totals completed cases & 12 & 29 & 2 & 43 \\
\hline $\begin{array}{l}\text { CASES NOT FINALLY DisPoSED of: } \\
\text { Prosecutor in default of brief- } \\
\text { Four months or more } \\
\text { Three months or more } \\
\text { Two and a half months or } \\
\text { more } \\
\text { Two months or more } \\
\text { One month or more } \\
\text { Plaintiff-in-error in default of } \\
\text { brief- } \\
\text { Four and a half months } \\
\text { Two and a half months }\end{array}$ & $\begin{array}{l}\cdots \\
\cdots \\
\cdots \\
\cdots\end{array}$ & $\begin{array}{l}1 \\
1 \\
2 \\
1 \\
1\end{array}$ & $\begin{array}{l}\cdots \\
\cdots \\
\cdots \\
\cdots\end{array}$ & $\begin{array}{l}1 \\
1 \\
2 \\
1 \\
1 \\
1 \\
1\end{array}$ \\
\hline Totals incomplete cases & 2 & 6 & $\cdots$ & 8 \\
\hline Total all cases & - & . & . & 51 \\
\hline
\end{tabular}

\section{Statistics of Results of Cases}

These are the methods of preparation and trial. What is the quality of the product, so to speak-what are the results? The mortality tables (Tables 1, 2, and 3) give the percentages of the types of dispositions of the cases- "nolles," dismissals, pleas of guilt, convictions upon trial, and so on. As stated in Chapter II, these tables have been made from every tenth case, being a tabulation of the results of one-tenth of the cases. Tables 7, 8, and 9 give these results or dispositions in accordance with a general classification of offenses. 
TABLE 7.-CITY CASES, MUNICIPAL COURT, 1919-20; DISPOSITION OF CASES CLASSIFIED BY CHARGES

\begin{tabular}{|c|c|c|c|c|c|c|c|c|c|}
\hline \multirow[b]{2}{*}{ Charge } & \multicolumn{4}{|c|}{ Verdicts of guilty } & \multirow[b]{2}{*}{$\begin{array}{c}\text { No } \\
\text { papers }\end{array}$} & \multirow[b]{2}{*}{$\begin{array}{c}\text { Nolle } \\
\text { prossed }\end{array}$} & \multirow{2}{*}{$\begin{array}{l}\text { Other } \\
\text { dis- } \\
\text { posi- } \\
\text { tion }\end{array}$} & \multirow[b]{2}{*}{$\left|\begin{array}{c}\text { Dis- } \\
\text { charged }\end{array}\right|$} & \multirow[b]{2}{*}{ Total } \\
\hline & $\begin{array}{c}\text { Plea } \\
\text { un- } \\
\text { known }\end{array}$ & $\begin{array}{l}\text { Plea } \\
\text { of } \\
\text { guilty }\end{array}$ & $\begin{array}{c}\text { Plea } \\
\text { of } \\
\text { not } \\
\text { guilty }\end{array}$ & $\begin{array}{c}\text { Plea not } \\
\text { guilty } \\
\text { changed } \\
\text { to } \\
\text { guilty }\end{array}$ & & & & & \\
\hline $\begin{array}{l}\text { Traffic law violation } \\
\text { Disorderly conduct } \\
\text { Suspicious person } \\
\text { Intoxication } \\
\text { Ofenses against chastity } \\
\text { Gambling } \\
\text { Offenses against public } \\
\text { health } \\
\text { Ofenses against public } \\
\text { safety } \\
\text { Offenses against property } \\
\text { Miscellaneous }\end{array}$ & $\begin{array}{c}6 \\
1 \\
1 \\
. \\
\because \\
i \\
. .\end{array}$ & $\begin{array}{r}345 \\
96 \\
22 \\
180 \\
85 \\
8 \\
9 \\
14 \\
2 \\
16\end{array}$ & $\begin{array}{r}161 \\
126 \\
126 \\
58 \\
74 \\
23 \\
8 \\
3 \\
3 \\
9 \\
10\end{array}$ & $\begin{array}{r}11 \\
1 \\
5 \\
8 \\
10 \\
\cdots \\
\cdots \\
1 \\
\therefore\end{array}$ & $\begin{array}{r}10 \\
1 \\
10 \\
\ddot{3} \\
\cdots \\
1 \\
1 \\
1 \\
1\end{array}$ & $\begin{array}{r}25 \\
7 \\
72 \\
11 \\
16 \\
4 \\
2\end{array}$ & $\begin{array}{r}2 \\
4 \\
3 \\
1 \\
1 \\
\cdots \\
\cdots \\
\cdots \\
\hdashline\end{array}$ & $\begin{array}{r}48 \\
59 \\
55 \\
18 \\
28 \\
18 \\
3 \\
3 \\
1 \\
1 \\
2\end{array}$ & $\begin{array}{r}608 \\
295 \\
294 \\
276 \\
217 \\
54 \\
23 \\
\\
20 \\
15 \\
30\end{array}$ \\
\hline Total & 9 & 777 & 598 & 36 & 27 & 141 & 12 & 232 & 1,832 \\
\hline
\end{tabular}

TABLE 8.-STATE CASES, MUNICIPAL COURT, 1919-20; DISPOSITION OF CASES CLASSIFIED BY CHARGES

\begin{tabular}{|c|c|c|c|c|c|c|c|c|c|c|}
\hline \multirow[b]{2}{*}{ Charge } & \multicolumn{4}{|c|}{ Found guilty } & \multirow[b]{2}{*}{$\begin{array}{c}\text { No } \\
\text { papers }\end{array}$} & \multirow[b]{2}{*}{$\begin{array}{c}\text { Nolle } \\
\text { prossed }\end{array}$} & \multirow[b]{2}{*}{$\begin{array}{c}\text { Dis- } \\
\text { charged } \\
\text { want } \\
\text { of } \\
\text { prose- } \\
\text { cution }\end{array}$} & \multirow[b]{2}{*}{$\begin{array}{l}\text { Other } \\
\text { dis:- } \\
\text { posi- } \\
\text { tion }\end{array}$} & \multirow[b]{2}{*}{$\begin{array}{c}\text { Dis- } \\
\text { charged }\end{array}$} & \multirow[b]{2}{*}{ Total } \\
\hline & $\begin{array}{c}\text { Plea } \\
\text { un- } \\
\text { known }\end{array}$ & $\begin{array}{c}\text { Plea } \\
\text { of } \\
\text { guilty }\end{array}$ & $\begin{array}{c}\text { Plea } \\
\text { of } \\
\text { not } \\
\text { guilty }\end{array}$ & $\begin{array}{c}\text { Plea } \\
\text { not } \\
\text { guilty } \\
\text { changed } \\
\text { to } \\
\text { guilty }\end{array}$ & & & & & & \\
\hline \multirow{7}{*}{$\begin{array}{l}\text { Offensea against pub- } \\
\text { lic safety } \\
\text { Offenses against the } \\
\text { person } \\
\text { Gambling } \\
\text { Offensea against } \\
\text { property } \\
\text { Violation of liquor } \\
\text { laws } \\
\text { Offensea against } \\
\text { chastity } \\
\text { Offenses against minors } \\
\text { Offenses against pub- } \\
\text { lic justice } \\
\text { Frauds } \\
\text { Offenses against pub- } \\
\text { lic health } \\
\text { Miscellaneous }\end{array}$} & 9 & 310 & 67 & 16 & 13 & 17 & 6 & 10 & 23 & 471 \\
\hline & $\ddot{z}$ & $\begin{array}{l}42 \\
79\end{array}$ & $\begin{array}{l}170 \\
124\end{array}$ & 11 & $\because$ & $\begin{array}{r}15 \\
4\end{array}$ & $\begin{array}{l}58 \\
\cdots\end{array}$ & $\begin{array}{l}7 \\
\therefore\end{array}$ & $\begin{array}{r}109 \\
58\end{array}$ & $\begin{array}{l}402 \\
283\end{array}$ \\
\hline & 3 & 99 & 91 & 4 & 2 & 15 & 14 & 2 & 32 & 262 \\
\hline & 5 & 125 & 29 & 20 & 3 & 12 & .. & 5 & 30 & 229 \\
\hline & $\begin{array}{l}3 \\
. \cdot\end{array}$ & $\begin{array}{r}55 \\
6\end{array}$ & $\begin{array}{l}37 \\
23\end{array}$ & 6 & $\because$ & $\begin{array}{l}7 \\
6\end{array}$ & 4 & $\begin{array}{c}2 \\
.\end{array}$ & $\begin{array}{r}31 \\
7\end{array}$ & $\begin{array}{r}141 \\
46\end{array}$ \\
\hline & $\begin{array}{c}6 \\
\ldots\end{array}$ & 11 & $\begin{array}{r}10 \\
9\end{array}$ & i & $\because$ & $\begin{array}{l}1 \\
2\end{array}$ & $\ddot{2}$ & $\begin{array}{l}1 \\
\cdots\end{array}$ & $\begin{array}{l}9 \\
4\end{array}$ & $\begin{array}{l}38 \\
26\end{array}$ \\
\hline & $\because$ & $\begin{array}{r}4 \\
12\end{array}$ & $\begin{array}{r}5 \\
12\end{array}$ & $\begin{array}{l}1 \\
1\end{array}$ & i & $\begin{array}{l}4 \\
6\end{array}$ & $\ddot{3}$ & $\begin{array}{l}1 \\
.\end{array}$ & $\begin{array}{l}1 \\
4\end{array}$ & $\begin{array}{l}16 \\
39\end{array}$ \\
\hline Total & 33 & 751 & 577 & 61 & 19 & 89 & 87 & 28 & 308 & 1,953 \\
\hline
\end{tabular}


The meaning of the terms used are too well known to require much explanation. "Discharged" are those in which, after trial, the court decided for the defendant. The Municipal Court has no jurisdiction to impose judgment in a felony case, even if the defendant enters a plea of guilty; so the "bound-over cases" in Table 9 include those in which there was a plea of guilty. This table shows that only 87 out of 683 cases resulted in the discharge of the defendant; and that, out of 555 cases which were heard, 468 were bound over to the grand jury, indicating, in the light of the results of the cases in the grand jury and county court, either that the mill of the Municipal Court does not perform its sifting functions efficiently, or that the cases are not well prepared.

TABLE 9. STATE EXAMINATIONS, MUNICIPAL COURT, 1919-20; DISPOSITION OF CASES CLASSIFIED BY CHARGES

\begin{tabular}{|c|c|c|c|c|c|c|c|}
\hline Charge & $\begin{array}{c}\text { Bound } \\
\text { over }\end{array}$ & $\begin{array}{c}\text { Dis- } \\
\text { charged }\end{array}$ & $\begin{array}{c}\text { Nolle } \\
\text { prossed }\end{array}$ & $\begin{array}{l}\text { Guilty } \\
\text { of lesser } \\
\text { offense }\end{array}$ & $\begin{array}{c}\text { Dis- } \\
\text { missed }\end{array}$ & $\begin{array}{l}\text { Other } \\
\text { dispo- } \\
\text { sition }\end{array}$ & Total \\
\hline $\begin{array}{l}\text { Ofenses against persons } \\
\text { Offenses against property } \\
\text { Offenses against peace } \\
\text { Offenses against public safety } \\
\text { Forgery offenses } \\
\text { Offenses against chastity } \\
\text { Frauds } \\
\text { Offenses against publio justice } \\
\text { Minors } \\
\text { Miscellaneous }\end{array}$ & $\begin{array}{r}181 \\
144 \\
82 \\
27 \\
11 \\
11 \\
6 \\
3 \\
1 \\
2\end{array}$ & $\begin{array}{r}37 \\
24 \\
8 \\
9 \\
2 \\
i \\
1 \\
1 \\
3 \\
2\end{array}$ & $\begin{array}{r}18 \\
19 \\
2 \\
5 \\
6 \\
2 \\
1 \\
4 \\
3 \\
\cdots\end{array}$ & $\begin{array}{l}13 \\
27 \\
\mathrm{i} \\
\because \\
\mathrm{i} \\
\because \\
\because \\
\therefore\end{array}$ & $\begin{array}{r}3 \\
4 \\
-i \\
2 \\
2 \\
1 \\
i \\
i\end{array}$ & $\begin{array}{c}8 \\
1 \\
1 \\
i \\
\because \\
\because \\
\because \\
\mathrm{i}\end{array}$ & $\begin{array}{r}260 \\
219 \\
93 \\
43 \\
22 \\
16 \\
9 \\
8 \\
8 \\
5\end{array}$ \\
\hline Total & 468 & 87 & 60 & 42 & 14 & 12 & 683 \\
\hline
\end{tabular}

\section{Dispositions Without Trial}

Attention should now be given the practice in those types of disposition whereby, without trial, cases are dropped or dismissed by or at the instance of the prosecutor, or he and the court accept a plea of guilt of a lesser offense than that charged. Tables 1, 2, and 3 show 1.47 per cent. of the city cases, 0.97 per cent. of state misdemeanors, and 1.78 per cent. of state examinations are "no papered," and 7.70 per cent., 4.57 per cent., and 7.95 per cent., respectively, are "nolled." In city and state misdemeanor cases there are, practically speaking, no degrees of offenses, and nothing to be gained by a plea of guilt of a lesser or different offense. If the charge be a felony, however, acceptance of plea of guilt of a lesser offense gives the Municipal Court jurisdiction to impose a fine or short imprisonment in a workhouse or other milder place of detention as compared with more lengthy confinement in the penitentiary if the defendant be ultimately found guilty of the felony. 
As shown by Table 3 , these lesser pleas were accepted in 1.15 per cent. of the state felony cases. A study of the time which elapses between arrest and the "nolle" disclosed that in city cases there was an average of 12.5 days, and in state misdemeanors, of 11.3 days.

Numerous situations arise which justify the dropping of cases without trial, and there is nothing illegitimate or necessarily suspicious about the "nolle" of a case. Nor are these percentages on their face necessarily excessive. But this power of the prosecutor is so dangerous, so fraught with possibilities of carelessness or corruption, that, both for the sake of the administration of justice and for the protection of the prosecutor himself against unjust suspicions, it is of the utmost importance that its exercise be surrounded with all practical safeguards.

\section{"No Papers" or "No-PAPERing"}

The expression "no papers" needs explanation. When an arrest is made prior to issuance of an affidavit, the case goes upon the docket and is therefore called in court. If the prosecutor decides at that early stage that the provable facts do not justify bringing any charge, no affidavit is issued, and, when the case is called in court, he responds that there are "no papers," and that is the end of the case. In "nolled" cases, on the other hand, the affidavit has been issued-that is, a charge has been made, and the "nolle" represents the determination on the part of the prosecution that, though the situation may have justified the making of a charge and filing of an affidavit, the absence of adequate proof or some other situation makes it just or advisable to drop the case at that point. The word "nolle" is an abbreviation of nolle prosequi, meaning "I am unwilling to prosecute."

This "no-papering" procedure has no statutory basis. No such procedure is mentioned in the statutes or recognized in common law criminal procedure. Consequently the law does not throw safeguards around its exercise, and, as actually practised in the Municipal Court, the prosecutor simply announces "no papers" without stating any reason, and the court hears nothing and does nothing except note "no papers" on the docket. An experienced official connected with the Municipal Court, when asked to explain the sort of situation in which "no-papering" was applied, answered: "If Burns is arrested and when the officer comes down here he finds that somebody knows Burns and that he has lived around Cleveland for a while, is a pretty good fellow, and will probably never be in trouble again, we simply decide never to go ahead with the case, and the case is marked 'no papers.'"

In almost all "no-papered" cases it is apparent that the trial prosecu- 
tor has no information as to the reasons for dropping the case, and simply accepts the word of the police officer. As a matter of fact, therefore, somebody in the police department, and not the court or prosecutor, makes the decision. Neither in the records or papers of the court nor in the files of the prosecutor's office is any statement or notation whatever made as to the reasons for "no-papering" the case. The reason, if ascertainable at all, is to be found only in the memory either of the police officer who gave the tip to the trial prosecutor to "no paper" the case, or in the memory of the office prosecutor who gave the tip to the police officer to give the tip in turn to the trial prosecutor.

\section{Nolles}

The statutes of Ohio contain no provision regulating practice in entering of nolles in the Municipal Court. Section 2919 of the General Code of Ohio prohibits the county prosecutor from entering a nolle without leave of court and without good cause shown in open court. There is no corresponding provision for the municipal prosecutor or Municipal Court. Naturally, the court can exercise some control, but even where the law prescribes consent of the court, the prosecutor is most instrumental in determining the question, for the court is necessarily dependent upon the prosecutor's statement of facts upon which a nolle is based. And in the hurly-burly of the Municipal Court nolles requested or suggested by the prosecutor are granted as a matter of course.

The nolle sometimes takes place during the trial of the case, when the developments at the trial suggest to the prosecutor that the provable facts are not sufficient, and sometimes the judge himself suggests a nolle. No record or notation is made, however, as to the reasons for the nolle nor at whose instance it was allowed.

In other cases the nolle is announced by the trial prosecutor just as the case is called. If he knows of the reasons, he seldom states them, and generally he acts upon word from the police officer in the case or from one of the office prosecutors. It is quite possible that he might have reasons of his own of which no one else knows and which are communicated to no one else. Whether the determination to "nolle" the case has its birth with the trial prosecutor, police officer, or an office prosecutor, there is no memorandum of such reasons made, with the exception that in cases of death or personal injury arising out of traffic violations there is some sort of a vague requirement that the reason for dropping the case be noted on the so-called "yellow card" in the police department. As we shall soon see, the rule is indefinite and its observance irregular. 
There is no regulation whereby permission to "nolle" the case is required from the chief prosecutor. For a short time after he came into office present Prosecutor Bell considered the enactment of such a regulation, but decided that he did not have the necessary clerical assistance.

In addition to the general statistics for 1919 and 1920, an intensive study was made of cases "no-papered" and "nolled" between January 17 to 31,1921 . These were the two weeks which preceded the commencement of this survey, and sufficiently recent to test the practice. Following is a list of these cases:

No.

44735

44872 (two defendants)

70863

71012

71261

71283 (two charges)

71321 (two defendants)

70852

71297

No.

44879

44866

44660 (two defendants)

44667

44697 (three defendants)

44706

44725

44754

44780 (four defendants)

44796 (two defendants)

44815

44822

44829

44831

44871

70877

70900

70970

$709851 / 2$

70989

71021

71034

71039
"NO PAPERS"

City Cases

Charge

Traffic ordinance

Suspicious person

State Misdemeanors

Obtaining goods by false pretenses

Obtaining money by false pretenses

Liquor law

Petit larceny

Liquor law

State Felonies

Fugitive from justice

Manslaughter

\section{NOLLES \\ City Cases}

Traffic ordinance

Traffic ordinance

Traffic ordinance

Suspicious person

Suspicious person

Bread ordinance

Suspicious person

Traffic ordinance

Suspicious person

Suspicious person

False police report

Traffic ordinance

Disorderly conduct

Suspicious person

Suspicious person

State Misdemeanorg

Conversion

Liquor law

Assault and battery

Liquor law

Liquor law

Assault and battery

Illegally practising medicine

Exhibiting scheme of chance 


\section{NOLLES-State Misdemeanors-(Continued)}

No.

71091

71212

71245

71229

71247

71249

71254

71255

71266

70853

70859

70861

71235 (three defendants)

71303

70911

70912

70917

70947

70959

71101

71279
Charge

Liquor law

Conversion

Assault and battery

Liquor law

Petit larceny

Conversion

Adultery

Fornication

Auto law

State Felonies

Fugitive from justice

Forgery

Operating motor vehicle without owner's consent

Robbery

Operating motor vehicle, etc.

Obtaining goods under false pretenses

Issuing check to defraud

Carrying concealed weapons

Fugitive from justice

Issuing check to defraud

Issuing check to defraud

Carrying concealed weapons

The prosecutor and his assistants were asked to give the reasons for dropping these cases. In practically none of them were they able to remember the reason. This was quite natural in view of the enormous number of cases handled. In none of them, however, did they go to any record for the answer. They described, in an abstract manner, various types of recurring situations which they treat as justifying the entering of a nolle, but did not concretely, by means of their recollection or reference to a record, bring any of these cases within these types. They did state that in manslaughter, personal injury, or property damage cases arising out of traffic accidents, reasons were noted upon the yellow sheet of the case in the police department. This trail was then followed:

The policeman making the arrest, making the investigation, or taking the complaint, if the case starts with a complaint to the police department, makes out a report with an original and three carbon copies. The original is white, two of the carbons are pink, and one carbon is yellow. The white copy goes to the record room at the central station. One of the pink copies is kept as a permanent record in the precinct. The other pink copy goes either to the city law department or to the detective bureau or to any other department which might be particularly interested in the case. The yellow copy is kept at the precinct and posted on a board. These yellow sheets include all sorts of complaints and reports, including petit larceny, theft of automobiles, unlocked doors, etc.

If the case be a traffic case, then, when it comes on for hearing in the 
Municipal Court, the officer usually takes this yellow sheet with him. This action is, however, optional and not uniform. In other classes of cases the yellow sheet is seldom taken. When the officer does take the sheet, the prosecutor may make some notation on it as to the disposition of the case, but there is no regular practice of that kind. The sheet is brought back to the precinct station and posted with the others there on file. These yellow sheets are apparently kept so as to allow the reporters or anybody else who is interested easy access to the day's grist of accidents, crimes, etc. Every month or two most of these yellow sheets are thrown away, so that they do not in any sense constitute a record of the police department.

We examined the complete files of the yellow sheets in the second and fourth precincts. In the second precinct some 600 to 800 of these reports were examined, running from March 12 to June 12, 1921. Only two of them contained notations by any prosecutor. These notations were as follows:

6/7 "No papers. No apparent violation. M. L. Samman, Assistant Prosecutor." (This was a case involving injury of a person from an automobile accident.)

"Insufficient evidence. S. Rosenberg, Prosecutor. 5/17/21." (This was a case involving damage to property arising from an automobile accident.)

At the fourth precinct from 200 to 300 of these sheets were examined, covering the period from May 25 to June 13, 1921. There were only three entries of any sort by a prosecutor-all three automobile cases. These entries were as follows:

"Will send out notice to Rawlin if Chizek wants it. Prosecutor Novario." (Chizek was the complaining witness.)

"No papers. Prosecutor Novario."

"Papers issued for careless driving and lights. M. L. Samman, Assistant Prosecutor."

These few cases with prosecutor's notations did not constitute all the traffic accident cases. The pink sheets, which are a part of the permanent records in the precinct office, never go to the prosecutor. The accident files in both Precincts 2 and 4, covering about two months, were examined without disclosing a single notation by a prosecutor. These yellow sheets to which the prosecutor had referred cannot serve as the slightest pretense for a record system. The prosecutor sees them in a very restricted class of cases, and, even in that class, sees them erratically and only when the police officer happens to bring one along. They are at best temporary memoranda in the police stations. 
The following cases were selected from the foregoing list of two weeks' "no papers" and nolles, and the police station records or sheets, to which the prosecutor had referred, were examined, with the following results:

\section{First Precinct}

No. 70861 William Proskner. Charge, operating motor vehicle without consent of owner. Disposition, nolle. The police record room had no record whatever of this case. The private files in Chief of Police Smith's office, however, showed that the case was taken directly to the grand jury, the defendant indicted, and later found guilty and sentenced to serve one to fifteen years by Judge Powell. There was no notation anywhere as to the reason for the nolle in the Municipal Court, and it was only an accident that, while searching Chief Smith's office on entirely different matters, this notation in this case happened to be seen.

No. 70915 Ben Weiger. Operating motor vehicle. Dismissed for want of prosecution. There were no records on this case.

No. 71194 Rafel Majeia. Grand larceny. Discharged. No record.

No. 71195 Marie Moore. Grand larceny. Discharged. No record.

\section{Second Precinct}

No. 71297 Henry Pack. Manslaughter. "No-papered." The defendant, while operating an auto, struck and killed two persons. On the record at the central office and on the pink sheet in the precinct appeared the following entry:

"Presented the case to Prosecutor Russick, who said there was not sufficient evidence to issue a warrant for the driver, who was arrested, charged with manslaughter."

There were no notations on the record either at the central office or the precinct made by the prosecutor, and the yellow sheet of this case had either been destroyed or mislaid before the time of the examination.

Arthur Brooks. "No-papered." Arthur Brooks killed Chapman Whippel while driving an auto at East 18th Street and Payne Avenue, N.E. In the report in the record room at the central station and on the pink sheet in the precinct station appears the following: "I presented the facts and statements of the witnesses in the above case to Prosecutor Novario, who issued 'no papers' as there was no violation of city law or State ordinances." The yellow sheet on this case had either been lost or destroyed and was not available at the precinct, and there was no notation anywhere by the prosecutor as to why the case had been "no-papered."

\section{Fourth Precinct}

No. 71062 Joseph Hopkins, Edward Mackin. Robbery. No record.

No. 71235 Harvey Hubner. Robbery. Nolle pros. No record.

Robert M. Harris. Robert M. Harris was driving 30 or 35 miles per hour, skidded and ran up on to sidewalk and hit three children, killing two of them, and was arrested, charged with manslaughter. There was no entry showing disposition of this case. 
Sam Ettinger. Sam Ettinger, on April 4, was going east on Superior Avenue, N.E., about 50 or 60 miles per hour, struck another car, and his car turned three complete somersaults in the air and stopped about 100 feet further down the street and killed two of the passengers in Ettinger's machine. The records at the central office and precinct showed no disposition of this case. As a matter of fact, Ettinger was discharged by the court, as shown by the memorandum of proceedings in Municipal Court on April 22.

\section{Acceptance of Pleas of Lesser Offense}

Section 4583 of the General Code expressly permits the Municipal Court, in a felony case, when the court is of the opinion that the offense is only a misdemeanor, to accept a plea of guilty of the misdemeanor or order the prosecutor to file an information for the misdemeanor and discharge the felony case. The statute does not specify any safeguards. Present practice of the prosecutor's office appears to be as loose and haphazard, without record and without regulation and without concentration of responsibility, as in the case of nolles. ${ }^{1}$

1 The case of Charles McCormack furnishes an illustration of the possibilities in existing methods and practices. McCormack was arrested on the public square of Cleveland on the night of Saturday, April 23, 1921, for pocketpicking on April 21. On the night of the arrest, about midnight, Assistant Municipal Prosecutor Kreisberg came to Lieutenant C.'s desk at the central police station with two other men for the purpose of inquiring about getting a bond for McCormack. McCormack's attorney was X, closely related to a well-known, influential Republican "politician."

The police blotter contains the words "Pocketpicking" and "Picked the pocket of William Smith." In a different ink, lines were drawn through these words, and, in both different ink and handwriting, there was substituted, "Petit larceny" and "stole \$33." The affidavit charges petit larceny; the bail bond charges pocketpicking. The former is a misdemeanor, the latter a felony. When the case was called before Judge A. on Monday morning, McCormack plead guilty and was fined $\$ 50$ and sentenced to thirty days. A motion for mitigation of sentence was overruled. The records contain no statement of reasons for or justification of this reduction. The case appeared as No. 25 on the prosecutor's docket for April 25, and appeared as No. 24 on the judge's docket in Judge A.'s room. The docket in Room 1 was written in green ink, and in the column for entering the charge appeared the charge " pocketpicking," over which, however, in pencil, was written "petit larceny." On the docket in Judge A.'s room, in which the case was heard and the entire docket of which was written in pencil, appears the word "pocketpicking" in pencil of the same color as the rest of the docket, and over this in red pencil, "petit larceny." Petit larceny does not bear to pocketpicking the relation of lesser degree of the same type of offense, as, for instance, manslaughter is a lesser degree of homicide than murder, or petit larceny a lesser degree of the same offense as grand larceny.

The following is McCormack's police record, according to the records in the Bureau of Criminal Identification of the Cleveland police department. Lieutenant 


\section{SUSPENSion of SENTENCES}

The mortality tables (Tables 1, 2, and 3) give the percentages of cases in which sentences were wholly suspended or reduced or carried out. Tables 10,11, 12, and 13 contain a more detailed analysis of the suspensions of sentences in the Municipal Court, classified both as to nature of charge and as to severity of the original sentence.

The high percentage of mitigations and suspensions, particularly in certain classes of cases, indicates an abuse or mistaken practice somewhere. The question arises as to the part played by the prosecutor. Frequently the court suspends the sentence immediately after rendering judgment at the end of the trial, and, therefore, in the presence of the prosecutor. In other cases the suspension of sentence takes place at an unannounced and unscheduled time, frequently without the presence of

Koestle, in charge of the bureau, states that Charles and Nicholas McCormack are the same person.

Record of Nicholas McCormack, alias William McKay, alias Harry Wilson, alias Frank Martin, alias Thomas Ward. Photo No. 17249, Cleveland, O., gallery.

As William McKay arrested at Elmira, N. Y., June 6, 1907. Charge, suspicious person. "P.P." Given hours to leave city.

As Nicholas McCormack, No. 788, arrested at Jersey City, N. J., November 10,1908 . Charge, pocketpicking. January 18,1909 , discharged by trial, and was arrested in court and taken to Brooklyn, N. Y., by officers from that city.

As Harry Wilson, No. 714, arrested at Syracuse, N. Y., June 9, 1910. Charge, disorderly person. "P.P." June 11, 1910, paroled by Judge Ryan.

As Frank Martin, No. 4442, arrested at Kansas City, Mo., November 24, 1910. Charge, "P.P." November 26, 1910, fined \$25. Paid.

As Thomas Ward, No. 6665, arrested at St. Louis, Mo., August 8, 1912. Charge, pocketpicking. Picking pockets on street cars with George Scott, No. 6664, and August alias Gus Murphy, No. 666, stole a pocketbook containing \$\$0, October 30, 1912. Case of Thomas Ward, convicted of grand larceny, and sentenced to two years, Jefferson City, Mo., penitentiary. Appealed to Supreme Court and released on $\$ 3000$ bond.

As Thomas Ward, No. 5601, arrested at Detroit, Mich., August 4, 1913. Charge, suspicious person, "P.P."

As Frank Martin, No. 34367, arrested at Philadelphia, Pa., December 30, 1916. Charge, inmate of gambling house.

As Nicholas McCormack, No. 4279, arrested at Pittsburgh, Pa., December 7, 1917. Charge, "P.P." December 8,1917 , fined $\$ 100$ or thirty days in workhouse. Paid.

As Nicholas McCormack, No. 16177, arrested at Los Angeles, Cal., May 1, 1918. Charge, suspected pickpocket.

As Nicholas McCormack, No. 17249, arrested at Cleveland, O., June 17, 1918. Charge, suspicious person. Suspected pickpocket. Taken from railway train at Union Depot, June 17, 1918. June 17, 1918, released to leave city. 
or consultation with the prosecutor. Even when he is present the prosecutor rarely protests or participates in any way in deliberation upon the question of suspension. Representing as he does the community, and being that representative presumably most familiar with the facts concerning both the offense and the offender, it would seem to be the proper function of the prosecutor to advance the considerations favoring or contradicting the suspensions. Sometimes he does not perform this function because the court has not given him the opportunity. There is, however, no indication that he has protested this exclusion or made any vigorous attempt to do his part.

TABLE 10.-STATE CASES CLASSIFIED BY CHARGES AND BY DISPOSITIONS AND DEGREE OF SUSPENSION OF SENTENCES

\begin{tabular}{|c|c|c|c|c|c|c|c|c|c|}
\hline \multirow[b]{2}{*}{ Charge } & \multicolumn{5}{|c|}{ Dispositions of cases } & \multicolumn{4}{|c|}{ Results of sentences } \\
\hline & $\begin{array}{c}\text { No } \\
\text { sen- } \\
\text { tence }\end{array}$ & Fine & $\begin{array}{c}\text { Im- } \\
\text { prison- } \\
\text { ment }\end{array}$ & $\begin{array}{l}\text { Fine } \\
\text { and } \\
\text { im- } \\
\text { prison- } \\
\text { ment }\end{array}$ & $\begin{array}{l}\text { Total } \\
\text { cases }\end{array}$ & $\begin{array}{l}\text { Sen- } \\
\text { tence } \\
\text { wholly } \\
\text { sus- } \\
\text { pended }\end{array}$ & $\begin{array}{l}\text { Sen- } \\
\text { tence } \\
\text { partly } \\
\text { sus- } \\
\text { pended }\end{array}$ & $\begin{array}{c}\text { Sen- } \\
\text { tence } \\
\text { exe- } \\
\text { cuted }\end{array}$ & $\begin{array}{l}\text { Total } \\
\text { sen- } \\
\text { tences }\end{array}$ \\
\hline $\begin{array}{l}\text { Assault and battery } \\
\text { Auto law violations } \\
\text { Gambling } \\
\text { Liquor law violations } \\
\text { Against public safety } \\
\text { Petit larceny } \\
\text { Against chastity } \\
\text { Against property } \\
\text { Against minors } \\
\text { Against public justice } \\
\text { Frauds } \\
\text { Against public health } \\
\text { Against person } \\
\text { Desecration of Sabbath } \\
\text { Intoxication } \\
\text { Against public peace } \\
\text { Misconduct in public office } \\
\text { Against State } \\
\text { Forgery } \\
\text { Miscellaneous }\end{array}$ & $\begin{array}{r}184 \\
43 \\
63 \\
51 \\
31 \\
34 \\
42 \\
32 \\
17 \\
11 \\
8 \\
7 \\
5 \\
1 \\
2 \\
3 \\
-\mathrm{i} \\
1 \\
9\end{array}$ & $\begin{array}{r}114 \\
211 \\
217 \\
173 \\
148 \\
51 \\
22 \\
27 \\
3 \\
14 \\
7 \\
8 \\
1 \\
4 \\
3 \\
1 \\
\cdots \\
\cdots \\
15\end{array}$ & $\begin{array}{r}26 \\
9 \\
1 \\
\cdots \\
26 \\
19 \\
7 \\
6 \\
8 \\
2 \\
\ddot{1} \\
\because \\
\therefore \\
\therefore \\
\therefore \\
\therefore \\
\therefore\end{array}$ & $\begin{array}{r}71 \\
28 \\
2 \\
\dddot{1} \\
68 \\
58 \\
17 \\
20 \\
5 \\
9 \\
1 \\
\because . \\
\because \\
\ddot{2} \\
\because \\
\ddot{2}\end{array}$ & $\begin{array}{r}395 \\
291 \\
283 \\
224 \\
180 \\
179 \\
141 \\
83 \\
46 \\
38 \\
26 \\
16 \\
7 \\
5 \\
5 \\
4 \\
2 \\
1 \\
1 \\
26\end{array}$ & \begin{tabular}{r}
72 \\
20 \\
115 \\
8 \\
17 \\
44 \\
47 \\
9 \\
24 \\
98 \\
1 \\
1 \\
1 \\
$\therefore$ \\
$\therefore$ \\
$\therefore$ \\
\hdashline \\
5
\end{tabular} & $\begin{array}{r}38 \\
92 \\
41 \\
38 \\
20 \\
20 \\
15 \\
14 \\
1 \\
3 \\
3 \\
3 \\
1 \\
\therefore \\
\therefore \\
\therefore \\
\therefore \\
\therefore \\
0 \\
4\end{array}$ & $\begin{array}{r}101 \\
136 \\
64 \\
127 \\
112 \\
81 \\
37 \\
28 \\
4 \\
24 \\
7 \\
5 \\
-3 \\
3 \\
3 \\
1 \\
2 \\
\ldots \\
\hdashline 8\end{array}$ & $\begin{array}{r}211 \\
248 \\
220 \\
173 \\
149 \\
145 \\
99 \\
51 \\
29 \\
27 \\
18 \\
9 \\
2 \\
4 \\
3 \\
1 \\
2 \\
\ldots \\
17\end{array}$ \\
\hline Total & 545 & 1,019 & 105 & 284 & 1,953 & 372 & 293 & 743 & 1,408 \\
\hline
\end{tabular}

The whole practice regarding suspension of sentences is excessively loose. Much of it is of doubtful validity. The statutes provide for suspension of sentence pending error proceedings in upper courts. The statutes also provide for suspension of sentence of imprisonment with a specified period of probation, the final carrying out or discharge of the sentence to be dependent upon the results of the probation period. Statutes furthermore provide for suspension of a sentence of a fine for a specified period during which the defendant is given opportunity to pay the fine. In practice these limitations are by no means observed. 
TABLE 11.-CITY CASES CLASSIFIED BY CHARGES AND BY DISPOSITIONS AND DEGREE OF SUSPENSION OF SENTENCES

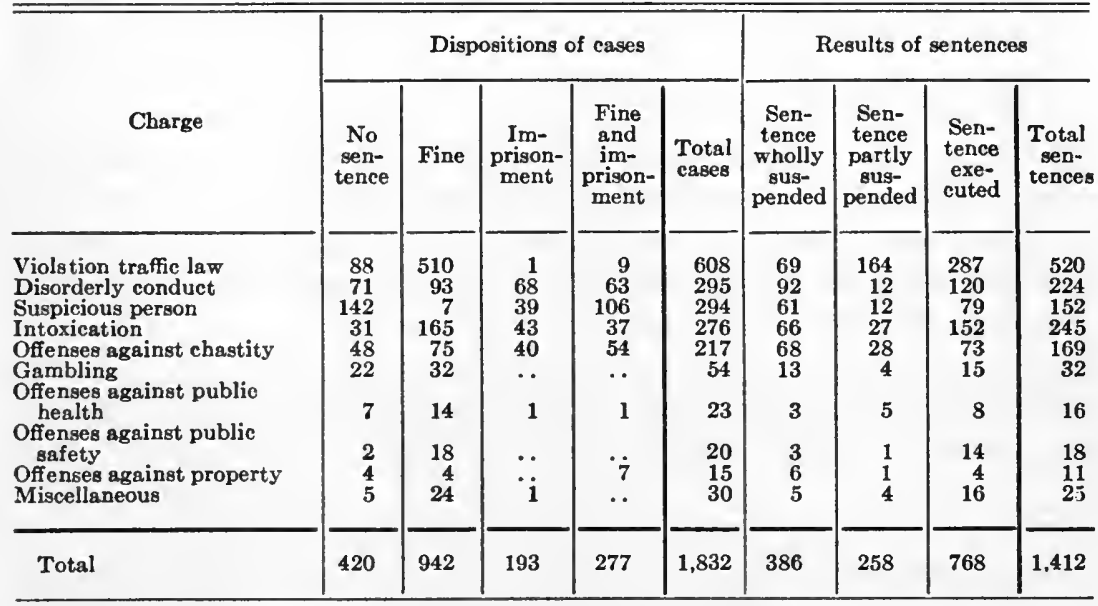

Sentences of imprisonment are suspended without probation for a definite period, and sentences of fines are suspended without a condition concerning the payment of a fine. Whatever the duties of the judges, it is unquestionably the duty of the prosecutor to watch the execution of the sentences so as to call to the attention of the court, or the appropriate official, instances in which the law is not being obeyed. As attorney for the public he can hardly conceive his work as completed without some attempt to ascertain whether the judgments he obtains correspond to the law and are carried out.

TABLE 12. SENTENCES CLASSIFIED BY TYPES AND BY DEGREE OF SUSPENSION, STATE CASES

\begin{tabular}{l|r|r|r|r}
\hline \multicolumn{1}{c|}{ Disposition } & Fines & $\begin{array}{r}\text { Impris- } \\
\text { onment }\end{array}$ & $\begin{array}{r}\text { Fines and } \\
\text { impris- } \\
\text { onment }\end{array}$ & Total \\
\hline $\begin{array}{l}\text { Wholly suspended } \\
\text { Partly suspended }\end{array}$ & $\begin{array}{r}184 \\
209\end{array}$ & $\begin{array}{r}80 \\
10\end{array}$ & $\begin{array}{r}122 \\
39\end{array}$ & $\begin{array}{r}386 \\
258 \\
768\end{array}$ \\
\hline Executed & 549 & 103 & 276 & 1,412 \\
\hline Total & 942 & 193 & 276 \\
\hline
\end{tabular}

The suspension of a sentence is often justified as a sword hanging over the defendant. The old sentence is made a hostage for future good conduct. There is obvious merit in this. The trouble is that the theory is 
not carried out. With rare exception the suspended sentence is promptly forgotten by everybody, and if the defendant comes back into the court upon a new or even the same charge, seldom if ever is the old sentence remembered.

TABLE 13.-SENTENCES CLASSIFIED BY TYPES AND BY DEGREE OF SUSPENSION, CITY CASES

\begin{tabular}{|c|c|c|c|c|}
\hline Disposition & Fines & $\begin{array}{l}\text { Impris- } \\
\text { onment }\end{array}$ & $\begin{array}{l}\text { Fine and } \\
\text { impris- } \\
\text { onment }\end{array}$ & Total \\
\hline $\begin{array}{l}\text { Wholly suspended } \\
\text { Partly suspended } \\
\text { Executed }\end{array}$ & $\begin{array}{l}213 \\
207 \\
599\end{array}$ & $\begin{array}{l}41 \\
17 \\
47\end{array}$ & $\begin{array}{r}118 \\
69 \\
97\end{array}$ & $\begin{array}{l}372 \\
293 \\
743\end{array}$ \\
\hline Total & 1,019 & 105 & 284 & 1,408 \\
\hline
\end{tabular}

\section{Mitigation of Sentences}

Mitigation of sentences is made upon motion regularly set for hearing. This gives the prosecutor full notice of the time when the motion will be considered; he is generally present in the court and has opportunity to advance arguments in favor of or against the mitigation. As with total suspensions, however, in practice he rarely takes any but a passive or negative part.

Section 13696 of the General Code of Ohio provides:

"Testimonx After Verdict or Confession, to Mitigate Penalty.When a person is convicted of an offense, punishable, either in whole or in part, by a fine, the court, by motion, may hear testimony in mitigation of the sentence. The court shall hear such testimony at the term at which the motion is made, or may continue the case to the next term or like terms as the case might have been continued before verdict or confession. The prosecuting attorney shall attend such proceedings on behalf of the State, and offer testimony necessary to give the court a true understanding of such case." (R. S. No. 7320.)

This careful treatment of motions in mitigation of sentence, including presentation of evidence by the prosecutor, is seldom observed. In practice the prosecutor conceives that his duty has been done when the trial of the case is finished and sentence has been pronounced. One of the judges of the Municipal Court described with considerable detail the procedure followed by him. The description made it apparent that cases before him receive more trial after sentence than before; that the facts are more carefully looked into after trial and verdict than before; that, in short, with very slight and casual information concerning the facts, 
judgment is rendered and sentence imposed, and then a more careful investigation of facts is made in passing upon a request for mitigation or suspension of the sentence. There is much to indicate that the practice is not limited to this judge. This shows a tendency to view the problem as one of treatment of the defendant as an individual rather than one of law enforcement. Such mingling of distinct purposes or theories regarding crime and the criminal intensify the difficulties of the prosecutor. His position is today solely that of a law enforcement officer, and his professional training is a training for law enforcement. The law which he enforces, however, applies to the execution of the sentence as well as to the commission of the crime, and this portion of his duties is almost completely neglected.

\section{The BaIl Bond}

Immediately upon his arrest the defendant is confined in the police station or city jail, unless he gives bond to secure his appearance at the hearing of the case, generally set for the following morning. In all cases except felonies the amount of this first bond is fixed by the clerk of the court. In felony cases the amount of the bond is fixed by one of the judges of the court, who, if not sitting at the time, is reached over the telephone. There is no regular rule or practice for consultation with the prosecutor. The judge may ask the prosecutor's advice, or the prosecutor may himself initiate a conference with the judge.

If, on the hearing, the defendant is convicted and sentenced and desires to carry the case to an appellate court, or if, in a felony case, he is bound over to the grand jury, he is required to give a second bond to secure the prompt filing of his case in the upper court or his appearance when arraigned, the amount of which is fixed by a judge of the court. Bonds to be given thereafter will be fixed by the Common Pleas or other higher court. The sufficiency of the surety is passed upon by the bond commissioners under a statute recently enacted.

The prosecutor, therefore, does not receive from the law the responsibility for determining either the amount of the bail bond nor the sufficiency of the surety. It can, without injustice, be said, however, that amid all the abuses regarding bail bonds, such as the illogical variability in amounts demanded, the inadequacy of the sureties, or the use of the professional bondsman, the prosecutor has been quiescent, though he is in position to know most of the evils. He should be best fitted by position and experience to be the public's crusader against these abuses.

There is, however, in relation to bail bonds in municipal cases, a definite statutory duty imposed upon the municipal prosecutor, namely, 
that of enforcing the bond after forfeiture. Bail bond collection cases are treated as civil, not criminal, and therefore placed in charge of the civil branch of the Director of Law's office. This work, however, constitutes an exceedingly important part of the administration of criminal justice, and an examination of the way in which it has been performed is properly included in a survey of the prosecution. The importance of the work cannot be overstated, since the bail bond fails to perform its part in the administration of criminal justice if there be a habitual and known failure to enforce the forfeited bond.

Table 14 gives the statistics of number and amount of forfeited bonds in municipal cases, with the judgments obtained and amount collected thereon covering the period January 1, 1916, to May 20, 1919. These are the latest data collected by the office of the auditor of the State of Ohio.

\section{TABLE 14.-NUMBER AND OUTCOME OF SUITS UPON FORFEITED} BONDS

\begin{tabular}{|c|c|c|}
\hline & $\begin{array}{l}\text { Number } \\
\text { of bonds }\end{array}$ & Amount \\
\hline $\begin{array}{l}\text { Bonds forfeited and delivered to Department of Law for col- } \\
\text { lection } \\
\text { Suits filed } \\
\text { Judgments rendered } \\
\text { Cases pending } \\
\text { Amount judgments obtained } \\
\text { Judgments for costs only } \\
\text { Judgments collected } \\
\text { Cost judgments collected } \\
\text { Judgments-no execution issued } \\
\text { Costs-no execution issued } \\
\text { Executions returned "no property" } \\
\text { Executions not returned } \\
\text { REcAPITuLATIoN: } \\
\text { Total bonds received by Department of Law } \\
\text { Suits brought } \\
\text { Judgments rendered } \\
\text { Judgments collected } \\
\text { Judgments costs only } \\
\text { Judgments costs only collected }\end{array}$ & $\begin{array}{r}143 \\
107 \\
68 \\
39 \\
54 \\
14 \\
14 \\
8 \\
22 \\
6 \\
22 \\
3 \\
\\
143 \\
107\end{array}$ & $\begin{array}{r}\$ 61,200.00 \\
46,900.00 \\
30,000.00 \\
16,900.00 \\
20,315.00 \\
32.55 \\
965.10 \\
16.35 \\
10,450.00 \\
16.45 \\
8,075.00 \\
855.00 \\
\\
61,200.00 \\
46,900.00 \\
20,315.00 \\
965.10 \\
32.55 \\
16.20\end{array}$ \\
\hline
\end{tabular}

The court had the power to reduce the amount of judgment below the amount of the bond, and, in fact, to render judgment for any sumeven for court costs only. The function of collecting the judgment is in the sheriff, not the prosecutor; consequently the prosecutor cannot be held entirely responsible for the results. Still, he cannot be absolved from all responsibility for a situation in which only 1.5 per cent. of the bonds have been collected, for a policy and practice of vigorous enforcement would certainly be more productive. 


\section{Hours of Work; Private Practice}

One excuse constantly advanced for the inadequacies of the prosecutor's performance is that, with the current volume of work, there is insufficient time to do things more efficiently. Much of the work must necessarily be done in the court-rooms, at the police department, and elsewhere outside of the office. Consequently an accurate time study taken at the office itself would be unfair and valueless.

The writer dropped into the office one afternoon about 4 . There was little activity. He was told that the rush period is at 8 in the morning, that being the time when the police and other prosecuting witnesses come in great numbers. So, within a few mornings thereafter, he arrived at 8 o'clock. None of the prosecutors had come in and there was no great stream of visitors. Not until nearly 9 did the stream accumulate or the prosecutors arrive. He casually dropped in on two or three afternoons around 3, having first ascertained that the members of the office were not at that time engaged in the court-rooms. He found several of the assistants absent. On other days there were sitting on the Municipal Court bench judges who continued the sessions into the afternoon, and on these afternoons the prosecutor's office remained active to a later hour. All this is not statistical data, and a thorough time study is impracticable. There can be no doubt of the immense quantity of work done by this office. The full working time of the members of it, however, is not given to the service, and the aggregate working hours of the office could unquestionably be increased without overtime or increase of force.

It is an unwritten rule of the office that members of the staff abstain from private practice during their connection with it. The Cleveland public has the feeling that this rule is not entirely complied with. However, at the beginning of this survey only one of the group, namely, A. L. Kreisberg, had his name on the door of a private law office and his name and office address in the city and telephone directories. While the survey was in progress his name was taken off the door, though the manager of the building states that he had severed his connection with the building fully a year earlier.

Private practice necessarily cuts into the time, energy, and attention which proper performance of the work demands. But that is not its most serious aspect. Lawyers engaged exclusively in private practice know the frequency with which the possibilities of conflicting interests of clients produce complex ethical problems. For an attorney who represents both public and private interests, these problems become more numerous and difficult. The private practice of a man in the prosecutor's office inevitably furnishes an opportunity and temptation to corruption 
in its most complex and subtle forms, from which only the strongest man, and one conscious of the finest ethical distinctions, can escape. But, more than that, even where there is no corruption, public suspicion may be aroused, and that is damaging to the administration of justice. The example of Caesar's wife may have been overworked; still, the standard applied to that lady, that not only her virtue should be unimpaired but her conduct such as to raise her above suspicion, is surely applicable to persons engaged in the administration of justice. ${ }^{1}$

${ }^{2}$ An illustration from real life in Cleveland illustrates the danger.

An automobile owned and driven by $R$. L. Smith had brushed one of a group of four men standing on the street. None of the four was injured. Smith was arrested on December 3,1920, charged with reckless driving, tried, and found guilty and sentenced to pay a fine of $\$ 100$ and to serve thirty days in the workhouse. A motion for a new trial was made, and Smith let out on bail pending the hearing of the motion, which was set for December 7. Up to that point Smith was represented by Attorney Arnold. Between December 3 and 7 Smith was visited by an attorney named H. L. Lavine, representing the four men on the street. Lavine asserted that he was a partner of Assistant Prosecutor Kreisberg, and that he "stood in" with the prosecutor's office and could get the sentence of thirty days' imprisonment removed and would himself pay Smith's fine, if Smith would pay $\$ 800$ in settlement of the civil damage claims of Lavine's clients. Lavine's office was in one of the rooms of the suite of offices on the door of which was Kreisberg's name, and Lavine's office telephone number was the same as that given in the directory for Kreisberg's office. One of the four claimants worked at the cigar-stand in the building in which this suite was located.

Smith proceeded to take steps to borrow the $\$ 800$ and expected a check on or about December 7, and arrangements were made to postpone the hearing for the motion for new trial to December 23. When the time for hearing arrived, Attorney Arnold was in the court-room. Lavine asked him to take no part in the hearing, and submitted a form of receipt for Smith's signature, to which Mr. Arnold objected on the ground that it might constitute evidence of the compounding of felony. In the meantime Attorney George Dissette had been retained to supervise the settlement of the civil claims, and the $\$ 800$ check had been deposited with him, and he in turn had deposited it in a bank, so as to have it in convenient shape for division among those to whom the money might ultimately be payable. Consequently Smith did not have the money in his hands when the motion was called on December 23. Judge XX, who heard the case, acting, as he states, under the impression that Smith had arranged to settle the matter with the claimants, entered upon his docket, "motion for mitigation granted, original sentence changed, days suspended, fine and costs to be paid." The judge then asked Smith whether he had arranged "restitution," to which Lavine answered that Smith had a check and was prepared to make restitution. The judge then handed the papers in the case to Smith, so that he might take them to the clerk's office and there pay the costs and fine. In the hallway between the court-room and the clerk's office Lavine engaged Smith in conversation and induced Smith to give him the papers, and then notified Smith that, unless he paid the $\$ 800$ within twenty minutes, he, Smith, would have to go to jail, 
and Lavine refused to go to Dissette's office for the money. In the absence of the papers the clerk refused to accept from Smith payment of the fine and costs.

In this critical situation Dissette was telephoned for and came over to the Municipal Court building. Lavine repeated his threat that unless the $\$ 800$ be immediately given him Smith would have to go to jail. Dissette requested Lavine to give the papers to the clerk, which was not done. The next day Smith retendered the fine and costs, which the clerk again refused to accept. Smith had planned a trip East, and Dissette advised him that, as he had twice tendered fine and costs, he could safely go.

He returned early in January and was promptly rearrested. He brought habeas corpus proceedings in the Common Pleas Court. Now, we have seen that, on the day of the hearing, Judge XX entered on his docket or calendar the order "motion for mitigation granted, original sentence changed, days suspended, fine and costs to be paid." At some later time this entry was erased and in its place inserted, "Motion for mitigation overruled, original sentence ordered executed." Strangely enough, the official record of the court, namely, the journal and execution docket for December 23, contained the entry: "Defendant not in court, bond forfeited, capias issued." That was a false entry; for Smith was in court on that day and the bond had not been forfeited. The Common Pleas Court held, however, that it was bound by the record, and could not entertain proof of the falsity thereof, and therefore refused to grant a writ of habeas corpus, and Smith was returned to the jurisdiction of the Municipal Court, where a further hearing occurred on January 13.

Kreisberg did not represent the municipal prosecutor's office at the original trial on December 3, nor at the strange happenings of December 23, but he did appear for the public in the habeas corpus case and at this later inning on January 13. Judge $\mathrm{XX}$ ordered the restoration of the original sentence, and, for some reason which is not quite clear from the records, added a fine of $\$ 200$ for contempt of court and Smith was sent to the workhouse on the original sentence. A few days later Judge $\mathrm{XX}$ suspended the fine in the contempt hearing and the original sentence of thirty days, leaving the original fine of $\$ 100$ and costs, which were paid. Before this Dissette had presented the matter to the Cleveland Bar Association. 


\section{CHAPTER VI \\ THE COUNTY PROSECUTOR'S OFFICE}

History

ПHE office of Prosecuting Attorney of Cuyahoga County was created contemporaneously with the creation of the county and is more than a century old. The statutes defining the general powers and duties of the office have undergone little change. In this century and more, however, the criminal law has grown enormously, and Cuyahoga County has developed from a community of isolated farmers to the most populous county in Ohio.

To the extent of available statistics, Table 15 states for the years $1863,1880,1890,1900,1910,1920$, and 1921 the population of Cuyahoga County, the number of indictments, the number of arrests in Cleveland, the number of prosecutors, assistants, and clerical force in the county prosecutor's office, and the total payroll of the office.

TABLE 15.-COMPARISON OF GROWTH OF THE POPULATION AND NUMBER OF ARRESTS, WITH THE NUMBER AND SALARIES OF THE COUNTY PROSECUTOR'S STAFF, 1863-1921

\begin{tabular}{|c|c|c|c|c|c|c|c|}
\hline Year & $\begin{array}{l}\text { Popula- } \\
\text { tion of } \\
\text { Cuya- } \\
\text { hoga } \\
\text { County }\end{array}$ & $\begin{array}{l}\text { Number } \\
\text { of in- } \\
\text { dict- } \\
\text { ments }\end{array}$ & $\begin{array}{l}\text { Number } \\
\text { of arrests } \\
\text { for city } \\
\text { of Cleve- } \\
\text { land }\end{array}$ & $\begin{array}{l}\text { Number } \\
\text { of county } \\
\text { prosecu- } \\
\text { tors on } \\
\text { criminal } \\
\text { side }\end{array}$ & $\begin{array}{l}\text { Size of } \\
\text { clerical } \\
\text { force, } \\
\text { criminal } \\
\text { side }\end{array}$ & $\begin{array}{l}\text { Payroll }{ }^{1} \\
\text { of office }\end{array}$ & $\begin{array}{c}\text { Salary of } \\
\text { chief } \\
\text { prose- } \\
\text { cutor }\end{array}$ \\
\hline $\begin{array}{l}1863 \\
1880 \\
1890 \\
1900\end{array}$ & $\begin{array}{l}196,943 \\
309,970 \\
439,120\end{array}$ & $\begin{array}{r}60 \\
187 \\
\ddot{512}\end{array}$ & $\begin{array}{r}1,687 \\
7,432 \\
9,616 \\
19,923\end{array}$ & $\begin{array}{l}1 \\
2 \\
2 \\
3\end{array}$ & $\begin{array}{l}\ddot{ } \\
\ddot{1}\end{array}$ & $\begin{array}{r}\$ 1,577.50 \\
2,689.60^{2} \\
12,260.00^{3}\end{array}$ & $\begin{array}{r}\$ 2,000.00 \\
1,999.92^{2} \\
3,500.00^{3}\end{array}$ \\
\hline 1910 & 637,425 & 595 & $7,185^{4}$ & 5 & 1 & $\begin{array}{l}19,500.00 \\
18,603.93\end{array}$ & $5,499.97$ \\
\hline 1920 & 943,495 & 2,762 & $27,615^{\delta}$ & 6 & 2 & $\begin{array}{l}37,500.00 \\
35,572,76\end{array}$ & $5,500.00$ \\
\hline 1921 & .. & 2,549 & $\ldots$ & 8 & 2 & $48,400.00$ & $5,500.00$ \\
\hline
\end{tabular}

1 This is whole payroll of office, including both civil and criminal branches.

2 Figures for 1887, as 1890 were not available.

2 Figures for 1902 , as 1900 were not available. $\$ 900$ for stenographer, and $\$ 6,300$ for county solicitor and his assistant and stenographer in addition to the above.

- Decline due to temporary "golden rule" policy.

- 79,897 warned and released. 


\section{Criminal Court in Operation}

At least two of the rooms of the Court of Common Pleas are constantly engaged in the trial of criminal cases, and in periods when, by reason of popular excitement or other pressure, the prosecutor is pushing matters, this number increases to four or even five. The two regular trial rooms are in an old building, very ugly and sordid in appearance. The rooms are large and with high ceilings, thus having good light. Though old, they could be easily rendered more clean, handsome, and dignified in appearance. In the back of one of these rooms a space is fenced off by a very high railing and this is open to spectators. There are no seats and the floor is level, so that those who do not get the favorable positions along the rail have to stand on their toes and are constantly pushing forward toward the rail. Naturally many of these onlookers grow weary and leave and their places are taken by newcomers. This commotion in the back of the room causes noise and prevents that hush and solemnity which we find in federal court-rooms. The other room has no railing separating the spectators from the space devoted to the trial, and incoming and outgoing spectators must walk across the main parts of the room. Furthermore, the judges seem to permit the pending trial to be interrupted with considerable frequency by receipts of verdicts in previous cases, disposition of plea of guilty cases, arraignment of new defendants, and other matters.

Otherwise the trials are conducted with an orderliness which is in contrast to the Municipal Court and compares not unfavorably with civil trials in the same Common Pleas Court. The jury-stand, witnesschair, and attorneys' table are arranged in an orderly fashion and those who have no immediate business in or about them are required to go to other parts of the room. By means of a little straining of eyes and ears even those back of the rail can hear and see what is going on. The extra court-rooms which are used irregularly for criminal trials are in the new court house and have the handsomeness and dignity characteristic of modern, monumental American temples of justice.

Among possible classifications, the cases in the criminal division of the Common Pleas Court may be divided into those in which public excitement pushes the prosecutor to unusual effort, and those where no extra lime-light has been turned on. It is these ordinary cases which best illustrate the administration of criminal justice.

The success of criminal law enforcement is, moreover, best judged by results in the general run of habitual offenses, and not by its sporadic triumphs in the occasional sensational murder cases. The young man who, by reason of mental and moral make-up or environment, has in 
him the potentialities of a professional or dangerous criminal, does not begin his career with a murder or large-scale robbery. His first offense is more likely to be a petty larceny or porch-climbing or small hold-up. If the administration of justice can be effective in stopping the development of his criminal career, this is the time and point for it to operate. If he "gets away" with his first case, the temptation to make a second "flier" at the speculative profits of crime may be increased. And the unjust verdict of guilty, which may cause disrespect for law and resentment against society, is more likely to occur in the everyday grist than in the relatively less numerous big cases.

Furthermore, most of us have a very large chance of going through life without being the victims or intended victims of the murder of passion or revenge. But we and our families and our homes are in daily danger of attracting the cupidity of the second-story man or hold-up artist. The general peace and security is more dependent on society's treatment of the regular flow of ordinary crimes than on the results of the few great murder cases which attract public attention and create public excitement. The ups and downs of public confidence in the law, as the sensational murder cases result in verdicts of guilty or not guilty, with the attempt to reform the administration of the law by means of alternate spasms of praise and blame of prosecutors and judges and alternately electing or recalling these officials according to the results in these sensational murder cases - this, as much as any other phenomenon, has stood in the way of that thorough and continuous improvement which would prevent the accumulation of the very situation which accounts for the miscarriage of justice in the head-line case.

Consequently, it is in the prosecutor's conduct of the regular run of cases that the efficiency of the prevailing system should be studied and judged.

The trial of two cases a day by the same prosecutor before the same court is habitual, the trial of three cases a day very frequent, of four cases not exceptional. In addition to the trials, there are generally each day several arraignments of accused "for receipt of the plea," and also the pleas of guilty with sentence thereon. The course of most trials is interrupted by these miscellaneous matters and by the receipt of the jury verdict in a previously tried case.

Just before entering upon the trial of the first case of the day the trial prosecutor receives from the assignment commissioner a package of papers consisting of the indictment and other pleadings, the names of witnesses, and notes of the testimony of the witnesses before the grand jury in cases which might be reached that day. It is quite apparent that 
he proceeds to try the case with little or no knowledge of its details almost up to the moment of trial, and that his only information consists of the names of witnesses and scribbled or scattered notes of their testimony before the grand jury. At these he has to glance continually to keep the case going. For questions to ask the witnesses he must rely largely on the promptings of the police officer, who sits at his side, or on inspiration from the answers to other questions given by the witness on the stand. One is reminded of the Italian commedia dell'arte, in which the players, not having learned their parts beforehand, take each line from the prompter and improvise the performance as they go along. Both these Italian actors and these trial prosecutors develop a speed and a skill of improvisation which are truly remarkable. But the latter have this disadvantage - that they are engaged in a combat for which the adversary is carefully prepared. The prosecutor does not, like the English barrister, have at his elbow a junior counsel who has carefully studied all the law and the facts, and a solicitor who has interviewed the witnesses and who supplies the trial lawyer with thoroughly prepared material.

The trial prosecutor does not receive, either at or before the trial, a comprehensive brief of the facts, setting forth the testimony which may be expected from the witnesses. Where the case involves no special diffculties of investigation or preparation, and especially where the case has been thoroughly developed by the police department, things may go well enough. It is obvious, however, that the State takes more chances than the defense and assumes the handicaps of unpreparedness.

The trial prosecutor does not seem to exercise particular care in selection of the jury. There is no preliminary effort to learn who the jurors might be and their social and political affiliations. The prosecutor contents himself with two or three general questions, such as: Do you know the defendant? Do you know the defendant's attorney? Do you know anything about the case? Do you know of any reason why you should not make an impartial juror, etc.? He does not always wait for the answers. In the course of the term he learns from experience in previous cases the names of the jurors who seem habitually and obstinately to hold out for the defendant. These he gets rid of. As every lawyer knows, the opening statements to the jury (made before the introduction of any evidence) furnish an opportunity for skilful advocacy, and many a case is won or lost in the opening statement; but here again one of the trump cards is dealt to the defendant's attorney. The prosecutor, knowing so little about the case at this early stage, is able to tell the jury only a very scanty, vague, and uninteresting story.

According to the statement of a prominent member of the force of 
former Prosecuting Attorney Samuel Doerfler, the system of keeping the trial prosecutor ignorant about the case until within a few minutes before trial was established by Mr. Doerfler because of his distrust of his own assistants. It was designed, it was said, to allow the assistants as little opportunity as possible to block or drop the prosecution. This certainly indicates that the former prosecuting attorney had little control over his assistants, and is a startling illustration of the distrust theory of government.

The present county prosecutor, Mr. Stanton, would probably deny lack of control over his assistants. The statutes gave him the power of selecting his assistants; but there can be little doubt that, following custom, he permitted a political organization or leader to have powerful infiuence in the selection.

A recent incident certainly tends to indicate that he does not have or does not exercise the appropriate amount of control over his organization. One Joseph Mazzeo was indicted for receiving a stolen automobile. There was a preliminary examination in the Municipal Court, Mazzeo had been indicted, failed to appear for arraignment, his bond was forfeited, and capias was issued. He was recaptured and pleaded not guilty. The trial was in progress on May 4,1921, the prosecutor's office being represented by Assistant Prosecutor Frank E. Boldiszar. In the midst of the trial Assistant Prosecutor Blase A. Buonpane walked into the court-room and requested a nolle. Boldiszar said nothing, and the request coming from a member of the prosecutor's office, was granted by the court and a nolle entered in the case. Previous to his incumbency in the prosecutor's office Buonpane had represented Mazzeo in this same matter of the stolen automobile at earlier stages of the case. For this reason James T. Cassidy, the first assistant prosecutor, had expressly instructed that there should be no nolle of this case. Buonpane continues in his position as assistant prosecutor. ${ }^{1}$

\section{OfFice Organization}

The office force of the county prosecuting attorney consists, in addition to himself, of the seven assistant prosecuting attorneys, two stenographers, and a county detective. This county detective, so called, though an experienced police officer, is used as a sort of general utility man and grown-up messenger boy. Until June, 1921, there was no managing clerk.

1 The trial judge states that the merits of the case justified a nolle. We intend to express no opinion on the merits of the nolle. 
There is a degree of specialization of the work of the assistants, one having charge of the presentation of cases to the grand jury, two or more are assigned regularly to the trial of cases, and others are reserved for special assignment in the more important cases. The prosecutor himself takes part in the more important cases and exercises some executive direction and control. Visitors can select the particular assistant with whom they will choose to talk, the stenographers attempting to do some sifting out so as to reduce the waste of time of the office.

The physical conditions of the offices, while not impressive nor adequate, compare most favorably with the conditions in the municipal prosecutor's office. The prosecuting attorney himself has a good-sized room in the suite devoted to the civil branch of the work. There is a fair-sized waiting-room. The suite used by the criminal assistants consists of a fair-sized waiting-room, part of which is railed off for the stenographers. There are five private offices, running from 150 to 225 square feet, the smallest occupied by the county detective and the other four by the assistants, two of whom occupy one of the rooms and three, another.

\section{Record SYsteM}

The record system in use in both the county courts and county prosecutor's office is in favorable contrast with that of the municipal offices. The county clerk maintains a well-indexed criminal docket, using the same system and the same thoroughness as in civil cases.

An office docket of all cases is kept, containing the name of defendant, the charge, the plea, and the final disposition. It contains the name of the assistant prosecutor who has charge of the case, but does not contain the name of the defendant's attorney. Nor do the dockets or records of the court clerk contain the name of the defendant's attorney. Each docket-book has an index attached. There is also the file of the cases, containing the original papers, on which are noted the steps taken in the case, with the notes from the grand jury rooms and any special information which may be of use in the trial of the case. Mr. Stanton has recently instituted a card system or docket in which pending but not completed cases are alphabetically arranged.

With some slight improvements the record system, in both the clerk's and prosecutor's offices, would enable both the prosecutor and public to ascertain the status of a case, past and present, and enable members of the prosecutor's staff to find without delay whatever information is in the office. 


\begin{tabular}{|c|c|c|c|c|}
\hline Name & Term & $\begin{array}{l}\text { Age at } \\
\text { com- } \\
\text { mence- } \\
\text { ment of } \\
\text { service }\end{array}$ & $\begin{array}{l}\text { Date } \\
\text { admitted } \\
\text { to bar }\end{array}$ & $\begin{array}{l}\text { Years ad- } \\
\text { mitted to } \\
\text { bar on com- } \\
\text { mencement } \\
\text { of service }\end{array}$ \\
\hline $\begin{array}{c}\text { Democratic } \\
\text { Samuel Doerfler, Prosecutor }\end{array}$ & $1916-1920$ & 41 & 1897 & 19 \\
\hline \multicolumn{5}{|l|}{ Assistants } \\
\hline Fred W. Green & $1916-1920$ & 45 & 1896 & 20 \\
\hline George Howells & $1913-1915$ & 35 & 1900 & $121 / 2$ \\
\hline John J. Babka & $1912-1919$ & 28 & 1908 & 4 \\
\hline Stephen M. Young & $1917-1920$ & 29 & 1910 & 6 \\
\hline William J. Corrigan & $1917-1920$ & 31 & 1915 & $11 / 2$ \\
\hline Felix T. Matia & $1916-1920$ & & 1914 & \\
\hline D. R. Rothlsopf & $1917-1920$ & 27 & 1914 & 3 \\
\hline Tim J. Long & $1918-1920$ & 33 & 1915 & $21 / 2$ \\
\hline Florence Allen & 1919-1920 & 35 & 1914 & 5 \\
\hline $\begin{array}{l}\text { A. W. Chaloupka } \\
\text { R. A. Baskin }\end{array}$ & $\begin{array}{l}1919-1920 \\
1918-1020\end{array}$ & $\begin{array}{l}33 \\
35\end{array}$ & 1917 & $\begin{array}{l}2 \\
71 / 2\end{array}$ \\
\hline Albert Lawrence & $1919-1920$ & 61 & 1880 & $39^{72}$ \\
\hline Frank Merrick & 1920 & 26 & 1916 & 4 \\
\hline Joseph Dembe & 1920 & 36 & 1914 & 6 \\
\hline Myles Frazier & 1920 & 31 & 1914 & 6 \\
\hline Thomas Dunlap & $1916-1918$ & 48 & 1890 & 25 \\
\hline \multicolumn{5}{|l|}{ REPUBLICAN } \\
\hline Edward C. Stanton, Prosecutor & 1921- & 32 & 1913 & $71 / 2$ \\
\hline \multicolumn{5}{|l|}{ Assistants } \\
\hline Geo. C. Hansen, civil & 1921- & 40 & 1899 & $201 / 2$ \\
\hline E. J. Thobaden, civil & 1921- & 56 & 1887 & 33 \\
\hline Henry Williams, civil & 1921- & 22 & 1920 & $1 / 2$ \\
\hline James T. Cassidy & 1921- & 34 & 1913 & $71 / 2$ \\
\hline John J. Sexton & 1921- & 42 & 1915 & $61 / 2$ \\
\hline Harry E. Parsons & 1921- & 46 & 1900 & 21 \\
\hline Frank E. Boldiszar & 1921- & 25 & 1917 & $31 / 2$ \\
\hline Eva L. Jaffa & 1921- & 28 & 1915 & $61 / 2$ \\
\hline Blase A. Buonpane & 1921- & $\begin{array}{l}29 \\
26\end{array}$ & $\begin{array}{l}1916 \\
1919\end{array}$ & 5 \\
\hline 1. Krews & & & & \\
\hline
\end{tabular}

\section{Personnel}

The present prosecutor is Republican and has been in office since January, 1921. His predecessor, Samuel Doerfler, was a Democrat. ${ }^{1}$ Above is a list of the personnel of this office during these two administrations, with the period of service, age at commencement of service, and number of years at the bar previous to service.

1 During a few months in 1920 R. A. Baskin was prosecuting attorney, succeeding Mr. Doerfler. who resigned before the end of his term. 


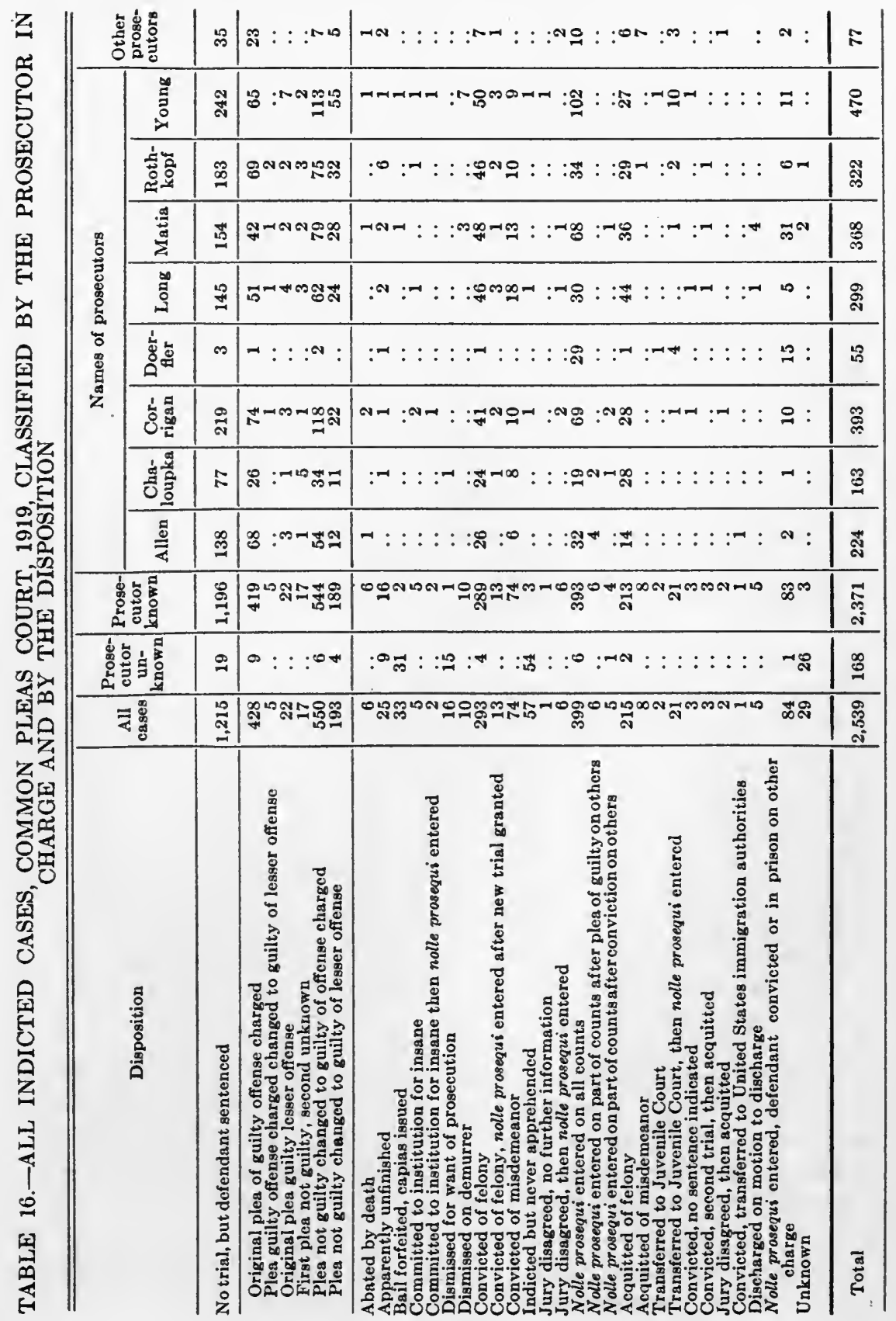


On the delicate subject of the ability of the members of the office, the same two prominent Democratic and Republican lawyers who had given their judgment upon the ability of the municipal prosecutors were consulted, and again their opinions were surprisingly similar. According to their judgment of the eight members of the force, one has exceptional trial ability, another is an able lawyer, a third has only fair ability as a lawyer, a fourth is a poor lawyer, while the remaining four have not had sufficient experience or standing at the bar to enable their professional brothers to know or judge of their ability.

Of the lawyers who answered the questionnaire, 92 expressed the opinion that the prosecutors were lacking in the necessary ability and competence, while only one or two expressed a contrary opinion.

The present prosecuting attorney, Mr. Stanton, served five years in the municipal prosecutor's office, during one of which he was chief. Judging by the methods and organization of that office at the end of his term, he did not there disclose the desire or the talent for that strong executive control or leadership whereby policies and standards are initiated and carried out and the administration of an office is freed from accumulated bad habits and molded into an effective, enlightened, and modernized institution. He became county prosecutor in January, 1921, since which date certain improvements have occurred, such as creation of the position of managing clerk and the beginnings of a card docket system. The period of his incumbency in that office, however, has been perhaps too short from which to judge whether or not he will develop the desire or the talent for such executive control or leadership.

As shedding some light on the work of individual prosecutors, a detailed study was made of the disposition of the 1919 cases, with classification according to disposition of the case, and with a further classification according to the particular prosecutor who had charge of the case. The results of this study are shown in Table 16. The column designated "All cases" gives the number of cases which received the dispositions noted in the first column. The column designated "Prosecutor unknown" contains the number of the cases in which the records fail to disclose the names of the prosecutor in charge. The next column gives the total of cases in which the records disclose the assistants who were in charge, and in the subsequent columns the cases are distributed among these assistants according to the records.

This illustrates a possible method of measuring or, at least, of obtaining some facts for measuring the work of the assistants. The small figures in the columns of some of the assistants indicate that they were 
engaged in work other than trials, such as preparation of evidence or presentation of cases to the grand jury.

The salary list of the county prosecutor's office follows:

Prosecuting attorney $\ldots \ldots \ldots \ldots \ldots \ldots \ldots \ldots \ldots \ldots \ldots, 500$

First assistant. . . . . . . . . . . . . . . . . . . . .

Second assistant . . . . . . . . .

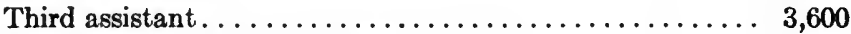

Remaining four assistants, each .............. 3,000 


\section{CHAPTER VII}

\section{OPERATION OF THE COUNTY PROSECUTOR'S OFFICE}

\section{Preparation of Cases}

$I^{\prime}$ $\mathrm{N}$ general, the prosecuting attorney and his assistants take no part in the investigation of the crime or the molding of the proof. $\mathrm{He}$ has no machinery, other than his busy assistants and the single county detective or general utility man, for detection of the offender or discovery of proof. He has no facilities for modern methods of criminal investigation. He pits his unpreparedness, with such assistance as he may obtain from the police department, against the carefully prepared case of the defendant's attorney. He takes the proof in the way it has been prepared by the police or municipal prosecutor, making the best of what he gets, or, in more serious cases, attempting to remedy the defects or omissions. ${ }^{1}$ An unusually sensational case sometimes affords an exception to this practice, but the exceptions are few.

1 The well-known Kagy murder case affords an interesting example of the dangers of this system. Harold Kagy was shot early on the morning of May 9, 1920, while he and two others were standing at a street corner. One of these two companions was named Joyce. There remains some mystery as to who the other may have been. The then Chief Justice of the Municipal Court, William H. McGannon, was accused of being the third person. He denied this, but has been convicted for perjury in making this denial upon his trial for the murder. Kagy was taken to the hospital on May 9 and was there until his death, thirteen days later. Obviously, the main issue was as to the identity of the person who fired the fatal shot and, obviously, the best proof of this identity would have been Kagy's death-bed statement. The rule of evidence regarding the admissibility of a death-bed statement is familiar to most lawyers. The main factor determining this admissibility is the knowledge of the dying man that he is dying. There is a fairly conventional and traditional method of ascertaining this factor. The police department entirely failed to obtain Kagy's death-bed statement, and permitted the statement to be obtained by two brothers of Kagy, who failed to obtain the necessary proof of Kagy's knowledge of his critical condition, with the result that the death-bed statement was excluded from the evidence. This failure might have been avoided if the prosecuting attorney's office had been called into the situation in time to take charge of the obtaining of the death-bed statement. Members of the police department visited the hospital from day to day, and were actually just outside the room at the time Kagy's two brothers took the statement. Though the case was the sensation of the day, there is no indication that during these thirteen days the prosecuting attorney took any step whatever to get in touch with or instruct the police department. Both Joyce and McGannon were acquitted. 
The period elapsing between the arrest and the presentation to the grand jury varies from a few days to 500 days, during which there is time for the disappearance of witnesses, the destruction or elimination of dangerous documents, and the coaching of possible witnesses, in addition to the effects upon the memories of witnesses made by the public discussion of the case in the press and elsewhere. No member of the county prosecutor's office is present in the office of the municipal prosecutor while the affidavit is prepared, nor in the Municipal Court during the preliminary examination. Owing to the constancy of the stream of work, practically no attention is given to the case, its proof or lack of proof, until the moment of presenting it to the grand jury.

The assistant who has charge of the presentation of the cases to the grand jury has generally, up to the very moment of presenting a case, no familiarity whatever with the case, its facts or proof. He simply calls in the witnesses whose names are noted on the papers which have come up from the municipal prosecutor. Sometimes, if this rather casual testimony before the grand jury proves inadequate or there are indications of the possibility of improving the proof of the case, an attempt is made to find additional testimony before the grand jury passes on the case.

TABLE 17.-AVERAGE NUMBER OF DAYS USED IN DISPOSING OF CASES ORIGINATING IN THE SEVERAL COURTS, COMMON PLEAS COURT, 1919

\begin{tabular}{|c|c|c|c|c|}
\hline \multirow[b]{2}{*}{ Court of origin } & \multirow[b]{2}{*}{$\begin{array}{c}\text { Number of } \\
\text { cases }\end{array}$} & \multicolumn{3}{|c|}{ Average number of days } \\
\hline & & $\begin{array}{c}\text { From arrest } \\
\text { to indictment }\end{array}$ & $\begin{array}{l}\text { From indict- } \\
\text { ment to dis- } \\
\text { position }\end{array}$ & $\begin{array}{l}\text { From arrest } \\
\text { to disposition }\end{array}$ \\
\hline $\begin{array}{l}\text { Municipal } \\
\text { Magistrates } \\
\text { Grand jury } \\
\text { Unknown }\end{array}$ & $\begin{array}{r}2,033 \\
89 \\
198 \\
5\end{array}$ & $\begin{array}{l}20.8 \\
26.2 \\
14.4 \\
25.4\end{array}$ & $\begin{array}{l}46.6 \\
40.2 \\
99.6 \\
36.4\end{array}$ & $\begin{array}{l}67.4 \\
76.4 \\
85.2 \\
61.8\end{array}$ \\
\hline Total & 2,325 & 18.0 & 51.3 & 69.3 \\
\hline
\end{tabular}

With exceptions, so rare as to be negligible, the testimony before the grand jury is not taken down stenographically or otherwise and no

'In cases originating in the grand jury arrest follows indictment, hence the first of the three averages is the reverse of the others in its column, being the time from indictment to arrest, rather than, as otherwise, from arrest to indictment. This is shown also by the fact that the third average is less than the second, contrary to all the other groups of cases. 


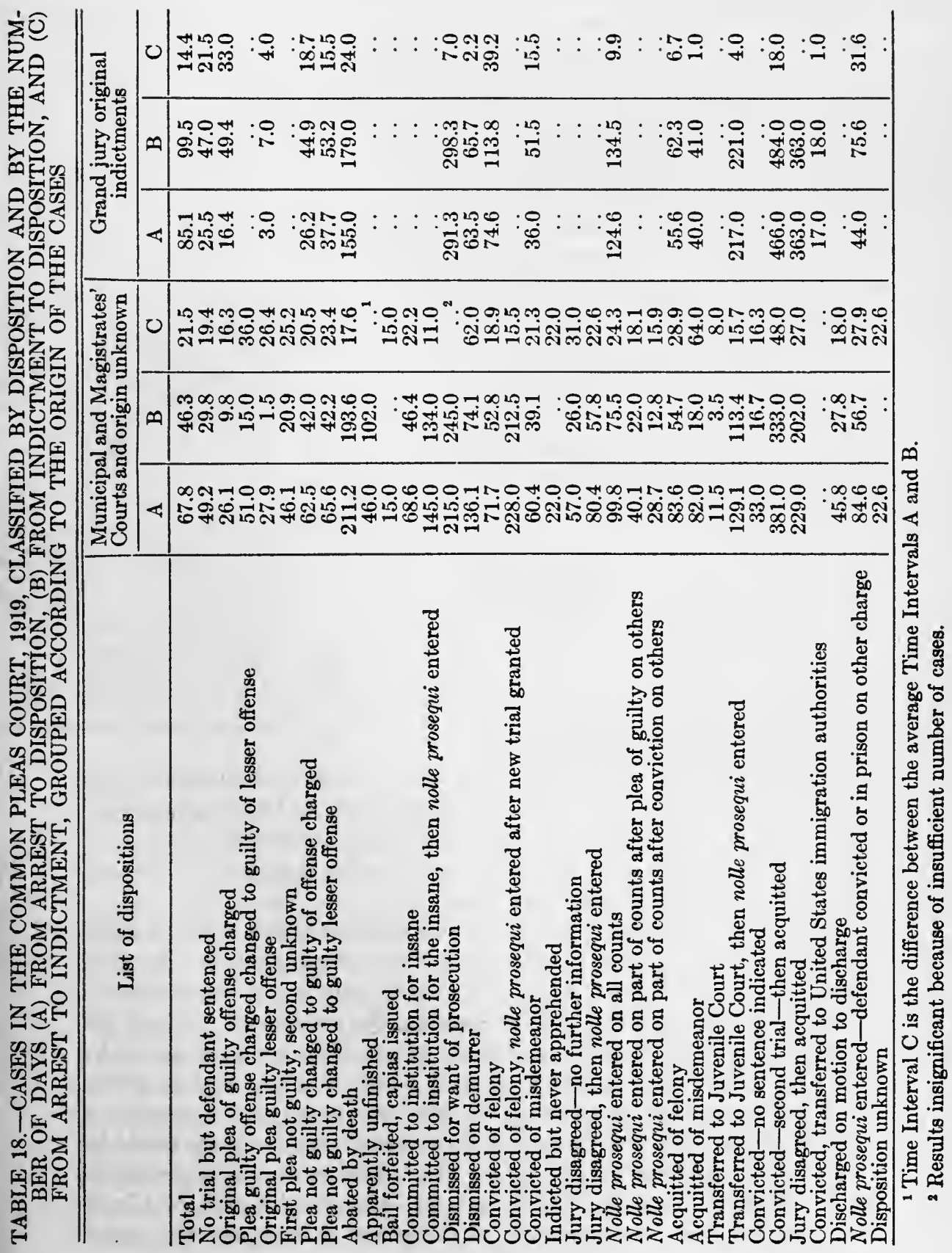


1. Total cases requiring action at end of April term

2. Indictments pending at end of April term

3. Cases bound over not acted on at end of April term

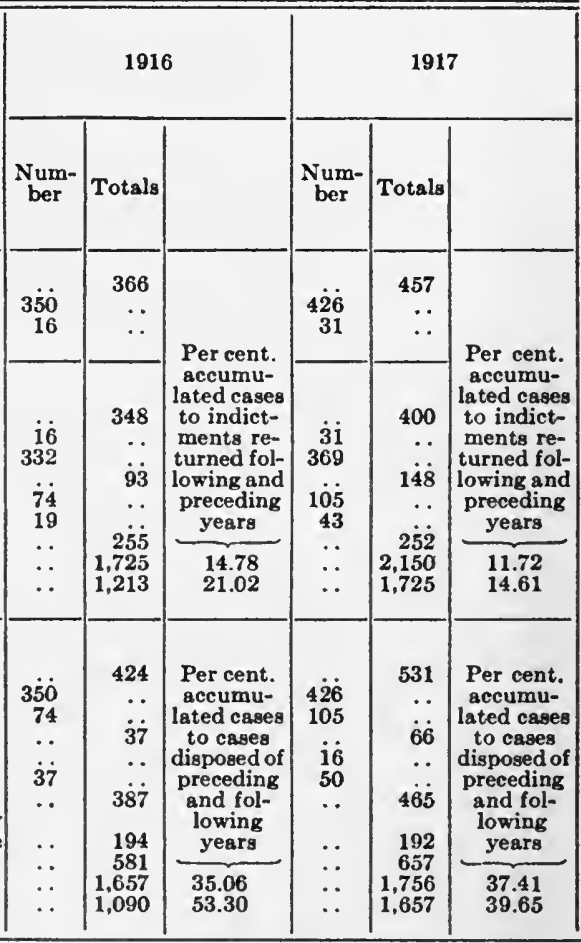

transcript of the testimony is made. The prosecutor in the grand jury room sometimes finds time to scribble on the papers a few rough notes of the testimony. We have seen that these rough notes offer all the trial prosecutor learns about most cases before jumping into the trial of them. It is a system of serial unpreparedness.

This lapse of time between the various stages of the cases was investigated statistically, with the results as shown in tables herewith. Table 17 shows, in all of the 1919 cases, the average number of days between arrest and disposition of the case, between the indictment and the disposition and between arrest and indictment. The averages are of all cases, including those in which there is a plea of guilty and in which, therefore, no further preparation for trial was required. Naturally, if contested cases only were included, the average time intervals would be greater than disclosed in this table. The classification is according to place where the case originated, namely, Municipal Court of Cleveland, magistrates' courts outside of Cleveland proper, and the grand 


\begin{tabular}{|c|c|c|c|c|c|c|c|c|c|c|c|c|}
\hline \multicolumn{3}{|c|}{1918} & \multicolumn{3}{|c|}{1919} & \multicolumn{3}{|c|}{1920} & \multicolumn{4}{|c|}{$\begin{array}{c}\text { Totals, a verage, and per cent. } \\
\text { aecumulation for five years, } \\
1916-1920\end{array}$} \\
\hline$\underset{\text { ber }}{\text { Num- }}$ & Totals & & $\underset{\text { ber }}{\text { Num- }}$ & Totals & & $\underset{\text { ber }}{\text { Num- }}$ & Totals & & $\begin{array}{c}\text { Total } \\
\text { of } \\
\text { num- } \\
\text { bers }\end{array}$ & $\begin{array}{c}\text { Total } \\
\text { of } \\
\text { totals }\end{array}$ & $\begin{array}{c}\text { Aver- } \\
\text { ages }\end{array}$ & \\
\hline $\begin{array}{r}822 \\
10\end{array}$ & $\begin{array}{r}832 \\
\cdots \\
\therefore\end{array}$ & & $\begin{array}{r}81 \dot{14} \\
22\end{array}$ & $\begin{array}{c}836 \\
\cdots \\
\cdots\end{array}$ & & $\begin{array}{r}521 \\
16\end{array}$ & $\begin{array}{r}537 \\
\because \\
\cdots\end{array}$ & & $\begin{array}{r}2,933 \\
95\end{array}$ & $\begin{array}{c}3,028 \\
\cdots \\
\cdots\end{array}$ & $\begin{array}{r}606 \\
587 \\
19\end{array}$ & \\
\hline $\begin{array}{r}10 \\
415 \\
\ddot{79} \\
7 \\
\therefore \\
\therefore\end{array}$ & $\begin{array}{r}425 \\
\ldots \\
\ddot{86} \\
\ldots \\
3 \ddot{39} \\
1,940 \\
2,150\end{array}$ & $\begin{array}{l}\text { accumu- } \\
\text { lated cases } \\
\text { to indict- } \\
\text { ments re- } \\
\text { turned pre- } \\
\text { ceding and } \\
\text { following } \\
\text { years } \\
17.47 \\
15.77\end{array}$ & $\begin{array}{r}282 \\
\mathbf{2 8 2} \\
\ldots \\
\because \\
\because \\
\because \\
\therefore\end{array}$ & $\begin{array}{r}304 \\
\ldots \\
\therefore \\
\cdots \\
3 \\
304 \\
1,735 \\
1,940\end{array}$ & $\begin{array}{c}\begin{array}{c}\text { accumu- } \\
\text { lated cases } \\
\text { to indict- } \\
\text { ments re- } \\
\text { turned pre- } \\
\text { ceding and } \\
\text { following } \\
\text { years }\end{array} \\
\mathbf{1 7 . 5 2} \\
\mathbf{1 5 . 6 7}\end{array}$ & $\begin{array}{r}\mathbf{1 6} \\
\mathbf{4 6 1} \\
\ldots \\
\ldots \\
\ldots \\
\ldots \\
\ldots\end{array}$ & $\begin{array}{r}477 \\
\ldots \\
\ldots \\
\because . \\
4 \ddot{7} \\
1,7 \dot{3} \overline{5}\end{array}$ & $\begin{array}{c}\text { Per cent. } \\
\text { accumu- } \\
\text { lated cases } \\
\text { to indict- } \\
\text { ments re- } \\
\text { turned pre- } \\
\text { ceding and } \\
\text { following } \\
\text { years } \\
27.49\end{array}$ & $\begin{array}{r}\dot{9} \dot{5} \\
1,859 \\
2 \dot{58} \\
69 \\
\ldots\end{array}$ & $\begin{array}{r}1,954 \\
\ldots \\
3 \ddot{2} \\
\ldots \\
1,6 \ddot{7} \\
8,763\end{array}$ & $\begin{array}{r}391 \\
19 \\
372 \\
65 \\
51 \\
14 \\
326 \\
1,753\end{array}$ & $\begin{array}{c}\begin{array}{c}\text { Average } \\
\text { per cent. } \\
\text { accumu- } \\
\text { lated cases } \\
\text { to indict- } \\
\text { ments re- } \\
\text { turned } \\
\text { preceding } \\
\text { years }\end{array} \\
{ }_{18.57}\end{array}$ \\
\hline $\begin{array}{r}822 \\
79 \\
\ldots \\
28 \\
. \\
\ldots \\
. \\
.\end{array}$ & $\begin{array}{r}901 \\
\ldots \\
\ddot{2} \dot{8} \\
\ldots \\
87 \dot{3} \\
258 \\
1,131 \\
1,948 \\
1,756\end{array}$ & $\begin{array}{c}\text { Per cent. } \\
\text { accumu- } \\
\text { lated cases } \\
\text { to cases } \\
\text { disposed of } \\
\text { preceding } \\
\begin{array}{c}\text { and fol- } \\
\text { lowing } \\
\text { years }\end{array} \\
58.06 \\
64.41\end{array}$ & $\begin{array}{c}814 \\
\ldots \\
\ldots \\
\ldots \\
. . \\
\ldots \\
\ldots \\
\ldots\end{array}$ & $\begin{array}{r}814 \\
\ldots \\
\cdots \\
\cdots \\
814 \\
231 \\
1,045 \\
2,027 \\
1,948\end{array}$ & $\begin{array}{c}\text { Per cent. } \\
\text { accumu- } \\
\text { lated cases } \\
\text { to cases } \\
\text { disposed of } \\
\text { preceding } \\
\begin{array}{c}\text { and fol- } \\
\text { lowing } \\
\text { years }\end{array} \\
\begin{array}{c}51.55 \\
53.64\end{array}\end{array}$ & $\begin{array}{r}521 \\
\ldots \\
\because \\
\cdots \\
\ldots \\
\because \\
\because\end{array}$ & $\begin{array}{r}521 \\
\ldots \\
\ldots \\
\ldots \\
521 \\
363 \\
884 \\
2,02 \dot{7}\end{array}$ & $\begin{array}{l}\text { Per cent. } \\
\text { accumu- } \\
\text { lated cases } \\
\text { to cases } \\
\text { disposed of } \\
\text { preceding } \\
\text { and follow- } \\
\text { ing years } \\
\underbrace{}_{43.61}\end{array}$ & $\begin{array}{r}2,933 \\
258 \\
i 6 \\
115 \\
\ldots \\
\ldots \\
\ldots \\
\ldots\end{array}$ & $\begin{array}{r}3,191 \\
\ldots \\
1 \ddot{13} \\
\ldots \\
3,0 \dot{0} \dot{0} \\
1,238 \\
4,298 \\
8,4 \ddot{78}\end{array}$ & $\begin{array}{r}638 \\
587 \\
51 \\
26 \\
3 \\
23 \\
612 \\
\\
248 \\
859 \\
1,69 \dot{6}\end{array}$ & $\begin{array}{c}\begin{array}{c}\text { Average } \\
\text { per cent. } \\
\text { cases ac- } \\
\text { cumulated } \\
\text { to cases } \\
\text { disposed } \\
\text { of preced- } \\
\text { ing years }\end{array} \\
\underbrace{}_{50.70}\end{array}$ \\
\hline
\end{tabular}

jury. "Unknown" represents cases whose place of origin could not be located.

Table 18 is an analysis of time intervals between arrest and indictment (presentation to grand jury) and between arrest and disposition, classified in accordance with the disposition-that is, these time intervals in the cases which resulted in plea of guilty or in those which were nolled, and so on.

These figures, it should be remembered, are averages. A case, for instance, in which the accused pleaded guilty in the Municipal Court would be a factor in making up the average.

A more intensive study was made of the time interval between cases bound over in July, 1919. This interval ranged from a minimum of 60 days to a maximum of 164 days, averaging 80 days in the 55 cases. These cases arose in the summer, probably while no grand jury was in session. But intervals such as these are by no means uncommon in cases arising at.other seasons, and summer is probably 
as favorable as any other period for disappearance of witnesses, impairment of recollection, and other damages to the effective administration of the criminal law.

The summer accumulation of cases, due to the absence of a grand jury and the vacation of some or all of the criminal court judges, produces a congestion at the beginning of what may be called the trial year, from which the administration of justice does not recover during the year and which is a fruitful cause of hurried, careless methods of preparation and trial. Table 19 is a study of the amount of this accumulation and its inevitably harmful effect. The accumulation is kept down by a feverish spell of trials toward the end of the April term of court, so that justice's summer vacation works backward and forward to impair efficiency.

An explanation may make Table 19 more intelligible. The April term of the court begins on the first Monday in April and ends on the first Monday in July, when the July term starts. The figures on line 10, namely, the cases remaining before the grand jury at the end of July term, represent the difference between the figures on lines 4 and 7 . The figures on line 13, namely, the total indictments ready for trial during the July term, represent the total of the figures of the next two lines, 14 and 15. During the summer of 1916 and 1918 court was held for a short time to allow pleas of guilty and thus eliminate some of the cases. During the summer of 1917 a special session was held to receive pleas of guilty and also to hold a few jury trials. The figures on line 19, namely, total cases undisposed of at end of July term, represent the difference between the figures on lines 13 and 16. The records show that about 76 per cent. of the cases are "true-billed" by the grand jury and 24 per cent. "no-billed." 1 Therefore, in line 20 it is assumed that 76 per cent. of the cases pending before the grand jury (line 10) will result in indictments.

One of the judges sitting in the criminal branch in January, 1921, was struck by the fact that 12 out of the first 16 cases before him in that

${ }^{1}$ The discrepancy between the 24 per cent. on this page and the 21.54 per cent. in column three of Table 3, page 95, indicating the percentage of no-billed cases as 21.54 , is only apparent and not real. The base upon which the percentages in Table 3 are calculated included all cases which originated in the grand jury and resulted in true bills, but did not include cases originating in the grand jury which were no billed, there being no record kept of this latter type. Table 19 deals with the accumulation in the grand jury of cases coming up from the examining courts, and therefore the base upon which the percentages were calculated in Table 19 does not include any cases which originated in the grand jury. It is the difference in these two cases which produced the difference in the figures 24 and 21.54 . 
month resulted in acquittals. He looked into the cause and came to the conclusion the fault lay in the serial or cumulative unpreparedness, to which we have called attention, accentuated just at this season by a change of administration in the prosecutor's office. ${ }^{1}$ With careful and thorough preparatory work in the earlier stages of a case, together with systematic filing of the information and good office organization, this harmful effect of change of administration could be minimized.

\section{Assignment of Cases}

Consideration of the opportunity of the trial prosecutor for preparation is necessarily connected with the system of the assignment of cases. The assignment of cases is in charge of the assignment commissioner of the criminal branch of the court. Cases are assigned for trial in the following order: first, all known criminals; second, defendants in jail; and third, bail cases. Within each one of these classes the cases are taken in numerical order. The rules of the Common Pleas Court provide that the prosecuting attorney shall furnish the presiding judge a list of known criminals against whom cases are pending, which the presiding judge certifies to the assignment commissioner. Like so many other rules, this is seldom observed.

Three or four days before the date set for trials of a group of cases the prosecutor receives from the assignment commissioner the list of the cases set for that day. When the day arrives, the cases go into one room or another in their numerical order, so that the prosecutor in any particular room cannot know in advance which of the cases will be assigned to the room in which he is acting. The assignment commissioner is able and willing to adopt and has urged the adoption of a system whereby each trial prosecutor will know several days in advance which cases will be assigned to the court-room in which he works.

\section{The Grand Jury}

No case is tried nor is any sentence imposed unless there is an indictment by the grand jury. This is true of those cases in which a preliminary examination has been held by the Municipal Court, as well as those which are first instituted in the grand jury. The latter class of cases forms between 9 and 10 per cent. of the whole. In over 90 per cent. of the cases, therefore, two preliminary examinations are held-one in the Municipal Court in the presence of the accused, and the second in the grand jury room without the presence of the accused.

1 County prosecutors are elected in November of even numbered years, and take office the following January. 
As a matter of fact, the grand jury does little more than register in formal shape the opinion of the prosecuting attorney that there is sufficient proof to warrant a trial. Very rarely does the grand jury indict when the opinion of the prosecuting attorney is to the contrary, and vice versa.

The prosecuting attorney plays practically no part in the selection of the personnel of the grand jury. The process of selection is as follows: A number of names are drawn from the jury wheel, and those so drawn are notified to appear at a designated time and place. ${ }^{1}$ A considerable portion of those who appear ask, for one reason or another, to be excused, and the excusing of them is a responsibility of the court. As the session of the grand jury proceeds others ask to be excused. The vacancies created by these excuses are filled by the court from names selected by the court, the judge being free to select whom he please. Naturally, the selection is made from social or political acquaintances of the judge.

Tables 20 and 21 show the number and percentages of grand jurors in the six terms of the court from April, 1919, to January, 1921, whose names were drawn for the grand jury, who failed to appear and who served during part of the term, and of those who were selected by the court, with the growth of the percentage of the jurymen selected by the court as the sessions progressed.

TABLE 20.-NUMBER OF GRAND JURORS APPOINTED BY PRESIDING JUDGE FROM SOURCES OTHER THAN THE ORIGINAL PANEL

\begin{tabular}{|c|c|c|c|c|c|c|c|c|c|c|c|c|c|c|c|c|}
\hline Term & $\begin{array}{c}\text { 18t } \\
\text { week }\end{array}$ & $2 \mathrm{~d}$ & 3d & 4th & 5th & 6 th & $7 \mathrm{th}$ & 8th & 9th & 10 th & $11 \mathrm{th}$ & 12 th & 13 th & 14 th & 15 th & $\begin{array}{l}\text { Aver- } \\
\text { age } \\
\text { for } \\
\text { whole } \\
\text { term }\end{array}$ \\
\hline $\begin{array}{l}\text { April, } 1919 \\
\text { September, } 1919 \\
\text { January, } 1920 \\
\text { April, 1920 } \\
\text { September, } 1920 \\
\text { January, 1921 }\end{array}$ & \begin{tabular}{r|}
9 \\
1 \\
1 \\
12 \\
4 \\
8
\end{tabular} & $\begin{array}{r}10 \\
4 \\
2 \\
12 \\
10 \\
8\end{array}$ & $\begin{array}{r}13 \\
7 \\
11 \\
13 \\
13 \\
12\end{array}$ & $\begin{array}{l}14 \\
10 \\
13 \\
13 \\
13 \\
12\end{array}$ & $\begin{array}{l}14 \\
10 \\
13 \\
13 \\
13 \\
12\end{array}$ & $\begin{array}{l}14 \\
11 \\
13 \\
13 \\
13 \\
12\end{array}$ & $\begin{array}{l}14 \\
12 \\
13 \\
13 \\
13 \\
12\end{array}$ & $\begin{array}{l}14 \\
12 \\
13 \\
13 \\
13 \\
12\end{array}$ & $\begin{array}{l}14 \\
12 \\
13 \\
13 \\
13 \\
12\end{array}$ & $\begin{array}{l}14 \\
13 \\
13 \\
13 \\
13 \\
12\end{array}$ & $\begin{array}{l}14 \\
13 \\
13 \\
13 \\
13 \\
12\end{array}$ & $\begin{array}{l}1 \dot{13} \\
\mathrm{i3} \\
13 \\
\cdots\end{array}$ & $\begin{array}{l}13 \\
\cdots \\
i 3 \\
\cdots\end{array}$ & $\begin{array}{l}\text { i3 } \\
\because \\
\mathrm{i3} \\
. .\end{array}$ & $\begin{array}{l}\mathrm{i3} \\
\cdots \\
\mathrm{i} \\
\cdots\end{array}$ & $\begin{array}{l}13.1 \\
10.5 \\
10.7 \\
12.8 \\
12.2 \\
11.3\end{array}$ \\
\hline $\begin{array}{l}\text { Total number } \\
\text { Average per } \\
\text { week } \\
\text { Average per } \\
\text { cent. }\end{array}$ & $\begin{array}{l}35 \\
5.8 \\
39\end{array}$ & $\begin{array}{l}46 \\
7.7 \\
51\end{array}$ & \begin{tabular}{c|}
69 \\
11.5 \\
77
\end{tabular} & $\begin{array}{c}75 \\
12.5 \\
83\end{array}$ & $\begin{array}{c}75 \\
12.5 \\
83\end{array}$ & \begin{tabular}{c|}
76 \\
12.7 \\
84
\end{tabular} & $\begin{array}{c}77 \\
12.8 \\
86\end{array}$ & \begin{tabular}{c|}
77 \\
12.8 \\
86
\end{tabular} & \begin{tabular}{c|}
77 \\
12.8 \\
86
\end{tabular} & $\begin{array}{c}78 \\
13.0 \\
87\end{array}$ & \begin{tabular}{|c|}
78 \\
13.0 \\
87
\end{tabular} & \begin{tabular}{c|}
39 \\
13.0 \\
87
\end{tabular} & $\begin{array}{c}26 \\
13.0 \\
87\end{array}$ & $\begin{array}{l}26 \\
13.0 \\
87\end{array}$ & $\left|\begin{array}{c}26 \\
13.0 \\
87\end{array}\right|$ & $\begin{array}{l}70.6 \\
11.8 \\
78.0\end{array}$ \\
\hline
\end{tabular}

A grand jury is composed of 15 members. Table 20 gives the number of persons on the grand jury selected by the judge himself entirely from

${ }^{1}$ If they fail to appear, nothing is done about it. No instance was discovered in which the prosecuting attorney followed up the failure of the summoned juror to appear. 
outside of the regular panel in the successive weeks of the session. In the last column is given the average number on the grand jury throughout the term who were thus personally selected. For instance, as shown by the table, in the April, 1919, term, during the first week nine out of 15 were thus selected from outside of the regular panel; and in the fourth week this grew to 14 , where it remained throughout the rest of the term, making an average for the term of 13.1 out of 15 thus personally selected. As shown by the lower lines of the table, taking the whole period covered by this study, namely, two years, an average of 11.8 , or 78 per cent., out of 15 were thus selected.

Table 21 gives the number of those whose names were drawn and who were not found at all, or who were notified and failed to appear, or who, having appeared, were excused at the beginning or during the term. Twenty-five names are drawn for each grand jury. The table shows, for example, for the September, 1919, term, of the 25 names, four were not found, one failed to respond to the summons and six were excused. The table also gives in terms of "man-weeks" the relative percentages of time given to this service by those drawn from the panel and those selected by the judge. Thus, in the September, 1919, term, 68 aggregate weeks of service were given by those drawn from the panel, and 157 weeks by the others, being 30 and 70 per cent. respectively of the total time of the grand jury.

TABLE 21.-NUMBER OF ORIGINAL PANEL AND JUDGE SELECTIONS (25 MEN IN PANEL FOR EACH TERM)

\begin{tabular}{|c|c|c|c|c|c|c|c|c|}
\hline Term & $\begin{array}{c}\text { Persons in } \\
\text { original } \\
\text { panel } \\
\text { not } \\
\text { found }\end{array}$ & $\begin{array}{c}\text { Notified } \\
\text { but } \\
\text { failed } \\
\text { to appear }\end{array}$ & $\begin{array}{l}\text { Number } \\
\text { excused } \\
\text { from } \\
\text { those } \\
\text { actually }\end{array}$ & $\begin{array}{l}\text { Total } \\
\text { man- } \\
\text { weeks } \\
\text { of grand } \\
\text { jury }\end{array}$ & \multicolumn{2}{|c|}{$\begin{array}{l}\text { Man- } \\
\text { weeks } \\
\text { from } \\
\text { panel }\end{array}$} & \multicolumn{2}{|c|}{$\begin{array}{c}\text { Man- } \\
\text { weeks } \\
\text { appointed } \\
\text { by judge }\end{array}$} \\
\hline $\begin{array}{l}\text { April, } 1919 \\
\text { September, } 1919 \\
\text { January, 1920 } \\
\text { April, 1920 } \\
\text { September, } 1920 \\
\text { January, 1921 }\end{array}$ & $\begin{array}{l}4 \\
3 \\
3 \\
6 \\
8 \\
8\end{array}$ & $\begin{array}{r}11 \\
1 \\
\because \\
\ddot{4} \\
3\end{array}$ & $\begin{array}{r}8 \\
6 \\
8 \\
13 \\
4 \\
7\end{array}$ & $\begin{array}{l}165 \\
225 \\
165 \\
180 \\
225 \\
165\end{array}$ & $\begin{array}{c}\text { No. } \\
21 \\
68 \\
47 \\
26 \\
42 \\
41\end{array}$ & $\begin{array}{c}\text { Per } \\
\text { cent. } \\
13 \\
30 \\
28 \\
14 \\
19 \\
25\end{array}$ & $\begin{array}{l}\text { No. } \\
144 \\
157 \\
118 \\
154 \\
183 \\
124\end{array}$ & $\begin{array}{c}\text { Per } \\
\text { cent. } \\
87 \\
70 \\
72 \\
86 \\
81 \\
75\end{array}$ \\
\hline $\begin{array}{l}\text { Whole totals } \\
\text { Average per week } \\
\text { Per cent. }\end{array}$ & $\begin{array}{r}24 \\
4 \\
16\end{array}$ & $\begin{array}{r}25 \\
4 \\
20\end{array}$ & $\begin{array}{r}46 \\
8 \\
46\end{array}$ & $\begin{array}{r}1,125 \\
188\end{array}$ & $\begin{array}{r}245 \\
41\end{array}$ & $\begin{array}{l}22 \\
\ldots\end{array}$ & $\begin{array}{l}880 \\
147 \\
\cdots\end{array}$ & $\begin{array}{l}\ddot{7} \dot{8} \\
\cdots\end{array}$ \\
\hline
\end{tabular}

There is no way of telling, with anything approaching statistical accuracy, which class of selections makes the better jurors. The evil of the present practice is that it does not correspond with the system contemplated by the law. That system provides, through the jury com- 


\begin{tabular}{|c|c|c|c|c|c|}
\hline 赵 & $\Rightarrow$ & & $\infty \rightarrow \infty$ & 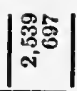 & \\
\hline 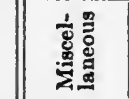 & $\infty$ & $\sim:::-$ & $: *:: \infty:::::^{*}:: \infty \quad::: \wedge:$ & $\stackrel{\infty}{\infty}$ & F \\
\hline 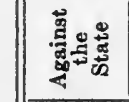 & & - & $:: \quad:: \quad::$ & $\infty=1 \quad$ & क \\
\hline 急 & - & $-:::: 10-1$ & $:-\infty::: \infty:: \sqcap:: \infty:::$ & 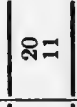 & ज्ञा \\
\hline 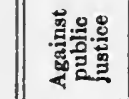 & -1 & $::::$ & $::::$ : : : & 政 & ה \\
\hline 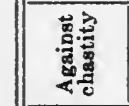 & \& & $\sim::: \approx-$ & $::::-:: *$ & 芯二 & 3 \\
\hline 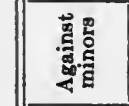 & $\approx$ & $\infty \quad::: 2$ & 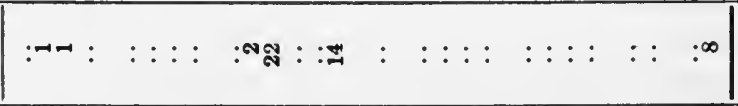 & $\mathrm{F}^{-}$ & $\stackrel{\infty}{\infty}$ \\
\hline 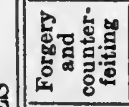 & is & 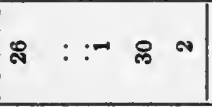 & $: \because+:$ & ठ్రిন & ฐ \\
\hline 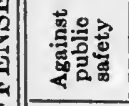 & $\mathrm{A}$ & $\vec{\nabla} \quad::: \quad q \quad:$ & 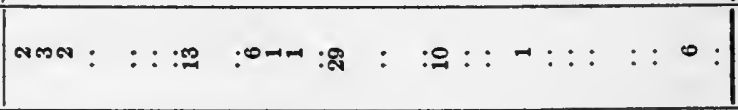 & एై & $\stackrel{\infty}{\infty}$ \\
\hline 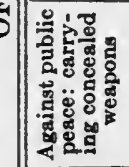 & 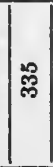 & 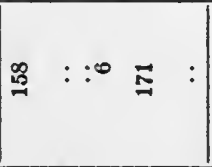 & $\infty-\infty-1: \infty:: 2:: \infty::::: \infty-$ & क్षా & (2) \\
\hline 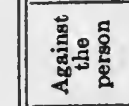 & $\vec{\Xi}$ & 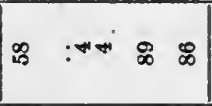 & : +ర్ర : & $\mid$ & ‥ \\
\hline 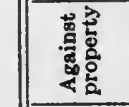 & I & 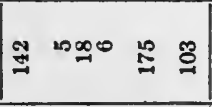 & man- :- : : & 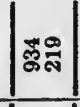 & 要 \\
\hline 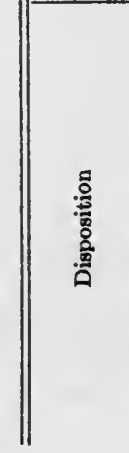 & 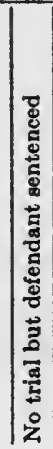 & 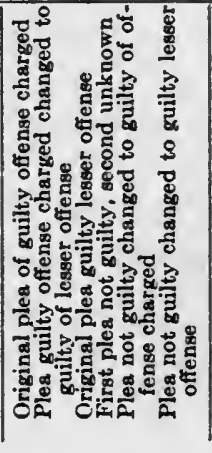 & 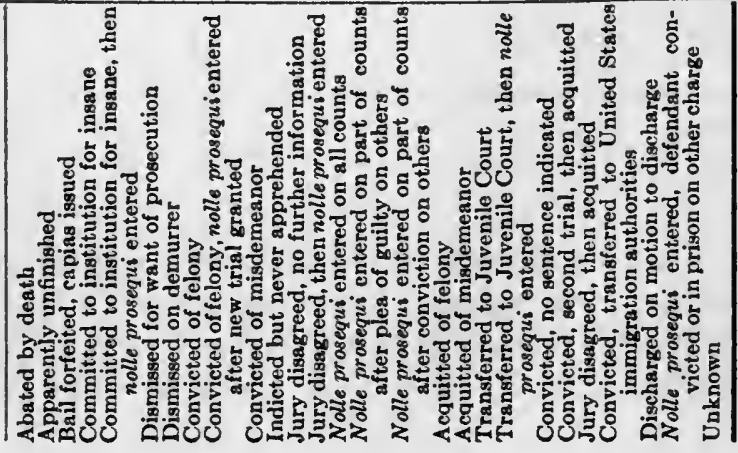 & 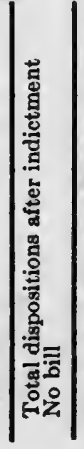 & 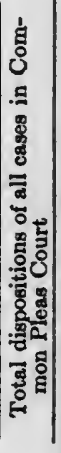 \\
\hline
\end{tabular}


missioners, a machinery for placing in the jury wheel an adequate number of names of qualified persons, and permits the judge to fill vacancies which the law contemplates will be few and occasional. Whenever the methods provided by law are departed from, there follow a confusion and dissipation of responsibility which open the door to carelessness and subtle forms of corruption.

In all this the prosecutor has not violated any express provisions of the law relating to him. But as he has a general function of law enforcement and responsibility for the prosecution of crimes, a responsibility which includes grand jury proceedings, he may fairly be blamed for his silence and drifting while this extra-legal system has developed.

\section{Statistics of Results of CAses}

Table 3 in Chapter II discloses the number of cases in Common Pleas Court in 1919, together with the number and percentages of the cases which, for one reason or another, were not tried, those which were tried and resulted in convictions or acquittals, and the percentages in which the sentences were carried out or suspended or mitigated.

Table 22 gives the data concerning these cases in greater detail, classified both according to the type of offense (offenses against chastity, frauds, offenses against persons, etc.) and according to the disposition or result (plea of guilt, plea of guilt of a lesser offense, nolled, conviction, acquittal, etc.).

These figures relate to the cases in which the grand jury found indictments and do not include cases which, though bound over by the Municipal Court to the grand jury, were ignored or "no-billed" by the latter body and therefore ceased at that point to have further history.

\section{"No-Billed" CASES}

Brief special attention should be given those types of disposition of cases which constitute dropping or dismissing the prosecution without trial. In the regular order of events following the transmission of the case from the municipal to the county authorities, the earliest of these dispositions is the ignoring of the case, as it is sometimes called, by the grand jury; that is, the determination of the grand jury to find "no bill" or indictment. As appears from Table 3, this cause of extinction occurs in 21.54 per cent. of the cases-a high percentage, indicating that many cases which the Municipal Court should have discharged reach the grand jury or that many "good" cases reach the grand jury in an ill-prepared condition.

A former assistant prosecutor, who had had charge of the work in the 
grand jury room for several terms, states that it was usually the practice to "no-bill" cases if the witness failed to appear upon being subpœnaed, without any further investigation of the case; that about 25 or 30 cases were presented to the grand jury in the course of a morning, so that, when the case reached its turn to go before the grand jury, if the proof was not sufficient and the case had no sensational attributes or special public attention, the prosecution was dropped then and there by means of the power of the grand jury to "no-bill" or ignore the case."

\section{Nolles and Acceptances of Pleas of Lesser Offenses}

As appears from Table 3, 12.33 per cent. of the cases in the Common Pleas Court were, after indictment, nolled on all counts-that is, completely dropped at the instance of the prosecutor. This is exclusive of 2.60 per cent. where charges are nolled because the defendant was under sentence for some other charge or nolled after reversal by upper court or jury disagreement. These items constitute 0.59 per cent., making 15.52 per cent. of nolles in all. This is, however, exclusive of other dismissals without trial which were not technically nolles, which item constituted 3.80 per cent., making 19.32 per cent. These percentages, if calculated exclusively on the cases which began in the Municipal Court, were respectively $9.11,2.36$, and 2.80 . In other words, 14.27 per cent. of the cases which had successfully passed the two preliminary examinations were later dropped.

"An illustration of the dangers which lurk in the "no-billing" process is furnished by the cases of Roland McGinty and Irving Schumacher. They were charged with stealing an automobile belonging to one H. M. Farnsworth. At about 1 o'clock in the morning of January 11, 1921, McGinty and Schumacher went to the garage where Mr. Farnsworth kept his car. Three hours later, about 4 o'clock, an Italian restaurant keeper in another neighborhood of the city noticed a car in front of his place of business and heard two men arguing as to which of them should go for some gasoline. The Italian called up the police station. A sergeant from the central police station came and placed both men under arrest. They proved to be McGinty and Schumacher and the car proved to be that of Farnsworth. On January 21 the case was called before the grand jury. Mr. Farnsworth voluntarily appeared and testified before the grand jury, but the case was no-billed. Thereafter Mr. Farnsworth inquired what had happened to the case and was informed that it was "nobilled" because it was understood that he did not wish to prosecute. Mr. Farnsworth states that he had never said anything to justify this inference. The "no-billing" of the case had the effect of releasing the defendants' bondsmen. The case was then again presented to the grand jury as an original case, and an indictment returned on April 15; but in the meantime the defendants had disappeared and have never been recaptured. 
The practice regarding nolles has always been careless. Section 2919 of the General Code of Ohio provides: "The prosecuting attorney shall not enter a nolle prosequi in any cause without leave of the court, or good cause shown, in open court." This presumes that the court looks into the facts carefully and exercises discretion. Actually, owing to the volume of cases passing through this court, the judge is practically dependent for his information upon the prosecuting attorney. In the last analysis, therefore, the power and the responsibility are those of the prosecutor.

The statutes of Ohio do not expressly provide for the acceptance, in felony cases, of a plea of guilt of a lesser offense than that charged and, consequently, do not regulate the procedure. In actual practice the court accepts the request of the prosecutor for permission to accept such plea and is necessarily dependent on the prosecutor's statement justifying that course.

The present prosecuting attorney, Mr. Stanton, instituted a rule to the effect that no nolle shall be entered by any of his assistants without the approval of himself or his first assistant, and that the reasons for the nolle be carefully and fully stated to the court and be carefully and fully noted both on the original papers on file in the prosecutor's office and on the docket in the prosecutor's office. If adhered to, these regulations would seem to be sufficient to minimize the abuse of the nolle.

Investigation was made as to the extent to which these regulations have actually been adhered to by Mr. Stanton's office, since his incumbency on January 1, 1921, by an examination of the records and papers in the 61 cases for the period January 1, 1921, to May 1, 1921, in which the pleas of guilt of a lesser offense were accepted and in which nolles were entered. Following were the results:

Forty-eight nolles were entered, in 15 of which no notation of the reasons appeared anywhere on the papers or records. Of the remaining 33 , the reason given in two of the cases consisted exclusively of the words "midst trial." In 26 of the cases the notation consisted of a reference to some other case in which the same accused had been convicted. Examination of these 26 other cases disclosed that in three of them the sentences had been suspended and in nine of them pleas of lesser offenses had been accepted. The remaining five of the nolled cases had short but informative notations, such as "defendant adjudged a lunatic," "defendant sentenced by federal court," etc. There were 13 acceptances of pleas of lesser offenses. In 12 of these no notation whatever appears. In one of these cases the records show that the acceptance of the lesser plea occurred after a previous verdict had been set aside and a new trial 
had been ordered by the court. The notation in the single case in which there was a notation consists of the words "midst trial."

Obviously, these slight and irregular notations fall far short of compliance with Mr. Stanton's stated regulation and very far short indeed of the recording system required to minimize the abuse of the nolle, on the one hand, and to protect the prosecutor from unjust suspicion, on the other.

On February 20, 1920, nolles in 410 cases were simultaneously presented to the court and entered. Some of these cases had been on the dockets since 1909. There were two 1909 cases, one 1910 case, four 1911 cases, five 1912, seventeen 1913, twenty-seven 1914, thirty-four 1915. In 99 of the cases special reasons for the nolles were stated, such as conviction and sentence in other cases, war record, absence of sufficient proof. In all the remaining 311 cases the reason given was either that the defendant had never been apprehended or that the bail bond had been forfeited and the defendant had never been reapprehended.

Some dead timber will accumulate in police departments and criminal courts, as elsewhere. Nor does the duty of capturing accused persons fall on the prosecutor. At the same time, as attorney for the State, the prosecutor might well be asked to check up pending cases from time to time, and thereby stir action by the police department in neglected cases. Such an accumulation as disclosed by the blanket nolle of 1920 indicates an inefficient administration of justice. The fact that a defendant has "skipped" his bond and not been recaptured would seem to be doubtful ground for a dismissal of the prosecution. As a blanket nolle of this kind affords an opportunity to an unscrupulous or careless prosecutor to drop a case which should be tried or kept alive, the statutory rule that nolles require a leave of the court in open court cannot well be followed unless nolles be considered one at a time.

TABLE 23A.-COMMON PLEAS COURT, 1919; SENTENCES CLASSIFIED BY TYPE AND BY EXECUTION AND SUSPENSION

\begin{tabular}{l|c|c|c|c|c|c}
\hline \hline & $\begin{array}{c}\text { Fine } \\
\text { and } \\
\text { costs }\end{array}$ & $\begin{array}{c}\text { Im- } \\
\text { prison- } \\
\text { ment }\end{array}$ & $\begin{array}{c}\text { Fine } \\
\text { and } \\
\text { im- } \\
\text { prison- } \\
\text { ment }\end{array}$ & $\begin{array}{c}\text { Total } \\
\text { misde- } \\
\text { meanor } \\
\text { sen- } \\
\text { tences }\end{array}$ & $\begin{array}{c}\text { Felony } \\
\text { sen- } \\
\text { tences }\end{array}$ & $\begin{array}{c}\text { All } \\
\text { sen- } \\
\text { tences }\end{array}$ \\
\hline Sentenced-total & 297 & 249 & 152 & 698 & 904 & 1,602 \\
Sentence executed & 275 & 193 & 120 & 588 & 663 & 1,251 \\
Sentence suspended & 22 & 56 & 32 & 110 & 241 & 351 \\
\hline
\end{tabular}

\section{Suspension of Sentences}

The statutes do not expressly authorize or regulate the suspension of a sentence, except during error proceedings in an appellate court or where 
the accused is placed on probation. As a matter of practice, suspensions are not so limited and the practice is exceedingly loose. The term "bench parole" is popularly given to suspension of sentences made by the trial court. They are sometimes given without consultation with the prosecutor, who, even when informed of the request for a suspension, does not, as a rule, protest or offer any argument on the question. Apparently he conceives his responsibility terminates with the original sentence except where the court specially requests information or action by him.

TABLE 23B.-COMMON PLEAS COURT, 1919; SENTENCES CLASSIFIED BY TYPE AND BY EXECUTION AND SUSPENSION; PERCENTAGES

\begin{tabular}{l|r|r|r|r|r|r}
\hline \hline & $\begin{array}{c}\text { Fine } \\
\text { and } \\
\text { costs }\end{array}$ & $\begin{array}{c}\text { Im- } \\
\text { prison- } \\
\text { ment }\end{array}$ & $\begin{array}{c}\text { Fine } \\
\text { and } \\
\text { im- } \\
\text { prison- } \\
\text { ment }\end{array}$ & $\begin{array}{c}\text { Total } \\
\text { misde- } \\
\text { meanor } \\
\text { sen- } \\
\text { tences }\end{array}$ & $\begin{array}{c}\text { Felony } \\
\text { sen- } \\
\text { tences }\end{array}$ & $\begin{array}{c}\text { All } \\
\text { sen- } \\
\text { tences }\end{array}$ \\
\hline Sentenced-total & 100.0 & 100.0 & 100.0 & 100.0 & 100.0 & 100.0 \\
Sentence executed & 92.6 & 77.5 & 78.9 & 84.2 & 73.4 & 78.2 \\
Sentence suspended & 7.4 & 22.5 & 21.1 & 15.8 & 26.6 & 21.8 \\
\hline
\end{tabular}

Tables $23 \mathrm{~A}$ and $23 \mathrm{~B}$ give the statistics as to the relative execution and suspension of sentences in the 1919 cases, classified according to deTABLE 24A.-COMMON PLEAS COURT, 1921; SENTENCES CLASSIFIED BY TYPE AND BY EXECUTION AND SUSPENSION

\begin{tabular}{l|c|c|c|c|c|c}
\hline \hline & $\begin{array}{c}\text { Fine } \\
\text { and } \\
\text { costs }\end{array}$ & $\begin{array}{c}\text { Im- } \\
\text { prison- } \\
\text { ment }\end{array}$ & $\begin{array}{c}\text { Fine } \\
\text { and } \\
\text { im- } \\
\text { prison- } \\
\text { ment }\end{array}$ & $\begin{array}{c}\text { Total } \\
\text { misde- } \\
\text { meanor } \\
\text { sen- } \\
\text { tences }\end{array}$ & $\begin{array}{c}\text { Felony } \\
\text { sen- } \\
\text { tences }\end{array}$ & $\begin{array}{c}\text { All } \\
\text { sen- } \\
\text { tences }\end{array}$ \\
\hline $\begin{array}{l}\text { Sentenced-total } \\
\text { Sentence executed }\end{array}$ & 18 & 45 & 12 & 75 & 155 & 230 \\
Sentence suspended & 12 & 42 & 8 & 62 & 126 & 188 \\
& 6 & 3 & 4 & 13 & 29 & 42 \\
\hline
\end{tabular}

gree of sentence. Tables $24 \mathrm{~A}$ and $24 \mathrm{~B}$ give similar information relative to the sentences imposed in the first three months of 1921 .

TABLE 24B.-COMMON PLEAS COURT, 1921; SENTENCES CLASSIFIED BY TYPE AND BY EXECUTION AND SUSPENSION; PERCENTAGES

\begin{tabular}{l|r|r|r|r|r|r}
\hline \hline & $\begin{array}{c}\text { Fine } \\
\text { and } \\
\text { costs }\end{array}$ & $\begin{array}{c}\text { Im- } \\
\text { prison- } \\
\text { ment }\end{array}$ & $\begin{array}{c}\text { Fine } \\
\text { and } \\
\text { im- } \\
\text { prison- } \\
\text { ment }\end{array}$ & $\begin{array}{c}\text { Total } \\
\text { misde- } \\
\text { meanor } \\
\text { sen- } \\
\text { tences }\end{array}$ & $\begin{array}{c}\text { Felony } \\
\text { sen- } \\
\text { tences }\end{array}$ & $\begin{array}{c}\text { All } \\
\text { sen- } \\
\text { tences }\end{array}$ \\
\hline Sentenced-total & 100.0 & 100.0 & 100.0 & 100.0 & 100.0 & 100.0 \\
Sentence executed & 66.7 & 93.3 & 66.7 & 82.7 & 81.3 & 81.7 \\
Sentence suspended & 33.3 & 6.7 & 33.3 & 17.3 & 18.7 & 18.3 \\
\hline
\end{tabular}


In paroles properly so called,- that is, the parole of prisoners by the authorities entrusted by law with parole powers,- the practice is for the paroling board or officer to ask for an opinion from the prosecuting attorney. This opinion is given without further effort on the part of the prosecutor to promote or obstruct the parole.

\section{The Bail Bond}

When a case is initiated by an indictment by the grand jury, followed by arrest, the accused is confined in jail unless he gives a bail bond to secure his appearance at trial. When a case comes through the Municipal Court, the bond given there remains in effect until an indictment has been found and the defendant arraigned for plea, and, if he pleads not guilty, another bond must be given to secure his appearance at the trial. If, in either class of case, the trial results in conviction and the defendant appeals, another bond may be required to secure his surrender if the judgment of conviction be affirmed. Neither the amount of the bond nor the qualification of the surety is determined by the prosecutor, though he has or can take the power to influence the decisions on these points.

It is his duty to watch the proceedings, have the defendant promptly arrested if the bond is not given, and have the bond promptly forfeited if the conditions thereof are broken. Until the passage of the recent statute regulating the procedure, it was also his duty to enforce forfeited bonds in all State cases, whether the bond was given and forfeited in the municipal or county court.

The records show a woeful laxity in the performance of these duties. ${ }^{1}$

${ }^{1}$ A recent illustration of the prevalent laxity in this matter is furnished by the bond enforcement case of State of Ohio v. George Poulley and M. L. Bernstein (No. 180756 of the Common Pleas Civil Docket). The petition was filed July 1, 1920. The petition sets forth that an affidavit was filed in the Municipal Court on July 26, 1915, charging the defendant, George Poulley, with violating the liquor law; that on August 10,1915, the defendant was found guilty, and on September 15, 1915, a bond was given by George Poulley, with M. L. Bernstein as surety, conditioned upon Poulley's prosecuting his petition in error in the Court of Appeals without unnecessary delay; that, as a matter of fact. Poulley never filed a petition in error in the Court of Appeals; that on June 12, 1920, Bernstein was called upon to bring the defendant into court, and upon failing to do so, the bond was forfeited. Bernstein was served with summons on this petition, the return of the summons made July 10, 1920. Poulley was not found. On October 27, 1920, the defendant was given leave to plead instanter and he filed his answer on the same date. The bond was permitted to sleep four years and nine months before being forfeited. For over two months the prosecutor overlooked the opportunity to take a default judgment on the bond.

On March 26, 1921, the case came before Judge Y., and the following entry 
The following is taken from pages 61 and 62 of the report of the Cuyahoga County Examiner of the Department of Auditor of State, Bureau of Inspection and Supervision of Public Offices:

The examination discloses that practically all services in connection with the taking of recognizances for appearance in criminal cases during the period covered by this examination have been conducted as matters of mere formality, and so far as the records and files disclose the fact that the object of such a recognizance is to safely insure the appearance of the accused for trial, has received little if any consideration.

What has been said of the taking of the recognizances also applies to all services performed in connection with the forfeitures and collection of same, as if readily verified by the following data taken from the records of the Common Pleas Court, to wit:

P. 61

Case No. 11272. Frank Hebole. Robbery. January 16, 1919, bond forfeited; no record of bond ever having been given.

Case No. 13902. John W. Brown. Pocketpicking. Bond forfeited January 16, 1919. No bond ever given in Common Pleas Court and none included in transcript.

Case No. 11465. Arthur Purnell. Burglary and larceny. Bond forfeited January 16, 1919, but there is no record of bond ever having been given.

Case No. 13498. Z. Barker. Issuing check to defraud. Bond forfeited February 12, 1919. No bond ever given in this case and the defendant was never apprehended.

Case No. 13820. John Soheat. Carrying concealed weapons. Bond forfeited January 16, 1919. Entry in docket of June 11, 1918, shows bondsman relieved of further responsibility.

That in several instances over two years had elapsed from the time a recognizance was taken until the same was forfeited.

That recognizances had been forfeited for a period of two years prior to having been reported to the county auditor or delivered to the prosecuting attorney.

That suit on forfeited recognizances had been entered for a period of two years prior to judgment being rendered.

That from one to seven continuances had been granted in many suits brought to recover judgment on forfeited recognizances.

P. 62

Forfeited Bonds

The following is a recapitulation of the results obtained in making an examination of the bonds given as security for the appearance in court of persons

appears upon the docket of the court: "Judgment for plaintiff for costs. Forfeiture, delayed five years, deprived defendant of opportunity to make effort to have George Poulley apprehended." 
charged with the violations of the criminal statutes, and forfeited in cases of their failure to make such appearance:

Total amount of bonds forfeited from August 26, 1916, to May 27, 1919. . . . . . . . . . . . . . . . . . . . . .

Total judgment rendered on forfeited bonds from August 26,1916 , to May $27,1919 . \ldots \ldots \ldots \ldots \ldots \ldots \ldots$

Total amount of bonds sued upon cases pending. . . . . . .

Total amount of judgment on forfeited bonds collected from August 26, 1916, to May 27, 1919......... $(\$ 1,100.00$ of this amount was collected on judgment rendered prior to the period covered by this examination)

Total costs incurred in suits brought on forfeited bonds from August 26, 1916, to May 27, 1919. . . . . . . . . . Total costs in suits on forfeited bonds collected from August 26, 1916, to May 27, 1919 . . . . . . . . . .

Total amount of judgments on forfeited bonds upon which no executions have been issued from August 26, 1916 , to May 27, 1919. . . . . . . . . . . . . . .

$\$ 263,400.00$

$59,262.28$

$100,300.00$

$2,701.53$

$1,680.65$

439.10

$13,885.00$

The preceding statement disclosed that the amount of judgments collected on forfeited bonds during the period covered by this examination, as compared with the amount of bonds forfeited, shows that but three-fifths of a cent is collected for every dollar forfeited; that the cost of collection is equal to the amount collected, not taking into consideration the salaries of the officials performing services in connection therewith, and that there is little if any effort made to issue executions on judgments rendered.

The statutes provide ample means for the elimination of the condition disclosed in connection with this subject, and the public officials who are by statutes vested with such power owe it to the community and themselves to use the authority so granted to make immediate correction of same.

While this survey was in progress the Ohio legislature passed a new statute regulating bail-bond procedure in Cuyahoga County. It has just gone into effect (July, 1921). It creates the position of bond commissioner appointed by the presiding judge of the Court of Common Pleas. This official succeeds to the function of the municipal and county court clerks in passing on the qualification of sureties. The statute prescribes in some detail regulations concerning the records of defendants in criminal cases and qualifications of sureties; such regulations could, however, have been put into effect in the past by rules of court or by the actual practice of the court clerks.

The statute transfers to the bond commissioner the duty to enforce forfeited bonds. This means a more divided responsibility than hereto- 
fore, and is in line with customary American practice of creating a new office to take over the duties which existing officials have habitually neglected, instead of providing existing offices with the type of men and office organization adequate for the work which logically belongs to those offices. In the last analysis it will be the duty of the prosecuting attorney to enforce the faithful performance of the bond commissioner's duties.

The new statute contains, however, at least two very valuable reforms. It makes the obligation of the bail bond a lien on the real estate of the surety from the date of the bond, and provides for the recording of these liens; and in actions on forfeited bonds it prohibits the court from giving judgment for any sum less than the full amount of the bond, except in cases in which the original defendant has surrendered or been recaptured.

\section{Cases in the Appellate Court}

About 13 per cent. of the contested cases which result in convictions are taken to the Court of Appeals on questions of law. The decisions of this court have an important bearing on the interpretation of the criminal laws and the validity of effective methods of law enforcement. In the interests of justice the man who carries his case to an upper court should not receive any undeserved and avoidable advantages from delays or technicalities. The protection of the public's side of these cases in the appellate courts forms, therefore, an important duty of the prosecutor.

One of the judges of the Court of Appeals complained that the prosecuting attorney failed habitually to file briefs in these cases. An investigation of the basis for this charge was made, with the following results:

In the 76 cases filed and concluded in the years 1919 and 1920, briefs had been filed by the prosecutor in only 20 . The plaintiff-in-error failed to file a brief in 22 cases. Eliminating these, on the principle that the prosecutor is not called upon to file a brief until his opponent's brief is filed, these records show that the prosecutor filed a brief in only 20 out of the 54 cases. Of the 76 cases, eight were dismissed for lack of preparation and eight for other reasons. Of the remaining 60 , the conviction was affirmed in 44 and reversed in 16 . In the 16 reversed cases no briefs were filed by either side in one case, while in the remaining 15 the prosecutor had filed briefs in four and failed to file briefs in 11. Taking the 60 cases in which the convictions were affirmed or reversed, the prosecutor lost 6.66 per cent. of them when he filed briefs, and three times as many, or 20 per cent., when he failed to file briefs. 


\section{CHAPTER VIII}

\section{THE FEDERAL COURT AND UNITED STATES ATTORNEY}

\section{Comparison is Possible}

$\mathrm{T}$ HE administration of justice in the federal courts does not fall within the scope of thissurvey. For purposes of comparison, however, some inquiry has been made into the actual workings of the enforcement of the federal penal laws. By reason of the relatively small scope of federal penal law as compared with the State and municipal criminal law, and the relatively specialized nature of the offenses which come into the charge of the federal authorities, the task of the federal judge, when he sits in the criminal branch of the court, or of the federal prosecuting attorney, does not present all the complexities and difficulties faced by the county and municipal officials. If, however, within its field, the administration of the federal criminal law in the same city presents a picture of relative orderliness, efficiency, the accomplishment of its ends, and the enlistment of public confidence, surely there are lessons implicit in these results which must not be neglected.

The following summary gives the results of the federal criminal cases in the Northern District of Ohio (the federal judicial district, which includes Cleveland) for the year ending June 30, 1920, as reported to the Attorney General of the United States and included in his 1920 report. The fiscal year for which these reports are made runs from June 30 to June 30 , and the year July 1, 1919, to June 30, 1920, furnished the official statistics nearest to the year of the county court tabulations in this report. The population of this district according to the census of 1920 was $3,195,651$.

Pending at close of June $30,1919 \ldots \ldots \ldots \ldots \ldots \ldots \ldots \ldots \ldots \ldots . \ldots 277$

Commenced during fiscal year . . . . . . . . . . . . . . . . 1,140

Terminated during same period $\ldots \ldots \ldots \ldots \ldots \ldots \ldots \ldots \ldots \ldots$

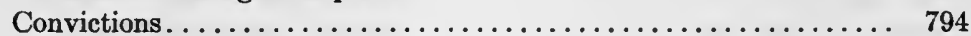

Acquittals. . . . . . . . . . . . . 11

Nolle prosequi or discontinued . ................... 156

Quashed, dismissed, demurrer, etc.................. 6

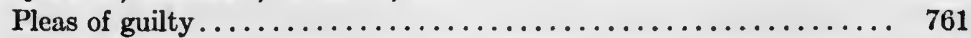

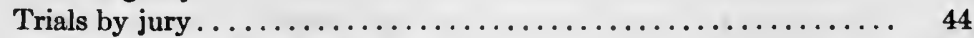

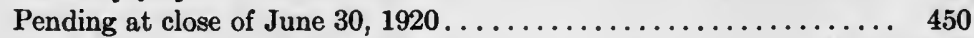

Fines, etc., imposed during year . . . . . . . . . . . . $\$ \ldots 131,327.06$

Realized on fines, forfeitures, etc. . . . . . . . . . . . $\$ 106,977.62$ 
Comparing these results with those in the county courts, the differences are striking. For instance, the percentage of pleas of guilt in the federal cases terminated during the year is 78.7 per cent. In the felony cases in the county courts (Table 3 ) pleas of guilt were obtained in 37.02 per cent. of all the cases; or, if cases of acceptance of plea of a lesser offense be eliminated, pleas of guilt of original charge were obtained in 30.38 per cent.; or, eliminating cases bound over to the grand jury but in which no indictment was found, there the percentages were 47.1 per cent. for all pleas of guilt and 38.7 per cent. for pleas of guilt of original charge.

Of the 967 cases terminated during the year, the federal authorities found it necessary to try only 44 cases, or 4.55 per cent., of which 75 per cent. resulted in convictions; whereas the 590 trials in the county cases represented 23.2 per cent. of all cases terminated during the year, with convictions in 62.2 per cent. 16.7 per cent. of federal cases disposed of during the year were nolled or otherwise dismissed without trial, whereas 41.01 per cent. of all State cases were dropped and 24.8 per cent. of the indicted cases were nolled or otherwise dropped.

These figures indicate a relatively high efficiency in the federal administration in the preliminary stages of sifting out of the cases and preparing them.

The Southern District of New York (composed chiefly of the original city of New York-Manhattan) is the busiest of the federal judicial districts and has nearly as many penal cases as the Cuyahoga County courts. As reported in the 1920 report of the Attorney General, in the year ending June 30,1920 , there were 1,879 criminal cases terminated in that district, of which 1,160 , or 61.7 per cent., resulted in pleas of guilty, and 1,221 , or 65 per cent., resulted in convictions.

Federal cases, like State cases, can be begun in the grand jury or in a court of preliminary examination, namely, before a United States Commissioner. The United States Commissioners undoubtedly keep some dockets or records of their own, but no dockets or records of the pendency of cases before commissioners or of the dispositions there are kept in the Cleveland district in the offices of the United States Clerk, and there are no official statistics of the history of cases in stages preceding the action thereon by the grand jury.

The United States Attorney's office in Cleveland keeps a book entitled "Complaint Docket," in which is recorded or presumed to be recorded the disposition previous to or by the grand jury of all cases which reach the stage of presentation to a commissioner. This book covers the Eastern Division of the Northern District of Ohio, which 
division includes Cleveland. The results of the tabulation of the cases for the year ending June 30, 1920, as disclosed by this book, are stated in Table 25.

TABLE 25.-SUMMARY OF CASES ON THE "COMPLAINT DOCKET" OF THE UNITED STATES DISTRICT ATTORNEY FOR YEAR ENDING JUNE 30,1920

Total cases in complaint docket. ..............

Cases which did not reach grand jury $\ldots \ldots \ldots \ldots \ldots \ldots \ldots \ldots$

Dismissed by commissioner. . . . . . . . 65

Transferred to other district. . . . . . . . . . 19

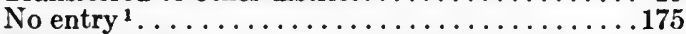

Miscellaneous................... 4

Presented to grand jury. . . . . . . . . . . . . . . . . $\ldots \ldots 44$

Presented direct $\ldots \ldots \ldots \ldots \ldots \ldots \ldots \ldots \ldots \ldots \ldots \ldots$

True bills.....................47

No bills......................... 10

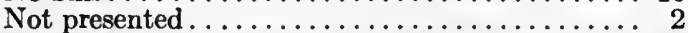

No entry . . . . . . . . . . . . . . . 25

Presented after binding over by commissioner . . . . . 1,370

True bills . . . . . . . . . . . . . . . . 1,166

No bills. . . . . . . . . . . . . . . . 104

No entry ................... 100

The Constitution of the United States requires a grand jury indictment in every case of "capital or otherwise infamous crime." This classification corresponds roughly with felonies. Consequently when a felony case is first heard by a United States Commissioner, there is the same sort of double preliminary hearings as in state felony cases. In crimes other than "infamous" the process of information, as distinguished from indictment, may be used with or without a preliminary hearing before the Commissioner. The accumulation of detail and drain upon facilities, human and otherwise, which double preliminary hearings entail, have caused the United States Attorney for the Southern District of New York, where the volume of work has increased rapidly, to use the process of information predominantly where such use is permitted by law, and, in graver crimes, to present the majority of cases directly to the grand jury. Francis G. Caffey, until recently United States Attorney for that District, states that, except for the issuance of warrants, arraignments, fixing bail, and like formalities, comparatively little use is made of the commissioners and that only occasionally is there a preliminary hearing before a commissioner.

1 "No entry" signifies that the docket failed to specify the disposition. It may not be amiss to venture a warning that, with the growth of the quantity of federal penal cases due to federal liquor legislation and the other extensions of federal criminal law, the quality of the administration of federal criminal justice will deteriorate unless care be taken to keep the record and statistical system and other instrumentalities abreast of this growth. 
As appears from Table 25, this development has not yet taken place in Cleveland, where the two hearings are held in a large majority of the cases. But even where this is true there is a striking contrast between the State and federal administration, in that a federal case is handled from beginning to end by the same prosecuting attorney's office, the United States Attorney and his assistants having charge of the case before the commissioner, the grand jury, and the trial jury; and, furthermore, the investigating and detecting machinery is a branch of the same department as that to which the United States Attorney belongs, namely, the Department of Justice. The Bureau of Investigation (corresponding in its functions to the detective branch of the police department) proceeds in its investigations under the direction of the United States Attorney. There is thus brought about a unity and continuity of method and responsibility which are absent from State cases. The procedure and atmosphere of the federal criminal courts are orderly and dignified, showing there is nothing intrinsic in the nature of criminal trials which makes disorder and lack of dignity unavoidable. 


\section{CHAPTER IX}

\section{THE LESSONS AND THE REMEDIES}

\section{General Considerations}

$\mathrm{T}$

HE facts of the situation suggest the remedies for the evils and inadequacies that have been revealed. In order, however, to propose changes, there must be some standard assumed toward which we are working. The proper road cannot be pointed out without some information as to where the traveler desires to go. What may we ask of the administration of criminal justice in any community?

The answer is obvious. The administration of justice should be free from corruption of any kind and be certain and expeditious. Its organization and operation should be such that, without any avoidable delay, the innocent are cleared of the charge of crime and the guilty discovered and punished. In so far as current methods and practices tend to avoidable delays, give avoidable opportunities for favoritism and other forms of corruption, unnecessarily increase the elements of chance or luck, produce indiscriminate results instead of, in the ordinary course of the day's work, a fair degree of justice, as and in accordance with the methods provided by law, to that extent the administration of justice falls below the most elementary and acknowledged standards.

The whole theory of our criminal procedure is based upon the assumptions, first, that it is consonant with justice that those who are guilty of a crime should be discovered and punished or otherwise specially treated, and those who are innocent have their innocence established; and secondly, that, as a deterrent of crime, criminal law and the administration of it can be effective only if that law and the machinery of its administration function so as to discover the offender and clear the innocent.

As tersely stated by Victor Cousin and quoted by Burdette G. Lewis in his book, "The Offender," "Punishment is not just because it deters, but it deters because it is felt to be just."

This "felt to be just" brings out another aspect of the problem, the importance of that which may be called the appearance of the administration of justice. Not only must justice be done in the ordinary 
course of the day's functioning, but the work of the criminal courts and prosecutors should have the appearance of doing justice. The aspect of things should be such as to cause the community to feel confident that the guilty will be discovered and punished and the innocent will be freed. Men whose situation might tempt them to commit crime may be deterred by the feeling that the chances of discovery and punishment are relatively certain. Men who feel criminally inclined, whose tendency is to enter a career of crime as a source of livelihood, would be more likely to go ahead in this career if the administration of justice in the community is a game of chance in which the odds are in their favor.

Not that the administration of justice is to be conceived as a machine, a Frankenstein, operating without heart, sympathy, discretion, or discrimination. But the fundamental American principle of justice according to the law is based on the conviction that men should be governed by general rules applied to the particular facts of each man's situation and not by the surmises, caprices, or prejudices of other men. The rules, whether legal or scientific and no matter how thoroughly and carefully developed, will always leave plenty of room for the play of the judge's common sense and sympathies.

Many people have a sort of vague feeling that a helter-skelter administration of justice, without careful ascertainment of facts or careful application of the laws, somehow produces a more desirable mixture of justice and humanity than is produced by the more orderly and careful trial methods. This is a complete fallacy. The whirligig too often snatches up the innocent or those who merit leniency and hurls them into punishment without giving them the time or opportunity to demonstrate their innocence or grounds for dealing leniently with them.

Therefore the organization, methods, and practices of the criminal courts and prosecutors and other agencies engaged in the administration of criminal justice should be such as to function with as great an exactitude as is possible in an apparatus of this nature and with a reduction to a minimum of the opportunities for favoritism, corruption, prejudice, luck, and carelessness. The procedure needs to be simplified so as to reduce as far as possible the number of steps or stages in which corruption, carelessness, or incompetence can play a part or which unnecessarily strain the resources, human and inanimate, devoted to the enforcement of the criminal law.

The present situation is to a considerable extent the result of the fact that in its prosecutors' offices Cleveland, like most American cities, is furnishing and supplying an apparatus disproportionate to the job on 
hand. Our public law offices have failed to institute modernized methods of office organization characteristic of the larger private law offices.

As the ability and character of prosecutors, judges, clerks and other officials, and of defendant's attorneys necessarily constitute so important a factor in the results, criminal practice needs to be given such a prestige as to attract and hold men of ability and character, and the prestige of the administration of criminal justice must be consciously promoted.

Our problem is, therefore, to suggest changes, easily obtainable and available, which will effect such organization, methods, practices, and prestige.

Many of the reforms suggested require merely the will to changethey can be effected by change in habits, manners, and customs; others will require amendments of court rules; others, amendments of city ordinances or the city charter; still others, amendments of Ohio statutes; an amendment of the Constitution of Ohio will be requisite to carry out at least one of the recommendations. Cleveland lawyers will know which of these modes of amendment will be necessary in each case, and whatever groups or agencies seek to produce any of these changes will easily ascertain the necessary type of legislation. This report will not, therefore, be burdened by pointing out, as each recommendation is discussed, either the particular class of legislation or the detailed provisions of such legislation.

\section{The Municipal Prosecutors}

The chief municipal prosecutor should be primarily an executive official, qualified by the kind of capacity and experience which makes an efficient executive of a large and important organization. It should be his province to assign the various subdivisions of the work of his office among his subordinates and to formulate and enforce the methods, practices, and regulations governing the work. He should map out, establish, and maintain the proper coördination between his office and that of the county prosecutor, between his office and the courts, between his office and the police department. The establishment and maintenance of standards in the methods of handling cases and interpretations of the law also fall within his province. As the head of the office, he should establish and maintain regular, systematic, and effective check upon the work of his subordinates and upon the work of the clerical and the other divisions of the Municipal Court. Moreover, he ought to make himself a leader for the community in matters relating to the administration of criminal justice in the Municipal Court. As long as he has his present jurisdiction, including the preliminary exami- 
nation in all State cases, he is one of the two or three most important officials in the city of Cleveland; and even if, as recommended later in this report, the charge of State cases from the beginning be transferred to the county prosecutor, the chief municipal prosecutor will remain one of the most vital city officials and second only to the county prosecutor in the domain of law enforcement.

Probably the second most important position, and one which should be established without delay, is that of managing clerk, whose functions would correspond to those of a managing clerk in a large modern law office. The duty of this official would be to keep the office working smoothly, in accordance with rules, regulations, and standards fixed by the chief prosecutor. He and his assistants would sift out the visitors and applicants at the office, so as to turn away those who have no business there and assign the others to the chief prosecutor, the assistant prosecutors, and the other officials in accordance with the specialization of work determined by the chief prosecutor. Furthermore, the managing clerk should act as the custodian and clearing-house of records, papers, and files of the office. The fixing of responsibility for the care and transmission of affidavits and other papers will help remove the danger of the loss of papers. Under the direction of the managing clerk should be the clerical department, with such clerks, stenographers, and messengers as may be needed to carry out the organization here outlined.

The subdivision of work among the assistants follows logically from the different types of activity involved and different classes or grades of offenses. For example, there is the distinction between cases brought to the office by persons other than the police and involving the informal conciliation which has been described, and cases brought in by the police. This could form the basis of one subdivision of the work. Some cases involve work of preparation outside of the office, which should be assigned to special assistants. The trial of the cases, also conducted outside of the office, forms a logical subdivision of the activities of the assistants. Cases differ in grade and kind-municipal cases, which represent violation of order, safety, and health regulations and involve neither vice nor criminal motive; municipal vice cases, as gambling and prostitution; state misdemeanors and state felonies. By means of specialization of this kind, office congestion will be reduced, just as street congestion is reduced by the specialization of the uses of the different streets as between pleasure, commercial, and industrial uses or heavy and light traffic. Each assistant will become expert in his work. The present system, or lack of system, whereby each visitor picks out his own assistant, produces congestion and avoidable opportunities for favoritism. 
In so far as it has any design at all, it may contemplate that the Italian visitor will seek out the Italian assistant, the Polish visitor the Polish assistant, and so on. This is, however, one of the things which Cleveland must eliminate. This tribalization of law enforcement is a species of corruption. The great immigrant population of Cleveland should be made to realize, and will probably be quite happy to realize, that justice in Cleveland is an American justice, and that no special favors are obtainable and no special punishment will be administered because the complainant or the defendant or the prosecutor belongs to one tribe or race or another. ${ }^{1}$

With so great a number of cases, the municipal prosecutor cannot keep pace with his duties and avoid the inefficiencies and wastes of congestion unless the operation of the office be fairly continuous. The present method of progress resembles the system in use for carrying logs down a wilderness stream, namely, an alternation of jams and drifts. This primitive method may have some justification in the transportation of logs through a wilderness, but is hardly appropriate to the prosecutor's office in a large American city. Even in the case of the logs some of the good ones get stranded along the shore. The lumber industry has evolved the log-picker, who goes back along the route and picks up and delivers these strays. The administration of justice has not evolved an analogous official.

Within the limits of reasonable practicability, the output of the office, so to speak, should be continuous, meaning thereby that the various types of work involved-investigation of facts, preparation of affidavit, preparation for trial and trial-should be continuous, each assistant or set of assistants assigned to these divisions of the work working throughout the working hours of the day. As arrests are made during the night and some of these night arrest cases will be on the Municipal Court docket the following morning, the investigation of facts and preparation of affidavits should, to some extent, proceed during the night, special assistant or assistants being assigned for that purpose. The notations and memoranda incident both to the sifting out of the cases and the preparation of those which are to be tried ought to be thorough and "routed" within the office, and filed so as to be at hand when and where needed. Not that the work should become purely mechanical-in fact, too much of it is mechanical now, in the sense of being without the exercise of human judgment and discretion. The system in a modernized business organization does not render the work

${ }^{1}$ Language difficulties can be easily cared for by a proper system of interpreters. 
of the chief executive and his assistants more mechanical. On the contrary, it frees them for more thought, originality, judgment, and efficiency.

The question immediately arises as to how many additional assistants may be needed to carry out a program such as here outlined. That number cannot be prophesied nor calculated in advance. The appropriate number will be a development of experience. The introduction of an improved system in any office always opens up the possibility of handling a greater volume of business without added force, and the chief prosecutor will be surprised how much more efficient work he will obtain from his present force with a good office system. Furthermore, the present agitation on the subject of crime and the making of this survey are based to some extent upon the feeling that the orderly, honest, and capable administration of criminal justice will itself reduce the amount of crime; and there is scientific justification for that feeling. If the recommendation discussed in a subsequent chapter, namely, that the county prosecutor be put in charge of all State cases, be carried out, the volume of the work of the municipal prosecutor's office will materially decrease. Until that is done, some increase of the number of assistants will, no doubt, be necessary. Just a few days before the writing of this report an additional assistant was authorized and appointed. Without, however, a supply of increased, adequate, and wellarranged office space, and the establishment of an adequate clerical force and office and record system, the mere increase in the number of assistants will not increase the efficiency of the work and will probably tend to intensify many of the defects which have been described. The new assistant will add at least one more person to the office jam; and six officials whose information and whose activities are unfiled, unrecorded, unwritten, and unknown are probably better for the community than seven.

\section{The County Prosecutor}

In the county prosecutor's office, the filing and clerical work and the disposition of visitors should, under the newly created managing clerk, be managed as befitting a large modern law office.

But, above all, the prosecuting attorney himself should be the executive of his department. It is his function to systematize activities of the office, assign the distribution of work among his assistants and subordinates, formulate and enforce the rules, regulations, practices, and methods of the office, and exercise a supervision and control over all the persons and facilities of his office so as to produce standards of 
efficiency in harmony with his policies. His activities and power as an executive ought to extend beyond the precincts of his immediate office. Through his duty to enforce, in his county, the criminal law of the State he is best fitted to be the chief executive of the administration of criminal justice. He should bear to the administration of criminal justice in Cuyahoga County the same relation which the Attorney General of the United States bears to the administration of the federal penal law. It is his function to coördinate the work of his office with that of the police department, the municipal prosecutor, the clerks of the courts, and the courts themselves. By reason of his responsibility for the presentation and trial of cases, and his right to investigate into and prosecute the malfeasance or non-feasance of other public officials, it is his function to watch the work of the police department, county and Municipal Court clerks, and all other persons with duties connected with the enforcement of the criminal law, and thereby guard against the failures of law enforcement due to official neglect or corruption. The law enforcement department of the public service, possibly the most vital of all activities of government, with its tremendous quantity of detail, its specialization and subdivision of labor, its adjustments between these subdivisions, its adjustments with the public-requires concentrated executive direction and responsibility. This direction and responsibility rest with the prosecuting attorney. More than that, the prosecuting attorney should be the leader in this field, the man who thinks through and originates policies and methods. Today it is too often the case that the prosecutor permits himself to be carried hither or thither by alternating currents of public cruelty or public sentimentality or blown about by gusts of popular or press excitement. $\mathrm{He}$ should be the captain who steadies the boat and at the same time discovers new or improved routes to the havens of public order, security, and morals.

\section{Municipal Court Procedure}

The arrangement and subdivision of work in the municipal prosecutor's office must necessarily dovetail into the procedure of the Municipal Court. The full benefit, for instance, of assigning specific classes of cases, such as city misdemeanors and state felonies, to specific trial assistants could not be obtained if these various classes of cases be thrown indiscriminately into the same morning's court docket. Careful preparation of a case would become partly wasted effort if the court procedure be so hurried as to give no opportunity for presenting the case well. These examples illustrate the necessity of some reforms in 
the court procedure if the prosecutor's office is to be made an efficient instrument, and the justification for some discussion of these reforms here, though the subject of the courts forms a separate division of this survey.

The court calendar is now based upon the jam and drift method. There is an overcongested calendar for a short period of the day, and then drift the remainder of the time. The time given to trial of cases should be sufficient to enable them to be heard in a manner befitting cases which involve the lives, liberties, and reputations of human beings. Each case should be as thoroughly presented and in as orderly a manner as the proof requires and the legal and factual issues justify.

\section{The Segregation of Trials or Calendars}

We have seen that most of the time the trial prosecutor stands around with nothing useful to do. His single routine question to the prosecuting witness, "What do you know about this case?" could easily be propounded by the judge. The time and ability of the prosecutor are wasted by this sort of procedure; and with a situation which cries for so much useful activity, this waste is inexcusable. If, therefore, there are classes of cases which normally can be as effectually tried without the presence of the prosecutor, those cases should be segregated upon the court calendar so as to release the prosecutor for service elsewhere.

On every indiscriminate calendar, composed of cases of every degree of importance and difficulty, there are many cases sufficiently clear and simple to warrant speedy and summary trial. The trouble is that these cases set the pace, and by a process of contagion affect the conduct of cases which merit a more patient inquiry into the facts and law, and the whole calendar tends to be given this hurried, inadequate, slipshod treatment.

Arthur C. Train, with long and varied experience as prosecutor in New York city, in his book, "The Prisoner at the Bar," describes the harmful effects of this hurly-burly method of calling and disposing of cases in police court. Speaking of the New York Police Court previous to its reorganization, he gives an analysis largely applicable to presentday Cleveland:

"The inordinate number of cases which the magistrates have to dispose of results oftentimes in an inconclusive method of hearing charges of misdemeanors or of felonies, which, if the defendant be held at all, must of necessity be tried in a higher court or, as the magistrates say, 'go downtown.' If the defendant 
be a man of some influence, with money to retain a boisterous and bully-ragging lawyer, the line of least resistance may lead the judge almost unconsciously to regard the case as having 'nothing in it.' If, on the other hand, the complainant be a man of independence and insistence, without perhaps a bit of pull, it is much easier to 'hold' a defendant than to assume the responsibility of 'turning him out.' In point of fact some magistrates are prone to shift the responsibility off their own shoulders and to 'hold' anyway. Thus there can be 'no kick coming' so far as they are concerned. There are also cases where, rather than take the time for a careful examination of the case, the magistrate will 'hold,' when, if he had really examined into it with the necessary care, he would find that there was no reasonable ground for his action. Now the grand jury is apt to find an indictment almost as a matter of course, and the defendant must then be placed on trial before a petit jury. In large measure this is the reason why the calendars of the criminal courts are crowded with cases which should never have gone beyond the police court, and why prisoners charged with homicide of ten lie for months in the Tombs before the petty business of the general sessions can be cleaned up sufficiently to allow time for their trial. In this way much of the work which should be done by the police judge is cast upon the already overburdened petit jury. The evil, however, does not stop there. When a petit jury finds that a majority of the cases brought before it have little or no merit, it frequently gets the idea that all criminal business is of the same character and that it is impanelled for the purpose of a general jail delivery. After a jury has 'turned out' 20 men in succession it can hardly be blamed for thinking that the twenty-first, who may be a real sinner, ought likewise to be sent home with the others to join his family. Respect for law cannot be maintained unless each part of the machine of justice does its full duty and assumes its own burdens and responsibilities" (p. 56).

There is slight practical difficulty in classifying the cases according to gravity and according to normal or habitual difficulty of proof. The statutory classification of city and state misdemeanors and state felonies is one basis, and the prosecutor can more successfully distribute these classes among his assistants if the court calendars followed a similar segregation, so that hearings of state felonies, for example, be set in a designated court-room at a designated time, and similarly for the other classes. Within these general classes, particularly state and city misdemeanors, there are types of cases, as, for instance, violations of local traffic ordinances, which normally present simple issues of fact or law and require little time, and others, such as larceny and fraud, which, being generally committed in a secretive or concealed manner, usually involve difficulties of proof and require more time for trial.

A segregated docket, separating the times or places of trial of cases which do not require the presence of the prosecutor from those which 
should be conducted by him, of city from state cases, state felonies from state misdemeanors, and, within these classes, cases normally triable in a summary or speedy fashion from those where justice demands less speed, would enable the prosecutor to obtain the most efficient results from the work and the ability of his assistants and make thorough preparatory work useful and effective. The appropriate importance of each case would stand out better if the case be upon a calendar devoted to cases of a certain degree of gravity than is possible in the present indiscriminate commingling. The disadvantages of keeping lawyers for the defense and witnesses waiting around would be reduced. There would be brought about an atmosphere of orderly and open administration of justice. Not the least important consequence would be to enhance the attractiveness of criminal practice and to encourage the better equipped and finer grained type of lawyer to accept service in criminal cases. The changed tone would react upon the accused, witnesses, and spectators; they could hear, see, and understand what is going on in the court-room. The result would be greater public confidence in the administration of justice.

The preparation of a segregated calendar as above outlined is, of course, a task of some difficulty, especially as certain complicating considerations have to be taken into account, such as the rest-hours of police officers who are on night service, the reduction of the time of confinement of defendants who cannot give bail, and other illustrations which will occur to those familiar with police courts. But the difficulties are not great and can be easily overcome by the willing coöperative action of a chief justice, prosecutor, and clerk of fair ability. The general principles and considerations are clear and simple, and there is no necessity for setting out here a detailed schedule of all the types of offenses, classifying each according to its appropriate place on such a calendar. A few illustrations will suffice. There are municipal cases, such as intoxication, street soliciting, suspicious person, ordinary traffic cases, in which the police officer makes the arrest on the spot on the basis of what he sees and in which there is rarely any issue of law or any issue of fact requiring investigation outside the police records. In such cases the whole prosecution consists of the testimony of the police officer, and there is nothing for the prosecutor to do. These cases should occupy a special part of the calendar. If, in any of them, there develops a situation or issue which the court believes to warrant the prosecutor's attention, the court could place the case on that part of the calendar for which the prosecutor will be needed.

Then there are cases of violations of both city and State regulations, such as smoke abatement, tenement house and other building regula- 
tions, in which the proof is prepared by the health or factory or building department or inspector and he is quite capable of presenting it. If the department has a case which requires the establishment of an important point of law, or an aggressive campaign against an habitual or arch offender, it could take the matter up specially with the prosecutor, who could have the case put upon a calendar for which the appropriate trial assistant will be in court.

Keeping houses of ill fame, gambling offenses, pocketpicking, are examples of municipal misdemeanors which generally involve either an issue of law or some difficulties of proof and which, therefore, normally require preparation on the part of the prosecutor and belong on that part of the calendar devoted to municipal cases with prosecutor present. Each of these may be expected to use considerable time. Larceny, assault, receiving stolen property, carrying concealed weapons, and liquor offenses are examples of state misdemeanors requiring similar treatment. In fact, most state misdemeanors, excepting violations of some State license and inspection regulations, automobile speed cases, and others in which the whole case is the report of a police officer or public inspector, fall within this same class.

\section{Arrest and Summons}

Under the present practice the process of arrest is the form of process by virtue of which jurisdiction is obtained in every case of every nature and the accused is brought into court. This is partly responsible for the present conglomerate calendar. As the arrested person must be confined in jail or give bail, it is only fair that he have, as his day in court, the next nearest court session, namely, the following morning. Almost every arrest involves the labor of bringing the accused to a police station and confining him or arranging for bail, all of which adds to the clerical labor incident to the keeping of police and court records. A large percentage of the new cases each morning are not ready for trial and continuance is allowed, involving the clerical details of entering the continuance on each of the records and reëntering the case on the later docket. With the enormous work thrown upon the administration of justice, every labor-saving device which does not harmfully affect the administration should be adopted.

Obviously, the summary process of arrest is designed to prevent escapes. It is a process appropriate to those classes of offenses, such as felonies or misdemeanors, with a motive which may strictly be looked upon as criminal (larceny, pocketpicking, suspicious person, carrying concealed weapons, etc.), or misdemeanors of the nature of habitual or 
commercial vice (keeping house of ill fame, gambling, etc.), which are usually committed by those professionally engaged in these offenses, or by persons who are transient sojourners in the city and migrate from town to town, or persons of erratic occupation or low and uncertain social status, and who, therefore, are under greater inducement to escape than to appear and stand trial.

The field of criminal justice in the modern American State and city has come to include, however, a large number of misdemeanors committed by persons who are permanent residents, engage regularly and habitually in a lawful occupation, have respectable friends in the city and a social status worth preserving, and for whom departure from the city would be a greater punishment than that provided by law for the offense. Sunday ordinances, violation of health, smoke, building, and nuisance ordinances, traffic cases not involving injury to persons, license ordinances, are examples of municipal misdemeanors of this type; automobile offenses not involving injury to persons or theft, labor, health, building and factory regulations, laws regarding minors, license laws, election laws, are examples of state misdemeanors. The use of the process of arrest in such cases is a waste of effort and an unnecessary drain on overburdened resources. The process of summons, such as is used in civil cases, would be just as effective. A summons is served on the defendant notifying him to appear in court at a designated time and place. The designation of time and place could be made to fit in with the system of segregated calendars above described. The process of arrest should be abolished and that of summons substituted in the appropriate types of cases.

\section{Stenographic Report of Testimony}

The testimony of the witnesses should be taken stenographically in the preliminary hearings of all felony cases in the Municipal Court, and also in the trials of all those misdemeanor cases, both city and state, which involve criminal motive, using "criminal" in its stronger implications, or habitual or commercial vice. The illustrations given above in other connections indicate these types of misdemeanors. One object of this would be to increase the orderliness and thoroughness of procedure, giving each case the importance that it deserves in the mind of judge and trial prosecutor and witnesses. The accused would have a better chance of hearing what the witnesses are saying about him, a fundamental privilege of which he is often deprived under present methods. A second object would be to reduce perjury. The witness who knows his testimony is being taken down in black and white will be more careful. A third object would be to effect improvement in the 
preparation of state felony cases. The county prosecutor's office is now dependent upon the random notes which may have been made at some stages of the matter by the police or municipal prosecutor's office, and in most cases today receives little more than the names of witnesses. In all cases which are bound over, therefore, the transcript of the testimony should be made and transmitted through the managing clerk of the municipal prosecutor's office to the managing clerk of the county prosecutor's office. In fact, it would be well to follow the English system and that in vogue in several of our States, namely, have the witnesses sign the transcribed testimony, which thereby becomes a deposition. In other cases, unless a perjury prosecution be deemed advisable, the stenographic notes should be kept in the files of the municipal prosecutor, the notes of each case being carefully filed with the papers of that case.

The segregation or arrangement of the court calendars follows logically from these classifications of the cases; and as the classes of cases in which the prosecutor's service is needed and for which he needs careful preparation and those which should receive considerable time for trial and those in which the evidence should be stenographically taken down, are, by and large and with easily cared-for exceptions, identical, the corresponding segregation of the calendars would result in affording the prosecution and the accused proper opportunity to prepare and present their cases, reduce to a minimum the waste of time spent idly in the court-room by attorneys on both sides, and give each case its appropriate setting.

\section{General Aspect of the Trials}

What we have just considered may seem to be somewhat mechanical and clerical details. But they are all of the utmost importance and in cumulative effect would enormously increase the effectiveness of the administration of criminal justice and the prestige of the Municipal Court, the municipal prosecutor's office, and criminal law practice. There remains to point out the possibilities open to the municipal prosecutor, if he will realize and exercise the leadership and constructive statesmanship which are his by virtue of his office. After all, the judge is dependent for his information upon the attorneys, and he needs the assistance of the attorneys to maintain the orderliness and dignity of procedure appropriate to the administration of justice. The prosecutor is not only the attorney for the plaintiff and a court officer, but also the representative of the public, with the peculiarly difficult and complex duty of presenting the public's side of the controversy while avoiding anything which savors of persecution or of deprivation of the defendants' 
fundamental civil rights. His position gives him the opportunity to bring about a procedure which fulfills universally recognized standards. Let him insist that every case be tried, so that the trial be really publicthat is, in a physical environment which is not only quiet and dignified, but which makes it possible for court and defendant and witnesses and court officers and spectators and reporters and the public to know what is going on. Probably the judges are quite willing that their courtrooms have the aspect of habitations of justice, and if there be a judge who does not harbor such a desire, he surely would not dare to resist the leadership of the prosecutor, supported as he undoubtedly would be by public opinion.

\section{Record Systems in Municipal Court and Prosecutor's Office}

The minimum requirement for the record or docket of a case is that it disclose all steps or stages thereof, and all orders and dispositions issued or made by the court; so that the attorneys or other persons interested can at any moment ascertain the status of any case, and the chief prosecutor or public can, from the records, tabulate the statistics of the administration of justice and appraise the work of those engaged in that administration. The system of record-keeping should be such as to minimize errors and reduce to a practicable minimum the time and trouble involved in finding and tracing the history of a case. Obviously, the full record or docket of any case ought to be contained at a single place or part of the records and the system of indexing such that this place or part may be easily and swiftly located.

We have seen how far short of these minimum standards the record system of the criminal branch of the Municipal Court of Cleveland falls. Immediate overhauling and modernizing are imperative. The excellent system developed by the clerk of the Municipal Court of Chicago will serve as a model from which to work. ${ }^{1}$

\section{Disposition of Cases by the Prosecutor Himself}

Special attention should be given to the regulations governing those actions of the prosecutor, both city and county, in which the final result and disposition of the case are determined by him or on the basis of information supplied by him, as distinguished from cases in which the disposition is made by the court or jury on the basis of sworn testimony.

1 Editor's Note: A complete description of the record system in use in the Municipal Court of Chicago was attached to Mr. Bettman's report, but because of lack of space has not been included in this publication. It is on file at the office of the Cleveland Foundation, and is accessible to anyone interested. 
These situations include the initias decision of the municipal prosecutor to issue no affidavit, the "no-papering" of cases, the entering of nolles, the "no bill" by a grand jury at the instance of the prosecutor, the acceptance of pleas of guilty of a lesser charge than the offense originally charged, and mitigations and suspensions of sentences.

\section{Conciliation by the Prosecutor}

The unofficial court of conciliation conducted by the municipal prosecutor, in which he sends for the accused and confers with complainants and accused and attempts to adjust their differences and then determines whether an affidavit shall or shall not issue, has been described. This all takes place in the privacy of the office of the prosecutor or assistant. There is not even the restraint which comes from the necessity of announcing the decision in open court. Absolutely no record is kept, and all that occurs and all the motives or reasons for the decision are recorded, if at all, only in the mind or private papers of the assistant.

This is too loose and dangerous a system. This kind of treatment is quite appropriate to some cases. There are controversies or acts of too petty a nature or too free from criminal motive or danger to justify arrest and prosecution, and it would be unwise to burden the overburdened court dockets with them. And, unless this conciliation work be taken over by the courts, it naturally falls within the prosecutor's field. But it offers both opportunity and temptation to permit the administration of criminal justice to be used for the collection of civil claims and for the assistant prosecutor to share in the benefits, financial or otherwise, therefrom. This opportunity and temptation should be reduced, so far as office system or practice and the chief prosecutor's executive control can reduce them. Therefore each assistant who engages in any such conciliation or decision not to prosecute should be required to make a daily written report to the chief prosecutor, on a form devised for the purpose, giving such matter as the names of the parties concerned, the nature of the charge, the terms of the conciliation or adjustment, and the reasons for non-prosecution. These reasons, moreover, should not be allowed to degenerate into formulas, such as "insufficient evidence," which disclose nothing, but should be sufficiently comprehensive to enable the chief prosecutor to pass upon their adequacy. By examining these daily reports, the chief prosecutor will be able to discover whether his office is lending itself too freely to the settlement of civil claims or dropping cases too lightly. 


\section{"No Papers"}

As the practice known as "no papers" has no statutory basis or restraints, it opens another avenue for favoritism or corruption which needs to be narrowed by office regulations. Where there has been an arrest without adequate basis for further prosecution, the practice is justifiable as a means for avoiding the clerical labor of drawing and filing an affidavit. But otherwise the procedure ought be as formal, open, and safeguarded as in the case of the statutory nolle. The regulation should provide that, in every case of "no-papering," the reasons for that action be set forth in full in writing by the assistant who makes the recommendation, and submitted for approval to the chief prosecutor or to his first assistant, if the chief delegates this authority to him, whose approval will also be written, and that then, when the case is called, the statement be read to the court.

\section{Nolles}

In state felony cases the approval of the court is required by law before a nolle may be entered by the prosecutor. The statutes contain no clear-cut provisions regulating nolles in the Municipal Court; but the authority of the court may undoubtedly be exercised to control the allowance of the motion to nolle. Where the nolle is at the prosecutor's instance, regulations similar to those described for "no-papering" should require the written statement of the assistant recommending the nolle of his reasons thereof, submitted to and approved by the chief prosecutor or delegated first assistant, the statement to be read in open court.

Where the justification for a nolle first transpires during the trial of a case, that fact and the approval of the court ought to be noted in the court entry and record and a written report thereon made by the trial prosecutor to his chief.

\section{"No Bills"}

Where the grand jury itself decides the evidence to be insufficient to warrant an indictment, the prosecutor is not necessarily responsible for that form of dropping the case. As a matter of fact, however, many "no bills" are returned by the grand jury on the strength of the prosecutor's own statement that he has no evidence to present or his own opinion of the inadequacy of the evidence presented. In these cases the "no bill" is then a procedure whereby the prosecutor dismisses prosecutions. It furnishes temptation and opportunity for hurried, careless, slipshod work. Regulations similar to those recommended for "no papers" and nolles, namely, a full written report by the assistant who 
recommends or brings about the "no bill," setting forth his reasons, would help to reduce this opportunity and temptation.

\section{Acceptance of Lesser Pleas}

Obviously the acceptance by the prosecutor of plea of guilt of a lesser offense than that charged should, for similar reasons, be governed by the same sort of regulation as has been described-written statement of reasons, submission to and approval by the chief prosecutor, presentation of the statement in open court.

\section{Suspension and Mitigation of Sentences}

The prosecutor is interested in the sentence, as well as the proof of the offense, and it is only proper that no sentence be suspended or mitigated without affording him an opportunity to be present and present his point of view. If he instigates or favors the suspension or mitigation, the requirement that a statement of his reasons be made, approved, and presented as in the other classes of actions covered by this chapter will reduce the opportunities for carelessness or favoritism.

The reports and statements described in this chapter should each be filed with the papers of the case, and, from and after the entry of the nolle or other disposition, be treated as public documents open to public examination.

\section{The Preparation of Cases}

A serious loss in efficiency is due to the fact that, particularly in felony cases and the more grave and vicious misdemeanors, the prosecutor's offices, municipal and State, do not get in touch with the preparation of the proof at a sufficiently early stage, with the result that valuable evidence is lost or not sought, or the search for evidence is not guided by the principles of the law of evidence or of the substantive law relating to the particular crime involved. Except in an occasional case of unusual prominence, the prosecutor, who represents the public's knowledge of the law and has the ultimate responsibility for the presentation of the public's case, does not take charge of the discovery and preservation of the evidence. The specialization of work in the prosecutor's office should include the assignment to the necessary number of assistants of this function of getting on the ground early in the search and acting as the advisers of the police and detective forces engaged in the search. As a matter of office routine and system, all information obtained by those or other assistants and the transcripts of the testimony in the preliminary hearings should be made available to the members of the 
office who prepare the affidavits and indictments and who present the cases to the courts and grand and trial juries, so that all information anywhere in the office is systematically placed where needed and where it can be most effectively used.

The present division of work and responsibility between the offices of the municipal and county prosecutors in every felony case is a fruitful source of inefficiency. The municipal prosecutor is under the temptation, to which he habitually succumbs, of feeling that all he has to do is to get the case through the Municipal Court and pass it up to the county authorities. Having no responsibility for the ultimate result, he feels no responsibility for preparing the case for that ultimate result. In this attitude he is supported by the court, which generally proceeds upon the assumption that the hearing need not be thorough, since all that is required is the discovery of some indication of a violation of law, with just enough evidence to point toward the defendant as the responsible party, thus enabling the whole matter to be passed on to the grand jury. When the case does reach the county prosecutor's attention, the time for successful preparation has often gone by. Witnesses have died or have been coached or their memories affected by what they have heard and read; important documents have disappeared. The problem of centralizing the duty and responsibility of preparation is difficult, but one that must and can be met.

The simplest solution and one which should be tried as soon as the necessary legislation can be obtained is to place all State cases, both misdemeanors and felonies, in the exclusive charge of the county prosecutor from the beginning, including the presentation of the cases to the Municipal or examining court. That would involve the enlargement of the force of that office, but correspondingly relieve the municipal prosecutor's office. The present division of the work in State cases is wholly illogical and harmful.

The effective preparation and presentation of cases require the constant coöperation and coördination between the prosecutor and the police department. In Cleveland, as generally in this country, the police department is a municipal and the county prosecutor a county organ. Mr. Stanton, the present county prosecuting attorney, states that he himself has had no difficulty in obtaining all desired assistance from the police department, and in his opinion that assistance will always be forthcoming, by reason of the zeal of the members of the police force to promote the success of the cases in which they participate as arresting or detecting officers. If, however, the county prosecutor's jurisdiction is enlarged to include all stages of State cases, the necessity for this coöpera- 
tion and coördination would increase and the contacts between these two departments become more continuous. Under those circumstances there may prove to be some difficulty in maintaining the necessary coördination and coöperation, and time and experiment may develop the conclusion that the only way to bring them about in a heavily populated community like Cleveland and surrounding territory is to consolidate city and county governments, at least to the extent of a consolidation of the prosecutors, police department, courts, and other departments engaged in the administration of the criminal law. But, at the very least, all State cases should be placed in the jurisdiction of the county prosecutor, and in the meantime, that is, until this change is made, coöperative arrangements should be made between the two prosecutors' offices, whereby the county prosecutor can keep in touch with and influence the preparation of felony cases from the beginning. And the Chief of Police should assign a detail of detectives to the county prosecutor, so that he may have conveniently at hand some detective force operating under his instructions.

Through the development of criminology, psychology, and kindred sciences, a corresponding development of methods of criminal investigation has taken place. American police departments and prosecutors have not taken full advantage of these developments, so that the methods of criminal investigation in the United States have not kept pace with the intensification of the law enforcement problems nor with the facilities furnished and indicated by modern science. This is a subject falling more largely in the police division of this survey than here; but, in view of the important place of the county prosecutor in the administration of criminal justice and his responsibility for the final trial of every important case, it would seem advisable that there be attached to his office an expert in criminal investigation to assist in the preparation of cases. As long as the municipal prosecutor handles State cases, such an expert in criminal investigation should also be attached to his office.

The question of the continuity of the criminal courts has a bearing upon the preparation of the cases. The crowding of the calendars just before the judicial summer vacation and the summer accumulation make for overhurried and, therefore, underdone preparation. The individual judges and prosecutors can easily arrange for a continuity of work, while giving each a fair rest. Criminal justice cannot afford a vacation.

\section{The Grand Jury}

A case which is worthy of presentation to the grand jury at all is worthy of a careful and thorough presentation. If the steps previous 
to this presentation be taken with the care and thoroughness which have been recommended in previous chapters, the grand jury assistants of the county prosecutor will receive material which will enable them to do their work well and thoroughly. Then a stenographic report and transcript should be made of all testimony before the grand jury. This will have the effect of spurring the assistant prosecutor to his best efforts; will have the effect of reducing careless or perjured testimony; will have the effect of placing in the hands of the trial prosecutor information which will assist him in the adequate presentation of the case to the trial judge and jury. As things are at present, where the prosecutor who presents the case to the grand jury receives in most cases little more than the names of witnesses, knows nothing of the case before he starts into the hearing of it and the hearing is not treated as sufficiently dignified even to take down what the witnesses say, if the case survives this stage at all, this stage becomes little better than a mechanical passing of the matter on to the next assistant.

The present situation raises, however, a deeper question as to the appropriate place of the grand jury in the administration of justice in a modern community. To what extent does the grand jury, as now used in Cleveland, perform a necessary and useful part? At present about 90 per cent. of the felony cases receive two preliminary examinations. This means that, previous to the actual trial of the case, the witnesses appear and testify at two separate times and places; that the time and energy of two successive prosecutors are enlisted in each case; that the clerical work is doubled and the executive work, such as that of the bailiffs, is doubled. This duplication, while it places an added strain upon an already overburdened machinery, does not itself demonstrate the uselessness of this double hearing. But the fact that the case is going before another preliminary tribunal has the effect, as has been stated, of making the work of the first of these two tribunals casual and careless.

The grand jury was originally an assembly of the neighborhood for the purpose of starting the prosecution of crimes with which the neighborhood was familiar by observation or reputation. It antedated the modern system of police departments and prosecutors, who now have charge of the original institution of prosecutions. In the era of royal, baronial, or executive despotism and tyranny, the grand jury came to be looked upon as an institution which would protect the people against the deprivation of their liberties by feudal barons, kings, and other oppressors. It is no longer needed as a bulwark of our liberties, as the trial courts and juries, together with other community institutions, are 
quite capable of protecting us against executive tyranny or persecution. Generally the grand jury does little more than rubber-stamp the opinion of the prosecutor. It is almost exclusively dependent upon him for its knowledge of the law, and for its information on the facts it is almost entirely dependent on his zeal and willingness. There will always be instances in which the inquisatorial powers of the grand jury are necessary for the initial discovery or proof of a violation of law, and in which, just as at present, the prosecution will be begun before the grand jury. At times it is needed to institute inquiry into the acts of public officials themselves, being presumably more independent of the accused officials than other organs of the administration of justice. For these situations the grand jury, both regular and special, continues to have a special and valuable function, for which it should be maintained. But where the prosecution is begun in a court of preliminary examination, if that examination be conducted in a careful and orderly way, there is, with rare exception, nothing valuable for the grand jury to do, and the duplication of preliminary hearings produces the inefficiencies which have been noted in this report. In short, one preliminary examination is enough. If the preliminary examination demonstrates the justification for a trial, the prosecutor should then file an information ${ }^{1}$ in the county court and the case be submitted at earliest practical moment to the trial court and jury.

This proposal is by no means revolutionary. As long ago as 1825 Jeremy Bentham, in his "Rationale of Judicial Evidence," asserted that the grand jury, as an institution, had then been useless for fully a quarter of a century. The discussion has been going on ever since. For almost a century Connecticut has been using the prosecutor's information instead of the grand jury's indictment as the normal mode of prosecution; and 18 States have constitutional or statutory provisions for abolishing the system of double preliminary examinations.

\section{Simplification of the Bail Bond System}

There can be no good excuse for delay or neglect in the collection of forfeited bail bonds. No type of case can possibly be more simple and easy. The pleading consists of a copy of the bond and the statement that it has been forfeited. The fact of its forfeiture is a matter of record, and there is rarely any defense or anything to prove. The best procedure would be that the forfeiture of the bond itself automatically constitute

1 "Information" is the technical name given to a statement or pleading of an accusation of crime made by the prosecuting attorney as distinguished from "indictment" made by a grand jury. 
a judgment on the bond. Where, as now, suit on the bond is required, there is no reason why the suit should not be filed immediately after forfeiture and judgment and execution obtained at the earliest moment allowed by law.

The bail bond system is another place in which an unnecessary number of steps are taken, with consequent waste of effort and excessive opportunity for neglect or worse. In every felony case bound over to the grand jury three is the minimum number of successive bail bonds required; and if the case be carried to a higher court or courts, the number will go to five or seven. If, as recommended in this report, double preliminary hearings be eliminated, this number would be automatically reduced by one. The first bond, namely, the one given at the time of arrest to secure appearance in the Municipal Court, is one which the accused desires to give quickly and for which generally he has had no opportunity to prepare in advance. The obtaining of this bond ought not be made unfairly difficult, and the accused should not perhaps be required at that time to find sureties who will stand good for his appearance at all later stages of the case. Thereafter, however, he will have ample time to prepare for subsequent happenings, and there is no good reason why the second bond, given when the Municipal Court decides the preliminary or final issue adversely to the accused, should not hold good throughout the case and secure the defendant's appearance at all later stages, including his surrender for imprisonment if he finally loses; especially as under the present statute the bond becomes a lien on the surety's property from the moment it is given. This reduction of the number of bail bonds in any case to two will materially decrease administrative and clerical detail and activity, and reduce the opportunities for neglects or corruption in the acceptance or the enforcement of the bonds.

\section{The Place Where Criminal Justice is Administered}

The office space given to the offices of the prosecutors should be made adequate-that is, sufficiently roomy and well arranged to enable the work to be done in an orderly, efficient manner.

When religion is the dominant emotion and interest of a people, they put their energies and their talents into their cathedrals. The buildings we erect and pay for show where our hearts lie. It is symbolic of the situation that Cleveland erected a magnificent new court-house for her civil courts and a magnificent new city hall for her civil officials, leaving criminal justice to thrive as best she may in the old, black, and battered structures. A majestic and dignified environment has its effect on all 
who come within it. The quality of justice will reflect the quality of its home. This vital institution, where the homes and lives and liberties of her people obtain security and protection, should receive from Cleveland a home worthy of its great function.

The question whether this home should be a single structure, or a central structure with branches in different parts of the city, presents somewhat complicating considerations. The work of the police department in connection with the criminal courts, such as confinement of arrested persons in jail, bringing them before the court and testifying at the trials, could be done more economically by means of district municipal courts attached to district police stations. Under any wise arrangement, however, the central building will house the prosecutors' and clerks' offices and all jury trials, as well as special courts, such as the children's court, the traffic court, and others. The housing in one central building of all these offices and courts, including the municipal prosecutor and the criminal branch of the municipal court, would produce a large saving of time, energy, and money in the administration of the criminal law and thereby promote its efficiency.

\section{Salaries, Terms, and Selection of Personnel}

The lawyers, the judges, even ex-prosecutors themselves, attribute to the present low scale of salaries for prosecutors and their assistants the disproportion which they believe to exist between the usual ability of the incumbents of those offices and the importance of the work in their charge. Certainly the compensation is low compared with the professional earnings of other members of the Cleveland bar. The influence of this factor of salary upon the caliber of men who accept public positions may, however, be overstated. After all, the motive of public service, together with the allurements and fascination of public office, the power and prestige which public office brings, and the magnitude of the matters entrusted to the public official, will always remain potent influences in obtaining men to fill them. Moreover, a prosecutor's office should attract able young lawyers, to whom the opportunity for service and experience can be made highly attractive. The size of his salary will not remove from the weak man all the temptations which the position affords him for using his position in furtherance of his fortune or career. Political machines and leaders will continue to prefer men whom they can control, and the size of the salary will not necessarily lessen the number of such men on the list of candidates. It would, therefore, be a superficial analysis to expect this feature of increased salary alone to work a magical change in the caliber of men in these positions. 


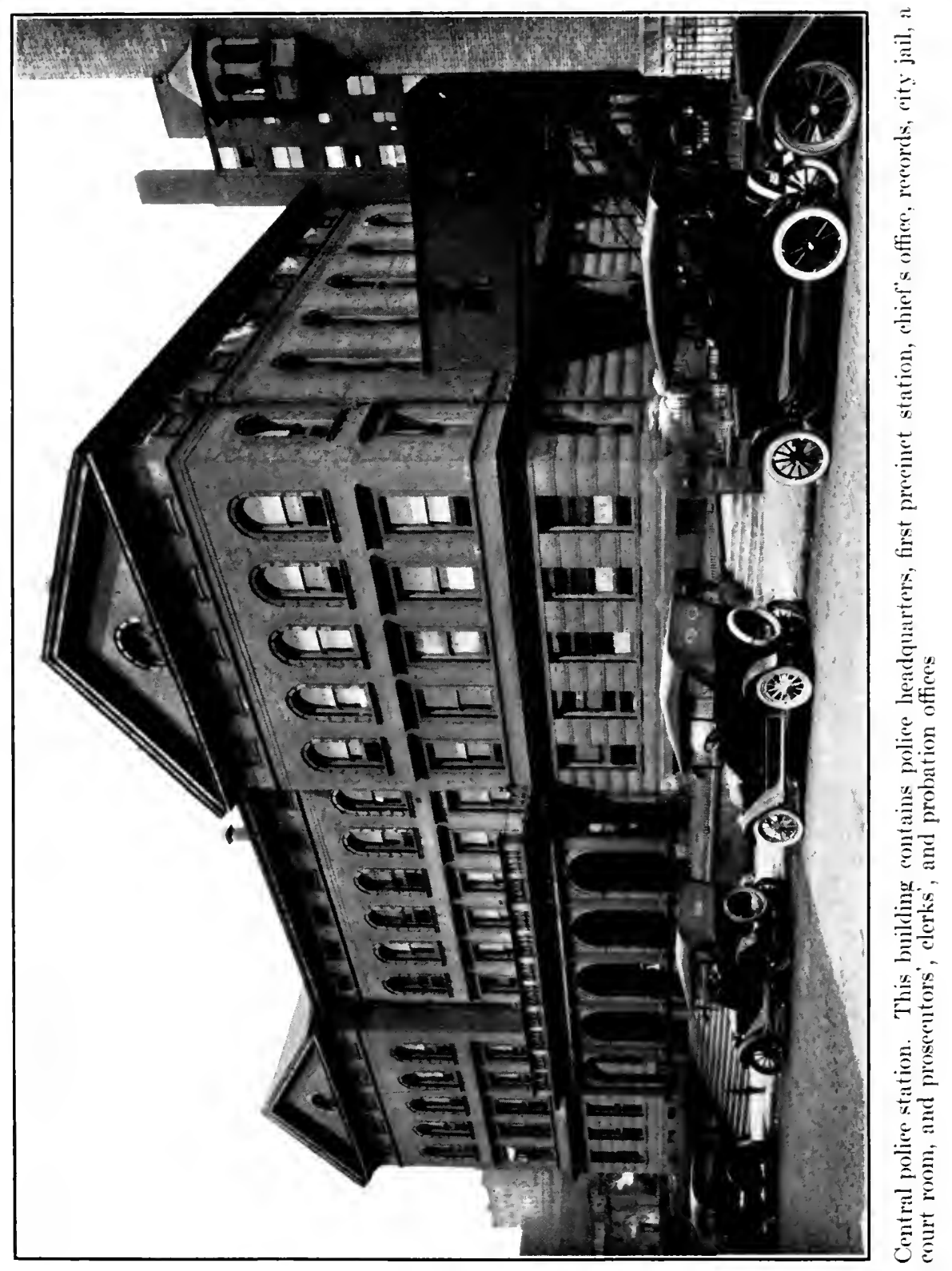




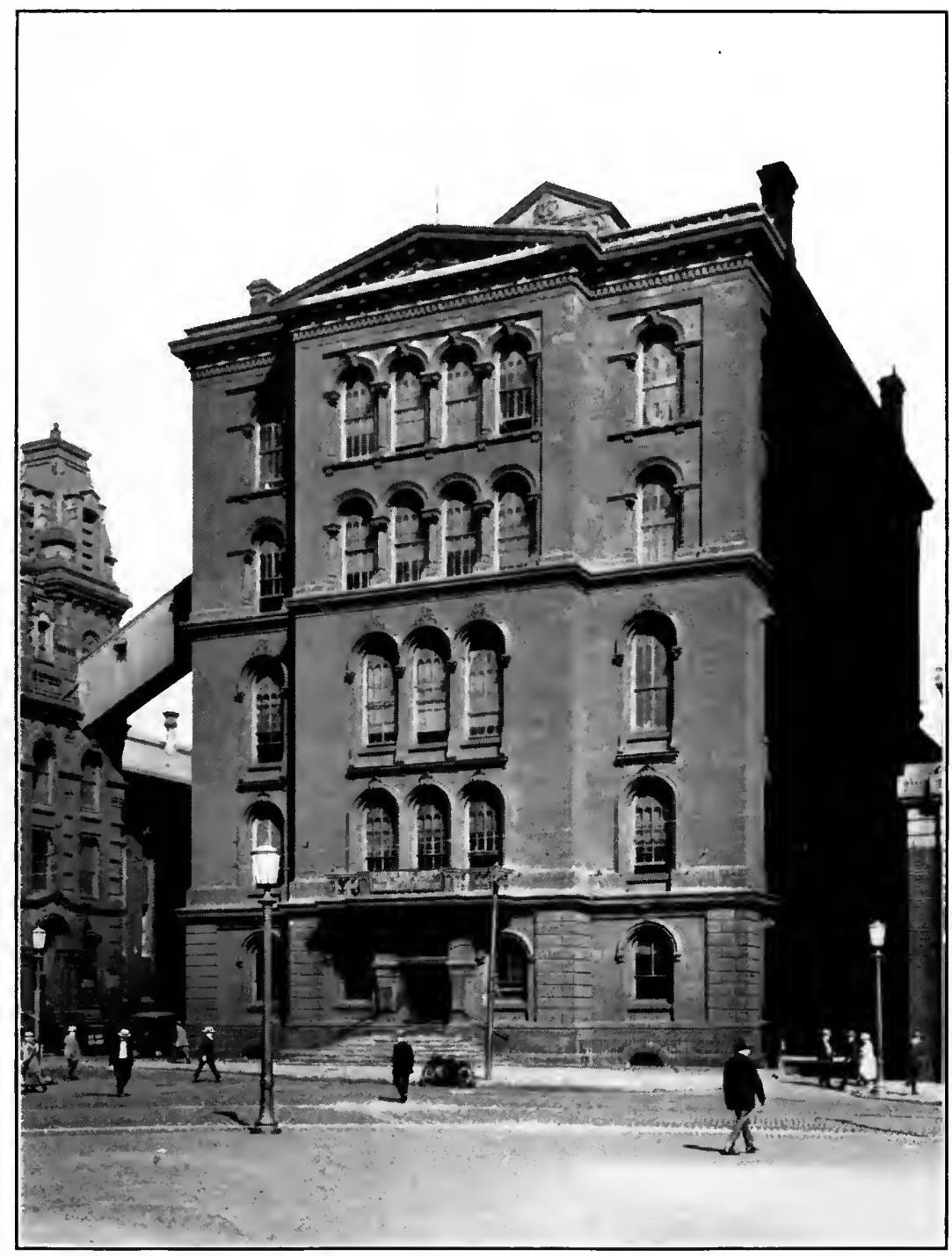

The "Old Court House" on the Public Square. This building houses two criminal court rooms, clerk's office, juvenile court, a branch of the public library, a law school, and a few county offices. A bridge connects it with the county jail 
Salary, however, does play a considerable part in the element of prestige. Taking human nature as it is, the man who receives $\$ 15,000$ per annum has an influence and an impressiveness on and over his fellowcitizens which the same man might not quite possess were his salary onethird of that amount or less. And, of course, the amount of salary plays a part in attracting men of talent. Better salaries will impair the customary excuse of the political leader that he cannot get good men to run for office.

The salary scale in the prosecutors' offices should be materially increased from top to bottom and made consistent with the importance of these positions and with the necessity of making them inviting to men of talent. An office such as that of prosecuting attorney of Cuyahoga County, with its million or more inhabitants, should have attached to it a salary of not less than $\$ 15,000$. Corresponding graded increases should be provided for the municipal prosecutor and for the assistants in the two offices.

There is no reasonable justification for the present short two-year term of office. The prosecuting attorney has questions of policy to determine, but they are more nearly administrative than legislative policies in their nature, and there is no logical reason for a short term. Four years would be none too long.

Furthermore, the frequent change in the personnel of the assistants or the change of assistants with each change in the political complexion of the chief is an absurd piece of inefficiency. With the exception of the first assistant, to whom the chief prosecutor delegates some of his discretionary powers and whom he can use for confidential matters, a competent assistant should be kept as long as he will stay. If the community cannot succeed in inducing the prosecutors or the political organizations to institute such a civil service system, this should then be established by law. The discharge of a competent assistant (other than the first assistant) for political motives should be treated by the Bar Association as unprofessional conduct on the part of the prosecutor, since he thereby subordinates the administration of justice to partisan politics. 


\section{CHAPTER $\mathrm{X}$}

\section{THE BAR AND THE COMMUNITY}

I

$\mathrm{N}$ the last analysis a community cannot escape the responsibility for the conditions and instrumentalities, inanimate and human, in and by which justice is administered in its midst. In any institution, however, there is necessarily some group within the community which, by reason of its opportunities for observation, and for the creation of conditions and atmosphere and for influence upon those engaged in the institution, must bear the greater share of responsibility. In the administration of justice, this group is, of course, the members of the bar.

\section{The BAR}

Law and custom prescribe that judges and prosecutors be chosen from the local bar. It is the lawyers who can give information to fellowcitizens regarding the caliber of candidates for these positions. Through disbarment proceedings and action of the Bar Association they can bring to bear special sanctions for the punishment of unprofessional practices and thereby create standards. In a word they may determine the tone of the administration of justice.

What has the bar of Cleveland, as a group, done or failed to do to improve the traditions, atmosphere, habits, and practices in the administration of criminal justice?

In 1921 the scandalous situation disclosed by the Kagy murder cases aroused the Cleveland Bar Association. William H. McGannon, chief justice of the Municipal Court, was with Kagy and Joyce shortly before the shooting and had spent part of the evening with them. Joyce was tried for the murder and acquitted. McGannon was tried twice, the first trial resulting in a disagreement of the jury and the second in acquittal. Joyce was a rather disreputable character and certainly no fit boon companion for the Chief Justice of the Municipal Court. The evidence in the three trials was full of contradictions and incredible statements, and the public felt sure that there had been some perjured testimony and subornation of perjury. The Bar Association forced the 
resignation of McGannon. It brought about the presentment to the grand jury of facts which resulted in a number of indictments for perjury and subornation of perjury in the Kagy murder trials, including the indictment of McGannon. Some of these, including McGannon's case, have resulted in convictions and others are still pending at the time of the writing of this report. The association contributed the services of a leading Cleveland attorney as special prosecutor and funds for the special investigations incident to the discovery of the evidence on which these perjury proceedings were based. Great credit is due to the president, officers, and members of the association for the energy and generosity with which they responded to this call for this public service.

In 1919 the community felt suspicious concerning certain aspects of the work of the office of the then County Prosecutor, Samuel Doerfler, particularly the alleged favoritism shown defendants who were represented by two former associates of Doerfler. The Bar Association appointed a committee to investigate. This committee was not able to assert with certainty proof of corruption in any particular case, but it did reprimond $\mathrm{Mr}$. Doerfler for permitting an atmosphere of favoritism to continue. The Bar Association, as distinguished from its committee, did not feel justified in acting in this instance.

According to its records and the statements of its secretaries, these two instances represent the public activities of the Bar Association relating to the administration of criminal justice in the past fifteen or twenty years. It has had active grievance committees, which investigate charges against individual lawyers. By the recent appointment of a permanent salaried executive secretary, the association has equipped itself to render more continuous and effective service. The Bar Association, as well as many individual lawyers, has given this survey active encouragement and assistance. However, the present deficiencies of the instrumentalities engaged in the administration of criminal justice represent an accumulation of many years' growth, much of which might have been foreseen and prevented. Neither the Cleveland Bar Association nor the bar of Cleveland as a group developed any machinery for continuous and habitual watch over these instrumentalities, nor have they taken the lead in either prevention or fundamental reform.

In this respect, the Cleveland association does not differ from the bar associations of other cities. Indeed, its aggressiveness in a situation even as scandalous as the McGannon affair is perhaps exceptional among bar associations in general. The outstanding characteristic of this action, however, is that it occurred after matters reached the stage of a public scandal and sensation and that it was directed at an individual case 
and not at the habits, practices, standards, and atmosphere of which that individual case was but an aggravated symptom or product.

\section{Criminal Practice and the Bar}

For purposes of this survey the following questionnaire was sent to all of the 1,418 members of the Cleveland Bar:

1. Kindly state anything that occurs to you, in as great detail as possible, concerning the administration of criminal justice in Cleveland, its merits and defects. Please include your opinion as to caliber of judges and prosecuting attorneys and defendants' attorneys in criminal cases and methods of trial.

2. What, if anything, ought to be done to improve the administration of criminal justice in Cleveland?

3. Did you ever hold a position in the office of Cuyahoga prosecuting attorney, and if so, when and what position?

4. Did you ever hold a position in the office of police or Municipal Court prosecutor, and if so, when and what position?

5 . While in private practice, what has been your policy and the policy of your law office regarding taking criminal cases?

6. To particularize, what class of criminal cases has it been your practice to accept or refuse, or what classes of clients in criminal cases has it been your practice to take or refuse?

7. State your reasons for said practice.

8. What is your practice with respect to obtaining release of clients and friends from jury service?

Feeling that the first questionnaire might have been overlooked by many lawyers who received it, a follow-up was sent by the chairman of the advisory committee of the survey, himself a member of the local bar. About 30 per cent. of the Cleveland bar had sufficient interest in the subject to send response. Of the 386 responses received, a considerable percentage contained no specific answers to any of the questions; the reason given was that the recipient had no occasion to go into the criminal courts and did not feel competent to answer the questions.

To questions 5,6 , and 7 , those relating to their policy of accepting criminal practice, the answers may be summarized as follows:

148 answered that they accept no criminal cases whatever.

52 answered that they accept them occasionally.

82 answered that they accept no such cases from regular clients in other matters.

20 answered that they occasionally accept cases where convinced of the innocence of the defendant or are impressed by some mitigating circumstances in the case.

12 answered that they take criminal practice regularly. 
The reasons given for refusing to accept criminal cases may be summarized:

The reasons of 28 were financial.

\section{7 were ethical.}

22 were æsthetic-a matter of taste.

19 were a feeling of incompetence in that class of work.

52 were a mere expression of preference for civil work.

As everybody knew before this survey was attempted, and as nearly everybody knows in every American city, except when regular clients are involved or an exceptionally large fee is in sight, most of the better grade of lawyers deliberately stay away from the criminal courts. As a result, with some notable and praiseworthy exceptions, the practice in those courts is left to the lawyers of lesser sensitiveness regarding professional practices. ${ }^{1}$ The answers to the questionnaire formed an interesting verification of this fact. The criminal branch of the administration of justice, dealing as it does with the protection of the community against crime, the promotion of the peace, safety, and morals of the inhabitants, the lives and the liberties of men, and, therefore, from any intelligent point of view, the more important branch of the administration of the law, has become a sort of outlaw field which many a lawyer avoids as he avoids the slums of the city.

\section{The Duty and Responsibility of the Bar}

The American bar has an exceedingly difficult problem. The American lawyer attempts to combine in a single individual the somewhat contradictory talents and different, though not contradictory, professional ethics of the English barrister and solicitor. There enter into much that he does not merely the motives of the advocate, but motives which may fairly be designated as commercial. In fact, by reason of this combination of barrister and solicitor, with many other characteristics of American life, a considerable percentage of the more able members of the bar largely withdraw from the field of advocacy. They get to look upon the courts as a place from which the successful man, by reason of his success, is able to stay away. They cease to care deeply about improving the caliber of the courts and practice, and become possessed of a fear of offending judges or prosecutors or political leaders, lest their displeasure have a harmful effect upon the amount of "busi-

1 Even those who, in the early stages of their careers, hold positions in the prosecutors' offices, tend later to withdraw from this field. 
ness" which flows into their offices. This destroys their willingness or ability to combat aggressively the abuses in courts and public offices.

The judges and lawyers of the criminal courts are members of this bar and reflect its standards more than appears on the surface and more than most lawyers are willing to admit. Basically, there is no ethical distinction or very little distinction between the prosecutor's entering of a nolle in a case against a friend of a political "boss" in order that he might gain or retain the favor of that "boss," and the refusal of the counsel of a leading bank to attack that prosecutor's entering of that nolle for fear that such an attack may enable that "boss" directly or indirectly to harm the bank. The element of trusteeship may be more obvious in the one case than in the other. But the principle that the lawyer is an officer of the law, a trustee of the administration of justice, is one voiced by writers on legal ethics and speakers at bar meetings amid the approving applause of the lawyers. These sentiments become meaningless gestures or hypocrisies, if they be not lived up to in practice. It behooves the bar of Cleveland, as the bars of all other American cities, to make an effort to reduce the commercialism of the practice of law and to intensify in American law practice the motives and standards which we look upon as characteristic of the English barrister.

At the very least, the lawyers of Cleveland can make an effort to increase the prestige of criminal law practice. More than they realize, the men whom they choose to honor by offices in their professional associations are men whose distinction comes from financial successes in private practice. Let them choose as the occasional recipient of honors a man who, whether on the public or the defendant's side of the table, has devoted himself, without stain or a lowering of professional standards, to the field of practice which is concerned with the lives and liberties of men and women and the peace and order of the community. Surely there has been and will be in Cleveland men who fulfill this specification, and, if they be honored, their kind will increase in number. The office of prosecuting attorney is the highest office in Cleveland in which the duties are the practice of law; and when a man receives and accepts that office, let his brother lawyers show their appreciation of the distinction. They will thereby acquire a better right to hold him to the highest ethical and professional standards.

This is not the place into which to enter into an extended discussion of the question so attractive to the layman, whether it be ethically right to represent a defendant whom the lawyer feels to be guilty. Lawyers must surely by this time have agreed upon the principle that, as every man is entitled to a trial according to law, every man is entitled to a lawyer and 
every lawyer is entitled to present the man's case regardless of the lawyer's opinion concerning his guilt or innocence. The lawyer, of course, should refuse to conduct the case in a manner not consistent with the finest ethical standards.

Criminal practice must be made a field in which the lawyer and the gentleman (in the American sense of that word) can feel at home. And one of the courses which might promote this is for the lawyers who are both lawyers and gentlemen to return to the first principles regarding the position of the lawyer as an officer of the law and accept criminal practice. If the man accused of crime knows that he can obtain firstclass talent at a reasonable compensation, he will have no excuse for taking his case to the shyster or police court hanger-on, and both the courts and prosecutors will then have some justification for feeling particularly suspicious and cautious in cases in which the defendants retain unscrupulous or disreputable lawyers. In this class of work, as in the civil practice, fees will vary according to the importance of the case and financial means of the client. The mere matter of office organization, so that the classes of work do not interfere with each other, is easily solved. When we stop to think about it, it is somewhat absurd to expect the administration of criminal justice to be in the best hands while best hands avoid it. As long as the criminal law is administered by lawyers, they, whether chosen and paid by the public or by the private client, will reflect the standards and attitude of the profession to which they belong. The bar is the pool from which they all flow. The composition of the waters of the pool determines the character of the water in the stream.

If we delve somewhat deeper into the causes of the relative failure of criminal practice to attract lawyers, we will discover that neither the greater lucrativeness of civil practice nor the physical conditions and general atmosphere of the criminal courts tell the whole story. Comparatively speaking, criminal cases do not present issues or problems of law which are as novel and varied as those in civil cases; and criminal practice consequently presents less opportunity for the stimulating intellectual processes used in working out questions of law which constitute one of the allurements of law practice.

On the other hand, the questions or issues of fact are more complex and fascinating in criminal than in civil cases. The problems and mysteries of human motive play a larger part, as well as questions relating to the mental and the moral characteristics or deficiencies of the parties to the case. Lawyers, however, receive no special training or education in these fields of human behavior and mental and moral deficiencies. To 
some extent a profession or branch of a profession acquires its prestige and its consequent attractiveness by reason of the special education and knowledge which its members require and possess. If some degree of education in criminal investigation, in psychology and kindred sciences of human behavior, and in psychiatry and sciences which deal with mental and moral diseases would come to be recognized as part of the requisite training of the criminal lawyer, the criminal field of law practice would gain a prestige which it does not now possess; not to speak of the greater competence which this special knowledge would bring.

This problem of increasing the prestige and attractiveness of criminal practice is difficult. We must strive and experiment for a solution. It is as important as any problem which a bar association can undertake to master.

\section{The Community}

The lawyers, however, are not all-powerful in the administration of justice. Judges and prosecutors are chosen by the electorate or the political organizations, and the lawyers constitute only a small fraction of these bodies. They are a portion of the Cleveland community influencing but in turn influenced by its standards. From the community the lawyers receive their temptations and their opportunities. The allurement of those temptations is furnished and the limitations of those opportunities are fixed by the community. The whole community must share praise or blame for the moral and intellectual standards of its administration of the law as of its other institutions. The community forces are, therefore, relevant factors in determining the quality of the administration of criminal justice.

Cleveland has grown with tremendous rapidity. This means that there have flowed into it, in the past twenty years, great portions of the recent immigrant streams from Europe. This naturally has intensified the problems of assimilation and adjustment incident to large immigrant populations. ${ }^{1}$ The strength of the two main political parties does not differ greatly, with the usual result that the leaders do some confederating in the distribution of positions and favors. The leader or organization of the successful party is sufficiently powerful to select those who are to fill the available positions. But neither of the two "machines," however, has developed to that degree of efficiency and close-knit organization where it, by its own means of control, enforces an organic unity and cohesiveness in the conduct of the public offices.

Because of the rapid growth of the city financially and industrially,

1239,538 are foreign-born, out of a total population of 796,836 . 
the opportunities for money making have been great and talk of money making is much in the air. The opportunities for a lucrative law practice are great, and young practitioners with ability and talent can easily obtain greater professional incomes than the salaries in the prosecutors' offices.

The theory of the American form of government and political organization is that the public applies its intelligence to the selection of its officials, trusting to those officials for the efficiency of their accomplishments. But, at least in the highly complex life of the rapidly growing American city, the theory does not completely succeed in practice. Experience tends to demonstrate that, in addition to and outside of our governmental and political institutions, we need non-official agencies with the function of surveying, measuring, appraising the work of the governmental and political agencies and keeping the public informed about that work in a way which the public can understand. Hence an institution such as the Cleveland Bureau of Municipal Research, whose interest is in the operation of the municipal government of Cleveland, particularly in its fiscal departments, and, by advice to and coöperation with the officials and by reports to the public, to improve methods and results.

As is the case with other American cities, Cleveland has developed no such civic agency in relation to the administration of justice. There are a number of organizations or groups which, from civic or commercial motives, watch special classes of cases, either with the object of promoting more efficient prosecution or of protecting persons from official persecution or injustice. Many of these do good work and the combined effect of their activities is valuable. For instance, the Cleveland Safety Council of the National Safety Council and the Cleveland Chamber of Commerce reports traffic violations and, through a permanent executive and a large corps of volunteers, carefully watches all traffic cases and calls attention to all failures of aggressive and intelligent prosecution. Similarly, the Advertising Club promotes the prosecution of "fake" advertisements; the Cleveland Animal Protective League looks after cruelty to animal cases; the Consumers League, violations of factory and employment laws; Dry Maintenance League, administration of the liquor laws; the Cleveland Humane Society, cases involving children and animals. The Retail Merchants Board of the Chamber of Commerce employs an attorney to render the same sort of service in cases of fraud, shoplifting, and other offenses harmful to retail merchants. The Women's Association for Justice and the Women's Protective Association aim particularly to protect ignorant persons and women involved in vice cases from injus- 
tice. There are others. Each of these, however, concentrates upon the conduct of some special type of case in which it has a special interest; none of them attempts to dig into fundamentals, or to study and improve the administration of criminal justice as an organic whole. For this the city has relied on the press, and on spasmodic special grand juries and special prosecutors and special "graft" investigations in times of clamor. In this basic field of law enforcement neither the Bar Association nor any other group has as yet created an agency for constant, thorough, and expert research into justice as it is administered.

Like the courts and the prosecutors' offices, the community itself has been using the jam and drift method. Every once in a while the accumulation of miscarriages of justice, scandals, and unpunished crimes arouses the community and it institutes a special grand jury investigation or a specially aggressive newspaper campaign or a survey, and then, forgetting that the accumulation was the inevitable result of the habitual defects in the machinery, it turns to something new, whereupon the old ways go on toward the next inevitable accumulation. Unfortunately, since royalty and autocracy have gone out of fashion, there is no device yet invented whereby the public can leave public matters entirely to public officials and at the same time get the results which it desires. Continuous public check, scrutiny, reform, praise, condemnation, election, discharge, are necessary.

Cleveland should establish a special agency to perform this checking and reforming function. This bureau should have the funds necessary to enable it to perform its functions thoroughly. Of existing organizations, the Cleveland Bar Association is the one which, for many obvious reasons, might well organize and maintain or, at least, supply professional talent to this Bureau.

The formulation in detail and the carrying out of those recommendations of this survey which are deemed worthy of adoption can be made the initial program of this bureau. Thereafter it would have the function of keeping a fairly continuous check upon the work of the criminal courts and of all officials and other persons engaged in any phase of the administration of criminal justice; in other words, not a survey of the past or of the accumulated driftwood of the past, but a continuous discovery of symptoms and of diseases in their incipiencies and continuous effort to prevent the diseases from gaining headway.

But, we hear the skeptic say, will not the same forces, political or otherwise, which cause a decline in standards in the administration of justice, proceed to starve or crush your bureau when it becomes an effective agency of reform? Then will you establish a second bureau to 
keep tab on the first? The answer is that if the community permits, that is just what will occur. A community cannot escape from itself. Powerful political organizations are bound to exist in American cities. They have necessary and useful functions to perform. But no political organization will ever be so powerful that it can resist the genuine desires or standards of the community. If the community be willing that its officials be controlled to the detriment of the administration of justice or any other public institution, no mere piece of machinery, official or non-official, will long succeed in standing in the way. Each intelligent step taken to remove an existing defect or institute an improvement leaves a permanent residuum of progress. In the end, however, the community must impose the standard. There is no possible method of escape from its indifference to a high standard of ethics and efficiency. If Cleveland cares not merely for the results in an occasional sensational or scandalous case, but for a high standard, applied hourly, daily, weekly, year in and year out, in the administration of criminal justice, it will attain that standard.

It is in the course of actually participating in a survey of the nature of this one, and in the process of developing suggestions for remedies, that one becomes conscious as never before of the unescapable influence of the atmosphere, the traditions, the ideals, the ambitions, and the standards of the community itself. 
: 


\title{
PART III \\ THE CRIMINAL COURTS
}

\author{
BY \\ REGINALD HEBER SMITH \\ AND \\ HERBERT B. EHRMANN
}




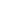

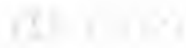

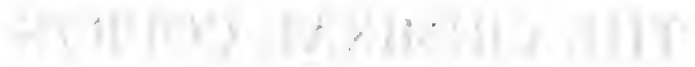

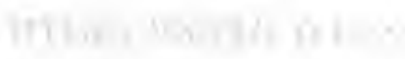

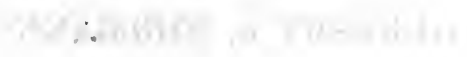

- 


\section{THE CRIMINAL COURTS}

CHAPTER I

\section{THE FUNDAMENTAL TROUBLE}

NALYSIS of the administration of criminal law in Cleveland reA veals a failure of self-government in one of the city's most vital functions. It does not, or should not, matter to the citizens of Cleveland that other large American cities have failed, for Cleveland has at times won national recognition for its pride and leadership in civic affairs. Moreover, the success of the democratic experiment in America requires that no community shall tolerate conditions found to exist in this city once the facts are known.

Care must be taken not to ascribe the Cleveland failure to the evil work of individuals alone, although undoubtedly there has been exploitation by those whose elimination would have a salutary effect. Their removal, however, would not effect a cure. On the contrary, popular clamor for a victim diverts attention from the real difficulties, which are not capable of so easy and dramatic a solution. The conditions which make exploitation possible must be removed before permanent improvement can be effected.

These conditions are, first, the persistence of a system of criminal justice become obsolete and wholly inadequate through the rapid growth of urban population and modern industrial life; and, second, the unorganized, uninformed, and socially indifferent attitude of the more intelligent portion of the citizenship, brought about by concentration on material prosperity to the exclusion of civic life. The pages of this report tell the story, often in bare statistical form, of how an inadequate system is made use of to defeat the ends of criminal justice in the absence of an informed and watchful social conscience.

Signs are not wanting that Cleveland is waking up to this situation. A growing perception and outspokenness on the part of some judges and other public officials is one of a number of such symptoms. Men of ability are coming forward to devote their services to the public interest; the Bar Association, the press, and the legislators from Cuyahoga County 
are becoming more alert. The "crime wave" and several notorious cases have aroused the community to action, with the result that Cleveland has taken the unusually courageous step of asking for and publishing a survey of its administration of justice. It remains to be seen whether this interest is a mere spasmodic outburst of energy, or whether Cleveland is really ready to undertake the task of changing underlying conditions, and, having changed the system, its sources and its atmosphere, to maintain an aroused and informed civic conscience which will prevent a relapse to old evils. 


\section{CHAPTER II}

\section{STRUCTURE OF THE PRESENT SYSTEM}

7 HE present method of administering criminal law is built upon two court systems, two prosecutors' offices, and a grand jury.

The criminal division of the Municipal Court has jurisdiction over misdemeanors, ${ }^{1}$ violations of city ordinances, and preliminary examinations in cases of felony. Its misdemeanor jurisdiction is reviewable by the Court of Appeals or the Common Pleas Court for errors of law only, so that the system avoids the evil of permitting two trials on the merits, which is so common to American cities with inferior and superior courts. A defendant who desires a jury trial must claim it seasonably ${ }^{2}-$ but there are relatively few such trials. ${ }^{3}$ The geographic jurisdiction of the Municipal Court is limited to the city of Cleveland.

When a person is arrested for a felony, the Municipal Court holds a preliminary examination, unless the defendant waives his right to such examination. If the court finds there is probable cause, or the examination is waived, the court has the power to "bind over" to the grand jury. The grand jury sits practically continuously except during July and August, which is another advantage over many cities. The prosecuting attorney for Cuyahoga County then presents evidence to the grand jury, and if a prima facie case is made out, the grand jury returns a "true bill," stating the crime for which the defendant is indicted, after which the case proceeds before a judge of the Common Pleas Court through the usual stages of arraignment, plea, trial, and disposition. In all its essentials the theory of handling felonies is the same as it has been for hundreds of years, and is now used, in village and metropolis alike, throughout the country.

The Common Pleas Court has geographic jurisdiction throughout Cuyahoga County, so that some of its cases come from petty magistrates

1 Misdemeanors are violations of State laws not punishable by imprisonment in the penitentiary.

2 Ohio General Code 1579, Section 24.

${ }^{3}$ In 1920 , out of 2,608 cases, there were only 15 jury trials. 
outside the city of Cleveland. The number of such cases is not large. ${ }^{1}$ Occasionally the grand jury returns an indictment without prior proceedings, usually where it would be inadvisable to warn the defendant by proceedings in an inferior court. ${ }^{2}$

This is the general structure of the Cleveland system. We now observe how it works in practice.

2 Among all cases begun in the Common Pleas Court in 1919, the number of such cases was 155 , or 4.8 per cent.

2 Among all cases begun in the Common Pleas Court in 1919, the number of original indictments was 306 , or 9.5 per cent. 


\section{CHAPTER III}

\section{THE SYSTEM IN PRACTICE}

\section{INFLUENCES Evoked BY ArRests}

$A^{s+2}$ STUDY of the practical working of criminal justice should begin with some consideration of the powerful dynamic agency released through the arrest of a man upon a serious charge. The instinct of self-preservation sometimes leads a felon to commit murder in resisting arrest, and once in custody, his whole being is concentrated upon the single idea of getting out. Parents and relatives, who had apparently given him up as a lost soul, rally loyally to rescue him from the penitentiary, often pledging their last cent for the purpose. Few felons are so disreputable that there is no one to fight for their liberty. The friends who do not come forward willingly are forced into line by every human incentive. It is often surprising how far and into what regions this active agency can penetrate. "Beginning in the slums, among the recidivists," observed the oldest judge on the Cleveland bench, "waves of influence are set up that reach higher and higher until they envelop respectability. Men with spotless reputations, whose motives cannot be doubted, will urge a judge to parole a professional criminal. How did they get there? The trail leads back to the slums-investigate the twilight zone."2

\section{The Professional Criminal Lawyer}

Another factor to be considered, partly the result of the foregoing and partly the result of many other causes, is the professional criminal lawyer. A poll of the bar of Cleveland shows that most lawyers dislike criminal practice, partly because of a feeling that it is detrimental to civil practice and partly because of professed ignorance or dislike of the required technique. The result is that a large part of the lucrative practice in the

1 During April, 1921, a number of gangsters were arrested for murder. The following day an audacious payroll robbery occurred. "Raising money for the boys' defense," remarked an old detective knowingly.

2 Following a most atrocious double murder and payroll robbery, a number of typical pool-room habitués were arrested as suspects. Bail of $\$ 40,000$ each for some of these men was promptly furnished from most respectable sources. 
criminal courts goes to a small number of specialists. Considering all the Common Pleas criminal cases begun in 1919, we find 244 lawyers appearing in a total of 363 cases, no single lawyer appearing in more than three cases, against 89 lawyers appearing in a total of 842 cases, ${ }^{1}$ no one appearing fewer than three times. About one-fourth of the privately retained lawyers appeared in more than two-thirds of the cases. Twentyeight lawyers appeared 10 or more times each in 492 cases, or one-twelf th of the lawyers in considerably more than one-third of the cases. Moreover, many of this small group of professional criminal lawyers are in politics. Were the system as invulnerable as Achilles, these political criminal lawyers would find the penetrable heel.

Opposed to these forces is the prosecutor's office, consisting chiefly of underpaid and often inexperienced assistants, with no personal interest in the cases, and without a tradition of energetic public service. Under such conditions the best system of criminal justice would be subjected to strain, and it is not surprising that the present antiquated system has broken down.

\section{Too Many Steps in the Procedure of Justice}

To a layman, or a lawyer in civil practice, the administration of criminal law means a jury trial in open court. The civil lawyer understands that in this ordeal by battle between the prisoner's champion and the prosecutor, the State is under a burden of strict rules of evidence which make convictions difficult to obtain. He may also realize the disparity in ability between the poorly paid prosecutor and the retained private lawyer, and the manifest failure of the State to assure adequate preparation for trial. ${ }^{2}$ What he fails to grasp fully, and what the layman also does not realize, is that the dramatic episode of a trial is relatively only a small part of the system.

In the first place, many offenses are committed for which no one is arrested. This is a problem of police administration. After an arrest is made, the police may release the prisoner because of insufficient evidence, or turn him over to other authorities. In Cleveland there is a practice in the police department of releasing, or "golden-ruling," first offenders, but this practice is rarely used in felony cases. These matters are all questions of police policy. Once a man is held, however, the judicial processes begin to operate. The police prosecutor may report "no

This is exclusive of cases where counsel was appointed by the court to aid indigent prisoners and cases in which more than one lawyer appeared for the defense.

2 This is dealt with in detail in the report on the prosecutor's office. 
papers," in which case the prisoner is released without further proceeding. Or the police prosecutor may move to "nolle"-i.e., nolle prosequi ${ }^{1}$ - the case, which also liberates the prisoner. The lower court may find that there is "no probable cause" and discharge the prisoner. The grand jury may fail to indict a defendant by returning a finding of "no bill." If a man is indicted, the prosecuting attorney in the Common Pleas Court may move to "nolle" the case. The defendant may plead guilty, either on arraignment or by change of plea later. In addition, among the cases begun in 1919, a number disappeared in ways not properly classed as dispositions; for instance, those who were never arrested after indictment and those who jumped their bail in the Common Pleas Court.

A diagram based upon a study of all cases begun in the Common Pleas Court during 1919, supplemented with information supplied by the police department with respect to disposition of felony cases outside of this court, would look approximately as in Diagram 1.

A more detailed picture may be gathered from Table 1 .

Classifying these dispositions under general heads, and adding the events that may occur before a case reaches the Common Pleas Court and after conviction, we have the following enumeration of different methods by which it is possible for an offender to escape under the guidance of an expert:

\section{Felonies and Misdemeanors (Municipal Court)}

1. "No papers"

2. "Nolle prosequi"

3. Discharge, want of prosecution

4. Discharge after hearing

Misdemeanors-Municipal Court
5. Suspended sentence
6. New trial
7. Appeal
8. Parole from workhouse

Felonies-Common Pleas Court

5. "No bill" by grand jury

6. Failure to arraign

7. "Nolle prosequi"

8. Discharge, want of prosecution

9. Not guilty after trial

10. Plea guilty of lesser offense

11. Suspended sentence

12. New trial

13. Appeal

14. Parole from institution

15. Pardon

Throughout this procedure there is always the possibility of the defendant jumping bail should his case assume a hopeless aspect.

${ }^{1}$ Literally and in practice this means, "I am unwilling to prosecute." This motion, which has a long history, is the secret of great power in the prosecutor's office. 
Of 1,000 Felony Arrests-

127 were disposed of by the police

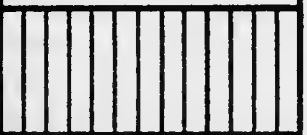

85 were "nolled" or "no-papered" by the police prosecutor

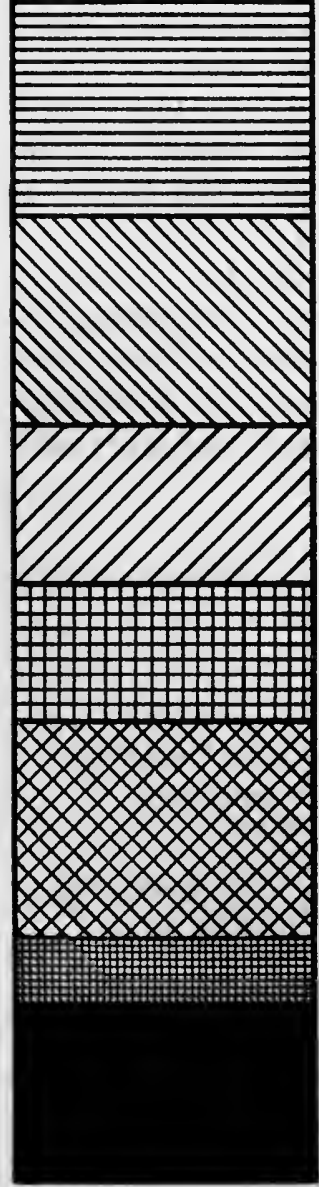

143 were discharged or dismissed or found guilty of a misdemeanor in Municipal Court

139 were "no-billed" by the grand jury

107 were "nolled" by the county prosecutor

91 made an original plea of guilty

148 changed the plea to guilty

42 were variously disposed of

\section{8 came to trial}

Diagram 1.-The disposition of each 1,000 cases of felony arrests

The proportions here represented are derived from Table 1. Beginning with item 6 the items are multiplied by .896 , which is the quotient of 2,901 divided by 3,236 ; $i$. e., by a factor reducing the items by as much as the total "bound over" $(2,901)$ is smaller than the total cases in the Common Pleas Court $(3,236)$. 


\begin{tabular}{|c|c|c|c|}
\hline 1919 & $\begin{array}{c}\text { Number } \\
\text { of } \\
\text { cases }\end{array}$ & $\begin{array}{l}\text { Per cent. } \\
\text { of } \\
\text { total cases }\end{array}$ & $\begin{array}{l}\text { Per cent. } \\
\text { Common } \\
\text { Pleas cases } \\
\text { exclusive of } \\
\text { "no bills" }\end{array}$ \\
\hline $\begin{array}{l}\text { 1. Total cases } \\
\text { 2. Disposed of by the police } \\
\text { 3. "No papers" and "nolled," Municipal Court } \\
\text { 4. Discharged, dismissed, or charges reduced to } \\
\text { misdemeanors, Municipal Court } \\
\text { 5. Bound over }\end{array}$ & $\begin{array}{r}4,499 \\
572 \\
382 \\
\\
644 \\
2,901 \\
\end{array}$ & $\begin{array}{r}100.00 \\
12.71 \\
8.49 \\
14.31 \\
64.48 \\
\end{array}$ & $\begin{array}{l}\cdots \\
\cdots \\
\cdots \\
\cdots\end{array}$ \\
\hline $\begin{array}{l}\text { Total cases begun in } 1919 \text {, Common Pleas Court } \\
\text { 6. "No bill" by grand jury } \\
\text { 7. Total disposed of in Common Pleas Court } \\
\text { 8. Total disposed of on plea of defendant } \\
\text { 9. Total disposed of not on plea of defendant }\end{array}$ & $\begin{array}{r}3,236 \\
697 \\
2,539 \\
1,215 \\
1,324 \\
\end{array}$ & $\begin{array}{l}\cdots \\
\cdots \\
\cdots \\
\cdots\end{array}$ & $\begin{array}{r}\cdots \\
100.0 \\
48.0 \\
52.0\end{array}$ \\
\hline $\begin{array}{l}\text { 10. Subdivisions of } 8 \text { : } \\
\text { a. Original plea guilty } \\
\text { b. Original plea guilty lesser offense } \\
\text { c. Original plea not guilty, changed to } \\
\text { guilty Original plea not guilty, changed to } \\
\text { guilty of lesser offense } \\
\text { e. Others }\end{array}$ & $\begin{array}{r}433 \\
22 \\
\\
550 \\
\\
193 \\
17 \\
\end{array}$ & $\cdots$ & $\begin{array}{r}17.1 \\
0.9 \\
21.7 \\
7.6 \\
0.7 \\
\end{array}$ \\
\hline $\begin{array}{l}\text { 11. Subdivisions of } 9 \text { : } \\
\text { a. Nolled for all causes } \\
\text { b. Not arraigned } \\
\text { c. Bail forfeited } \\
\text { d. Dismissed or discharged } \\
\text { e. Trial, not guilty of felony } \\
\text { f. Trial, not guilty of misdemeanor } \\
\text { g. Trial, guilty of felony } \\
\text { h. Trial, guilty of misdemeanor } \\
\text { i. Others }\end{array}$ & $\begin{array}{r}536 \\
57 \\
33 \\
31 \\
215 \\
8 \\
293 \\
74 \\
77\end{array}$ & $\begin{array}{l}\cdots \\
\cdots \\
\cdots \\
\cdots \\
\cdots \\
\cdots \\
\cdots \\
\cdots\end{array}$ & $\begin{array}{r}21.1 \\
2.2 \\
1.3 \\
1.2 \\
8.5 \\
0.3 \\
11.6 \\
2.9 \\
2.9\end{array}$ \\
\hline $\begin{array}{l}\text { 12. Subdivisions of } 11 \text { a: } \\
\text { a. Nolled after commitment for insanity } \\
\text { b. Nolled after new trial granted } \\
\text { c. Nolled after jury disagreement } \\
\text { d. Nolled after plea guilty on other counts } \\
\text { e. Nolled after conviction on other counts } \\
\text { f. Nolled after transfer to Juvenile Court } \\
\text { g. Nolled because defendant already sen- } \\
\text { h. Nolled on all counts, no reason assigned }\end{array}$ & $\begin{array}{r}2 \\
13 \\
6 \\
6 \\
5 \\
21 \\
84 \\
399\end{array}$ & $\begin{array}{l}\cdots \\
\cdots \\
\cdots\end{array}$ & $\begin{array}{r}0.1 \\
0.5 \\
0.2 \\
0.2 \\
0.2 \\
0.8 \\
3.3 \\
15.8\end{array}$ \\
\hline
\end{tabular}

1 This table is composed of figures from three different sources: item 2 is from the records of the Division of Police; items 3, 4, and 5 are from summaries of the figures of the execution docket of the Municipal Court from December 19, 1918, to December 31,1919 , and the remainder are from the survey statistics of the cases begun in 1919 in the Common Pleas Court. Since this court handles cases besides those from the Municipal Court, the totals, 2,901 ("bound over") and 3,236 ("no bill" plus "total disposed of"), are not identical. In Table 1, 4,499 is regarded as the base, and the proportions of various dispositions for all Common Pleas cases are assumed to apply to the 2,901 cases bound over. See Table 3 in the report on prosecution. 
With all these avenues of escape open, it is not surprising that Cleveland has had extreme difficulty in punishing its criminals or in restraining crime by swift and certain justice. The business of justice is like a complicated game, the odds favoring him who has the intense desire to win plus the skill of an expert on his side. As between defendants, the advantage lies wholly with the habitual offender, who has played the game before and knows the expert to employ. The situation is portrayed in Diagram 2.

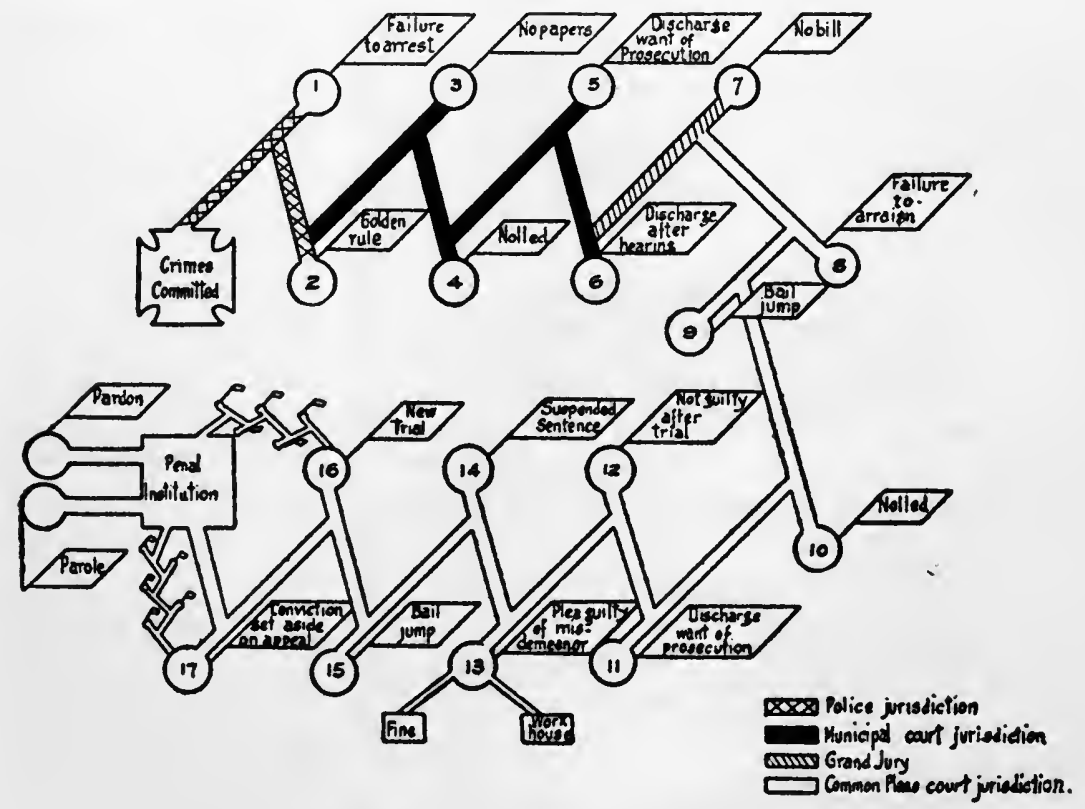

Diagram 2.-The path of justice

How the System is "Worked" for Weak Spots

The files of the Bureau of Criminal Identification of the Cleveland Division of Police contain the records of the most successful players of this game. Only a few examples can be given here because of lack of space. Most of the men are criminals by profession, though some are only occasional offenders. It is interesting to note by contrast the decisive results of Federal prosecution where the offender runs afoul of the Federal law. Unless noted otherwise, the place is Cleveland. 
No. 10238

1911 Robbery

1911 Attempted burglary

1911 Violating parole

1914 Forgery

1915 Burglary and larceny

1915 Suspicious person

1915 Assault to rob (two cases)

1916 Assault to rob

1916 Burglary

1916 Contempt of court

1916 Intoxication

1916 Intoxication

1916 Burglary and larceny

1919 Burglary and larceny

1919 Robbery

1919 Suspicious person

1920 Burglary and larceny

1921 Suspicious person
Disposition or explanation

"Bench parole"

Discharged in Municipal Court

Turned over to Ohio State Reformatory

No bill

Plead guilty to petit larceny

Sentence, 30 days

"Bench parole"

No bill

Not guilty

Discharged

Suspended sentence

Sentenced, $\$ 25$ and 30 days

"Nolled"

Plead guilty to petit larceny

Not guilty

Discharged

Plead guilty to petit larceny

Sentenced to $\$ 25$ fine

No. $12919^{1}$

1914 Assault to rob

1919 Receiving stolen property (automobile body)

1920 Suspicious person

1920 Auto-stealing (five indictments)

"Nolled" in Common Pleas Court

Disagreement

"Nolled"

Guilty; appeal; petition in error never entered; sentenced to Ohio State Reformatory

1921 Murder and robbery (while out Sentenced to be electrocuted on bail after conviction on fourth charge)

No. 10480

1910 Assault and battery

1911 Assault and battery

1911 Assault and battery

1911 Assault and battery

1911 Indecent language

1911 Assault and battery Violating sidewalk ordinance

Discharged

Suspended sentence

Discharged

Suspended sentence

Discharged

Discharged

1911 Assault to kill (fractured victim's skull with iron bar)

1911 Murder (assault)

1917 Murder (shooting)

Convicted of assault and battery

Plead guilty to manslaughter. Sentence, one year

Convicted of manslaughter

No. 10482

1897 Grand larceny

Sentenced, $\$ 100$ and 30 days for receiving stolen property

Discharged

1906 Assault and battery

1911 Violating Sunday law (saloon open)

1911 Assault and battery

1911 Murder

Discharged

Plead guilty to assault and battery; suspended sentence

1 Head of an organized band of auto thieves. See Ohio Motorist, February, 1921. 
No. 10482-Continued

Year

1915 Carrying concealed weapons

1916 Receiving stolen property (automobile)

1916 Receiving stolen property (automobile)

\section{Disposition or explanation}

Discharged

Indicted November 14, 1916

"Nolled" April 10, 1919

Indicted November 14, 1916

"Nolled" March 15, 1918

No. $7042^{1}$

1905 Grand larceny (30 pairs shoes)

1910 Burglary and larceny

1913 Suspicious person

1914 Suspicious person

1914 Grand larceny (automobile)

1915 Suspicious person (pocketpicking)

1915 Suspicious person

1916 Pocketpicking

1917 Suspicious person

1917 Rape (identified by victim)

1917 Suspicious person (pocketpicking)

1918 Suspicious person

1918 Violating auto law

1918 Grand larceny

1918 Robbery (wounded two policemen in escaping)

1918 Murder (killed policeman in es- Not arrested caping)

1919 Grand larceny (safe-blowing)

1909 Burglary and larceny

1909 Petit larceny

1910 Burglary

1910 Petit larceny

1910 Petit larceny

1911 Grand larceny

1913 Grand larceny

1913 Grand larceny

1913 Grand larceny

1916 Forgery

1916 Petit larceny Assault and battery ?

Disturbance

1916 Housebreaking (two cases)

1916 Robbery

1917 Robbery (three cases)

1917 Robbery

1917 Robbery (post-office)
Plead guilty to petit larceny

No bill

Discharged

"Nolled"

Turned over to Geneva authorities

Discharged

Discharged

Never arraigned

"Nolled"

Discharged in Municipal Court

"Nolled"

"Nolled"

Discharged in Municipal Court

Not arrested

Not arrested

No. 9407

Sentence, $\$ 25$ and 30 days

Houston, Texas; sentenced to $\$ 100$ and three months

Suspended sentence

No papers

Toledo, O.; sentenced to Ohio State Reformatory

State of Washington; sentenced to penitentiary

Discharged in Municipal Court

Discharged in Municipal Court

Discharged in Municipal Court

Discharged

Discharged

Discharged

Discharged in Municipal Court

"Nolled" (because of Federal action), see below

Sentenced by Federal court, seven years in Atlanta Penitentiary

1 Arrested in 1919 for the larceny, robbery, and murder of 1918 and the grand larceny of 1919; plead guilty to homicide on the murder; judge found second degree murder and sentenced him for life June 27, 1919. Other cases "nolled." 
If we observe the operation of the system over a series of years its weaknesses become clearer. Through the industry and courtesy of George Koestle, superintendent of the Bureau of Criminal Identification, of the Division of Police, the figures on the dispositions of felony cases for years 1914-1920 inclusive are available in Table 2. The arrangement has been changed somewhat, and a number of adjustments made with the approval of Mr. Koestle, but otherwise the basic figures given are exactly as compiled by the Bureau.

TABLE 2,-DISPOSITION OF FELONY CASES, 1914-1920, FROM THE RECORDS OF THE DIVISION OF POLICE

\begin{tabular}{|c|c|c|c|c|c|c|c|}
\hline & 1914 & 1915 & 1916 & 1917 & 1918 & 1919 & 1920 \\
\hline $\begin{array}{l}\text { 1. Total number felony arrests } \\
\text { 2. Total accounted for by ac- } \\
\text { tion other than that of } \\
\text { Municipal or Common } \\
\text { Pleas Court } \\
\text { 3. Cases pending in Municipal } \\
\text { Court } \\
\text { 4. Cases disposed of by Mu- } \\
\text { nicipal Court } \\
\text { a. Bound over to grand } \\
\text { jury } \\
\text { b. "Nolle prossed" } \\
\text { c. Discharged in Muni- } \\
\text { cipal Court } \\
\text { 5. Total cases, Common Pleas } \\
\text { Court } \\
\text { a. Cases in which no true } \\
\text { bill is found } \\
\text { b. "Nolle prossed" } \\
\text { c. Tried and acquitted } \\
\text { d. Number insane } \\
\text { e. Balance found guilty or } \\
\text { plead guilty } \\
\text { I. Sentenced but pa- } \\
\text { roled } \\
\text { II. Returned as parole } \\
\text { violators } \\
\text { III. Sentence suspended } \\
\text { IV. Miscellaneous } \\
\text { V. Sentence carried out }\end{array}$ & $\begin{array}{r}82 \\
50 \\
1,573 \\
1,263 \\
122 \\
186 \\
1,398 \\
279 \\
154 \\
26 \\
\ldots \\
939 \\
240 \\
11 \\
61 \\
627\end{array}$ & $\begin{array}{r}278 \\
32 \\
1,847 \\
1,491 \\
125 \\
\\
231 \\
1,794 \\
\\
338 \\
268 \\
43 \\
\ldots \\
1,145 \\
272 \\
\\
24 \\
77 \\
772\end{array}$ & $\begin{array}{r}57 \\
2,348 \\
1,916 \\
173 \\
\\
259 \\
1,963 \\
\\
501 \\
260 \\
64 \\
\cdots \\
1,138 \\
283 \\
\\
17 \\
72 \\
2 \\
764\end{array}$ & \begin{tabular}{|r}
441 \\
54 \\
3.116 \\
2,443 \\
263 \\
\\
410 \\
2,829 \\
623 \\
494 \\
151 \\
2 \\
1,559 \\
340
\end{tabular} & $\begin{array}{r}494 \\
80 \\
2,987 \\
2,432 \\
227 \\
328 \\
2,636 \\
768 \\
395 \\
72 \\
1 \\
1,400 \\
233 \\
22 \\
170 \\
6 \\
969\end{array}$ & \begin{tabular}{|r}
625 \\
57 \\
2,778 \\
2,120 \\
210 \\
\\
448 \\
\\
3,325 \\
\\
745 \\
662 \\
234 \\
4 \\
1,680 \\
216 \\
27 \\
231 \\
14 \\
1,292
\end{tabular} & $\begin{array}{r}822 \\
63 \\
2,903 \\
2,235 \\
294 \\
\\
374 \\
\\
2,891 \\
\\
617 \\
933 \\
182 \\
1 \\
1,158 \\
\\
81 \\
4 \\
40 \\
50 \\
20 \\
1,003\end{array}$ \\
\hline
\end{tabular}

Glancing at Table 2 makes it apparent that the "crime wave" has not been created wholly by a "yellow press." It must be noted also that this table includes only the serious criminal cases (felonies), so that the table would be unaffected by temporary strictness or relaxation in dealing with offenses usually the subject of reform, such as drunkenness, gambling, and prostitution. The population of Cleveland increased 42 per cent. 
from 1910 to 1920 , yet arrests for serious crime since 1914 only have increased 122 per cent., cases bound over 77 per cent., and the number of cases in the Common Pleas Court over 100 per cent. The number which were actually found or which pleaded guilty had increased 79 per cent. in 1919, but in 1920 dropped to 23 per cent., the lowest figure since 1916.

It happens that the period covered furnishes an opportunity to demonstrate the ability of the criminal lawyer to find the weak spots in the system. For some time before 1914, and for several years thereafter, Cleveland justice tended toward "sentimentalism," expressed by an excessive use of the "bench parole" (probation), more fully considered in a succeeding chapter. Shortly after the entry of this country into the World War the attitude of the public changed, and with the advent of the "crime wave" shifted to the opposite extreme. Judges responded by cutting bench paroles from 25 per cent. of the sentences in 1914 to 7 per cent. in 1920 .

This gradual shutting off of the judicial "parole" forced the criminal lawyer to look elsewhere for relief. The principal sources of such relief were: (a) "nolles" in the Municipal Court; (b) discharges at the preliminary examination in the Municipal Court; (c) "no bills" by the grand jury; (d) "nolles" in the Common Pleas Court; (e) trial and acquittal by juries. A glance at the figures shows that all these sources have been called upon. Although the number of felony dispositions in the Municipal Court increased only 84 per cent. from 1914 to 1920 , the number of "nolles" in that court increased 140 per cent. and the number of discharges 101 per cent. The number of dispositions in the Common Pleas Court increased 106 per cent. in the same period, but the number of "no bills" increased 121 per cent., the number of "nolles" 506 per cent., and the number of trials and acquittals 600 per cent. The increasing tendency to keep cases away from the discretion of the court is more marked in the Common Pleas Court than in the Municipal Court, probably because the lower court had already been "worked" almost to the saturation point.

Apparently there is a kind of Gresham's law in the administration of criminal justice. Just as cheaper currency tends to drive out dearer, so the slacker agencies tend to oust the stricter of jurisdiction. Diagrams 3 and 4 show plainly this tendency.

The increasing severity of the courts is shown in Diagram 3, which gives the change in the percentage ratio of sentences executed to all sentences. All cases which reached the judge for disposition, by plea or conviction, are included. The curve of all cases sentenced, based on a percentage of all the cases disposed of by the court, shows the increasing tendency to keep cases away from the judge, chiefly by "nolling," trial and acquittal, and "no bill." 


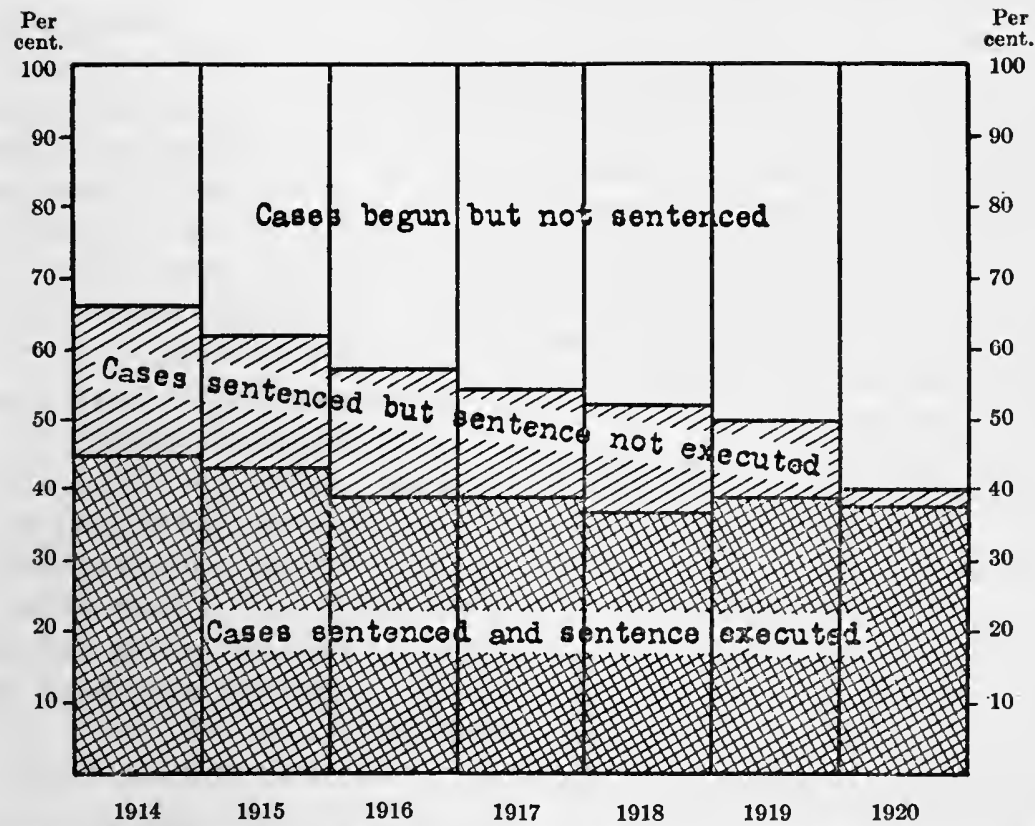

Diagram 3.-Comparison of severity in sentencing with decreasing tendency to bring cases to sentence. (Common Pleas Court, 1914-20)

Diagram 4 shows the same tendency in more specific form, the percentage of "bench paroles" of cases sentenced being compared with the

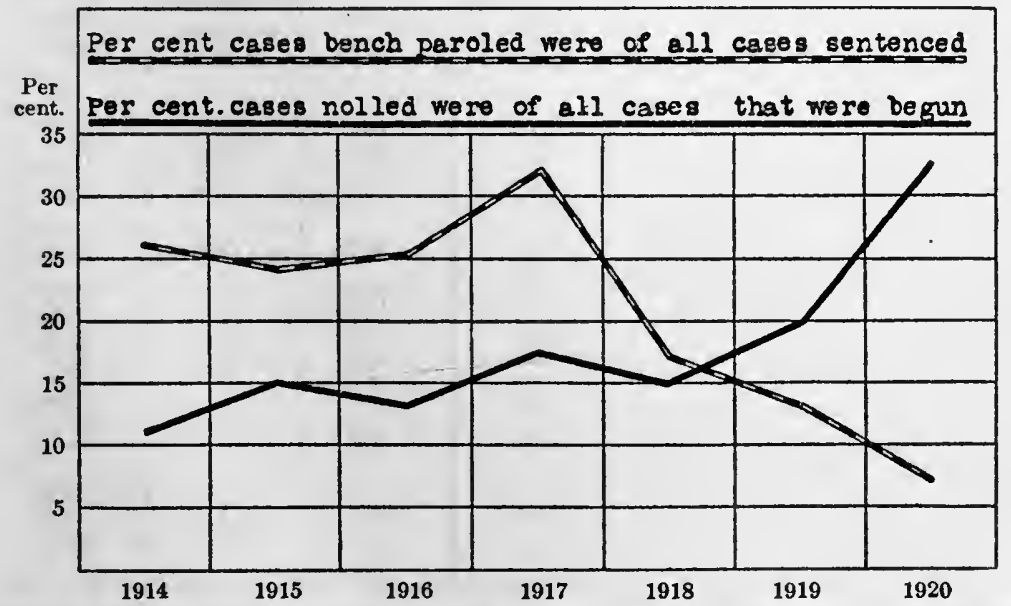

Diagram 4.-Comparison of decline of "bench paroling" with increase of allowing "nolle prosequi" 
percentage of cases "nolled" of all cases disposed of. The reciprocal action is clear.

How the system is "worked" for weak spots may also be seen in Tables 3 and 4 by comparing the dispositions and suspended sentences of Common Pleas cases obtained under the guidance of the most sophisticated criminal lawyers, with the results in other cases. For the purposes of these tables, criminal lawyers with political affiliations were chosen. A list of all lawyers having more than 10 cases each begun in 1919 was sent to a Cleveland lawyer thoroughly familiar with the local bar. This lawyer, without knowing the figures for any names in the list, marked the attorneys with political leanings and his judgment was accepted. The figures are not as significant as a selected list would show because the names chosen for political affiliations include several high-minded men who are not primarily criminal lawyers at all. The comparison does not necessarily throw discredit upon the lawyers selected: it does reveal a system which lends itself to manipulation. It is to be regretted that the absence of proper records prevents a similar comparison being made for the earlier stages of the cases in the Municipal Court.

TABLE 3.-DISPOSITIONS OF CASES OF 27 POLITICAL LAWYERS ${ }^{1}$ COMPARED WITH DISPOSITIONS OF ALL OTHER CASES BEGUN IN 1919 IN THE COMMON PLEAS COURT

\begin{tabular}{|c|c|c|c|c|}
\hline & $\begin{array}{l}\text { Number } \\
\text { of cases of } \\
27 \text { political } \\
\text { criminal } \\
\text { lawyers }\end{array}$ & $\begin{array}{l}\text { Number } \\
\text { of all } \\
\text { other } \\
\text { cases }\end{array}$ & $\begin{array}{l}\text { Per cent. } \\
\text { of cases of } \\
27 \text { political } \\
\text { criminal } \\
\text { lawyers }\end{array}$ & $\begin{array}{c}\text { Per cent. } \\
\text { of all } \\
\text { other } \\
\text { cases }\end{array}$ \\
\hline $\begin{array}{l}\text { Total cases } \\
\text { Total pleas of guilty } \\
\text { Original pleas of guilty } \\
\text { Original pleas of not guilty changed } \\
\text { to plea of guilty } \\
\text { Original pleas of not guilty changed } \\
\text { to plea guilty of misdemeanor } \\
\text { Other pleas } \\
\text { Total disposed of by trial } \\
\text { Guilty of felony after trial } \\
\text { Guilty of misdemeanor after trial } \\
\text { Not guilty of felony after trial } \\
\text { Not guilty of misdemeanor after } \\
\text { trial } \\
\text { "Nolled" on all counts } \\
\text { All other dispositions }\end{array}$ & $\begin{array}{r}412 \\
147 \\
10 \\
101 \\
\\
33 \\
3 \\
127 \\
60 \\
17 \\
50 \\
\\
104 \\
34\end{array}$ & $\begin{array}{r}2,127 \\
1,068 \\
418 \\
\\
449 \\
\\
160 \\
41 \\
463 \\
233 \\
57 \\
165 \\
\\
8 \\
295 \\
301\end{array}$ & $\begin{array}{r}100.0 \\
35.7 \\
2.4 \\
\\
24.5 \\
\\
8.0 \\
0.7 \\
30.8 \\
14.6 \\
4.1 \\
12.1 \\
\\
25.2 \\
8.3\end{array}$ & $\begin{array}{r}100.0 \\
50.2 \\
19.7 \\
\\
21.1 \\
7.5 \\
1.9 \\
21.9 \\
11.0 \\
2.7 \\
7.8 \\
0.4 \\
13.9 \\
14.2\end{array}$ \\
\hline
\end{tabular}

'Having more than 10 cases each among all cases begun in 1919 in the Common Pleas Court. 
The sagacity of the criminal lawyers may be seen in the fact that they allowed scarcely more than a third of their clients to plead guilty as compared with more than half of the others; that of those who did plead guilty, proportionately only one-sixth as many pleaded guilty upon arraignment as compared with the others, showing a tendency on the part of the criminal lawyers not to surrender until they had made a deal with the prosecuting attorney, or until it was clear their cases were hopeless; that of those who pleaded guilty the proportion who were allowed to plead guilty to a lesser offense was half again as great as in the other cases. Most striking is the proportion of nearly twice as many cases "nolled" by the prosecuting attorney, and 50 per cent. more cases tried by jury.

Even during a period in which judges were stiffening in the matter of "bench paroles" and suspended sentences, the political criminal lawyer has been able to snatch some advantage for his clients, although the courts have not yielded in this respect as much as other agencies. Of those who were sentenced, proportionately 20 per cent. more secured suspended sentences when represented by these lawyers than when represented by the bar at large.

TABLE 4.-SENTENCES AND SUSPENSION OF SENTENCES OF THE CASES OF 27 POLITICAL LAWYERS ${ }^{1}$ COMPARED WITH THE SENTENCES AND SUSPENSION OF SENTENCES OF ALL OTHER CASES BEGUN IN 1919

\begin{tabular}{l|r|r|r|r}
\hline & $\begin{array}{r}27 \text { political } \\
\text { criminal } \\
\text { lawyers }\end{array}$ & $\begin{array}{r}\text { All } \\
\text { other } \\
\text { cases }\end{array}$ & $\begin{array}{r}\text { Per cent. } \\
\text { of cases } \\
27 \text { lawyers }\end{array}$ & $\begin{array}{r}\text { Per cent. } \\
\text { of other } \\
\text { cases }\end{array}$ \\
\hline Total cases & 412 & 2,127 & 100.0 & 100.0 \\
No sentence indicated & 182 & 755 & 44.2 & 35.5 \\
Total sentenced & 230 & 1,372 & 55.8 & 64.5 \\
Total sentence suspended & 58 & 293 & 14.1 & 13.8 \\
Total sentence executed & 172 & 1,079 & 41.7 & 50.7 \\
Total sentenced for felony & 124 & 780 & 30.1 & 36.7 \\
Total sentence felony suspended & 38 & 203 & 9.2 & 9.5 \\
Total sentence felony executed & 86 & 577 & 20.9 & 27.1 \\
Total sentence misdemeanors & 106 & 592 & 25.7 & 27.8 \\
Total sentence misdemeanors sus- & 20 & 90 & 4.9 & 4.2 \\
pended & 86 & 502 & 20.9 & 23.6 \\
cuted sentence misdemeanors exe- & 40 & 257 & 9.7 & 12.1 \\
Total misdemeanors sentenced to & fine only & & & \\
\hline
\end{tabular}

1 Having more than 10 cases each among all cases begun in 1919 in the Common Pleas Court. 


\section{What Steps MaY Be Eliminated}

We have now seen enough of the system in operation to understand the fundamental difficulty, leaving to one side questions of personnel. The steps in the administration of justice are too numerous, involve too many agencies, and are too loosely guarded. It is the old difficulty of weak links in.a chain. All unnecessary links should be eliminated and those remaining should be made as strong as possible.

Those steps which may be eliminated to advantage are probably already obvious. The study of the county prosecutor's office brings out the folly of expecting efficient handling by the prosecuting attorney of cases which were dealt with in their vital stages, without his knowledge or attention, first by the police, and then by the police prosecutor. ${ }^{1}$ The futility of entrusting the power to "nolle" to two sets of prosecutors is equally clear. Three different judicial agencies are asked to discharge the defendant because there is no prima facie case against him - the $\mathrm{Mu}^{-}$ nicipal Court at the preliminary examination, the grand jury on presentment by the prosecutor, and the Common Pleas Court on motion to discharge or for a directed verdict.

The hardship on the State's witnesses in attending this multiplicity of hearings and continuances needs no comment, nor the fact that the State loses valuable testimony by this process of attrition. We have already seen that, of cases beginning in the Municipal Court, approximately 42 per cent. die in that court and the grand jury room, but it is not possible to tell how many other cases which survive these stages finally perish for lack of evidence which was available at the earlier stages. The average time from indictment to disposition of all Common Pleas felony cases begun in 1919-originating in the Municipal Court-was 46.3 days, but the average time from arrest to disposition was 67.8 days. This entire excess of 21.5 days per case is unnecessary and injurious. Also, as will be seen later, the dragging out of cases is largely responsible for bail bond trouble, since a speedy trial would often do away with the necessity of bail. It is, moreover, an injustice to a defendant to put him in a position where he may be called upon to furnish at least three bonds-first after arrest, then after being bound over, and finally after indictment.

A glance at Diagram 2 will show that all the steps in the Municipal Court, together with the grand jury, may be dropped to advantage. It should be enough if a judge finds there is probable cause to hold a defendant for trial, and the judge might better be a Common Pleas judge

1 See report on prosecutor's office. 
than a Municipal Court judge. The grand jury proceeding might be retained for special investigation only.

The trinitarian aspect of felony jurisdiction is the product of historical causes only. In feudal England, when the Common Law system was beginning, the king sent his judges on tour throughout the realm, so that the court sat for a certain time only in each county. It became necessary for local magistrates to examine and hold suspected felons in the interim, and for a grand jury of neighbors to meet occasionally to examine into all crimes committed in the county as preparation for the coming of the court. This custom was carried into pioneer America. ${ }^{1}$ The function of holding suspected felons, admitting them to bail, and recognizing witnesses was conferred on justices of the peace. ${ }^{2}$ In 1852 this ad interim jurisdiction was conferred upon the police court of Cleveland, and this was continued in the Municipal Court Act of 1910. Today, however, the Common Pleas Court is permanently resident in Cleveland, and sits, or can sit, continuously throughout the year. Full exclusive felony jurisdiction could be conferred upon this court without any practical difficulty or injustice.

It may be queried whether there is any reason for continuing jurisdiction over misdemeanors in the Municipal Court. After consideration of the Municipal Court's work in this respect, ${ }^{3}$ it is recommended that this jurisdiction also be conferred on the Common Pleas Court. Again the reason for the separate jurisdiction is historical, due to the necessity of disposing of minor causes promptly, without waiting for the "terms" of the higher court. The Municipal Court inherits through the police court and justices of the peace. ${ }^{4}$ It is not true that petty criminal causes may safely be entrusted to judges of inferior quality. Such cases may not require a high order of legal ability; they emphatically need men of high character on the bench; for no other court comes so close to the lives of the mass of the people, or has a greater opportunity to inculcate respect for our institutions.

There are no legal difficulties in the way of transferring full criminal

1 See Act of 1790, providing for government of the Northwest Territory, increasing the "terms" of the Common Pleas Court. See also Ohio Constitution, 1802, Article III, dividing the State into "circuits."

${ }^{2}$ See Act of 1804, specifically conferring this power on justices of the peace.

3 See Chapter V.

4 Misdemeanor jurisdiction also exists in the Probate Court, but this was at one time eliminated from Cuyahoga County in 50 O. L. 84 (1852). See Sec. 13424.

5 This is generally true of all criminal cases. 
jurisdiction in all causes to the Common Pleas Court. The constitution provides simply that the jurisdiction of this court shall be fixed by law. ${ }^{1}$ All that is necessary is an appropriate statute.

There may be more difficulty with respect to abolishing the grand jury and substituting therefor, if necessary, the prompt and compulsory information of the prosecuting attorney. Article I, Sec. 10, of the Ohio constitution provides that "no person shall be held to answer for a capital or otherwise infamous crime unless on presentment or indictment of a grand jury." A similar provision has been strictly construed. ${ }^{2}$ An amendment to the constitution of Ohio would be necessary to administer justice in metropolitan communities without the compulsory use of a grand jury. Such a result, however, would be well worth the effort. There is no difficulty with respect to the Federal constitution. ${ }^{3}$

\section{Results of Unified Court in Detroit}

It may be said by the cynical that the organic changes suggested will do no good because the trouble is with "human nature." This sort of reasoning would never have advanced civilization beyond the stage of private vengeance and the blood feud. "Human nature," meaning thereby its least admirable traits, is effective only so far as opportunity and reward exist for wrongful effort. Reduce these, and improvement invariably results. Tangible evidence of this truth is seen in the recent history of Detroit. Before April, 1920, Detroit criminal justice was administered much as in Cleveland-by two sets of courts, with much duplication of judicial machinery. In April, 1920, the entire criminal jurisdiction of the city was vested in one court, which constitutes a unified tribunal with plenary jurisdiction over all offenses-ordinance violations, misdemeanors, and felonies. The result may be seen in Table 5 .

These figures become more impressive in the light of the "crime wave" in other cities. Credit for the betterment undoubtedly belongs largely to an increase in the police force and better methods of administering that department. Nevertheless, the Detroit police department, in its bulletin for March, 1921, makes the following significant acknowledgment:

"Any statement of the improved crime condition of the city of Detroit should take into account the work of the Municipal Court."

${ }^{1}$ Article IV, Sec. 4.

2 Lougee v. State, 11 Ohio, 68.

${ }^{3}$ See Hurtado v. People, 110 U. S., 516. Michigan never had a provision guaranteeing grand jury procedure. 
TABLE 5.-THE DETROIT COURT; POLICE RECORD OF FOUR MAJOR CRIMES OF PROFESSIONAL NATURE

\begin{tabular}{|c|c|c|c|c|c|c|c|}
\hline 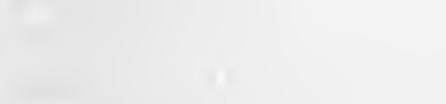 & 1921 & $\begin{array}{l}\text { Average } \\
\text { preceding } \\
\text { five years }\end{array}$ & 1920 & 1919 & 1918 & 1917 & 1916 \\
\hline $\begin{array}{l}\text { BREAKING AND ENTERING DWELL- } \\
\text { INGS: }\end{array}$ & & & & & & & \\
\hline $\begin{array}{l}\text { January } \\
\text { February }\end{array}$ & 38 & 126 & 64 & 131 & 143 & 95 & 199 \\
\hline $\begin{array}{l}\text { February } \\
\text { BREAKING AND ENTERING Busi- } \\
\text { NESS PLACES: }\end{array}$ & 42 & 110 & 78 & 130 & 155 & 77 & 109 \\
\hline $\begin{array}{l}\text { January } \\
\text { February }\end{array}$ & $\begin{array}{l}35 \\
46\end{array}$ & 122 & 99 & 114 & 162 & 124 & $\begin{array}{r}110 \\
83\end{array}$ \\
\hline ROBBERY: & & & & & & & \\
\hline $\begin{array}{l}\text { January } \\
\text { February }\end{array}$ & 53 & 77 & 112 & 62 & 83 & 85 & 45 \\
\hline $\begin{array}{l}\text { February } \\
\text { LARCENY FROM PERSON: }\end{array}$ & 35 & 66 & 98 & 53 & 99 & 50 & 30 \\
\hline $\begin{array}{l}\text { January } \\
\text { February }\end{array}$ & $\begin{array}{l}37 \\
19\end{array}$ & $\begin{array}{l}52 \\
51\end{array}$ & $\begin{array}{l}46 \\
39\end{array}$ & $\begin{array}{l}59 \\
42\end{array}$ & $\begin{array}{l}51 \\
45\end{array}$ & $\begin{array}{l}44 \\
77\end{array}$ & $\begin{array}{l}58 \\
53\end{array}$ \\
\hline
\end{tabular}

Table 5 deals with four selected crimes for two months. The direct influence of the new unified court on the crime situation may be seen in Table 6, based on the record of all crimes for twelve months.

The increased number of misdemeanor complaints, arrests, and police

TABLE 6.-RESULTS OF UNIFIED CRIMINAL COURT IN DETROIT

\begin{tabular}{|c|c|c|}
\hline & $\begin{array}{c}\text { For the year ending } \\
\text { April, } 1920\end{array}$ & April, 1921 \\
\hline $\begin{array}{l}\text { FELoniEs: } \\
\text { Complaints } \\
\text { Arrests } \\
\text { Disposed of by police } \\
\text { Disposed of by court } \\
\text { Convicted by court }\end{array}$ & $\begin{array}{c}13,195 \\
7,491 \\
4,383 \\
3,108 \\
1,664 \text {, or } 51 \text { per }\end{array}$ & $\begin{array}{c}13,795 \\
11,115 \\
7,246 \\
3,869 \\
2,648 \text {, or } 70 \text { per } \\
\text { cent. }\end{array}$ \\
\hline $\begin{array}{l}\text { Mrspemeanors: } \\
\text { Complaints } \\
\text { Arrests } \\
\text { Disposed of by police } \\
\text { Disposed of by court } \\
\text { Convicted by court }\end{array}$ & $\begin{array}{l}37,929 \\
32,415 \\
13,394 \\
19,021 \\
16,410 \text {, or } 86 \text { per } \\
\text { cent. }\end{array}$ & $\begin{array}{l}40,858 \\
35,315 \\
19,465 \\
15,850 \\
14,222 \text {, or } 90 \text { per } \\
\text { cent. }\end{array}$ \\
\hline
\end{tabular}

1 These figures may be profitably compared with 4,262 felony cases disposed of by judicial process in Cuyahoga County in 1919, of which 37.1 per cent. were convicted on plea or after trial. 
dispositions is explained by the increased activity of the department in handling gambling and other minor offenses.

A description of the operation of the unified criminal court is contained in the Journal of the American Judicature Society, April, 1921, and August, 1920 (Vol. IV, Nos. 6 and 2), and in the Journal of Criminal Law and Criminology, November, 1920 (Vol. XI, No. 3). The changes effected by the establishment of this court in making justice swifter and more certain are worth careful study. 


\section{CHAPTER IV}

\section{THE BENCH AND ITS BACKGROUND}

\section{IMPORTANCE OF THE BENCH}

$\mathrm{T}$

JEE administration of justice is not a purely mechanical process. Its satisfactory conduct depends more than any industry on the human factor, because the administration of justice deals with the evaluation of human souls, and not with commodities or operations capable of measurement. Among these human factors the judges hold the place of unique responsibility. Their attitude at the trial often determines the result. They have it in their power to suspend sentences, to grant new trials, to eliminate delay, to reduce perjury, to assure better selection of jurors, and, theoretically at least, to pass on motions to "nolle" cases before them. It is obvious that strong judges, capable of inspiring respect and unafraid, may save even an archaic system from absolute failure. ${ }^{1}$ No system of administering justice can rise higher than the quality of its bench, although it may go much lower. In order to understand the Cleveland situation, therefore, it is a necessary preliminary to understand the bench and the influences to which it may be subject.

\section{Personnel}

Thumb-nail sketches are rarely likenesses and serve no good purpose if used merely to tag the individual subjects. As a group, however, such sketches may be useful in conveying a composite impression of the bench of Cleveland. The summaries given coincide with the common view of many members of the bar who otherwise differ widely in political and social outlook. The unanimity of opinion was surprising.

It should be remembered, however, that the bench as a whole is rated much lower than the individuals composing it. The picture of the judges would not be complete without the cheap, tawdry background which robs the subjects of their dignity and subdues the individual's good points. It is with the nature of this background that this chapter is chiefly concerned. 
The Common Pleas bench, as it was in April, 1921, is commonly characterized as follows:

In respect of legal ability it consists of two judges who, by reason of long experience on the bench, have acquired a wide knowledge of the law and practice; five judges of fair native ability, some of whom need experience to become good judges; two judges of mediocre ability; one judge not tried out sufficiently to afford a basis for judging legal qualifications; one judge of practically no juristic qualifications, and one whose unusual legal gifts make his presence on the bench a decided asset. In respect of faithfulness to duties, the list includes one judge who is notoriously unpunctual, several others designated as somewhat "lazy," and one who is occasionally guilty of gross neglect of his duties. Two judges possess considerable dignity of character, but others are characterized as "playing politics," "weak before popular clamor," "publicity getters," etc. One judge is remarkable for social-mindedness, which makes him fertile in constructive ideas, but sentimental in dealing with criminals. The personal habits of all but one of the judges seem to be above serious criticism.

As a group, the Common Pleas bench would probably compare favorably with county courts in other metropolitan jurisdictions. Criticism largely centers on its want of fine traditions, ${ }^{1}$ absence of dignity, and lack of independence in thought and action. These qualities will be considered later.

The Municipal Court bench is characterized as follows:

In respect of legal ability the court contains four judges who might be said to measure up to the requirements of the office-one by reason of long experience on the bench; another because of previous experience as a justice of the peace; a third for his long experience at the bar and his previous official connection with the court; and a fourth by reason of

${ }^{1} \mathrm{~A}$ bench with high traditions would probably not have instituted, or at least not approved of the conduct of, the suit of State ex rel. Powell v. Zangerle, a petition in mandamus brought by the judges to compel the payment of increased salaries to themselves, as voted by the legislature. The constitutional question involved in the increase of salaries during term of office was a delicate one, yet in this suit a favorable decision by a judge of the same court in another county was accepted as final. The counsel for the judges drew the demurrer for the defendant, and no appeal was taken from the decision. Grave doubt has subsequently been thrown on this decision by the State ex rel. Metcalfe v. Donahey, a Supreme Court opinion holding that the increase may not be paid to Court of Appeals judges during the same term of office. It is irrelevant that the judges ought to be paid larger salaries. Most detrimental to the dignity of the bench was the patronizing attitude of the bar that it was glad to see the judges get more money, constitutionally or not. 
years of private practice in a representative Cleveland firm. Two of the others are credited with fair ability, three are mediocre, and one apparently has no qualifications worth mentioning. The list includes two judges characterized as "playing politics," and two others designated as "gallery players."

On the whole, the personnel of the municipal bench is inferior in quality and ineffectual in character. A close observer of the Cleveland courts for years states that the present Municipal Court judges are not much superior to the old justices of the peace, and that whatever increased dignity they appear to possess arises entirely from the improved physical setting.

It is the almost universal belief among men whose opinion may be valued that the Municipal Court judges are irreproachable in respect of being influenced by money considerations. The survey did not attempt to follow up such vague and isolated charges as were brought to its attention, for two reasons: In the first place, actual corruption is impossible to prove without the power to compel testimony. Moreover, it is not indicative of the real trouble, since an occasional dishonest judge cannot make a venal bench, nor is an incorruptible bench enough to assure a proper administration of justice.

\section{Recent Changes in the Election Laws}

In considering the present personnel of the bench, especially in the Common Pleas Court, a brief summary of recent changes in the mode of nominating and electing judges becomes important.

For many years prior to 1908 there had been little change in the law pertaining to nomination and election of judges. 88 Ohio Laws 455, Sec. 12 (1891), had provided two methods of nomination-first, by caucus or convention, primary election, or certification of the executive committee of an established political party, and second, by petition signed by a certain number or percentage of the voters. In 97 O. L. 226 (1904) a change in detail was made in the provision as to nomination by petition. The prevailing method of nomination was by party convention, the petition method being rarely used.

99 O. L. 217, Sec. 12 (1908), provided for nomination by direct vote unless the county controlling committee desired a nominating convention, in which case the delegates were to be elected at the primary. Nomination by petition was not disturbed. As a matter of fact, nomination by convention still persisted, and nomination by petition remained the unsuccessful recourse of the "independents."

Until 1911 election of judges was by party ballot, but 102 O. L. 5, Sec. 
2, known as the "Non-Partisan Judiciary Act," provided that there should be no designation as to party upon the election ballot. This provision is in effect today.

In 1912 the new constitution provided in Article V, Sec. 7, that all nominations "shall be by direct primary elections or petition as provided by law."

In 1913 the "Direct Primary Law" was passed (103 O. L. 476), wiping out the nominating convention, and providing for nomination by direct primary, nomination papers to be signed by 2 per cent. of the voters. 106 O. L. 542 (1914) eliminated the necessity of having voters sign such nomination papers for the primaries, and this constitutes the law today (General Code, Sec. 4969). Nomination by petition outside of the primary is retained (G. C., Sec. 4999), and is now used to a considerable extent.

If it is possible to draw any comparisons between judges of the Common Pleas bench produced under the older system and newer modes of selection, it is suggested that the line be drawn between the election of 1910 and that of 1912. The former election may be said to mark the end of the period of partisan judiciary and convention nomination, and the latter to begin the present era of wide-open elections and direct nominations.

The Municipal Court had its beginning at the time of experimentation with nominating and election machinery. 101 O. L. 364 (1910) provided for nomination by direct vote, following the form of 99 O. L. 217, Sec. 12, for other judges and for election in the same manner as provided for other municipal officers. 102 O. L. 155, Sec. 5 (1911), is similar as to nomination, but the provision as to election is eliminated, probably to bring the judges under the general law for the election of judicial officers passed the same year, 102 O. L. 5, Sec. 1-6. In 1914, 106 O. L. 274 (now G. C., 1579-5), provided that judges of the Municipal Court should be nominated as other municipal officers,-by petition only, Cleveland Charter, Sec. 3, 1913,- -and elected as other judicial officers, in non-partisan election. Practically, the existence of the Municipal Court has been entirely in the period of direct primary and non-partisan elections.

\section{Apparent Effects of These Changes}

For the purpose of summarizing recent history of the personnel of the bench, two diagrams are printed. Diagram 5 shows Common Pleas judges who have served from 1900 to the present date, with political affiliation, mode of first coming to the bench, date of election or appointment, age on admission to the bar, and subsequent legal experience. 


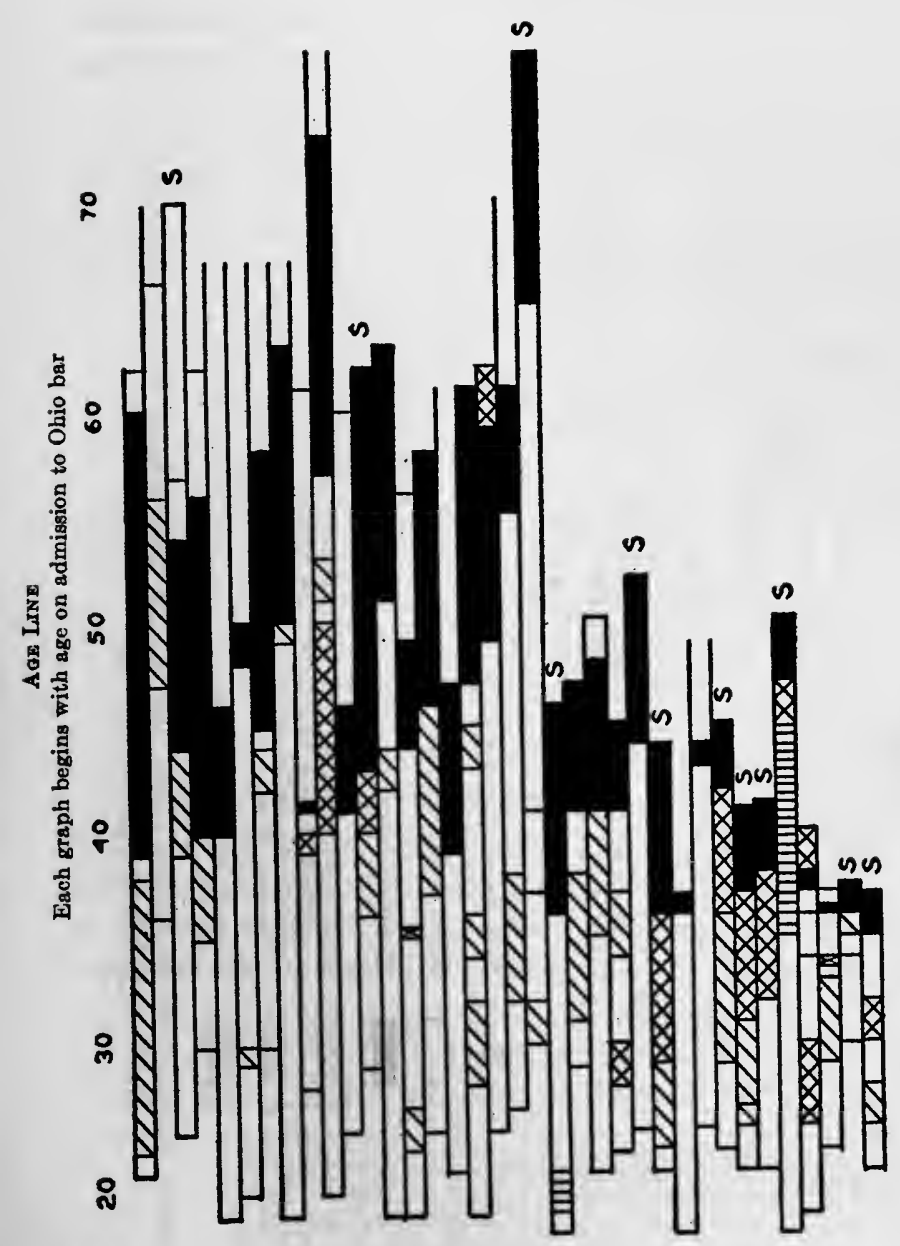
కై

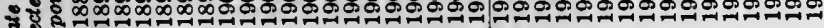

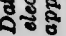

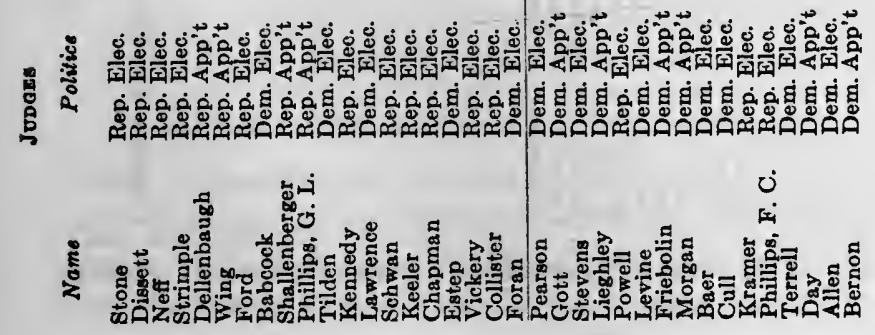

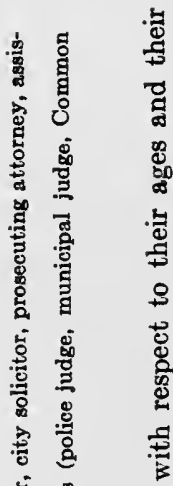

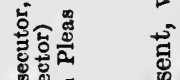

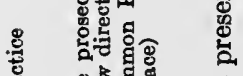

㟧 :

\&

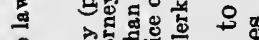

究

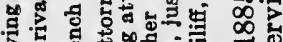

a

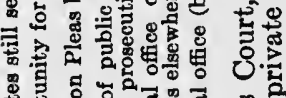

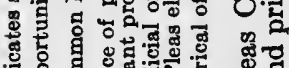

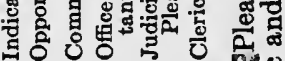

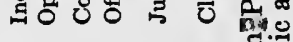

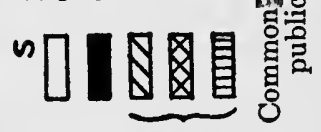

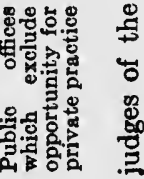

$\because$

ङ

焉 
Diagram 6 shows the same facts for the Municipal Court judges since the organization of that court. Many of the judges set down as appointed were subsequently elected. ${ }^{1}$
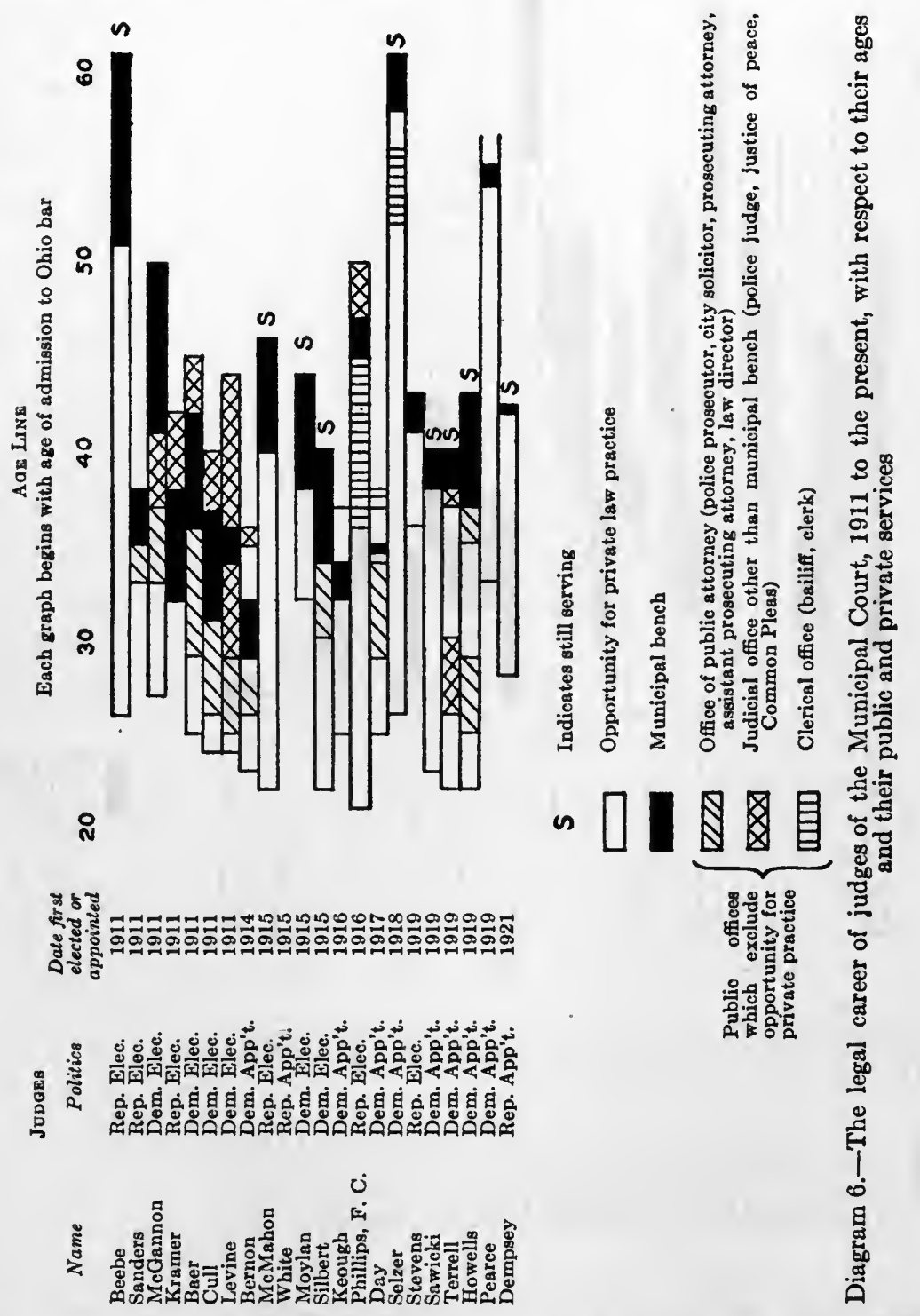

1 The charts may not be precise in every detail, but should be sufficiently accurate for general deductions. 
Turning to Diagram 5, it is at once apparent that with the election of 1912 a much younger group of men began to appear on the bench. A ruler laid across the chart along the line of 40 years of age shows only two judges beginning their service under that age before 1912, and eight judges after 1912. Similarly a line drawn across 45 years of age shows only nine out of 20 before 1912 and 15 out of 16 after that date. A comparison is given in Table 7 .

TABLE 7.-AGE ON ELECTION OR APPOINTMENT, COMMON PLEAS COURT

\begin{tabular}{c|c|c}
\hline \hline Age & $\begin{array}{c}\text { Judges on bench, } \\
1900-1910\end{array}$ & $\begin{array}{c}\text { New judges, } \\
1912-1921\end{array}$ \\
\hline $35-39$ & 2 & 9 \\
$40-44$ & 7 & 6 \\
$45-49$ & 5 & 1 \\
$50-54$ & 2 & 0 \\
$55-59$ & 3 & 0 \\
$60-64$ & 0 & 0 \\
$65-70$ & 1 & 0 \\
\hline
\end{tabular}

Another noticeable difference is the quality of the experience brought to the bench by the judges before 1912 compared with the later group. The shaded areas in Diagram 5 represent experience which necessarily or largely excluded private practice, and conversely, the white areas represent opportunity for such practice. Table 8 summarizes the

TABLE 8.-OPPORTUNITY FOR PRIVATE PRACTICE, COMMON PLEAS COURT

\begin{tabular}{c|c|c}
\hline \hline $\begin{array}{c}\text { Years of } \\
\text { opportunity } \\
\text { for private } \\
\text { practice }\end{array}$ & $\begin{array}{c}\text { Judges on bench, } \\
1900-1910\end{array}$ & $\begin{array}{c}\text { New judges, } \\
1912-1921\end{array}$ \\
\hline $0-4$ & & \\
$5-9$ & 1 & 3 \\
$10-14$ & 3 & 5 \\
$15-19$ & 5 & 4 \\
$20-24$ & 4 & 4 \\
$25-29$ & 4 & 0 \\
$30-34$ & 2 & 0 \\
\hline
\end{tabular}

amount of opportunity for private practice. Before 1912 most of the judges were apparently well seasoned in the private practice of the law, whereas after that date the majority had been trained chiefly in the office of inferior judge or prosecutor. Since the difficulties of trial and 
consequences of decisions and rulings can be best appreciated by the man who has "been through the mill," it is not surprising that the Cleveland bar displays no little impatience toward the bench. Table 9 indicates the comparative inexperience of the newer judges.

\section{TABLE 9.-TOTAL YEARS OF EXPERIENCE, COMMON PLEAS COURT}

\begin{tabular}{c|c|c}
\hline Years & $\begin{array}{c}\text { Judges on bench, } \\
1900-1910\end{array}$ & $\begin{array}{c}\text { New judges, } \\
1912-1921\end{array}$ \\
\cline { 2 - 3 } $0-4$ & 0 & 0 \\
$5-9$ & 0 & 1 \\
$10-14$ & 3 & 6 \\
$15-19$ & 7 & 8 \\
$20-24$ & 2 & 0 \\
$25-29$ & 3 & 1 \\
$30-34$ & 1 & 0 \\
$35-40$ & 1 & 0 \\
\hline
\end{tabular}

The Municipal Court has been in existence for nine years only, under practically one method of selecting its judges, so that Diagram 6 does not contain much material upon which conclusions may be based. Many members of the bar, however, are of the opinion that there has been progressive deterioration in the quality of judges first reaching that bench by the election method.

The present personnel of the Common Pleas bench includes seven Democrats and five Republicans; the Municipal Court, six Democrats and four Republicans. Since Diagrams 5 and 6 contain only the dates of first elections and appointments, they are not well adapted for judging whether a non-partisan bench has been secured. Since 1911 the elections of judges have resulted as follows:

\begin{tabular}{l|l|l|l|l|l}
\hline \multicolumn{2}{c}{ Municipal Court } & \multicolumn{3}{c}{ Common Pleas Court } \\
\hline Date & \multicolumn{2}{c|}{ Parties } & Mayoralty & Date & \multicolumn{2}{c}{ Parties } & Governor \\
\hline 1911 & 4 Dem., 3 Rep. & Democrat & 1912 & 5 Dem., 0 Rep. & Democrat \\
1913 & 1 Dem., 2 Rep. & Democrat & 1914 & 2 Dem., 4 Rep. & Republican \\
1915 & 5 Dem., 2 Rep. & Republican & 1916 & 2 Dem., 1 Rep. & Democrat \\
1917 & 2 Dem., 2 Rep. & Republican & 1918 & 4 Dem., 2 Rep. & Democrat \\
1919 & 6 Dem., 1 Rep. & Republican & 1920 & 4 Dem., 2 Rep. & Republican \\
\hline
\end{tabular}

The Municipal Court has probably been a true non-partisan institution from the beginning. The predominance of Democrats elected to this 
bench is due somewhat to the vacancies which occurred during Governor Cox's two terms as governor. There were nine vacancies before 1921, eight of which were filled by Governor Cox with Democrats, some of whom replaced several Republicans. The strong tendency on the part of the voters to reëlect men already on the Municipal bench secured the election for most of these appointees.

Elections to the Common Pleas bench have shown a growing tendency to become non-partisan, despite the fact that there is now somewhat of a reaction toward party sponsorship. ${ }^{1}$

\section{The Underlying Cause for Dissatisfaction}

The changes in election machinery were in large part the result of the progressive wave which swept the country in the first decade of the century. ${ }^{2}$ They represent a revulsion against intolerable political conditions then flourishing, ${ }^{3}$ and it was impossible to foresee all the effects of the steps when proposed by the new leadership. Cleveland has now had ten years' experience of the wide-open method of selection, and although few would care to return to the bossed party conventions, it is safe to say there is scarcely a man in Cleveland able to weigh the qualifications for the bench who does not deplore present tendencies and fear them.

It is not altogether a question of comparing the intrinsic ability and integrity of the new judges with the old. Such a comparison might not be wholly unfavorable to some of the younger judges. Nor does the reason lie entirely in the fact that the judges are coming to the bench younger and less experienced than formerly, and that a few are markedly unsuited for judicial careers. These are symptomatic conditions only. Most serious is the present cheapening of the judicial office, so that neither the bar, the press, nor the judicial incumbents themselves any longer respect it. Young lawyers who would have viewed the bench

${ }^{1}$ See issue of the Cleveland Press, October 30, 1920, for an advertisement by the Republican Executive Committee consisting of a "slate" of judges captioned "Republican Judicial Candidates." The Press has been one of the foremost proponents of the non-partisan election of judges.

${ }^{2}$ See Mr. Tannehill's appeal to the progressive and Roosevelt vote in introducing the direct primary amendment at the Constitutional Convention, Ohio C. C., 1912, Proceedings and Debates, p. 1239.

8 "The chief cause of the frequent failure of representative government lies in the corrupt, boss-controlled, drunken, debauched, and often hysterical nominating convention," says the sponsor for the direct primary provision, ibid., p. 1239. 
with reverence formerly, now give voice to their disrespect, and retired and even sitting judges are openly cynical.

The situation is summed up in the universal comment that the judges are generally above the suspicion of taking direct money bribes, but find it difficult to forget the coming election. ${ }^{1}$ To judges who have had little or no private practice before beginning their public careers, the matter of insuring reëlection is especially urgent.

Here again the trouble lies in attempting to adapt the democracy of the town meeting to a great cosmopolitan population. Direct nomination and non-partisan election of judges produce fairly satisfactory results in a small community, where everyone knows the nominees, and fitness for office is a matter of common appraisal. Judges from country districts are frequently sent to the Cuyahoga Common Pleas Court to help handle the crowded docket in that court, and Cleveland lawyers, on the whole, prefer these outside judges to the members of the local bench. Superior legal ability generally and greater disinterestedness are conceded to these country judges. In a community of nearly a million population, however, containing many voters who cannot even read English, it is not possible for more than a small proportion of the voters to know anything about the fitness for office of the numerous candidates for judicial office. This small group could carry the city by aggressive leadership, ${ }^{2}$ but so far there has been no such leadership. The result has been that a judge facing reëlection has had to insure his survival through one or several of the following ways: catering to petty bosses who control votes; patronizing certain influential groups-racial, religious, or industrial; general publicity in the newspapers or otherwise. Whichever way the premium is paid, the judge and his high office are degraded.

In considering the effects of these influences, the words of judges and prominent lawyers are freely quoted in this report in order to convey as much as possible of the local feeling. Even if some of the statements seem extreme, it should be remembered that the fact responsible men speak in this way of the bench is itself a factor of importance. The observations proceed from men full of reverence for the bench as an institution and a desire to see it restored to its historic dignity.

1 This difficulty is not experienced by judges alone. The County Treasurer's office is placarded with this amusing apology: "The County Treasurer is not responsible for the increase in your taxes. The increase was carried by vote of the people at the last election."

${ }^{2}$ The recent victory of the Coalition Judicial ticket in Chicago is an example. 


\section{Importance of the Petty Politician}

Catering to politicians is probably the least common mode of assuring reëlection for Common Pleas judges, and not the most desirable for the Municipal judges. It is not only distasteful, but dangerous. Undoubtedly, under the older methods of selection, there were forces which impelled a judge to heed the wishes of the great chieftains of the party, but it must have been less subversive of morale to deal with chiefs, who interfered rarely, than to listen continually to the unvoiced threats of petty vote controllers specializing in criminal law. When one considers that most professional or habitual criminals engage these political lawyers to defend them, the unwholesomeness of the condition is clear.

Moreover, it is often difficult to say where influence ends and "goodfellowism" begins. ${ }^{1}$ Both judges and prosecutors have often risen through politics, and it would not be surprising to find that they have not forgotten some of their old associates. The effectiveness of the political criminal lawyer has already been discussed ${ }^{2}$ in a general consideration of the system, and reference may be had to Tables 3 and 4.

No statistics on this subject can be secured for the Municipal Court, but prevalent opinion is that "influence" and "good fellowism" flourish still more successfully in that court. This is to be expected where great haste and inadequate record keeping afford a screen behind which operations may be conducted. ${ }^{3}$ It is not uncommon for lawyers to call judges on the telephone to talk about their cases. Usually publicity at the trial will thwart any tendency to favoritism by the court. In one

${ }^{1}$ Even in civil cases, where the alertness of opposing counsel minimizes the danger of favoritism, complaints are not uncommon. "Before some of the judges," remarks one lawyer, "my first worry is to wonder what 'drag' opposing counsel has with the court."

2 See Chapter III.

${ }^{3}$ An ex-Municipal Court judge states that when asked to defend his former office boy, he advised him to see the "boss" of his ward and not to waste time with a mere lawyer. An attorney relates that a professional criminal asked him to secure a continuance until he could get his councilman. The papers in this case were subsequently withdrawn. One of the leading firms in the city advised a client in an automobile manslaughter case to take his medicine "because the evidence against him was conclusive." The defendant retained a councilman-lawyer, however, and after several continuances was discharged.

Care should be taken not to make a blanket charge that all judges cater to politicians. Specific instances could be cited where judges have courageously stood out against politics in their court. 
case on a charge of rape the defendant, a politician of low order, had a reputation for slipping out of "scrapes" through influence. On the day of the preliminary hearing the court-room was filled with representatives of various women's societies, and the man was bound over. The ways of "influence" are so devious, however, that not even full publicity will avail where there is a determination to protect. "Tim" Raleigh openly and decently maintained an establishment for the placing of election, baseball, and racing bets. It was operated, as a Common Pleas judge had expressed it, "not with the connivance, but with the acquiescence, of everyone," and apparently was regarded as a public service institution. Owing to the vigorous attacks of the Cleveland Press, arrests were made and a trial forced. It is reasonable to suppose that no one in authority sincerely desired to convict Raleigh, who had obtained tacit, if not express, consent to the conduct of his business. The Press had tried Raleigh in its columns and convicted him, even to the extent of publishing names of men who had placed bets. Nevertheless Raleigh was acquitted, under such circumstances that the judge, jury, prosecutor, and police could each lay reasonable claim to having acted conscientiously and yet point the finger of suspicion at the other. ${ }^{1}$

${ }^{1}$ Warrants against Raleigh were sworn on November 11, 1920, on which date Raleigh was arraigned and pleaded not guilty. The case was continued to November 24 , then to December 8 , then to December 16 , when a jury was demanded. The case was then continued to February 7, 1921, and then to March 7.

There were two charges against Raleigh, one under Sec. 13060 , relating to selling chances on a pool on the result of an election, and the other under Sec. 13062, for keeping a place where books and slips for wagers were kept and exhibited. No charge was brought under Sec. 13054, for keeping a room to be used for gambling, probably because, under an old decision by Fiedler, Police Judge, gambling in this section was construed to mean a game for stakes. (State v. Lark, 3 O. N. P. 155.)

The State proceeded to trial under Sec. 13062. Judge Silbert overruled the defendant's demurrer that no crime was charged under this section of the code. The State introduced as evidence some racing charts which anyone could purchase in Cleveland, several pads of blank forms, available for recording wagers, a record book in code which was not deciphered, and some slips of paper bearing notations of what might be wagers, chiefly on the results of election, but partly on baseball and horseraces. There was no evidence that a witness had placed a wager or had seen a wager placed.

At the close of the State's case the defendant's attorney moved for a directed verdict and was overruled. Judge Silbert then instructed the jury in substance that the evidence bearing on election bets should not be considered because an election was not "a trial or contest of skill or endurance of man or beast" according to the statute. It cannot be said that the judge was unreasonable in his construction of the statute. The jury returned a verdict of not guilty, which it might well have done in view of the charge and the evidence. The prosecutor then "nolled" the 


\section{The Influence of Groups}

More important in its effect on the bench than the tendency to respond occasionally to political influence is the bid for support which many judges make to different groups and factions in the city. This is almost entirely a new influence upon the judiciary. "In order properly to play the game," observes one of the more sophisticated judges, "it is necessary for a judge to attend weddings, funerals, christenings, banquets, barbecues, dances, clam-bakes, holiday celebrations, dedications of buildings, receptions, opening nights, first showings of films, prize-fights, bowling matches, lodge entertainments, church festivals, and every conceivable function given by any group, national, social, or religious." Several of the judges have a reputation for "handshaking" nearly every night in the week. One judge of fine, simple nature is reported to have been inveigled into making a speech on the educational and moral value of motion pictures at the first showing of a particularly salacious film. The judge, of course, had not seen the picture. Another judge is said to have refereed a prize-fight. In the past the saloon, as the neighborhood center, has been assiduously courted. ${ }^{1}$ Three judges of unquestioned character campaigned by visiting the saloons in the different foreign sections of the city, and were presented to long lines of foreignspeaking voters with the aid of an interpreter. No drinks were bought, not a cent was spent, only handshakes were exchanged, yet this was deemed essential campaigning. All three were reëlected.

\section{Racial and Religious Appeal}

One of the most disturbing features is the intensifying of racial and religious appeals. A man is elected or appointed because he is a Pole, a Jew, an Irishman, a Mason, a Protestant, and it is sometimes difficult for a committee to reject a candidate without being charged with discrimination. On the other hand, an even more vicious tendency has

charge under Sec. 13060, which he was justified in doing if, as stated by him, he had no more evidence of selling chances than that already introduced. The police did not admit having any more evidence than that already offered. If all of the parties acted in good faith and told the truth, the case is simply one of a failure by the police to secure adequate evidence.

${ }^{1}$ In a campaign speech addressed to an audience containing many saloon-keepers a judge is quoted as saying the following: "I am a candidate for an office that is important, especially to men like you. You might have a little unfortunate trouble and get into the police court-when you do, you want a man on the bench who is your friend." 
begun to appear-the formation of organizations with the avowed or unavowed purpose of "knifing" every candidate who is not of a particular religion, nationality, or color. It is estimated that one such organization last fall, through the expedient of issuing thousands of marked ballots at churches and other places, succeeded in swaying 50,000 votes among the regular nominees. The marked ballot carried nothing to indicate the sectarian nature of the organization, which bore a title similar to that of the Civic League, an impartial organization, and it is not to be supposed that so many voters knew of the dominant motive behind the marked recommendations.

\section{Labor Organizations}

From time to time, as at present, fierce industrial controversies rage in Cleveland, and there, as elsewhere in the United States, in contrast with England, courts are drawn into the economic struggle. Naturally, therefore, each group is alert to bring its pressure-be it voting strength or dominant public sentiment-to bear upon the courts and to be concentratedly watchful of the group interests. Another manifestation, therefore, of the use of group power is the active participation of certain of the labor organizations in the election of judges. Like other groups, these organizations have often not taken a broad view of a judge's fairness and ability. "The unions have lost faith in the courts," states one of their most respected leaders; "they believe the man who has the influence gets by." So believing, they tend to act on their beliefs and fears-fears not wholly unjustified in past American experience. If a judge renders a decision, however conscientiously made, which is believed to be adverse to the interests of a labor organization, he is apt to be marked for the slaughter. Even a passing remark may be taken to stamp a judge as anti-union and be used to defeat him. ${ }^{1}$ Naturally,

1 Judge R. M. Morgan rendered a decision in Taylor and Boggis Foundry Company v. Iron Molders' Union, limiting the extent of picketing during a strike. The union construed this decision as hostile, and fought him at the primary as "an enemy of the union." Although Morgan had been making an able judge, he was badly defeated. Even the party organization did not support him. The union claimed the credit of assisting in his defeat.

Judge F. B. Gott was opposed for reelection in 1918 because "one of our members was called before Judge Gott about a year ago and he asked this brother what he done with his money, and he told him he was a member of the - Union. The judge in turn told him he had better drop the union, so he also must have a grudge against labor unions." The "member" referred to had failed to comply with an order of the court as to an allowance for his wife and children, giving as an 
the converse is also true, that unions will support those "who will give us a square deal when we get into trouble." It is not surprising that this condition produces a judge who flourishes his union card on the bench, and in a suit quantum meruit for work done, campaigns for reelection by observing that "a non-union man isn't entitled to receive the union rate of wages." A former judge relates that when he was on the bench two well-known union leaders were introduced to him by his clerk-" "no particular business, just to let me know they were on the map."

This situation naturally tends to undermine the character of the judiciary.

There are some critics, notably attorneys for large employers, who would explain all of Cleveland's troubles in administering justice with the observation that "Labor is on top." Little good can come from taking such a simple partisan view. The influence of organized labor is only one of many symptoms of an unhealthy system. If organized labor disappeared completely, the system would be just as unsound and unsatisfactory. The country has had the converse experience with judges imbued wholly with the viewpoint of big business and wants no more of it. The folly of exposing a judiciary to every wind that blows, and then blaming a particular wind, is apparent.

\section{Bar Association and the Civic League}

The two organizations to which the voting public would naturally turn for leadership in the selection of judges are the Bar Association and the Civic League. The Bar Association contains the men who are best able to weigh the attainments of a judge and who have intimate personal knowledge of all the candidates. The Civic League exists largely for the purpose of furnishing the people of Cleveland with unbiased estimates of the qualifications of public officers. Its wide membership places it above suspicion of ulterior motives. Yet neither the Bar Association nor the Civic League has been wholeheartedly accepted by the people of Cleveland as a guide. That other influences have been at times more potent may be seen in the list of judges who have failed of reëlection since 1912. Judges who have done well in office and become seasoned should, if possible, be returned to office, if the bench is to de-

excuse that part of his wages went to pay union dues. The judge told him his legal and moral obligation to his family came ahead of the union. In 1912 Judge Gott had led the ticket; in 1918 he was defeated, running fifth in a field of eight candidates. 
velop fine traditions and attract men who seek the bench as a life-work and not as a political stepping-stone. Moreover, it is an expensive work to train young and inexperienced men, and the training should not be wasted.

For the most part, in the following list only indorsement of the Bar Association are given, because they were substantially the same as those of the Civic League.

In 1912 Judges Chapman and Ford, two of the most able Common Pleas judges in recent years, were defeated. They were the first and second choice respectively of the straw vote of the Bar Association. In the same year former Judges Keeler, Schwan, and Strimple were defeated, but in these instances the vote of the electorate coincided with the vote of the Bar Association. Those retained in office were Judges Phillips and Babcock, the third and sixth choices of the Bar Association, and those newly elected, Judges Gott, F. E. Stevens, and Pearson, the fifth, eighth, and ninth choices.

In 1914 Judge Collister, the first choice of the Bar Association, failed of reëlection, and Judge Ford, again the second choice, although he had been off the bench for two years, was defeated. Judge Friebolin, who had received an eight to five indorsement over his opponent, failed of reëlection. The successful candidates who ran against these men were Judges Vickery and Neff, third and fourth choices respectively, Judge Kennedy, and newly elected Judges Levine and Powell.

In 1916 three judges were candidates for reëlection and all were elected.

In 1918 Judges Gott and Stevens failed of reëlection. Although the Bar Association vote for that year is not available, these men are concededly two of the ablest on the bench. Judge Morgan, a hard-working, conscientious judge of considerable ability, failed at the primaries. The successful candidates who ran against Judges Gott and Stevens were Judge Pearson, who was reëlected, and Judges F. C. Phillips, Baer, and Kramer, who were newly elected.

In 1920 three judges whose election was contested were returned to office, all of them having been indorsed by the Bar Association in its straw vote. For the new judge the Association preferred Judge George S. Addams, Judge of Insolvency and Juvenile Court, to Judge Florence Allen, who was the sixth choice of the Bar Association, and who led the ticket. The Civic League strongly indorsed Judge Allen.

In the history of the Municipal Court only one judge has failed to be retained in office, and this one was originally appointed. In the first election in 1911 the Bar Association, which had urged the establishment 
of the new court, made an active campaign to elect its choice of the judges to the first bench and succeeded. The vote of the Association for 1913 is not available. The three candidates recommended by the Civic League were elected. In 1915 the choices of the association for Chief Justice and for the three six-year terms were elected, but all three of its selections for the four-year terms were defeated.

The vote of the Bar Association for 1917 cannot be located, but three of the Civic League's preferences were elected and one defeated.

In 1919 five of the choices of the Bar Association were elected and two defeated.

In this connection it might be interesting to glance at the list of judges who have resigned from the bench, all of whom were indorsed by the Association and the Civic League.

Before 1912 resignations were infrequent, but during the eight succeeding years the following have resigned ${ }^{1}$ from the Municipal bench: Judges Sanders, Bernon, Keough; and from the Common Pleas bench: Judges G. L. Phillips, F. E. Stevens, and Estep. Judge Sanders was subsequently appointed street railway commissioner. Judge Bernon was appointed Common Pleas judge; Judges Phillips and Estep resigned because of age and ill health. The remainder have returned to the private practice of law. It may be said that all of these men were above average ability for their respective benches.

One reason for the partial ineffectiveness of the Bar Association and the Civic League is the fact that, as a general practice, neither organization makes a fight for its recommendations, except by publishing their indorsements in the newspapers. When a real effort is made to elect its choices, as at the launching of the Municipal Court, the entire list may be elected. Few people are influenced merely by reading a list of recommendations, and many voters live beyond the city limits. Meanwhile the influence of the ward politician, the appeal to race, religion; class solidarity, and prejudice, have won the mass of the voters. Moreover, the two associations begin their efforts after the primary, so that often they have little or no enthusiasm for their own indorsements. ${ }^{2}$ These bodies have a splendid opportunity for intelligent leadership, and since the advent of woman suffrage, a new and powerful source of support.

There has been another reason for the failure of the Bar Association to lead. For a time it was like most other bar associations in the coun-

1 Exclusive of resignations after election to a higher court.

2 "There is no such thing as Bar Association candidates," observes a prominent lawyer, "only those whom they prefer-the lesser of two evils." 
try, functioning chiefly to eulogize the dead. It has bestirred itself occasionally when vacancies occurred on the bench, and through committees has conferred with judges regarding changes in rules and practice. It has made possible such reforms, as the establishment of the Municipal Court, certainly a great improvement over the justices of the peace. It has maintained an organization for dealing with grievances against individual attorneys, which has probably functioned as well as most grievance committees. Until recently it had never set itself the definite task, however, of supplying educational advantages to its members, or of lifting the standard of admission to the bar, or of cleansing the profession of pirates and evil practices, or of improving the personnel of the bench. For these reasons the Association was not highly regarded even by its own members, or recognized as a public-spirited organization generally.

This situation is changing at the present time. Under recent leadership, notably that of its present head, John J. Sullivan, and a professional secretary, A. V. Abernethy, the Cleveland Bar Association promises fruitful activity. It holds frequent meetings, addressed by experts on various phases of the law and practice, publishes monographs, maintains an energetic legislative committee, and takes a general lead in matters of chief concern to bench and bar. The vigorous efforts of its executive committee resulted in the prompt retirement of Chief Justice William H. McGannon, in the appointment of Judge John P. Dempsey to succeed him, and the naming of a special prosecutor to purge the city of the disgrace of the three Kagy murder trials. Prominent and busy members of the Association have given generously of their time to aid the Cleveland Foundation Survey. If the Association makes a permanent and dynamic tradition of its present energy and responsiveness toward ethical and public questions, it is certain to capture and hold the confidence of the voting public. ${ }^{1}$

\section{Publicity}

Editorially, newspaper support of candidates for the bench has in the main been wisely given. What effectiveness the recommendations of

1 Some of the members do not yet share the outlook of the leaders. At the meetings on February 16 and 23, 1921, occurred debates over a motion to indorse a bill for the Statutory Organization of the Bar of Ohio. One of the chief grounds of opposition was that the bill contained by inference the admission that some lawyers needed disciplining. A Common Pleas judge who had won a reputation for public service, partly through his own fight against shysters and attendant parasites, opposed the motion on the ground that "lawyers were just as honest as other men."

The motion was lost, 59-49. 
the Bar Association and the Civic League have had is due chiefly to the coöperation of the press. The gravest criticism that can be made of the increased editorial power of the newspapers in relation to the bench is that sometimes it comes perilously close to dictating important decisions, and that always the fear of it tends to weaken independence of mind. ${ }^{1}$ In a community where the administration of justice may be interfered with by many unseen causes, however, newspaper vigilance has often been exerted in the interest of the public welfare.

\section{Self-Advertisement}

The real evil in the use of the power of the press lies not in its editorial policy, but in its news column, where the daily publication of a judge's name may lead the public to vote for a judge as naturally and unreasoningly as it asks for the most widely advertised brand of soap. Some publicity is, of course, not only justly earned by a judge, but highly desirable from the public viewpoint, as, for instance, when a judge inaugurates a reform, or hands down a decision on an important and unusual question. Such publicity means public education. However, quantity of publicity is more telling than quality. The average voter soon forgets in what connection he has read a judge's name, and knows only that some names on the ballot look familiar and some strange. Then the law of "suggestion" makes him vote for the advertised name.

This kind of voting in Cleveland has produced some curious results. At least two candidates, hitherto unknown to the public and of no marked fitness for the bench, were elected to the Municipal Court because they bore the same names as two retired Common Pleas judges who had built up good will through many years of service. In one election a blacksmith carried Cuyahoga County as candidate for Chief Justice of the Supreme Court of Ohio because his name was similar to that of the well-known judge of the Probate Court. At the next succeeding election for the Supreme Court the same man ran third in a field of seven.

The continued advertisement of a judge's name--or the name of a prosecutor who would be judge-may take place without, and even

1 The dilemma of the judges is clearly brought out in a story related by a court reporter of one of the local papers. A judge who had been ridiculed by this paper, in delivering an address, severely arraigned the press for attempting to influence the court and juries. The reporter walked in toward the close of the address and was discovered by the speaker. As soon as the talk was concluded, the judge rushed to the reporter and whispered, "For — sake, don't handle me too rough tomorrow." 
contrary to, the wish of the editor. ${ }^{1}$ The newspaper reporters who cover the courts naturally want copy. The judges, too, desire copy and the combination, unchecked, is bringing the bench into a disrepute which attaches alike to the conscientious judge and the guilty "juggler" on the bench. ${ }^{2}$ The least judicial and most immoderate judges get their actions into the papers because "it's news," while strict and competent attention to judicial duties is too commonplace for mention. Several years ago a Municipal Court judge began to sentence traffic-law violators with such a heavy hand that he furnished copy to the reporters for weeks. A society woman receiving a workhouse sentence made "a story." In the fall this judge was a candidate for the Common Pleas bench, and although opposed by the press, led the field by a big majority, partly because of the advertisement he had received. A judge now on the Municipal Court bench started the same tactics in the winter of 1921, fining the liquor law violators-for the most part foreigners making "home brew"-unprecedented sums. The newspapers promptly responded with publicity. Many of the defendants were sent to the workhouse to work out fines ranging from $\$ 500$ to $\$ 3,000$ at 60 cents a day. These unfortunates were immediately dubbed "lifers," and a fresh run of publicity started, with photographs and interviews. ${ }^{3}$ The judge then injected new life into the news by calling publicly for criticism and suggestions. Evidently the comments he received were not wholly favorable, because he soon relaxed his campaign. As a matter of fact, by means of motions in mitigation, quietly allowed, this judge was not exacting greater penalties than his more moderate colleague in the next room, but of this the public was not aware. ${ }^{4}$ The man who paid his

1 When the Cleveland Press sought to fix responsibility for the Raleigh farce, one of the principals remarked: "I don't care what they say about me so long as they keep on publishing my name."

2 "The Jugglers" is the title of a novel caricaturing the administration of justice in Cleveland-by Ezra Brudno, 1920.

${ }^{3}$ It is comforting to know that most of these workhouse commitments were quietly released-with little publicity, however. Out of 59 defendants committed by this judge in January, for failure to pay fines, by April 19, 23 had sentences suspended by the judge, 24 were paroled by the Parole Board, 7 paid the balance of their fine, and 1 died. The average time actually served was thirty-one days.

4 In January this judge's average fine (exclusive of workhouse and appealed cases) was, before mitigation, $\$ 376.62$; after mitigation, $\$ 176.61$. His colleague's average fine was $\$ 299.12$; after mitigation, $\$ 180.17$. Cases begun in January but sentenced after January averaged $\$ 322.58$ before mitigation, and $\$ 122.58$ after mitigation. The second judge for the same class of cases averaged $\$ 269.23$ before mitigation, and $\$ 135.90$ after mitigation. 
huge fine without making a motion in mitigation was penalized for not having a lawyer who "knew the ropes." The judge justifies his conduct on the ground that he never intended the large fines to be paid; that they were simply warnings and had a wholesome deterrent effect.

\section{Exploitation of the Police Court}

The two judges cited are perhaps most extreme examples, but even without such campaigns the police court furnishes lime-light enough. To serve in the police court during election year is a political asset, and the schedule of the judges is apparently conveniently arranged so that all judges facing reëlection are given the opportunity to serve on the criminal side during the preceding nine months. If necessary, the regular sitting of a judge not up for reëlection is shifted to a colleague who is.

In November, 1913, the following Municipal Court judges were candidates to succeed themselves: Judges Beebe, Cull, and Sanders, and although we have no record of the regular assignments for this year, these three men served on the criminal division during most of the year.

In November, 1915, the following judges were candidates to succeed themselves: Judges Baer, Bernstein, Kramer, and McGannon, all of whom were assigned to the criminal division during this year. The one other judge who was assigned for a term did most of his service after the election.

In November, 1917, the following judges were candidates to succeed themselves: Judges Beebe, Cull, and Keough, all of whom were assigned to the criminal division during this year. The only other judge who was assigned for a term apparently yielded a portion of his assignment to the others.

In November, 1919, the following judges were candidates to succeed themselves: Judges Moylan, Pearce, Howells, Terrell, Selzer, Silbert, and Sawicki, the first five of whom were regularly assigned to the criminal division. Judges Silbert and Sawicki, however, were worked in shortly before election-Judge Silbert for more than three months and Judge Sawicki for one month:

The election for Common Pleas judges is held in the even years, and here again a relationship exists between service on the criminal division of the Municipal Court and the judge's candidacy for the Common Pleas bench the same year.

In 1914 Judges Levine and Sanders were candidates for the Common Pleas Court, and during the same year both served on the Criminal Division. In 1916 no Municipal Court judges were candidates. In 
1918 Judges Baer, Kramer, F. C. Phillips, and Cull were candidates for the Common Pleas bench, and all served in the criminal division, the first three by assignment, and the last being given a month by courtesy or exchange. In 1920 Judge Beebe was a candidate, and although not regularly assigned to criminal work, served over five months in that division.

The success of this kind of publicity is seen in the fact that out of a total of nine new Common Pleas judges elected since 1912, six are former Municipal Court judges, and a seventh is a former assistant county prosecutor. Only two Municipal Court judges have been defeated for the Common Pleas bench.

Of the six former Municipal Court judges, four started their careers as police prosecutors. Out of 18 Municipal Court judges elected since its organization, eight began in the police or county prosecutor's office. This tendency has become less evident of late, however, since out of nine Municipal Court judges now serving, only two began as police prosecutors. It is difficult to say what has caused this shift, unless it be a change in the quality of police prosecutors, who now seem to be moving into the county prosecutor's office or becoming police court lawyers. ${ }^{1}$ The injury to the prestige and self-respect of the bench through the conscious exploitation of the criminal branch needs no comment.

There is apparently no established practice in the Common Pleas Court of using the criminal division for publicity purposes in election year, although it is undoubtedly so used on occasions. Sometimes a candidate for reëlection will take two terms as presiding judge of the criminal branch before election, as Judge Ford in 1912, Judge Lieghley in 1914, Judge Powell in 1916, and Judge Kennedy in 1920. The temptation and perhaps even the necessity of bench publicity are unfortunately present in the Common Pleas Court as in the Municipal Court. ${ }^{2}$

1 The quality of police prosecutors is part of the study of that office, rather than of the bench. Newton D. Baker, the first city solicitor to appoint police prosecutors, inaugurated a policy of appointing "youngsters with ideals fresh out of the law school." The ability of his keen juniors to improve their opportunities soon landed five out of six on the Common Pleas bench, with scarcely any of the seasoning which comes from private practice.

${ }^{2}$ A judge who would not be classed as a self-advertiser was hearing an important injunction suit which lasted several days. After court had adjourned for the day, the case still pending, a reporter stopped the judge as he was leaving the bench with, "Just give me the high points, Judge." Wearily, but patiently, the judge detailed the day's progress for the reporter. The impropriety of a judge reviewing for the press a case pending in his own court apparently shocked no one. 


\section{Character of the News}

As long as newspapers print as news every extreme utterance or irrelevant whimsy, they will fail to educate the public to a relevant appraisal of the bench. It is easy to understand why a newspaper which prints the following about a judge cannot defeat him at the polls: "Municipal Judge — ate candy as he listened to testimony Friday. 'It keeps one from getting nervous,' the Judge says."'1

Another form of publicity which the present mode of selection has brought into prominence is the advertisement which must be bought. Where formerly judges were timid about such a small matter as distributing cards, there is no hesitancy today about elaborately conceived advertisements. Pictures showing a judge listening kindly to the whispers of a poor litigant or being appraised by an appreciative public are some of the forms of campaign publicity.

\section{Campaign Funds}

There is one aspect of purchased publicity which ought to be stopped immediately, namely, the solicitation of campaign funds, especially among lawyers. So far the reports of such funds concern only a few judges, but unless curbed, other judges will be compelled to permit collections in their behalf. It would be difficult to conceive a more degenerating influence than the giving of campaign funds by lawyers in behalf of a judge before whom they expect to practise.

\section{RECOMMENDATIONS}

From the foregoing it will be seen that the wide-open elective system in Cleveland has up to the present time developed no predominant de facto method of appointment. The community has been unable to avoid the chaos regarded as an impossible result by the American Judicature Society. ${ }^{2}$ Its bench, therefore, reflects the many influences at work upon it. Rarely does a judge represent the purposeful, discriminating choice of the community.

Only in the filling of vacancies has a real appointive power asserted itself. Unfortunately, the local executive committee of the political

'A judge known for his efforts along constructive lines caught a former chief of police "cribbing" someone else's speech on a public occasion. The editor of one of the papers which made a sensation of the exposure congratulated the judge with the remark, "This is the best thing you've ever done." "How about my part in ridding Cleveland of justices of the peace?" queried the judge. "Oh, that was all right," replied the editor, "but this is the biggest yet!"

${ }^{2}$ Bulletin IV-A, American Judicature Society, p. 9, 1915, Chicago. 
parties has usually seized these opportunities, the Bar Association not being, as a rule, aggressive.

\section{Appointed and Elected Judges}

Owing to the frequency of vacancies caused by resignation and death, it is possible to draw a comparison between men appointed by the Governor to fill unexpired terms and those who became judges for the first time through election. Of course, most of those appointed were subsequently elected, but the comparison is relevant only to the modes of selection in the first instance. Care should be taken not to regard the list as furnishing typical examples of elected and appointed judiciaries, since this would be misleading. Governors, in making appointments to fill short unexpired terms, are not guided by the same sense of responsibility as governors in other States charged with the responsibility of naming judges for life. The nominees must in any case face an election in a few months, ${ }^{1}$ so that the sense of responsibility to the public is largely outweighed by the necessity of securing the continued support of the local machine. The local organization is not made up, in the main, of men of great intelligence or vision, because of the abhorrence of politics felt by men of this type. Selfish personal motives or the instinct of political self-preservation dominate the local machine, and its nominations to the Governor are apt to represent payments for political debts, or the best chance to win the subsequent election. "Has he earned it and can he win?" asks the local committee, and the Governor usually queries, "Is he decent?" 2 The public has the best chance when the party in power fears defeat at the next election, or when some dramatic episode focuses attention on the forthcoming appointment. ${ }^{3}$

With these qualifications, the lists of judges first appointed and first elected may be compared. On the whole, the opinion is probably warranted that the appointments, especially those to the Municipal

1 Appointed judges must defend their office at the next succeeding election.

2 "The mere fact that he has no brains will not disqualify him for the appointment," said one man who has an intimate knowledge of these appointments over a period of years; "unfortunate is the man who has nothing to recommend him but qualifications for the office!"

3 The excellent appointment of John Dempsey in March, 1921, to succeed W. H. MeGannon as Chief Justice of the Municipal Court, is an example. Governor Davis and the local committee set a wholesome precedent by virtually accepting the nominee of the executive committee of the Bar Association. It would be advisable, however, if the Bar Association committee sent in several names instead of one when vacancies occurred. 
Court, do not include men as conspicuously unsuited for judicial office as a few of those elected.

It should also be remembered that the judges elected to the Municipal bench in the first election in 1911 were "hand-picked" and virtually appointed. Both lists include men of outstanding ability, and there is apparently no lesson to be learned by comparing the age and previous experience of the men in the two lists. All the judges known for their talent in securing publicity are contained in the elected list. Probably the only clear moral which can be drawn is that a heavily embarrassed system of appointing produces as good, but not as poor, results as the present method of popular election. The lists follow:

\section{Common Pleas Bench}

Judges elected and appointed since 1900

$\begin{array}{ccl}\text { Appointed } & \text { Elected } & \\ \text { 1900-1911 } & 1900-1911 & \\ \text { Shallenberger } & \text { Babcock } & \text { Keeler } \\ \text { G. L. Phillips } & \text { Tilden } & \text { Estep } \\ & \text { Kennedy } & \text { Vickery } \\ & \text { Lawrence } & \text { Collister } \\ & \text { Schwan } & \text { Foran } \\ & 1911-1921 & \\ \text { 1911-1921 } & \text { Gott } & \text { Cull } \\ \text { Lieghley } & \text { Pearson } & \text { Kramer } \\ \text { Friebolin } & \text { F.E. Stevens }{ }^{1} & \text { F.C.Phillips } \\ \text { Morgan } & \text { Powell } & \text { Terrell } \\ \text { Day } & \text { Levine } & \text { Allen } \\ \text { Bernon } & \text { Baer } & \\ & & \end{array}$

\section{MUnicipal Codrt}

\begin{tabular}{ll|r} 
Bernon & Beebe & \\
White & Sanders & \\
Keough & McGannon & 1911 \\
Day & Kramer & $\begin{array}{c}\text { Elec- } \\
\text { Selzer }\end{array}$ \\
Sawicki & Baer & \\
Terrell & Cull & \\
Howells & Levine & \\
Pearce & McMahon \\
Dempsey & Moylan \\
& Silbert \\
& F. C. Phillips \\
& F. L. Stevens
\end{tabular}

${ }^{1}$ Subsequently appointed after being defeated for reëlection. 


\section{The Use of Vacancies}

If the opportunity were skilfully employed, vacancies might be used to improve greatly the personnel of the bench, since appointed judges have a large advantage in the ensuing election. This is a matter for the Bar Association to take up with the local executive committees of the parties, with a view to inducing these committees, as in the Dempsey case, to accept the nominees of the Association. The Bar Association should either hold a primary and recommend the winners to the Governor, or recommend several alternate choices so that the Governor may have some latitude.

\section{Selection in the Usual Course}

With respect to the selection of judges in the usual course, the following methods are recommended in order of preference:

(1) The appointive method, with provision for a retirement election whereby a judge runs against his own record.

(2) A modified appointive method, as, for example, an elective Chief Justice who appoints his associates. ${ }^{1}$

(3) A modified elective system whereby judges are elected for a short first term, but if reëlected, then for progressively longer terms. Judges standing for reëlection should not run against other candidates, but only against their own records. The single question presented to the electorate should be, "Shall this judge be retained?"

If the judge is defeated, his successor should be chosen at the next succeeding election.

These three recommendations, in order of preference, are probably in inverse order of probability of achievement. It is, therefore, most useful to consider the third suggestion. The provision for a short trial term gives the public an opportunity to learn what character of a judge it has chosen. If the short term record is satisfactory, the judge will be returned for a longer term, thus giving the community the benefit of his judicial growth and experience. By eliminating a campaign against rivals and confining a judge to the single issue of his service on the bench, it is hoped that many of the evils of electioneering will be eliminated and that a tradition will be established of giving practically a life tenure to

1 It is not intended here to discuss at length various suggested plans. They have already been the subject of searching study. See Bulletin $I V-A$, American Judicature Society, 1915, Chicago. 
able judges. Cuyahoga County has already established such a tradition with respect to the probate judges, who have been usually unopposed at elections. Such a tradition can be established for the other courts if the judgeships are not "scrambled" among a field of candidates.

\section{Joint Committee on the Judiciary}

Even under such a plan, however, it would be necessary to select new candidates for the initial and special elections. It would become necessary for Cleveland to mobilize its most influential and intelligent forces so as to bring about concentration of electoral power on the most desirable candidates. In Cleveland the strongest forces are the party organizations and the press, and the most intelligent, the Bar Association and the Civic League. The following suggestion is already in the minds of many thinking men of Cleveland of both parties, and if put into effect, would do much to improve the personnel and standing of the bench.

There should be a joint committee on the judiciary, composed of not more than three members of the executive committee of each of the major party organizations and of the Bar Association, and representatives of the leading civic organizations. This joint committee should then select a slate of candidates to be supported at the primaries and at the election. From the coöperation which the press has given in the past to occasional joint efforts of this sort, such a plan would almost certainly be welcomed and supported by the great dailies of Cleveland.

Of course, the mere indorsement of a joint slate would not be sufficient. The political organizations of each party would have to produce results at the polls, and to the Bar Association and Civic League would fall the task of organizing and directing the intelligent citizenship. 


\section{CHAPTER V}

\section{THE MUNICIPAL COURT}

$\mathrm{T}$

THE present Municipal Court was launched in 1912 with fine civic enthusiasm, in the belief that Cleveland had finally attained a modern city court. ' It is not within the scope of this report to consider whether or not the high hopes of those days have been realized so far as its civil jurisdiction is concerned, but nine years of experience do not justify any satisfaction with the handling of criminal causes. Lawyers and public officials appraise the criminal division of the Municipal Court when they persist in calling it, as they called its predecessor, a "police court."1

\section{Physical Conditions}

Civil causes, however small, are heard in the imposing new City Hall on the lake front, in court-rooms of dignity and charm; criminal causes, outside of the few jury trials held in the City Hall, are tried in the old police court-rooms at the corner of West Sixth Street and Champlain Avenue, N.W. This small building is used for police headquarters, bureau of criminal identification, office of city prosecutor, probation office, clerk's office, city jail, as well as court-house, and is inadequate for all these purposes. Several years ago the city voted $\$ 1,250,000$ for a new jail and criminal court. The commission began work on the lake front and then asked for additional bonds for the building. The voters of Cleveland refused the request, and the city has, therefore, gained nothing but an excavation. It is not necessary to build edifices like the City Hall or County Court-house, but a community which could erect those buildings should not accept the present stalemate with respect to an institution even more vital to its citizenship. A simple, modern criminal court-house and jail is an immediate necessity. One way of securing it speedily would be to compel the leading citizens of Cleveland

1 Since this report is based upon a study of the court as it was in the early months of 1921, it is in no sense a criticism of the new Chief Justice, Judge Dempsey, who was appointed in March, 1921, and who was unable to attack the problems in the criminal branch until May because of the unprecedented congestion of the civil list. On the contrary, Judge Dempsey has given evidence that he appreciates many of the evils and shortcomings pointed out in this chapter, and has already, on his own initiative, begun some badly needed reforms, such as the division of cases into sessions, and the starting of process in certain cases by court summons. 
to attend one of the daily sessions of the "police court." A former municipal judge has recommended that "the place should have a hose turned on it." After this is done, a carpenter, a painter, an electrician, and an expert on ventilation should be called. Their services would make the place tolerable until new quarters are available. Little can be done, however, to relieve the extreme congestion of the auxiliary departments. It is greatly to the credit of the clerks' and probation officer's staffs that they have been able to work with any degree of success amid such an environment.

\section{DeCORUM}

Accepting the court-rooms as they are, little can be said for the conduct of cases therein. From 150 to 300 cases a day are assigned to the two court-rooms, and the visitor is immediately struck with the lack of orderliness in handling the list. The lawyer who has only an occasional case, perhaps an ordinance violation, may wait with his clients and witnesses from nine o'clock until two, not knowing when his case will be reached. This apparent chaos is, of course, to the advantage of the regular "police court lawyer," who has a number of cases each morning.

The decorum in Room 1 is somewhat better than in Room 2, but the first room has higher ceilings and is better adapted for hearings. On a day during the period covered by the survey Judge Howells was sitting in Room 1 and Judge F. L. Stevens in Room 2. In neither room did the proceedings reveal the necessary dignity of a court. The rooms were crowded with lawyers, defendants, witnesses, police, hangers-on, and sightseers, many chewing gum or tobacco, even when addressing the court. In Room 2 an attorney was waving a cigar in the judge's face by way of emphasizing his argument. Crowded around the bench were lawyers, witnesses, and officials, almost screening from view the testifying witness. Others in the court-room were standing about talking and were occasionally asked by the judge to be quiet in order that he might hear the testimony-this, although the witness chair was placed directly against the judge's bench. The only person who seemed to be able to follow the testimony was a young woman reporter from one of the newspapers who took up a position behind the witness-chair.

In order to make themselves heard in this court-room, lawyers and others have to lean over the bench to address the judge. ${ }^{1}$ This produces

1 Formerly the end of the bench was open so that attorneys, politicians, etc., could go in back of the bench to whisper. When Judge Levine was in the Municipal Court he had long arms put on the ends of the bench, so that all conversation had to be held across it. These arms are now a permanent part of the equipment. 
an impression of a confidential communication, which, although false, lends color to the belief that certain lawyers have "pull with the judge."

The question of decorum lies with the judges. A space should be cleared before the bench and on both sides, marked off with a railing, and no one should be allowed within the inclosure except attorneys in good standing. Everyone should be compelled to sit while the court is in session, and if every seat is taken, no additional persons should be admitted. Any talking during a hearing should be immediately suppressed. Several years ago Judge Selzer had the witness-chair moved away from the bench so that its occupant could not give the appearance of talking for the judge's ears only. On account of the poor acoustics and confusion in the court-room the chair is again next to the bench. It should be moved away, and if order is maintained, a witness can make himself heard clearly enough.

\section{Separate Sessions Recommended}

Separate sessions dealing with different groups of cases should be established, as, for example, one for misdemeanors and ordinance violations criminal in nature; one for felony examinations; one for women offenders; and one for violations of ordinances only quasi-criminal in their nature. Possibly the last mentioned might be held in the City Hall in order that otherwise law-abiding citizens may await their turn and have their cases heard in an atmosphere less suggestive of crime and degradation. During the trial of a sexual offense the court-room should be cleared of everyone not concerned in the particular case. It may also be possible to hold different sessions in the morning than in the afternoon. At present there is a rough division of cases, Room 1 being used for "city cases" (ordinance violations) and Room 2 for "State cases" (misdemeanor and felony examinations). ${ }^{1}$

\section{Shifting Cases from One Judge to Another}

One of the assistant clerks has discretion to decide whether the list in one room is congested so that cases should be transferred from one session to the other. Since a lawyer may get along better with a certain judge than another, or the disposition of a judge may be known to be strict or lax in certain classes of cases, this discretion often exposes the

In 1920 these cases were divided as follows: felony examinations, 3,064; State misdemeanors, 11,843; ordinance violations, 11,181. Since 1912 felony examinations increased 204 per cent.; misdemeanors, 167 per cent.; ordinance violations, 376 per cent. 
clerks in charge to great pressure to transfer cases from Room 2 to Room 1 , and vice versa. It is impossible to ascertain how many cases are shifted upon solicitation, ${ }^{1}$ but the atmosphere is charged occasionally with rumors that certain cases are "thrown" before a particular judge.

Table 10 may be significant as showing the tendency to shift cases. During the winter of 1921 Judge Stevens sat in Room 2, and in January startled the community by his severity in handling cases of State liquor law violations which came up properly in Room 2. Judge Howells, sitting in Room 1, acquired a reputation for being only moderately severe in handling such cases, so that it was regarded as more advantageous to be tried by Judge Howells than Judge Stevens. Judge Sawicki sat for Judge Howells during one week in January.

TABLE 10.-SHIFTING OF CASES IN MUNICIPAL COURT, JANUARY, 1921

1. Total arraigned in January and ultimately disposed of by

2. Number disposed of in January by

3. Number arraigned in January but "passed" into succeeding months ultimately tried by

Subdivision of Group No. 3:

a. Arraigned before Stevens, tried by Howells

b. Arraigned before Howells, tried by Stevens

c. Arraigned before Sawicki, tried by Stevens

d. Arraigned before Sawicki, tried by Howells

It so happened that Judge Stevens became more moderate after January 31 , due perhaps to the rather unfavorable reception of his spectacular procedure, and Judge Howells grew stricter, perhaps unconsciously influenced by Judge Stevens' severity, so that the shifted defendants did not profit greatly. Table 11 shows these dispositions.

TABLE 11.-ORIGINAL DISPOSITIONS OF CASES IN MUNICIPAL COURT, JANUARY, 1921

\begin{tabular}{|c|c|c|c|c|c|}
\hline . & $\begin{array}{c}\text { Number } \\
\text { fined }\end{array}$ & $\begin{array}{c}\text { Average } \\
\text { fine }\end{array}$ & "Nolled" & $\begin{array}{c}\text { Dis- } \\
\text { charged }\end{array}$ & Total \\
\hline $\begin{array}{l}\text { a. Arraigned before Stevens, tried } \\
\text { by Howells } \\
\text { b. Total tried by Stevens } \\
\text { c. Total tried by Howells }\end{array}$ & $\begin{array}{r}12 \\
249 \\
100\end{array}$ & $\begin{array}{r}\$ 271.42 \\
452.21 \\
294.45\end{array}$ & $\begin{array}{r}2 \\
18 \\
7\end{array}$ & $\begin{array}{l}14 \\
44 \\
59\end{array}$ & $\begin{array}{r}28 \\
311 \\
166\end{array}$ \\
\hline
\end{tabular}

1 The records of the clerk's office are discussed later. 


\section{Scant Atrention to Individual Cases}

With the cases organized into different lists for different sessions, it may be possible to avoid some of the waste time now involved in waiting for cases to be reached. The principal advantage, however, would be to enable the judges to give more attention to individual cases. Unless a case is of public importance, has news value, or has interested influential people, it is apt to be disposed of before one can say the proverbial "Jack Robinson." This results practically in depriving of his day in court the poor or ignorant petty offender, and plays directly into the hands of the defendant with "wire-pulling" friends. Table 12 gives the number of dispositions in the criminal branch compared with the number in the civil branch of the Municipal Court, showing the amazing discrepancy between the time devoted to deciding questions involving, on the whole, petty property rights, compared with those involving individual liberty.

\section{TABLE 12.-COMPARISON OF NUMBER OF CIVIL AND CRIMINAL} CASES PER JUDGE, MUNICIPAL COURT, 1919

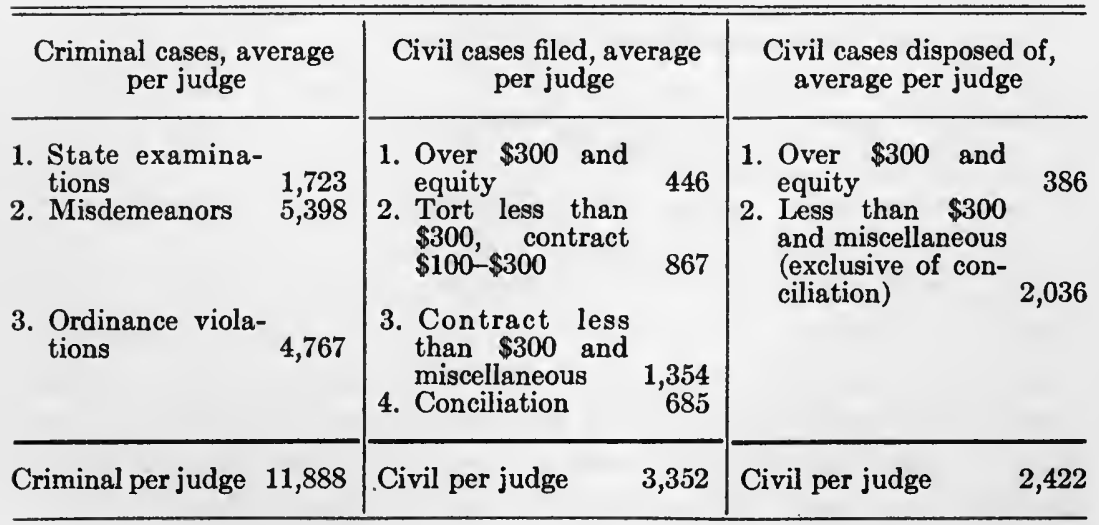

In the hurly-burly of the day's work the judge cannot examine closely into statements and excuses of lawyers, police prosecutors, and police officers, and this affords opportunities either to escape the law by "putting it over" the judge or hastily to punish the innocent.

\section{Bad Effects of Many Continuances}

Most serious of all is the practice of continuing or passing cases. Rule 3, of the Municipal Court,' criminal branch, relating to con-

1 "Motions for a second continuance must be in writing, setting forth the facts and reasons therefor (unless dispensed with by the court). 
tinuances, has become atrophied. It is the object of every police court lawyer to get his case continued as many times as is necessary to disgust the witnesses for the State,- -who have been wasting their time in a most disagreeable place,- -and to cause the prosecuting police officer to lose interest in the case in the face of more pressing matters.

Table 13, based upon a study of every tenth case in the criminal branch for a period of two years, gives the average time between arrest and disposition. It is to be noticed that it takes the least time to find a defendant guilty, a longer time to discharge him, and the longest time to "noll" or dismiss his case. This table is based on all cases, including those ill-advised offenders who allow their cases to be heard on the same day as the arrest, so that the intervals are shorter than they would be if the table were confined to continued cases.

TABLE 13.-AVERAGE NUMBER OF DAYS BETWEEN ARREST AND SENTENCE, MUNICIPAL COURT CASES, 1919-20, CLASSIFIED BY DISPOSITION AND BY TYPE OF CASE ${ }^{1}$

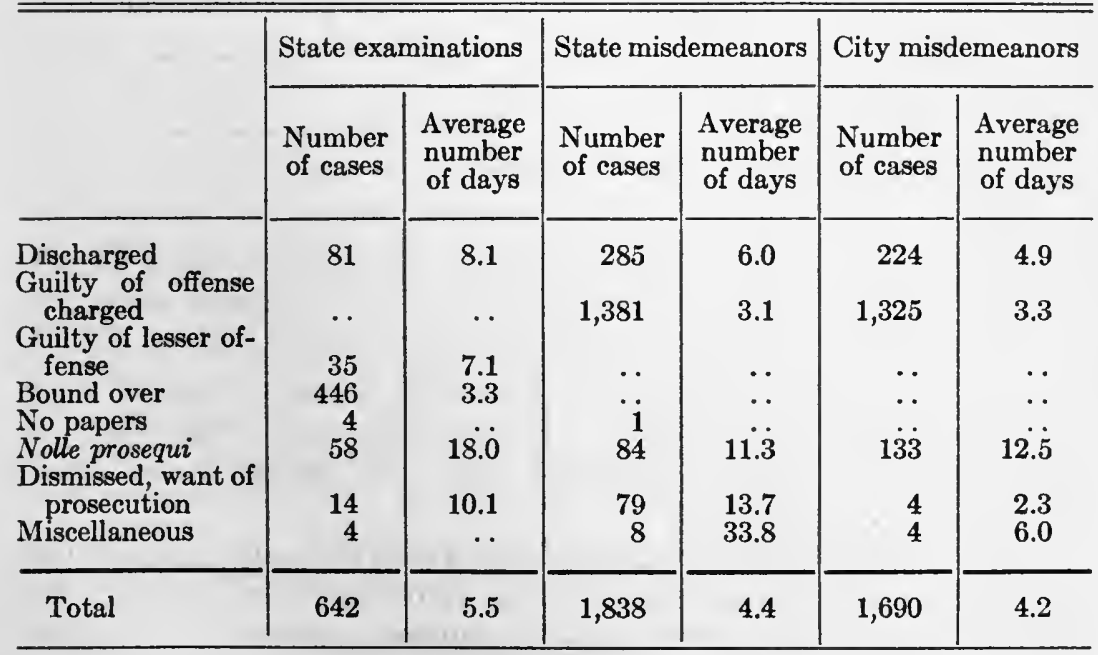

A study of cases of violation of the State liquor law (Table 14), brought before the court in January, 1921, shows that cases which were disposed of in the same month received severer fines, contained a smaller per-

1 The number of these cases is not equal in the aggregate to the total number of cases, because the data of time interval are not available in every case. The term "sentence" means the final disposition of the case, whether or not found guilty, except in those cases in which action, such as mitigation, was taken by the court after sentence: in the latter case the term "sentence" is used in its literal significance. 
centage of "nolles" and discharges, and a much greater number of workhouse commitments than the cases which were "passed" into succeeding months.

\section{TABLE 14.-CASES OF LIQUOR LAW VIOLATION ARRAIGNED IN JANUARY, 1921 1}

Sentenced in January

Discharged in January

"Nolled" in January

\begin{tabular}{|c|c|c|c|c|}
\hline Total & 417 & 100 & . & .. \\
\hline $\begin{array}{l}\text { Sentenced after January } 31 \\
\text { Discharged after January } 31 \\
\text { "Nolled" after January } 31\end{array}$ & $\begin{array}{r}74 \\
28 \\
9\end{array}$ & $\begin{array}{r}67 \\
25 \\
8\end{array}$ & $\begin{array}{l}309.45 \\
\quad \ldots \\
\ldots\end{array}$ & $\begin{array}{l}4 \\
\cdots \\
\cdots\end{array}$ \\
\hline Total & 111 & 100 & .. & . . \\
\hline Grand total & 528 & .. & .. & .. \\
\hline
\end{tabular}

Cases in which continuances are of most advantage to the defendant are those in which the witnesses are disinterested bystanders, as in automobile accident cases resulting in charges of manslaughter or driving while intoxicated. "Continuances kill accident cases," says a police officer posted in the court-room. "The witnesses won't come down and swelter, or else they move in the meantime. The regular lawyer's game is to tire out the witnesses." 2

Such continuances not only enable the guilty to escape, but play into the hands of unscrupulous lawyers who desire to use the criminal court to exact payment of a civil claim for damages, whether well founded

1 Exclusive of cases appealed.

2 A typical case is No. 67557, manslaughter charge, the complaint all eging reckless driving while drunk. The notes in the police records and statements secured tend to establish clearly that the defendant was going at an excessive rate of speed and was intoxicated. The two police officers whose testimony would have been most positive as to the intoxication were not called, and the case was continued after at least one of the important witnesses had testified. The entries are:

"July 22, continued to July 29, continued to August 26, continued to September 16, continued to September 30, discharged by Judge _..." 
or not. ${ }^{1}$ If the case were tried immediately upon its merits, such lawyers would be unable to use the machinery of criminal law as instruments for extortion.

\section{The "Motion in Mitigation"}

The tendency cannot be effectively curbed, however, unless the "motion in mitigation" is eliminated from the practice of the court. This motion, apparently peculiar to the police court, makes a farce of judicial business, more than any other single factor. After a defendant has been adjudged or has pleaded guilty, the court imposes sentence. To the uninitiated the case is over, but this is not so. A "motion in mitigation" is then made, which is sometimes granted the same day, after trial, and sometimes ruled upon weeks and even months later, after many continuances. $^{2}$ Thus the court satisfies the complaining witness in open court, and has the opportunity later to placate the defendant's lawyer. Lawyers report instances where their clients were found guilty, though clearly innocent (in the belief of the defendant's lawyer), and upon protesting against the "outrage" of a conviction, were advised to make a "motion in mitigation." This they did, and the motion was later granted.

The "motion in mitigation" affords the setting for the performing judge, enabling him to do "stunts" which get into the front page of the newspapers, and then to undo the damage quietly at a later date. Mention has already been made of Judge Stevens' campaign against liquor law violators during January, 1921, and the notoriety which resulted from it. Considering the fines for this offense during 1919 and 1920 (taking every tenth case), 61 per cent. were less than $\$ 200$ and 99 per cent. less than $\$ 400$. About 26 per cent. of these sentences were suspended. The average original fine imposed by Judge Howells for January, 1921, was $\$ 299.12$, and the average fine imposed by Judge Stevens (exclusive of five appealed cases) ${ }^{3}$ for the same period was $\$ 468.72$. Excluding cases sentenced to the workhouse for failure to pay fines,

${ }^{1}$ Several cases of alleged extortion have been brought to the attention of this survey.

2 On November 23, 1920, Louis Ettkin was fined $\$ 200$ and costs for violating the liquor law, and the same day the fine was changed to $\$ 100$ and costs. Notice of motion in mitigation was given, and the case continued eight times until February 21,1921 , when the execution docket shows the entry, "motion in mitigation overruled." The original file, however, shows that at some stage $\$ 75$ was suspended, so that Ettkin paid $\$ 25$ and costs on February 21 . Meanwhile bond had been forfeited twice and the forfeitures set aside.

'The inclusion of appealed cases would make Judge Stevens' average a trifle higher. 
Judge Stevens' average fine was $\$ 376.62$. The average amount actually paid in Judge Howells' cases was $\$ 180.17$ and in Judge Stevens' cases (exclusive of workhouse commitments), \$176.61. The "motion in mitigation" is thus seen to be a leveler of fines in this particular group of cases.

It is said that the "motionin mitigation" serves the purpose of allowing a defendant time to pay his fine, and after the fine is paid, the motion is overruled as a matter of form. Undoubtedly the motion is used for this purpose and also to allow the court time to investigate the defendant to ascertain whether the fine imposed is a just one. The vice of the motion is that the court apparently disposes of the case, and at a later date, when no witnesses are present, makes a change. This vice is intensified by a system of record keeping, discussed later, which makes it difficult to find out what actually happened in a particular case. The court should make its investigation before sentence, not afterward, and the sentence once imposed, should stand. This could be accomplished by continuing a case for sentence to a certain day after the issue of guilt is determined, in case the court wishes further advice as to the condition of the defendant. This method would be more apt to impress the defendant with the seriousness of the court than the game of thimble played with motions in mitigation.

The extent to which these motions are used may be seen in the fact that of 314 fines for liquor law violation in cases originating in January, 1921 ,- exclusive of cases subsequently appealed or committed,- - totaling $\$ 101,650$, motions for mitigation were made in 193 cases and allowed in 114 cases, reducing the fines by $\$ 42,135 .^{1}$ Of these fines, 131 were over $\$ 200$ each, totaling $\$ 75,500$, in which 103 motions in mitigation were made, 85 of which were allowed for a total reduction of $\$ 39,150$, or nearly 52 per cent. in amount. An average of 15.43 days was required to overrule a "motion in mitigation" and an average of 35.15 days to grant it. In cases where the fines were more than $\$ 200$ each, an average of 23.5 days was required to overrule the motion and 36.24 to grant it. As in the case of the hearing on the merits, delay favors the party who can keep longest alive his motion in mitigation.

\section{The "Police Court Ring"}

Owing to the fact that no record is kept of attorneys in cases before the criminal branch of the Municipal Court, no statistical data can be submitted of the attorneys practising in this court. It is common knowl-

1 This is exclusive of cases where fine was suspended in whole or in part on the day the fine was imposed. Counting such suspensions with the motions in mitigation, the total reduction from original fines was $\$ 48,885$, or 32.3 per cent. in amount. 
edge, however, that certain attorneys monopolize most of the business, and in a rough fashion divide the practice among themselves. Thus one group represents prostitutes, another pickpockets, another suspicious persons, etc. Any one connected with the court knows the names of these attorneys.

Theoretically, there is no objection to a limited group practising in a particular court. Indeed, under wholly different conditions a limited group of advocates would serve to facilitate the administration of justice by focusing responsibility for the ethical conduct of cases on a definite group. In the "police court" of Cleveland exactly the opposite has resulted. Men of ability as lawyers, or of fine sensibilities, shun this court, so that there is a tendency for men of less refinement to drift into the practice. The activities of these men are nowhere spread upon the record; they involve people who dare not or do not know how to complain. Some of these lawyers were formerly police prosecutors, in which capacity they made the acquaintance of habitual offenders and professional crooks; some are city councilmen with a voice as to the salaries of certain court attendants and a control over votes, which a weak judge cannot entirely overlook; others are connected in various ways with people of political importance.

In the trail of the police court lawyer come the "runner" and the "professional" bondsman, not even subject to the slight check of belonging to the legal profession. Some of the bondsmen are notorious characters, others operate gambling places in the guise of "political clubs." The presence of these men in the corridors of the court-rooms gives rise to rumors of "underground" connections with certain prosecutors, which, even if false, greatly damage respect for the courts in the minds of the unfortunate and their friends.

In some cases these lawyers and "runners" have been compelled to pay back to clients money which they extorted under the claim of "influence." Years ago a police prosecutor, now a Common Pleas judge, tried and convicted one of these men for obtaining money under false pretenses, before the very judge with whom the lawyer claimed to have influence. Judge Howells became for a time so disgusted with lawyers defending prostitutes that he arbitrarily refused to permit any lawyer to represent a prostitute before him. He had just fined a prostitute $\$ 10$ when the police prosecutor whispered to him to suspend the sentence. The lawyer also urged suspension on the grounds that his client could not pay the fine. On inquiry the judge learned that the girl had paid the lawyer a fee of $\$ 75$. It is said that formerly a custom obtained of raiding prostitutes when the city needed money, and although this custom has 
been stopped if it ever existed, there is some opinion to the effect that they have been occasionally arrested when their lawyers needed money. Except in an unusual case, the prostitute fares as well or better in court without any police court lawyer, especially since the establishment of the Woman's Probation Department under Mrs. Antoinette Callaghan.

TABLE 15.-PERSONS ARRESTED FROM JANUARY 1, 1918, TO DECEMBER 14, 1918, RELEASED ON BAIL BONDS SIGNED BY

AND REPRESENTED BY. AND ATTORNEYS:

\begin{tabular}{l|r|r}
\hline \multicolumn{1}{c|}{ Disposition of cases } & Number & Per cent. \\
\hline Bound over to grand jury & 30 & 14.0 \\
Workhouse sentences & 20 & 9.3 \\
Workhouse sentences suspended & 27 & 12.6 \\
Money fines only & 5 & 2.3 \\
Money fines suspended & 4 & 1.9 \\
Discharged & 44 & 20.7 \\
"Nolled" & 59 & 28.0 \\
Bo papers & 11 & 3.1 \\
Nond forfeited, capias & 7 & 2.8 \\
\hline Total & 6 & 100.0 \\
\hline
\end{tabular}

It is no longer necessary for police court runners to look over the contents of the "bull pen" for old and new clients." Some look over the police blotter, and, it is charged, sometimes secure the release of prisoners on personal bond (without surety) in order to make them retain the lawyers in question. For some of the lawyers this is unnecessary because their clientele and reputation are established.

'These men were called counsel for the "International Association of Pickpockets." The firm has not been active in the Municipal Court since the grand jury investigation of 1919. The figures are submitted, however, as showing a state of things which probably exists as to some other Municipal Court lawyers, if the records were available for study. Pocketpicking has fallen off greatly since this firm ceased to be active. One member is an ex-police prosecutor; the other has since been convicted of arson, case reversed on error in the Supreme Court; both men were formerly associates of a prosecuting attorney for Cuyahoga County.

2 "One visit to the central court is usually sufficient for a stranger-one day's visit to the place being as complete as a month's sojourn within its desolate walls. * * * Yet there are a few lawyers in this city who make a practice of habituating the place, picking up such crumbs as these, managing somehow to exist on them. They can be seen every day, a half-dozen or so of them, waiting in eager expectation for the herd to be driven in from the pen; and if one of them looks as though he might have $\$ 5$ about him, he is besieged by anxious solicitors, ready and willing to take his case."-Kennedy and Day, Bench and Bar of Cleveland, 1889. The spirit of the place has not altered greatly in over thirty years. 
Until recently the lawyer himself could be bondsman for his client. Happily, this vicious practice is ended by a court rule, but not without leaving an indication of the activities of a certain group of lawyers who acted as bondsmen for clients whom they represented.

The length of their trail can be judged from figures in Table 15, compiled by the Bureau of Criminal Identification, Division of Police.

These cases included 125 known criminals whose pictures were in the Rogues Gallery at the time of their arrest. These were disposed of as in Table 16.

\section{TABLE 16.-DISPOSITION OF CASES OF 125 KNOWN CRIMINALS}

\begin{tabular}{l|c|c}
\hline \multicolumn{1}{c|}{ Disposition } & Number & Per cent. \\
\hline Bound over & 18 & 14.4 \\
Fined, suspended & 1 & 0.8 \\
Workhouse & 12 & 9.6 \\
Workhouse, suspended & 18 & 14.4 \\
Discharged & 24 & 19.2 \\
"Nolled" & 38 & 30.4 \\
No papers & 6 & 4.8 \\
Bond forfeited, capias & 5 & 2.0 \\
No disposition & 3 & 2.4 \\
\hline Total & 125 & 100.0 \\
\hline
\end{tabular}

Many of these criminals were notorious offenders, and some were subsequently implicated in murders in Cleveland. Some of those not included in the list of known criminals have later been added to this class by the police.

It cannot be said that the judges are individually responsible for the record shown by these cases. In the great majority of the felony charges the defendants were bound over for the grand jury." In the other cases the story is told in the number of cases "nolled" and "no-papered" by the police prosecutor. The former is done by motion before the court; but the absence of centralized judicial administration through a watchful and directing administrative head, the great confusion of the court, and lack of a courageous, highly skilled, and completely disinterested prosecutor, or failing that some "amicus curiae" upon whom the court can rely for disinterested advice, are largely responsible for the court's part in cases "nolled" and sentences suspended. The police court lawyer is

${ }^{1}$ An ex-judge stated that he informed one of these attorneys that all of his clients accused of pocketpicking were guilty. They would never take the stand for fear the police would fasten their record upon them. 
most adept in taking advantage of those conditions which inevitably make for abuse of law and the defeat of its purposes.

\section{Bail Bonds}

Because of the reaction occasioned by the "crime wave" and obvious breakdown of the courts, the bail bond situation in the Municipal Court has received a wrong emphasis. In the matter of assuring the attendance of the defendant in court, bail is not a serious problem. During the nine years of the Municipal Court to January, 1921, there have been approximately 2,200 forfeitures of bail bonds which had not been set aside either by producing the defendant or through purging him of contempt. Compared with 170,137 cases disposed of during this period, this is a relatively small number. Of 562 cases of liquor law violation before the court in January, 1921, only six bond forfeitures were still outstanding on April $19,1921$.

The real evil in the situation is not the matter of easy bail, but the disreputable professional bondsmen who make a business of exploiting the misfortunes of the poor, and whose connection with "runners" and "shysters" tends to prostitute the administration of justice in the inferior courts. To eliminate the professional bondsmen requires not a stiffening in the matter of bail, but a removal of the necessity of bail wherever possible, and a relaxation where such a removal cannot be accomplished.

A step forward was made in the provision for cash bail in G.C., Section 1579-20. The tendency of cash bail to drive out the professional bondsmen to some extent is apparent. Another excellent provision is Rule 10, of the criminal branch of the Municipal Court, providing for the release of a defendant upon a personal bond without surety, where the offense charged is a misdemeanor punishable by fine only or a violation of a city ordinance. This rule should be extended to cover other minor infractions of the law which may be punishable by short terms of imprisonment. From what can be learned, however, the administration of this rule has not been wholly successful. The clerks in charge have established a practice of requiring someone to "vouch" for the defendant before releasing him on personal recognizance. This has apparently revived the opportunity for the professional bondsman and the runner, who are active on the trail of arrested persons in order to get them out on a bond without sureties. Rule 10 requires that a defendant, in order to be released on a personal bond, must have had a known place of residence within the city of Cleveland within six months next preceding his arrest. It should bz an easy matter for the clerk's office to establish this fact by the testimony of a neighbor, without requiring anyone to 
"vouch" for the defendant. At any rate, professional bondsmen and runners should not be accepted, for it is against the spirit of the rule to retain the hold which these parasites have on the petty offenders. How far the enforcement of the rule has drifted from its original purpose may be gathered from the fact that persons charged with vagrancy are sometimes released on personal recognizance, although the very nature of the charge would preclude a known residence for six months and the police blotter shows an entry of "no home."

The establishment of the office of bail bond commissioner in the spring of 1921, followed by the appointment of John J. Busher to that position, should assure an improved operation of this rule. The matter should be worked out in conference between the Chief Justice, the bail bond commissioner, and the chief clerk.

A most beneficial step would be the establishment in petty offenses of beginning process by means of a summons instead of a warrant. It is absurd that known residents of Cleveland should be arrested for violation of traffic and other ordinances and for misdemeanors not serious in their nature. This not only provides opportunity for the professional bondsman and imposes unnecessary hardship upon the accused, but also involves an enormous waste of time by members of the police force, the clerk's office, and the jail attendants. In such cases it should be sufficient, if the policeman handed the accused a summons to appear in court upon a certain day. The summons has replaced the warrant in many other cities. ${ }^{1}$ In Detroit it has an extensive use and has proved to be a most successful labor-saving device. In that city a warrant is not issued unless the accused fails to respond not only to the original summons, but to an alias summons issued on the day of his non-appearance in court. In Cleveland an informal summons has already been established in the police prosecutor's office. In certain classes of cases, notably neighborhood quarrels and the like, the police prosecutor summons the party into his office in an endeavor to straighten out the difficulty without the intervention of the court. In theory, at least, this

1 This is also true in England. "It is considered very improper to issue a warrant for the arrest of a person whose attendance can be secured by summons. In a recent trial at the Old Bailey, where a shopkeeper was on trial for receiving stolen property, it appeared that he had been arrested upon a warrant. The judge inquired particularly why a warrant had been issued, and then stated that a summons would have been sufficient."-Criminal Procedure in England, by John D. Lawson and Edwin R. Keedy, Report of the Committee on Reform in Legal Procedure of the American Institute of Criminal Law and Criminology, Journal of Criminal Law and Criminology, vol. 1, pp. 595, 748; reprinted in Sen. Doc. No. 495, 63d Congress, 2d session, and Massachusetts Law Quarterly, vol. 5, p. 171. 
informal procedure is a considerable step forward, but it is obviously vulnerable to abuse and does not go far enough. The summons should not be a discretionary matter with the prosecutor, but should be made the normal mode of beginning of judicial process in certain classes of cases.

There will always remain, however, a residue of cases in which a bail bond with sureties is necessary. The number of such cases may be considerably reduced by the prompt compulsory trial of cases and by the erection of a jail with decent and adequate facilities.

These steps should reduce to a minimum the number of cases in which a professional bondsman may hope to make a profit. By eliminating the opportunity for such business, those who are now engaged in it will seek a living elsewhere. So far as it may be impossible to eliminate the professional bondsman, his business should be regulated like that of the "loan sharks" in many jurisdictions.

\section{The Clerk's Office}

In this section is discussed only that part of the clerk's office which handles the records for the criminal division. This office is in the Police Court Building, and is altogether inadequate for records, files, or human beings working therein.

The Chief Clerk, Peter J. Henry, devotes most of his time and attention to this office rather than the civil branch. ${ }^{1}$ He is well intentioned, quick in human sympathy, and his popularity with his employees does much for the esprit de corps of the staff. The first assistant, James Cantillon, is an earnest, hard-working man, who was unfailing in his patient coöperation with the survey. Like all those who have known only one way of doing things for a long time, both are inclined to be somewhat hostile to suggested innovations. To one acquainted with the lack of physical facilities and the antiquated method of record keeping which prevails, it is a constant source of wonder that the system works at all, however badly.

The method has apparently been inherited from the old Police Court, and is not in any sense adequate for the present needs. ${ }^{2}$ A record system should accomplish three things: first, enable the clerks and the judges to prepare and follow each day's business; second, leave an accurate, easily accessible record of what has happened in each case to date; third, automatically build up statistics which the Chief Justice and the public

${ }^{1}$ Contrary to the practice of ex-Chief Justice McGannon, who apparently neglected the criminal branch almost entirely.

2 In 1912, when the Municipal Court succeeded the Police Court, the total number of cases was 7,788. In 1920 the number was 26,088, an increase of 235 per cent. 
ought to know as an authoritative basis for appraisal of the courts' work and the basis of its continuous improvement.

Under the system in use the clerks can make up a day's docket fairly well, but there is no adequate way of following the day's business and there is complete failure to secure the second and third objects.

The principal record kept is the "Execution Docket," which is not a docket and has nothing to do with executions. Two sets of records are used, one for "city cases" and one for "State cases." These books are, in fact, journals of the court's business, and the entries for each day are copied therein from penciled notations on the original papers. Thus a case may appear on 10 different pages, if continued nine times, the crossreferences to continued cases being forward only and not back, so that while it is possible to trace the history of most cases forward from an entry on a given day, it is not possible, in this book, to trace it back to its origin. Even to run it forward means passing the eye over many entries of other cases until the name sought is located, and often the name is spelled differently in different places. Sometimes trace of the case is lost because it was advanced for trial before the continuance date, or the defendant did not appear on the day set, or the clerk made an error in copying the date to which the case was continued. A case is not given a file number until it is disposed of, and if brought up for further disposition gets a second and even a third number. At least seven times as long is required to get the history of a case from this record as would be the case if all the steps were entered in one place, under file number and name. Moreover, since no number is given until the case is finished, it is difficult to ascertain from this record which of several cases pending against the same defendant is being considered. On disposition, many cases are often grouped and given the same file number.

Pending cases are indexed by cards filed alphabetically, so that it is possible to consult the card, ascertain the date set for trial, and extract the original papers from a box containing all cases set for trial on the particular date.

The only approach to a history of the case is found on the file papers themselves, where the plea is entered, with the continuance date, the final disposition, and the name of the judge making final disposition. Nowhere is there a record of the attorney who appeared, or the prosecutor in charge, or the judge in any preliminary stage. As the notes are in pencil, it is not unusual to find an entry cancelled or erased and a new disposition written above the old.

To locate the case of John Stewart it would be necessary to perform the following acts, which might be profitably contrasted with the process 
of finding the history of a sales order in any modern mercantile business. A beginning is made by consulting an index book where the names are entered alphabetically according to the first letter only, so that one must go through a long list of names beginning with the letter "S". If the name is finally found (and the index has some omissions), the reference is to a folio page of "Execution Docket." If there are several cases of the same name, it is necessary to know the approximate date or else employ a process of elimination. With the folio page one finds an entry relating to John Stewart. It is then necessary to follow the entry forward through all the continuances, trying to pick the name out of many others on the dates given. Finally an entry is reached which disposes of the case, and unless a motion in mitigation is made, with further continuances, the case receives a number, usually in combination with other cases. ${ }^{1}$ At the end of each day's cases in the "Docket" the names of both judges are stamped, so that it is not possible from this record to ascertain the judge who disposed of the case.

With the number of the case one goes to the files, which are kept numerically. ${ }^{2}$ The penciled notations in the file will then tell the dates of the warrant and plea, continuances and disposition, and the name of the judge disposing of the case is stamped on the margin. If one wishes to know before whom John Stewart was originally arraigned, or before whom a new trial was held, or if one has so many cases that it is impractical to hunt through the original files, then one consults the "Judge's Docket," which is a journal of each day's work kept in two series of books, one for Room 1 and the other for Room 2. The names of judges regularly sitting in these rooms do not ordinarily appear in the "Judge's Docket," so that it is necessary to know the handwriting of each judge to be certain as to identity. This procedure for studying cases in this court is naturally complicated further by occasional errors inevitable in a system of this kind, and by some cases with unusual features, which do not fit comfortably into it. ${ }^{3}$ Moreover, the information when obtained is incomplete. The only record books which are at all adequate are the bail forfeiture book, showing the history of such forfeitures,-exclusive

1 If bail was forfeited, the case is not given a number and is not filed with the other cases. When the forfeiture is set aside, the clerk usually remembers to go back to the forfeiture entry and note the new folio page.

2 On account of lack of room, files more than three years old are stored in the loft under a thick layer of dust.

To obtain a reliable history of cases of liquor violation appearing in the "Execution Docket" for January, 1921, only, required many days, when a ledger system of keeping records would have yielded the information in as many hours. 
of the question whether they have been collected, which is the work of the prosecuting attorney,--and a little volume giving the dates when cases are bound over for the grand jury, and the dates when transcripts are made out in such cases.

The objection offered to maintaining a ledger of cases instead of a daybook-"Execution Docket"-is that it would involve more work and more books. The former objection may be doubted because the present method involves writing the name and charge in each entry, even for continuances, whereas a ledger would show this information once and for all. Moreover, if a difference in record keeping were made between felonies, misdemeanors, and relatively trivial ordinance violations, much labor might be saved, especially if advantage were taken of modern bookkeeping devices.

We regard the question of record keeping as one of first importance. The activities of police court hangers-on are to a large extent dependent upon the assurance that they will leave no tracks behind them, and the watchful interest of the press and the public is baffled into inaction by obstacles which make vigilance too difficult. Moreover, the failure of the system to meet modern needs makes for informal action on the part of some of the judges, and informality in the court breeds suspicion and disrespect.

\section{RECOMMENDATIONS}

Other questions relating to the Municipal Court will be discussed under specific headings of a general nature. If the Municipal Court is retained as an institution, ${ }^{1}$ the following recommendations are made at this time:

1. Adequate court-house and jail, pending the securing of which the present building should have all alterations necessary to make conditions tolerable, and to remove the sordid aspect of the surroundings.

2. A few physical devices for keeping the crowds in the court-room away from the judge's bench.

3. Increased formality in the court-room and strict maintenance of decorum.

4. A division of the cases into sessions according to their nature and the requirements of decency.

5. Orderly handling of the list, together with an established policy as to transferring cases from one session to another.

6. A stricter rule as to continuances, enforced absolutely.

7. Abolition of the "motion in mitigation."

${ }^{3}$ Its amalgamation with the Common Pleas Court has already been recommended, p. 246, supra. 
8. The registering, before being heard, of every attorney who appears for a defendant.

9. Extension of the judge's term on the criminal division from three months to six months or a year, discretion remaining in the Chief Justice to alter such terms.

10. Conferences 'before each swinging of terms between the judges going out, the judges going in, and the Chief Justice, to determine policies in handling cases so as to avoid injustice resulting from the whims or political exigencies of judges, and to promulgate, alter, and secure enforcement of court rules.

11. Close coöperation between the Chief Justice, the clerk, and the police in ridding the court-room and corridors of "runners" and their kind.

12. Formation of a permanent committee of the Bar Association to assist the Chief Justice in cleaning out and keeping out the "shysters" and their followers, this committee to designate as associate members certain probation officers and representatives of social agencies actually working in the police court.

13. Legislation giving the judges summary power to award damages to any defendant in the court, equal to twice the amount paid by such defendant to any runner or lawyer, upon solicitation or upon any representation as to influence with any judge or other public official. ${ }^{1}$

14. A statute or ordinance fixing the charges of professional bondsmen, scaled according to the security given such bondsmen, and clothing the judges with summary power to award damages equal to twice the amount paid in violation of such statute or ordinance. The bondsman should be required to file his affidavit with the bond as to the fee and securities received.

15. Blanket permission to any defendant pro se, or any private attorney representing such defendant, to conduct prosecution for any alleged violations of any statutes or ordinances intended to regulate the business and practice of the court. It would help the situation greatly if the Legal Aid Society undertook to enforce penalties for these violations.

16. Extension and closer supervision of the rule allowing for personal recognizances.

17. The formal beginning of process in minor offenses by means of a court summons.

18. The establishment of an entirely new fling system in the criminal branch of the Municipal Court.

1 The Suspicious Persons ordinance covers soliciting, but it is not directly in the interest of anyone to see that it is enforced. 
CHAPTER VI

\section{THE COMMON PLEAS COURT}

\section{History and JuRisdiction}

$\mathrm{T}$

YHE center of the judicial system is the Common Pleas Court, established in 1788 by an Act for the Government of the Northwest Territory. The Constitution of 1802 continued the Common Pleas Court, dividing the State into three circuits, each circuit to have a president and not less than two associate judges. The judges were appointed by the general assembly for a seven years' term. Today, after numerous changes, there are 12 judges in Cuyahoga County alone holding office for six years, nominated in direct primary or by petition and elected on a non-partisan ballot. The salary is $\$ 8,000$ per annum.

This court has original jurisdiction of all felonies, upon indictment by a grand jury, and other offenses where the exclusive jurisdiction is not vested in an inferior court. It, therefore, disposes of all the serious cases and most of the misdemeanors from the country districts of the county.

At the present time four Common Pleas judges sit regularly in the criminal division, although only a few years ago two judges, or even one judge, were adequate for the entire volume of criminal business. The figures cited in Chapter I show that the necessity for this increase lies not only in the increased number of cases, but in the tendency to dispose of cases by trial rather than by plea of the defendant.

\section{Physical Conditions}

Physically, the arrangements are a handicap to efficiency. Two courtrooms, the office of the clerk of the criminal division, and the criminal assignment commissioner's room are in the old county court-house on Public Square, but the prosecutor's office is in another building, and two sessions are usually held in the new court-house on the lake front. Because the court is thus scattered through three buildings, much time is lost, especially in getting witnesses and jurors from one court-house to another. Although the criminal clerk's office is in the old court-house, many journal entries, court orders, etc., are made up in the main office 
of the clerk of courts in the new building, so that the records cannot be kept in one place, and of ten precious time is lost in transmitting important court entries and orders. The two rooms in the old court-house are dingy, but large enough. In one of the rooms there are chairs for spectators, but the other has only a bare space, railed off. All of the rooms in the new court-house are commodious and handsomely appointed. Only a few chairs, however, are provided for spectators.

\section{DECORUM}

The decorum is a considerable improvement over the Municipal Court, but not what it should be, considering the fact that each room has not only a clerk, but a bailiff whose chief business it is to maintain order. ${ }^{1}$ The judges themselves, on the whole, do not seem to mind an atmosphere of unrest. In cases of public interest the packing of spectators behind the rail reminds one of the New York subway in rush hours. Confusion is inevitable. Chairs or benches should be provided, and no spectators admitted when the seating capacity of the room is exhausted.

Formalities, the symbols of dignity, which are familiar in an eastern court-room, are lacking. The judges wear no gowns; recesses are taken by the judges simply by getting up and leaving the bench; their return is unheralded by the court bailiff. Smoking in the court-room during a recess is not unusual. An air of familiarity is noticeable among the judges, and between them, the lawyers, and the court attendants. Although it is, of course, an exaggeration to say, as did the late Judge Foran, that "the courts are run like bar-rooms," it is perhaps true that the court-room, in dignity of atmosphere, does not rise above a salesman's display room in a hotel. ${ }^{2}$

\section{Terms of the Court}

At the present time the criminal division is active for only three terms during the year, totaling ten months. There is no court during July and August, in consequence of which many persons are confined over the summer awaiting action of the grand jury, and the September

1 The county supports a bailiff for each of the 12 judges at a salary of $\$ 1,820$ per annum, and the total annual expenditure of the bailiff's department is $\$ 52,000$. It is a question whether this expense could not be greatly reduced by the establishment of messenger service from the assignment room, and the use of guards only when the number of spectators warrants it.

2 It should be said that the decorum varies somewhat according to the judges on the bench, and that the conduct of civil causes is largely free from the atmosphere of confusion and informality surrounding many criminal trials. 
term is thereby congested. From 1912 to 1918 inclusive there was a summer term, but this was abandoned in 1919, although at that time criminal cases were increasing greatly. It has recently been suggested by one of the judges that the April term be extended to include July. Owing to the fact that the civil business of the court is practically suspended during the summer, at least one session could be maintained, on the criminal side, with no hardship on the judges.

\section{Lack of an Executive Head}

This court disposes of more than 3,000 criminal cases and 10,000 civil actions a year. In addition to the 12 judges, it has a varying supervisory control over the clerk's office, the two assignment commissioners' offices, the jury commissioners, the jury and grand jury, bailiff's office, and, including the judges, comprises a salary budget of over $\$ 375,000$ per year. This great enterprise, organized for the business of administering justice, is without any executive head whatsoever.

General Code, Sec. 1558, confers the power of making rules and regulations and assigning business upon the "judges of the Common Pleas Court." The judges hold occasional meetings to discuss pending matters, and by a process of rotation each judge becomes in turn presiding judge, or presiding judge of the criminal division. A bill was introduced at the last session of the legislature creating a permanent Chief Justice, but was defeated because of a rider providing for three additional judges. It cannot be said that the legislature was unwise in refusing to pass the bill in that form. Unless a real executive head to the organization has been appointed to study its needs and guide its administration with authority, the question of how many, if any, additional judges are needed cannot be decided intelligently.

\section{"LOAFING JUdGes"}

Much is heard among Cleveland lawyers of the "laziness" of certain of the judges. Recently a judge of the Court of Appeals stirred up a hornet's nest by declaring that "half of the judges are loafing." Although such blanket accusations are necessarily unjust to many hardworking judges, and create the impression that the best judge is the one who sits longest in his room, ${ }^{1}$ there is undoubtedly much justification for

1 Not only do many judges do their hardest work off the bench, but some of the best judges require a certain amount of leisure. Nevertheless, a judge who is late, even habitually so, in his room is a drag on the administration of justice. He causes witnesses to chafe and disappear and lawyers and clients to lose time, as well as respect, for the courts. 
the feeling that business could be handled more expeditiously. No permanent improvement will be effected by the humiliating procedure of timing the judges, as has been done by the press, on occasions. What is needed is not for the judges to punch a time-clock, but a high professional atmosphere with an executive head allocating the work and watching its progress.

Some evidence of the advantage of proper organization under a Chief Justice may be gathered from the experience of the Municipal Court, which has had an administrative Chief Justice from its inception. This evidence is not as strong as it might be, because Judge William H. McGannon, for nine years the head of the court, was by no means an ideal Chief Justice. Now that the judge has been compelled to resign, there is a tendency on the part of some to exaggerate his accomplishment while in office. The history of the criminal branch of this court shows a headship lacking vision and constructive ability, and failing utterly in dignity. Nevertheless, Judge McGannon was a "hustler" and kept his associates at work.

On May 7, 1920, occurred the Kagy murder. Aside from the question of his innocence or guilt, this event threatened the judge with loss of reputation by reason of his close connection with the affair, his notorious associates, and the impending exposure of his private life. It is small wonder that from then Judge McGannon did not devote himself to his work with the same zeal as before. On November 26, 1920, he was indicted, and his fight for exoneration and liberty continued practically until his resignation in March, 1921. During this period he prepared for and faced two extended murder trials. It was not only mentally but physically impossible for the judge to devote much time to his duties as Chief Justice. One would expect the trial list to become clogged after May 7, 1920, and jammed after November, 1920. This is exactly what happened.

Diagram 7 shows the number of civil cases filed each month compared with the number of civil cases awaiting trial. ${ }^{1}$ In each group the cases on the conciliation docket are omitted. It is to be observed that until June, 1920, the list followed roughly the number of cases filed by from one to two months. Note the unusual rise of the list after the Kagy

${ }^{1}$ An effort was made to secure the monthly record of civil dispositions for 1920 and the first three months of 1921 , but the statistical clerk for the court could not supply the figures from which such a calculation could be made. The figures used were obtained through the courtesy of Frank J. Murphy, clerk of the civil branch and the office of Charles L. Kaps, assignment clerk. 
murder, not related to the fluctuation in the number of cases filed, and the precipitate movement after November, 1920.

For purposes of comparison the civil list of the Common Pleas Court and cases filed is also charted (Diagram 8). The state of the Common Pleas list could be obtained only as of the beginning of each term, and not by months, so that the terms only are charted. The elimination of monthly fluctuations makes the Common Pleas list seem to follow the

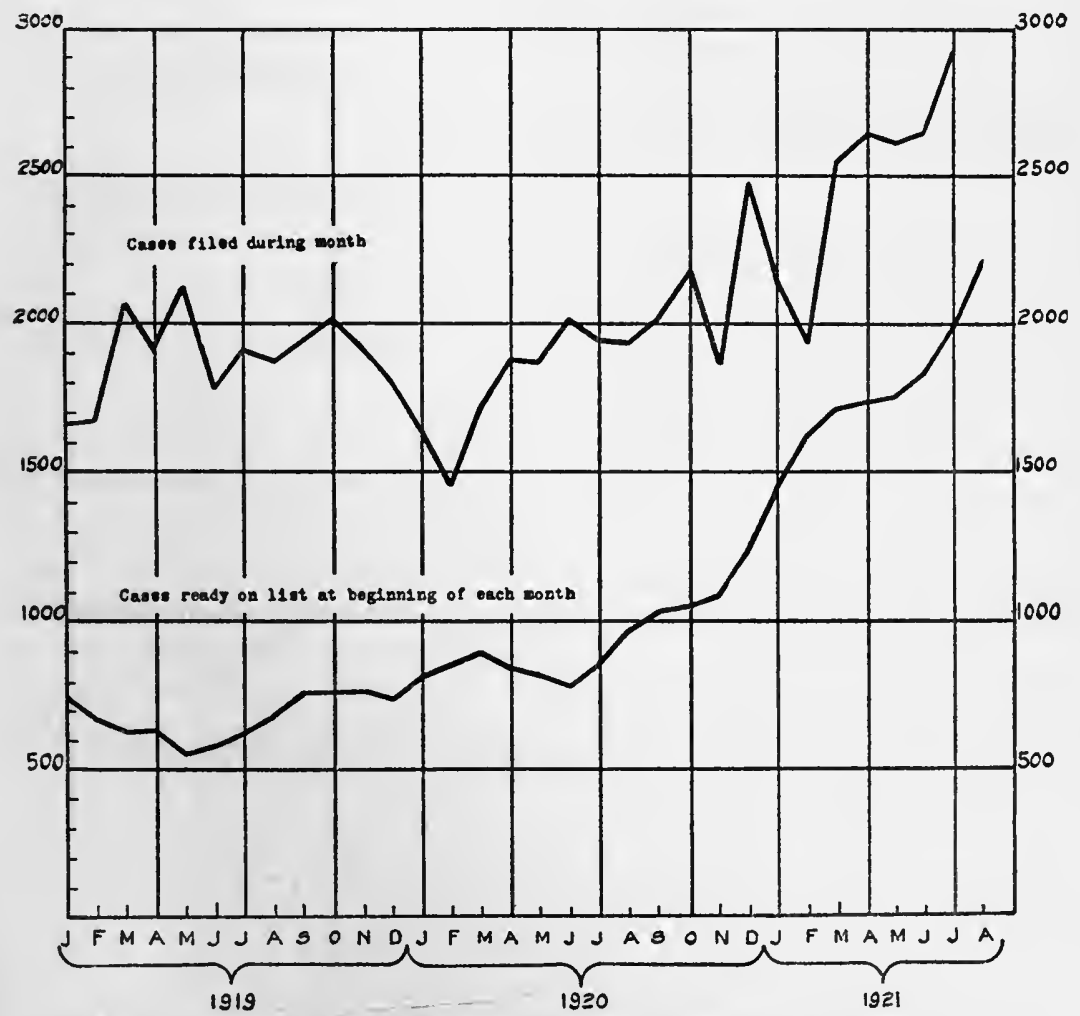

Diagram 7.-Cases ready on list compared with cases filed, Municipal Court

cases filed more closely than in the Municipal Court. It is to be observed that despite the steady increase in the number of cases, the list shows no such precipitate break as in the lower court. The higher level in the spring of 1921 is attributed partly to the assignment of more judges to the criminal division.

A correct 'record of the hours of attendance by the judges might also afford instructive comparisons on this point. Such a record is kept by 
the bailiffs of the judges, but considerable doubt attaches to their accuracy because of the fact that Judge McGannon is recorded as attending his court for full months during December, January, and February, 19201921, when he was actually preparing for and was bodily present at two long trials involving his own liberty. Accepting the figures as they

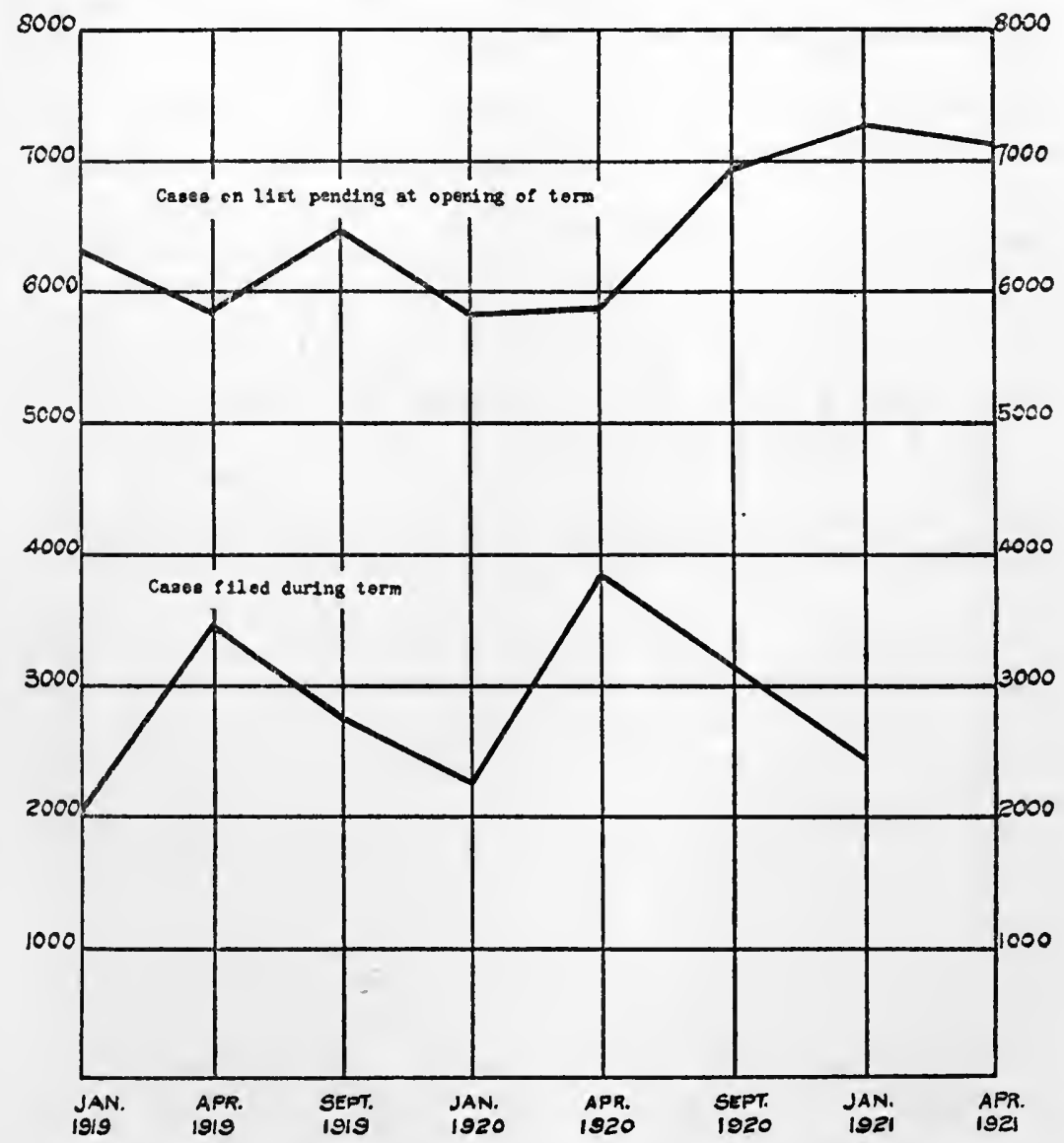

Diagram 8.-Cases ready on list compared with cases filed, Common Pleas Court

stand, however, without allowing for any tendency on the part of bailiffs to give their judges the benefit, even when there is no doubt, the record shows a substantial deficit of judicial hours worked for the months of September, October, November, December, January, and February of 1920-1921 as compared with similar preceding periods. Beginning with 
1917-1918, when the records for 10 judges are first available, the figures in hours are:

$\begin{array}{cccc}\text { September-March } & \text { September-March } & \text { September-March } & \text { September-March } \\ \text { 1917-18 } & 1918-19 & 1919-20 & 1920-21 \\ 7,638 \text { hours } & 7,533 \text { hours } & 7,767 \text { hours } & 7,338 \text { hours }\end{array}$

The hours of attendance from 1920-21 are the lowest in the period, despite the fact that the number of cases has been rapidly increasing during this time. Compared with the next preceding year there is a falling off of 439 hours, equivalent to nearly a week and a half per judge. There is little doubt that a more accurate record would disclose a greater deficit.

\section{Fluctuating Policies}

The custom of rotating judges in the positions of presiding justice of the civil and criminal divisions of the Common Pleas Court necessarily means a fluctuating policy with regard to the promulgation and enforcement of court rules and practice. This has become of more importance since the establishment of an assignment commissioner in the criminal division in February, 1919. Before that time the lists were in the hands of the prosecutor's office, and any judge in the criminal division who happened to be approached disposed of pleas of guilty and motions to "nolle." In order to prevent " angling" for a particular judge, the Assignment Commissioner now sends such pleas and motions, when advised beforehand, to the presiding judge. This means that the policy in such matters varies with the rotating judges. There is also a great difference among judges in their supervision over the system of selecting petit and grand juries. Perhaps the greatest weakness of continually changing the directing head is seen in the enforcement of court rules; for example, Rule 21, relating to continuances for absent witnesses. The policy regarding "passing" cases (i.e., putting them over for hearing at a later date) has also varied. This is of considerable importance because one of the first objects of a skilled criminal lawyer is to get his case "passed" as often as possible, in the hope of disgusting the State's witnesses and wearing out the interest of the police and prosecutor. In the September term, 1920, Judge Bernon, then presiding judge of the criminal division, stiffened up in the matter of "passing," and in the January term, 1921, Judge Allen asked for an affidavit before "passing" a case. The attorneys, however, then presented affidavits from their clients, and in the April term, when Judge Allen became presiding judge, she issued an order requiring an affidavit of due diligence by the attorney and the presence of the defendant in court before passing any case.

${ }^{1}$ The summer months are excluded because of the vacation period. 
The seriousness of laxity in passing cases is well known to everyone connected with the courts. Statistically, there seems to be a direct correlation between the length of time cases have been pending and the mode of disposition. Considering all of the criminal cases begun in 1919, we find the average time per case for different classes of disposition to be as in Table 17.

TABLE 17.-AVERAGE TIME PER CASE BY CLASSES OF DISPOSITION

\begin{tabular}{|c|c|c|c|c|}
\hline \multirow{2}{*}{ Disposition } & \multicolumn{2}{|c|}{$\begin{array}{l}\text { Average number days, } \\
\text { arrest to disposition }\end{array}$} & \multicolumn{2}{|c|}{$\begin{array}{l}\text { Average number days } \\
\text { indictment to } \\
\text { disposition }\end{array}$} \\
\hline & $\begin{array}{l}\text { From } \\
\text { inferior } \\
\text { courts }^{1}\end{array}$ & $\begin{array}{l}\text { Original } \\
\text { indict- } \\
\text { ments }\end{array}$ & $\begin{array}{l}\text { From } \\
\text { inferior } \\
\text { courts }^{1}\end{array}$ & $\begin{array}{l}\text { Original } \\
\text { indict- } \\
\text { ments }\end{array}$ \\
\hline $\begin{array}{l}\text { Guilty on first plea } \\
\text { Change of plea to guilty } \\
\text { Change to plea guilty lesser offense } \\
\text { Guilty of felony by jury. } \\
\text { Not guilty of felony by jury } \\
\text { "Nolled" because of defendant's } \\
\text { sentence or imprisonment } \\
\text { Dismissed or discharged on motion } \\
\text { or demurrer } \\
\text { "Nolled" on all counts, no reason } \\
\text { assigned } \\
\text { "Nolled" after conviction or dis- } \\
\text { agreement } \\
\text { No bill by grand jury } \\
\text { Arrest to true bill }\end{array}$ & $\begin{array}{r}26.1 \\
62.5 \\
65.6 \\
71.7 \\
83.8 \\
84.6 \\
106.0 \\
\\
99.8 \\
181.4 \\
215.0 \\
29.3 \\
24.4\end{array}$ & $\begin{array}{r}16.4 \\
26.2 \\
37.7 \\
74.6 \\
55.6 \\
44.0 \\
\\
63.5 \\
\\
124.6\end{array}$ & $\begin{array}{r}9.8 \\
42.0 \\
42.2 \\
52.8 \\
54.7 \\
56.7 \\
58.7 \\
75.5 \\
163.7 \\
245.0 \\
\cdots \\
\cdots\end{array}$ & $\begin{array}{r}49.4 \\
44.9 \\
53.2 \\
113.8 \\
62.3 \\
75.6 \\
\\
65.7 \\
134.5\end{array}$ \\
\hline
\end{tabular}

These figures need little comment, since they indicate clearly the need of a sustained policy of firmness in the matter of passing. Under the present system of rotation this will never be obtained.

\section{Inability to Use Personnel to Best Advantage}

Another result of rotating is to make impossible using the abilities of the particular judges to the greatest advantage. The success of any business enterprise requires that it use its personnel in such a way as to employ the abilities thereof to the utmost and to minimize its weaknesses. The administration of justice is no exception. On the civil side, a judge who may do fairly well in tort cases or simple contract, may be beyond

1 The column for cases coming from inferior courts is the more reliable because based upon approximately 10 times as many cases as the original indictments. 
his depth in equity or in disposing of motions. The criminal side has its own requirements. It needs not so much able jurists as men of common sense and firmness, known to be unapproachable by lawyers, prosecutors, or politicians, and inspiring respect that should border on awe.

A judge may be inadequate on the civil side, and yet make a competent criminal judge. Conversely, a judge gifted in theoretical knowledge of the law may be a poor criminal judge, because of his tendency to see abstract theories and not problems of human character.

Tables 18 and 19, based upon cases begun in 1919, show how widely some of the judges vary in performance of duties on the criminal bench. Only judges disposing of at least 100 cases are included, which accounts for the omission of certain judges.

In order to interpret the figures in Tables 18 and 19 more easily, secondary tables, given in Table 20 , will be helpful. These secondary tables show how the judges rank by dispositions of cases tried by them. A summary of this table is given in Table 21.

It will be noticed in Part I of Table 20 that Judge Levine leads easily in the number of cases originally pleading guilty, and that he still leads the list in Part II, followed by Judge F. E. Stevens and Judge Cull. A partial explanation of the readiness to plead guilty before these judges is seen in Part V, where the same two men are at the top of the list and Judge Cull is a close fourth. It will be noticed that Judges F. E. Stevens, Pearson, Kennedy, and Phillips lead among those accepting a plea of guilty to a lesser charge. This should be compared with Part VI, which shows the leniency of the judges toward misdemeanors, reflected in a combination of fines only, plus suspended workhouse sentences. Except Judges Levine and Cull, who led on original pleas of guilty, the first four in this list correspond closely with the first four in Part III.

In Part IV of Table 20, cases "nolled," only those cases "nolled" on all counts with no explanation are included. In this list Judge Kennedy leads as widely as Judge Levine in Part I. In February, 1920, Judge Kennedy allowed a "blanket nolle," which included over 50 cases begun in 1919. A large percentage of these cases, however, are not included here because an explanation was given, and many of them would have been "nolled" in due course even had there been no "blanket nolle." It is safe to say that Judge Kennedy would still head the list after allowing for the "blanket nolle."1

${ }_{1}^{1}$ Presiding judges during the term in which most of the 1919 cases were disposed of were Judges Foran, Stevens, Powell, Kennedy. One would naturally expect these judges to lead in pleas of guilty, changes of pleas, and "nolles." Judge F. E. Stevens alone is high in all of these dispositions, however. 


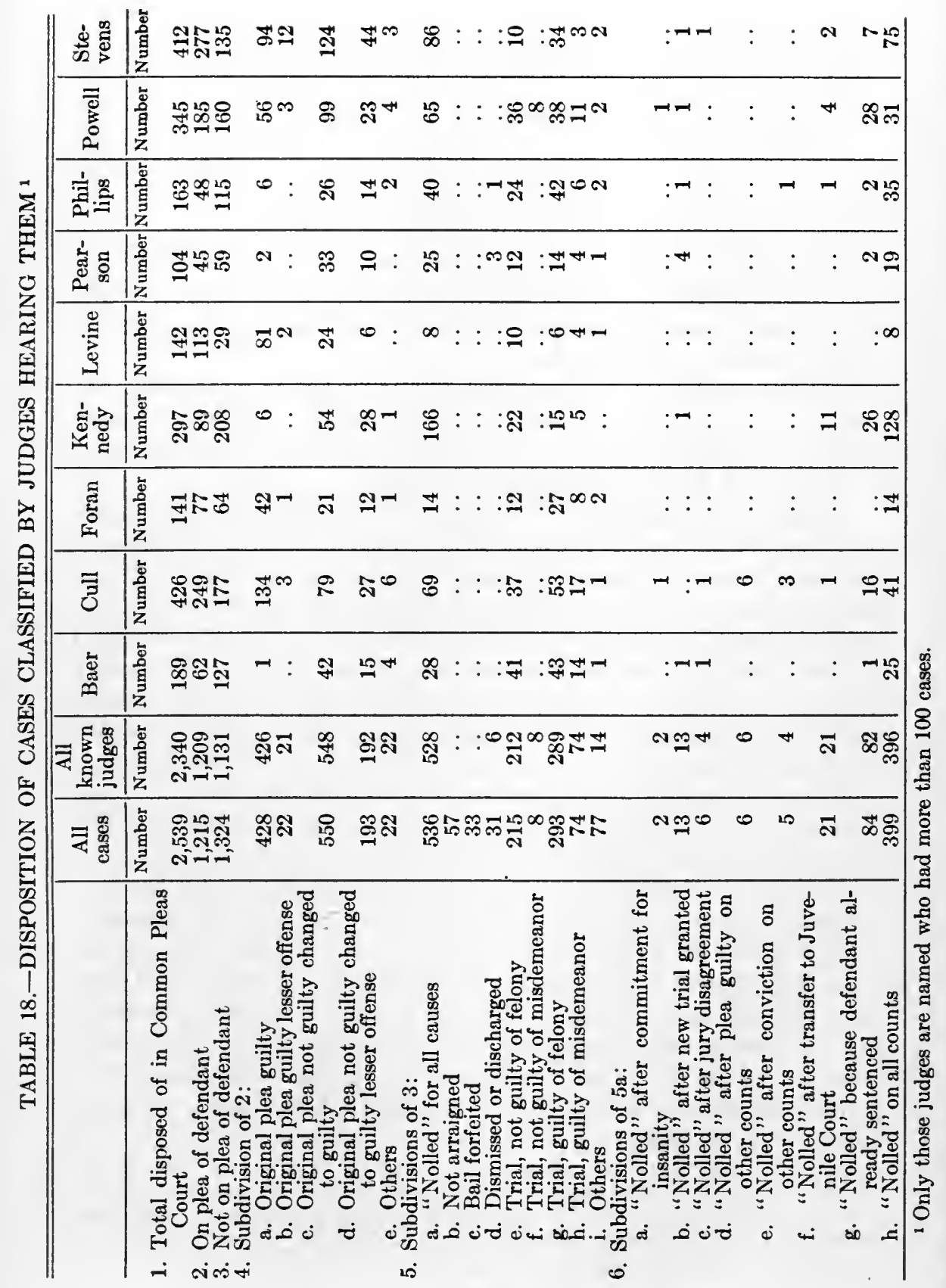




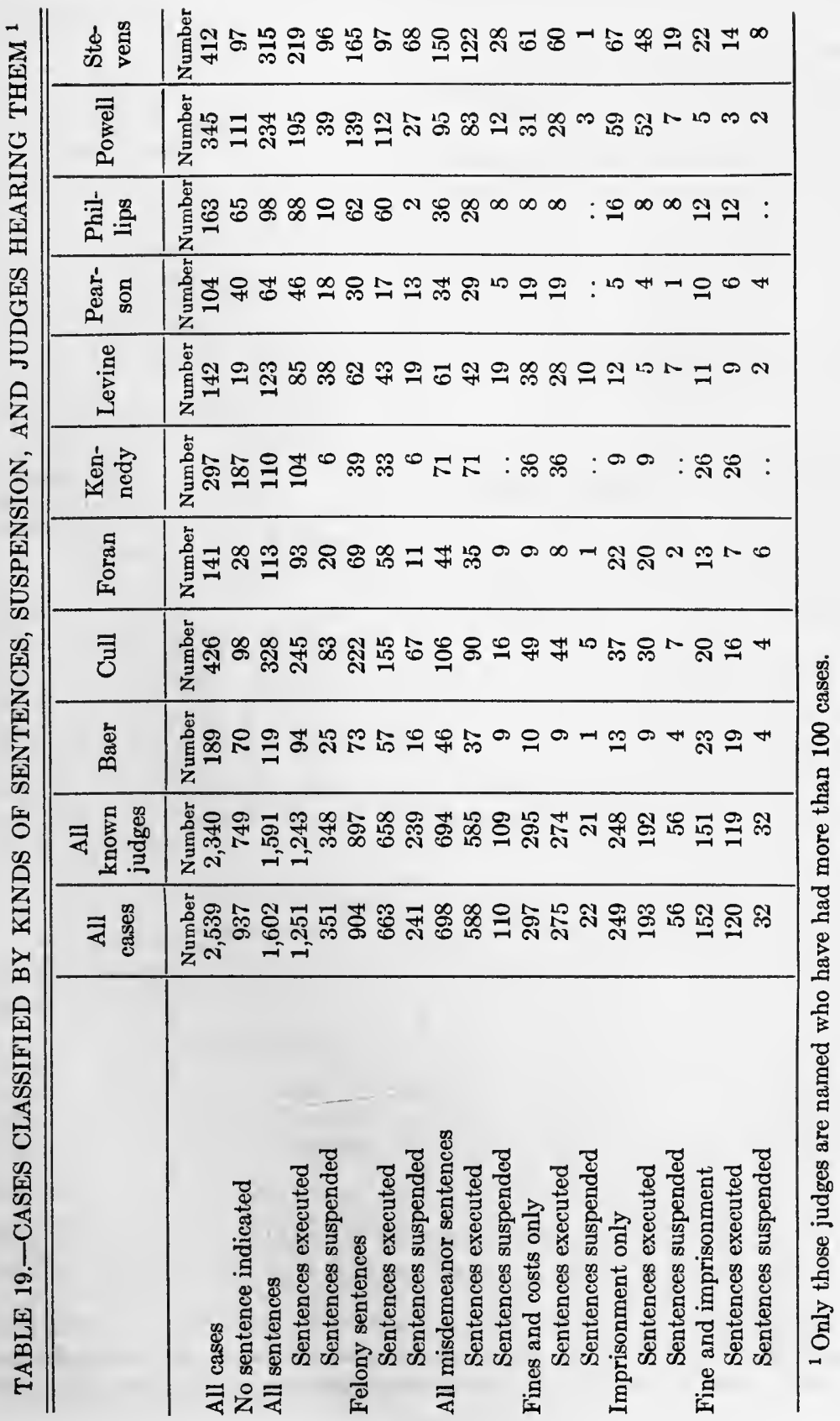



POSITIONS IN CASES TRIED BY THEM

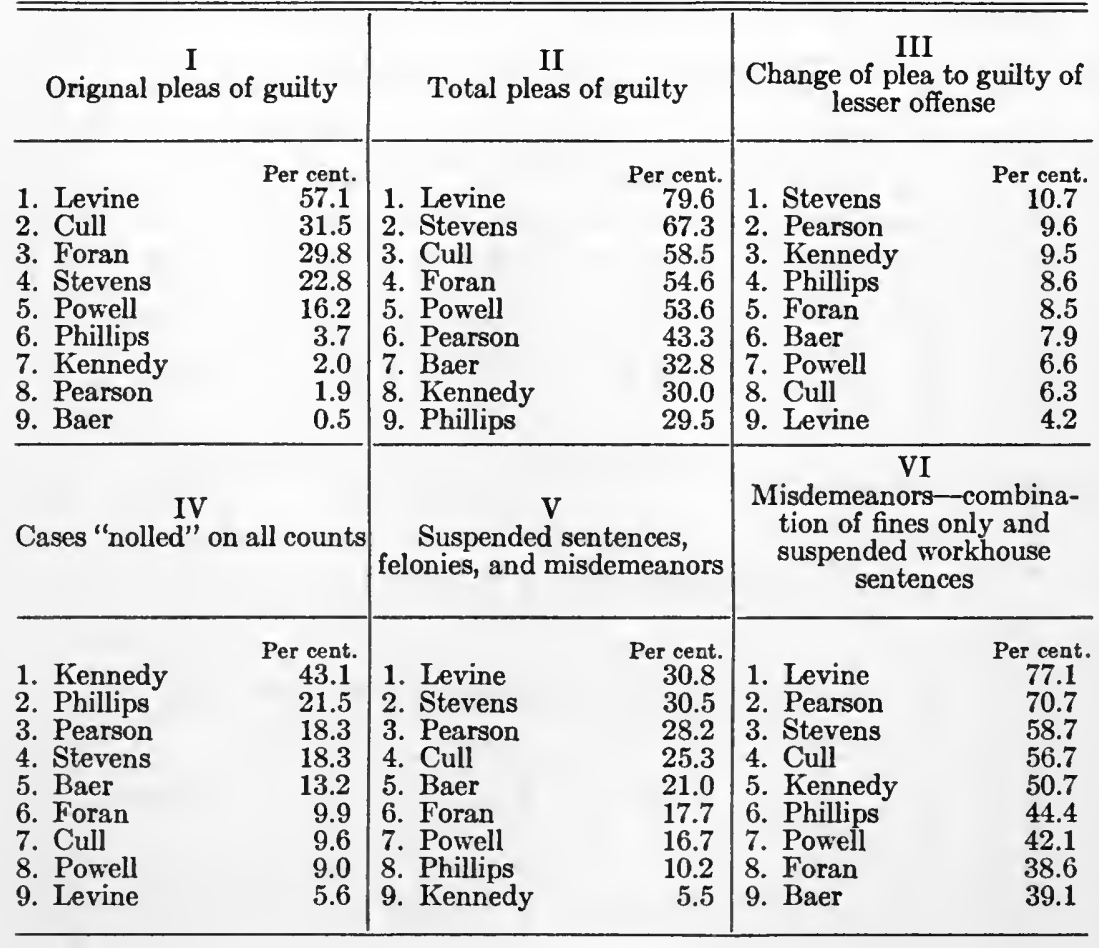

VII

Cases Tried by Jury

\begin{tabular}{|c|c|c|c|c|c|}
\hline & $\begin{array}{l}\text { Per cent. } \\
\text { all cases }\end{array}$ & $\begin{array}{l}\text { Per cent. } \\
\text { found } \\
\text { guilty }\end{array}$ & & $\begin{array}{l}\text { Per cent. } \\
\text { all cases }\end{array}$ & $\begin{array}{l}\text { Per cent. } \\
\text { found } \\
\text { guilty }\end{array}$ \\
\hline $\begin{array}{l}\text { 1. Baer } \\
\text { 2. Phillips } \\
\text { 3. Foran } \\
\text { 4. Pearson } \\
\text { 5. Powell }\end{array}$ & $\begin{array}{l}52.0 \\
44.2 \\
33.4 \\
28.8 \\
26.9\end{array}$ & $\begin{array}{l}58.3 \\
66.7 \\
74.6 \\
60.1 \\
52.8\end{array}$ & $\begin{array}{l}\text { 6. Cull } \\
\text { 7. Kennedy } \\
\text { 8. Levine } \\
\text { 9. Stevens }\end{array}$ & $\begin{array}{l}25.2 \\
14.2 \\
14.1 \\
11.4\end{array}$ & $\begin{array}{l}65.5 \\
47.9 \\
49.6 \\
78.9\end{array}$ \\
\hline
\end{tabular}

It is interesting to note that generally the sequence in Part IV of Table 20 is the inverse of Part II. Also, the first four who lead the "nolles"1

${ }^{1}$ It may be indicative of the character of the work required of a presiding justice that Judges Powell, Kennedy, and Stevens were among those trying the smallest percentage of cases. Judge Foran, the remaining judge who presided during this period, had fewer 1919 cases than the others. 
lead the changes of "plea to guilty of lesser offense" in Part III, although the order is shifted about, Judges Stevens and Pearson changing places with Judges Kennedy and Phillips.

Judges Baer and Phillips lead easily in the percentage of cases tried, and Judges Kennedy, Levine, and Stevens show the smallest number disposed of by verdict of a jury. The percentage of convictions after trial is also given, but here the basic figures become so small in some instances that conclusions are hardly justified. The results, however, would probably coincide with the opinion of the bar, that a jury before Judges Kennedy or Levine is more apt to bring in a verdict favorable to the defendant than before Judges Stevens or Phillips.

TABLE 21.-SUMMARY OF RANKS OF EACH JUDGE IN THE SEVEN DISPOSITION CLASSES OF TABLE 20

\begin{tabular}{l|c|c|c|c|c|c|c}
\hline & $\begin{array}{c}\text { Original } \\
\text { pleas of } \\
\text { guilty }\end{array}$ & $\begin{array}{c}\text { Total } \\
\text { pleas of } \\
\text { guilty }\end{array}$ & $\begin{array}{c}\text { Changed } \\
\text { to plea } \\
\text { guilty } \\
\text { lesser } \\
\text { offense }\end{array}$ & "Nolled" & & $\begin{array}{c}\text { Fines } \\
\text { tence } \\
\text { sus- } \\
\text { pended } \\
\text { only and } \\
\text { sentence } \\
\text { to } \begin{array}{c}\text { work- } \\
\text { house } \\
\text { suspended }\end{array}\end{array}$ & $\begin{array}{c}\text { Tried } \\
\text { by jury }\end{array}$ \\
\hline Baer & 9 & 7 & 6 & 5 & 5 & 9 & 1 \\
Cull & 2 & 3 & 8 & 7 & 4 & 4 & 6 \\
Foran & 3 & 4 & 5 & 6 & 6 & 8 & 3 \\
Kennedy & 7 & 8 & 3 & 1 & 9 & 5 & 7 \\
Levine & 1 & 1 & 9 & 9 & 1 & 1 & 8 \\
Pearson & 8 & 6 & 2 & 3 & 3 & 2 & 4 \\
Phillips & 6 & 9 & 4 & 2 & 8 & 6 & 2 \\
Powell & 5 & 5 & 7 & 8 & 7 & 7 & 5 \\
Stevens & 4 & 2 & 1 & 4 & 2 & 3 & 9 \\
\hline
\end{tabular}

Further comment on the characteristics of the judges is rendered unnecessary by the figures themselves. It is sufficient to know that in so far as the group of 1919 cases may be analyzed, there are wide variations among the individual judges. Moreover, there are characteristics which are not portrayable in statistics, but of which a Chief Justice would be cognizant. Judges with a priori theories about crime and its treatment, judges too accommodating to the wishes of prosecuting attorneys or professional criminal lawyers, judges with settled bias against different classes of witnesses, judges who try cases for the newspapers, should be, so far as possible, limited in their service on the criminal division.

It would be an unwise procedure, however, to make permanent assignments to the criminal division. Experience has shown that such a practice tends to make the judges "bloodthirsty or mushy." This is the principal weakness in the plan of the Detroit Criminal Court. Nor 
should future assignments be announced prematurely, thus encouraging lawyers and even prosecutors to "string it along until so-and-so gets on the bench." A Chief Justice with full power to make assignments could not only select the best adapted material, but also break up any such attempted liason.

\section{Assigned Counser}

In Cleveland assigned counsel play a large part, quantitatively, in the administration of justice. Counsel appointed to defend an indigent person receives $\$ 10$ for preparation of the case, and $\$ 10$ per day in court up to $\$ 50$. A larger sum is allowed in capital cases. In 1920 assigned counsel were paid the sum of $\$ 32,500 .^{1}$

There is no fixed policy with respect to appointing counsel. At the opening of the term, lawyers desiring such practice give their cards to the judge. Formerly the prosecuting attorney recommended lawyers. but under Samuel Doerfler an order was issued forbidding this practice. As a rule, very young attorneys or incompetent older men are appointed, because successful lawyers do not seek the business. In important cases the judges seek to appoint abler men, and some eminent lawyers have served on such appointments from a spirit of professional duty. In the usual run of cases, however, the appointing of counsel is not taken very seriously. "It doesn't make much difference," remarks one judge, "the defendants are usually guilty anyway."

It is apparent that such appointments must to some extent become a reward to habitués of the court-room. Among the 1919 cases, exclusive of instances in which more than one counsel appeared, 114 were appointed once, 31 twice, 25 three times, 14 four times, 9 five times, 7 six times, 3 seven times, 2 eight times and 1 nine times. One hundred and seventy appointed lawyers appeared a total of 251 times, compared with 36 who appeared a total of 189 times.

There is an impression in Cleveland that the appointed counsel usually induces his client to plead guilty and pockets his modest fee for the persuasion. This apparently is not true. Considering the 1919 group of cases, 40.7 per cent. of all cases of appointed counsel pleaded guilty, as compared with 41.7 per cent. of cases of privately retained attorneys. Less than 1 per cent. of such cases pleaded guilty on the first plea, as compared with 2.6 per cent. of the retained lawyers, but this may be because the court protected such unrepresented defendants as seemed unwilling

1 This may be compared with $\$ 41,072.76$ allowed the prosecutor's office for salaries in the same year. The prosecutor's office is responsible for at least six times as many cases as the assigned counsel, in addition to handling the civil business of the county. 
to plead guilty upon the arraignment. In the cases of assigned counsel 12.7 per cent. were allowed to plead guilty to a lesser offense, as compared with 9.3 per cent. of the private attorneys.

TABLE 22.-CASES CLASSIFIED BY DISPOSITION AND BY COUNSEL APPOINTED, NOT APPOINTED, OR UNKNOWN

\begin{tabular}{|c|c|c|c|c|c|c|c|}
\hline Dispositions & $\begin{array}{c}\text { All } \\
\text { cases }\end{array}$ & $\begin{array}{l}\text { Coun- } \\
\text { sel un- } \\
\text { known }\end{array}$ & $\begin{array}{l}\text { Per } \\
\text { cent. }\end{array}$ & $\begin{array}{c}\text { Ap- } \\
\text { pointed }\end{array}$ & $\begin{array}{l}\text { Per } \\
\text { cent. }\end{array}$ & $\begin{array}{c}\text { Not } \\
\text { ap- } \\
\text { pointed }\end{array}$ & $\begin{array}{l}\text { Per } \\
\text { cent. }\end{array}$ \\
\hline Total cases & 2,539 & 754 & 100.0 & 527 & 100.0 & 1,258 & 100.0 \\
\hline Total pleas of guilty & 1,215 & 474 & 62.8 & 216 & 41.0 & 525 & 41.7 \\
\hline Original plea of guilty & 428 & 393 & 52.1 & 2 & 0.4 & 33 & 2.6 \\
\hline $\begin{array}{l}\text { Original plea of not } \\
\text { guilty changed to plea }\end{array}$ & & & & & & & \\
\hline $\begin{array}{l}\text { of guilty } \\
\text { Original plea of not guilty }\end{array}$ & 550 & 41 & 5.4 & 142 & 26.9 & 367 & 29.2 \\
\hline $\begin{array}{l}\text { changed to plea of } \\
\text { guilty of misdemeanor }\end{array}$ & 193 & 8 & 1.1 & 68 & 12.9 & 117 & 9.3 \\
\hline Other pleas & 44 & 32 & 4.2 & 4 & 0.8 & 8 & 0.6 \\
\hline Total disposed of by trial & 590 & 18 & 2.4 & 193 & 36.6 & 379 & 30.1 \\
\hline $\begin{array}{l}\text { trial } \\
\text { Guilty of misdemeanor }\end{array}$ & 293 & 11 & 1.5 & 118 & 22.4 & 164 & 13.1 \\
\hline after trial & 74 & 3 & 0.4 & 18 & 3.4 & 53 & 4.2 \\
\hline $\begin{array}{l}\text { trial } \\
\text { Not guilty of misde- }\end{array}$ & 215 & 4 & 0.5 & 57 & 10.8 & 154 & 12.2 \\
\hline meanor after trial & 8 & & & & & 8 & 0.6 \\
\hline $\begin{array}{l}\text { "Nolled" on all counts } \\
\text { All others }\end{array}$ & 399 & 83 & 11.0 & 61 & 11.6 & 255 & 20.3 \\
\hline Al! others & 335 & 19 & 2.8 & 57 & 10.8 & 99 & 7.9 \\
\hline
\end{tabular}

Except in the matter of pleas of guilty, however, the retained lawyers show much better results. ${ }^{1}$ The assigned lawyers tried out 37 per cent. of all their cases, and acquitted 29 per cent. of all tried; retained counsel tried 30 per cent. of all their cases and acquitted 42 per cent. of all tried. Assigned counsel succeeded in having 11.6 per cent. of all cases "nolled," as compared with 20.3 per cent. of retained counsel. Of those sentenced for felony, assigned counsel secured a "bench parole" for 19 per cent.; retained counsel, for 30 per cent. Of those sentenced for misdemeanor, assigned counsel secured suspended sentence for 12.5 per cent., retained counsel for 14.7 per cent.; assigned counsel secured 14.3 per cent. money fines, as compared with 44.1 per cent. money penalties by the privately retained lawyers.

1 This is purely on a quantitative basis, without determining-what, of course, could not be ascertained-whether in fact indigent defendants are to a greater extent than paying clients guilty defendants. 
Tables 22 and 23 give the basic figures for assigned and retained lawyers. In the first table the cases having no counsel are also given, but they afford no comparable information, as may be seen. Defendants who have no counsel consist chiefly in those who admit guilt or have not been arrested.

TABLE 23.-SENTENCES CLASSIFIED BY EXECUTED AND SUSPENDED SENTENCE AND BY COUNSEL APPOINTED AND NOT APPOINTED

\begin{tabular}{|c|c|c|c|c|}
\hline & \multicolumn{2}{|c|}{ Counsel appointed } & \multicolumn{2}{|c|}{$\begin{array}{l}\text { Counsel not } \\
\text { appointed }\end{array}$} \\
\hline & Total & $\begin{array}{l}\text { Per cent. } \\
\text { of whole }\end{array}$ & Total & $\begin{array}{l}\text { Per cent. } \\
\text { of whole }\end{array}$ \\
\hline Total cases & 527 & 100.0 & 1,258 & 100.0 \\
\hline No sentence indicated & 170 & 32.3 & 507 & 40.3 \\
\hline Total sentences & 357 & 67.7 & 751 & 59.7 \\
\hline Total sentences suspended & 60 & 11.4 & 170 & 13.5 \\
\hline Total sentences executed & 297 & 56.3 & 581 & 46.2 \\
\hline Total sentenced for felony & 246 & 46.7 & 377 & 30.0 \\
\hline Total sentences suspended, felony & 47 & 8.9 & 115 & 9.2 \\
\hline Total sentences executed, felony & 199 & 37.8 & 262 & 20.8 \\
\hline Total sentenced for misdemeanors & 111 & 21.0 & 373 & 29.7 \\
\hline Total sentences misdemeanors suspended & 14 & 2.6 & 55 & 4.4 \\
\hline Total sentences misdemeanors executed & 97 & 18.4 & 318 & 25.3 \\
\hline Total misdemeanors sentenced to fine only & 15 & 2.8 & 165 & 13.1 \\
\hline
\end{tabular}

The question of adequate representation for the indigent defendant or litigant is of considerable importance if democratic government is to succeed. Undoubtedly the free use of the appointing power places the poor defendant in a much more favorable position in the Cuyahoga Common Pleas Court than in many other courts throughout the country. $\mathrm{He}$ is not, at least, compelled to sell his last article of value or deprive his family of necessaries in order to obtain what in theory is not the subject of purchase. The service which the state provides for him, however, is evidently inferior, and to some extent goes to crumb-gatherers. For this service the State pays a sum large enough to retain the services of an adequate firm of competent attorneys. The establishment of a Voluntary Defender's office is recommended, under the joint supervision of a committee of the judges and of the Bar Association. No statute would be necessary, the only requisite being sufficient confidence in the organization for the courts to assign cases to it. This matter should receive the careful consideration of the Common Pleas judges and the Bar Association. 


\section{BaIL Bonds}

Owing to the recent establishment of a bail bond commissioner, ${ }^{1}$ it is unnecessary to discuss conditions which have hitherto prevailed. From our investigation, however, it may be stated that the professional bondsman has practically no existence in the Common Pleas Court. Past abuse was connected mainly with collecting forfeited bonds, the responsibility for which rests chiefly on the prosecutor and not on the court.

It would be a wholesome practice, however, if the court inquired into a prisoner's previous record before fixing bail in a felony case. The practice of letting professional criminals out on moderate bail and with questionable bondsmen is inviting danger to the community. ${ }^{2}$ This has become exceptionally serious where the defendant is out on bail pending a bill of exceptions after conviction, considered in the chapter on appeals.

The worst feature of the bail situation is not that in a few serious cases the defendant jumps bail and his surety is not compelled to pay. Considerably more demoralizing in its effects is the use of bail to secure the defendant's liberty while his lawyer attempts to wear out the State's case by delay. Jail cases are quite properly tried first, so that a defendant on bail starts off with an opening wedge of delay. Under the conditions in which the criminal law had its rise, the right to bail was of prime importance, since months might elapse between arrest and convening of the court. Under the slow-moving Cleveland system bail is still most important because of unnecessary delays incident to it, but the defendants have turned this "shield into a sword." Under a system where the defendant in the usual case would be tried within a week after arrest or information against him, the importance of bail would fade into a trifle. Really to eliminate the abuse of bail, therefore, fundamental changes must be made in the system, to insure the swift movement of the course of justice.

One judge has called attention to a peculiar phase of the bail question - the practice of jailing the prosecuting witness in a robbery or larceny

${ }^{1}$ G. C., Sec. 13523-1, 13524-1, 13550-1, 13529-1. A feature of the act is that in suits for penalties it takes away from the court all power to render a judgment less than the full amount of the bond, except where the principal has been surrendered or arrested.

${ }^{2}$ A typical case is that of a professional shoplifter who, on December 6, 1919, stole two silk dresses valued at $\$ 200$ from the May Company, and a Hudson seal coat valued at $\$ 525$ from the Lindner Company. She was let out on bail totaling $\$ 2,000$ and jumped it twice, the last time permanently. Suits are still pending against the bondsman. Her associate in the offenses was fined $\$ 5.00$ in one case and "nolled" on the other. She was represented by a typical political criminal lawyer. 
case in default of bail. The statute authorizes such detention of important witnesses where adequate bail cannot be furnished. In some cases, no doubt, it is necessary to confine State's witnesses, especially where the witnesses are indifferent or unfriendly. It is ridiculous, however, to confine the complainant in a robbery case. Cases have been called to our attention where the complainants have been in jail for over a month, and where a man robbed of a few dollars was imprisoned 106 days while the robber-subsequently convicted-was at liberty on bail furnished by friends. This is "looking-glass justice." One judge has mitigated the hardship in such cases by directing the assignment commissioner to place them at the head of the trial list. The only real cure, however, is a greater exercise of common sense on the part of the committing magistrate.

\section{The Clerk's Office}

The Clerk of Courts, Edmund B. Haserodt, ${ }^{1}$ operates the most satisfactory office connected with the administration of criminal justice in Cleveland. Much of the information needed by the survey was obtained from the records in this office or with the assistance of the clerk's courteous staff, notably John J. Busher, chief deputy in the criminal division, and Mrs. Elizabeth Graham, secretary to Mr. Haserodt.

The chief records kept are: (a) A docket in ledger form with a page for each case, opened immediately on receipt of transcript from the inferior court; ${ }^{2}$ (b) a journal containing notes of the court's action each day, kept chronologically; (c) daily calendars of the judges from which the other records are made up; (d) a "conviction book," containing ample notes on convictions by terms; (e) a record of indictments; (f) a bail bond record. An alphabetical index is maintained referring to the docket number of the case, and a brief summary is kept in the original file papers.

The most comprehensive record of a case is kept in the docket, to which reference is usually had for information. Since this is the only place where anything like a full history can be obtained, it is suggested that this docket be made complete and include information not strictly within the clerk's jurisdiction. At present only the names of appointed counsel are entered, but the names of all counsel should appear. When-

${ }^{1}$ Mr. Haserodt's term expired August 1. Mr. Busher became bail bond commissioner July 26.

2 This docket is of the general nature recommended for the criminal branch of the Municipal Court, but much more extensive than is necessary for the latter. 
ever the court takes any action, it is suggested that the names of the judge and the prosecutor responsible be also entered in the docket. At present the docket ends with sentence, or other disposition,-unless there are exceptions, - but the history might easily be extended to cover subsequent events, such as a clear notation that the man was received at the penitentiary, and when he was paroled therefrom. Where bail is forfeited, a reference might be made to any suits to collect the bail. This, of course, would involve more work, but much time might be saved by eliminating the journal, which seems to be a useless duplication. Some simple method should be devised for following cases in which several defendants are involved, since the process of entering the steps consecutively, regardless of particular defendant, tends to make the record confusing. Also, the appearance of the docket might be much improved by typewriting the entries.

The most serious handicap to efficiency is the division of the office between the two court buildings, thus scattering the records and causing delay and misunderstanding. This is most clearly seen in cases of convictions affirmed by the Court of Appeals, where weeks sometimes pass before a mandate reaches the old court-house. This phase of the work is more fully considered under appeals.

The Clerk of Courts is elected every two years, and it is customary for a new clerk to discharge practically all the 'employees and engage a new staff. Obviously, the short term and spoils system are bad for the continuous effective administration of this office. The term should be lengthened if the office is not made appointive and a tradition established for retaining efficient employees. At present these employees are not under the civil service, but $\mathrm{Mr}$. Haserodt has attempted to comply with the requirements of the civil service both in selecting employees and in the matter of payroll.

\section{The Assignment Commissioner}

Two years ago this office was created to take the management of the list out of the prosecutor's office. Under the capable direction of the assignment clerk, Archie J. Kennel, the office has given considerable satisfaction to those who sponsored the change. The Common Pleas Court has facilities for disposing of criminal cases with surprising promptness, if the practice of "passing" and continuing was properly curbed. The office of Assignment Commissioner may be especially useful in notifying counsel and witnesses, thus saving much of the time ordinarily lost by waiting around the court-house for cases to be reached. Mr. Kennel has devised records which enable him to obtain prompt informa- 
tion respecting the judges or attorneys acting in a particular case, and these records were of much assistance in the survey.

\section{RECOMMENDATIONS}

The following is a summary of recommendations pertaining to the Common Pleas Court:

1. The establishment of a permanent executive head of the court with a modern court organization.

2. Certain physical changes, particularly the holding of all sessions under one roof; the keeping of all records in one place; facilities for seating spectators, and a rule forbidding any one not a lawyer or court officer to stand while court is in session.

3. The adoption of such formalities as will add to the dignity of the court-room, and the enforcement of due decorum by the court officers.

4. The elimination of the custom of "passing cases" except for urgent reasons.

5. The establishment of a Voluntary Defenders' office under the joint supervision of the judges and the Bar Association.

6. Modification of the custom of jailing prosecuting witnesses.

7. Greater care in allowing bail to professional and habitual criminals.

8. Certain detailed changes in methods of keeping records. 


\section{CHAPTER VII \\ THE COURT OF APPEALS}

\section{HISTORY AND JURISDICTION}

$7{ }^{\mathrm{HE}}$ Court of Appeals, created by constitutional amendment in 1912, inherits through the circuit courts established by the constitutional amendment of 1883 , which in turn succeeded the district courts established by the constitution of 1851 . These district courts were originally established to relieve pressure on the Supreme Court, and the present Court of Appeals still holds this position. It has no original criminal jurisdiction, but has final appellate jurisdiction in all matters except felony cases and cases of public or general interest. Inasmuch as the Supreme Court cannot be required to pass on the sufficiency of evidence, ${ }^{1}$ except where it has original jurisdiction, and in any case must grant leave before a petition in error may be filed, ${ }^{2}$ the jurisdiction of the Court of Appeals, even in felony cases, is practically final. ${ }^{3}$

Until recently the appellate procedure in misdemeanor cases in the Municipal Court was first to the Common Pleas Court, thence to the Court of Appeals. A petition in error may now be filed immediately in the Court of Appeals, without the intermediate review by the Common Pleas Court. ${ }^{4}$ Another change which ought to expedite appealed cases is the passage of the Boylan Bill in April, 1921, constituting Cuyahoga County as a separate district and forming a new district out of the counties with which it was formerly joined.

The judges of the Court of Appeals, of which there are three for each district, are organized with headquarters at Columbus, make their own rules, and determine what opinions shall be published. The judges of each district make rules to fit local needs, as, for instance, the rule promulgated by Judges Washburn, Vickery, and Ingersoll during 1921,

${ }^{1}$ G. C., Sec. 13751.

${ }^{2}$ G. C., Sec. 13756.

${ }^{3}$ There is a right of appeal to the Supreme Court where the constitutionality of a statute is involved. G. C., Sec. 13571.

'G. C., Sec. 1579-36. See Luthringer v. State, 11 O. App. 294. 
automatically advancing criminal cases for hearing. ${ }^{1}$ Admirable regulations are the constitutional provision requiring concurrence of all judges of the court to reverse a judgment upon the weight of the evidence, ${ }^{2}$ and the statutory provision for appeal by the State to establish a precedent in criminal cases. ${ }^{3}$

The Court of Appeals has a monopoly in Cuyahoga County of the dignity which is proper and necessary to a court. It has escaped the degradation which has pursued the other courts of the county, partly because of the nature of its business and partly because of its ample and impressive physical appointments.

\section{Dispatch of Business}

In the dispatch of criminal business the court would probably compare favorably with similar courts in other jurisdictions, although in view of the universal delay in handling appeals this should not be cause for satisfaction. Among all cases begun in the Common Pleas Court in 1919, 39 felony cases were taken to the Court of Appeals on error, averaging seven months and ten days between the filing of the petition in error and the decision of the Appellate Court. The court seems to dispose of cases from inferior criminal courts with more speed, however, since 11 petitions from inferior courts entered in the Common Pleas Court in 1919 were reviewed by the Court of Appeals in the same calendar year as the filing of petitions in that court. Of the seven cases of liquor law violation heard in January, 1921, by the Municipal Court and taken to the Court of Appeals on error, all were disposed of before April 19, 1921. That there must have been severe congestion in the handling of civil cases, however, is evidenced by the passage of the Boylan Bill. It remains to be seen whether this cutting down of geographic jurisdiction will enable the court to expedite felony cases as well.

\section{Results of Appealed Cases}

It may be said that the Court of Appeals is hardly a factor in the breakdown of the administration of criminal law. Of the 39 felony cases appealed, 25 resulted in convictions affirmed, six were dismissed by the plaintiffs-in-error or by the court, and seven were reversed or discharged. Among all cases begun in the Common Pleas Court in 1919, less than three-tenths of 1 per cent. moved nearer to freedom by virtue of a peti-

1 The power to make such a rule is conferred in G. C., Sec. 1523.

${ }^{2}$ Constitution 1912, Article IV.

${ }^{3}$ G. C., Sec. 13764 . Of course, a defendant once acquitted may not be tried again regardless of the outcome of the State's petition. 
tion in error, and of all convicted of felony after trial, only 2.4 per cent. succeeded in this way. The chief ground for reversal was that the verdict was against the weight of evidence. All the petitions in the 11 misdemeanor cases resulted in affirmed convictions. Of the seven cases of liquor law violation, the Court of Appeals reversed five for error of the police court judges. Five of these liquor cases had been tried before Judge F. L. Stevens during his campaign against such offenders, and four of these were reversed.

\section{Failure of Clemk's Office to Act Promptly}

The Clerk of Courts is the same for the eighth district Court of Appeals as for the Common Pleas Court. This office has already been considered in connection with the latter court. It is, however, in the handling of proceedings on petition in error in the Court of Appeals that the clerk's office is chiefly defective. A comparison of the dockets of the Court of Appeals with those of the Common Pleas Court shows that in the 32 felony convictions affirmed there is an average spread of twenty-four days between the date of the decision as noted in the former record and the date as noted in the latter. In one case the spread was eighty days and in two cases over sixty. This means that several weeks or even months may elapse after the upper court has affirmed conviction before the sheriff receives a capias from the clerk of the criminal branch of the Common Pleas Court. The gap is probably due to the fact that no successful effort has been made to overcome the physical gap between the main office of the clerk on the lake front and the criminal branch on the square. When the Court of Appeals affirms a conviction, the following steps occur: the bailiff of the Court of Appeals takes the opinion to the Clerk of Courts, who makes out the mandate and journalizes the entry; the case is then sent from the mandate clerk to the cost clerk, from the cost clerk to the filing clerk, and from the latter to the clerk of the criminal division, who makes out a capias for the sheriff.

It is obvious that where so many steps and so many persons are involved, delays and errors are apt to occur in conveying to the sheriff official notice of the action of the Court of Appeals. In the case of Rosario Spinello, No. 9211, Common Pleas Court, the mandate was lost entirely and the defendant, whose conviction for manslaughter was affirmed by the Court of Appeals on January 14, 1918, was not arrested by the sheriff until a year later. Mere accident resulted in the discovery that the convicted man was still at liberty. Spinello knew that his conviction had been affirmed, but naturally preferred to remain at liberty on bail pending action of the authorities. 


\section{Bail Bonds Pending Error}

Not all defendants remain as honestly quiescent as Spinello, however. For instance, among the 39 felony cases mentioned above, there is John Loggio, No. 17336, who was convicted of shooting with intent to wound on October 29, 1919; filed a petition in error, but dismissed the petition on his own motion May 3, 1920. The Common Pleas Court noted this action on July 22 and issued a capias, but in the meantime Loggio had fled to parts unknown. Similarly Meyer Goldberg, No. 17448, convicted of robbery on February 5, 1920, had his conviction affirmed January 10, 1921. The Common Pleas record shows the following: "1-31-21-Judgment of Court of Common Pleas affirmed; 2-25-21-Bond forfeited, capias." Goldberg was still at large when the study was made. A curious case is that of William Allen, No. 15874, whose conviction was set aside by the Court of Appeals, but who jumped his bail despite this fact, probably before the upper court rendered its decision. Allen is still at liberty, although his case would probably be "nolled" if he returned. In two other cases of the same group the last entry is "capias" issued: Anton Kabel, No. 15327, and Joseph McLaughlin, No. 15303. It is probable, however, that these defendants were subsequently apprehended.

In other cases there was apparently an attempt to jump bail, judging by the time necessary to place the defendant in custody after the capias was authorized. In view of the fact that of the 39 cases appealed seven were reversed and at least half of the remainder were in custody pending the proceedings in error, this proportion of actual and attempted bail jumping is quite large.

Other recent cases are Julius Pettianto, No. 18178, convicted of autostealing, whose petition in error was dismissed November 22, 1920, for want of preparation, such action noted by the Common Pleas Court December 8, 1920; bond forfeited and capias issued December 23, 1920; Harry Cohen, No. 14746, convicted of pocketpicking May 6, 1919; conviction affirmed December 24, 1919; noted by Common Pleas Court January 2, 1920; bond forfeited January 14, 1920. In none of the bail forfeiture cases had any money been collected on the bail bonds at the time of this study.

\section{RECOMMENDATIONS}

It is for the new Clerk of Courts to solve the problem of organizing his office so that the clerk of the criminal division receives instant notification to issue a capias upon the action of the Court of Appeals in affirming a conviction. So far as possible the records should be kept in one place, and steps between the handing down of the opinion of the 
upper court and the order to issue a capias should be eliminated or postponed. Other suggestions have been made, namely, that the defendant must be in court when the Court of Appeals announces its decision, and that the decision shall not be made public until a capias is in the hands of the sheriff.

If some such procedure were adopted, it would no longer be possible for a defendant to wait until his last chance was clearly gone and then have ample time to put his house in order before leaving the State. It would not, however, prevent a defendant from jumping bail before the decision is announced, or from deliberately abusing the appeal process in order to gain time. From the number of petitions dismissed on motion of the plaintiff-in-error, or for lack of preparation, it is obvious that there it such abuse. One notorious automobile thief participated in a most atrocious double murder and payroll robbery while his attorney was considering the advisability of filing a petition in error after conviction for auto-stealing.

A step which would reduce bail jumping and abuse of appeal is the refusal of bail to a defendant after conviction of a crime professional in its nature, like auto-stealing, robbery, pocketpicking, etc. The facts of each case must determine the discretion of the court. Here, however, there is a legal difficulty. G. C., Sec. 13698 (108 O. L. 18, 1919), provides as follows:

"When a person has been convicted of any bailable offense * * * and gives notice in writing to the trial court of his intention to file or apply for leave to file a petition in error, such court $* * *$ may, and if such person is not confined in prison shall, suspend execution of sentence or judgment for such fixed period as will give the accused time to prepare and file ${ }^{*} *{ }^{*}$ a petition in error, and such suspension shall be upon condition that the accused enter into a recognizance with sureties

G. C., Sec. 13700 , provides in effect that a defendant already out on bail need file no further recognizance pending proceedings in error. Formerly the question of bail after conviction was discretionary with the court in all cases. The compulsion placed upon the court where the convicted defendant is already at liberty is a mistaken policy, and should be removed at the next session of the legislature.

1 The italics are our own. 


\section{CHAPTER VIII}

\section{SUSPENDED SENTENCES, “NOLLES," AND PLEAS OF GUILTY TO LESSER OFFENSE}

W

$\mathrm{E}$ have already seen that about 20 per cent. of all felony cases are nolle-prossed in the courts, that over 8 per cent. of those indicted are allowed to plead guilty to an offense less serious than the indictment, and that of those convicted, about 22 per cent. receive suspended sentences. With respect to offenses less than felonies in the Municipal Court, about 7 per cent. are "nolled" and 42 per cent. of those convicted receive suspended sentences. One would suppose that in releasing defendants on such a wholesale scale the court must realize what it is doing.

Yet Justice acting with veiled eyes is never better exemplified than by the judge attempting to handle one of these questions. ${ }^{1}$ Obviously, the judge should be in possession of adequate information before he can act with fairness to the defendant or the community, yet under the existing system it may be only by chance that he learns the true situation.

Let us suppose a man convicted of felony and given an indeterminate sentence in the Ohio State Reformatory. Under Sections 13706-13715 of the code the judge may "parole" this defendant if he is a first offender. ${ }^{2}$ He is importuned by the defendant's lawyers and besieged by his relatives and friends. Evidence of previous good character is supplied in quantity, and pledges of good behavior are heaped upon the judge. To whom shall the judge turn for a disinterested recital of the true situation?

1 The process of suspending sentence and placing the defendant under surveillance is known in most jurisdictions as "probation." The discussion in this chapter extends as well to suspending workhouse sentences as to "paroling" more serious offenders.

2 "In all prosecutions * * * where the court has power to sentence and it appears that the defendant has never before been imprisoned for crime $\quad * \quad * \quad *$ said court may suspend execution of sentence and place the defendant on probation.

Sec. 2 excludes certain crimes from the operation of this statute, and Sec. 3 gives the court power to suspend execution of sentence at any time in jail or workhouse cases. 
Police and Prosecutors not Best Advisers to the Court

Police officers who aided the prosecution, if such can be found, may be helpful, but they know only part of the story, often have a bias, and are not trained to the difficult task of appraising the possible results of treatment outside of an institution. Moreover, police witnesses vary in different cases so that the court must rely on many advisers with many different standards of judgment and varying outlook upon life.

The only other source of information is the prosecuting attorney, who has the advantage of being easily accessible and known to the judge. Here again there is the possibility of bias against the prisoner, often engendered by the heat of a contest, of favoritism because of friendship for the defendant's lawyer, or because of political influence. Even if the prosecutor is wholly impartial, as he often is, he usually knows only those facts necessary to a conviction, and has not burdened his mind with those "imponderables" necessary to the formation of a judgment on the question of probation. Even the previous record of the prisoner, sent by the Bureau of Criminal Identification to the prosecutor's office, containing merely such bald facts as arrests and convictions, rarely reaches the judge, and perhaps is not even known to the particular prosecutor in charge. ${ }^{1}$

\section{Public Clamor Followed}

In the old game of "Donkey" the blindfolded player often relies upon the cheers of the onlookers to guide him to the spot where he can pin the animal's tail in its proper place. In like manner the judges, deprived of the opportunity of forming their own judgment upon all the facts, are often prone to follow the clamor of the press and public. When the cry is "thumbs up," paroles issue in abundance, but when it is "thumbs down," both the good and the wicked travel the same road. When Tom L. Johnson was mayor, a humanitarianism not adequately guided by science in the handling of offenders began which did not reach its sentimental climax until several years ago. The Chief of Police started to release without trial all first offenders in certain minor crimes, becoming thereby nationally known as "Golden Rule" Kohler.

1 Writing to a parole officer under date of December 20,1920, the prosecutor's office says: "These two boys broke into a confectionery store and helped themselves to about $\$ 112$ worth of cigars and smoking materials. The court accepted a plea of guilty to petit larceny in the case, hence their sentence to workhouse. There is no previous record against these boys." The "two boys" mentioned were in fact two aliases of the same criminal, whose amazingly long police record is No. 10238, printed on page 239 of this report. 
The idea spread from police to judge, from misdemeanor to felony, until, as an editor of one of the Cleveland papers put it, "a lawyer regarded it as a personal insult if a judge sent his client away." Under the Davis régime this false idealism was perverted into good-fellowism, and the damage was done. Cleveland became known as an "easy town," which it certainly was.

\section{Cases "Paroled" in January, 1917}

In the January term of 1917,254 men pleaded guilty or were convicted of felonies and 135 were paroled by the court. It should be remembered that these men were a selected bad lot, since by the decimating processes of the system most of those who had anything in their favor had escaped in the police court, in the grand jury room, in the prosecutor's office, or by pleading guilty to a misdemeanor instead of the original charge of felony. Yet over 53 per cent. of this dangerous group went practically unpunished. For purposes of comparison, a page of the conviction book for this January, 1917, term is reproduced, the word "paroled" appearing in the last column where such action was taken. Note the large number of crimes of a professional nature which were unpunished. ${ }^{1}$

This page should be contrasted with the page reproduced from the conviction book for September term, 1920.

In this term 257 men pleaded guilty or were convicted of felonies, and 30 were paroled, or a little more than 11 per cent. This represents reaction to the "crime wave" and a revolt against "good-fellowism." The contrast is a witness to the effect of public clamor upon the judicial mind, since there probably was about the same proportion of confirmed evildoers and meritorious offenders in the 1917 term as in the 1920 term.

The judge who presided during the 1917 term has declared that 80 per cent. of cases paroled never get into trouble again. Whether or not this is true, ${ }^{3}$ it does not justify paroling blindly. A too free use of parole

1 "B. \& L." means burglary and larceny, "P. P.," pocketpicking, "C. C. W.," carrying concealed weapons; "O. M. V.," operating motor vehicle without consent of owner. The fact that this happens to be the term of any particular judge makes no difference. The record of nearly every judge prior to 1917 would have been similar. The trouble is not so much with any particular judge as with a system which compels him to guess in the dark.

2 To appreciate the force of this revolt the November, 1920, votes for Republican candidates for President and Governor should be compared.

Detective Koestle, of the Bureau of Criminal Identification, agrees with this estimate. 


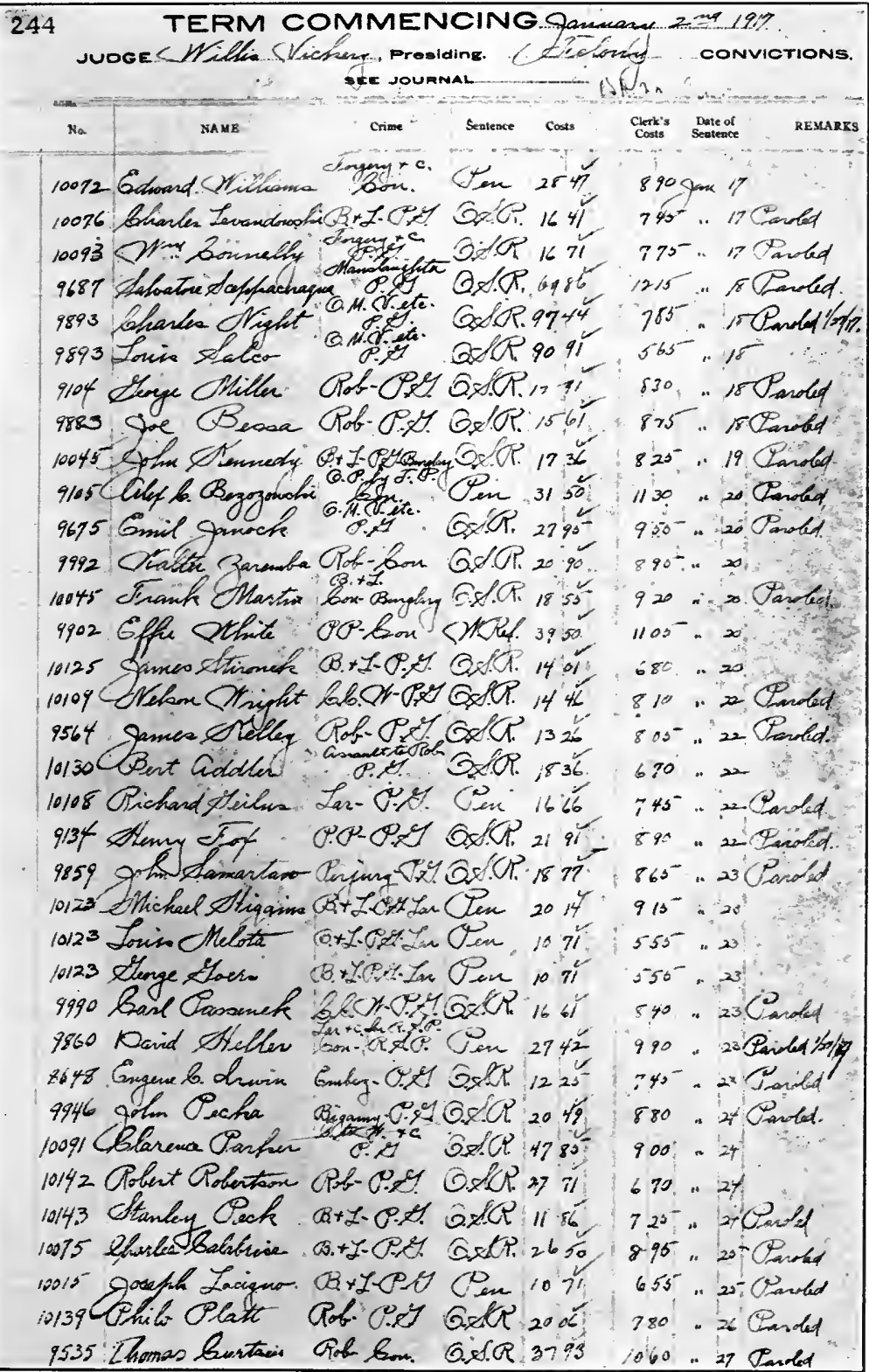

Page from the conviction book, January, 1917, term of Common Pleas Court, showing the number of paroles 
TERM COMMENCING dept...?, 192.

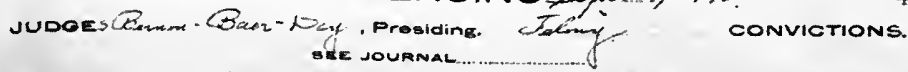

Inement

No.

NAบ:

Critec

Scutence corts

Clest's Thate of
Corts: Sectifence

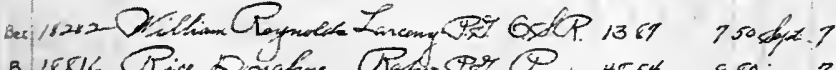

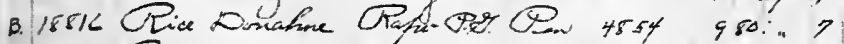

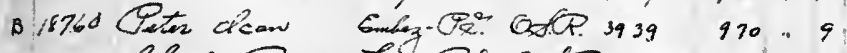

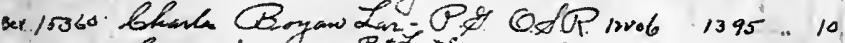

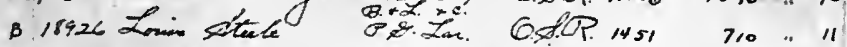

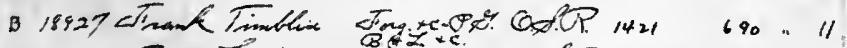

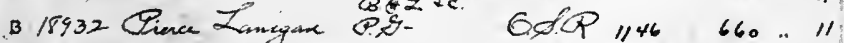

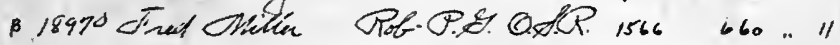

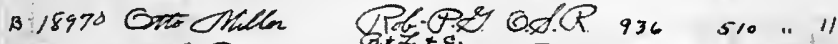

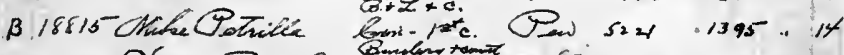

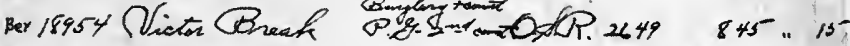

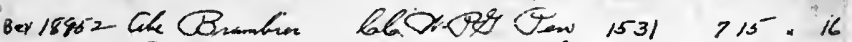

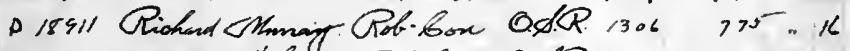

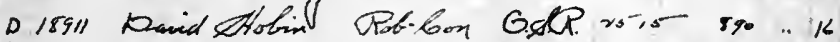

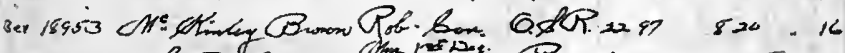

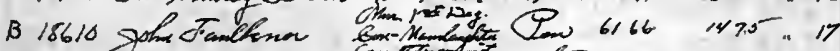

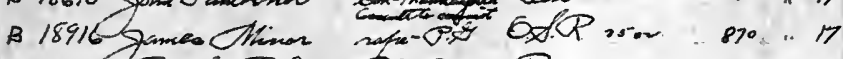

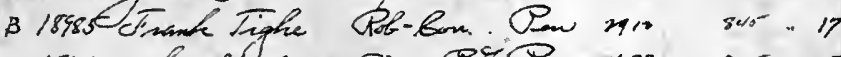

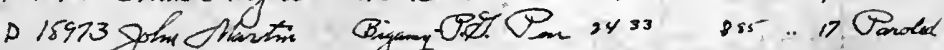

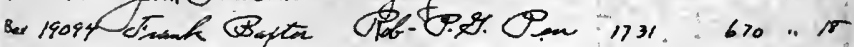

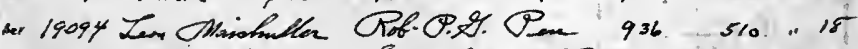

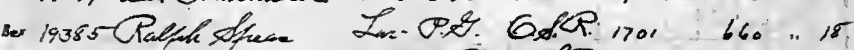

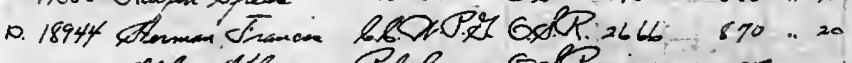

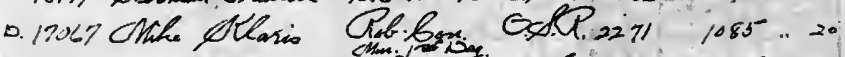

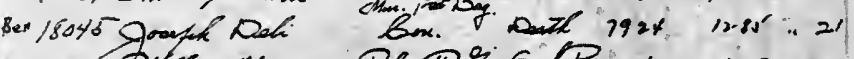

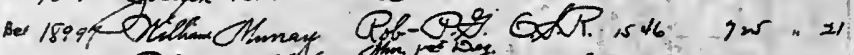

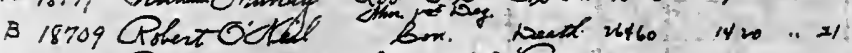

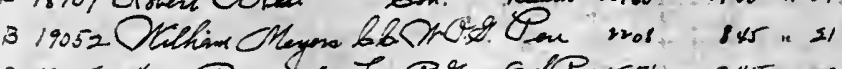

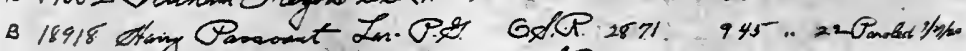

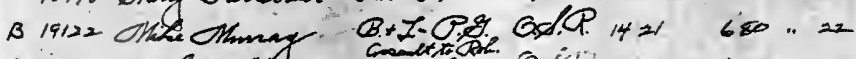

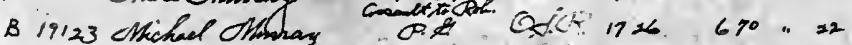

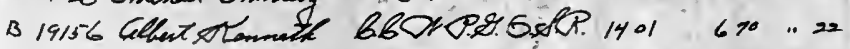

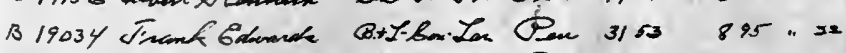

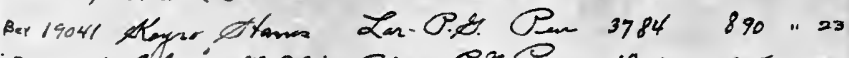

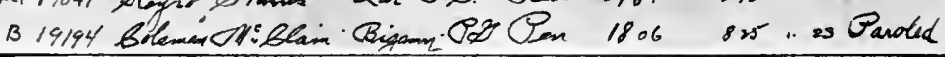

Page from the conviction book. September, 1920, term of Common Pleas Court, showing the relatively small number of paroles 
certainly encourages others, if not the defendant himself, to "take a chance" where their "pal" got off so lightly.

It should always be remembered that the parole represents leniency to men proved guilty and involves no question of punishing innocent men with which it is of ten sentimentally confused. Every possible precaution should, therefore, be taken to protect the public from the 20 per cent. who admittedly get into trouble again. In a court with proper facilities for obtaining information such a large percentage would not be freed to prey upon the community.

It is not possible to study the history of each individual felon paroled in January, 1917, but even without such a study, from the facts already known to the Bureau of Criminal Identification, it is possible to indicate the loose operation of the "bench parole." Undoubtedly there is much more which has not got into the police records of Cleveland. ${ }^{2}$ It should be remembered that the "bench parole" was intended as a helping hand for the erring and not as an additional device to facilitate the escape of crooks. Nevertheless, owing to the absence of any responsible informant, the court has to some extent unintentionally established another loophole.

Of those paroled in January term, 1917, at least eight were then known to the police of Cleveland as having been arrested for or convicted of serious offenses, five having "done time" before, and one having sentence previously suspended. Two of these men actually had cases pending in the Municipal Court at about the same time. One of them, Frank Nolan, was given a suspended sentence under an alias in the lower court just before he was paroled on the more serious charge in the Common Pleas Court. Of these eight men, four have not been arrested in Cleveland since the charge on which they were paroled. The others have since had criminal records, including one notorious robber who finally landed in the penitentiary, and one professional pickpocket who still plies his trade in Cleveland with occasional interruptions by the police.

1 One of the judges of the new Detroit court tells of three successive larcenies by different messengers of the Western Union, the first two receiving probation and the third offender being punished severely to stop what seemed to be the beginning of an epidemic.

2 Not only are many arrests not recorded, especially for minor offenses, but many offenses are committed for which no arrests are made. The late Judge Foran called attention to the fallacy of using the police record only to determine whether the defendant is a "first offender." He may have been a continuous offender for years and have always escaped arrest. 
Fifteen others of those paroled have since been known to the police, five of them being returned to the reformatory or penitentiary as parole violators-three for robbery, one for forgery, and one for violation of the automobile law. Of the nine remaining, one was killed while committing a burglary in Cleveland a few months after his parole, six have been arrested in Cleveland for robbery, burglary and larceny, autostealing, and violating the automobile law; two have been arrested in other cities for larceny, and one has been located in San Quentin State Prison, where he is serving sentence for bank robbery.

\section{Paroling in the Dark}

Admitting that to parole or not to parole is a question often involving the most difficult judgments, and that a low percentage of errors is represented by eight men already known to the police and at least 19 men who continued careers of crime thereafter out of a total of 135, it is a safe assumption that few of these men would have escaped with parole if the judge had been supplied with a thorough, impartial report in each case. The number of professional or hardened criminals is always a low percentage of the total who get into serious trouble, and such men can usually be "spotted" by the time they get before the Common Pleas Court on serious charges, provided the responsibility for investigating them is placed in one agency and there is no question of ability or integrity.

It is no answer to the urgent need for such an agency to assume that the matter of the "bench parole" is a question of the ability and conscientiousness of the particular judges. It is true that some judges are more lenient than others, and some are susceptible to persuasion, especially if applied by politicians ${ }^{1}$ or newspapers, ${ }^{2}$ but the fundamental trouble remains. Avoidable mistakes will always be made when judges are asked to decide in the dark.

The story is told of an ex-judge, then president of the Bar Association, who began a hue and cry about the leniency of the courts. Upon being shown by the county examiner his own record of "paroling" while judge,

${ }^{1} \mathrm{~A}$ weak judge heeds a politician not because he desires to do so, but because he sees no escape. If such a judge were armed with a carefully prepared report on the defendant, he could successfully meet such importunities in an unworthy case.

${ }^{2} \mathrm{~A}$ former reporter relates the following story about a judge who is no longer on the bench: During a recess in the trial of a misdemeanor case, the reporters bet that they could make the judge sentence the defendant although the court had seemed inclined to favor him. A reporter then remarked to the judge, "You are not going to let that bad egg go, are you, Judge?" Sentence was promptly pronounced. 
he promptly subsided. The late Judge Foran personally related that he recently "paroled" an embezzler upon many representations of good character made to him. A week later the parole officer brought in a record of conviction for stealing 20 barrels of whisky many years before, and only then the judge awoke to the fact that he had been this man's counsel at the former trial! In the Plain Dealer, April 7, 1921, is published a letter by Judge Cull to the County Council of the American Legion in which the judge writes of a veteran who pleaded guilty to perjury, " * * * nevertheless, after having sentenced him, some questions arise in my mind, and I know of no place to turn to to secure a friendly interest in the prisoner unless it is from your organization." On March 11, 1918, one Andrew Kebort pleaded guilty to the charge of robbery, and for some reason was not sentenced. About a year later an Assignment Commissioner was appointed and he began to press for disposition of ripe cases. Purely for the purpose of completing the record, apparently, the presiding judge ${ }^{1}$ caused an entry to be made on June 9, 1919, sentencing Kebort to the Reformatory and suspending the sentence. ${ }^{2}$ In the meantime, on August 31, 1918, Kebort had been convicted and sentenced to the workhouse for petit larceny, and on July 16,1919, after stealing an auto and robbing three people, he shot and killed one man and wounded two others while resisting arrest.

An ex-Municipal Court judge states that one of his colleagues, a man of unquestioned integrity, suspended sentence in the cases of certain gamblers because he had no information that they ran a notorious place. It was the former judge's opinion that a prominent city official wanted to "get something" on this judge, and so he was led into the trap of releasing well-known offenders. ${ }^{3}$ A former judge states that during his term on the criminal bench July 14 was heralded as "Emancipation Day" because the cases of $\mathbf{7 5}$ negro prostitutes had been continued to that day. He was advised to suspend their sentences, and if they were brought in again to send them to the workhouse. This he did, but when they came in again, many under assumed names, it was almost impossible to identify them.

1 The original trial judge was no longer on the Common Pleas bench.

"The political lawyer who defended Kebort is reported to have "blamed" the resurrection of this case upon the establishment of the Assignment Commissioner's office.

3 This same man observes that while on the bench he felt like the baby Emperor of China, wondering who would poison him next-the police, detectives, or prosecutors. 


\section{"Nolling" Cases}

What is true of the "bench parole" and suspended sentences is equally true of the judge attempting to pass on the prosecutor's motion to "nolle" a case. Owing to the judges' inability to act intelligently on such motions, they have become largely a matter of form only, the judge accepting the prosecutor's statement of the facts. In the rush of the day's business it is nearly impossible for the judge to go fully into any case before granting the motion nolle prosequi.

Many cases are "nolled" because the defendant is already in the penitentiary, or has been convicted or acquitted on another indictment growing out of the same act, or because there is a patent defect in the indictment. It is easy in such cases for the prosecutor to convince the judge. In other cases, however, the prosecutor is presumably exercising his judgment on the merits, and this often results in the function of judge and jury being quietly exercised by an assistant prosecutor. Since these motions are usually made orally, and no court record of the reason is made, the lack of opportunity for judicial curiosity furnishes an easy mode of escape in many cases.

At least once in the official life-time of every prosecutor it is necessary to "clean house," viz., to clear the docket of hundreds of cases which have been accumulating for years but which, for one reason or another, should be "nolled." These include old cases in which the defendant has never been apprehended, or bail has been forfeited, or there have been sentences or acquittals on other charges growing out of the same deed. This clean-up takes the form of a "blanket nolle," presented on motion to the presiding judge of the criminal division. In February, 1920 , such a motion, containing over 400 cases, was presented to Judge Kennedy. The utter futility of a judge's attempting to pass judgment on the merits of so many cases at one time is obvious. ${ }^{1}$

The motion nolle prosequi is another example of the decay of an institution which flourished successfully under the rural conditions of its origin, but which threatens to become a menace in a great modern city. Where the few criminal cases furnish diversion for the town, where the prosecutor is a marked man among his fellow-citizens, where interest in the crime and the criminals lightens the harvest and shortens the winter evenings, there can be little abuse of the motion nolle prosequi. Such checks are lost, however, in the rush and roar of a great city, especially

${ }^{1}$ No detailed analysis of the cases in the above "blanket nolle" is here made because that is properly a part of the study of the prosecutor's office. The point made here is the helplessness of the judge. 
the typical American metropolis, with its mounting crime rate, its lack of a tradition of disinterested public service, and the insidious ramifications of political influence.

If the motion is retained, it should be made a real motion, so that the independent discretion of the judge is one with that of the prosecutor. Here, as in the case of the parole, the judge must be able to rely upon an impartial and thorough investigation.

\section{Recommendations}

Before proceeding to a consideration of the agency which should advise the court, a number of preliminary suggestions which seem essential may be made.

\section{Preliminary Suggestions}

The motion to "nolle" should be in writing, and should specify the reasons for the refusal to prosecute.

No "bench parole" or "nolle" should be granted until ample notice that the court contemplates such action is-

(1) Delivered to the complaining witnesses.

(2) Delivered to the police officers in charge of the case.

It should also be in the discretion of the court to direct that notices of motions to "nolle" be posted publicly in the court-house. This will protect the court and prosecutor against being compelled to act on an ex parte presentation by friends of the accused. An exception to the rule should be made in the case of violations of ordinances, non-criminal in nature, and perhaps of trivial misdemeanors.

The "blanket nolle" should be absolutely limited to cases involving no exercise of judgment, as most of the cases in such motion are at present, viz., old cases in which bail is forfeited, defendants not apprehended, or previously sentenced or acquitted for the same act. Before the motion is allowed, copies should be delivered to the Bureau of Criminal Identification for information and advice, and to the press for publication. ${ }^{1}$

The agency upon which the court should rely in disposing of criminal cases should be an adequate Probation Department, under a single head, appointed by the Common Pleas Court, organized to handle the criminal business before all the courts in city and county, exclusive of juvenile cases. A Probation Department should exercise a double function,

1 John A. Cline, ex-prosecutor of Cuyahoga County, reports that when in office he gave a list of cases in "blanket nolle" to the press two weeks before the motion was made, with notice that he would "nolle" unless someone appeared to object. This should be made a rule of court, but the publication should be after, not before, the motion is made. 
namely, to follow up cases placed in its custody, and to advise the court as to disposition after conviction, or upon a motion to "nolle." The first function is not here considered because it belongs more properly under a discussion of the general treatment of offenders, but the latter is vital to the present question.

\section{An Adequate Probation Department}

The disqualifications of the police and prosecutor's office as the court's reliance have already been discussed. ${ }^{1}$ What is needed is a department which makes a business of studying offenders as human beings, which will make use of the excellent records kept by the Bureau of Criminal Identification, but round out these records as to offenses, and supplement them with the many considerations which never appear on a court docket.

Such probation as there is in Cleveland ${ }^{2}$-if what there is may be dignified by the name-is another proof of the rapid growth of the city and the apathy of its citizens toward the human aspects of government. One would have to travel far to find a great center which is guilty of such gross neglect. Three men and three women probation officers, forced to labor without clerks or stenographers, is the sum of what has been provided, and that grudgingly. These six are attached to the Municipal Court, none to the Common Pleas Court. ${ }^{3}$ Paroling defendants to relatives, detectives, clerks, and even stenographers in the prosecutor's office ${ }^{4}$ has made a joke of probation, but the Common Pleas Court has had no other agency afforded it. Mrs. Antoinette Callaghan and her two assistants in the Municipal Court understand their task and work hard over the women probationers, but theirs is an impossible problem. The men's Probation Department has apparently never been taken seriously by the city. Until James Metlicka came into office there was not, he says, even a system for recording payments, the checks being jumbled into a drawer or carried around in some one's pocket.

These feeble beginnings of probation should not be made the basis of judgment on the institution. A totally new conception of probation

1 Page 323, this chapter.

2 Exclusive of the Juvenile Court.

- There is also one volunteer officer from the Woman's Protective Association.

- The Central Municipal Court in Boston, serving a population much smaller than that of Cleveland, has 26 probation officers, 15 clerks, a medical director, and an assistant director. In addition there are 19 probation officers attached to the district courts of the city, and nine probation officers to the Superior (County) Court. There are also many trained volunteer workers from social agencies working in conjunction with all the courts. 
must be grasped, and a professional staff, adequate in numbers and personnel, established. Salaries should be commensurate with the importance of the office, and no man is too big for head of the staff. ${ }^{1}$ Above all, the department must be kept out of politics.

\section{A Central Bureau of Information}

The Probation Department should establish as part of its work a Central Bureau of Information respecting persons charged with crime, containing the court records of offenders, together with all essential data relating to family, environment, physical and mental condition, etc. Such a record would aid the department in its treatment of offenders, and put it in a position to advise the court fully before disposition is made. In addition, valuable statistics would be collected to warn the people of Cleveland in time to forestall another breakdown.

The idea of such a Central Bureau has recently been gaining ground in Cleveland. The so-called "Day Bill," enacted into law this spring (G. C., Sections 13523, 13524, 13529, 13550), establishing the office of Bond Commissioner, imposes on the new office the consolidation of criminal records to be made up and transmitted by the Municipal and County Clerks. The educational value of this legislative beginning is considerable, and it should not be difficult, now, to transfer this duty, together with other collateral responsibilities, to the Probation Department when established. At a meeting of the Cleveland Bar Association May 7, 1921, the establishment of an advisory board of criminal prevention was recommended, to aid in the meting out of sentences, discharges, and paroles. Although the concrete measure suggested may not be the one best adapted to accomplish the purpose sought, this resolution places the Bar Association on record as recognizing a great need.

A probation staff, adequate for the needs of Cleveland, would mean a new expense, but whether an additional expense or not would depend on the economy effected in other much less essential branches of the government. Even if every cent appropriated meant additional cost, the expense is one which a civilized community cannot shirk. No man can compute what has been the cost to Cleveland of the failure to provide means for salvaging the redeemable portion of its erring citizens and of blindly unleashing on the community its worst enemies to pillage, terrorize, and murder. Even less calculable is the insidious effect upon the moral tone of the community.

${ }^{1}$ Until a few months ago the head of the probation work in Detroit was Edwin Denby, now Secretary of the Navy. 


\section{CHAPTER IX}

\section{MOTIONS FOR NEW TRIAL}

\section{Frequency}

$\mathrm{E}$

VEN after a case has gone through the trial stage and the jury has returned a verdict of guilty, there are still chances of escape for the defendant. Not only is there possibility of "parole" and appeal, but also a likelihood that the trial judge himself may grant a new deal by setting aside the verdict. In the group of Common Pleas cases begun in 1919 there were 292 original convictions for felony before known judges, 95 motions for new trial, of which $41^{1}$ were allowed by the judges. Fourteen per cent. of all convictions were thus set aside, and 43 per cent. of all motions for new trial allowed.

Table 24 shows such motions by trial judges.

TABLE 24.-MOTIONS FOR NEW TRIAL, BY JUDGES

\begin{tabular}{|c|c|c|c|}
\hline Judge & $\begin{array}{l}\text { Total } \\
\text { convictions }\end{array}$ & $\begin{array}{l}\text { Motions for new } \\
\text { trial refused }\end{array}$ & $\begin{array}{l}\text { Motions for new } \\
\text { trial allowed }\end{array}$ \\
\hline $\begin{array}{l}\text { Baer } \\
\text { Cull } \\
\text { Day } \\
\text { Foran } \\
\text { Henderson } \\
\text { Jewell } \\
\text { Kennedy } \\
\text { Kramer } \\
\text { Levine } \\
\text { Pearson } \\
\text { Phillips } \\
\text { Powell } \\
\text { Stephenson } \\
\text { Stevens } \\
\text { Thomas }\end{array}$ & $\begin{array}{r}44 \\
52 \\
1 \\
27 \\
2 \\
3 \\
16 \\
3 \\
6 \\
16 \\
43 \\
40 \\
2 \\
35 \\
2\end{array}$ & $\begin{array}{c}8 \\
8 \\
1 \\
1 \\
\cdots \\
\because 8 \\
\ddot{8} \\
\ddot{2} \\
9 \\
9 \\
5 \\
1 \\
4 \\
1\end{array}$ & $\begin{array}{c}3 \\
10^{2} \\
\because \\
i \\
2 \\
1 \\
4 \\
1 \\
1 \\
\ddot{4}^{2} \\
4 \\
10^{3} \\
\cdots\end{array}$ \\
\hline Total & 292 & 53 & 41 \\
\hline
\end{tabular}

1 Three followed pleas of guilty.

2 Two cases involving same crime.

3 Four cases involving same crime. 


\section{ANALYsis of Results}

Generally, the large percentage of new trials granted indicates poor work by the juries, since in most instances the new trial is granted by the trial judge because the verdict is against the weight of the evidence, and not because of erroneous rulings of the judge. In such cases a new trial is the only safeguard against rank injustice. From a study of the records in Cleveland, however, it is apparent that in most cases there is no real intention to grant another trial. The verdict is simply set aside in order to effect one of the many other adjustments. Table 25 shows the outcome of all the new trials granted in the group considered.

TABLE 25.-DISPOSITION OF 41 NEW TRIALS GRANTED IN 1919

\begin{tabular}{|c|c|c|c|c|}
\hline No. & Indictment & $\begin{array}{l}\text { Judge at } \\
\text { first trial }\end{array}$ & $\begin{array}{l}\text { Judge, final } \\
\text { disposition }\end{array}$ & Nature of final disposition \\
\hline 1 & Rape & Baer & Pearson & $\begin{array}{l}\text { Pleads guilty to assault and } \\
\text { battery, workhouse and } \\
\text { fine }\end{array}$ \\
\hline 2 & Burglary and larceny & Baer & Baer & $\begin{array}{l}\text { Pleads guilty to lesser of- } \\
\text { fense, Ohio State Reform- } \\
\text { atory }\end{array}$ \\
\hline 3 & Burglary and larceny & Baer & Baer & $\begin{array}{l}\text { Pleads guilty to lesser of- } \\
\text { fense, Ohio Penitentiary }\end{array}$ \\
\hline 4 & $\begin{array}{l}\text { Carrying concealed weap- } \\
\text { ons }\end{array}$ & Cull & Cull & Costs \\
\hline 5 & Murder first degree & Cull & Cull & $\begin{array}{l}\text { Pleads guilty to second de- } \\
\text { gree murder, life sentence }\end{array}$ \\
\hline 6 & $\begin{array}{l}\text { Carrying concealed weap- } \\
\text { ons }\end{array}$ & Cull & Stephenson & Nolled \\
\hline 7 & Burglary and larceny & Cull & Cull & "Bench parole" \\
\hline 8 & $\begin{array}{l}\text { Burglary and larceny } \\
\text { (brother of above) }\end{array}$ & Cull & Cull & "Bench parole" \\
\hline 9 & Pocketpicking & Cull & Kennedy & $\begin{array}{l}\text { Pleads guilty to petit lar- } \\
\text { ceny, } 10 \text { days }\end{array}$ \\
\hline 10 & Neglect to support & Cull & & Continued \\
\hline 11 & Violating auto law & Cull & Cull & "Bench parole" \\
\hline 12 & Burglary and larceny & Cull & Cull & "Bench parole" \\
\hline 13 & $\begin{array}{l}\text { Carrying concealed weap- } \\
\text { ons }\end{array}$ & Cull & Cull & $\begin{array}{l}\text { Decree vacated, original } \\
\text { sentence ordered executed }\end{array}$ \\
\hline 14 & Burglary and larceny & Foran & Foran & $\begin{array}{l}\text { Pleads guilty to petit lar- } \\
\text { ceny; } 30 \text { days and fine, } \\
\text { suspended sentence }\end{array}$ \\
\hline 15 & Grand larceny & Henderson & Pearson & Nolled \\
\hline 16 & Abortion & Jewell & Pearson & Nolled \\
\hline 17 & Auto-stealing & Kennedy & Kennedy & $\begin{array}{l}\text { Dismissed, want of prose- } \\
\text { cution }\end{array}$ \\
\hline 18 & Burglary and larceny & Kennedy & Cull & "Bench parole" \\
\hline 19 & Grand larceny & Kennedy & Kennedy & $\begin{array}{l}\text { Pleads guilty to petit lar- } \\
\text { ceny, } \$ 50 \text { fine }\end{array}$ \\
\hline 20 & Cutting to wound & Kennedy & Kennedy & $\begin{array}{l}\text { Pleads guilty to assault and } \\
\text { battery, } \$ 50 \text { fine }\end{array}$ \\
\hline 21 & Grand larceny & Kennedy & Kennedy & Nolled \\
\hline
\end{tabular}


Continued

\begin{tabular}{|c|c|c|c|c|}
\hline No. & Indictment & $\begin{array}{l}\text { Judge at } \\
\text { first trial }\end{array}$ & $\begin{array}{l}\text { Judge, final } \\
\text { disposition }\end{array}$ & Nature of final disposition \\
\hline 22 & Robbery & Kramer & Kramer & $\begin{array}{l}\text { Pleads guilty to assault } \\
\text { and battery, } 30 \text { days and } \\
\text { fine }\end{array}$ \\
\hline 23 & Rape & Levine & Pearson & Nolled \\
\hline 24 & Manslaughter & Phillips & Pearson & Trial, not guilty \\
\hline 25 & Shoot to kill & Phillips & Stevens & Nolled \\
\hline 26 & $\begin{array}{l}\text { Housebreaking and lar- } \\
\text { ceny }\end{array}$ & Phillips & Bernon & Nolled \\
\hline 27 & $\begin{array}{l}\text { Housebreaking and lar- } \\
\text { ceny }\end{array}$ & Phillips & Baer & Nolled \\
\hline 28 & $\begin{array}{l}\text { Receiving stolen prop- } \\
\text { erty }\end{array}$ & Powell & Powell & Nolled \\
\hline 29 & Grand larceny & Powell & Baer & Trial, not guilty \\
\hline 30 & Cutting to wound & Powell & Powell & $\begin{array}{l}\text { Pleads guilty to assault } \\
\text { and battery, } 30 \text { days }\end{array}$ \\
\hline 31 & Cutting to wound & Powell & Phillips & $\begin{array}{l}\text { Pleads guilty to assault } \\
\text { and battery, } 60 \text { days }\end{array}$ \\
\hline 32 & Manslaughter & Stevens & Stevens & "Bench parole" \\
\hline 33 & Cutting to wound & Stevens & Stevens & $\begin{array}{l}\text { Pleads guilty to assault } \\
\text { and battery, } 6 \text { months }\end{array}$ \\
\hline 34 & Robbery & Stevens & Stevens & $\begin{array}{l}\text { Pleads guilty to assault } \\
\text { and battery, } 30 \text { days }\end{array}$ \\
\hline 35 & Robbery & Stevens & Stevens & $\begin{array}{l}\text { Pleads guilty to assault } \\
\text { and battery, } 30 \text { days }\end{array}$ \\
\hline 36 & Robbery & Stevens & Stevens & $\begin{array}{l}\text { Pleads guilty to assault } \\
\text { and battery, } 30 \text { days }\end{array}$ \\
\hline 37 & Robbery & Stevens & Stevens & $\begin{array}{l}\text { Pleads guilty to assault } \\
\text { and battery, } 30 \text { days }\end{array}$ \\
\hline 38 & Burglary and larceny & Stevens & Stevens & $\begin{array}{l}\text { Pleads guilty to petit lar- } \\
\text { ceny, } 30 \text { days }\end{array}$ \\
\hline 39 & Burglary and larceny & Stevens & Stevens & $\begin{array}{l}30 \text { days and costs, sus- } \\
\text { pended sentence, returned } \\
\text { as parole violator }\end{array}$ \\
\hline 40 & Pocketpicking & Stevens & Stevens & $\begin{array}{l}\text { Pleads guilty to petit lar- } \\
\text { ceny, } 30 \text { days }\end{array}$ \\
\hline 41 & Arson & Stevens & Powell & Nolled \\
\hline
\end{tabular}

Since only two cases out of 41 new trials granted actually went to trial, it is apparent that this motion is negligible for the purpose originally intended. This is perhaps natural in view of the fact that a defendant once convicted is more willing to plead guilty to a lesser offense than before trial. In all, 18 such pleas were accepted. In view of the number of convictions for "cutting to wound" set aside on this basis, it seems as if the judges were using the new trial to accomplish "rough justice," since most cases of this character are the result of brawls. Some of the defendants, however, seem particularly fortunate. In the rape case, No. 1, the conviction was set aside on evidence which should have been available at the trial, and the defendant was allowed to plead guilty to 
assault and battery when there was no doubt as to his being guilty of at least an attempt to rape. The victim was a twelve-year-old girl. Nos. 2 and 19 were hardened criminals with long records, yet the latter particularly received gentle treatment, being fined $\$ 50$ and set free to continue his career.' It need hardly be said that at least the same thorough consideration should be given to the disposition of a case after the conviction has been set aside as is urged in the preceding chapter. ${ }^{2}$ It should be said that No. 9 was a case in which the prisoner, an old offender, aided the police materially in other cases, and the readjustment of his case was at the request of the police.

Ten cases were "nolled" after new trial granted, and one dismissed for want of prosecution. Generally, where a judge sets aside a conviction because the verdict was not sustained by the evidence, and the State has no further evidence to offer, a "nolle" is a proper disposition. At least two of these cases, however, had the unusual feature of a new trial being ordered after a plea of guilty. In No. 21 the defendant was sentenced to the Ohio State Reformatory, a note in the prosecutor's office reading, "Defendant pleads guilty to stealing a Dodge touring car, 1919 model, of the value of $\$ 1,000$." A motion for a new trial was granted four months later, and a few weeks thereafter a motion to "nolle" the case was allowed. In No. 16 the defendant was indicted for auto-stealing with a count for operating a motor vehicle without the consent of the owner. He pleaded guilty to the count on March 1, 1920, and was sentenced to the Reformatory. On June 7 a motion for a new trial was allowed, and on June 29, 1920, the case was dismissed "for want of prosecution." Inquiry develops the fact that the owner of the car was not notified of any new trial, and in April, 1921, still believed the original

1 This criminal came before the court again within a few weeks on an indictment for burglary and larceny. The judge granted a motion to discharge, but within a month this man was arrested for another "job" in Elyria, and his operations were temporarily interrupted by a sentence to the penitentiary by the Lorain County Court.

2 No. 19017 in the Common Pleas Court, a 1920 case, illustrates the slipshod methods which damage the prestige of the court. The defendant was convicted of incest with his fifteen-year-old sister-in-law, and the testimony was that he had cohabited with her many times. It is reported that he had confessed his guilt to the officers before trial. On November 5 he was sentenced to the penitentiary, and later on the same day a motion for a new trial was filed. On November 12 the motion was allowed, a plea of guilty to assault and battery accepted, and the defendant sentenced to thirty days in the workhouse. The Humane Society, which had charge of the child, was not notified of this action and learned of it only by examining the court record. 
sentence was executed. The following note by Assistant Prosecutor Corrigan is the only explanation of record:

"This case was called for trial by Judge Kennedy by mistake of the prosecutor's office. The wrong witnesses were subpœnaed. I stated to the court this fact and requested a continuance until the next day, at which time I would be ready for trial. The request was refused and the court peremptorily dismissed the defendant. There was no trial. No jury was impanelled."

Six defendants received a "bench parole" after new trial grantedfive from Judge Cull and one from Judge F. E. Stevens or by Judge Powell for Judge Stevens. In one of Judge Cull's cases the defendant had pleaded guilty and then was granted a "new trial." One gets the impression in some of these cases that the judges, believing the defendants entitled to probation, use the device of granting a new trial to get them out of the Reformatory. Then, by a fresh plea of guilty, new sentence, and "bench parole," the desired result is accomplished. While this procedure in the hands of the two particular judges is not likely to be abused, there should be a definite rule against it. The general use of the new trial for this purpose might easily disrupt the entire penal law of Ohio and make the judges a target of continuous pressure and solicitation.

\section{Clear Policy Recommended}

It is time for the judges of the Common Pleas Court ${ }^{1}$ "to formulate a clear policy regarding new trials. The large number indicates-(a) poor quality of jurors; (b) weak or befogged charges by judges to the juries; (c) rearrangements to conform to the conscience of particular judges, but not to the law; (d) yielding to solicitation of the defendant's lawyer or relatives. A trial is not only an expense to the county, but, as has already been seen, it is a difficult matter to bring an accused as far as trial on the indictment. The steps in the administration of justice need drastic curtailing and not extension by a fictitious use of a new trial. The ends of justice will be served by confining this motion strictly within its legitimate scope.

${ }^{1}$ On account of the state of the records, a study of motions for new trials in the police court is extremely difficult. Moreover, such motions are relatively rare because of the scarcity of jury trials in that court. Where a judge tries without jury, he will not usually admit error in his own rulings, since he would not have made the rulings unless he believed them to be correct. New trials are, however, sometimes granted in this court by the judges, and where this is done, the considerations applicable to the Common Pleas Court apply with added force because of the cloudy records. Complete deception of complainants and public may be accomplished by the new trial in the Municipal Court. 


\section{CHAPTER $\mathrm{X}$}

\section{PERJURY}

\section{Meaning of the McGannon Trial}

FTER the second trial of Judge McGannon for the murder of A Harold Kagy, the air was filled with observations that a look behind the scenes in this case would reveal the whole trouble with Cleveland justice. This, of course, could not be so, since the trial of a Chief Justice for second degree murder, in the glare of publicity, is not a typical case in any administration of justice. In order really to learn about the system, it is far more helpful to watch the experienced "dip" or "big-job" man darting in and out of the net.

Through the effective work of Special Prosecutor William L. David in securing convictions for perjury, including that of Judge McGannon, we now know for certain that at the bottom of the second McGannon trial lay a something older than the written history of man-false testimony. Instead of secret powerful influences, we find the familiar story of perjury induced by love, hope of gain, and fear of destitution. Nevertheless, in his exposure of wholesale perjury Mr. David is also revealing one of the real weaknesses of the Cleveland system.

Those familiar with the administration of justice in Cleveland would probably agree that in the trials for the murder of Harold Kagy, Cleveland is paying the penalty in disgrace for its apathy toward the crime of perjury. In the second McGannon trial the court appeared helpless and prostrate before palpable perjury. ${ }^{1}$ Criticism of the presiding judge for weak handling of the case is unavoidable. Miss May Neely, "star" witness for the State, had made a most detailed disclosure at the first trial, but at the second trial refused to testify, claiming privilege from self-incrimination. The attitude of this witness made a farce of the procedure of justice. Her answers to simple questions as to what she observed on the night of the killing consisted largely in unresponsive expostulations that "Judge McGannon did not kill Harold Kagy," and in parroting the formula, "I refuse to answer on the ground that it would tend to either disgrace or incriminate me." Puzzled as to how

${ }^{1}$ After the trial the judge who presided is reported to have expressed his opinion to the Bar Association that perjury had been committed. 
the reply to simple questions as to what she saw could incriminate the witness, the judge asked her to explain to him privately the reasons for such a position. After this private explanation the judge supported Miss Neely whenever she refused to reply. However, he allowed the prosecuting attorney to examine Miss Neely fully in the absence of the jury, during which Miss Neely testified that she had told the truth at the first trial. It is manifest that the private explanation to Judge Powell was to the effect that the witness perjured herself at the first trial, since no other excuse would cover a refusal to answer the questions put to her. The situation then apparently became one where a witness informally tells a judge that she lied in her previous testimony, but under oath says that she told the truth. Under these circumstances a court sensitive of its position would have known how to deal with such a witness, even if not roused to action by her attitude earlier in the case.

The fact that Judge Powell did not vindicate the dignity of the court is typical of the general attitude toward perjury. Lawyers and judges tell of cases in which witnesses admitted perjury, but nothing was done. "The average witness has no respect for his oath," says a former Common Pleas judge; "in three out of five cases, civil or criminal, the judges and lawyers know some of the witnesses lied."

\section{Laxness in Punishing Offenses Against Justice}

The statistics for the Common Pleas cases begun in 1919 yield impressive evidence of this callousness toward corruption of the court's process. Out of more than 3,000 cases, only 27 were for offenses against public justice, of which 20 were bribery and 7 perjury. This was probably an unusually large number of such cases because of the indictments returned by the special grand jury in 1919. In view of the firm conviction of the bench and bar that perjury and subornation of perjury are common, this showing of less than 1 per cent. charged with such crimes is significant. Even these cases were disposed of as follows:

No bill by grand jury

Dismissed for want of prosecution $\quad 12$

"Nolled" on all counts 7

Acquitted by jury 3

Pleaded guilty 1

Convicted by jury 1

Total dispositions $\quad \frac{27}{27}$

Total found or pleaded guilty $\quad 2$

"Bench parole" 1

Total punished $\cdot \frac{1}{1}$ 
Behind the McGannon trial, therefore, is a community which recognizes the prevalence of crimes against public justice but seeks to vindicate the law in only a handful of cases in a year for such offenses and allows all but one offender to escape. ${ }^{1}$

\section{RECOMMENDATIONS}

The attitude of the courts and public toward this kind of offense is not induced wholly by indifference, however. The perjury statute, G. C., Sec. 12842 , provides as a penalty imprisonment in the penitentiary "not less than one year nor more than ten years." Undoubtedly the severity of this statute is a partial explanation of the paralysis of its enforcement.

The statutes relating to the giving and obtaining of false testimony should be amended in the penalty clause so that a judge could impose a severe fine or a workhouse sentence. Following this, an active campaign against perjury in civil and criminal actions would upset the old tradition and replace it with a wholesome respect for an oath. One judge has suggested a special prosecutor to handle perjury complaints alone. The vigor and success of Special Prosecutor David has opened the way for the new tradition. The campaign should not stop with the witnesses, however, but should reach beyond to the lawyers responsible for their offense. In this respect the Cleveland Bar Association has an imperative duty and opportunity. In the last analysis, however, the judges cannot delegate their responsibility to campaigns and prosecutors. Alert and strong judges, jealous of the sanctity of their court, constitute the only lasting insurance against the practice of perjury.

2 The drugged state of the public conscience is indicated by Petition No. 188262, filed by one of those indicted in the McGannon perjury investigation against Judge McGannon for balance due for services "in influencing Mary Neely to change her attitude in her testimony in a law-suit wherein he was charged with murder. * * * " An attempt was made to withdraw this petition upon the indictment of the petitioner for the crime set out in his own petition. 


\section{CHAPTER XI}

\section{JURIES}

\section{General Dissatisfaction}

T WE service performed by juries does not lend itself to appraisal by the statistical method. Without knowing the facts in each case one is not able to conclude whether an acquittal, disagreement, conviction, or verdict was or was not justified. Even if the facts are known, it might well be that reasonable men differ in the inferences to be drawn from such facts. Since it is both impossible and undesirable to retry cases in this survey, one is forced to rely upon opinion evidence as to the quality of service rendered by jurors in Cuyahoga County.

The testimony of judges and lawyers is almost unanimous on the point of dissatisfaction with juries. "I have held court here two months and have never seen a business man on one of my juries," an out-of-town judge is quoted as saying after serving an assignment to Cuyahoga County. "Jurors recruited from the caverns of Ali Baba in the desert," remarked the oldest judge on the bench, with the hearty approbation of a large audience of lawyers.

We have already observed the large percentage of convictions set aside principally because of the poor work of juries. Although no new trial may be granted for error in acquitting a defendant, we may assume that the average jury errs much more on the side of leniency than severity. The community has probably suffered considerably because of this tendency, in view of the fact that acquittals have increased 600 per cent. since 1914. Juries are blamed for the large number of disagreements during the January, 1921, term of the Common Pleas Court. Upon receiving a surprising verdict of acquittal the judge who presided at the trial is quoted as observing to the jury that "it is apparently now lawful to attack a man with an axe, provided the blunt side only is used."

\section{History}

In judging the operation of the jury system, its history in Cuyahoga County should be considered. There is no doubt that opportunities for corruption and actual dishonesty have greatly decreased in recent 
years. Lawyers tell the story of a long fight between counsel for the great public service corporations and the personal injury attorneys, in which the jury system was debauched by campaigns for the allegiance of enough jurors to insure victory at the ensuing trials. In those days the jury commissioners made up lists of jurors from names submitted by various persons so that it was a relatively easy matter for an influential corporation or a tort lawyer in large practice to secure picked men on the jury lists. Then in some mysterious manner these names were drawn from the wheel. In the ten-year period from 1905 to 1915 , out of a total of 11,126 names placed in the jury wheel, 386 names appeared a total of 2,317 times, or an average of six times each. In the course of the ten years 5,489 names were drawn from the wheel and 388 names were drawn 1,923 times, or nearly 40 per cent. of the total drawn. "It is entirely safe to say, however, that if the drawings had been left to chance, as the law intends, it would have been impossible to have drawn out so many repeaters."

\section{The Present System}

During the past few years the system has been changed so that many of the glaring defects have been obviated. Under the present method, when the court instructs the jury commissioners to secure a certain number of jurors' names to be placed in the wheel, the commissioners make a rough estimate of the number necessary to call in order to qualify the number requested. The commissioners then roughly divide the total which they must call into the number of electors, and use the quotient as a key number. Thus, if the presiding judge requests 3,500 names for a term, the jury commissioners estimate that it would take 10,000 names to qualify this number, and dividing 10,000 into the total number of electors they secure, for example, the key number $20 .^{2}$ The commissioners then take every twentieth name upon the polling list, and send out a form letter to each name and address checked, asking the addressee to report for examination upon a certain date. Next occurs the first examination of prospective jurors by both commissioners, which proceeds until at least 3,500 names are accepted. The list of those accepted is then certified to the clerk of courts and the list is spread on the journal of the court. The clerk copies the list on slips of paper, and in the

1 The Municipal Bulletin, January, 1916, pages 3 to 6.

${ }^{2}$ Rule 23 (b) requires that the court designate a key number, but owing to the necessity of securing names from each ward in proportion to its population, the commissioners have adopted their own method of securing a key number. 
presence of the jury commissioners the slips are placed in the wheel, the wheel locked, and the key given to the presiding judge, from whom the clerk must get it each time a jury is required to be drawn. Formerly the custody of the key, as well as of the wheel, was given to the clerk, but the change was made when the system was reformed a few years ago. ${ }^{1}$

The names once placed in the jury wheel become the sole source of petit juries in both civil and criminal cases, and to some extent of grand juries. The drawings are made by the clerk and sheriff. Every other week the presiding judge orders that a certain number of names be drawn from the wheel as petit jurors, and for each term the presiding judge of the criminal division orders a number of names to be drawn for grand jurors. Separate drawings are made for juries in first degree murder cases, and in such cases the venire must be returned at least fifteen days before the date set for trial. When the original is returned, the clerk draws an alias venire without further order of the court, and the alias is composed of two names for every one not found on the original venire. The alias is returnable forthwith, and both original and alias are served on the defendant and his attorney three full days before the trial. If a jury for the first degree murder trial cannot be secured from the original and the alias, the judge issues further orders until the jury is complete.

In the case of petit jurors, exclusive of first degree murder cases, service is made by letter postpaid and the sheriff's return is stamped upon a paper containing the entire list. . In murder cases and for grand juries the sheriff actually serves summonses.

The petit jurors summoned by letter are expected to serve unless excused by the presiding judge. Those who answer the letter and are not excused are sent to the rooms of the jury bailiff, who assigns them to various cases as the need arises. In the case of the grand jury, "if the number is insufficient, the court may issue a special venire to the sheriff and command him to summon the persons named therein and to attend forthwith as grand jurors" (Sec. 11431). Since the original venire drawn from the wheel for grand juries rarely produces enough qualified men, the judge usually selects additional persons, often a majority of the talesmen.

This is the system under which Cleveland juries have been recently selected. Although the personnel of the grand jury is largely dependent upon the presiding judge, this institution is so much a part of the prose-

${ }^{1}$ To the retiring clerk, Mr. Haserodt, much credit is due for the improved operation of the system. 
cuting machinery that it is considered in the study of the prosecutor's office. With respect to petit juries, improvements over the older system are: first, substitution of chance for selection upon solicitation; second, reduction of length of service from a term to two weeks, thus reducing the hardship on individual citizens and the opportunities for corruption; third, unlocking the door to the room in which the drawings take place.

\section{WEAKNESSES}

The fundamental weakness in the present jury system is inherent in all attempts to make trial by jury work in a great modern city. Personal service by the sheriff or his deputies upon thousands of jurors during the course of the year is impracticable and expensive, and compelling attendance by mailed summonses is difficult. Indeed, the late Judge Foran, in his report on the selection of jurors dated February 28,1921 , doubts whether the present method is a proper compliance with G. C., Sec. 11297-1, providing for substituted service by mail, even granting the validity and effectiveness of that statute. ${ }^{1}$ The suggestion that the number of jurors be cut down by extending the term of service for the individual juror again increases the difficulty of securing fit men who can sacrifice so much time from commercial and industrial pursuits. Even with only two weeks to serve, the number of people who are excused by the jury commissioners and the court is disproportionately large.

Another weakness of the system is that there still remains some small margin of discretion in the selection of jurors which is vested in a minor official; namely, the jury bailiff. When a jury is called for, the jury bailiff selects a group from among the idle jurors in his room and sends them down. ${ }^{2}$ No matter how honest a jury bailiff may be, this situation will create suspicions which tend to undermine respect for justice. Lawyers complain that in trying against a public service corporation, for instance, they sometimes find a disproportionate number of its employees on the jury, and, vice versa, in trying against some of the ablest tort lawyers, they find a surprisingly large number of jurors

${ }^{1}$ Judge Foran aptly quotes "Henry IV":

$$
\begin{aligned}
& \text { "Glendower: 'I can call spirits from the } \\
& \text { "Hasty deep.' } \\
& \text { "Hotspur: 'Why, so can I, or so can any } \\
& \text { man;--but will they come when } \\
& \text { you do call for them?" }
\end{aligned}
$$

${ }^{2}$ Rule 23 (9) of the Common Pleas Court directs the jury bailiff to assign jurors in the order in which they are drawn, but apparently practical difficulties have forced the breakdown of this rule. 
of the same nationality as the foreign plaintiff. Whether such suspicions are founded upon mere coincidence, or exist only in imagination, the remedy is simple. The names of all jurors waiting to be called should be placed in a jury wheel in the assignment room or in some other public place, and, as new juries are called for, should be drawn from the wheel in the presence of attorneys for all the parties. Some jurors might thus serve more continually than others, but this objection is outweighed by the fact that a feeling of absolute fairness would be created.

The jury commissioners are commanded by G. C., Sec. 11423, to "select such number of judicious and discreet persons, having the qualifications of electors of such county, as the court may direct," and further that "no person shall be selected who shall not, in the judgment of such commissioners, be competent in every respect to serve as a juror." It will thus be seen that, except for certain statutory exemptions, the commissioners are unlimited except as to electors, and in Ohio there is not even a literacy test for electors. To the commissioners falls the task of weeding out of the electors great numbers of foreignspeaking citizens, besides ignorant and shiftless native whites and blacks. Even if the commissioners were well-paid officers and men of large ability, which they are not, the task could scarcely be performed with thoroughness. ${ }^{1}$ Hitherto the office of commissioner has been a political trinket, yielding only $\$ 300$ per year. The Common Pleas judges made a wise change this spring by appointing as commissioners the two assignment commissioners, Virgil A. Dustin and Archie J. Kennel, both able men. This step should be productive of some improvement.

\section{First Examination of Jurors}

The failure of the jury system, however, has a deeper cause than any schematic defect. In Cleveland, as in many other large cities, most citizens of means or intelligence avoid service. This avoidance has become traditional, so that it is a kind of mild disgrace for a socalled "respectable citizen" to allow himself to be caught for jury service-like being swindled, for instance. Table 26 shows the results of the letters and preliminary examination by the jury commissioners for

${ }^{1}$ In Boston the preliminary examination is made by the police in a house-tohouse canvass. Since in Massachusetts naturalized citizens must be able to read English, the police need only eliminate the morally and physically unfit. Although a policeman is hardly an ideal judge of a juror's qualifications, he has only his own precinct to canvass, which makes the task relatively easier. 
the January term, 1921. For purpose of comparison, Wards 11 and 14, largely of shifting white, foreign, and negro population, and the recognized prosperous suburbs of Cleveland Heights, Lakewood, East Cleveland, and Shaker Heights are given separately. The reasons given for the failure to qualify on this examination are those recorded by the commissioners, although some rearrangement has been necessary in order to assimilate kindred excuses into as few classes as possible. Credit is due Thomas Gafney and Gibson H. Robinson, the retiring commissioners, and William H. Ence, their bailiff, for keeping such a record. No record of the kind is available for prior terms.

TABLE 26.-REASONS FOR FAILURE TO QUALIFY OF 6,520 PERSONS CALLED FOR JURY SERVICE, CLASSIFIED BY TYPICAL RESIDENTIAL SECTIONS

\begin{tabular}{|c|c|c|c|c|c|c|c|}
\hline $\begin{array}{l}\text { Reasons for failure to } \\
\text { qualify }\end{array}$ & Totals & Ward & $\begin{array}{l}\text { Ward } \\
14^{2}\end{array}$ & $\begin{array}{l}\text { Cleve- } \\
\text { land } \\
\text { Heights }\end{array}$ & $\begin{array}{l}\text { Lake- } \\
\text { wood }\end{array}$ & $\begin{array}{l}\text { East } \\
\text { Cleve- } \\
\text { land }\end{array}$ & $\begin{array}{l}\text { Shaker } \\
\text { Heights }\end{array}$ \\
\hline $\begin{array}{l}\text { 1. Letters returned } \\
\text { 2. No answer } \\
\text { 3. Illness, etc. } \\
\text { 4. Physical disability } \\
\text { 5. Literacy and language } \\
\text { 6. Military order, con- } \\
\text { tributing to } \\
\text { 7. Business } \\
\text { 8. Home duties } \\
\text { 9. Financial } \\
\text { 10. Occupational } \\
\text { 11. Age } \\
\text { 12. Served recently } \\
\text { 13. Away or late } \\
\text { 14. Deceased } \\
\text { 15. No explanation } \\
\text { 16. Serve later } \\
\text { 17. By judge } \\
\text { 18. In reformatory } \\
\text { 19. In jail } \\
\text { 20. In penitentiary } \\
\text { 21. Letterfrom New York } \\
\text { 22. Not citizen } \\
\text { 23. Paroled } \\
\text { 24. Too busy }\end{array}$ & $\begin{array}{r}857 \\
1,826 \\
565 \\
220 \\
919 \\
\\
16 \\
89 \\
457 \\
7 \\
634 \\
265 \\
269 \\
285 \\
33 \\
43 \\
11 \\
16 \\
1 \\
1 \\
2 \\
\\
1 \\
1 \\
1 \\
1\end{array}$ & $\begin{array}{r}48 \\
43 \\
15 \\
4 \\
32 \\
\\
.2 \\
10 \\
.7 \\
7 \\
1 \\
7 \\
2 \\
2 \\
\ldots \\
\ldots \\
. \\
1 \\
\ldots\end{array}$ & 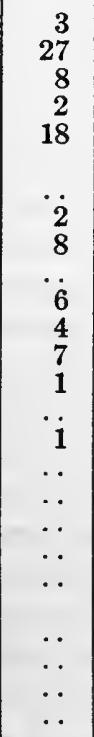 & $\begin{array}{r}7 \\
60 \\
10 \\
5 \\
\ldots \\
\\
2 \\
3 \\
18 \\
19 \\
7 \\
5 \\
13 \\
.2 \\
\ldots \\
\ldots \\
\ldots \\
\ldots \\
\ldots\end{array}$ & $\begin{array}{r}8 \\
71 \\
26 \\
3 \\
6 \\
\\
1 \\
2 \\
27 \\
15 \\
11 \\
4 \\
17^{3} \\
\ldots \\
\ldots \\
0 \\
1 \\
\ldots \\
\ldots \\
\ldots\end{array}$ & $\begin{array}{r}9 \\
30 \\
15 \\
2 \\
\ldots \\
1 \\
1 \\
18 \\
\cdots \\
4 \\
5 \\
1 \\
11 \\
\ldots \\
\ldots \\
\ldots \\
\cdots \\
\ldots \\
\ldots \\
\ldots \\
\ldots \\
\ldots\end{array}$ & $\begin{array}{c}\because \\
6 \\
\ddot{6} \\
\cdots \\
\cdots \\
\cdots \\
\cdots \\
\cdots \\
\cdots \\
\cdots \\
\cdots \\
\cdots \\
\cdots\end{array}$ \\
\hline $\begin{array}{l}\text { 25. Total not qualifying } \\
\text { 26. Total qualifying }\end{array}$ & $\begin{array}{l}6,520 \\
3,968 \\
\end{array}$ & $\begin{array}{r}181 \\
74 \\
\end{array}$ & $\begin{array}{l}87 \\
58\end{array}$ & $\begin{array}{r}151 \\
75\end{array}$ & $\begin{array}{l}192 \\
128\end{array}$ & $\begin{array}{l}97 \\
69 \\
\end{array}$ & $\begin{array}{r}29 \\
5\end{array}$ \\
\hline 27. Total letters sent & 10,488 & 255 & 145 & 226 & 320 & 166 & 34 \\
\hline
\end{tabular}

1 Colored and shifting.

${ }^{2}$ Foreign-Poles, other Slavs, and Greeks.

${ }^{3}$ Majority were late. 
It will be observed that in the four better sections, about 37 per cent. of those who did not qualify simply ignored the summons,-No. 2, "no answer,"-as compared with 28 per cent. for the total-including these suburbs, and 26 per cent. for Wards 11 and 14. In other words, those whose ignorance might excuse them for not responding made a much better showing than the "substantial citizens," who knew too much to heed the summons. It also seems that the exclusive suburbs are much more unhealthful than the poor districts,-No. 3, "illness, etc.,"-since in those sections 12 per cent. of those who did not qualify were excused because of illness, compared with 8.7 per cent. of the total of Wards 11 and 14. Illness is reported proportionately almost 50 per cent. more often in the most desirable residential districts.

In the four suburbs 9 per cent. of those who did not qualify reported that they were away at the time of the summons,-No. 13, "away or late,"-or received it too late, as compared with 4.4 per cent. of the total, and 3 per cent. in Wards 11 and 14 . Since the shifting population in the suburbs is much smaller than in the poorer sections, one may conclude that the excess of excuses of this type represents winter vacations, business trips, or subterfuge.

No conclusion can be drawn from the increase of "home duties" excuses-No. 8-in the suburbs, because most of those excused for this reason were women, and women electors were not called proportionately from the different sections. This was due to the fact that two polling lists were used by the commissioners-an old one before the suffrage amendment was passed, and the new one for 1920. It is to be hoped that women from these and kindred sections will not shirk their jury duties as their husbands and fathers have done. Such women, on the whole, have more leisure than any other group of citizens, and, as a rule, they possess the qualifications of good jurors. Some judges and lawyers already profess to see a higher grade of juries owing to the advent of women. Others, however, feel that the women jurors who have been serving are generally not noticeably superior to male jurors and that their presence has brought neither harm nor benefit to the system.

It should be observed that literacy and language disqualifications were practically unknown in the selected suburbs. Also, it is worth noting that in the suburbs only 6.2 per cent. of those not qualifying could not be located, compared with the general average of 13.1 per cent. "Business," No. 7, and "financial," No. 9, represent those excused because their presence was vital to their business, or because they could not afford the financial loss involved in jury service. A large proportion of the "business" excuses were from men operating a "one- 
man" business, or if in a country district, a "one-man" farm. A favorite excuse in the rural settlements was that the notice was received "too late,"-No. 13,-reflecting the slowness of the midwinter mails in the country, or the tendency on the part of farmers to call periodically at the local post-office.

"Occupational," No. 10, includes chiefly those excused because employed in occupations exempted by the statute, G. C., Sec. 11444public officers, clergymen, priests, physicians, police, and firemen. Most of this group were public employees of various kinds.

It is to be noticed that only 16 were excused because "contributing to a military order"-No. 6. Probably among those who failed to answer were additional contributors to such orders, who held this exemption as a secondary defense in case of trouble caused by ignoring the summons. Although the members contributing to military societies number in all only $600,{ }^{1}$ this bizarre method of escape does much harm to the public morale in performing jury service. In effect, it means that influential citizens may purchase immunity from an important civic duty at five dollars a head.

Present statutes exempting contributing members are G. C., Sec. 5195 , in substance the original provision, and G. C., Sec. 11444, where contributing members have been recently added as specific exemptions. The section first cited also exempts such members from "labor on the public highways," thus adding a quaint touch of the mediæval "corvee" to the distinction." This exemption reveals somewhat the decay of democracy. Originally Ohio frontier conditions required that all ablebodied white male citizens be made part of the militia. Then, as conditions settled, a system of volunteer companies developed. In 1857 the members of such companies were excused from jury service or service on roads, 54 O. L. 49-50, Sec. 11. Then came the Civil War draft laws, establishing the principle that immunity from military service might be purchased. Shortly thereafter "contributing members" were added to the personnel of the independent companies, and these noncombatants ${ }^{3}$ shared in the immunities granted to the others. This anti-

1 Four societies, numbering 150 members each.

${ }^{2}$ It exists, however, in rural districts of Ohio.

3 The most recent statute exposes the contributing member to the possibility of performing military duty within the county limits. It is doubtful whether this remote contingency will restrain the jury slackers as a whole from continuing to avail themselves of the exemption. The previous statute, which imposed no obligation on contributing members beyond the payment of a fee, had been held unconstitutional. Hamann v. Heekin, 88 O. S. 207 (1913). 
democratic exemption ought to be abolished, just as the principle was abolished in the draft laws of the Great War.

\section{The Second Examination of Jurors}

In addition to the examination before the commissioners, a second opportunity for jurors to escape is granted when qualified jurors are drawn from the wheel and summoned finally for service by mail. The

TABLE 27.-RESULTS OF SECOND EXAMINATION OF JURORS, CLASSIFIED BY WARDS AND OTHER POLITICAL SUBDIVISIONS

\begin{tabular}{|c|c|c|c|c|c|c|c|c|c|}
\hline Ward & $\begin{array}{l}\text { Total } \\
\text { serv- } \\
\text { ing }\end{array}$ & $\begin{array}{c}\text { Served } \\
\text { regu- } \\
\text { larly }\end{array}$ & $\begin{array}{c}\text { Post- } \\
\text { poned } \\
\text { and } \\
\text { served }\end{array}$ & $\mid \begin{array}{c}\text { Served } \\
\text { part } \\
\text { time } \\
\text { (ex- } \\
\text { cused } \\
\text { orpost- } \\
\text { poned) }\end{array}$ & $\begin{array}{c}\text { Total } \\
\text { not } \\
\text { serv- } \\
\text { ing }\end{array}$ & $\begin{array}{l}\text { Ex- } \\
\text { cused }\end{array}$ & $\begin{array}{l}\text { Post- } \\
\text { poned, } \\
\text { never } \\
\text { served }\end{array}$ & $\begin{array}{l}\text { Not } \\
\text { found }\end{array}$ & $\begin{array}{l}\text { No } \\
\text { record }\end{array}$ \\
\hline $\begin{array}{c}1 \\
2 \\
3 \\
4 \\
5 \\
6 \\
7 \\
8 \\
9 \\
10 \\
11 \\
12 \\
13 \\
14 \\
15 \\
16 \\
17 \\
18 \\
19 \\
20 \\
21 \\
22 \\
23 \\
24 \\
25 \\
26 \\
\text { Drstricts } \\
\text { East Cleveland } \\
\text { Lakewood } \\
\text { Cleveland Heights } \\
\text { Shaker Heights } \\
\text { Miscellaneous } \\
\text { Not located in any } \\
\text { ward }\end{array}$ & $\begin{array}{r}29 \\
53 \\
40 \\
29 \\
36 \\
108 \\
37 \\
25 \\
24 \\
28 \\
32 \\
16 \\
14 \\
20 \\
66 \\
50 \\
23 \\
37 \\
26 \\
14 \\
26 \\
32 \\
27 \\
51 \\
25 \\
55 \\
31 \\
29 \\
21 \\
1 \\
93 \\
96\end{array}$ & $\begin{array}{l}20 \\
43 \\
39 \\
24 \\
30 \\
92 \\
32 \\
18 \\
19 \\
27 \\
29 \\
13 \\
13 \\
19 \\
53 \\
46 \\
21 \\
32 \\
21 \\
11 \\
22 \\
27 \\
25 \\
43 \\
21 \\
47 \\
25 \\
26 \\
18 \\
1 \\
82 \\
71\end{array}$ & $\begin{array}{r}8 \\
7 \\
1 \\
4 \\
5 \\
13 \\
5 \\
6 \\
5 \\
1 \\
3 \\
3 \\
1 \\
1 \\
10 \\
4 \\
2 \\
5 \\
2 \\
2 \\
3 \\
3 \\
1 \\
8 \\
4 \\
8 \\
6 \\
3 \\
2 \\
10 \\
23\end{array}$ & 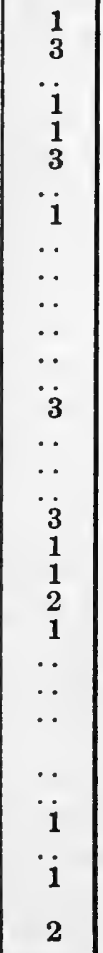 & $\begin{array}{r}5 \\
5 \\
4 \\
4 \\
5 \\
21 \\
8 \\
12 \\
10 \\
8 \\
9 \\
3 \\
3 \\
1 \\
17 \\
14 \\
5 \\
13 \\
10 \\
8 \\
15 \\
10 \\
5 \\
15 \\
14 \\
22 \\
7 \\
10 \\
6 \\
23 \\
46\end{array}$ & $\begin{array}{r}1 \\
3 \\
2 \\
2 \\
2 \\
13 \\
2 \\
5 \\
2 \\
1 \\
\cdots \\
31 \\
92 \\
10 \\
3 \\
6 \\
4 \\
4 \\
6 \\
4 \\
3 \\
7 \\
2 \\
8 \\
2 \\
4 \\
4 \\
11 \\
\\
14\end{array}$ & $\begin{array}{r}2 \\
1 \\
4 \\
0 \\
2 \\
6 \\
2 \\
4 \\
4 \\
4 \\
7 \\
1 \\
1 \\
131 \\
3 \\
1 \\
3 \\
4 \\
3 \\
5 \\
3 \\
5 \\
11 \\
8 \\
5 \\
5 \\
1 \\
6 \\
20\end{array}$ & $\begin{array}{r}1 \\
0 \\
\because 2 \\
1 \\
1 \\
3 \\
3 \\
2 \\
2 \\
1 \\
2 \\
1 \\
1 \\
1 \\
91 \\
2 \\
2 \\
1 \\
2 \\
1 \\
2 \\
2 \\
1 \\
2\end{array}$ & 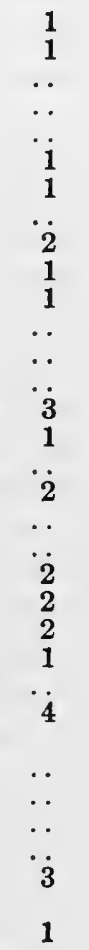 \\
\hline Total & 1,194 & 1,010 & 159 & 25 & 338 & 126 & 132 & 51 & 29 \\
\hline
\end{tabular}


initiated again ignore the letter. Those who respond may present their excuses to the presiding judge. Table 27, compiled from records in the jury commissioners' office, shows the number excused on this second occasion.

Table 28 is a comparison of the total letters sent out, the number who qualified, the number drawn for service, and the number serving

TABLE 28. SUMMARY BY SELECTED RESIDENTIAL DISTRICTS OF THE NUMBERS OF JURORS CALLED, QUALIFIED, AND SERVED

\begin{tabular}{l|r|r|r|r|r}
\hline \hline Residential districts & $\begin{array}{c}\text { Total } \\
\text { letters } \\
\text { sent out }\end{array}$ & $\begin{array}{c}\text { Total } \\
\text { qualified } \\
\text { for service }\end{array}$ & $\begin{array}{r}\text { Total } \\
\text { drawn } \\
\text { for service }\end{array}$ & $\begin{array}{r}\text { Total } \\
\text { served } \\
\text { regularly }\end{array}$ & $\begin{array}{r}\text { Total } \\
\text { served }\end{array}$ \\
\hline Ward 11 & 255 & 74 & 41 & 29 & 32 \\
Ward 14 & 145 & 58 & 21 & 19 & 20 \\
East Cleveland & 166 & 69 & 38 & 25 & 31 \\
Lakewood & 310 & 118 & 39 & 26 & 29 \\
Cleveland Heights & 226 & 75 & 27 & 18 & 21 \\
Shaker Heights & 37 & 5 & 1 & 1 & 1 \\
Total for city & 10,448 & 3,968 & 1,532 & 1,010 & 1,194 \\
\hline
\end{tabular}

regularly and part time. For purposes of comparison, Wards 11 and 14 and the four suburban districts are again listed separately. Of these, Ward 14 makes the best showing, qualifying almost as many as East Cleveland, but showing a higher per cent. serving of those actually drawn.

A summary table of the excuses accepted by the judge is also given (Table 29). This is not classified by wards because some cards were misplaced while tabulating the results and they are not included.

TABLE 29.-REASONS FOR EXCUSING PERSONS FROM JURY SERVICE, JANUARY TERM, 1921 (RECORDS FOR 65 JURORS MISSING)

$\begin{array}{lrlr}\text { Illness } & 40 & \text { Served recently } & 5 \\ \text { Physical disability } & 7 & \text { Away or late } & 11 \\ \text { Literacy and language } & 3 & \text { No explanation } & 18 \\ \text { Contributing member of mili- } & & \text { Too many jurors } & 38 \\ \quad \text { tary society } & 1 & \text { End of term } & 6 \\ \text { Business } & 7 & \text { Miscellaneous } & 1 \\ \text { Home duties } & 11 & \text { Total } & 164 \\ \text { Occupational } & 11 & & \end{array}$

\section{OCCUPATION OF JuRORS}

No record is kept anywhere of the occupation of jurors. Through the courtesy of the presiding judge and the jury bailiff, L. M. Jalos, a 
record was kept for four weeks during April and May, at the request of the survey. This is given in Table 30. The occupations listed are those given by the jurors to the jury bailiff, and therefore probably represent the most optimistic appraisal which a man may place upon his own capacities. It means little if a man calls himself a painter, merchant, superintendent, etc., unless more is known about his specific occupation. An attempt has been made to assimilate kindred occupations into general classes, but the grouping probably does not meet all requirements. If so, separate figures are given for each occupation, so that a regrouping is comparatively easy.

TABLE 30.-THE OCCUPATIONS OF JURORS, APRIL 18-MAY 18, 1921, AS REPORTED BY THEM, BY GROUPS OF RELATED VOCATIONS

\begin{tabular}{|c|c|c|c|c|c|}
\hline & No. & $\begin{array}{c}\text { Per } \\
\text { cent. }\end{array}$ & & No. & $\begin{array}{c}\text { Per } \\
\text { cent. }\end{array}$ \\
\hline Cluass 1. & & & Salesman & 24 & $\cdots$ \\
\hline Executive & 12 & 3.2 & Clerk & 20 & $\ldots$ \\
\hline Office manager & 1 & $\ldots$ & Telephone operator & 2 & . \\
\hline Department manager & 2 & . & Agent & 2 & . \\
\hline Telephone night manager & 1 & . & Secretary & 1 & .. \\
\hline Delivery route manager & 1 & $\ldots$ & Class 6. & & \\
\hline Sales manager & 2 & . & Merchants and tradesmen & 22 & 5.8 \\
\hline President & 1 & . & Merchant & 5 & $\ldots$ \\
\hline Superintendent & 4 & . & Grocer & 7 & . \\
\hline Cluass 2. & & & Butcher & 2 & . \\
\hline Technical and artistic & 10 & 2.6 & Grocery store manager & 1 & . \\
\hline Draftsman & 1 & . & Meat dealer & 1 & . \\
\hline Electrical engineer & 1 & . & Laundryman & 1 & . \\
\hline Civil engineer & 3 & . & Baker & 4 & - \\
\hline Chemist & 1 & . & Barber & 1 & \\
\hline Transportation expert & 了 & . & Class 7. & 3 & 0.8 \\
\hline Artist & 2 & . & Saloon-keeper & 1 & $\ldots$ \\
\hline Designer & 1 & .. & Hotel-keeper & 1 & .. \\
\hline Class 3 . & & & Poolroom proprietor & 1 & .. \\
\hline Contractors & 6 & 1.6 & Class 8. & & \\
\hline Teaming contractor & 2 & . & Domestic & 42 & 11.1 \\
\hline Electrical contractor & 1 & . & At home & 38 & . \\
\hline Building contractor & 2 & . & Nurse & 4 & . \\
\hline Auto livery & 1 & & Class 9. & & \\
\hline Cluass 4. & 6 & 1.6 & Farmer & 8 & 2.1 \\
\hline Insurance agent & 2 & .. & Class 10. & & \\
\hline Real estate agent & 4 & . & Service employees & 20 & 5.3 \\
\hline Class 5. & & & Chauffeur & 4. & . \\
\hline Clerical & 68 & 17.9 & Footman & 1 & . \\
\hline Bookkeeper & 5 & . & Janitor & 1 & . \\
\hline Stenographer & 5 & . & Gardener & 3 & . \\
\hline Cashier & 2 & . & Watchman & 5 & . \\
\hline Accountant & 3 & . & Guard & 1 & . \\
\hline Collector & 1 & .. & Cook & 1 & $\cdots$ \\
\hline Teller & 1 & .. & Porter & 2 & . \\
\hline Claim agent & 1 & .. & Elevator operator & 1 & . \\
\hline Saleslady & 1 & & Furnaceman & 1 & . \\
\hline
\end{tabular}




\begin{tabular}{|c|c|c|c|c|c|}
\hline & No. & $\begin{array}{c}\text { Per } \\
\text { cent. }\end{array}$ & & No. & $\begin{array}{r}\text { Per } \\
\text { cent. }\end{array}$ \\
\hline Class 11. & & & Street-car yardman & 1 & \\
\hline Skilled workers & 30 & 7.9 & Railroad signal block op- & & \\
\hline Painter & 6 & . & erator & 1 & $\cdots$ \\
\hline Carpenter & 16 & . & Telegraph lineman & 1 & . \\
\hline Electrician & 3 & .. & Railroad man & 1 & .. \\
\hline Decorato & 1 & . & Class 17. & & \\
\hline Plumber & 2 & . & Metal workers, repairers, & & \\
\hline Mason & 1 & . & laborers & 85 & 22.4 \\
\hline Enameler & 1 & $\ldots$ & Machine hand & 2 & $\ldots$ \\
\hline Cuass 12. & & & Steel worker & 4 & $\cdots$ \\
\hline Needleworkers & 7 & 1.8 & Pipefitter & 1 & . \\
\hline Furrier & 2 & $\ldots$ & Pattern manufacturer & 1 & . \\
\hline Tailor & 3 & . & Iron chipper & 1 & 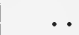 \\
\hline Bushelman & 2 & . & Welder & 1 & . \\
\hline Cuass 13. & & & Assembler & 2 & \\
\hline Special workers & 16 & 4.2 & Iron worker & 3 & \\
\hline Chairmaker & 1 & .. & Temperer & 1 & . \\
\hline Tentmaker & $\overline{1}$ & . & Cable splicer & 1 & 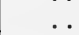 \\
\hline Potter & 1 & . & Sheet-metal worker & 2 & 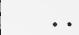 \\
\hline Printer & 6 & .. & Electrical worker & 1 & .. \\
\hline Windowmaker & 1 & .. & Boilermaker & 1 & .. \\
\hline Shade finisher & 1 & .. & Boiler-tube welder & 1 & \\
\hline Artificial limb maker & 1 & . & Rod-mill worker & 1 & . \\
\hline Asbestos worker & 1 & $\ldots$ & Tool grinder & 2 & . \\
\hline Movie operator & 1 & . & Coremaker & 1 & . \\
\hline Cigar manufacturer & 1 & $\ldots$ & Machine operator & 1 & . \\
\hline Grease maker & 1 & . & Car builder & 1 & . \\
\hline Cluass 14. & & & Machine hand & 1 & . \\
\hline Foremen & 5 & 1.3 & Molder & 2 & \\
\hline Shop foreman & 1 & .. & Solderer tinware & 1 & . \\
\hline Dock foreman & 1 & . & Auto-body builder & 1 & \\
\hline Foreman auto works & 1 & . & Elevator erector & 1 & . \\
\hline Barn boss & 1 & . & Machinist & 18 & . \\
\hline Railroad track foreman & 1 & .. & Auto mechanic & 2 & \\
\hline Class 15. & & & Car repairman & 1 & \\
\hline Inspectors, etc. & 11 & 2.9 & Die and toolmaker & 4 & .. \\
\hline Auto inspector & 2 & . & Blacksmith & 1 & . \\
\hline Machinery inspector & 1 & . & Millwright & 3 & \\
\hline Fire inspector & 1 & .. & Galley man, American & & \\
\hline Street railroad inspector & 1 & $\ldots$ & Express & 1 & . \\
\hline Tool inspector & 1 & . & Teamster & 4 & .. \\
\hline Car inspector & 1 & . & Stonecutter & 1 & .. \\
\hline Estimator & 1 & . & Woodworker & 1 & . \\
\hline Stock-keeper & 3 & . & Toolmaker & 1 & . \\
\hline Class 16. & & & Truck driver & 4 & \\
\hline $\begin{array}{c}\text { Engineers, conductors, and } \\
\text { allied occupations }\end{array}$ & 27 & 7.1 & $\begin{array}{l}\text { Laborers } \\
\text { CuAss } 18 .\end{array}$ & 10 & \\
\hline Railroad switchman & 5 & . & Sailor & 1 & 0.2 \\
\hline Street-car conductor & 5 & . & Cluass 19 & & \\
\hline Engineer & $\mathbf{5}$ & . & Retired & 1 & 0.2 \\
\hline Fireman & 3 & . & & & \\
\hline Stationary engineer & 4 & 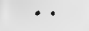 & & & \\
\hline Brakeman & 1 & & Grand total & 380 & 100.0 \\
\hline
\end{tabular}


It may be said that the list of occupations, even allowing for some inflation natural to man's desire for dignity, fairly represents the bulk of Cleveland's population. This is probably true, but a system designed to select for the difficult task of administering justice "judicious and discreet persons, competent in every respect to serve as jurors," does ill to produce even a cross-section of a great unassimilated industrial population. The qualifications for a competent juror are high.

Experience shows that the best juror is a man of integrity and intelligence, with some education and an unwarped outlook on life. Such men are not usually found among the lowest or the highest walks of life. Those who have not the ability to rise to some extent, or are embittered by the experience of poverty, make equally bad jurors with the very rich whose property interests tend to bias judgment. There is little danger to the jury system from the latter group, however, because it is rarely represented on juries, but the former presents a serious problem.

\section{Haven of the Unemployed}

The winter of 1920-21 coincided with the greatest unemployment since 1914. It is to be assumed that in general, when a factory reduces its force, the least competent workers are laid off first. The action of the presiding judge of the January term, 1921, in permitting jurors to serve an additional two weeks if they desired, and longer on permission of the court, gives some gauge for ascertaining the number of men who preferred $\$ 2$ a day on the jury to unemployment. During that term 77 jurors elected to serve more than the regular two weeks. ${ }^{1}$ The following list shows the "repeaters" on petit juries in the January term, 1921:

28 served 3 weeks each, equalling 42 juror terms.

9 served 4 weeks each, equalling 18 juror terms.

40 served 12 weeks each, equalling 240 juror terms.

77 jurors served 300 juror terms.

The total number of jurors who actually served during this term was 1,194 , leaving a balance of 1,117 jurors who served two weeks and less. Assuming that these jurors served full two-week terms each, we find that 77 jurors (6.4 per cent.) served more than one-fifth of the time, and 40 jurors ( 3.3 per cent.), nearly one-sixth of the total time! A few of these repeaters may have been retired men who enjoy the experience, but, on the whole, they consisted of men who were tiding over a period of unemployment by attempting to perform one of the most difficult tasks of democratic government at $\$ 2$ per day.

1 From a list supplied by the County Clerk's office. 


\section{Recommendations}

Trial by jury is guaranteed by the Ohio constitution, and it is inconceivable that the people of Ohio would desire to abolish jury trial even if an amendment could be obtained. As it is now working, however, in large cities like Cleveland, justice in particular cases is being poorly administered and the dignity of the courts generally impaired. The system will not work satisfactorily until the intelligent citizens of the community assume a different attitude towards their obligations of citizenship. No remedy, therefore, will be effective unless the fundamental attitude is changed. It is a platitude, but nevertheless true, that a democracy worth the greatest sacrifices in war is equally worth preserving in peace. Something drastic should be done to dispel the scorn for jury service which has been collecting for many years. The most effective educational campaign might be started at once by an imposing list of prominent and busy citizens of Cleveland pledging themselves to perform jury service when called upon. Noblesse oblige!

Other steps to be undertaken are: First, the maintenance in office of jury commissioners who take their work with the utmost seriousness, and not as in the past, as a part-time recreation of minor politicians. The appointment of the assignment clerks to the commission should bring about a change for the better, but the court should always maintain close touch with the methods pursued. Real discretion exercised by the jury commissioners in the matter of excluding jurors who have no qualifications except indigence, and in firmly refusing to accept excuses made for the occasion, would certainly result in improving the personnel of the juries. Second, the rules of the court and the statutes of the State should be so amended as to insure the validity of service by mail, and the practice maintained in strict conformity with the law. A few fines for contempt of court for failing to respond to mailed summonses would quickly put an end to the present wholesale ignoring of the court's call. Third, the legislature should be asked to abolish the exemption of contributing members of military societies. Fourth, discretion now resting in the jury bailiff with respect to assigning idle jurors to cases should be eliminated and open selection by chance substituted therefor. Fifth, the adoption of the rule recommended by the late Judge Foran providing that judges shall not excuse any citizen called for jury duty except in case of death in his immediate family, or in case of great emergency, where the juror is likely to sustain a serious or irreparable loss if required to perform jury service. 


\section{CHAPTER XII}

\section{SUMMARY OF RECOMMENDATIONS}

\section{Organization and System}

\section{$T$}

HE criminal law in Cleveland is administered by three courts. The Court of Appeals reviews cases for errors of law only, and for our purposes may be dismissed from further consideration with the statement that it performs its special duty satisfactorily and gives rise to no particular difficulty. The Court of Common Pleas is the great trial court, with criminal jurisdiction over felonies, that is, over the more serious offenses. The Municipal Court on its criminal side has jurisdiction over misdemeanors, that is, over the lesser offenses, over violations of city ordinances, and over the preliminary hearings in felony cases.

While a lawyer from Mars might fail to understand the reason for this sort of double-decked jurisdiction, based on the more or less arbitrary differentiation between cases in which the punishment may be imprisonment in the penitentiary and those in which such punishment is not lawful, and might wonder why an intelligent community did not marshal and concentrate in a single court all its forces for combating the criminal in order to eliminate the waste and loss of power caused by duplication of effort and overlapping of functions, yet it must be remembered that this dual situation is the result of historic development. Prior to the growth of great industrial cities, when the population was homogeneous and lived in rural communities, serious crimes were rare in occurrence and the business could be attended to by the judges who went around the circuit holding court for a term, that is, for a week or so, in the several county-seats. To provide for a prompt determination of petty offenses and to afford an immediate preliminary hearing in serious cases the system of local courts grew up. The jurisdiction of the lower court was expanded to keep pace with the community it served, and the pressure of business extended the term of the higher court until it was obliged to hold sittings through the year and became a localized court. The final result is two courts substantially alike from any organic point of view, operating entirely independently in the same community. This anom- 
alous condition, be it understood, is not the result of evil schemings by any persons or groups of persons: it has been produced by a series of successive developments, each one of which seemed at the time wise and calculated to promote the ends of justice.

These two courts embody within themselves many lessons learned from experience, and, while they unquestionably need improvement to conform to the changed conditions of the city's life, care must be exercised in any adaptation or merger of their functions not to lose the elements of strength which they contain. Double trials on the facts, which are the greatest curse of the double system of courts, have already been eliminated in Cleveland-a forward step which Massachusetts, for example, has never been able to accomplish despite repeated efforts by the bar and judicature commissions.

The Municipal Court possesses a good form of organization. The act which created this court and provided for a Chief Justice with power to order and arrange the business of the court was hailed at the time of its adoption as a great constructive improvement by the most competent legal critics. It still affords a machinery for the efficient dispatch of business far superior to that possessed by the majority of American courts. There is a tendency to decry this form of organization because one Chief Justice lacked the character to utilize it to its best advantage. This is putting the cart before the horse. The requirements for the successful administration of justice are three: sound controlling ideas, sound organization, and sound men. A breakdown proves that one of these conditions has been violated, but it does not follow that the other two were at fault. Any radical alteration (other than that later suggested) of the present form of organization of the Municipal Court would be a step backward and would throw away an accomplishment of which Cleveland should be proud.

The Common Pleas Court, though lacking as excellent an organization as the Municipal Court, possesses power to make its own rules and to regulate its business. It is thus equipped to conduct its work in a reasonably efficient manner. To vest this power in the court is such obvious common sense that the fact would not merit comment except that numerous courts in other jurisdictions have not been given even this much self-government. In this particular, therefore, Cleveland is certainly not below the average condition.

To further facilitate the prompt and orderly dispatch of business the office of Assignment Commissioner has been established. The way has thus been opened for the elimination of the enormous waste of time and productive energy of attorneys, parties, and witnesses waiting for their 
cases to be reached, which is a scandal of such venerable antiquity that in many jurisdictions it has been given up as hopeless and is regarded as somehow a necessary adjunct to the judicial system.

To the credit of the County Clerk, the Common Pleas Court has been practically ridden of professional bondsmen. Through a recent statute limiting the number of bonds on which any individual may go surety, and creating the office of Bail Bond Commissioner, this great gain should be effectively retained in the Common Pleas Court and as effectively extended to the cases in the Municipal Court. Thus, one of the worst by-products of our criminal system is being eliminated in Cleveland, although the nefarious traffic is still profitably pursued just outside the portals of many other American courts of justice.

The power lodged in the prosecuting attorney to "nolle pros" a case, that is, to throw a case out of court by saying "I do not wish to prosecute" it, is logically and necessarily a part of the authority which must be vested in that important official. There is, however, today a wide-spread suspicion that the power is perverted in many instances for improper purposes. The full bench of the Massachusetts Supreme Judicial Court has this year heard charges preferred by the Attorney General against a county prosecuting attorney involving alleged abuses of this power.

It is notorious that the records and statistics of many American courts are inefficient and inadequate, and that this unbusiness-like conduct is a productive cause of difficulty. This is in part true in Cleveland, but not as to the work of the County Clerk's office or the Bureau of Criminal Identification, both of which deserve cordial praise for their general excellence.

\section{Personnel: Elections}

The 12 judges of the Court of Common Pleas are nominated by direct primaries and are elected by popular vote. Their tenure of office is only six years. The yearly salary is $\$ 8,000$.

The 10 judges of the Municipal Court are nominated by petition and are elected by popular vote. Their tenure of office is only six years. Their yearly salary is $\$ 7,500 .^{1}$

The appraisal of the personnel of the bench is so intimately bound up with the difficult question of whether judges can properly be selected by popular vote that it has been given extensive consideration in preceding chapters; but it may here be noted that many of the weaknesses inherent in this method have been attacked in Cleveland and that some progress has been made toward minimizing their dangerous effect. 
All the judges are elected on a non-partisan ballot and non-partisan elections have, in fact, been secured to a very real extent. Despite the traditional ingratitude of democracy, Cleveland has done tolerably well in keeping her judges on the bench either by reëlecting or by promoting them. Of the nine judges elected to the Common Pleas bench since 1912, six were Municipal Court judges; only two Municipal Court judges have failed as candidates for the higher bench. In the Municipal Court only one judge has been defeated for reëlection. In Common Pleas elections all the judges were reëlected in 1916 and 1920, but in other years the record has been almost the reverse.

When one considers the broad outlines of the situation in Cleveland and realizes that the necessary fundamentals for a splendid administration of justice were largely at hand, that by virtue of superior organization and technique her courts were in a position to render conspicuous service to the community through prompt, efficient, and vigorous enforcement of the laws, and that her past record for carrying through large judicial reforms gave promise of a continuing progressive development, it comes as a rude shock and a bitter disappointment to find that in actual operation during the past years this system has been grossly abused and the opportunities wasted almost beyond recall. Because inherently it had such fine possibilities, the actual breakdown of Cleveland's administration of the criminal law is a tragedy.

\section{The Defects and Evils in the Present System}

\section{Disrespect for Law}

It has already been stated that of the fundamental factors requisite for a decent administration of justice the underlying and basic element is a sound tradition of respect for law. The most perfect court system could not function long unless it were supported and sustained by good citizenship.

There are distressing signs that Cleveland has been in the throes of reaction and that from the pinnacle of a highly developed sense of civic responsibility she has fallen not merely to the general level, but into depths of apathy and indifference far below. Concrete proof of such an indictment cannot, in the nature of things, be easily afforded except as its truth is recognized and admitted by leading citizens of Cleveland themselves. But to the outsider there are certain objective manifestations which indicate that a deteriorating influence has been at work.

The public plays a direct part in the administration of justice at elections, by jury service, and through the facilities it grants to the courts, 
and exercises an indirect, but no less important, influence through an enlightened public opinion which recognizes and sustains what is good and vigorously condemns what is wrong.

When civic pride was strong, Cleveland built her County Court House and City Hall, which afford dignified and adequate accommodations for certain of her courts. Since then the needs of the courts have been given little heed. The Common Pleas Court is forced to work disjointedly and wastefully in two separate buildings, and two of its courtrooms are hardly suitable. The criminal sessions of the Municipal Court are carried on under conditions which are a disgrace.

The jury system, despite its improvement since 1915, remains a constant and most dangerous source of weakness in the judicial system. This is not essentially due to faulty technique in calling or selecting the jurors, but is due to the plain fact that the citizens avoid service in a wholesale manner unheard of in most jurisdictions. It is hard to believe, but it is nevertheless a fact that in Cleveland a citizen may buy immunity from jury service for a nominal sum by contributing to a military organization. For such a condition no condemnation is too severe. The State of Ohio should take to heart the lesson taught by the selective service acts in the Great War that the responsibilities of citizenship in a democracy are not matters for barter and sale.

The giving of false testimony under oath seems to be rife in an unparalleled degree. While the blame for wide-spread perjury attaches in first instance to the public's officials for their failure to cope with it, the final responsibility for this condition which makes a mockery of the processes of law must be laid at the door of a community which produces so many persons willing to violate their oath and which, after it has become fully aware of the situation, goes on about its other business indifferent and unconcerned, tolerating the fact that of 27 persons charged in one year with this and kindred crimes, only one was brought to punishment. ${ }^{1}$ Through the centuries the finger of scorn has been pointed at Nero fiddling while Rome burned, but what shall be said of a community which, engaged in private gain, allows the spirit of perjury to stalk unrestrained through its halls of justice?

${ }^{1}$ Since this sentence was written, concrete proof of what a community, under proper leadership, can accomplish through the force of public opinion has been afforded. After McGannon, former Chief Justice of the Municipal Court, was acquitted on the charge of first-degree murder, he and others who were witnesses at the trial were indicted for perjury as a result of a determined public opinion and wise Bar Association action, and on this charge he was convicted. 


\section{Evils in Organization}

Turning to matters of organization and system, it is apparent that Cleveland, in common with other cities, suffers from an antiquated and cumbersome criminal procedure utterly unsuited to the modern conditions of her industrial urban life. This produces maladjustment, waste, and friction; it places enormous handicaps on society in its effort to defend itself from criminals. Admitting that the protection of the innocent man, unjustly accused, is the most important single consideration, it is still true that his interests and the interests of the community would best be served by a system of few, simple, effective safeguards and checks which would operate equally in all cases. For the average man, and certainly for the man without funds or friends, it would be safer to have one trustworthy refuge, like the cat in Assop's fable, than to have a score of possible escapes, none of which may work. In the fable the fox was caught, but in Cleveland, if he were a professional fox, he would be very likely to escape.

The evil of this overcomplicated system is that it has become unwieldy. It gets enmeshed in its own technicalities and defeats its own purpose. It fosters and makes possible the "professional" criminal lawyer, who finds it worth while to test and tamper with it until he discovers the weak spot through which his client may escape. The system may guarantee immunity for innocence, but it tends also to guarantee immunity for crime. The prosecutor is at a disadvantage before the professional criminal represented by the "professional" criminal lawyer, who can gain victory in any one of eight ways: by a police discharge after arrest, by a "nolle pros" or discharge after preliminary hearing in the Municipal Court, by the grand jury's failure to indict, by "nolle pros" in the Common Pleas Court, by acquittal before the jury, by the granting of a new trial, or by a bench parole. Outside of this curriculum, the system engenders delay, and if enough delay can be gained, the case may have to be dropped for lack of prosecution. Or, finally, as a last resort, bail may be forfeited and the criminal leave for parts unknown. In the retinue of the professional criminal lawyer is the professional bondsman, who is a "runner" in odd moments, and who stands surety on bail bonds aggregating a sum big enough to stagger a surety company, ${ }^{1}$ but which occasions him little concern, for he feels quite confident that suit will never be brought to enforce any of the bonds.

The judges are not responsible for this archaic procedure, but in-

1 The so-called Day Bill, already referred to, limits the number of bonds, and this very recent law, if properly enforced, should entirely change this situation. 
stead of trying to make the best of a bad situation, they have made it worse. They cannot be held entirely accountable for failing to check the extensive "nolle prossing" of cases by the prosecuting attorneys, because they have no independent source of information to enable them to act with discrimination, but they are open to severe censure for their laxness with regard to continuances and their abuse of the right to a new trial.

In both courts the passing or continuing of cases is badly handled. The cumulative effect of the delays thus obtained in many instances is to make the case become so stale that no one wants to prosecute it and no witnesses are left with which to prosecute it. Apparently, if the defendant's lawyer can drag a case along for over sixteen weeks, the law of averages will do the rest. As a general proposition in Cleveland, unless the State can bring a criminal to trial within one hundred and fifteen days his case will be "nolle prossed" or discharged on motion or dismissed for want of prosecution.

It is shocking to the sense of a lawyer to learn how the judges grant new trials for purposes utterly distinct from the solemn purpose for which the right to new trial is embodied in our law. The power of the court to grant a new trial exists to prevent gross miscarriage of justice, as where newly discovered evidence indicates the serious possibility of error or where the judge feels bound by the oath of his office to countermand the jury's verdict as being contrary to the law or the evidence. Instead of keeping this high prerogative of justice inviolate, it has been prostituted apparently for the purpose of allowing individual judges to work out their individual ideas as to the proper disposition of a case. To grant a "new" trial when there has been no trial because the defendant pleaded guilty is an abuse of judicial power. To grant a new trial after a conviction for a definite offense, with no idea of having a new trial, but in order to accept a plea of guilty for a lesser offense, is usurpation of power. This is not administering justice according to law, and judges who thus depart from their plain duty must expect to have their motives attacked and to encounter a diminished respect for themselves and their office.

Similarly, the judges of the Municipal Court who allow "motions in mitigation" and then retract or reduce sentences imposed after a finding of guilty are rapidly undermining public confidence in the integrity of the legal system. This "motion in mitigation" is an anomaly. After the determination of guilt, a judge should impose sentence only after he has decided what is just, and having made the decision, should abide by it. A judge who sentences a man before he has made up his mind 
and a judge who cannot make up his mind are both unfit for judicial office.

It would seem that the decadence of the general public spirit had affected the judges and sapped their spirit of courage and independence. Perjury committed in open court has passed without challenge. A lying witness should be stopped short and warned, and failure to heed the warning should be summarily punished by imprisonment for contempt. In the case of Bar Association v. Sleeper, a recent proceeding against an attorney in Massachusetts, the Justice of the Supreme Judicial Court who heard the case became convinced that the defendant was deliberately giving false testimony and disbarred him. This is, perhaps, an extreme illustration but it serves to demonstrate how much a fearless and strong judiciary can do, and on occasion ought to do, in sternly repressing the ever-present menace of perjury.

The judges have been entirely too free in granting paroles, but the real difficulty here is that Cleveland has provided the Municipal Court with a grossly inadequate probation force and the Common Pleas Court with no probation staff at all. A strong probation force of character and intelligence is universally recognized as an indispensable auxiliary department of a modern criminal court. Nearly everywhere the principle of effective probation work is established, but Cleveland is in this respect a decade behind other cities and is paying the penalty. In Cleveland the fact is ignored that the criminal courts exist not only to separate the guilty from the innocent, but to segregate out from among the guilty those who are professional criminals in order to restrain them. In the warfare which society must continually wage against crime, the courts are the outposts. The criminal who breaks through or escapes from that first line of defense cannot be apprehended until after he has committed another crime. In the absence of the intelligence service which a trained probation force can supply, the courts cannot and do not deal effectively with the habitual criminal. Cleveland has become known to the underworld as a snug harbor and she pays dearly for this unenviable reputation, as the fast mounting record of arrests for felonies bears witness.

It is perhaps not surprising that a system which tolerates these abuses should rush to the opposite extreme and deal harshly with persons who are not criminals and are not even accused of crime. In Cleveland today men who are needed as witnesses and whose only fault is poverty are put in jail and kept in jail for weeks and months. Except in most unusual circumstances, to deprive a man of his liberty in this way is a downright outrage. A bench, a bar, a community too callous to rise in pro- 
test against such a practice, even if it be rare, must have forgotten or lost in marked degree the instinctive American sense of fair play.

The business of the courts is not transacted with the dignity and decorum demanded by the seriousness of their work. Disorderly conduct among witnesses and spectators that calls for sharp reprimand is not checked. The attitude of respect and reverence is so dependent on proper physical surroundings that inevitably there is least dignity in the criminal sessions of the Municipal Court, which are held in unclean, untidy, ill-arranged rooms. Here come the first offenders and immigrant offenders and here they receive their first impression of the majesty of the law. A justice of the Supreme Court of the United States could not long maintain dignity in such quarters, for no nervous system can withstand the pressure of such an environment.

The clerk's office of the Municipal Court for criminal business is not better accommodated and doubtless this fact accounts in large measure for the inaccuracy and inadequacy of the records and for the disorderly state of the lists.

\section{Personnel: Politics}

The average quality of the personnel of the judiciary is not as high as is needed for a proper administration of justice. There are judges sitting who ought not to be on the bench in Cleveland or anywhere else. The morale, or what lawyers would call the "tone," of the bench is weak.

While it may be true that the judges of the Common Pleas Court are not markedly inferior to the general caliber of judges chosen elsewhere by the methods of popular election now in vogue, this standard of comparison is not high enough to afford ground for much reassurance. In the Municipal Court, where the disintegrating forces seem first to have had their effect, the situation is worse, and Cleveland has very recently been forced to oust from this court one judge who was bringing opprobrium on the entire bench.

This condition is due partly to the comparatively short tenure of office, but it is primarily and chiefly attributable to the method by which the judges are selected.

Presently we must consider how far it is true that popular election of judges is at the root of most of the trouble in Cleveland on the ground that such a method is bound to produce inferior judges. But even assuming for the moment that the people may, under proper circumstances, select their judges wisely, it is obvious that the particular method employed in Cleveland, despite certain good features, is operating badly.

The short tenure requires the judges to campaign frequently, and as 
they always have to face vigorous competition, they are forced to campaign strenuously or risk retirement. Thus, the most damaging and most dangerous features of the elective method are not only given full play but are intensified. In the course of such electioneering the judges are forced to speak and act in a manner inconsistent with and repugnant to any decent conception of judicial office. With the bogey of reëlection constantly hovering in the foreground, the covert pressure exerted by groups and organizations cannot be disregarded as it should be. The political lawyer, with his control of votes, becomes a man of importance, to be placated if possible. As his potential competitors at the next election who are off the bench are continually striving to create and develop their own influence in the community, the judge on the bench must do likewise. He must become known, his name must be seen in the papers, and therefore he gets an assignment to sit in the criminal sessions of the court because criminal cases have superior news value. The doing of justice forbids the granting or receiving of favors, but in an open election the judge must beg for votes and, after he has lost his private practice through years of service on the bench, he must beg hard. It is next to impossible to make an effective political speech without at least impliedly promising something to somebody. Such conditions destroy scruples and cause a progressive deterioration from bad to worse, so that in Cleveland today we find judges permitting the solicitation of campaign funds from lawyers who practise before them and the insertion of large paid advertisements of themselves in the papers. In one instance, a judge has assumed to administer justice in a court-room adorned with political placards urging all those in attendance to vote for him.

The method of selecting judges now obtaining in Cleveland puts a premium on self-advertisement and compels the currying of favor. It is thoroughly bad. Its immediate correction is a problem of outstanding importance.

\section{Suggestions AND RECommendations}

In the preceding pages an effort has been made to point out the more important defects in Cleveland's administration of criminal justice, and it is now in order to consider what definite, feasible, constructive things may be done to eliminate or abate these evils. Recommendations as to many details are contained in the main report in their appropriate places; it is attempted here to present only those suggestions which, by reason of their larger import, call for special attention and discussion.

There is no panacea for the existing ills nor is there any royal 
road to democratic self-improvement. These suggestions will not bring about the millennium, but they are respectfully offered in the firm belief that their adoption will effect substantial and genuine improvements.

\section{As to Personnel}

The needed improvement in personnel cannot be effected by lopping off a head here and there and trusting to luck for the future. The only permanent way to secure better judges is by devising a better method for selecting them and keeping them after they have been selected.

It is the consensus of opinion of the bar and the unanimous conviction of the ablest students of our legal institutions that strong and wellqualified judges are most certainly secured when they are appointed by the Executive and hold office for life, subject, of course, to removal for misconduct. On the evidence, there is every reason to believe that this method of selection, or a modification of it, plus long tenure, would do more than anything else to revolutionize the present state of affairs. If it be within the field of possibility, this is unquestionably the goal to be striven for. On the other hand, one cannot ignore the fact that in this matter, as in matters affecting standards of admission to practice, the bar does not seem to possess public confidence and is unable to gain acceptance of its views. On this point there is a gulf of misunderstanding between laymen and lawyers that has not been bridged. The body of the people seem determined to retain the power of selecting their judges, and wherever that is so, the only practical step is to make the elective system operate at its maximum possible efficiency.

Within the limits insisted on by the democratic impulse, much can be done. Almost every conceivable method of selecting judges has been tried in the various States and, as Dean James Parker Hall made clear in his address before the Ohio Bar Association in 1915, each method can point to a success in some State. As an extreme illustration, judges are elected in Vermont by the legislature for two-year terms. Theoretically this is as bad a plan as could be devised; but actually in Vermont good judges are chosen and hold office for life. Popular election of judges has done splendidly in Wisconsin, where the tradition has grown up of steadily reëlecting the judges.

The secret in obtaining good judges is that back of the methodwhatever it is-there must be a tradition which makes the selecting group realize that it is clear public policy to retain judges in office except for grave mental, moral, or physical defects. This tradition has been built up in New York, Wisconsin, Vermont, Connecticut, and elsewhere, but seems not to exist in Cleveland (with the exception, strangely enough, 
of the Probate Court), and it cannot be secured overnight. Its growth may, however, be aided.

To that end the following principles should be incorporated into the elective system, if that is to be retained in Cleveland. Judges in first instance should be elected as they are now. Their first term should be comparatively short, say, six years. At the end of that time they should run for reëlection for a longer term of, say, ten or twelve years, and for this purpose they should run against their own record, not against a motley group of other candidates. In other words, the voters decide a plain issue: Shall the judge be retired or shall he be retained? The third term should be even longer and consist of, say, twenty years. In the event of the retirement of a judge a special election, in which he could not be a candidate, would be held.

Such a plan will reduce very greatly the amount of electioneering and the constant interruption of judicial work thereby occasioned. For a judge to run against his own record is infinitely less degrading than the scramble for votes in the open field. The question of reëlection or retirement will be an issue of moment and on it all the responsible agencies in the community can focus their attention.

The tendency will clearly be to retain judges in office; the average tenure will be substantially longer. The enormous advantage of the longer tenure is this: There is a splendid tradition of service, the heritage of centuries, which attaches to the judicial office and which elevates every man who takes the oath of that office. This tradition, constantly at work, plus the experience gained as the years go by, takes inferior men, if need be, and develops them into superior judges.

The method suggested in no respect deprives the community of its right to select its own servants and to discharge those with whom it is dissatisfied. For that reason it is a feasible method. And, as it is calculated to make the method of popular election operate at maximum instead of mediocre efficiency, it would give results.

It is pertinent to ask whether the elective method has ever had a fair chance to demonstrate how much it could do. For the determination of all other questions by popular vote the tremendous organization and work of the political parties is required. Without them all voting would be blind. In judicial elections, partisan activities have quite properly been eliminated. This tends to leave the voters entirely in the dark, to be enlightened only by the mirage of cheap publicity. Democracy demands responsible leadership. Under the suggested plan, wise leadership is the only hope for securing competent judges in first instance. It may well be that the most effective guidance would come from the party 
heads, the bar, and perhaps representatives of other organizations acting in concert to decide upon and support the best available candidates; but here, as in all judicial issues, the predominating influence should come from the bar. A hitherto disorganized bar which has not taken itself seriously cannot wonder that the public has declined to follow its weak leadership. But there is every reason to believe that a well-integrated bar, such as is now taking shape in Cleveland, conscious of its public obligations, would build up a record of public service by keeping its own house in order and, by promoting the better administration of justice, would win the public respect and confidence which underlie the acceptance of leadership. It must be remembered that despite all the hue and cry and jokes about the profession the individual man will, when the occasion arises, place absolute confidence in the individual lawyer. Were this not so the legal business of the community would have been taken out of the hands of lawyers long ago. But for leadership the bar must act collectively, and until recently the bar has not felt the sense of its own solidarity or the sense of its responsibility as a group.

The Cleveland Bar Association is today in many respects one of the best associations in the United States. It should continue along the lines of its present development. In the selection of former Judge McGannon's successor its voice was heard and heeded. The above outlined plan would give it a real opportunity to throw the full weight of its combined influence in the right direction as the issues of election and reëlection of judges come before the people.

\section{As to Organization}

In considering recommendations for improved organization it must be remembered that system is a servant and not a master. Good men can give good government despite the handicap of weak organization. Bad men can produce nothing but bad government no matter how effcient the system may be. In judicial affairs system exists for the same purposes and plays exactly the same part as in business affairs. It is designed to make work more efficient by eliminating waste effort and friction, to afford those records which make possible unified control and wise direction through an executive head, and to secure and compile the facts as to the undertaking, its assets and liabilities, which yield the needed information for the guidance of the public.

1. In organizing itself promptly to detect and adequately to restrain the criminal, it is plain common-sense strategy for the community to marshall all its forces in one court. A unified court for the transaction 
of all criminal business, as has been established in Detroit, is strongly recommended because it is bound to be superior to split jurisdictions, divided responsibility, and uncoördinated effort.

To accomplish this result in Cleveland a new court is not needed: all the criminal business of the Municipal Court can be transferred to the existing (and additional) sessions of the Common Pleas Court.

If this entire step is not deemed immediately practicable, then the next best thing is to transfer to the Common Pleas Court complete jurisdiction over felonies by taking out of the Municipal Court the preliminary stages and the preliminary hearing. This would at once eliminate the worst duplication in the present system and would relieve the Municipal Court judges, who now have entirely too many cases to be able to give them proper attention.

The Common Pleas Court should be given a thoroughly modern form of organization, with complete power to make its own rules of procedure and control its own business, under the supervision and leadership of a permanent Chief Justice. The present plan of rotation has all the weaknesses of the old Roman plan of two consuls alternating in power. Definite responsibility is nowhere. The essential importance of this form of organization will steadily be seen in connection with subsequent recommendations.

2. Provision should at once be made for the establishment of an adequate probation staff, including medical advisers, either for a unified court or for both the present courts. The personnel should be appointed by the Chief Justice or respective Chief Justices to hold office during good behavior. To the probation force should be committed the task of collecting fines, non-support orders, and the technical custody of persons adjudged guilty who need actual supervision but not imprisonment. The courts should have power simply to put the case on probation, or to impose sentence, suspend sentence, and put the defendant on probation; for breach of the terms of probation the punishment is the automatic execution of the original sentence. The details for the organization of the staff should be worked out by a committee of the Bar Association in conference with the National Association of Probation Officers.

3 . The abuse in the granting of new trials and continuances cannot wisely be stopped by depriving the court of all power to order any new trials or continuances. Such matters must always be left to the sound discretion of the judges. But the disastrous tendency toward laxness and carelessness in the exercise of this discretion, as well as personal laziness, which is the product of the present loose, irresponsible organization in the Common Pleas Court and the demoralization of the organi- 
zation of the Municipal Court, can be speedily curbed by the determination of a Chief Justice who can get at the facts and call on an offending judge for an explanation. A thoroughgoing system of records, such as obtains in the New York City Magistrates' Court, will enable a Chief Justice to detect promptly and to stop such abuse of judicial power. And in this task the Chief Justice should have the coöperation of a Bar Association committee on the administration of justice which can, through a professional secretary, keep its own vigilant watch on the situation.

4. Further safeguards should be thrown about the use of the nolle prosequi. The motion should be filed like any other motion, and should specify the prosecutor's reasons for declining to prosecute. This change should be effected by rule of court, and it should always be in the courts' further discretion whether the complaining witness should be notified and whether there should be general notice by publication.

It would clear the prevailing atmosphere if the court should immediately promulgate a rule providing (1) at least seven days' notice to the complaining witness and the Bureau of Criminal Identification of the filing of every such motion, and (2) definite days for the hearing and determination in open court of such motions. This rather rigid rule of procedure could be altered when circumstances altered.

5. The practice of jailing complaining witnesses in default of bail should be abandoned. Such witnesses should be released on their personal recognizance except in cases where the Chief Justice or acting Chief Justice orders otherwise for cause shown at a hearing in which the witness is represented by counsel. As, by hypothesis, these persons are indigent they must be afforded counsel at public expense.

6. The assigned counsel system should give way to the more modern, more efficient, more economical "public defender" system. The greater success attending the assignment of all cases of all accused poor persons to one central responsible agency has been demonstrated in Los Angeles. The legislature of California, in its last session, made provision for extending this system throughout the State. Because of the generally upset conditions in Cleveland it is recommended that, for the time being at least, this work be entrusted to quasi-public, rather than public, hands. The precedent of the New York Voluntary Defenders' Committee is applicable. To accomplish this improvement neither a statute nor an appropriation is required. The work of representing poor persons in criminal cases is so closely analogous to the work of representing poor persons in civil cases, now undertaken by the Legal Aid Society, that the two functions should be combined in one agency, as has been done 
in New York. This one legal aid organization should be created, supervised, and controlled by a special committee of the Bar Association which is the properly responsible body. Having available such an organization, the courts could, and, if the organization merited confidence, would assign to its attorney, in charge of its criminal work, all the cases now entrusted to assigned counsel. In view of the general experience throughout the country it would be surprising if a budget of $\$ 32,500$ (the cost of assigned counsel in 1920) did not enable such an organization to handle 528 cases, of which only 194 required trial, more efficiently and justly than they are now handled. To this quasi-public defender office the Municipal Court judges could refer cases when, in their opinion, the defendants needed counsel for a fair trial. This office would, in cooperation with the probation staff, be of material assistance in securing that information which the court needs to arrive at a just sentence. Finally, such an organization, through its constant contact with the criminal work of the courts and through its reports, would be the sort of guardian and watcher which is essential if the public is to be kept intelligently informed of what goes on in its legal institutions.

7. The provision of law exempting citizens from jury duty for contributing to military organizations should be repealed forthwith.

8. Whether or not the seemingly useless method of indictment by grand jury should be retained is only a part of the major problem of the reform of our whole criminal procedure. Our criminal procedure everywhere lags behind the civil. The only available safe path of progress seems to be the step by step process of constant experimentation, revision, and adaptation. Such work calls for a Judicial Council, a perpetual body, consisting of not less than five and not more than 15 judges and lawyers appointed by the Chief Justices and holding office during their pleasure. If a Judicial Council can be secured, it is of minor importance whether that body has rule-making power or merely advisory power. A Judicial Council, which is a permanent commission on judicature, serves to connect up all the parts of the judicial system which, for many reasons, it is impossible to coördinate through amalgamation. As it affords a clearing-house of ideas, it becomes the advisory steering committee for the judicial business as a whole. Roughly, it is analogous to the board of directors in a large industrial company. The growing realization that only through some such body can our courts be brought up to date and kept up to date is well attested by the fact that the Massachusetts Judicature Commission in its 1921 report emphasizes the need for a Judicial Council as its cardinal recommendation. The conferences which are now held in Cleveland from time to time between 
representatives of the Bar Association and the judges constitute a laudable step in this direction.

The recommendations of a Judicial Council would be worked out in coöperation with other agencies in the community and would be presented to the courts, the bar, the legislature, or the public, as the case might be. Its recommendations would have the supreme merit of being based on a continuous study of the administration of justice. This is the converse of the method heretofore followed in America. The community has paid exclusive attention to its business affairs and has left its institutions to care for themselves, to stagnate, to be outgrown, or to become archaic as the life which these institutions were supposed to regulate rapidly altered its character and complexion in every particular. Periodically, when conditions became absolutely unbearable, a momentary attention would be given to the matter, a wave of reform would sweep the community, changes would be made with pathetic confidence that at last perfection had been attained, then interest would wane, the current of our national life would sweep swiftly on, growing, altering, and developing, and in a few years the whole process would have to be repeated. If all the recommendations herein made had the power to give Cleveland a perfect administration of justice and were adopted tomorrow, in ten years' time the courts would again show signs of breaking down. This is inevitable. Law regulates life. Life is constantly in flux and it will break down any static organization. To keep our legal institutions abreast of the times the formation of a Judicial Council is earnestly recommended.

9. Assuming that the Municipal Court is to retain a portion of criminal jurisdiction, then steps should be taken to recognize the fact that it is a court of equal dignity, responsibility, and importance with the Court of Common Pleas. It is not an "inferior" court, nor does its business consist of "petty" cases. In its work for the prevention of crime and the inculcation of respect for our institutions, it is the supreme court in importance if not in rank. The judges of the Municipal Court should be selected under the plan earlier suggested; and they should be paid as much as the judges of the Court of Common Pleas.

10. The city should at once furnish not merely decent but really suitable accommodations, so that the criminal sessions and the criminal division of the clerk's office may be housed in a manner compatible with the dignity of their work.

The system of clerks' records should be modernized. Primarily the ledger or docket system should be employed, and on the page assigned to each case (entered numerically and cross-indexed alphabetically) all the 
facts in the history of the case should be entered. Through the use of standardized headings, which is easily possible because all cases follow the same general routine, it then becomes feasible without enormous labor to draw off and compile those general controlling facts and tables which enable a Chief Justice actually to be an executive head and which the public are entitled to have interpreted and reported to them through court reports and the press. Although the detail of a clerk's office must be left to the clerk, it is important that the process of revising should get down to details and that all such slack practices as the stamping of both judges' names on the docket-which is nothing more or less than a false record-should be eliminated.

11. The elimination of the "shyster" lawyer who gets his cases through "runners" is difficult. Of all methods that have been tried, the work of the public defender in Los Angeles is the most efficacious and, therefore, if a proper quasi-public defender office is established in Cleveland, it is reasonable to suppose that the nefarious business of the "runners" may be curtailed to the point where it will no longer be profitable. The "shyster" lawyer, in so far as he transgresses the law or the ethics of the profession by solicitation, must be dealt with by the Bar Association.

12. This evil, as well as that of the professional bondsman, can automatically be further reduced by the proper use of the summons instead of an arrest in cases involving minor offenses and violation of city ordinances.

13. The peculiar proceeding used in the Municipal Court called the "motion in mitigation" has no place in a proper administration of justice and should be abolished.

\section{Civic Responsibility}

A persistent effort has been made in all these pages to bring home the fact that the tradition of respect for law and of civic pride in our legal institutions is by far the most compelling force for justice. Tradition is our heritage of social experience. It is the conscience of the group, and it affects every citizen, every witness, every lawyer, every judge in the community. Like conscience, it becomes dulled through scorn and neglect.

Cleveland's traditional spirit and sense of civic responsibility must be awakened. Brass bands will not do it, but through education and the actual undertaking of work for the public much good may be accomplished. Let the leaders of the community lead. There are at least two points where an immediate attack may be begun. If the public conscience refuses to condone perjury, convictions will follow. Extended 
perjury cannot exist without some lawyers taking some part in it. A lawyer who knowingly permits perjury to be committed in court is a false minister of justice and it is the duty of the Bar Association to disbar him. Jury service must become again an accepted civic responsibility. It might serve the purpose for the Chamber of Commerce, the Civic League, the labor unions, and other organizations professing an interest in public welfare to compare jointly their membership lists with the lists of the jury commissioners to determine how many of their members fail to qualify for jury service and why.

No outsider can hope to do more than to try to point the way. For all these recommendations there must be supplied by Cleveland men those details which are always required for the successful adaptation of general principles to particular local conditions.

Here is a definite call for immediate, practical public service. To study, digest, and weigh these recommendations requires patient, selfsacrificing effort, and actually to apply those which commend themselves will require courage and persistent effort. If this task is earnestly undertaken by the community, it may be that from the very undertaking will begin a resurgence of the tradition of civic pride that in former years gave Cleveland her preëminence. 


\section{PART IV \\ CORRECTIONAL AND PENAL TREATMENT \\ BY \\ BURDETTE G. LEWIS}




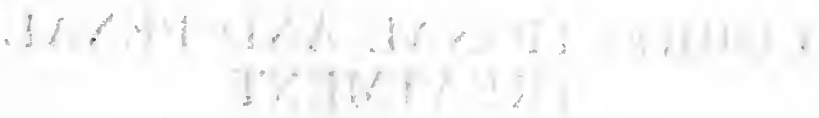

$$
\begin{aligned}
& \text { - } 1 \text {, }
\end{aligned}
$$$$
-
$$ 


\section{CORRECTIONAL AND PENAL TREATMENT}

\section{CHAPTER I \\ PENAL INSTITUTIONS FOR ADULTS}

\section{The Department of Public Welfare}

7 HE Department of Public Welfare of the city of Cleveland is divided for administrative purposes into four subdepartmentsthe Division of Health, the Division of Charities and Correction, the Division of Employment, and the City Immigration Bureau. In the Division of Health are the following bureaus, each under the control of a chief: Communicable diseases, child hygiene, public nurses, food and drug inspection, chief chemist, and laboratories and sanitation. The last has two persons in charge. In the Division of Charities and Correction are the following agencies: Bureau of Outdoor Relief, city hospital, tuberculosis sanatorium, city infirmary, workhouse, parole office, the boys' home, and the girls' home.

The charter provisions give the Director of Public Welfare wide powers. They read in part as follows:

"The Director of Public Welfare shall manage and control all charitable', correctional, and reformatory institutions and agencies belonging to the city; the use of all recreational facilities of the city, including parks, playgrounds, public gymnasium, public bath houses, bathing beaches, and social centers. ${ }^{1} \mathrm{He}$ shall have charge of the inspection and supervision of all public amusements and entertainments. He shall enforce all laws, ordinances, and regulations relative to the preservation and promotion of the public health, the prevention and restriction of disease, the prevention, abatement, and suppression of nuisances, and the sanitary inspection and supervision of the production, transportation, storage, and sale of foods and food-stuffs. He shall cause a complete and accurate system of vital statistics to be kept. In time of epidemic he may enforce such quarantine and isolation regulations as are appropriate to the emergency. He shall have the supervision of the free employment office. The Commissioner of Charities and Correction shall be the deputy officer of public welfare. 
"The Commissioner of the Division of Health shall be the health officer of the city and shall, under the direction and control of the Director of Public Welfare, enforce all ordinances and laws relating to health, and shall perform all duties and have all the powers provided by general law relative to the public health, to be exercised in municipalities by health officers; provided that regulations affecting the public health, additional to those established by general law for the violation of which penalties are imposed, shall be enacted by the council and enforced as provided herein.

"The Commissioner of the Division of Employment shall have charge of the free employment office established to assist persons in securing employment. He shall extend such information and assistance to immigrants and strangers and perform such duties in the collection of labor statistics and information relative to labor conditions in the city as may be required by ordinance."

A study of the organization and work of the present director's office shows clearly that there has never been developed any machinery or plan of work which would permit the director to exercise adequate control over the various divisions. The department is, in fact, an example of the failure of statutory enactment alone to effect a considerable change. It is a paper federation of bureaus, divisions, departments, and institutions without administrative cohesion.

The sincerity and good purpose of the director of the department are unquestioned. He has never stood in the way of any good work; he has accepted cheerfully aid given him. The new city hospital and the new psychopathic hospital now under construction in his department show clearly the director's desire to carry out the recommendations of the Hospital and Health Survey. The changes he has directed to be made at Warrensville City Infirmary are indicative of the same desire.

Within the Division of Charities and Correction the director exercises some control over the workhouse because of his active interest in the parole of prisoners. He has changed the officers and appointed an administrative board, besides making certain structural changes in the girls' home. But his supervision over the city infirmary, the Bureau of Outdoor Relief, and the boys' home is limited to occasional visits and to haphazard consideration of their work. Moreover, his appointment of advisory boards for the girls' home, for the city hospital, and for the employment bureau has had little significance, because he has never followed up their work. The boards were never given specific tasks and no effort has been made to keep up their interest. He has apparently even left the chiefs of divisions and superintendents free either to accept or to reject his suggestions, as suited their fancy.

We do not mean to make excuses for the director's failure to meet his 
major opportunities, but it would be unjust to let him appear as a "scapegoat" for the perfectly apparent indifference of a whole city and the impotence of so many of the heads of welfare agencies and societies. Moreover, the people have been willing to accept the high civic standing of the director as a substitute for adequate appropriations and a real welfare program for the city.

\section{Recommendations}

1. The people of Cleveland should be made to realize that the Department of Public Welfare, combining, as it does, a Health Department with a Division of Charities and Correction, offers an unusual opportunity to demonstrate a great economy in municipal service under the supervision of a single director.

2. The Director of Public Welfare should exercise direct control over all the work of the department in such a manner that general policies are formulated under his supervision, and every employee of the department feels responsible to him.

3. The director should have an assistant, or deputy director, who should, in accordance with the charter, supervise the correctional institutions.

4. The director should have the kind of secretary who can supervise and coördinate the work of the institutions with the employment bureau, the Bureau of Outdoor Relief, and the parole department.

5. The director should see to it that the health commissioner cooperates under the director's supervision with other divisions, institutions, and public schools of the city, with the other hospitals in the city, with the Western Reserve University Medical School, and with all the social agencies upon a well-thought-out public welfare and health program for the city, which would make the institutions diagnostic, treatment, and preventive health centers.

\section{The City Jail and Central Police Headquarters}

The city jail occupies the same building as police headquarters, Rooms 1 and 2 of the Municipal Court, and the offices of the adult probation officers. The jail is under the general jurisdiction of the Division of Police. The entire municipal building is in a dilapidated and uncaredfor condition. Obviously, the jail has been allowed to suffer more than other parts of the building. It is a dark, dingy place. This is on account of the type of construction by which the limited amount of light from the outside finds entrance only on two sides of the building. The dingy appearance is accentuated by rusty iron work, filthy old iron toilets, and dirty, blackened walls. Rats and vermin live on easy terms with the 
inmates of the jail. We were assured by officers in charge that a continual campaign is waged unsuccessfully against vermin, but when one considers the method used in the fight, one must conclude that its endlessness is inevitable.

The jail is almost entirely devoid of equipment or furnishings, except those supplied when the building was built. Each cell contains an iron toilet and a plank, 20 inches wide, extending the length of the cell, which is used for a bed. Not even a blanket is furnished the prisoners. The stock of dishes used for feeding the prisoners consists entirely of cups.

On the second floor is a small room, about 8 by 12 by 14 feet, that has been set aside as a "hospital" "in case one of the girls gets sick." This "hospital ward" is outfitted with a single bed and a small wash-stand. There is no toilet or running water or other convenience.

Near the hospital room is the "bull pen"-a bare room, about 10 by 15 feet, adjacent to the municipal court-rooms, where prisoners are detained awaiting their turn before the judge. It is often necessary to put from 30 to 50 men in this room, and at one time 80 persons were crowded into it.

The population of the jail on Sunday, May 1, consisted of seven women and about 50 men. These were found segregated into three groups. All of the women were placed together in one ward, on the sides of which were cells opening either on the ward or on an open space. None of these cells had doors. The prisoners ranged in age from twenty to thirty. In one ward on the first floor there were 11 men, and in another ward on the second floor about 30 . There appeared to be no grading or segregation except according to sex and except as the cases had or had not been disposed of by the court.

The city jail is used for the detention of prisoners charged with violations of ordinances and other minor offenses. The period of detention varies from ten or twelve hours to three or four days. The longer stay happens only in cases where the municipal judge, at the hearing, "continues" the case. If a prisoner is bound over for the grand jury, he is transferred at once to the county jail.

The prisoners are served no food at public expense during the first twenty-four hours of their commitment. If they have funds of their own, they may purchase food at a nearby restaurant. After twenty-four hours the city furnishes a sandwich and a cup of coffee, morning and evening. Prisoners are allowed to use the public telephone to communicate with friends, family, or counsel for the arrangement of bail or for other matters pertaining to their cases. There are no facilities in the jail except a lavatory in the corridor. 
Talking with some of the prisoners brought out stories, afterward checked up, of the careless and indifferent manner in which prisoners are handled in this wretched place. Two extreme cases are presented here, not because they are typical of the way prisoners are treated, but in order to show what may happen under the present system.

A man arrested by the Cleveland police on May 12 at 5.45 P. M., near Euclid Beach, was taken to the central police station and held for investigation under no court charge. He was released May 19 at 6.30 P. м. He claims he was never booked on any charge, but was told he was suspected of having committed murders and other crimes in Detroit and Boston. Detroit, Boston, and Toledo detectives came to Cleveland and stated they were unable to identify him as the man connected with the crimes. During the time the prisoner was at central station he was confined in the jail. Bread, salt, and water were supplied by jail officials, but the prisoner was compelled to spend his own money to buy other food. Almost all his money was spent for food and cigarettes for himself and others. The jail was very crowded, and he was forced to sleep four nights on the cement floor with nothing under him. He had no covering and no pillow. During the other nights he slept on the board bed in the cell, without mattress, covering, or pillow. He did not remove his clothing during the entire time he was in jail. He was not provided with a towel. Because of his arrest the prisoner lost a good position as chauffeur, and at the time of the investigation he was without work and money. When released he was ill and was told to see a doctor. The doctor found he had tonsillitis and bronchitis in a severe form, which the prisoner says he caught because of the manner in which he was handled at the city jail.

The prisoner's wife stated that she was arrested at home on May 12 at 10.30 P. M., and taken to central police station, where she was held for investigation until May 17 at 11.30 A. M. No charge was made against her. She was told she was held for investigation in connection with her husband, who was suspected of being connected with murders in Detroit and Boston. During the time the woman was in jail she did not remove her clothing; she had no towel and was compelled to sleep on a board bench or bed without mattress, covering, or pillow. On May 16 she was placed in the "hospital cell" on account of her weakened condition. Here she had a bed with a mattress, a covering, and a pillow. Jail officials supplied her with bread, salt, and water, but she had to send out for other food. One night the jail was so crowded she had to share her board bed with another woman.

The only record to be found in the jail proper was the jailer's docket. 
This contained the name of the prisoner and the charge only. Each prisoner's name and charge are entered when the prisoner is brought in; the name is scratched off when the prisoner is released from jail. In the police office are more complete records, dealing with the facts of the complaint, the name of the officer making the arrest, and the name and address of the prisoner.

\section{Recommendations}

This structure should be abandoned, as it is wholly inadequate from every standpoint. Until then the following recommendations should be followed:

1. The interior of the jail and other parts of the building should be cleaned and kept clean.

2. Prisoners should be provided with blankets, adequate and sanitary cots, bedding, toilet, and bathing facilities.

3. Prisoners should be supplied wholesome food at the expense of the city; luxuries they should be required to purchase at their own expense, but the officer in charge should see to it that no prisoner is required to pay exorbitant prices for any food.

4. The hospital room should have complete equipment.

5. There should be more careful segregation of prisoners.

6. An adequate record system should be installed, which would permit the superior officers of the department to ascertain just how prisoners are treated.

\section{The Warrensville Workhouse}

The Correction Farm at Warrensville, where the workhouse, the city infirmary, the tuberculosis hospital, and the girls' home are situated, is about 12 miles from Cleveland. The workhouse building, a comparatively new, two-story structure, well lighted and ventilated, is in the form of a square, enclosing completely a large yard which is used by the prisoners. The institution is built on the dormitory plan, and has only a few cells on the second floor of one section of the building. Each cell accommodates a number of prisoners. The dormitories themselves are well lighted and ventilated, but the dormitory plan and the form of the structure defeat the very purpose for which such an institution is intended. The prisoners are thrown together more or less indiscriminately, except when at work, and that is seldom. This structure and the city infirmary represent the period when architects were intent on the details of picture making rather than the purposes for which a building is to be used. 
In addition to the dormitories there are a small, poorly equipped hospital, an excellent kitchen, splendid dining-rooms, a fairly good laundry, and shops.

The superintendent is assisted by a chief clerk, a stenographer, and about 30 officers, exclusive of night-watchmen and engineers. The inmates are used as assistants to the officers and in some cases are in charge of subdepartments. The officers are paid $\$ 60$ a month, which, in view of the location of the institution, seems small.

The superintendent, C. J. Burns, is, in our opinion, wholly unfitted for the position he occupies, and if retained, should be assigned to parts of the work which do not call for so much training, experience, and personality. In our judgment it is not "in him" to be a good institutional superintendent, and he makes a mistake in trying to be one. It is no disgrace for a man not able to do one kind of work to acknowledge it and to undertake work he is well fitted to perform.

The census of the institution varies between 400 and $800 ; 480$ is a fair average. The commitments vary between 4,000 and 6,000 a year, about 700 of whom are women. The women's section, with a capacity of 150 , had a daily average population of 52 in 1919, and during the past year and a half has had a still smaller number of inmates. The inmates represent all grades of offenders, from petty short-term delinquents to prisoners charged with serious crimes, or habitual offenders charged with ordinary offenses, for which they are permitted improperly to serve in this institution. There were at the time of the investigation about 40 Federal prisoners, few of whom were charged with serious crimes. Most of them were violators of the prohibition law.

In order to determine the general characteristics of the male population, the army Alpha Group Test was applied by the surveyors to one out of every five of a considerable number of the so-called petty offenders and to a considerable group of the so-called more serious offenders. Contrary to expectations, the results of these tests showed a higher level of intelligence and adaptability than was expected. In fact, the intelligence level of the population compared more favorably with that of reformatories and prisons for so-called serious offenders than is usual in the case of workhouse inmates.

Because of the prevailing idleness and the resulting demoralization as well as the general lack of plan and purpose which characterize the management, discipline cannot be said to be good, although outward appearances might convince one of the contrary. There is no general plan under which the institution is administered. Each officer is a power unto himself. He may place a man in a punishment cell and report the 
matter to the superintendent, or he may take a man from a cell and report to the superintendent afterward. No written report of any kind is required, either as to the complaint against the prisoner or as to the method used in punishing him. There is no organized method of getting prisoners' complaints or officers' charges before the superintendent for consideration, nor is there any general plan of review of the disciplinary work of the institution. The fact that a man is assigned to a bed, that he is known throughout the institution by the bed he occupies, and that the officer in charge is supposed to remember the appearance of the man and to see that he gets into the right bed is sufficient commentary upon the administrative and disciplinary practices of this institution.

The superintendent assured us that he visits the punishment cells daily and talks with every man and knows everything that is going on about the institution. He stated that he was able to give the punishment record and individual history of every man. However, when asked for the punishment record and history of one Sloan, an inmate who had died, the officer who had punished Sloan a short time before had to be sent for to give from memory whatever details he could. There was no record in the office of the alleged facts related.

During one of our visits to the institution 15 or 16 men arrived under sentence and we observed the process of reception. The officer in charge handed the clerk the commitments of the group of prisoners being received in the anteroom to the bath-house. After the men had entered the room the prisoners who thought they were "lousy" were asked to step up, whereupon two negroes came forward. They were taken into the bath-house, divested of their clothing, and required to stand under the showers. Afterward new clothing was distributed to them and they were assigned to their "beds."

All underclothing of these two men was placed in a receptacle to be burned, and the outer clothing, after being superficially examined for lice, was packed away in boxes with moth-balls. The officer in charge said close watch was kept on the new men, and if lice were discovered, the men were sent to the barber-shop to have their hair clipped and "anquintin" applied. As to the presence of vermin in the dormitories, the attitude seemed to be that, although effort was made to get rid of them, their complete avoidance was considered practically impossible in such an institution. The procedure outlined covers the reception of prisoners at the workhouse, except for a rough classification which separates Federal from other prisoners and men with long from men with short sentences.

The hospital is in charge of a visiting physician, who comes to the 
institution daily from the city infirmary. Every man in the institution is permitted to go to the hospital whenever he wishes. It is not necessary for him to have a permit, nor is any written record kept of such visits except in the office of the hospital. An interne keeps a very good record of the men who visit the hospital and indicates the diagnoses by simply stating the complaint: for example, "John Jones, sore throat." The record does not specify the treatment nor the length of time under treatment unless the man is a bed patient; then the daily chart record is depended upon to show how long he is in bed and the other facts supposed to be recorded on the chart.

The modern and rather expensive woodworking plant is evidence that those who planned this institution failed to realize how impossible it is to employ short-term offenders in an industry such as this, which requires skill, previous training, and considerable specialized experience. The plant is idle because men cannot be found to operate it. Before prohibition, an occasional experienced cabinetmaker, furniture worker, or carpenter was sent to the institution for intoxication or petty assault, but since prohibition has come, commitments of this type have stopped.

A few men were found at work in the broom shop, which has fair equipment, but the work is carried on in an aimless, listless manner, and little is accomplished. Women have been taken out of the laundry and given ironing only, because, according to the superintendent, the Federal prisoners were found to be particularly good in the laundry, and it was considered safer to have them here than working outside the buildings. In view of the fact that laundry work is traditionally women's work, this plan seems to us a very poor one.

During our survey many men were seen pretending to be busy cleaning dormitories and making beds. The superintendent explained that in order to keep as many men as possible busy, one group of men cleaned one-half of the dormitories in the morning and rested in the afternoon, while the half which had been resting in the morning cleaned the remainder in the afternoon. It was perfectly apparent that this division of labor was not sufficient to keep the men really occupied.

Some of the men, whom the superintendent feels he can trust, are engaged about the farm and in the dairy. The general manual labor about the institutions situated on this tract is performed by the prisoners. Our visit to the horse and dairy barn showed clearly that these buildings are kept in good condition and are well supervised.

We discussed with the superintendent the possibility of more outside work for prisoners, suggesting road work. We described how Major Lewis Lawes, as superintendent of New York City Reformatory, had 
taken 500 unclassified young reformatory inmates to the country, where they had lived in a cantonment-like institution and had continued to live and work there for four years, without walls, bars, locks, or guns. These young men were much more difficult to handle than Cleveland workhouse prisoners, and yet during this time there were but 40 attempts at escape a year, with a yearly average of only five successful escapes. To this account the superintendent looked at the surveyor incredulously and said nothing.

During a discussion of the treatment of drug addicts, the investigator stated that in his experience manual labor in the open air was one of the best restoratives for drug addicts. The superintendent replied that this was utterly impossible with the addicts which came to him, as they were so emaciated they would die if sent out to work. Pointing to an inmate lying in bed, upon whose face the death pallor had already stolen, the superintendent said, "Would you require this man to work with a pick and shovel?" and seemed to think that the discussion was closed.

During the three months of January, February, and March, 1920, there were 39 escapes, and in July, August, and September of the same year 58, or a total of 97 for six months of that year. That there should be so large a number of escapes from this institution in so short a time is proof enough of the inability of the superintendent to manage the institution as it should be managed.

A modern reception service should be installed, so that on arrival at the institution every inmate should go through an adequate prescribed routine. The record of his arrival should be entered in the proper record books. All clothing in every case should be removed and immediately sterilized and washed or, if necessary, burned. After a bath and an initial physical examination, in order to discover the presence of any disease or vermin, the prisoner should be furnished a clean institutional uniform, including under and outer clothing, stockings, and shoes. His finger-print identification record should then be taken and filed. The man should remain in quarantine at least two weeks, which is the time required for the incubation of any ordinary disease. During this time he should be given the Army Group Test and a psychiatric examination, if the psychological test or observation indicates this to be necessary. He should also be interviewed by the officers responsible for school work and other work, and a written record made of the interviews. All these records should then be placed in the hands of the superintendent of the institution, who as soon as possible should have a personal interview with the man. Care should be taken to assign each man to the kind of work he is fitted to do, and if the prisoner has not had a common school 


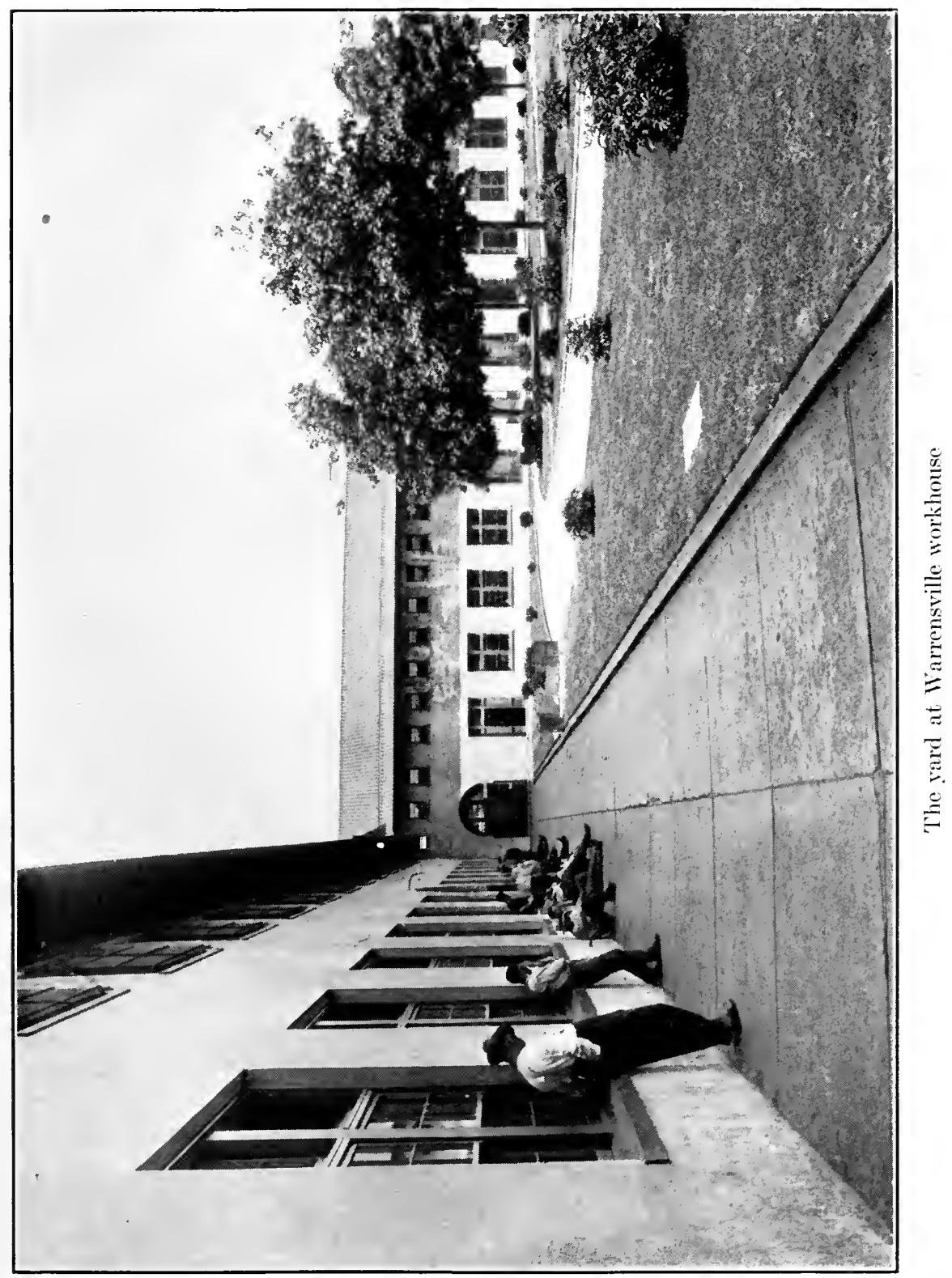




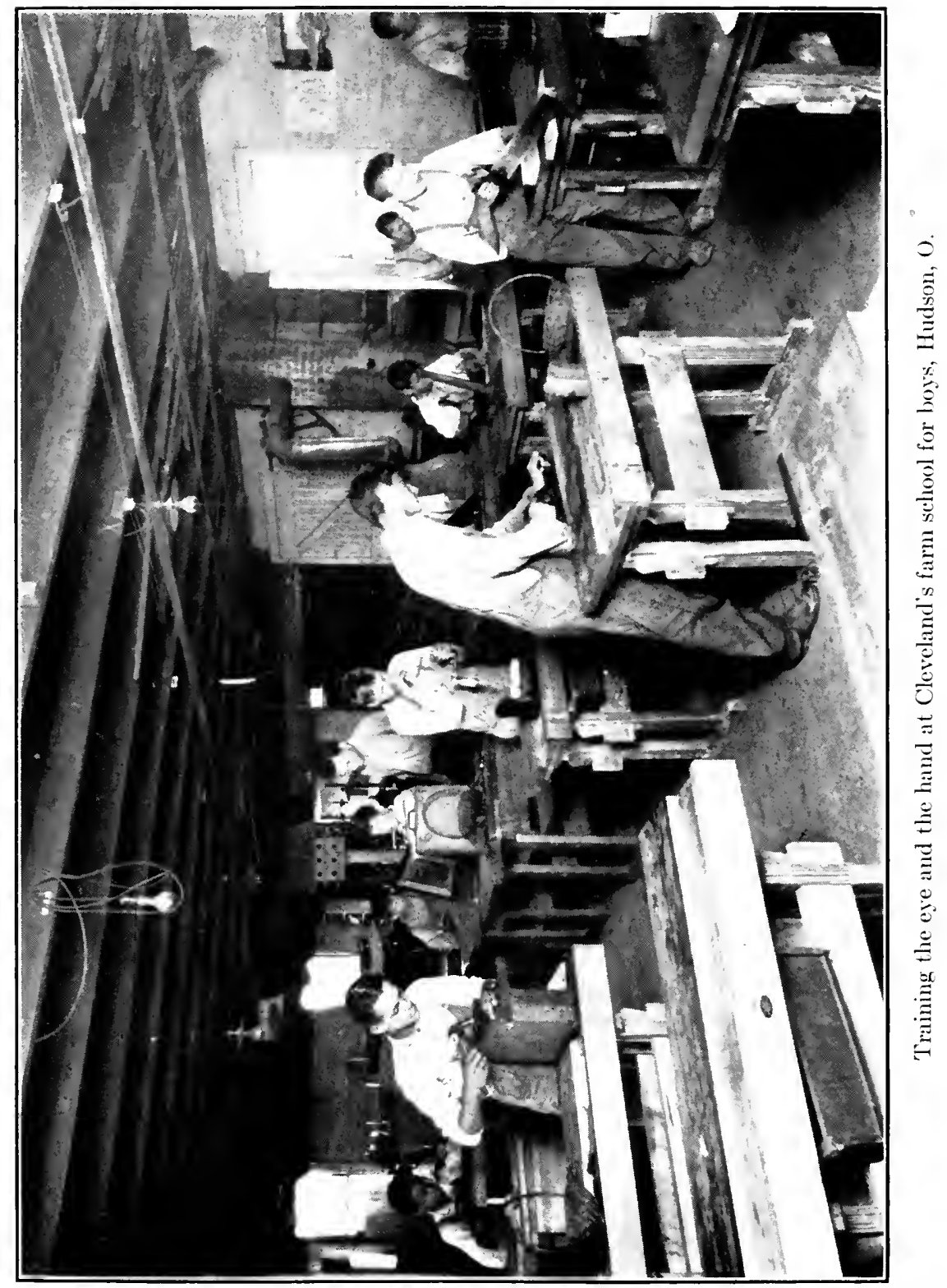


education or cannot read or write the English language, he should be sent to school for part of the day.

A careful record should be kept of his conduct, effort, and performance during his stay through the adoption of a credit marking system, which can be used to clear up disputes concerning his record of conduct and performance at the end of each week.

Where so many men are received and discharged during a month, it is advisable to have a finger-print record of every man before discharge, to be compared with the print taken after conviction and at the time the prisoner is received at the institution. This is the system adopted in New York to prevent men from hiring some one else to serve their terms. A comparison of the finger-print taken immediately after conviction with the one taken upon arrival at the institution and before discharge prevents these substitutions. Under the present system it is possible for John Jones to make a bargain with Henry Smith to permit Jones to answer for Henry Smith when Smith's name is called to be discharged. This swapping of identities may account for the rumors, for which there was no time for investigation, that persons sentenced to the workhouse for considerable periods are seen upon the streets of Cleveland in a very short time. At any rate, the adoption of this identification comparison ended such a scandal in New York.

When the clearing-house and probation investigations are completed, copies of all the reports should be sent with his commitment papers, so that the institutional authorities may have all information as soon as the man arrives. This avoids duplicating investigations and checks up inaccuracies of statement which the prisoner is frequently willing to make after all the reports have been checked up and his confidence has been won.

\section{Recommendations}

The summary of our recommendations for this institution is:

1. A man of strong personality, thoroughly equipped for this type of correctional work, should be employed as superintendent.

2. The inmate population should be studied to determine the aptitudes and the mental and physical ability of the men, and these should be utilized as a basis for determining what work is to be found for the prisoners to perform.

3. The Director of Public Welfare should employ a specially equipped person to establish a system of employment for inmates of the workhouse.

4. The dormitories should be changed into single rooms, so as to put an end to the present mingling of prisoners.

5. The city Superintendent of Schools should be requested to work 
a out system of education for the workhouse and to supply teachers to carry on the work.

6. Modern reception, classification, credit marking, and administrative systems should be established.

7. A modern system of identification should be made the basis of administration and parole work.

\section{The County JaIL}

The county jail, under the jurisdiction of the sheriff of Cuyahoga County, is an old-fashioned, insanitary, and inadequate institution. It has 136 cells- 120 for men and 16 for women. Of the men's cells, 115 are in use, and one padded cell is used occasionally, since refractory prisoners are placed in a strait-jacket in a side room provided for the purpose. The cells in the men's section are in a block four tiers high, and instead of being placed back to back, according to the conventional Auburn plan, have gallery fronts facing the outside walls of the building. These walls are fitted with doors facing the outside windows. The backs of the cells face a center court about 12 feet wide. This center court is roofed over by stone flagging, which serves as a flooring for the second tier of cells and forms a continuous gallery for the same tier. There are four large openings guarded by iron rails to this flooring, from which guards can view the prisoners exercising in the court. The openings also help to ventilate the lower tier of cells and the lower court, which is known as the "bull pen." Prisoners mingle indiscriminately in the "bull pen" during exercise periods, except in the case of murderers or dangerous agitators.

Each cell is about seven feet wide and eight feet long, except on one side, which is about 10 feet wide. The front of the cell is constructed of latticed iron bars. Each cell contains two cots covered with clean bedding, an old black insanitary toilet, and running water.

The so-called women's prison is in a section separate and apart from the men's prison. The cells are arranged in a block four tiers high, with four cells to the tier, all of which face an open court.

Each prisoner is provided one towel and a piece of soap. On the day of our inspection some of these towels were dirty. The toilets were very dirty and corroded. No toilet paper was provided. The cells were not clean, and the corridors were indeed very dirty. The deputy guard in charge of the prison stated that the prisoners were bathed once a week. There were four shower-baths in a fair condition in a separate room of the building.

From a sanitary standpoint the most serious condition in the prison 
is the antiquated plumbing, which cannot be made adequate or safe except by installing a new system. Feeding prisoners in their cells is another drawback, as it permits prisoners to hide food in their cells, which attracts all sorts of vermin.

The kitchen is in the basement. The kitchen equipment is provided by the sheriff, who is allowed 45 cents a day to pay for food and cover the cost of the food service. The kitchen equipment consists of one mediumsized kitchen range, one copper boiler in fair condition, one copper urn in good condition, and one small ice-box.

The food served on the day of inspection was clean, of good quality, and well served when one considers that the prison was never constructed to permit the easy transfer of food from the kitchen in the basement to the various cells. The diet, however, is monotonous. Breakfast consists of bread and coffee; supper, of coffee and bread. There is some variation in the dinner; for example, on Fridays there are pea soup with potatoes, bread, and coffee; on Thursdays boiled corned beef and cabbage, bread, and coffee; on Wednesdays and Saturdays, mutton or pork, beans, bread, and coffee; on Tuesdays, pork or mutton, bread, and coffee; and on Mondays boiled beef or pork, bread, and coffee.

The padded cell is only occasionally resorted to, as more refractory prisoners are sent to the psychopathic ward of the city hospital, or occasionally to the State Hospital for the Insane, which is not far away. One room was improvised to serve as a hospital, and a doctor is supposed to visit the prisoners daily. Serious cases are sent to other hospitals.

Visitors are admitted to the cell block and guarding is restricted to drawing a screen at the end of the "bull pen" to separate visitors from prisoners. This is a dangerous practice, and should be ended at once, as wide experience has proved conclusively that such arrangements are no safeguard against the smuggling in of all sorts of contraband articles, such as knives, razors, pistols, saws, and drugs. The only safe method of receiving visitors in such institutions is to have separate quarters in a section of the building where one officer can watch a single prisoner and his or her visitors continuously during the whole period of the visit. If there is more than one prisoner to watch at a time, the guard is helpless.

In the jail proper there are 24 employees, five of whom are on night duty. These officers go to court with cases. The deputy in charge explained that on an average four of the officers were out of the prison daily, taking cases to the penitentiary at Columbus and to other institutions. The officers receive a monthly salary without board or maintenance. Until the prison has a better trained and higher type of guard or otheremployee, it will continue to do unsatisfactory work. Some of the men: 
are undoubtedly faithful, but nearly all of them have had insufficient training. It is extremely important that prisoners brought to a detention prison for trial should be in the hands only of the most capable, conscientious, high-minded, and responsible employees.

\section{Recommendations}

1. The present jail should be abandoned as soon as possible, but while in use it should be kept decidedly cleaner and the administration improved at once.

2. The kitchen should be equipped with a roaster, to permit the roasting of meats: boiled beef and stews become too monotonous.

3. The walls should be painted and the windows kept clean.

4. Every man should be required to keep his towel clean.

5. The cells should be kept clean and free from vermin, and in particular the toilet bowls should be cleaned and kept in that condition.

6. A sufficient salary should be paid to permit the employment of guards who understand the responsibilities of their position, and whose language is less, rather than more, profane than that of the prisoners under their charge.

7. A simple but adequate record system should be installed in the office, so that a continuous check may be kept upon the movement of prisoners.

8. Prisoners should be sent to the psychopathic ward of the city hospital and should not be placed in strait-jackets in the prison or kept in a padded cell, except upon rare occasions, where there is some real reason for confining them in the prison.

9. There should be better classification of the prisoners, so that there be less intermingling than there is at present. 


\section{CHAPTER II}

\section{CORRECTIONAL AGENCIES FOR MINORS}

\section{The Juvenile Court}

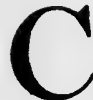

LEVELAND has gained in population, according to the United States census, at the rate of 40.3 per cent. in the last ten years. During the thirteen years from 1907 to 1920 the number of boys brought into the Juvenile Court of Cleveland rose from 984 in 1907 to 2,524 "official" cases in 1920 , a gain of 1,540 cases, or 156 per cent. If to this number of delinquent boys "officially" brought into court there be added the 1,724 boys "unofficially" in court in 1920, the increase in cases of boys dealt with by court in 1920 over the number in 1907 is 3,264 , or over 331 per cent. In other words, the number of delinquent boys brought into the Juvenile Court is increasing from three to eight times as fast as the population. Among the causes contributing to this increase in the burden of the court are the extension of the jurisdiction of the court to include the cases of young people up to the age of 18 instead of 16 which was the former limit, and new legislation creating additional categories of offenses. The figures show the growing burden of the court but are not intended to indicate the increase in juvenile delinquency. ${ }^{1}$

According to the report of the chief probation officer for the year 1920, the total number of cases handled by the judge and attachés of the court was 6,540 , summarized as follows:

Official Cases:

\begin{tabular}{lr} 
Delinquent boys. $\ldots \ldots \ldots \ldots \ldots \ldots \ldots \ldots \ldots \ldots \ldots \ldots \ldots \ldots$ & 2,524 \\
Delinquent girls $\ldots \ldots \ldots \ldots \ldots \ldots \ldots$ & $58 \ldots \ldots \ldots \ldots \ldots$ \\
Neglected cases (involving 638 children) $\ldots \ldots \ldots \ldots \ldots$ & 326 \\
Dependency cases (involving 714 children) $\ldots \ldots \ldots \ldots \ldots$ & 341 \\
Consent to marry $\ldots \ldots \ldots \ldots \ldots \ldots \ldots \ldots \ldots \ldots$ & 13 \\
\hline
\end{tabular}

Total official cases . . . . . . . . . . . . . . . . .

Unofficial Cases:

Boys. . . . . . . . . . . .

Girls . . . . . . . . 187

ApuLts:

Male............................. 760

Female.......................... 81

Total unofficial cases.....................,

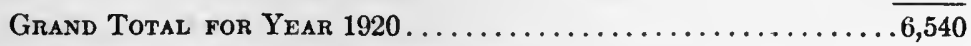

${ }^{1}$ Cf. Delinquency and Spare Time, by Henry W. Thurston, one of the reports of the Cleveland Foundation Recreation Survey. 
About 600 juveniles are upon probation at a time. To look after these, as well as the neglected and dependent children, the court has a staff of four men and 12 women probation officers. Some investigation is made of all "official" cases, and an attempt is made through the "Confidential Exchange" of the Associated Charities to make use of the particular organization which has some knowledge of the child or the family. Although full records have been obtained through the exchange in some cases, in the majority the records are incomplete and in many consist only of the probation officer's reports. These investigations are supplemented by mental examinations in the discretion of Miss Marion Wilcox, who is the connecting link between the courts and the clearing-house in case investigations.

All the information obtained is placed before the judge in the original form, without compilation or interpretation, except as supplemented by the probation officer who made the investigation and who is always present at the court hearing of the case. The judge sometimes reads the original reports, but more frequently relies upon the verbal statements and recommendation of the probation officer.

As most of the court hearings are usually held during two or three days a week, the number of cases on the docket frequently aggregates 70 , and occasionally more. The records of the verbal statements of the probation officer are those contained in the shorthand notes of the hearing which are later transcribed and added to the records, with the notation describing the disposition of the case.

It is evident that the staff is too small. There should be two additional clerk-stenographers and two additional typists, besides four additional probation officers, to handle "official" cases. There should also be five additional field investigators for "unofficial" cases. The additional clerk-stenographers and typists would relieve investigators of the necessity of spending so much time compiling reports and would permit these officers to furnish much fuller and more detailed reports than are furnished by them at present. In any event, the new "control blank," which is a marked improvement over the old card form, should provide on its face for the scoring of homes and neighborhood environment by the probation officer, in accordance with well-known standardized requirements, as well as three or four word summary of the mental examination. Attached to this "control blank" should be a summary of the facts in the case, headed by a recommendation, after discussion of the case in the probation officers' staff meeting and after approval by the chief probation officer or his first assistant. All the papers in the case 
should be attached to the summary and should go before the judge, as at present, for his consideration.

If the suggestions contained therein were followed, the court would be less severely handicapped than at present, and the number of re-appearances of delinquent boys in court, who are finally committed to institutions, would be less than is indicated by the summary, in Table 1, from the 1920 report of the chief probation officer.

\section{TABLE 1.-COMMITMENTS OF BOYS}

City Farm School, Hudson, Ohio. ...................... 93

Boys' Industrial School, Lancaster, Ohio . . . . . . . . . . . . . . . . 245

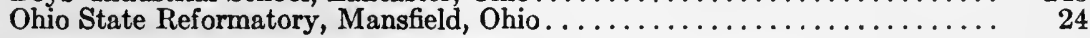

\begin{tabular}{l|c|c|c}
\hline \hline $\begin{array}{c}\text { Number of } \\
\text { commitments }\end{array}$ & City Farm School & $\begin{array}{c}\text { Boys' Industrial } \\
\text { School }\end{array}$ & $\begin{array}{c}\text { Ohio State } \\
\text { Reformatory }\end{array}$ \\
\hline First & 29 & 55 & 6 \\
Second & 40 & 71 & 3 \\
Third & 13 & 61 & 4 \\
Fourth & 7 & 40 & 3 \\
Fifth & 3 & 8 & 3 \\
Sixth & -1 & 5 & 1 \\
Seventh & $\ldots$ & 2 & $\cdots$ \\
Eighth & $\cdots$ & 1 & 24 \\
Ninth & 93 & 245 & \\
\hline
\end{tabular}

One of the greatest weaknesses of the Juvenile Court is the fact that it is housed in the old criminal courts building which, with all its sordid associations, is not a proper place for a juvenile court. If the court were in a building adjacent to the detention home or in a school building, its effectiveness and its power for good would be vastly increased. The Juvenile Court quarters should not be included in the proposed new county criminal courts building and county jail.

In order to carry out this idea of separation it might be better to organize the Juvenile Court somewhat as it is in the city of Cincinnati, as part of the Court of Common Pleas. In that event the court would handle insolvency and other domestic relations matters not connected with the actual trial of children's cases in quarters in the new court building, and all children's court matters and dependency work in quarters associated with the schools or with the Juvenile Detention Home.

This last suggestion is offered with some reluctance for the reason that, as juvenile courts are only in process of development, it would 
seem wise that they should develop in accordance with local conditions. In Cleveland the coöperation of the court with the schools indicates the greater importance at present of continuing in this direction, rather than transferring the court from insolvency jurisdiction to Common Pleas jurisdiction.

Our study of the Juvenile Court in Cleveland has been limited chiefly to a consideration of its activities from the social point of view. In its final implications the court is one of the greatest agencies upon which Cleveland must depend for the healthy development of its child life.

Moreover, the interest displayed by Judge George S. Addams in the work of the various organizations in the Welfare Federation and other social agencies indicates that these organizations are getting benefit from his wide experience in dealing with the children of the city. The particular interest of the judge in the boys at Hudson Farm is most helpful, and increases the effectiveness of that hopeful place to a marked degree. Furthermore, this kindly judge, by reason of the breadth of his interests and desires and his sensible and colorful outlook upon life, brings to bear upon each case the point of view which tends to gloss over the petty and unimportant and to concentrate upon the larger and more significant issues. The children of Cleveland know that the Juvenile Court is no "snubbing" post, and that Judge Addams is neither a species of lion tamer nor a narrow-minded purist.

In order to cope with the situation the court and its attachés should be actively participating in a continuous survey of conditions of child life in the city, and should not limit themselves to the consideration of delinquent and dependent children alone. The court cannot deal adequately with such children unless it is a clearing-house of the city's child life.

Great emphasis is placed upon the fact that the probation office "clears" through the Associated Charities clearing-house every morning at 10. But at the present time the clearing-house is little more than a record office to indicate which agencies are at work on a case. The court is rather poorly served, as a clearing-house out of touch with actual cases means little or no effort to "clear" cases upon the basis of information submitted for the purpose of assigning specific agencies to each case for definite work upon it. The Probation Department, better than any other agency, could see to it that all this work is vitalized.

The clearing-house of the Associated Charities is a great constructive achievement, but even if it were vitalized by continuous close contact with "flesh and blood" rather than "paper" cases, it would still be unable to furnish for the use of the Juvenile Court an adequate moving picture of the social life of the city, especially as it affects children. 
The all-important clearing-house of Cleveland child life is the Department of Education. Unfortunately, it is not as serviceable to the Juvenile Court as it might be. It is not attempting to do all it should, and its available forces for attacking the various problems of childhood are too much scattered. They cannot function properly for school purposes, and they present an aspect of confusion to the judge and to the attachés of the Juvenile Court. This is particularly unfortunate, for the opportunities for coöperation are very great, and the various workers within the school system and the other associations appear eager to respond to Judge Addams' desire for coöperation.

Leonard P. Ayres pointed out, in the School Survey of Cleveland, that the health work of the city school system was retarded because the Director of School Health Work was responsible to the Director of Schools for health work in the schools and to the city Superintendent of Schools for education in public health. This same overlapping is present in other divisions of school work. Miss Claire Walters, psychologist for the boys' school, makes most of the examinations of children in the Juvenile Court, and after September 1 will have charge of all school children appearing in court. She is also the agent of the School Department of Attendance, and is under the direct supervision of the Assistant Superintendent of Schools, Frank G. Pickell.

Dr. Bertha Luckey is Director of the School Psychological Clinic, which is under the direction of Assistant Superintendent of Schools Eldridge. Dr. Luckey's principal work is the examination of school children referred to her by the teachers, to determine whether they should be assigned to special classes. There are three assistant examiners. This department makes no routine examination of delinquents, but occasionally cases are referred to it by the Department of Attendance or by the Juvenile Court.

Dr. Luckey has also applied intelligence tests to nearly 5,000 children in the first grade. Dr. W. W. Thiesen, Director of the School Department of Reference and Research, has also applied these tests in the course of his studies of school problems, using the children of the sixth grade, who are preparing for junior high school. Thus Dr. Thiesen and Dr. Luckey are both giving group intelligence tests, but from a somewhat different standpoint.

Special education in the schools also lacks coördination. Assistant Superintendent Pickell has charge of special education of delinquents in the boys' school, the Juvenile Court Detention Home, the boys' farm at Hudson, and the girls' school at Warrensville. Assistant Superintendent Albert C. Eldredge has charge of this work as it relates to mental defec- 
tives, and H. D. Bixby as it relates to sense defectives, speech correction, and orthopedic class work.

Special education, psychological measurement, the medical and psychiatric work of the schools should be coördinated under one assistant superintendent of schools, who should work in the closest coöperation with the Juvenile Court and the Associated Charities Clearing-house. If for any reason medical and special educational work cannot be placed under one person, special education and psychological measurement should be so combined and a psychiatric division should coördinate the school medical work, the special educational work in the schools, and the psychiatric work of the Juvenile Court. In this way the records of physical, mental, and dental examinations in the school department would be available for use in the Department of Special Education and in the Juvenile Court.

If Cleveland were to coördinate special education and psychological measurement, as Detroit has done, and were to add psychiatric examination, child delinquency and the various social maladjustments of children which are reflected in the children's court would be greatly reduced. In Detroit, Professor Charles S. Barry, of the University of Michigan, with the aid of a corps of assistants, has examined within the past year over 4,000 children with Binet tests. The results of these examinations are extremely important. They have shown that when children are classified according to general intelligence, all types of children progress more rapidly. They have also demonstrated the need for differentiating courses of study for different types of ability, and have greatly stimulated teachers to take into account the individuality of their pupils. Various agencies in Detroit have shown eagerness to avail themselves of the information obtained by the psychological clinic, and the examinations have been used not only in placing dependent children, but also by the judge of the Juvenile Court.

To those who say that it is not the business of a juvenile court to have close relations with educational work, let it be said that the function of the juvenile court, as of the school system, is to serve the children, and since the children will profit most through the closest coöperation of the court and the schools, these two great agencies must consider the welfare of the children and not the legal or customary divisions of court and school work. Coöperation may be secured by careful planning and supervision without any overlapping of administrative functions. In fact, duplication of investigations, examinations, and reports may be avoided in this way. 


\section{Administrative Shortcomings}

The significance of numerous basic needs, such as the provision of simple but comprehensive records of work done and of facts ascertained, is not appreciated. Altogether too much depends upon Chief Probation Officer Thomas L. Lewis and his assistants to "remember" details. This applies both to court work alone and to its coöperation with other agencies.

Too much of the chief probation officer's time is devoted to the consideration of individual cases. The position of chief probation officer in the Juvenile Court is one which calls primarily for a trained executive. He should have a capable assistant to supervise the record system, and this assistant should see to it-(1) That a modern control card or sheet is made out for every complaint, a copy of which should follow the assignment of the case from the court to the detention home, to the Probation Department, to the institution or agency; (2) that an adequate official file is kept of each case which should be the public official record, containing such things as the certificates and official citations and state ments; and (3) a probation or court record file containing all other records pertaining to each case, with a first-page summary containing the essential information up to date. The official file should be open for public inspection; the probation and court record file should be confidential but not secret. It should also be the duty of this assistant to see that all complaints are properly entered, assigned for investigation either to a probation officer or to some agency through the clearing-house, or to both a probation officer and an agency, that the facts of record are correctly copied into the form used by the probation officer and by the clearing-house and that the reports come back promptly, as at present too much time elapses between complaints and assignments and between assignments and reports of investigation.

The chief probation officer, relieved of details by such organization of his work, could devote his time to initiating conferences with school officials, private agencies, different divisions of the city Department of Public Welfare, and officials of the various State and county institutions, upon whose coöperation the success of his work depends to a degree yet unrealized. It is not necessary to cite records to show that many "background" facts are not getting the consideration their importance warrants. The chief probation officer should have time to devise ways and means of remedying this situation without duplication of effort and at the lowest total cost. At the present time no information from the probation office accompanies or follows any commitment to any institution. Information acquired by the clearing-house is used only by 
the Juvenile Court and the clearing-house, and finally there is a complete breakdown of the follow-up system in both probation from the court and parole from the various institutions. After leaving the institution a case too frequently is lost track of until it is again brought to attention through delinquency. As a result, from 25 per cent. to 30 per cent. of the work done is lost.

\section{Investigations}

According to the chief probation officer's report for 1919 there were 3,338 "unofficial" cases, as follows: boys, 2,137; girls, 298; male adults, 721; female adults, 106; letters of warning, 79. In 1920 there were 2,752 cases, divided as follows: boys, 1,724 ; girls, 187 ; male adults, 760 ; female adults, 81 . It is altogether admirable for the Probation Department to adjust as many cases as possible without bringing the child into court or before the judge in formal fashion, but it is a somewhat unwise procedure in Cleveland, where there is an inadequate record and follow-up system to inform the court of the details of unofficial cases in particular. Under present conditions the judge is hardly in a position to know enough of the pertinent facts with respect to any particular unofficial case. In fact, no one but the chief probation officer himself could, from a study of the records, determine what has been done. Every such case should be carefully registered in the clearing-house and no final decision should be made without the specific concurrence of the judge entered upon the unofficial records of the court.

We are not impressed by those who urge that a juvenile court judge should pass upon the details of each case, for that would mean he would be his own chief probation officer. We are, however, strongly of the opinion that it is the duty of the chief probation officer to furnish to the judge a complete summary of each case, and that the judge, in writing or upon the minutes of court, should direct the chief probation officer in making final disposition of so-called "unofficial" cases.

There should be as careful a record of essential details in "unofficial" cases as there is in "official" cases. Apparently this is overlooked by the officials of the court, for Mr. Lewis, the chief probation officer, reeeives all complaints. A complainant gives his story verbally to $\mathrm{Mr}$. Lewis, who then decides whether:

(a) To handle the case himself, or

(b) To have an affidavit prepared and filed covering the subject matter of the complaint, or

(c) To have the case investigated by a probation officer.

A study of cases shows that not enough care is used in jotting down, 
in report form, all the facts for future investigation. It is obviously wrong practice to have the investigation of 2,500 to 3,500 "unofficial" cases per year depend at vital points upon the ability of the chief probation officer to remember important details. The methods used lead the probation officer to decide upon a line of action, either without investigation or with only partial investigation. Few cases can be handled wisely without thorough knowledge of the child himself, the facts concerning his family life, the attitude of the parents and all the environmental conditions, yet in this Probation Department many scores of cases are handled by people who depend upon their own ability to "size up" the situation through personal interviews and without reports from social workers, a psychiatrist, or a probation officer.

\section{General Criticism}

The obvious weaknesses of a system which places too much emphasis upon the conduct of children and too little upon the responsibility of parents are present here. There are, of course, commendable attempts to avoid punishing the child for the offenses of parents. Evidently the court officials aim to protect the child from such mistakes, but of ten the traditional practices which are accepted as a basis for action lead to undesirable results. It could not be otherwise where there are too few home and field investigations. It is also the natural result where the attempt is made to guide parents and children by telling them in effect, "Do so and so and you will be punished," when the emphasis should be in effect, "You must do so and so for the good of your children."

Cleveland has vested in its Juvenile Court jurisdiction over dependent children, delinquent children, and widows' pensions. Strictly speaking, dependency and widows' pensions are not proper subjects for juvenile court administration, which carries over too many traditional practices from courts for adults. It is doubtful if probation officers will do as efficient child placement work as some of the other organizations, although there is no inherent reason why they cannot be trained to perform placement work properly. The various agencies coöperating through the Associated Charities Clearing-house, the Division of Outdoor Relief of the Public Welfare Department of the city, the various hospitals under the jurisdiction of or coöperating with the city Health Department, are also vitally concerned. The best organization for Cleveland would probably be one in which the Probation Department could call upon the Associated Charities clearing-house, upon the school and upon the Division of Outdoor Relief for investigation and information. In that case the Welfare Federation might organize a child welfare bureau to function 
partly in response to specific requests of the Juvenile Court Probation Department, partly on its own initiative, and partly in response to requests from other sources. If $\$ 25,000$ in private funds were available to pay and equip an executive for such a clearing-house investigation committee, the latter could secure the active coöperation of the newspapers, as well as of reluctant or busy officials and private persons, who could see the great advantages flowing from the intensive development of this work.

Judge Addams should not fail to have all cases examined either by a skilled psychiatrist or clinical psychologist, if possible, or, if not, by the Bureau of Juvenile Research in Columbus. The ability of the judge and the chief probation officer to "size up a case" with skill is not disputed, and this ability undoubtedly increases with experience, but Cleveland cannot afford to depend upon that ability, however great, as a substitute for a more comprehensive study of its delinquent children. Judge Addams can also help develop still further the remarkable child welfare clinics of the public schools by using them more frequently.

We question the adequacy of Mr. Lewis as chief probation officer as we have envisaged that office. Mr. Lewis has many good qualities, but he lacks those qualifications which are essential to the greatest success of probation work in the Juvenile Court of the future. The greatest chance for the success of this court in Cleveland is through the development of the widest coöperation with the schools, where its success has already been notable. The chief probation officer should be a man of the best training, specifically for work with children. Not only should he be acquainted with educational and public health methods, but he should have a rank and salary equal to those of an assistant superintendent of schools. Such a man would be in a position to secure a maximum of coöperation with the schools.

\section{Summary of Recommendations}

In summary form, our recommendations are:

1. The budget of the court should be increased $\$ 22,000$ a year, to permit an increase of the judge's annual salary to $\$ 8,000$, of the chief probation officer's salary to $\$ 5,000$, and to allow the employment of nine additional officers, two additional clerk stenographers, and two additional typists, and to pay whatever additional expenses this improved service requires.

2. A highly trained and experienced person should be employed as chief probation officer, to have rank equivalent to that of an assistant 
superintendent of schools, who should be able to secure the maximum coöperation with the schools and all public and private agencies in the city. The duties of the chief probation officer of the Juvenile Court should become wholly executive.

3. A more effective record system should be established. There should be a complete interchange of records between the Juvenile Court and the public schools, the Associated Charities clearing-house, the Detention Home, the various institutions to which children are committed by the Juvenile Court and the Division of Outdoor Relief of the Department of Public Welfare.

4. In order 'to increase their own effectiveness and coöperation with other agencies, the Board of Education and the Superintendent of Schools should place all functions with respect to special education under the supervision of one assistant superintendent of schools.

5. The health work of the schools should include consideration of mental hygiene. A capable psychiatrist should be placed, if possible, in the Division of Special Education as part of an organization composed of workers in the various fields, or at the head of such a group to make psychiatric as contrasted with psychological measurements of school children, or, if this is not possible, he should be the special representative of the head of schools and the liaison between the Division of Special Education, the school dispensaries, and the Juvenile Court. Psychological measurements in that event should be made in the Division of Special Education. There should be a mental and physical examination of every child brought to the attention of the Juvenile Court or its Probation Department, and an extensive interchange of records of examinations among all the agencies interested before the case comes up in court for formal action.

6. If the functions of probation and parole in the Juvenile Court be not separated, a sufficient number of probation officers should be employed at once to permit effective parole work, not now performed at all, for children released upon parole from the various institutions. The history of every case, as far as it is known to the probation officer, should accompany or follow the commitment papers of every case committed to an institution. It should be the business of the probation officer to summarize the clearing-house information, with the information concerning medical, psychological, and psychiatric examinations and the child's school record.

7. In order to increase the effectiveness of the work for dependent children and pension work a joint investigation bureau should be estab- 
lished with a paid secretary, capable of coöperating with all public and private agencies.

8. The Children's Court should be removed entirely from the criminal courts building and quartered either in a new building adjacent to the Detention Home or in a public school building.

9. If it becomes advisable to change the Children's Court from Insolvency Court jurisdiction to Common Pleas Court jurisdiction, the work for children should be kept separate and apart from work for adults and domestic relations work not directly affecting children, so that the latter need not be brought in personal contact with the sordid details of such cases.

10. Judge Addams should exert his own influence and the prestige of the court to the furtherance of the fullest coöperation with the public schools, in particular, and with the other public and private agencies of the city.

\section{The Detention Home}

The Cleveland Detention Home is, unfortunately, located at a considerable distance from the Juvenile Court, thus greatly impairing its usefulness to the court and to the Probation Department. It consists of a remodeled mansion, used for offices and staff residence, and a fire-proof extension which is thoroughly modern, except for the provision of dormitories instead of private rooms. The county has recently acquired an adjoining property, thus providing space for a fairly good playground. It was intended, at the time of the original purchase, to convert the residence into a home for dependent children under the care of the Juvenile Court, but this plan was given up because the building could not, within reasonable expense, be made fire-proof, and, therefore, under the provisions of the city ordinances, it could not be used for housing children. There is sufficient room on the combined plots owned by the county to house the probation office and Juvenile Court and still leave the same amount of playground space that is now being used. Such an arrangement, from an administrative viewpoint, would be highly desirable, though the present location of the Detention Home is not as central as would be desirable for a probation office and Juvenile Court.

The excellent new building, which has two stories and a basement, has a roof designed for use as a playground. The second floor, which is used exclusively for boys, contains officers' quarters, two dormitories, five cells, a dining-room, pantry, playroom, and toilet facilities. The first floor, laid out in much the same manner, is used exclusively for girls. In the basement are located the kitchen, laundry, storehouse, a room about 23 by $86 \frac{1}{2}$ feet used as a gymnasium, and shower-baths. 
The basement also has a reception room for new arrivals. The building is clean and sanitary throughout.

The Detention Home staff consists of a superintendent, Miss Laura A. Marlow, appointed by the Juvenile judge; a girls' matron and boys' master; a housekeeper, two cooks, a laundress, a man acting as engineer and fireman, a bookkeeper, a nurse, and a teacher. There are also one or two relief officers and a night-watchman.

Children under eighteen may be sent to the Detention Home either by the probation officer or the Juvenile judge. The police and truant officers may also turn over to the Detention Home children under eighteen to be detained until they can be produced in court. The number of boys varies considerably from day to day. There are rarely less than 50 or more than 90 , though there have been at times over 100 . When newcomers arrive, they are carefully bathed, their heads are treated with a solution of larkspur, or washed with coal oil, their clothing fumigated and put away for future use, and fresh clothing is given them. Practically no information, except the name, age, home address, and charge, is received with the new arrival. A physical examination is given by a non-resident physician.

The home has no adequate means of segregation. There are two dormitories for boys and two for girls, and when these are not overcrowded, it is possible to segregate the younger from the older children.

The only facilities for school purposes consist of one small room where six or eight of the younger girls receive instruction, under a teacher appointed by Assistant Superintendent Pickell, of the Educational Department of the city. Boys are given instruction in the Boys' School, a block and a half from the home, which is under the jurisdiction of $\mathrm{Mr}$. Pickell. The boys who attend this school are taken back and forth morning and afternoon by a relief officer from the Detention Home.

Children may be detained in the Detention Home from a few hours to several months. When a child is to be released, a written order from the court is presented to the superintendent by the individual into whose custody the child is given. The superintendent has no knowledge of the conditions of release or of what becomes of the child afterward.

The greatest criticism to be offered in the boys' department is the utter lack of suitable employment. Under the supervision of the two officers in charge, a matron-housekeeper and a male officer, the work of keeping the place in order is done by the boys themselves. There is a woeful lack of indoor recreational facilities and a failure to take advantage of such outdoor facilities as a good playground on the roof. This failure to use the roof was explained by the officer in charge as due to past mis- 
behavior on the part of two boys who had been allowed to play there. During our visit there were about 30 boys playing noisily in the playroom. The officer commanded quiet and then lined the boys up, and, turning to the investigator, said that he would now tell him about the boys. The following questions were then asked:

Officer: What is your name?

Boy: John Smith.

Officer: How many times have you been here?

Boy: Three times.

Officer: What are you here for this time?

Boy: Stealing.

Officer: Did you ever go to Lancaster?

Boy: Yes.

Officer: You broke parole from Lancaster, didn't you?

Boy: Yes.

Officer: And then you stole and had to come back here?

Boy: (In a crestfallen manner) Yes.

The officer then passed to four other boys with similar questions. Much the same answers were given in each case. The officer then said that boy No. 2 was a very bad boy and could be depended upon to lie and to steal if he had the chance. The investigator interrupted this brutal interchange by talking directly with the boys.

There is practically no oversight of the boys' dormitories at night. A watchman, whose bedroom is nearby, visits the dormitories once an hour "to ring up." There is nothing to prevent the grossest kind of immorality, and although the officer in charge admitted that he was aware of the existence of this problem, the night-watchman is still the only reliance against it.

The Girls' Department is under much better supervision than the Boys' Department, except that there is some lack of supervision in the dormitories and not enough work or directed recreation. The laundry furnishes employment for older girls. There is a resident school teacher for the Girls' Department, but only girls under fourteen, of whom there are few, are required to attend school. The girls are sometimes allowed to play on the roof. It should be possible to provide them with many simpler and more beneficial occupations.

The medical examinations made by the visiting doctors from Fairview Park Hospital are not always adequate or timely. Sometimes the doctors have barely begun work when the telephone orders them to return to the hospital for some emergency. This situation could perhaps be remedied if the visiting staff of the hospital could be induced to become 
responsible for the work at the Detention Home, and an interne were provided who should be held responsible for the ordinary medical work at the Detention Home, subject to the general direction of the visiting staff.

Coöperation with the schools should be encouraged. The present plan of conducting practically all school work in the home deprives the children of a chance to go to school in a regular school building, and of the opportunity to secure training in industrial classes. It also reduces the school work to the level of perfunctoriness into which detention schools degenerate, since the management cannot offer to a teacher the inducements which can be offered by a school system whose work with delinquents is conducted not in a detention home, but in a school building.

\section{Recommendations}

1. The recent plan of coöperation with the boys' school should have been extended instead of being abandoned.

2. A better program for both work and play should be provided for the boys' department. The Cleveland school system offers excellent suggestions for use along these lines.

3. It is altogether wrong and indefensible that from 30 to 50 boys should be kept in small quarters in comparative idleness, some few of them for periods of several months.

4. Although the man who was supervisor of the boys' department during the spring has many excellent qualities, his entire lack of understanding of the problems connected with his institution nullifies his effectiveness, and unless this can be changed, there should be a change of supervisors.

5. Criticism may well be made of the present salary scale ( $\$ 60$ a month), which is hardly enough to secure the services of a really competent person.

\section{The Boys' School}

Cleveland maintains a special school for truant, delinquent, and incorrigible boys, known as the Boys' School. It is a part of the public school system and is under the direct supervision of Assistant Superintendent Pickell, of the Department of Education, who personally approves all admissions. Applications to Mr. Pickell are made through the Department of Attendance after all attempts at adjustment by family appeal and school transfer have failed. No routine mental examinations are made before admission, although a fairly good social study is conducted. The officer or teacher recommending admission may apply to 
the psychological clinic for special examination, but this is seldom done. It is admitted by Mr. Pickell that a certain amount of odium is attached to the compulsory attendance of children in this school, which is known locally as "the bad boys' school."

Mental examinations are conducted principally by Miss Claire Walters, of Mr. Pickell's division. So far as could be learned, these results are used only for the classification of the feeble-minded boys in the school. A general classification of all boys on the basis of intelligence is not undertaken.

As already stated, there is close coöperation between this school, the Detention Home, and the Juvenile Court. The work of the school is divided into three parts-regular grade work carried on as special class instruction, manual training and handicraft work, and the Department of Psychological Examination and Placement.

The regular grade and special class work presents no features that are not found in other similar class-room work. Teachers in charge of special classes are not employing modern methods of teaching this type of child. It has been found that there is practically no direct bearing of the psychological examinations upon class-room work. The work is mechanical, and the only clear advantage it has is that of relieving the grades in the regular public schools of certain backward children.

In one particular at least the vocational and manual training work in the Boys' School is above the average. This is the printing department. This. department is in charge of a man who, besides being a master printer, is a devoted student of boy life, as well as a capable teacher with initiative and ingenuity. All these traits are reflected in the quality of work being done in the pressroom.

The course of study for this work has been adapted to the various requirements of vocational education with unusual understanding: one part correlates history, another geography, a third arithmetic, and so on.

The class in handicrafts, which is also under capable direction, includes basketry, weaving, knitting, and the like. The kind of work turned out is far above the average usually found in similar classes elsewhere. It should be pointed out, however, that this work is performed by boys who are practically normal. Nevertheless, the secret of success in these two departments is undoubtedly the fact that those in charge are working in the closest and most harmonious relation with the Division of Psychological Measurement and Placement.

The woodworking department is not up to the average manual training work found in grade schools, although some of the objects are fairly well made. The work seems commonplace, because the instructor lacks 
freshness and resource. Only the most obvious lines of work are being followed and the most obvious and commonplace opinions expressed about the work by the teacher. This department presents an ideal opportunity for incorporating some of the principles of free-hand and mechanical drawing, as well as for teaching some of the simpler truths of geometry, but nothing of this kind is done. On the whole, it seems that the most vital features of manual training work are being ignored.

The Department of Psychology and Placement is under Miss Walters' directions. Fundamentally, this department exists for the purpose of studying, adjusting, and replacing the truant, backward, and delinquent children sent from the public schools to the Boys' School. Its purpose is the application of mechanical tests for the purpose of discovering, according to Terman's Revision, the mental age of children with reference to its effectiveness. We quote the following from the Cleveland Hospital and Health Survey:

"The important relationships of juvenile delinquent boys to mental diseases and other disorders of the mental system are well understood, and many efforts are made to secure psychiatric and psychological examinations that will throw light on this subject in individual cases. Miss Claire Walters, who is attached to the Boys' School, makes 'intelligence tests.' At her suggestion the services of the psychiatrist attached to the Probate Court were employed. At the Boys' School and Detention Home children were observed while their cases were pending or while awaiting placement, but, of course, this observation was not made by those trained to detect the most significant alterations in behavior" (p. 480).

There are many evidences of the fact that much thought has been given to the question of measurement, and that the intention of the founders was clearly to establish contact with all bureaus, courts, and institutions which could profitably be related to this work, but the work has not thus developed, indicating the need for a change in administrative control, which we have previously recommended.

\section{Recommendations}

1. The school is one of the most potent constructive agencies for the prevention of delinquency in the State, and its principles should be extended throughout the city.

2. At the present time manual education is not being offered in the public schools below the junior high school, except incidentally or through special classes for defectives.

3. Judge Addams of the Juvenile Court should be encouraged to continue committing boys to this school, since by doing so he is setting 
an example in coöperation between correction agencies and the school system.

4. Boys should not be committed to this school except after mental examinations, supplementing social investigation.

5. It is easily conceivable that readjustments in the ordinary public schools might be made on the basis of some such examinations without the need for admission to this school.

6. Feeble-minded delinquents could then be adjusted directly through the Department of Special Classes in the city school system.

7. These examinations could be made by Miss Walters, as at present, or more properly through a mental clinic, comprising a capable psychiatrist as well as a clinical psychologist, whose assistant Miss Walters should be.

8. The administration of the school should be based on scientific principles and on a scientific classification of the boys in all lines. The printing division and handicraft work are examples of a good beginning. Probably a better and more comprehensive examining system and course of study could be worked out, adapted to the particular needs of each child. The school might well adapt many of the methods developed by the extraordinary Moraine Park Private School in Dayton, Ohio.

9. When schools for delinquents and truants have set the example, it will then be necessary for the city to extend to all schools proper classification and differentiation in education based upon actual experience in Cleveland. When this is done, delinquency growing out of truancy and lack of interest in studies or failure to keep up in school will in all probability be drastically checked.

\section{The Cleveland Boys' Farm at Hudson}

The Cleveland Boys' Farm, opened in 1903, is about 35 miles from the city. As indicated by its name, it is a city farm colony institution. There are eight frame cottages, a power plant, greenhouse, school-house, barns, shops, laundry, and central kitchen. The population usually averages about 140 boys, who range in age from ten to eighteen years. The staff consists of the superintendent, eight cottage fathers and eight matrons, a principal of the school, a farmer, an engineer, and a general utility man. The general training offered by the institution consists of farming, gardening, housework, with limited opportunities for a few students in mechanical work, and good opportunities for prevocational and vocational work. While the equipment for manual work is limited, this handicap is somewhat compensated for by the small numbers to be 
taught and the intimate relationship existing between instructors and pupils.

Boys are committed to this institution nominally by the Juvenile Court, but in practice by virtue of a "gentlemen's agreement" between the court and superintendent. The superintendent, John A. Eisenhauer, personally visits the Detention Home at Cleveland and selects the candidates for the farm. As a result he is able to carry out a well-graded classification system along the cottage lines. This promotes more constructive efforts with the boys.

When the superintendent visits the Detention Home in the city with a view to selecting candidates for his institution, he gets some facts with respect to their history from the matron of the home, but practically nothing in record form. When a boy arrives at the farm he is accompanied by a commitment paper; beyond this there are no facts or other information available to the superintendent. The latter may visit the Boys' (Truant) School and learn from Miss Walters something of the mental traits and personal characteristics of each boy. This is furnished verbally in most cases and not, as a rule, in written form, except when a psychological report is necessary. The probation office and the Juvenile Court supply information only by special request.

In order to determine the intelligence level of the population as a whole, Dr. Herman M. Adler's assistant, E. K. Wickman, administered group intelligence tests to all the boys of the school, 121 in number, except 14 who were engaged about the farm. The ages of the boys examined vary from eight to fifteen years. The results for 118 are classified below. ${ }^{1}$

The results in the cases of three boys were omitted because of doubtful information concerning chronological ages. The results as a whole are computed in mental ages according to the mental age norms of the

1 TABLE 2.-INTELLIGENCE SURVEY OF CLEVELAND BOYS' FARM

\begin{tabular}{|c|c|c|c|c|c|c|c|c|c|c|}
\hline Intelligence quotient & $\begin{array}{c}\text { Below } \\
9\end{array}$ & 9 & 10 & 11 & 12 & 13 & 14 & 15 & Total & $\begin{array}{r}\text { Per } \\
\text { cent. }\end{array}$ \\
\hline $\begin{array}{l}40-49 \\
.50-59 \\
60-69 \\
70-79 \\
80-89 \\
90 \text { and over }\end{array}$ & $\begin{array}{l}\because \\
\because \\
\dddot{1} \\
\dddot{1}\end{array}$ & $\begin{array}{l}\cdots \\
\cdots \\
\ddot{2} \\
4\end{array}$ & $\begin{array}{l}2 \\
8 \\
3 \\
3\end{array}$ & $\begin{array}{l}\cdots \\
\ddot{5} \\
6 \\
2 \\
5\end{array}$ & $\begin{array}{l}3 \\
3 \\
2 \\
1 \\
2 \\
6\end{array}$ & $\begin{array}{r}2 \\
2 \\
2 \\
2 \\
14\end{array}$ & $\begin{array}{l}2 \\
2 \\
7 \\
2 \\
9\end{array}$ & $\begin{array}{r}2 \\
\dddot{2} \\
1 \\
4 \\
10\end{array}$ & $\begin{array}{r}2 \\
7 \\
15 \\
25 \\
17 \\
52\end{array}$ & $\begin{array}{r}1.7 \\
5.9 \\
12.7 \\
21.2 \\
14.4 \\
44.1\end{array}$ \\
\hline Total & . & .. & .. & $\therefore$ & .. & .. & .. & .. & 118 & 100.0 \\
\hline
\end{tabular}


Delta 2 Scale of Hagerty's Intelligence Examination, and these in turn are reduced to approximate intelligence quotients. We believe the results give a general estimate of the intelligence of the boys.

It appears that 44 per cent. of the boys have adequate intelligence; 14 per cent. are somewhat backward, and 40 per cent. are retarded or somewhat inferior. The definitely inferior number about 24 boys out of a total of 118. The results as a whole indicate that the greater proportion of the boys are of average or above average mental development and able to do regular school work, but it is also clear that the institution is confronted with a problem of education and training subnormal children, since out of 118,25 are retarded in their mental development and 24 are inferior mentally.

The educational work of the institution is under the general supervision of Assistant Superintendent Pickell, of the Cleveland Department of Education. In addition to general training the superintendent himself gives personal thought and oversight to character building and training in ethics. The discipline is the same as that usually found in institutions of this type. Corporal punishment is permitted and can be administered only in the presence of and with the consent of the superintendent. Nothing severe is countenanced. Usually punishments consist of deprivation of privileges, extra work, short rations, or prolonged stay in the institution.

Paroles and discharges are arranged chiefly over the telephone by the probation officer or the judge of the Juvenile Court. It is almost always a verbal arrangement. The superintendent's duty begins and ends with the boy in the institution. There is no follow-up or parole work whatsoever, either by the institution or the Juvenile Court Probation Department.

This is the most hopeful of Cleveland's penal institutions, not because of its buildings or equipment, but because of the intelligent leadership of the superintendent and his assistants. It is the best example of intelligent thrift we have seen in the institutional life of Cleveland. There are, however, serious administrative defects:

The administrative plan of the institution is faulty. Its superintendent is appointed by the Director of Public Welfare, but the latter has had no further active responsibility in the matter. The Juvenile Court is concerned with commitments and recalls, and is supposed in a vague way to have further supervising powers, but as a matter of fact does not exercise them. The Probation Department acts as agent for the court in placing and releasing boys from the institution, but is otherwise unconcerned; hence the superintendent is responsible to no one, and succeeds because its present head is both capable and conscientious. 
It has no adequate knowledge of the social and mental histories of its wards.

It keeps only the usual school work record of its inmates and a record of infractions and bad conduct, but no system of recording progress.

It furnishes no supervision, directly or indirectly, of boys on parole, nor does it receive any information concerning their progress or failure while on parole.

\section{Recommendations}

1. The Director of Public Welfare should appoint a representative group of citizens to act as an advisory board for this institution; an administrative code should be worked out, setting forth the duties and responsibilities of such an advisory board, its relation to the Department of Public Welfare, the Juvenile Court, and the probation office, and providing for a proper reception and classification system for inmates, a system of records, and an adequate parole plan. These should be in thorough accord with the spirit, purposes, and work of the Juvenile Court, the Detention Home, the Juvenile Probation Department, and the Department of Public Welfare.

2. A regular plan should be formulated for the exchange of information to the end that this institution shall receive the fullest possible family and individual history of all inmates from the Associated Charities clearing-house.

3. There should be one final and supreme supervisory authority exercised over the institution. If for any reason it be deemed advisable for the Juvenile Court to continue any manner of supervision over this institution, a clearer demarkation should be made between executive and judicial functions, so that this important experiment of administrative and judicial coöperation be allowed to develop normally. All school and other productive work of the institution should be coördinated through mental and industrial tests. There should be the fullest development of the medical service.

\section{The Girls' Farm at Warrensville ${ }^{1}$}

The Girls' Farm at Warrensville consists of a single wooden structure containing two stories, an attic, and a basement, with a capacity of 39 .

1 The first examination of this institution by the survey was made in May, 1921 . At that time there was in progress a fundamental reorganization. Since then the present superintendent has taken office. In order to appraise the results of this reorganization Mr. Lewis made another inspection in January, 1922, and changed his statement from the form in which it appeared in the first releases of the survey to the form in which it appears here.-Raymond Moley, Director of the Foundation. 
This capacity is usually exceeded. Recent alterations have provided four bath-tubs, two showers, six toilets and lavatories, well-lighted and ventilated dormitories, a dining-room and kitchen on the first floor, a school-room, and a living-room. The building is a serious fire menace. The boilers and furnace are in the basement, and the clearance between the top of the furnace pipe and the ceiling is about one foot. A small heater for hot water is attached to the plant. The connection between this heater and the smokestack has a clearance of 15 or 16 inches from the ceiling, which consists of floor beams and flooring for the rooms above.

The institution prior to the appointment of an advisory board by the director in 1920 was administered without any thought-out plan. It was neither a home, a school, a correctional institution, nor a recreational center, but a little of each.

Such records as came to the institution were kept in bureau drawers. There was no accounting system worthy of the name. Receipts and memoranda of past transactions were kept on miscellaneous slips of paper. It was impossible, by consulting the records, to find out anything about the institution. There seemed to be an almost total lack of appreciation of the problems connected with the attempt to train and guide the type of girl committed to its charge.

The training consists of housework and school work and gardening. The housework is simply cooking, cleaning, making beds, and the like. An attempt is made to teach the girls the art of cooking and homemaking. The investigators who visited the farm are all of the opinion that the housework is well performed. The girls themselves appear to be attractively and simply attired and very well behaved. Everything about the place indicates intelligent and able management. The advisory board, appointed by the Director of Public Welfare, has suggested many improvements. The new superintendent is bringing the administration of the farm up to the level of the boys' farm. The city should furnish equipment which the school so much needs.

The course of study provided for these delinquent girls contained several periods a week of algebra, geometry, and art; one period a week for French, hygiene, and vocational guidance. These subjects were obviously unsuited to the institution and the new superintendent, Miss Colver, has completely reorganized the school.

\section{Recommendations}

1. A thoroughly experienced woman should be kept in charge.

2. Methods of good business administration should be adopted, such 
as the use of proper filing cases and a store-room for supplies. A good system of accounting should be installed.

3. Household art, physiology, hygiene, dressmaking, millinery, and kitchen gardening should be the basic subjects for instruction.

4. A matron should be engaged for all-night duty, and additional officers employed for day duty in the school.

5. The windows of the cellar and the first floor should be made secure against intrusion from without. Girls should be permitted to go to work outside of the institution only when accompanied by a responsible and capable woman officer of the girls' school.

6. The present building should be moved to a proper location as soon as possible, and upon the new site one additional modern cottage should be erected to accommodate the girls who cannot be sent there now. 


\section{CHAPTER III}

\section{PROBATION}

1

HE city of Cleveland employs probation officers in the Municipal and Cuyahoga County employs them in the Juvenile Court. Probation work in Common Pleas Court is supposed to be performed by parole officers attached to the State Reformatory at Mansfeld and the penitentiary in Columbus. While a detailed study of the work of the State Parole Department did notfall within the scope of this survey, it is obvious that the small staff of officers attached to these two State institutions is overwhelmed with parole work and can give little time to probation work in the various counties. The Common Pleas judges in Cleveland have for a long time recognized that they cannot depend upon the parole officers of the State to conduct the painstaking investigations which the modern probation system requires. As a consequence, these judges are attempting to settle cases in advance through the imposition of sentences or by change of disposition. No matter how well intentioned the judge, the fact that he changes his dispositions so frequently in itself has a tendency to lower respect for the courts as impartial tribunals, for to the ordinary criminal a favorable change of disposition means that the court or some officer has been "seen." This attitude of offenders must be appreciated in planning a proper correctional system for Cleveland.

Municipal Court judges observe this tendency of the Common Pleas courts and have pushed it to absurd extremes. The number of cases municipal judges have to handle, the speed required, and all of the conditions surrounding the courts are productive of results which are unworthy of Cleveland. Other branches of this survey have observed in detail how cases are handled. We have confined ourselves to a study of the results of their work as these are reflected in the disposition of cases sent to the Warrensville workhouse. A portion of the results of this study are summarized in Tables 3 and 4 and graphic comparisons of the figures in the tables are presented in Diagrams 1 and 2, the former illustrating material in Table 3 and the latter the material in Table 4. 
This analysis indicates clearly that Cleveland courts are attempting to perform not only the services of a court, but also those of a well-

TABLE 3.-ANALYSIS OF SENTENCES TERMINATED DURING THE MONTHS OF JANUARY, FEBRUARY, AND MARCH, 1920, CLASSIFIED BY THE KIND OF SENTENCE IMPOSED BY THE COURT

\begin{tabular}{|c|c|c|c|c|c|c|c|c|c|c|c|}
\hline \multicolumn{2}{|c|}{$\begin{array}{c}\text { Kind of } \\
\text { sentence }\end{array}$} & Labor & $\begin{array}{l}\text { Labor } \\
\text { and } \\
\text { costs }\end{array}$ & $\begin{array}{l}\text { Expi- } \\
\text { ration } \\
\text { and } \\
\text { costs }\end{array}$ & $\begin{array}{l}\mathrm{Pa} \text { - } \\
\text { roles }\end{array}$ & $\begin{array}{l}\text { Court } \\
\text { orders }\end{array}$ & $\begin{array}{c}\text { Es- } \\
\text { capes }\end{array}$ & $\begin{array}{c}\text { Still } \\
\text { in }\end{array}$ & Misc. & \multicolumn{2}{|c|}{ Totals } \\
\hline \multicolumn{2}{|c|}{$\begin{array}{l}\text { Time, fine, and } \\
\text { costs } \\
\text { Time and fine } \\
\text { Time and costs } \\
\text { Time only } \\
\text { Fine and costs } \\
\text { Fine only } \\
\text { Costs only }\end{array}$} & $\begin{array}{l}33 \\
61 \\
10 \\
24 \\
\dot{4}\end{array}$ & $\begin{array}{l}66 \\
\dot{3} \dot{7} \\
\dot{2} \dot{3} \\
\ddot{2}\end{array}$ & $\begin{array}{c}107 \\
\dot{63} \\
\ldots \\
\ldots \\
\ldots\end{array}$ & $\begin{array}{r}68 \\
17 \\
1 \\
3 \\
\dot{2}\end{array}$ & $\begin{array}{r}17 \\
23 \\
8 \\
2 \\
1 \\
1 \\
1\end{array}$ & $\begin{array}{r}22 \\
4 \\
11 \\
\ddot{2} \\
\cdots\end{array}$ & $\begin{array}{l}1 \\
\cdots \\
\cdots \\
\cdots \\
\cdots\end{array}$ & $\begin{array}{l}8 \\
2 \\
2 \\
\cdots \\
\cdots \\
\cdots \\
\cdots\end{array}$ & $\begin{array}{r}\text { Num- } \\
\text { ber } \\
322 \\
29 \\
199 \\
13 \\
53 \\
1 \\
9\end{array}$ & \begin{tabular}{r}
\multicolumn{1}{|r}{ Per } \\
cent. \\
51.4 \\
4.6 \\
31.8 \\
2.1 \\
8.5 \\
0.2 \\
1.4
\end{tabular} \\
\hline \multirow{2}{*}{ Totals } & Number & 132 & 128 & 170 & 91 & 53 & 39 & 1 & 12 & 626 & 100.0 \\
\hline & Per cent. & 21.1 & 20.4 & 27.2 & 14.5 & 8.5 & 6.2 & 0.2 & 1.9 & & \\
\hline
\end{tabular}

TABLE 4.-ANALYSIS OF SENTENCES TERMINATED DURING THE MONTHS OF JULY, AUGUST, AND SEPTEMBER, 1920, CLASSIFIED BY THE KIND OF SENTENCE IMPOSED BY THE COURT

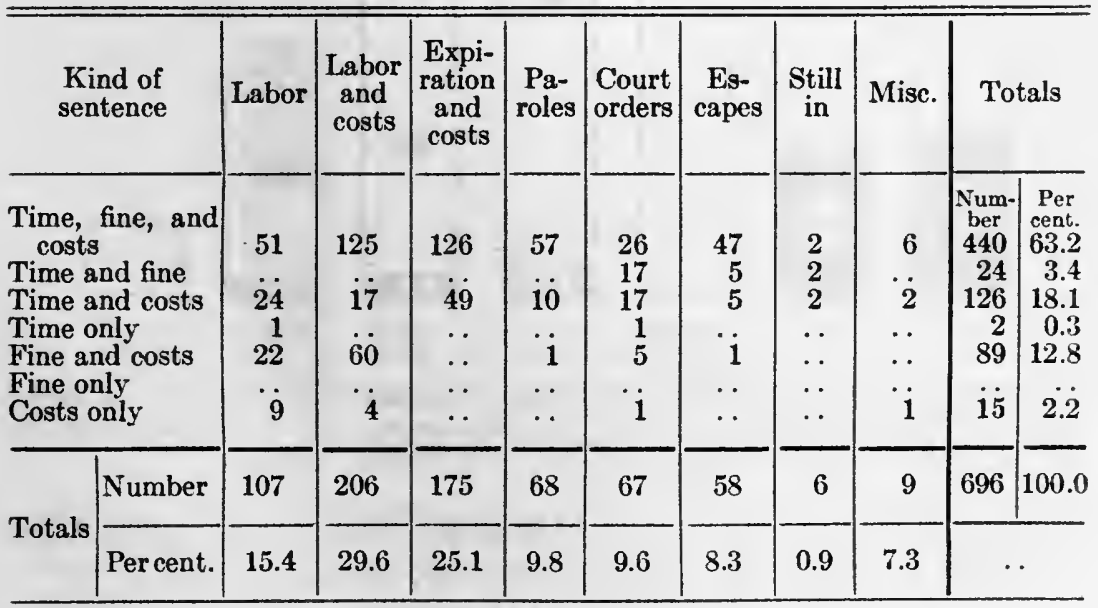

conducted correctional system. The frequency with which fines are resorted to, the relatively large number of sentences terminated by court order, and the kind and length of sentences imposed indicate that the 
municipal courts have made dispositions of cases which, under all circumstances prevailing, place a serious check upon the development of a modern correctional system. This is brought out even more strikingly by Tables 5 and 6 , which indicate the quotient of the fine plus costs

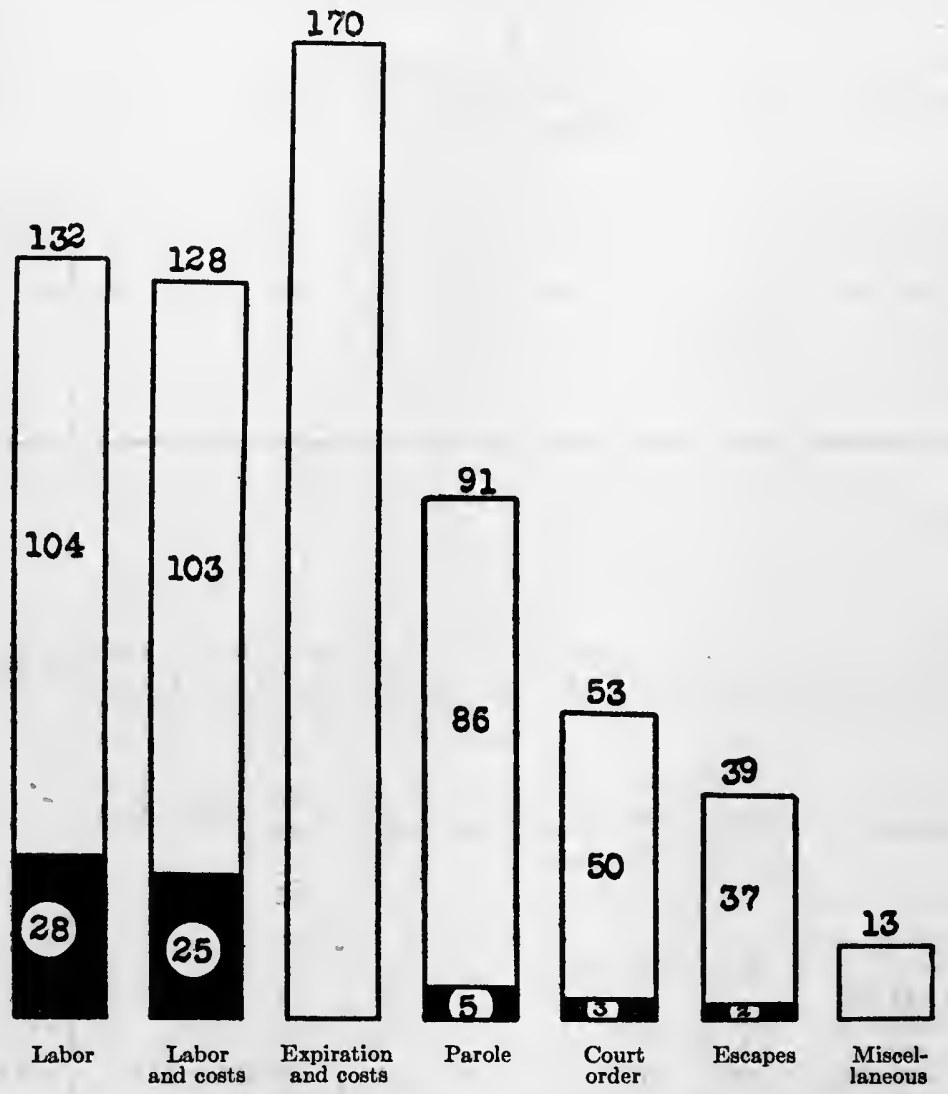

Diagram 1.-How the sentences of 626 prisoners received at the Workhouse during January, February, and March, 1920, were terminated. The black portions of the columns represent sentences which consisted only of fines and costs

divided by 60 cents per day, which is the common rate utilized for computing fines into days where prisoners do not pay their fines.

These tables show that 258 , or 40.12 per cent., of these cases expired in sixty days or less, and that practically 293 , or 46.80 per cent., expired in six months or less. These analyses, and the other studies made during the course of this survey, indicate the crying need for a thoroughly 
modern and efficient city probation department. It is our conclusion that judges of municipal courts could further the development of such

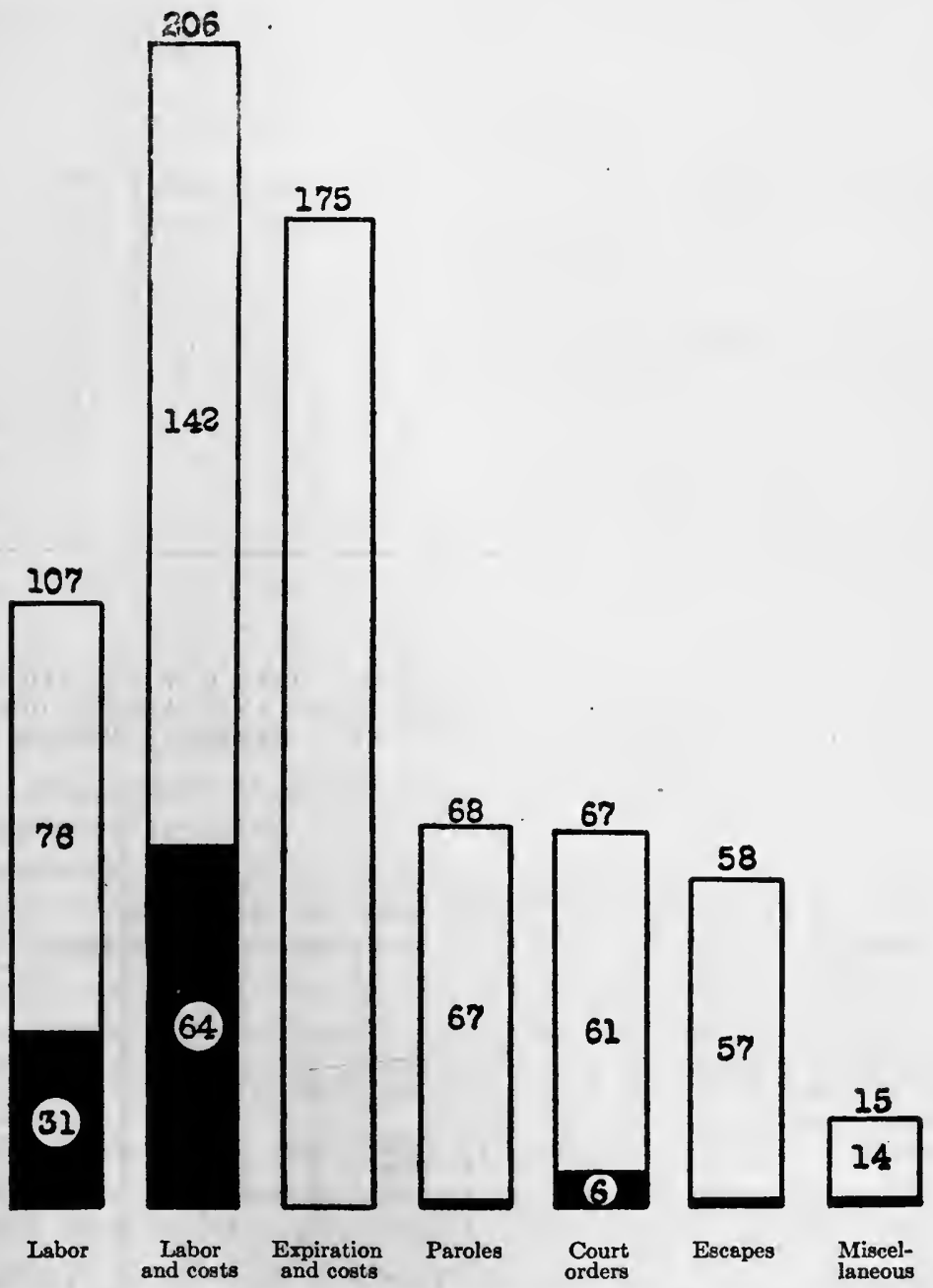

Diagram 2.-How the sentences of 696 prisoners received at the Workhouse during July, August, and September, 1920, were terminated. The black portions of the columns represent sentences which consisted only of fines and costs.

a modern department by refusing to impose sentence without adequate information and demanding that the city provide a probation system which would furnish them with information to be utilized in making 
disposition of cases. The fact that the present probation system is inadequate, that the officers are much overworked, and that a cry of false

TABLE 5.-ANALYSIS OF SENTENCES IN 258 CASES, EXPIRING DURING THE MONTHS OF JANUARY, FEBRUARY, AND MARCH, 1920, BY LENGTH OF SENTENCE AND BY THE MANNER IN WHICH THE SENTENCE WAS TERMINATED

\begin{tabular}{|c|c|c|c|c|c|c|c|c|}
\hline $\begin{array}{l}\text { Manner of } \\
\text { termination of } \\
\text { sentence }\end{array}$ & $\begin{array}{c}1-9 \\
\text { days }\end{array}$ & $\begin{array}{c}10-19 \\
\text { days }\end{array}$ & $\begin{array}{c}20-29 \\
\text { days }\end{array}$ & $\begin{array}{c}30-39 \\
\text { days }\end{array}$ & $\begin{array}{c}40-49 \\
\text { days }\end{array}$ & $\begin{array}{c}50-59 \\
\text { days }\end{array}$ & $\begin{array}{l}\text { Total } \\
1-59 \\
\text { days }\end{array}$ & $\begin{array}{c}\text { Per } \\
\text { cent. } \\
\text { of } 626 \\
\text { cases }\end{array}$ \\
\hline $\begin{array}{l}\text { Labor } \\
\text { Labor and costs } \\
\text { Expiration and costs } \\
\text { Paroles } \\
\text { Court orders } \\
\text { Escapes } \\
\text { Still in } \\
\text { Miscellaneous }\end{array}$ & $\begin{array}{l}2 \\
\cdots \\
\cdots \\
\cdots \\
\cdots \\
\cdots\end{array}$ & $\begin{array}{r}13 \\
6 \\
4 \\
1 \\
2 \\
1 \\
\cdots \\
\cdots\end{array}$ & \begin{tabular}{r}
14 \\
5 \\
1 \\
\hdashline$i$ \\
$\cdots$ \\
$\cdots$
\end{tabular} & $\begin{array}{r}51 \\
26 \\
39 \\
7 \\
5 \\
7 \\
9\end{array}$ & $\begin{array}{r}11 \\
12 \\
14 \\
5 \\
2 \\
\cdots \\
\cdots \\
\cdots\end{array}$ & $\begin{array}{r}6 \\
11 \\
8 \\
1 \\
\dddot{1} \\
\cdots\end{array}$ & $\begin{array}{r}97 \\
60 \\
66 \\
14 \\
10 \\
9 \\
\because 2\end{array}$ & $\begin{array}{l}0.15 \\
0.10 \\
0.11 \\
0.02 \\
0.02 \\
0.01 \\
0.01\end{array}$ \\
\hline Total prisoners & 2 & 27 & 21 & 137 & 44 & 27 & 258 & 0.41 \\
\hline
\end{tabular}

TABLE 6.-ANALYSIS OF SENTENCES IN 293 CASES, EXPIRING DURING THE MONTHS OF JANUARY, FEBRUARY, AND MARCH, 1920, BY LENGTH OF SENTENCE AND BY THE MANNER IN WHICH SENTENCE WAS TERMINATED

\begin{tabular}{|c|c|c|c|c|c|c|c|c|c|c|}
\hline \multirow{2}{*}{$\begin{array}{l}\text { Manner of } \\
\text { termination of } \\
\text { sentence }\end{array}$} & \multirow[b]{2}{*}{$\begin{array}{c}60-69 \\
\text { days }\end{array}$} & \multirow[b]{2}{*}{$\begin{array}{c}70-79 \\
\text { days }\end{array}$} & \multirow[b]{2}{*}{$\begin{array}{c}80-89 \\
\text { days }\end{array}$} & \multirow[b]{2}{*}{$\begin{array}{c}90-99 \\
\text { days }\end{array}$} & \multirow[b]{2}{*}{$\begin{array}{c}100- \\
124 \\
\text { days }\end{array}$} & \multirow[b]{2}{*}{$\begin{array}{c}125- \\
149 \\
\text { days }\end{array}$} & \multirow[b]{2}{*}{$\begin{array}{c}150- \\
174 \\
\text { days }\end{array}$} & \multirow[b]{2}{*}{$\begin{array}{l}175- \\
199 \\
\text { days }\end{array}$} & \multicolumn{2}{|c|}{ Totals } \\
\hline & & & & & & & & & Days & $\begin{array}{l}\text { Per } \\
\text { cent. } \\
\text { of } 626 \\
\text { cases }\end{array}$ \\
\hline Labor & 4 & 23 & 2 & 2 & 1 & 2 & & 1 & 35 & 0.05 \\
\hline $\begin{array}{l}\text { Labor and costs } \\
\text { Expiration and }\end{array}$ & 3 & 22 & 7 & 8 & 16 & 4 & 3 & 2 & 65 & 0.10 \\
\hline costs & 11 & 17 & 20 & 10 & 25 & 12 & 4 & 1 & 100 & 0.16 \\
\hline Paroles & 1 & 15 & 8 & 3 & 12 & 4 & 4 & 2 & 49 & 0.08 \\
\hline Court orders & . & 3 & 3 & 1 & 5 & 1 & & 1 & 14 & 0.02 \\
\hline Escapes & $\ldots$ & 9 & 4 & 3 & 1 & 2 & 4 & $\ldots$ & 23 & 0.04 \\
\hline Still in & $\cdots$ & $\because$ & 1 & $\cdots$ & $\because$ & . & $\cdots$ & .. & $\because$ & \\
\hline Miscellaneous & . & 4 & 1 & . & 2 & . & . & $\cdots$ & 7 & 0.01 \\
\hline Total cases & 19 & 93 & 45 & 27 & 62 & 25 & 15 & 7 & 293 & 0.47 \\
\hline
\end{tabular}

economy is now insistent ought not discourage judges and citizens generally in pressing for this much-needed reorganization of Municipal Court work. 
The probation system of Cleveland Municipal Courts has two distinct branches-probation for adult men and probation for adult women. Technically, probation for both men and women is under the supervision of the chief probation officer, James Metlicka. As a matter of fact, Mr. Metlicka has charge only of male adult probation. Mrs. Antoinette Callaghan regards herself as chief of the Woman's Probation Department, holds herself wholly independent of Mr. Metlicka, and conducts her branch of the work as an entirely separate unit. ${ }^{1}$

The physical conditions under which this department is carried on constitute a serious handicap to effective work. It is housed in a small room adjoining Municipal Court-room No. 1, and accommodates Mr. Metlicka and his two assistants.

When observed on May 2 and 3, the office was continually crowded. Three probation officers were attempting to carry on investigation work with individuals, receive reports, collect money, make out receipts, and at the same time keep track of the court-room. They were actually receiving prisoners placed on probation by the court. As a further aggravation, each probation officer must be his own clerk, as no clerk or typist is provided. The record work is crude and unsatisfactory. The records are of little value. The filing system could hardly be called a system, and the entire volume of work is done under a strain which makes good work impossible.

The chief probation officer collects from $\$ 3,000$ to $\$ 5,000$ a month from probationers. Until a short time ago large amounts of this money were carried on his person, as he banked money but once or twice a week. His accounts are audited but once a year. Mr. Metlicka could not tell the surveyor how many people were on probation. He said the number fluctuated rapidly, and since he had neither clerk nor stenographer, it was impossible to keep this and many other vital matters up to date. He referred to past reports as the only source of information on such points.

Examination of the files of the department show that its work is confined to the investigation of police reports and cases requested by the judge, prosecutor, or police, which are reported upon generally by one of the two assistants. The reports are written in pencil on different kinds of stationery, and filed generally, if at all, in this form. Reports

1 There ought to be better coöperation between Mrs. Callaghan of the women's division and Mr. Metlicka of the men's division and with the Women's Protective Association. Mrs. Callaghan can bring this about, as Mr. Metlicka is more than anxious to do his part and works in perfect harmony with the Women's Protective Association. 
to judges or to the police department are, as a rule, in verbal form. There are no stenographic or other notes. There is a small report card, which becomes a part of the permanent file, and some, but not all, of the facts obtained by investigation are placed upon this card.

Obviously, the adult probation work is lacking in efficiency. It is clear that there is no real administrative ability back of the work; that the court gives no decisive direction or oversight; that the chief probation officer is without a constructive plan, but makes an effort day by day to meet the problems of that day. In view of the absurd conditions under which he undertakes so vast a work, the wonder is that he does anything at all. We are of the opinion that the chief responsibility for this condition must rest upon the Chief Justice of the Municipal Court, who has power to appoint additional help, to cause a reorganization of the work, and to provide better quarters.

Mrs. Callaghan labors under practically the same handicaps that confront Mr. Metlicka. She has two associates-one a college graduate and the other, a young colored woman, who has had considerable experience in the Colored Y.W.C.A.

Mrs. Callaghan has a definite organization, a definite plan of work, a consistent and fairly well-kept record of what she has done and is doing, a fair system of reports, and a follow-up system which, while not adequate, is as well thought out and as well administered as lack of facilities will permit. She stated frankly that she had little occasion to call upon Mr. Metlicka's division, because there was rarely anything in common in the cases under consideration. She said that whenever she called upon Mr. Metlicka she found him ready to coöperate. On the other hand, we found that she makes use of the Children's Bureau of the Welfare Federation, of the work performed by Miss Walters in the Boys' School, and frequently calls upon the latter for mental tests of probationers.

The Women's Protective Association maintains an office which opens into Municipal Court-room No. 2. The Association's work in the Municipal Court is non-official. It tries to be of assistance to both divisions of the Probation Department, and is willing to furnish field investigations and assist even in clerical work. It is difficult to believe, however, that its work can be effective unless a harmonious working basis is established between the official Probation Department and the Association. If this organization could be used officially, perhaps under the direction of the Chief Justice of the Municipal Court, its coöperation might make the probation office effective, for the Association not only has trained workers and a competent administrator at its head, but 
also a well-organized plan of work, essentials which the official Probation Department lacks.

A modern Probation Department, serving as an aid to the court in conducting impartial inquiries and as a potent agency for effecting the rehabilitation of offenders, has long since passed the experimental stages and is now a primary essential of every community. In considering alternative plans for the development of an effective probationary system in lieu of the present inadequacies, we have inquired particularly whether better results could be obtained if probation work in the Common Pleas Courts were left in the hands of the State Board of Administration and the probation work of Municipal Courts were placed either under the control of the Board of Administration or were permitted to remain under the jurisdiction of the city government. In this connection consideration has been given to possible modern developments which might flow from coöperation of the Parole and Probation Departments of the new State Department of Public Welfare and its Bureau of Juvenile Research, particularly if that Bureau were expanded into a psychopathic clearing-house, classification and research institution for adults as well as juveniles.

After a full inquiry, with the opportunities to consider the problem with the Governor of the State and the various State officials, the investigator reached the conclusion that the desired policy is to be found in the so-called Gorrell Bill. The chief feature of this bill, as amended, is its provision that probation work should be carried on under the jurisdiction and supervision of the various county courts. This provision, if enacted, will permit the courts in Cuyahoga and other counties to conduct their own probation work subject to the inspection and supervision of the State Board of Administration or its successor, the Department of Public Welfare. We are of the opinion that the enactment of this law would lead to extensive developments in various counties in accordance with their ability or desire to develop probation work, and that these developments or experiments in probation work would lead to helpful rivalry between the counties in developing this necessary division of judicial administration. It is our belief that the results obtained by such competition would more than outweigh any disadvantages that might flow from lack of common probation standards. At any rate, the legislature could authorize the State Department of Public Welfare so to exercise regulatory supervision over the work of the various counties as to prevent unwholesome rivalry or unwise experiments.

This raises the question of the manner in which a proper investiga- 
tion staff is to be developed, and the number of persons required for such work. A capable and resourceful chief probation officer, an office manager, two chiefs of field investigation, 20 parole officers, eight clerks and stenographers should be employed at once to begin the work. Such a staff should be increased gradually until the number of probation officers reaches at least 56 . The recommended immediate staff is smaller by 14 than that provided for the Parole Commission of New York, which handles about 5,000 cases per year, under a system which might well serve as experience for consideration in developing a real Probation Department for Cleveland and Cuyahoga County.

After considering the situation in Ohio, we are convinced that it is not advisable from any point of view to hold back the development of probation in Cleveland pending the possible extension of the work in the State Bureau of Juvenile Research. The people of Cleveland'should develop in their school system, in the psychopathic and city hospitals, in the various other hospitals, the Normal School, the Western Reserve University Medical School, and in the Health Department, mental and other diagnostic services which would insure the most careful examination of every individual handled by the courts, whether ultimately placed on probation or sentenced to an institution. The fullest development of this service would work a revolution in court, probation, and institutional activities. ${ }^{1}$ The city has the opportunity to provide, in its contemplated new court-house, office building, and jail, adequate quarters for an examining staff of physicians, psychiatrists, psychologists, probation officers, and other necessary attachés of a modern probation system. Ordinary cases could be examined in the new building at a minimum cost, while more difficult cases could be sent to the city and psychopathic hospitals, now under construction.

\section{ReCommendations}

1. The courts should stop trying to make final disposition of so many cases and reduce the number of changes in dispositions.

2. A capable chief probation officer and 20 adult probation officers

1 The investigator has given considerable attention to the identification system in operation in Cleveland. The work appears to be thoroughly reliable and within its limits competent, but the scope is too limited, because of the studied opposition of habitual criminals and of the unthinking opposition of the occasional citizen who, for some reason or another, associates finger-prints with crime. This opposition is not well founded, for the reason that finger-print identification has been applied throughout the army, is utilized by many banks and private corporations and by public bodies in this and other countries, and is the least objectionable identification record yet devised. 
should be employed at once. An adequate office should be provided for the department, and a capable follow-up record system and field investigation system should be adopted. The chief probation officer should be the liaison officer between the Municipal Courts and the other official and non-official organizations capable of assisting the courts in determining all the facts of the personal, family, social, educational, and industrial histories of prisoners.

3. The courts in the various counties of the State should be authorized to organize their own probation departments.

4. The Common Pleas and the Municipal Courts should join with other public and private agencies in establishing proper diagnostic and treatment centers in the public schools, the city's new general psychopathic hospital, the various hospitals, the School of Education, the Western Reserve University Medical School, the Health Department, and the large industries of Cleveland.

5. If the two courts are combined on their criminal side, as recommended in the section of this Survey devoted to the criminal courts, the chief probation officer of the Juvenile Court should become chief probation officer of the combined city and county criminal court. 


\section{CHAPTER IV}

\section{PAROLES, COMMUTATIONS, AND PARDONS}

\section{$7 \mathrm{HE}$ Ohio General Code vests the managers of the workhouses with considerable discretion in discharging and paroling inmates committed thereto. ${ }^{1}$}

In the city of Cleveland the Director of Public Welfare, the parole

1 Sections $4133,4134,4135,4136$, and 4137 of the code granting the authority to release, re-arrest, and return inmates of the workhouse, read as follows:

"Discharge and record thereof. An officer vested by statute with authority to manage a workhouse, may discharge, for good and sufficient cause, a person committed thereto. A record of all such discharges shall be kept and reported to the council, in the annual report of the officer, with a brief statement of the reasons therefor.

"Parole of inmates. Such officer also may establish rules and regulations under which, and specify the conditions on which, a prisoner may be allowed to go upon parole outside of buildings and enclosures. While on parole such person shall remain in the legal custody and under the control of the officer, and subject at any time to be taken back within the enclosure of the institution. Full power to enforce the rules, regulations, and conditions, and to retake and reimprison any convict so upon parole, is hereby conferred upon such officer, whose written order shall be sufficient warrant for all officers named therein to authorize them to return to actual custody any conditionally released or paroled prisoner. All such officers shall execute such order the same as ordinary criminal process.

"Violation of parole. Such officer may employ or authorize any person or persons to see that the conditions of a parole are not violated, and in case of violation to return to the workhouse any prisoner so violating his parole, and the time between the violation of the conditions of such parole, or conditional release by whatever name, as entered by order of the officer on the records of the workhouse, and the reimprisonment or return of the prisoner, shall not be counted as any part or portion of time served under his sentence.

"Return of paroled to custody. Any prisoner at large upon parole who fails to return to the actual custody of the workhouse as specified as one of the conditions of his parole, or commits a fresh crime and is convicted thereof, shall be, on the order of the officer, treated as an escaped prisoner and subject to the penalties named in Sec. 12840. But no parole shall be granted by any such officer without previous notice thereof to the trial judge.

"Officers to have police powers. The superintendent, assistant superintendent, and each guard of the workhouse shall have such powers of policeman as may be necessary for the proper performance of the duties of his position." 
officer of the department, and the superintendent of the workhouse jointly exercise the powers conferred by law upon the director alone.

\section{Administration}

The parole officer prepares the records of prisoners whose cases are under consideration for parole. The so-called records are in reality the results of his own and the director's personal investigations, as no information about cases is furnished by the courts or the probation officers save what appears upon the commitment papers. The director hence puts in a great deal of time upon the investigation and consideration of individual cases.

Under the existing arrangement, extensive consideration of cases is largely labor lost, for the workhouse keeps practically no records. When a man presents himself for consideration, information concerning him is furnished verbally by the superintendent of the workhouse. If the superintendent's recommendation is favorable and the man has a letter from a friend or an alleged former employer or an alleged relation, his chances of parole are good. If he is paroled, he is merely turned out of the institution and allowed to look after himself without supervision, unless there is an unremitted fine to look after or some adjustment with respect to children, in which case the parole officer looks after the case. Many men who spend the winter at the workhouse at the city's expense are released when the ice goes out with the hope that they may get jobs on the lake during the navigation season. Under prevailing conditions adequate and necessary supervision of men on parole is impossible.

Director Blossom and Parole Officer Miller are conscientious and use good judgment in handling cases, but the whole system of parole is so crude and undeveloped as to be wholly inadequate. Under existing conditions, where there is no record system either in the institutions or in the central office, a single parole officer should not be required to handle more than 50 cases. If an adequate system of institutional and parole records were installed, such as we are filing with the Survey Committee as a part of this report, a single parole officer should be able to handle 100 cases.

If the courts did not attempt to handle the cases by the form of sentence imposed, by the great number of changes in dispositions and the number of recalls, the pressure exercised by the prisoners would doubtless have forced a better parole system long ago, but, although the judges are admittedly without adequate information concerning the prisoners, they are apparently content not only to guess and guess again, but also to change their guesses frequently in particular cases, 
as statistics collected in the course of this survey clearly show. In this connection we confine ourselves to a study of the manner in which 626 and 696 prisoners previously sentenced to the workhouse were released therefrom during January, February, and March, 1920, and during July, August, and September, 1920, respectively.

TABLE 7.-SUMMARY OF THE MANNER IN WHICH 626 AND 696 PRISONERS WERE RELEASED FROM THE WORKHOUSE DURING STATED PERIODS IN 1920

\begin{tabular}{l|c|c|c|c}
\hline \hline Manner of release & $\begin{array}{c}\text { January, } \\
\text { February, } \\
\text { and March, } \\
1920\end{array}$ & $\begin{array}{c}\text { Percentage } \\
\text { of } 626\end{array}$ & $\begin{array}{c}\text { July, } \\
\text { August, and } \\
\text { September, } \\
1920\end{array}$ & $\begin{array}{c}\text { Percentage } \\
\text { of } 696\end{array}$ \\
\hline Labor & 132 & 21.1 & 107 & 15.4 \\
Labor and costs & 128 & 20.4 & 206 & 29.6 \\
Expiration and costs & 170 & 27.2 & 175 & 25.1 \\
Paroles & 91 & 14.5 & 68 & 9.8 \\
Court orders & 53 & 8.5 & 67 & 9.6 \\
Escapes & 39 & 6.2 & 58 & 8.3 \\
Still in & 1 & 0.2 & 6 & 0.9 \\
Miscellaneous & 12 & 1.9 & 9 & 1.3 \\
\hline Total & 626 & 100.0 & 696 & 100.0 \\
\hline
\end{tabular}

Table 7 shows the great preponderance of court action and the relative infrequency of parole department action in bringing about the release of prisoners at the workhouse.

Space does not permit detailed analysis here of the data ${ }^{1}$ summarized in Table 7 and also in Tables 2 to 6 inclusive. From the material at hand the conclusion may be drawn that judges, in sentencing prisoners to the workhouse, are seriously overworking fines and do not give sufficient attention to the factors which determine whether prisoners are fit to return to the community as law-abiding citizens. The courts in Cleveland, like the courts all over the country, are confining their action too closely to the determination of innocence or guilt, and have not only lost sight of the equally significant consideration of preparing prisoners for return to society, but also, in attempting to determine in advance how long prisoners shall remain in correctional institutions and the manner of their release, have so hampered and restricted the institutions that the latter have not been able to function adequately. Courts, pro-

1 The detailed analysis is contained in 10 statistical tables which, because of the limitation of space, are filed with the Cleveland Foundation, where they may be consulted by those interested. 
bation officers, institutions, and parole departments all have their parts to play, but they must not be allowed to function in isolation. The laws, no less than the mental habits governing the work in Cleveland, should be so modified that these agencies can and will function together.

The insistent claim as to the proneness of prisoners on parole from State institutions to commit serious crimes led us to try to determine the truth or falsity of these charges. As there was not sufficient time at our disposal to complete such a study, and preliminary investigation indicated that there were not enough cases to demonstrate beyond doubt that the charges were true, we applied to Warden P.E. Thomas, of the penitentiary at Columbus, and were furnished by him with an analysis of the number of cases received at the penitentiary during the years 1918, 1919, and 1920. The percentage of parole violators among those received for each of the years is reported as follows:

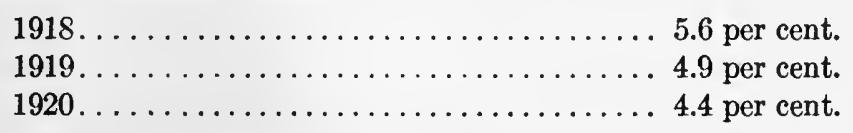

Warden Thomas states that his figures for the eight years from 1913 to 1921 show only 196 , or 4.15 per cent., of 4,713 prisoners serving indeterminate sentences, previously paroled from the penitentiary, who were returned parole violators. Also that about 18 per cent. of the total population of the penitentiary at the present time previously served terms in the State Reformatory at Mansfield. If we are to accept these figures at their face value, the charges against the system in Ohio are clearly disproved, for the percentage of violators is phenomenally low. Only a most careful investigation would show clearly why the percentage is so low. It is necessary to determine whether released prisoners have gone to other States, whether they have been clever enough to use others as "cat's-paws," or whether the police in the various Ohio cities and the parole work of the penitentiary have allowed a number to operate with immunity. These would be fruitful lines of inquiry, and until they have been followed, the parole system is entitled to considerable benefit of the doubt.

In order to bring about the most efficient court, probation, institutional, and parole work, we recommend that a law be enacted somewhat similar to the New York legislation (Chapter 579 of the laws of 1915 of the State of New York, as amended by Chapter 287 of the laws of 1916), ${ }^{1}$ pursuant to which offenders of various classes, if twice con-

1 Copies of these statutes were attached to this report but were omitted because of lack of space. They are on file at the office of the Cleveland Foundation. 
victed of any one of a number of offenses within twenty-four months or three times previously within any period, if sentenced to imprisonment in any institution, must be given an indeterminate sentence not to exceed two years, which may be terminated by the parole commission at any time. Another section of this law provides that judges imposing sentence to imprisonment in a workhouse similar to the one at Warrensville shall be members of the parole board which determines the time a prisoner is to remain in the workhouse and his eligibility for parole. The law also gives judges sentencing prisoners to the penitentiary absolute veto power over the parole commission's release on parole. Such a method depends for its success not only upon the care exercised by judges, but also upon the use of an infallible system of identification which, as we have already set forth, must become the corner-stone of any efficient correction system.

The recent enactment of the so-called Norwood Bill ${ }^{1}$ complicates the situation in Ohio. This law attempts to strike at the reported evil of too frequent paroles by penitentiary authorities by requiring the courts to fix, within the limit prescribed by law, a minimum period of duration of all sentences in all felony cases, except in the case of treason and murder in the first degree.

The objections to this measure we set forth in a memorandum to Governor Davis, who refused to approve the bill, which, however, became law without his signature. ${ }^{2}$ The objections as given in the letter were:

1. It will produce confusion and serious inequalities because of the individual differences in minimum sentences which will be imposed in the various courts.

2. It will lead to the imposition of short sentences in some courts for offenses committed by frequent offenders, who will become sullen agitators and disturbers in the penitentiary if the Board of Clemency or the Board of Parole, its probable successor, imposes the usual requirement of a longer stay within the prison enclosure before such a repeater is allowed to go out upon parole.

3. It is not the best way in which to achieve the results the introducer and many of its supporters evidently had in mind as necessary and important.

4. It will seriously hamper, if not prevent, the progressive development of the proper administration of the penitentiary and of the parole law, since the whole tendency of its administration will be to place emphasis upon penalties imposed by the various judges alleged to be necessary to fit the crime and to

1 See Appendix II.

2 A substitute bill was submitted as a part of this report, but was omitted because of lack of space. It is on file at the office of the Cleveland Foundation. 
push into the background questions of reformation and restoration of the prisoner as a law-abiding citizen.

We recommend in its place the enactment of a law similar to Chapter 579, of the laws of the State of New York for the year 1915, pursuant to which the court sentences the prisoner to the penitentiary for the statutory maximum but with no minimum. Within ninety days after the prisoner is received at the penitentiary the results of a full study of all the information the court had at the time the prisoner was sentenced and of all information the parole board and the penitentiary officials are able to secure in addition, are embodied in a classification report which is forwarded to the judicial officer presiding in the court where sentence was imposed, with a recommendation of what minimum requirement shall be imposed upon the prisoner as a condition of his parole. If the judicial officer presiding approves the recommendation, he affixes his signature to the report. If he disapproves, he so states in writing, and if he so desires, he indicates in writing upon the face of the report in the space provided what minimum requirement he thinks should be imposed. In any event, after this return is received by the parole commission, it notifies the prisoner what the minimum requirement shall be and both it and the prisoner know that the prisoner cannot go out upon parole until the judicial officer presiding in the court in which sentence was imposed gives his approval thereto in writing. follows:

The principal arguments in favor of this law may be summarized as

1. It breaks down the Chinese wall between the courts and the penitentiary, and forces reasonable coöperation between these two most important correctional forces.

2. It avoids the imposition of minimum sentences by different judges which produce bitterness and lack of respect for the courts in the minds of the very persons who are in most need of gaining more respect for courts and the lawthe prisoners themselves.

3. It places a reasonable check upon any undue leniency of ministerial officials and in most cases will give their work judicial sanction.

4. It provides a channel through which the judicial authorities may exercise proper control over punishment and become officially and vitally interested in administration and the rehabilitation of the prisoner.

5. It allows the judicial officer to express his judgment as to minimum requirements, not when the prisoner is sentenced when conditions are abnormal and only some of the facts about the prisoner and his crime are known, but after a much more complete investigation of the prisoner's record and environment has been made and after much more is known about the peculiar and particular characteristics of the prisoner himself.

For five years such a law has been in successful operation in New York city, and there is now a likelihood that its provisions will be made 
applicable to State prisons. It is looked upon with favor by judges and penologists generally.

We, therefore, urge the repeal of the Norwood Bill.

It must be expected that the Norwood law will largely increase the demands for executive clemency and conditional pardons in order to overcome the inequalities of the minimum sentence imposed by the judges in the various courts of the State. In some States the judges in one section place on probation a man who steals chickens, while in another section of the same State such a man is sentenced to imprisonment from two to eight years. Demands for executive clemency and conditional pardons mean not only a vast increase in the work of the Governor's office, but also develop a tendency to break away from the present system, which vests in the Board of Clemency rather than the chief executive officer of the State the duty of determining whether a man shall be released on parole or recommended to the Governor for executive clemency or pardon. This development is particularly unfortunate, as the executive clemency and pardon should be reserved for obvious miscarriage of justice or in recognition of unusual conduct during imprisonment.

We have been furnished with a tabulation of pardons and commutations granted by the Governors of Ohio in 1915-1916 and 1917-1918, which indicate that the present tendency in Ohio already is for the Governor to exercise functions which should be reserved for consideration of the Pardon and Parole Department of the State government. The too free exercise of the pardon and commutation powers of the Governor is open to criticism because it seriously interferes with the proper functioning of corrective agencies. ${ }^{1}$

Table 8 shows the pardons and commutations granted in the years 1915 to 1918 inclusive.

In 1915 and 1916 life sentences were reduced to terms varying from one year and two months to thirty years; and indeterminate sentences of one to fifteen and twenty years were changed to terms carrying from one month to twelve years. During 1917 and 1918 life sentences were reduced to terms varying from nine months to nineteen years and indeterminate sentences of one to twenty and thirty years were reduced to terms varying from twenty days to fourteen years.

It may be that the Governor, recognizing the imperfections of the Ohio Indeterminate Sentence Law, was attempting to right obvious in-

IFor a more detailed study of the exercise of the governor's pardoning power for a period of twenty-two years see the report prepared for the Ohio Institute for Public Efficiency, Appendix IV. 


\begin{tabular}{|c|c|c|c|c|}
\hline \multirow[b]{2}{*}{ Offense } & \multicolumn{2}{|c|}{ 1915-1916 } & \multicolumn{2}{|c|}{$1917-1918$} \\
\hline & Pardons & $\begin{array}{c}\text { Commu- } \\
\text { tations }\end{array}$ & Pardons & $\begin{array}{c}\text { Commu- } \\
\text { tations }\end{array}$ \\
\hline $\begin{array}{l}\text { Murder, first degree } \\
\text { Murder, second degree } \\
\text { Homicide } \\
\text { Manslaughter } \\
\text { Shooting to kill } \\
\text { Shooting to wound } \\
\text { Cutting to kill } \\
\text { Cutting to wound } \\
\text { Assault to kill } \\
\text { Maiming } \\
\text { Rape } \\
\text { Assault to rape } \\
\text { Having carnal knowledge of insane women } \\
\text { Abortion } \\
\text { Incest } \\
\text { Burglary of inhabited dwelling } \\
\text { Burglary } \\
\text { Burglary and larceny } \\
\text { Grand larceny } \\
\text { Robbery } \\
\text { Robbery and operating motor vehicle with- } \\
\text { out owner's consent } \\
\text { Safe-blowing } \\
\text { Pocketpicking } \\
\text { Theft of automobile } \\
\text { Horse-stealing } \\
\text { Having burglar tools in possession } \\
\text { Receiving stolen goods } \\
\text { Forgery } \\
\text { Embezzlement } \\
\text { Extortion } \\
\text { False pretenses } \\
\text { Blackmail } \\
\text { Carrying concealed weapons } \\
\text { Attempt to dynamite cars } \\
\text { Arson } \\
\text { Burning building with intent to prejudice } \\
\text { insurer } \\
\text { Non-support } \\
\text { Bigamy } \\
\text { Perjury } \\
\text { Unlawful transportation of female for pur- } \\
\text { pose of prostitution } \\
\text { Contributing to juvenile delinquency } \\
\text { Aiding prisoner to escape } \\
\text { Mong }\end{array}$ & 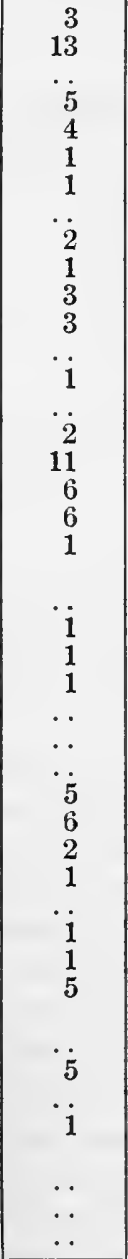 & 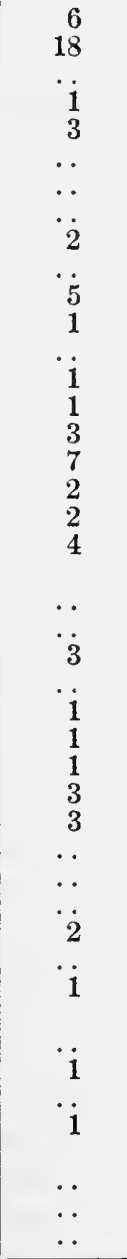 & 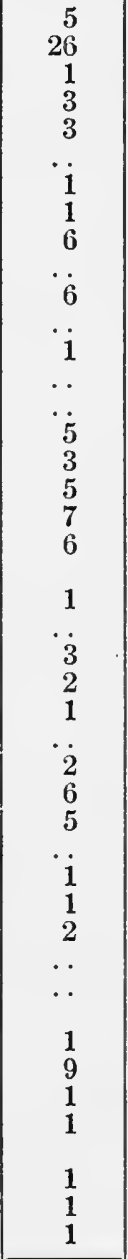 & 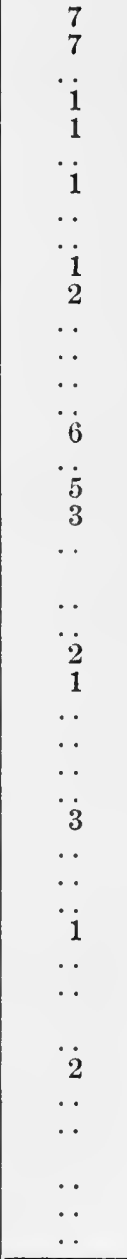 \\
\hline Sub-total & 93 & 73 & 118 & 43 \\
\hline Total & & 66 & & 61 \\
\hline
\end{tabular}


justices, but free use of the power of the Governor is not the best remedy for such conditions. A Governor of a State is too busy to attend to these matters and may easily be imposed upon. This is indicated by the typical causes for pardons and commutations assigned in the applications submitted to the Governor or stated by the Governor in taking action. Among these were the following:

Recommended by county officials and reputable citizens

Recommended by prison officials

Recommended by trial judge and prosecuting attorney

Good prison record

Desire to join relatives in another State

Imminent danger of death

Long term and good prison record

Because of doubt as to guilt

Strong evidence of reform and repentance

Lack of mental responsibility

Weak circumstantial evidence

Poor health and good conduct in prison

Worthy of a pardon in honor of a holiday

Ignorance of our American laws

A serious objection to the wide use of executive clemency is the encouragement it gives to disreputable lawyers to "bleed" relatives and friends of prisoners by making promises of pardon which they hope to secure.

\section{RECOMMENDATIONS}

The summary of recommendations is as follows:

1. The Department of Public Welfare in Cleveland should have an appropriation for an adequate parole system.

2. The Norwood Bill, enacted by the 1921 session of the Ohio Legislature, should be repealed.

3. A law similar to the Indeterminate Sentence and Parole Law of New York, known as Chapter 579, Laws of 1915, as amended by Chapter 287 of the Laws of 1916, should be adopted so that the courts and institutional authorities may coöperate to the greatest advantage.

4. The governor should not exercise the pardon, parole, and commutation powers vested in him by the State constitution, except to right obvious wrongs where there is no other legal remedy, or in the event of any unusual conduct. All other cases should be passed upon first by the Division of Pardons and Paroles, and should go to the governor only upon the recommendation of that division. 


\section{CHAPTER V}

\section{THE PROPOSED NEW CRIMINAL COURT, COUNTY JAIL, AND POLICE HEADQUARTERS BUILDING}

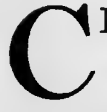

LEVELAND'S postponement of the erection of a new building or buildings to house criminal courts, insolvency and juvenile courts, police headquarters, and city and county detention prisons has brought one compensation: namely, that of being now in a position to build in accordance with the most modern plans and at a great reduction in cost. As a result of extensive public discussions and reports, the people of Cleveland are now in a better position to pass intelligently upon proposed plans and to determine the most practicable administrative and building programs.

Any solution of the problem is conditioned to a certain extent by what has already been done. The city plan committee of the Chamber of Commerce, under date of January 26, 1921, expressed the opinion that all business offices of the city and county should be removed from the present civil courts building and that building used exclusively for the courts; and that the criminal court should be housed in a more imposing building than that which would be necessary for the county treasurer and other county offices, or the police department, detention rooms, police headquarters, and the like. The committee was further of the opinion that the latter should be housed in a completely utilitarian type of building. The suggestion was made that the site to the west and north of the court-house be left for the office services of the county, the departments of the treasury, auditor, recorder, engineer, and the like, for in this way excavation already begun on the present site need not be entirely lost.

While many of the suggestions of the Chamber of Commerce committee are worthy of serious consideration, they do not seem to give sufficient attention to the desirability of placing police headquarters, county and city jails, the various criminal courts, prosecutors' offices, jury-rooms, witness-rooms, and probation offices in the same building. Time and energy spent in making transfers and in providing a staff of officers for courts, jails, and other offices housed in separate buildings 
will then be saved, besides the cost of maintaining separate identification and other record systems for courts, prosecutors, police, city, county, and State institutions. Opportunity for this complete and necessary record system ought not to be lost through a system of building construction and housing which would make it prohibitive.

In making this change Cleveland would be taking another step forward in eliminating evil conditions which result from sentencing prisoners to terms in the county jail. City and county jails should be used exclusively as detention prisons; terms should be served in the city, county, and State institutions provided for that purpose.

If we are to disregard for the moment the cell blocks for the jails, and if the requirements of the Group Plan Commission limit the architect, as is claimed, we are of the opinion that the latter has made an acceptable layout of rooms and offices. However, the requirements of the Group Plan Commission are such as to preclude any possibility of combining a modern jail with the remainder of this building, as a modern jail cannot be planned except in a building where the cells are in wings permitting plenty of light and air, proper classification of prisoners, and proper courts for exercise in the open air.

The building commission should not be stampeded into accepting an architectural design which limits the possibility of thoroughly modern and up-to-date criminal administration. If the commission were to yield this point, it would repeat the mistakes made in designing the Warrensville workhouse and the city infirmary at Warrensville.

There is danger that the commission may swing to the opposite extreme, for there are some who believe that the courts should be housed in a building of classic design, and that anything is good enough for a jail and almost anything good enough for a police headquarters. This is an erroneous viewpoint, for the reason that poor design and bad taste lower the whole tone of administration and thus indirectly increase the cost of administration. This has been demonstrated in public institutions in the East, as well as the fact that the office building type of construction can be used to advantage in public buildings.

The whole tendency in modern office building construction is to build four walls, provide elevators, stairways, fire-escapes, and proper corridors, and arrange the remainder of the interior as tenants desire. There is no difficulty in constructing a modern hotel in devoting two stories or a part of the building to a theater, dining-room, or banquet hall.

We are, therefore, of the opinion that unless the Group Plan Commission can change its requirements, as reported, so as to permit a 

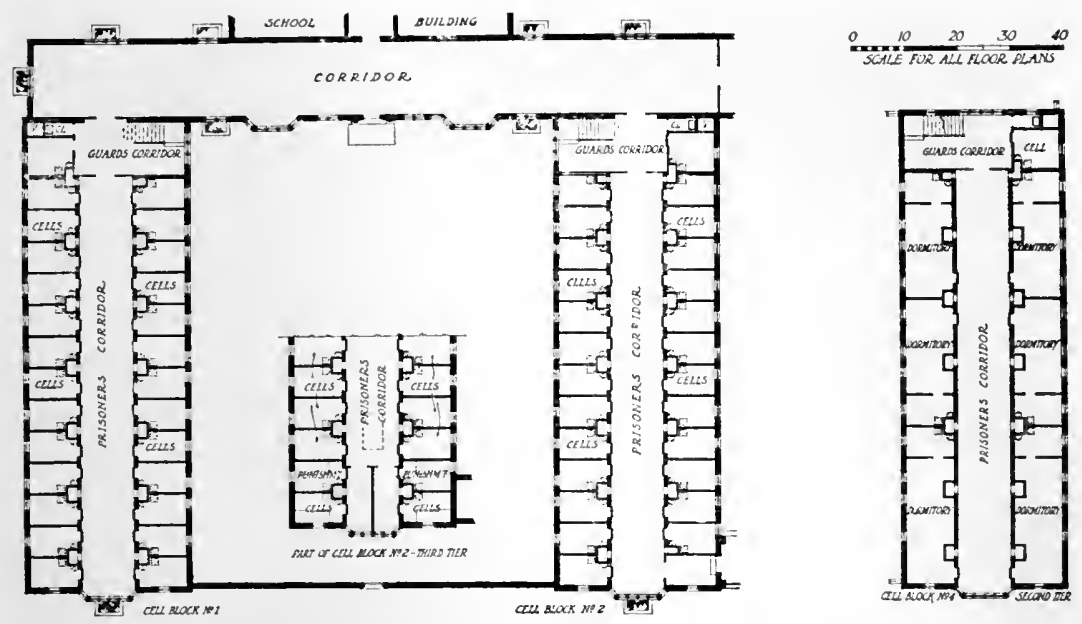

Fig. 1.-Typical floor plans of cell blocks, Westchester County Penitentiary and Workhouse, White Plains, N. Y. Alfred Hopkins, architect

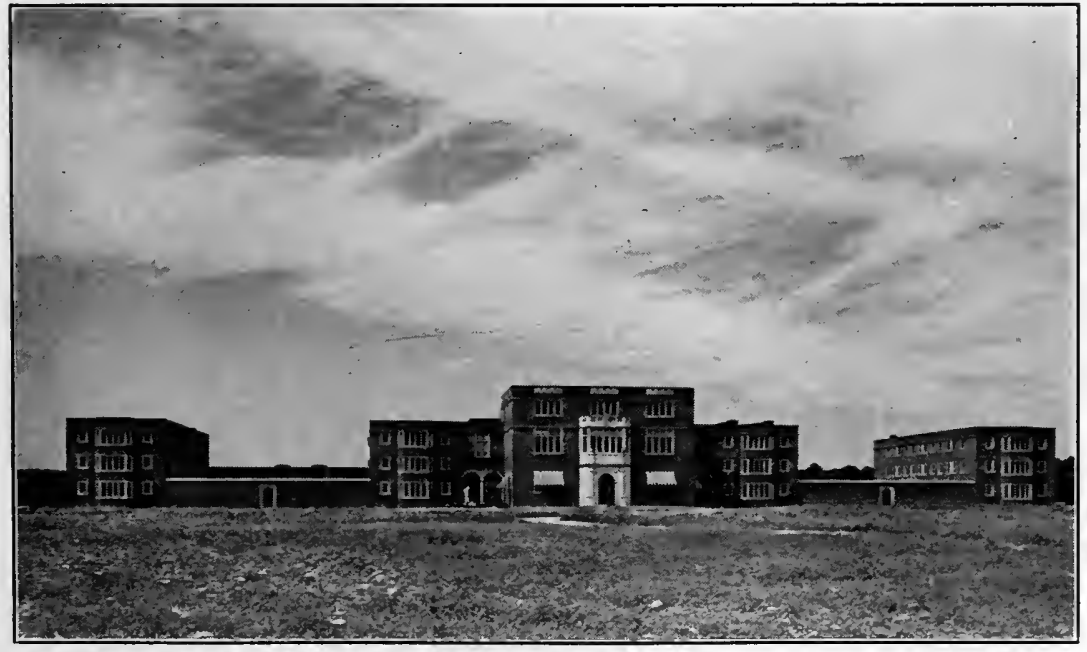

Fig. 2.-General view, Westchester County Penitentiary and Workhouse. Alfred Hopkins, architect 


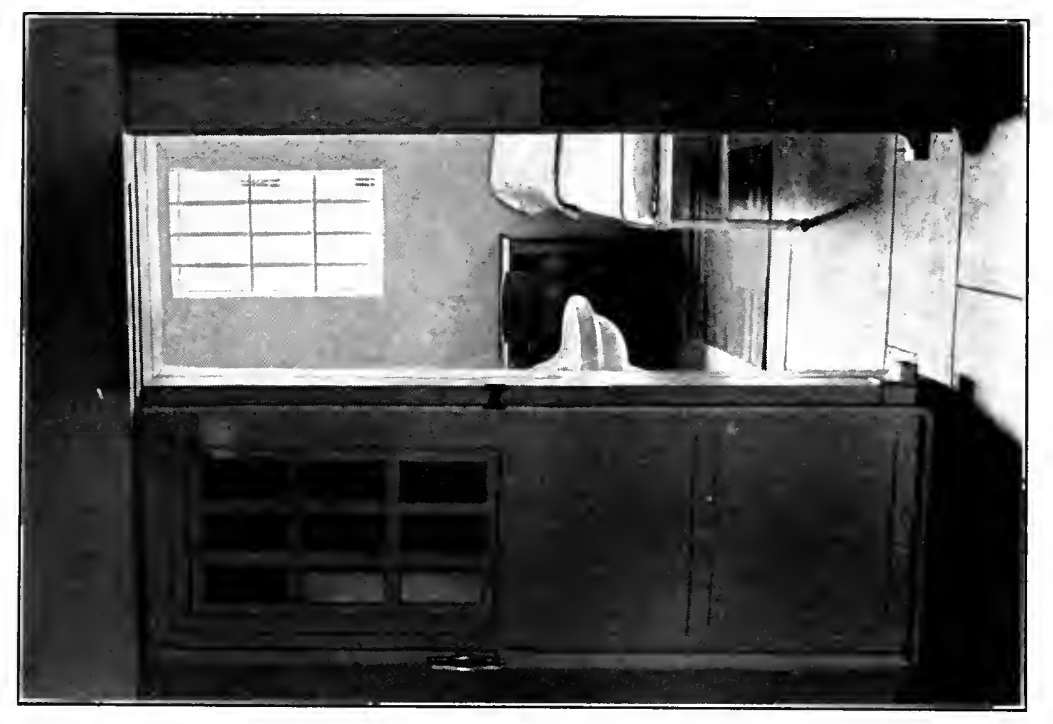

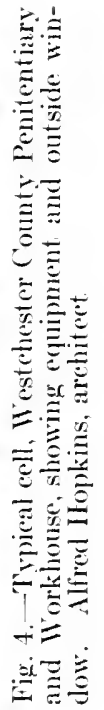
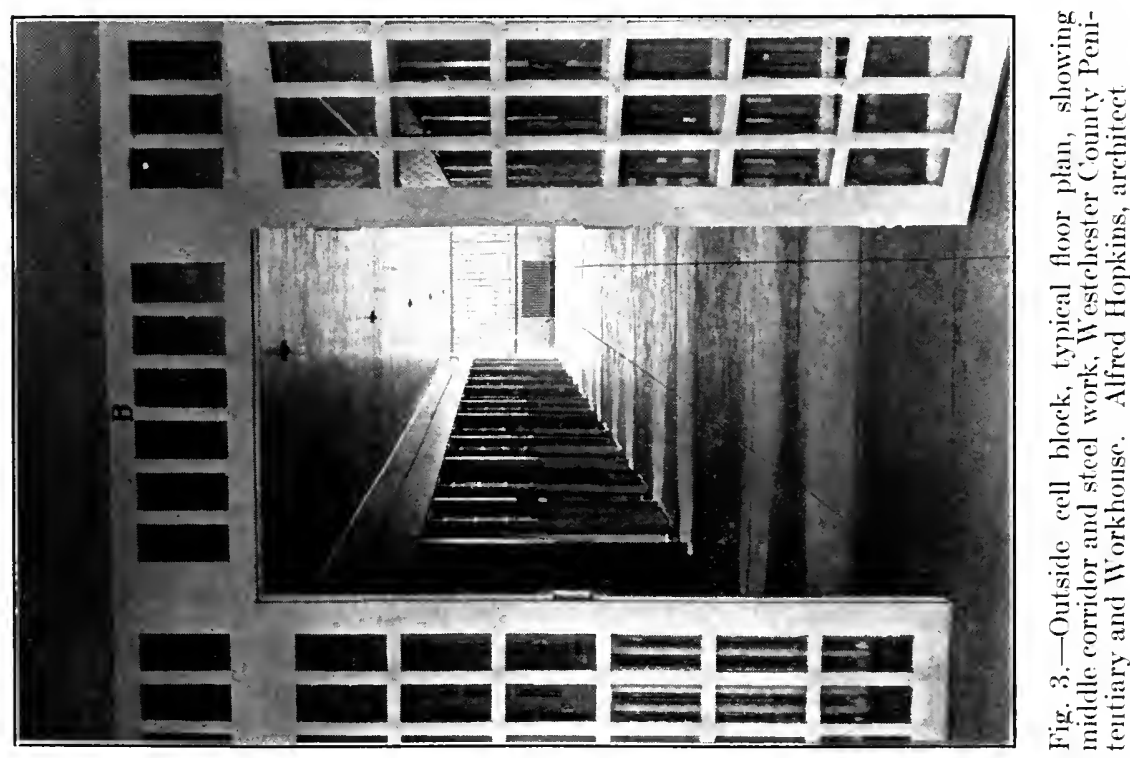
higher building with three wings containing three cell blocks which might extend either toward the lake or toward the present Civil Courts Building, it is advisable to build a structure of office building type to contain the criminal court, prosecutor's office, police headquarters, and county and city jails upon the site on the public square now occupied by the county jail and old court-house. This site is more favorably situated with regard to transportation and population to be served than that on the Mall. It would not be difficult to wreck the buildings on the old court-house and county jail site if temporary quarters can be rented for the county jail and the criminal courts.

Since there is sufficient land, a building with wings for cell blocks could be constructed to the greatest advantage. If the commission wishes to have interior cell construction of the modernized Auburn type for so-called desperate criminals awaiting trial, a small section of one wing could be utilized for this purpose, leaving the remainder of the building with the outside cell construction, thus providing complete classification, which is not possible under the Auburn plan. The great advantage of the outside cell for most cases awaiting trial is too obvious to require comment here. The Westchester County (N. Y.) institution has demonstrated that such a building can be made as secure as the inside cell construction of the Auburn type.

If the plan of the building is changed in the manner suggested, the three wings containing three cell blocks of outside cell construction should be separated from police headquarters, Municipal Court, and Common Pleas Court by corridors with exits and entrances on appropriate floors, in accordance.with the typical floor plan of the cell blocks of the Westchester County penitentiary and workhouse at White Plains, New York, the plan of which is shown in Fig. 1. The space between the three cell blocks can be used as two outdoor exercise courts for the prisoners of different classes to exercise at different times. If this plan is used, space should be left between the ends of the cells and the cell block side of the corridors so that prisoners on each tier may be served food at tables, in order to avoid feeding prisoners in their cells or in a common dining-hall. This cell block construction not only provides a maximum of light and air, as is indicated by Fig. 1, but secures the best type of cell. (See typical cell, Fig 4.) In order to prevent prisoners from letting down strings from outside windows to the sidewalk on the sides of such a building, it will be necessary to erect a wall as high as the top of the second tier of cells. With such a system as the one outlined, Cleveland would avoid creating criminals while waiting to determine innocence or guilt. It is not tenable to argue 
that this jail system cannot be made architecturally desirable, for the general view of the Westchester County penitentiary and workhouse shown in Fig. 3, proves the contrary. Moreover, the low cost of the Westchester County structure shows clearly that it cannot be ruled out on the grounds of expense.

\section{Recommendations}

The summary of recommendations is as follows:

1. Police headquarters, criminal courts, prosecutors' office, and county and city jails should be housed in a single building of the office building type.

2. The jail section should be included in three wings containing three cell blocks, with a complete separation of each tier of each block by utilizing outside cell construction, reserving the space between these blocks for exercise courts.

3. Wherever the sides or ends of the cell blocks are on the sidewalk line or may be approached from the ground level, they should be surrounded by a wall extending from the top of the second tier of the cell block.

4. All food should be prepared in a single kitchen for both the city and county jail sections, and it should be served at tables set up in spaces at the corridor ends of the cell blocks.

5. The two jails should be served by one laundry and one emergency hospital.

6. A single system of identification and other primary records should be maintained. These should be open to constant use, under proper regulations, by all the courts, the police, the prosecutors, and the probation officers.

7. The Juvenile Court should be eliminated from the plans for this building and provided for as previously recommended, either in a new building to be erected adjacent to the Detention Home or in a public school building.

8. If the Group Plan Commission cannot be prevailed upon to allow an office building type of construction on the Mall, this structure, as recommended, should be placed upon the site of the present county jail and criminal court building.

9. The county building commission should avail itself of the services of consulting architects, so that the most economical and modern type of structure may be provided. In carrying out this plan the studies of the present architect should be utilized as far as possible, and the building commission should not feel bound by any previous mistakes. 
The consideration of expenditures made up to the present should not outweigh that of present savings of cost, improvements in service, and permanent economy of operation and maintenance.

10. Legislation should be passed to keep the court from sentencing any one to a term of imprisonment in the existing county jail or any new county or city jail which may be erected. 
-

$-$ 


\section{PART V \\ MEDICAL SCIENCE AND \\ CRIMINAL JUSTICE}

BY

HERMAN M. ADLER, M.D. 



\section{MEDICAL SCIENCE AND CRIMINAL JUSTICE}

\section{CHAPTER I \\ PSYCHIATRY AND CRIME}

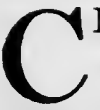

LEVELAND, like many other communities, is beginning to recognize the medical and more especially the psychiatric aspects of delinquency and crime, though as yet this recognition is confined to a relatively small part of the community, even of the official community. Some provision has already been made for psychiatric service, but only in more or less isolated centers which are not as yet correlated, and which, therefore, fail to give comprehensive attention to the entire field. The immediate problem, therefore, is to determine upon a policy which will utilize all the existing elements and yet insure expansion and development.

Specialists in the different fields of delinquency, dependency, and criminality are fully awake to the problem; there is even some general public interest in the subject as a result of the publicity given to it during the war. In Cleveland this is especially true, because the education and health surveys have dealt with the question, each from its particular angle.

Nevertheless, from the special point of view of the administration of criminal justice much more must be done to remove the general belief that delinquency and crime are entirely under the volitional control of the individual. The result of this attitude has been to make the treatment applied in each case dependent in a large measure on the degree of anger or annoyance to which the community has been aroused. Vindictive and punitive treatment, even though exercised by a group, loses little of the personal element. The community says to the delinquent: "You could behave yourself if you wanted to. If you break the laws, it is because you intended to, and therefore we are going to get even with you." The delinquent says to the community: "You do not need to be so rough with me, because it is in your power to be more lenient. If you 
are rough, it is because you want to be unfair to me, and therefore I have a perfect right to hit back if I can."

There was a time when medicine was practised on much the same basis, and even when chemistry was regarded from this point of view. All the ailments of the human body were believed to be the machinations of evil spirits. The reactions of chemical substances in the retort were thought to be presided over by good and evil spirits. The scientific attitude which has removed these personal elements in the fields of pure science and of medicine is capable of doing the same in criminology. The introduction of exact methods in medicine has never interfered with the highest effectiveness of personality and character in the application of the science to the individual sufferer. In the same way the introduction of knowledge into the field of delinquency does not diminish the value of personal skill and of the so-called "human element" in its application to the administration of justice.

When the public becomes convinced that there are in the community specially trained persons who understand delinquency and are able to evaluate the various factors in a case of behavior difficulty, the result will be like that already witnessed in the field of public health. Few persons today have to be coerced to be protected against disease or to be treated when they are ill. Our dispensaries and hospitals clearly testify to that fact. When the public has learned to regard behavior difficulties, delinquency, and crime as manifestations of mental difficulties requiring treatment, just as physical ailments do, and provides institutions and officers to deal with these troubles as mental disease, rather than from the point of view of punitive justice, we shall be able to record advances as notable as those of the public health movement. And just as public health machinery has made large cities and small country villages healthy places in which to live, so this new public mental health movement will make our communities safe and sane places in which to live. 


\section{JUVENILE BEHAVIOR PROBLEMS}

\section{The Need for Mental Health Stations}

$\mathrm{T}$ JHERE is probably no one who has not passed through difficulties during childhood. Indeed, the great majority believe they have been saved from becoming delinquent by some fortuitous circumstance, by the strict discipline of their parents, by the friendly offices of others, or perhaps that they were not saved but have in some way merely outgrown delinquency or "gotten by" in other ways. To those who look back from a secure position in society upon an adventurous and unlucky childhood or youth, it must appear that every individual has been, at one time or another, more or less delinquent. "There, but for the grace of God, goes John Bunyan," expresses their unconscious feeling when they consider criminality. Whatever truth there may be in this, it does not adequately explain the phenomenon of delinquency in its serious forms to one who differentiates between the significance of a single act and a series of reactions as disclosed by a study of the career of a delinquent individual. Regarded with the objectivity of the behaviorist, acts which may appear to be identical are found to have an entirely different significance. This is a point of view which the law-the emphasis of which is on the crime rather than on the criminal-does not, as yet, sufficiently recognize, though the law, to be sure, does recognize two groups of offenders needing special treatment-the irresponsible and the juvenile.

In dealing with adult criminals, a finding of feeble-mindedness or of insanity seems to some like condoning the crime, while to others that decision is merely the pronouncement of what they believe to be a wellestablished truth, namely, that all criminals are ipso facto insane or feeble-minded. However, all the partisanship and bitter feeling often aroused in cases of serious adult criminality are either absent or in abeyance in the case of juvenile delinquents. The entire development of the Juvenile Courts rests on the willingness of the community to believe that the child is not accountable for his misconduct in the same sense as the adult.

From the point of view of the behaviorist, one cannot hazard any 
generalizations as to the causation of delinquency, but must make each case the subject of independent study. These considerations, pushed a little further, make us realize that similarity of behavior between youthful individuals does not imply identical causes, and therefore does not demand identical treatment. Perhaps nothing will help this point of view to gain general recognition so much as the introduction of facilities for consultation with mental and behavior experts, of which the general public may avail itself.

Parents, teachers, even children themselves, may be taught to consult the mental health station about their private affairs without fear of hostile criticism or condemnation, confident that though the experts may not be able to solve their problems, they will at least give non-partisan counsel. There will be no question whether the expert is for or against them any more than in the case of the hospital physician. The question will be merely what is the matter and what can be done.

In this work all the agencies of the community should assist. The public health system, especially with its public health nurses reaching into the homes, should direct cases suited to the mental health station. All the welfare agencies, through their social service, should daily discover cases requiring the assistance of a mental health officer. The police could easily be instructed in the nature of the cases that should be directed to the public health stations.

All of this field work, however, depends upon the existence of properly equipped mental health stations as bases. These stations, as a rule, so far as they exist in Cleveland and other communities, resemble dispensaries more than hospitals. This out-patient service, if properly conducted and enlarged, will take care of a large percentage of the cases. There are certain cases, however, which either for diagnosis or for temporary or preliminary treatment, require something more than outpatient treatment. For these, observation or temporary care stations should be provided.

The present plans in Cleveland include a psychopathic hospital as part of the city hospital, and ultimately a psychiatric institute in connection with Lakeside or Fairview Hospitals. The psychopathic hospital will take care of certain cases of juvenile delinquency in which the psychotic and psychopathic factors predominate. It is not likely, however, that such institutions will be able to care for a large number of behavior cases which require observation, but in which, nevertheless, the psychotic factor is either of minor importance or absent altogether.

In order to meet the requirements of the situation the Boys' School and the Detention Home would either have to be converted into behavior 
observation clinics with assistants and staff suitably trained in psychiatry; or, if they are to be retained as custodial or educational institutions, a new type of institution would have to be provided. The Bureau for Juvenile Research at Columbus, which is a link in the institutional chain, might serve in certain respects as a model for a local institute. The chief defect of the bureau, as was emphasized by Dr. Thomas W. Salmon in the health survey, is that it deals with cases only after they have been committed.

What is needed, then, in addition to the psychopathic hospital at Cleveland and the Bureau for Juvenile Research at Columbus, is a Children's Institute at Cleveland, either as a branch of the Columbus bureau or of the psychopathic hospital, or an independent unit affiliated and coördinated with the Juvenile Court, the Department of Education, the psychopathic hospital, and the University. It is preferable to keep such an institute distinct from the psychopathic hospital because the emphasis on mental disease has a deterrent effect upon the public, and also because the work of such an institute is sufficiently important to merit exclusive attention.

With some such provision the city of Cleveland would be able to deal effectively with the general problem of "criminal behavior" by attacking the problem at its source-in childhood. The saving in human careers, quite aside from the effect upon the safety of life and property, would more than repay the community for the relatively small expenditure involved.

\section{The Juvenile Behavior Problem in the Schools}

Speaking solely from the point of view of the relation of mental studies to delinquency, the Cleveland schools are now very inadequately equipped to deal with behavior difficulties and the educational treatment of such cases. The facts which compel this conclusion have already been indicated by Dr. Salmon in Part VI of the health survey.

The Department of Education, as in all our larger cities, has provided special classes for children with retarded or low intelligence. The Boys' School might be considered a special class for behavior difficulties in boys. Educational and vocational questions are considered in practically all cases of juvenile delinquency, especially at the Boys' School, and the physical condition also is carefully considered by the school physicians. But all this is done in a more or less uncorrelated way. The physician works from too narrow a point of view. To him a boy who is a ward of the court on account of delinquency, if he has any physical defect or ailment, is exactly the same as any other case suffering from the same 
physical troubles. The intelligence rating, as well as the educational and vocational tests, are made in the same way. What is entirely lacking is the interpretation of the behavior difficulties, and for this the social factors, which are fully as important as the physical or intellectual factors, must be studied. A careful analysis, not only of the environmental conditions under which the child is living, but also of his antecedents, his inheritance, and his social past, must be made. So far as this is done at all in Cleveland it is done by the overworked and understaffed Probation Department of the Juvenile Court and by the Boys School.

From this point of view it is obvious that the community must assume an entirely different attitude toward its correctional and reformatory institutions. When it comes to treating juvenile behavior problems, we have an even blinder faith in the curative effects of punishment than have the criminal courts themselves. We erect buildings in which we gather the children who have had trouble at home or in school, or in the streets and parks of our cities, and by the application of what is commonly referred to as "strict discipline," we propose to relieve them and ourselves of their difficulties.

The officials who preside over these institutions are usually as ill equipped for constructive and scientific work as the domestics and window-washers of a hospital to carry out medical and surgical measures of relief. It would never occur to any one, in these days of modern medicine, to entrust a ward full of sick persons to the professional care of a cook, and yet that is what we do over and over again in our correctional and reformatory institutions. When we examine their provisions for grappling with this sort of work, is there a single institution in this country which has provided for its wards the same grade of personnel, the same training and expertness, that we find in a good general hospital?

\section{Recommendations}

1. A Division of Mental Health should be created in the Department of Education.

2. This division should be either coördinated with the division dealing with physical health, or be kept distinct from it so that mental health shall be given independent importance and authority.

3. The Mental Health Division should include the present psychologic clinics.

4. The mental health work should be closely coördinated with the Division of Special Education, or even merged with it, provided the mental health work does not thereby suffer partial or total eclipse. 
5. The mental health staff should be under the direction of a competent psychiatrist.

6. The director and staff of the Mental Health Division should devote full time to the work.

7. A sufficiently large and comprehensive staff should be provided to assure that the work is performed in a satisfactory manner.

8. The Division of Mental Health should coöperate with the Juvenile Court, the Detention Home, the Welfare Federation, and the Department of Public Welfare, and all such public or private agencies as deal with problems of child welfare.

\section{The Juvenile Behavior Problem in the Courts}

The Juvenile Court is practically dependent upon the city health department and coöperating private organizations for the physical welfare of the children passing through the court, and largely on the Department of Education for mental tests. There are no regularly appointed medical or mental examiners attached to the court.

In regard to physical health, only children committed to the Detention Home or the Boys' School are examined. A physician and a nurse serve on part time in connection with these two institutions. There is a full-time dentist. In addition, the court often sends cases to hospitals, namely, the city hospital, Fairview Hospital, and Lakeside Hospital. The Humane Society furnishes the services of a physician for occasional cases. Judge George S. Addams, the Juvenile Court judge, hopes to have a nurse on duty at the court who will give a preliminary examination to all children, whether committed or not, as they pass through, and also a physician to examine all cases in the court every day. At present there is no money to permit such an arrangement.

The mental examinations connected with the Juvenile Court consist almost entirely of mental tests. These are applied under the direction of Dr. Bertha L. Luckey, the chief psychologist of the Board of Education. Dr. Luckey and her assistants examine especially children who have turned out to be problem cases in the special schools. Boys sent to the Boys' School by the court are examined by Miss Claire E. Walters. Miss Walters has her office in a temporary building at the Boys' School. She also examines the girls and dependent boys at the Detention Home nearby. If, in the opinion of the psychologist, a case requires further study, it is referred to the Bureau of Juvenile Research at Columbus, or a psychiatrist may be called in to make a special examination. There is no psychiatrist on the staff of the court, the school board, or the Department of Health, so that, naturally, these special examinations are made 
but rarely. As a result, the reports of examinations which come back to the judge are confined merely to a statement of the findings and only in the more serious cases of feeble-mindedness is a recommendation for commitment to the State institution risked by the examiner.

The Juvenile Court is officially without equipment for making medical and special mental examinations. Whatever is done is at the personal request of the judge. The results of the various examinations are reported to him, and frequently Miss Walters appears as a witness. Neither Miss Walters, Dr. Luckey, nor their assistants receive any extra compensation for this work. Other psychiatrists and medical examiners, if they appear as witnesses, receive ordinary witness fees.

In spite of all these handicaps the work is extremely well done, although necessarily limited by inadequacy of equipment. Judge Addams recognizes the value of the work, however, and is not only inclined to follow recommendations made, but strongly recommends an extension of this work. The relation between the judge and the special examiners is one of close coöperation on both sides. The relation of these examiners to the probation officers is less close, although through the influence of the judge and the chief probation officer the facts disclosed by examination are utilized by the latter in selected cases. Much, however, could be done to improve this part of the work. The same may be said of the relation between the special examiners and the officers of the Detention Home.

\section{Recommendations}

1. A mental and physical examination should be made of every child brought to the attention of the Juvenile Court, and careful records should be kept of the results of each examination.

2. The examinations should be made whenever it appears advisable to the examiners.

3. The present excellent coöperation between the Juvenile Court and the Department of Education should be extended so as to make available for both such facilities as each may be able to provide. This applies especially to the suggested creation of a Division of Mental Health in the Department of Education. Such a division might profitably, and with little increase of staff, contribute to the Juvenile Court much needed information in regard to the intelligence, mental qualities, and personality of each child under consideration by the court. 


\section{THE ADULT CRIMINAL}

\section{Progress of Mental Examination}

$\mathrm{A}^{\mathrm{D}}$ DISCUSSION of the medical relations bearing upon the adult criminal is a matter of few words, so far as the present practice in Cleveland is concerned. Except for the occasional perfectly obvious case, practically no use is made of medical and more especially mental treatment in dealing with adult offenders. The majority of citizens and officials no doubt believe, as a high prison official in another State said-" "Of course, the out-and-out feeble-minded or insane prisoners need special attention, but surely the doctors have no interest in the normal prisoner." Does it not depend upon the attitude with which one approaches the question of treatment whether mental experts are to concern themselves solely with the end stages of mental disease or deficiency, or with the interpretation and treatment of all cases of behavior difficulties, assuming them to be in the main problems of mentality? The use of the word normal should be prohibited as misleading in the field of behavior difficulties.

Experience in some of our reformatories and penitentiaries has conclusively shown that the study of mentality yields information which no modern institution can neglect. One need merely refer to the well-known work at Sing Sing, Concord, Elmira, and Bedford Hills, not to mention the institutions of New Jersey, Michigan, and Illinois, and especially the United States Disciplinary Barracks at Fort Leavenworth, Kansas. The elaborate plans for a psychiatric clinic in the new prison at Sing Sing clearly indicate what the New York State officials think of this work as an adjunct of the penal system. And what has come more and more to be considered indispensable in an institution has proved itself of similar value to the courts. Mental examinations and personality studies are now insisted upon as a sine qua non in the work of practically all the Juvenile Courts of the country.

There is every indication that this work has so far established itself that criminal and police courts are also availing themselves of the advantages. Thus, the Municipal Courts of Chicago, Boston, Detroit, and 
Baltimore have psychopathic clinics or laboratories to which are referred all doubtful cases. No city has as yet worked out a system by which all cases coming before the court are considered from the mental angle. When, as often in court work, selection is made by untrained persons, important cases are frequently overlooked. Routine sorting examination of all cases, with more intensive study of those shown by first examination to require further investigation, is the only safe way.

As long as the public regards this work as a mere frill or an expression of maudlin sympathy for the criminal, of course, it will not be encouraged. What the uninitiated do not realize is that work of this kind is a very matter-of-fact and practical step toward the better administration of the law, as well as real economy.

\section{The Nature of Mental Examinations}

Although in general the public has become familiar with the fact that mental examinations are made in many cases where there is no reason to suppose that insanity exists, there is a great deal of doubt in the minds of many as to the nature of the methods and the information they may be expected to yield. It may not, therefore, be amiss to give briefly the outlines of this work.

Mental examinations, as they are now made, may be divided into two main groups: The first, or psychometric method, sometimes called the psychological tests, consists in the application of certain standardized sets of tests with the object of determining the native mental ability, or, as it is called, the "intelligence" of the subject. Various forms of tests are now used, but practically all of them are based upon the work of the French scientist, Alfred Binet, who, together with his collaborator, Theodore Simon, published in the years 1905 to 1908 the first scale for the measurement of intelligence in children.

This scale is arranged in accordance with the idea that as a child grows older and his mentality develops he is able to perform more and more complicated acts and to carry out more and more complex intellectual processes; so that, if we arrange a series of tests, questions, and problems in the order of their difficulty and present them to a child, we may be able to infer his degree of development by the point in such a series beyond which he is unable to answer questions satisfactorily. The scale thus arranged by Binet has since been tried out on a large number of school children, and as a result of this experiment it has been possible to arrange the tests in groups of six for each year. Since publication, these tests have been used to such an extent as to indicate thoroughly the existing need of such measurement. 
It soon developed that there were in the schools and elsewhere individuals who, on being subjected to these tests, failed more or less widely to come up to the grade corresponding to their actual age, and since the tests had originally been arranged for age groups, it was said that their chronological age or actual age was, let us say, twelve years, and the mental age as determined by the scale was, let us say, nine years.

As the tests have become more definitely standardized, and as new tests have been devised and come into use, the exact definiteness with which the mental ages were stated ten years ago has gradually become subject to modification. Thus, while in the case of school children of twelve or less it is reasonably satisfactory to express their deviation or subnormality in terms of years, it is not so clear when the method is applied to older persons. When applied to adolescents, and especially to adults, these methods have frequently given rise to incredulity on the part of many; an instance of such a case is when an individual of twentyfive years who is guilty of a felony, and perhaps has a wife and children, and in other respects appears to be mature, is said to have the mind of a child of nine years as determined by the mental tests.

The reason for this apparent discrepancy is the fact that the original Binet scale and its modifications and amplifications hold with considerable accuracy for children of twelve and less, because the innate intelligence reaches its full development at about the age of puberty. This statement is not true in an absolute sense, but for present purposes is sufficiently accurate. The development which goes on after the age of puberty, during the age of adolescence, and until full adolescent maturity is reached, is a growth in strength, power, and the use of the innate ability through acquired habits and experience.

As this is the period during which the greatest apparent progress is made, when the change from childhood to adult maturity is visibly going on, it is difficult at first glance to reconcile this fact with the previous statement in regard to the maturing of intelligence. A child of twelve or fourteen may have as much intelligence as an individual of twenty-five or thirty years, and yet the adult will far exceed the child in intellectual performance and ability. This is because the older person is able to use his intelligence much more effectively because his emotional control, equilibrium, and judgment are much greater than those of a child. Less difficulty would undoubtedly be experienced in this regard had we a measure of the development which takes place during the adolescent period corresponding to the one we now have for the mental development during childhood.

The psychometric tests, therefore, give us a fairly accurate statement 30 
of the degree of intelligence of any individual. All inferences regarding the maturity of the individual in other respects, namely, emotional control, forbearance, responsibility, honesty, self-denial, respect for others, and the other attributes of personality which determine an individual's place in the social scale, can be determined only roughly. We can compare one individual with another in regard to his intelligence rating and can say with considerable precision by how much one excels another. For the period of adolescent development, no such exact measurement is possible, and we have to be content with a "more or less," "better or worse," standardization.

So striking have been the results achieved by means of the BinetSimon tests that in the ten years since the first publication this type of measurement has become firmly established in schools, courts, and institutions, in fact, wherever child welfare is concerned.

Other scales have been devised which furnish the information in a somewhat different way, perhaps with greater precision than the original Binet scale. Aside from the first important modification of the scale, the so-called Stanford Revision, by Professor Terman, of the Leland Stanford University, there has been developed a point scale by Professor Yerkes, and a number of special tests, such as those of Dr. William Healy, Dr. Guy Fernald, Professor Whipple, and many others.

The problem of giving an intelligence rating to the soldiers of the draft army during the late war gave an impetus to another form of test which has been claiming attention in the schools, namely, that of the so-called "group tests." This method, based in general upon the same logic as the Binet tests, was so arranged that any one who can read and write may perform the test. The method consists in an instructor reading certain instructions to the group, who are equipped with pencils and test blanks, and who then carry out the instructions, answering questions and solving problems in accordance with printed statements, while the instructor keeps time. In this way as many as 1,000 men can be examined simultaneously.

The scores made on these tests, which are now usually referred to as the army tests, are expressed in figures: the highest possible score, for instance, was 212 . The performance varied throughout the entire range from 0 to 212. In order to express the result in a usable form the score is divided into five groups, designated by the letters $\mathrm{A}$ to $\mathrm{E}$ as follows: $A$, very superior; B, superior; C, average; D, inferior; E, very inferior. It was found that so many men fell into the $\mathrm{C}$ or average group that it became necessary to divide this into two more groups, $\mathrm{C}$ plus and $\mathrm{C}$ minus, high average and low average respectively. The score necessary 
for a commission was judged, as a rule, to be either A or B. The men of $\mathrm{E}$ intelligence included the feeble-minded, the defective, and, in the main, men not fitted for the army because of low mentality.

In evaluating the mental status of an individual who, for one reason or another, is a subject for examination, more than intelligence rating is required. This further information is obtained by means of certain mental examinations which have as their object the determination not so much of the qualitative mental ability as of the existence of diseased or abnormal functionings or reactions. We might visualize this by saying that in the intelligence field we are taking a measure, just as we might measure the height of an individual, and that the differences are differences in mental stature. In the second form of examination, namely, the psychiatric examination, we are looking not for differences in height, but for pathological processes comparable to disease processes in the field of physical health. This type of examination seeks to determine the existence or absence of certain symptoms of disease, and when found, to evaluate their significance and the severity of the condition. It yields information upon which may be based such diagnosis as mental disease or the less severe pathological conditions, sometimes called psychopathic personality.

The study of the mentality of an individual from the point of view of psychiatry requires something further, however, than merely testing the mind or the nervous system. One cannot dissect the living human being and deal with one portion only. One of the characteristics of a living organism is that every part is in relation with every other. Nowhere is this more important than in the pathology of the mind. Of late a great deal of attention has been paid to the influence on mentality of certain factors which lie outside the nervous system. The existence of physical disease elsewhere in the body, as, for instance, in the delirium of fever, various intoxications and auto-intoxications, the effect of digestive disturbances, and, above all, the more newly disclosed effects of various glands and organs, such as the thyroid and the sex glands, are examples of these factors. It will be clear, therefore, that the examination of mentality from this point of view cannot be conducted with the same apparent exactness as is often possible in the investigation of the mental age. It must also be clear that this type of investigation requires the application of all the medical knowledge available and must, therefore, be made by a medical man with special experience in this field.

There is another point which must be understood in order to appreciate why medical, especially psychiatric, knowledge must be applied in addition to the intelligence rating. As we have seen before, the intelli- 
gence test is a matter of measuring mental stature. While these methods must be applied with the greatest care in order to be of any value and, therefore, require the services of a highly trained specialist, they nevertheless do not require any medical or pathological knowledge. In the elucidation of behavior difficulties we are confronted with a problem which is comparable less to an educational problem than to a problem of health. Even though our object is not to pin a label on the individual and find him either insane or feeble-minded, nevertheless we must arrive at a diagnosis of health by exclusion, for in no other way can a diagnosis be made. We cannot make a diagnosis of health or of sanity. We can only make a diagnosis of "no evidence of disease found." We can positively identify only the signs and symptoms of disease. In the absence of such we are justified in assuming that a person is healthy. It must be clear, therefore, that in making this sort of judgment upon the mentality of individuals and in elucidating the mental factors in behavior reactions a true knowledge of mental pathology is necessary in order to allow this judgment by exclusion.

The fact that psychiatrists are interesting themselves more and more in the behavior problems of the non-insane should not be interpreted as an indication that the psychiatrist is endeavoring to adjudge everybody insane. But, on the other hand, the commonly held fallacy that the psychiatrist has no interest in the problems of the non-insane or mentally healthy individual should be also dispelled.

\section{Criminal Detection By the Police}

\section{Departmental Health Work}

The only medical officer officially connected with the Division of Police is the police surgeon. Only one police surgeon is employed. The present surgeon, Dr. G. P. O'Malley, has held this office since December, 1920. The duties of the police surgeon are, first, physical examination of all applicants for appointment to the police force, and, second, care of sick and disabled members of the force. It will be seen from this that he is concerned only with the health of members of the force itself and not at all with medical or health problems connected with the work of the police.

Even in this restricted application the work of the police surgeon is not adequately provided for. There are too many men to be examined and the equipment provided is in many respects inadequate. During March, 1921, there were 800 men to be examined. Blood tests are not being made, although the police surgeon believes that such tests should be made in every case. Neither the physical examinations of applicants 
to the force nor the examination of men representing themselves as sick can now be made in any but a superficial way.

The police surgeon has no office-merely a desk in the office at the central station. There is no room where men can undress, and as a result the examinations cannot satisfactorily be made. A change is contemplated in this respect, and new quarters are to be provided at the Eighth Precinct.

The present officer, Dr. O'Malley, offers the following criticisms and recommendations:

1. Better working facilities with complete equipment for making thorough examination and also for emergency treatment.

2. Medical and clerical assistance. The city should be redistricted and a police surgeon hired for each district. There should be two assistants hired immediately to enable the eity to be divided into three districts.

3. A card index and records of all cases entered should be kept, and for this office space and help are required. There should be a system of records to show exactly the number of times each man reported sick and how much time he loses.

4. To obviate the possibility of malingering there should be a constant checking up of the records. These should also show whether or not a man is in such poor health that he is unable to perform active duty.

5. If an officer is sick too often, he should be called before a medical board and given a thorough examination, at which time his family physician should be present, if desired.

6. All cases of pension should be handled by such a board.

7. The police surgeon as well as the police officers should be entitled to pension. This is not the case at present.

Malingering in the police department seems to be somewhat of a problem from the point of view of health work. The men live scattered throughout the town and at times it is impossible for the surgeon to call upon all of them on the same day they report sick. Sometimes it is two days or more before the surgeon can see a case. The men are aware of this, and the surgeon believes they take advantage of the fact to take a day off. Dr. O'Malley believes that as much as 12 per cent. of the sickness might be designated as malingering, although he has no means of saying definitely, because no records other than the daily sick report have been kept.

\section{Public Health Problems}

For all health work outside the department itself, including general cases coming to the attention of the police and the examination of suspects and prisoners, the police depend upon the Division of Health. 
The city is districted, and the Division of Health maintains district physicians. The police may call upon these in cases requiring medical attention. The district physicians are supposed to confine themselves to the care of the indigent sick in their homes and to protect the community from contagious disease. In actual practice the police call upon the district health offices in many cases other than those specifically mentioned.

The police, furthermore, are instructed to remove any arrested person who requires medical treatment to the nearest hospital, preferably the city hospital, and a police guard is furnished in case such a person is kept at the hospital. There is a special ward at the city hospital for such persons, in which windows are barred, doors locked, and a guard constantly in attendance.

The police, however, render assistance to the general public in health matters. Owing to the fact that the police are always available for call, people refer cases to them, especially emergency cases, which should properly be taken care of by private physicians. The police keep on file the names and addresses not only of the district physicians, but also of certain private physicians who have certified their willingness to take emergency cases. Vice cases are referred to the Public Venereal Disease Clinics and to the Woman's Protective Association. The Division of Health maintains a diagnostic clinic for venereal diseases at No. 64 Public Square and the Fairview Clinic for Social Diseases at 3305 Franklin Avenue, mainly for treatment. The diagnostic clinic, under the federal government during the war, was taken over by the city in September, 1919. The Fairview Clinic was started August 16, 1920. These clinics handle private as well as court cases. Under the general code all vice cases are to be referred for diagnosis at the discretion of the judge. There seems to be considerable laxity, however, in referring cases. Rape cases are occasionally handled at these clinics, although, as a rule, such cases are referred to the city hospital.

It appears, therefore, that the problems of health, either of the police force or of the general public, in so far as the latter comes in contact with the police and the courts, are provided for adequately-if not in practice, at least in theory. The further improvement of this service and the raising of the general level of its efficiency is a question of applying present knowledge and furthering development along well-established lines.

\section{Examination of Suspects and Prisoners}

There are certain other problems of medical relations, however, of growing importance in connection with crime detection which concern 
the police and the crime-detecting agencies more than is commonly supposed.

The police have contacts with criminal and semi-criminal elements, which in many cases, if properly utilized, might result not only in better understanding of the general subject of crime, but actually in a more effective dealing with it. A patrolman on the beat can no longer adequately perform his full duty in a city such as Cleveland by merely representing in theory, and not in practice, the majesty of the law. To be the eyes of the law and of the community his powers of observation must be trained, so.that he may be able to distinguish the significant from the adventitious.

This is not the place to discuss the details of police administration and police personnel. But it is relevant to consider here the equipment and skill necessary for individual police officers to secure the information needed to determine many important problems of the mentality and reliability of witnesses, and the relative honesty or dishonesty of witnesses, suspects, and prisoners. One cannot depend upon chance in this matter nor the haphazard school of experience. A very precise preparation must be made by the authorities to provide the necessary training. There seems to be no escape from the conclusion that the Division of Police should in some way be provided with the services of a specialist in mental science, particularly in its application to the problems of criminal behavior.

The work of the police surgeon in his professional supervision of the health of the police force; of the district health officers, in their relation to the physical health of the community in general, and of prisoners, suspects, and accidental cases in particular, should be strengthened by the introduction of three health officers-two to act as assistants to the present police surgeon in his routine work, and the third a specialist who should devote his time and energies to the mental aspects of the police department both within and without the force. Such a specialist would serve not only as an advisor in the department, but also as a teacher. Mental health work should really be a subdivision of the health department, and it is not unlikely that before long the health department of every large city will develop a special division for mental health.

The problems which present themselves for solution by mental science in connection with police work are:

First, the general problem of the existence of mental disease or mental defectiveness in persons under observation.

Second, the very important and broad problem of pathological personalities. In a great number of cases this seems to be one of the impor- 
tant underlying factors in the interpretation of behavior disorders. A greater interest in these problems and a more intelligent application of the knowledge obtained in their scientific solution are essential if we are ever to reduce the seriousness of a large group of problem cases. In order to make clear the meaning of this one needs merely to refer to the relationship between the psychopathic personality and vagrancy, non-support, desertion, inebriety, drug addiction, and the types of delinquency in which sex difficulties are a decisive factor.

There are certain special relations in addition to these general ones in which mental science may be of assistance to the police. Two especially demand attention:

First, the general question of malingering, which is to some extent a factor within the police force and is of the utmost importance in relation to the analysis of individual delinquents and criminals. The value of a testimony, the reliability of a witness, the question whether an individual is shamming insanity, injury, or disability, may often be solved or at least determined by applying the rules of mental examination to the individuals under observation.

The second has to do with forced confessions or the so-called "third degree." A suspect is apprehended and many points of circumstantial evidence point to his being the criminal or at least implicated in a criminal affair. But the chain of evidence is by no means complete, and the suspect denies more or less successfully his guilt or complicity. Under such circumstances a confession, if gained, may be corroborated by evidence now easy to secure. Such a confession almost invariably simplifies the work of the police to such a degree that in many cases they are bent on securing a confession rather than objectively securing the available evidence.

It is not our wish here to discuss this method from the legal nor the police aspect. From the point of view of the scientist it is a clearly ineffectual and dangerous method. Not only is it apt to be misleading, but its chief fault is that it tends to accustom police officers to seek the easiest way out of a difficult situation, rather than to apply the best methods of scientific investigation.

However, confessions probably will continue to be sought, and in connection with this work a specialist in mental examination would prove of assistance. A careful mental examination will disclose whether a person is able to give reliable information, whether he is suggestible and to what degree, and therefore whether he will accept readily the suggestions of the "third degree." Furthermore, laboratory methods are of considerable aid in determining whether a person is withholding informa- 
tion, whether he shows well-marked emotional reactions, and many other points now too often ignored in the prosecution of unscientific investigations.

\section{Recommendations}

1. Three additional police surgeons should be appointed to serve as assistants to the police surgeon.

2. These surgeons should be employed on full time.

3. They should include in their duties medical and surgical attention to the suspects and prisoners lodged in the police jail.

4. One of the assistant police surgeons should be an expert in psychiatry, and should be known as the mental health officer.

5. The mental health officer of the police department should serve full time.

6. The mental health officer should devote his time to the mental problems in connection with the police force and the police work.

7. The mental health officer should make a mental and personality examination of every candidate for appointment to the police force and should record his findings.

8. Reëxaminations of every member of the police force should be made by the surgeon and mental health officer once every year.

9. The mental health officer should be present whenever possible at all special examinations of prisoners and suspects, especially in the case of examinations conducted with the purpose of obtaining so-called "confessions."

\section{Crime Detection by the Coroner's Office}

"The office of coroner has long been a subject of comment and unfavorable criticism in this country. Physicians and medical societies have made frequent efforts to secure a more efficient administration of the duties devolving upon this office. Laws have been enacted establishing other offices as well as State boards and commissions which have gradually taken away many of the duties formerly belonging to the coroner. The importance of the office has so decreased that little attention is given by the political parties or by the voters to the candidates who seek election to the position. And even less attention is given by the public to the actual administration of the office by the men elected."

Thus begins the report of the investigation made by the Coroner's Committee of the Municipal Association of Cleveland in 1912, and in the nine years which have passed since the publication of this report practically nothing has been done to correct conditions or to apply any of the recommendations made at that time. With minor changes the report is valid today. 
The office of coroner in Ohio is governed entirely by statute. The Ohio constitution of 1802 provided that one coroner should be elected in each county; but no provision for this office is contained in the present constitution. Under statute one coroner is elected in each county in the even-numbered years, who holds office for two years from the first Monday of the January following his election. The statutes make no provision for deputy coroners or other assistants, although reference is made to "the official assistant of the coroner," for whom, however, no appropriation is made. Because of the advantage of medical knowledge in this work it has been the custom to nominate physicians for the office of coroner.

The coroner's chief duty is to determine in cases of sudden or unexplained death the causes of death and whether it resulted from unlawful means, and, in the latter case, to fix responsibility for the crime and name the perpetrator. It is obvious, therefore, that a consideration of the office of coroner is well within the scope of a survey of the administration of justice.

Upon the proper execution of the coroner's duties depends, in no small measure, the strict enforcement of the law in homicide cases. A lax performance of these duties, whether due to carelessness, intentional neglect, or merely to ignorance, gravely affects the community. Public safety, especially in large and congested centers of population, requires now, as perhaps never before, that the inquiry into the cause of death shall be conducted according to the best modern theories and with the most expert knowledge and skill. It is easy to simulate an accident or suicide and therefore the definite determination that violence has been used may be well-nigh impossible unless the utmost skill and scrupulous scientific accuracy are brought to bear. It is clearly unsafe to trust such work to any but a highly competent pathologist and medico-legal expert.

The coroner's duties are given in the following excerpt from The Coroner's Office, Efficiency Series, Report No. 2, issued by the Municipal Association of Cleveland in December, 1912:

\section{Inquests}

The main duty of the coroner is holding inquests. Sections 2856 and 2857 of the General Code provide for the holding of inquests and set forth the method of procedure as follows:

"Section 2856. When informed that the body of a person whose death is supposed to have been caused by violence has been found within the county, the coroner shall appear forthwith at the place where the body is, issue subpœenas for such witnesses as he deems necessary, administer to them the usual oath, and proceed to inquire how the deceased came to his death-whether by violence 
from any other person or persons, by whom, whether as principals or accessories before or after the fact, and all circumstances relating thereto. The testimony of such witnesses shall be reduced to writing, by them respectively subscribed, except when stenographically reported by the official stenographer of the coroner, and with the finding and recognizances hereinafter mentioned, if any, returned by the coroner to the clerk of the Court of Common Pleas of the county. If he deems it necessary, he shall cause such witnesses to enter into recognizances, in such sum as may be proper, for their appearance at the succeeding term of the Court of Common Pleas of the county to give testimony concerning the matter. The coroner may require any and all such witnesses to give security for their attendance, and if they or any of them neglect to comply with his requirements, he shall commit such person to the prison of the county, until discharged by due course of law.

"Section 2857. The coroner shall draw up and subscribe his finding of facts in writing. If he finds that the deceased came to his or her death by force or violence, and by any other person or persons, so charged, and there present, he shall arrest such person or persons, and convey him or them immediately before a proper officer for examination according to law. If such persons, or any of them, are not present, the coroner forthwith shall inform one or more justices of the peace, and the prosecuting attorney, if within the county, of the facts so found, in order that the persons may be immediately dealt with according to law."

The terms used in Section 2856 have been construed by the Ohio Supreme Court (62 O.S. 307) as follows:

"A death 'caused by violence' is a death caused by unlawful means, such as usually call for the punishment of those who employ them. A body 'is found' within the county when it is ascertained by any means that it is within the county."

"'Death is supposed to have been caused by violence,' whenever from such observation as he may be able to make, and from such information as may come to him, the coroner is, for reasons of substance, led to surmise or think that death has been so caused."

As thus'interpreted by the Supreme Court, the statute, in referring to "death by violence," means intentional killing as distinguished from mere negligence. No criminal negligence act has thus far been passed in Ohio, and the terms of the present statute are certainly not intended to confer general jurisdiction upon the coroner in cases of accidental deaths by railroads, street cars, in manufacturing plants and the like, except in cases where death is supposed to have been caused by "unlawful violence" and not mere negligence.

However, there is one exception to the general rule, namely, that Secs. 926-7 seem to require the coroner to hold inquests in all reported cases of fatalities occurring by explosion or accident connected with a mine, regardless of the question of criminality. Moreover, the statutes now provide (Secs. 212-3) that in cases of death occurring without medical attendance it shall be the duty of 
the undertaker to notify the registrar of vital statistics of such death and, if such death appears to the registrar to have been caused by unlawful or suspicious means, he shall refer the case to the coroner for inquest.

The statutes further provide (Secs. 6268-9), in cases where the death of an inmate of a licensed maternity boarding-house or lying-in hospital is reported to the board of health, that such board of health shall forthwith call upon the coroner to hold an inquest unless the certificate of a legally qualified physician is exhibited specifying the cause of death.

The practical effect of Sec. 2856, giving the coroner jurisdiction to act in cases where "death is supposed to have been caused by violence" is to make it discretionary with the coroner in what cases he shall act; and renders it practically outside the power of the courts to regulate the actions of the coroner in this regard. The language of this section is so broad that the extent of the coroner's authority is left almost wholly to his discretion and good faith; and any criticism of his having assumed jurisdiction unnecessarily could be met with the general rule that a public officer's acts are presumed to be according to law and in good faith. In brief, the coroner is his own guide as to the number of inquests he will hold.

\section{Autopsies}

The statutes provide (Sec. 2495) that "The county commissioners may allow a physician or surgeon, making a postmortem examination at the instance of the coroner or other officer, such compensation as they deem proper." Although the coroner may determine in what cases autopsies shall be performed, and who shall perform them, the commissioners thus have entire discretion as to compensation, and in practice their wishes largely control as to the kinds of cases in which autopsies shall be made. Autopsy fees and the relative number of autopsies performed vary greatly, therefore, in different counties.

Formerly in Cuyahoga County the coroner distributed the autopsies among favored physicians or hospital internes. Under the present administration the coroner has assigned this work to his "deputy," Dr. Droege, and under an agreement between the county commissioners and Dr. Droege he performs all autopsies at a uniform charge of $\$ 15$ and confines his examinations to cases of supposed homicidal death.

\section{Further Duties}

Where the coroner attends upon the body of a deceased person it is his duty (Sec. 2860) to notify friends or relatives of the deceased if known, or if not known, to advertise the fact of death in a newspaper.

He is required (Secs. 2859 and 2861) to make an inventory of all articles of property found on or about the body, and to return the inventory (Secs. 2861-3) and the articles described therein to the Probate Court, where such property other than money becomes subject to the order of the Probate Court, for its preservation or other disposition, the rights of administrators and executors (Sec. 2684) being fully recognized. The statute directs that such property (Sec. 2863) as is unidentified or unclaimed shall be advertised and sold at public sale 
annually by the Probate Court and the proceeds paid into the county treasury. However, money found shall be applied first (Sec. 2862) to paying the expenses of saving the body, and of the inquest and burial, and the remainder shall be paid into the county treasury, where, on proper proof being offered, such money as well as the proceeds of property sold shall be paid over to the claimant entitled to it.

\section{Anomalous Duties of Ohio Coroners}

In addition to the duties which it would seem properly belong to the office of coroner, he is by statute in Ohio made a process server, both for the Common Pleas Court (Sec. 2835), where the sheriff is an interested party, and for the Probate Court (Secs. 1596 and 1599), generally, and in certain cases (Sec. 11435) he may further be called on for summoning a jury. Moreover, he is given the additional duties (Sec. 13606) of endeavoring to arrest convicts escaping from the penitentiary, and (Sec. 9914) of apprehending persons selling liquor contrary to law within two miles of the place where an agricultural fair is being held.

In all these latter cases he is assigned duties-although his services in such instances are extremely rare-which are already enjoined upon other officers by law, or for the performance of which the courts are given the power to make special appointments in case of need. These special duties are clearly a survival of the days when deputy sheriffs were a rarity and when the office of coroner was not regularly filled by a practising physician.

\section{Compensation}

The coroner's office is the only office still maintained on a fee basis. His remuneration for his services is dependent entirely upon fees earned, the amounts of which are scheduled (Sec. 2866) as follows:

(a) For viewing a dead body, three dollars.

(b) For all necessary writings and the return thereof, 10 cents per 100 words.

(c) For traveling to the place of view, 10 cents per mile.

No special fee is provided for the hearing of testimony in connection with inquests, and the coroner's compensation in such cases, other than the fee for viewing the body, is dependent on the allowances for necessary writings connected with making up the records from the testimony and the other incidents of the case. The statutes do not contemplate the making of autopsies by the coroner in person and no fee is specified for this work.

The staff of the coroner is appointed by the county commissioners, the tenure of office being subject to their pleasure. The staff is under the jurisdiction of the coroner, although he has no authority to discharge individuals. There is little interest in the election of the coroner, the name of the nominee appearing usually at the end of the ballot.

The coroner receives no specified salary, his compensation being dependent on the collection of fees, the only county office still thus main- 
tained. For viewing a dead body he receives a fee of $\$ 3.00$, no matter where the body may be located nor the length of time consumed in reaching it. For traveling expenses 10 cents per mile is allowed. The statutes do not provide special fees for the performance of autopsies by the coroner. As a matter of practice, the county commissioners allow a fee of $\$ 25$. There is no specified fee provided for the taking of testimony at inquests, compensation for this depending upon the allowance for the necessary clerical work. There is no provision for extra fees and no allowance to meet the expenses in especially complicated cases. Salaries and wages for the staff are as follows: morgue keepers, $\$ 137.50$ per month; janitors, $\$ 110$.

The present coroner of Cuyahoga County, A. P. Hammond, M.D., has been in office since January, 1921. Dr. Hammond has been a practising physician and still devotes some time to general practice. He keeps daily office hours at the Morgue, from 8.30 to 12 and from 1 to 3 o'clock. All who have come in contact with Dr. Hammond are unanimous in their commendation of his serious attitude toward his work and his desire to coöperate in every way. The community is fortunate in having such an officer in this very important position, especially in view of the antiquated conditions under which this work is being performed in Cuyahoga County.

The statutes lay down no requirements for the office of coroner except that he must not practise as an attorney or counselor-at-law.

The present practice in the coroner's office in regard to stenographic service is to secure a stenographer from a typewriter company on the authority of the county prosecutor. A fee of 10 cents per 100 words is all the compensation available, although this sum appears to be less than the salary of a regular full-time stenographer. It has been the practice in the past for the coroner to employ a stenographer at his own expense.

Autopsies are performed by physicians selected by the coroner for this duty. As a rule, a qualified pathologist has been employed for this work. For this reason practically all the autopsy work has been of a high order, a circumstance which is all the more fortunate since it is due to the good judgment of the coroner, rather than to the provisions of the law.

There are four morgue keepers and two janitors. One of the morgue keepers serves as a clerk, keeping and filing the records. He assists at autopsies and acts as coroner when the latter is absent. The present incumbent was formerly an undertaker and expert embalmer. He has held his present position for eight years. The other three morgue keepers do general utility work, such as answering the telephone, taking messages, receipting for property and money found on bodies brought in by the 
police, making entries in property books, etc. They work eight hours a day, seven days a week, as the morgue is never closed. No bond is required and no special qualifications are named for these positions. However, the feeling among the morgue keepers is that they should be licensed and bonded and that a qualification for this position should be experience as a licensed embalmer, especially on account of the possible danger to the community of careless handling of the bodies of persons who have died of contagious disease.

The two janitors are responsible for caring for the two floors of the morgue. One of the janitors serves as relief màn to give the morgue keepers one day off a week. The morgue keepers and janitors are appointed and paid by the county commissioners. The discipline is not good, and the staff, as might be expected under the conditions, lacks esprit de corps. On account of the valuables and other property which is continuously passing through the morgue, the staff must often find themselves in positions where their honesty may be questioned, a circumstance which further tends toward bad morale and consequently lessened efficiency in the service.

In addition to the above, there is a special constable attached to the coroner's office who serves the necessary legal papers in subpœnaing witnesses. This officer is allowed considerable discretion in deciding which witnesses to subpœna. Usually the selection depends entirely upon his judgment. The fee for this work is paid by the county treasurer through the auditor, and the total sum varies considerably in amount in a year. It is said that formerly considerable sums were paid over annually for such service.

\section{Relation to Police}

The Division of Police sends the coroner a copy of its reports on criminal cases. The coroner also makes a report to the police of all cases coming to his notice. If a dead body is discovered in surroundings indicating violence, the police assume responsibility for all weapons and other objects which might serve as evidence and exhibits. The coroner takes possession of the body and personal belongings. The police later turn over to the prosecutor all property in their possession.

The police emergency or ambulance conveys bodies to the morgue in practically all cases. This has become the custom only of late, since the police emergency has superseded the old ambulance service which used to be in the hands of undertakers. Occasionally bodies are brought to the morgue in undertakers' wagons. A policeman accompanies the body and makes a list of the clothing and property found. The morgue keeper 
makes an examination of the clothing of the corpse in the presence of the police officer, making an inventory of all property found, and an entry in the property book which the policeman signs as a witness. There is thus a double check on all property.

In murder or suspected murder cases the clothing is put in a bag and kept in the morgue, available for use in evidence. In criminal cases clothing and property are released to relatives only on order of the prosecutor. Bullets taken from bodies are carefully preserved and importance is attached to the necessity of proving that the bullet submitted as evidence was actually the one taken from the body. Some years ago a case occurred in which a person indicted for murder was not convicted because of careless handling of the evidence, which in this instance was a bullet. In the case of bodies which are in an unidentifiable condition, due to exposure or long immersion in water, or to trauma, the skill of the expert embalmer has proved of value to the morgue by so restoring the bodies that identification was possible.

In manslaughter.and murder cases police officers or detectives are present at the autopsies. There is naturally a great deal of coöperation between the coroner's office and the police in detecting crimes, evidence often being obtained in the morgue in regard to the exact cause of death, the nature of the weapon used, and many other details which prove of value to the criminal detective agencies. The police sometimes bring suspects to the morgue for "third degree" purposes, suddenly confronting the suspect with the body of the victim.

\section{Relation to Courts}

The coroner and his assistants have relations with the Municipal Court, the grand jury, the Common Pleas Court, and the Probate and Juvenile Court.

The coroner or his assistants are subject to call as witnesses in the Municipal Court before the cases are bound over to the grand jury. The coroner testifies before the grand jury, submitting for its use copies of the report of the autopsy and the inquest. In all Common Pleas Courts the coroner or his assistants testify in murder cases. The present coroner is of the opinion that this testimony would be of more value if the coroner himself performed the autopsy. The coroner, as well as all the assistants and employees, are, of course, subject to subpona in court to prove corpus delicti.

The Probate Court law of 1920 makes the coroner custodian of all property in coroners' cases. All unclaimed money is held for a year and then turned over to the Probate Court. A property list is made and 
must be filed by the morgue keeper and the coroner. Property of any amount or value may be released to relatives or other claimants upon order by the Probate Court. If, however, the property is of considerable value, it is turned over to an especially appointed administrator. The order from the Probate Court releasing property is carefully filed at the morgue in the property book.

The relations of the coroner to the Juvenile Court are of little importance, as the coroner and his assistants are rarely called upon to appear in this court.

\section{Relation to Prosecutors}

The nature of the coroner's duties and functions necessitates much contact with the prosecutor's office. The effectiveness of the service is somewhat influenced, therefore, by the personal relations existing between these officers. The present coroner and the city prosecutors are on friendly terms, and as a result, coöperate satisfactorily. The county prosecutor decides in which cases to hold autopsies. A representative of the county prosecutor's office is usually present to assist in coroner's inquests. The coroner and his assistants are often called to the police station to give information regarding the bodies and to aid the police in preparing cases. During the trial they are often called upon to testify in court. The coroner and his assistants are called in by the prosecutor to establish the corpus delicti and to bind the prisoners over to the grand jury.

\section{Relation to the Bar}

Lawyers acting as counsel in both civil and criminal actions may come to the morgue for information or evidence. A lawyer may attend the coroner's inquests and may question witnesses, but cannot enter objections.

\section{Relation to the Medical Profession}

Physicians report to the coroner cases of sudden death, usually by telephone. The coroner then decides whether or not to claim the case. When the coroner decides not to assume jurisdiction, the physician may perform the autopsy himself, either at the morgue or at his own office.

\section{Administrative Relations}

The coroner issues certificates to undertakers through the Board of Health. Sometimes the district physicians feel they cannot issue death certificates because of suspicious circumstances, and so report to the Board of Health, which in turn reports to the coroner. The city chemist analyzes stomach contents, secretions, and excretions obtained from the body in suspicious cases. In all cases of death occurring without medical 
attendance within the city limits the district physician may view the body and report "Cause of death unknown." In cases of sudden death without medical attendance occurring in the county outside of the city of Cleveland, the sheriff performs the functions which, within the city limits, are performed by the police. He notifies the coroner when such cases are found, and accompanies the coroner to the body. The sheriff takes the weapons and all suspicious objects; the coroner claims the body and the property on it. In the case of probable suicide the coroner also takes possession of the gun or other weapon.

The county commissioners " $O$. K." all bills of expense of the coroner's office. There is no supervision of the county work. At present both the municipal and county administration are Republican. One of the morgue keepers who is a Democrat stated to the investigator that there are no political troubles.

The present coroner is on friendly terms with the county prosecutor. They coöperate in inquests and in other activities connected with their duties. This has not always been the situation, and difficulties have occurred because of strained relations between coroner and prosecutors.

\section{Equipment}

The public morgue was created by special statute passed in 1896 (92 Ohio Laws, 678). It was placed in care of the coroner, who is directed to see that all dead bodies received are properly preserved until identified or claimed for burial; to collect from friends or relatives of such deceased persons not residing in the county a sum not to exceed $\$ 10$; and to have photographed all bodies not properly identified.

The morgue occupies a two-story building. On the first floor are the office of the morgue keeper and a safe for property, a well-equipped autopsy room, and a viewing hall. The morgue has capacity for 100 bodies at a time. This space is arranged in four sections, the first of which only is cooled by refrigeration, because of the fact that it is easier to embalm bodies which have not been frozen. Hence most of the bodies are kept in the non-refrigerated sections. On the second floor are the coroner's office, a safe for property, and the office of the assistant clerk, a wellappointed inquest room, and files and records which go back to 1828 . These files and records are kept in the inquest room. The filing cabinets contain the following data in each case: viewing slip, inquest slip, a carbon copy of the police report of criminal cases, testimony of witnesses, and the autopsy records, all filed together in a folder. 


\section{Death Records}

Only the knowledge that we are dealing with a very serious subject prevents us from treating in a lighter vein some of the results of the coroner's work as performed under present conditions. Indeed, we cannot entirely suppress a sense of the ridiculous when we read over the list of causes of death as officially recorded by the coroner of Cuyahoga County for the year 1919.

The first entry for the year is:

No. 22942: "Could be suicide or murder," a reassuring statement and one calculated to promote confidence in the guardians of public safety.

Again a few lines further along we read: No. 22957- "Auto accident or assault." Certainly this expresses a doubt which the public would be interested to have resolved further.

No. 23178: "Aunt said she complained of pneumonia, looked like narcotism." Is it necessary to dwell on the extraordinary convenience of having the subject thus obligingly perform the work of the coroner by confiding the diagnosis and thus settling at the same time the cause of subsequent demise?

No. 23203: "Believe strychnia used-viewed as suicide." Is itnot possible to know whether strychnia was or was not used?

No. 23241: "Looks suspicious of strychnine poisoning," and this suspicion must forevermore poison the mind of anyone who turns the pages of the coroner's record because the county of Cuyahoga did not believe it important to know whether this was a case of homicide, suicide, or an accident.

Consider from the point of view of law enforcement and the public safety such records as these:

No. 22964: "Found dead."

No. 22987: "Found dead in shanty."

No. 22990: "Head severed from body."

No. 23035: "Could be assault or diabetes."

No. 23050: "Premature or abortion."

No. 23135: "Found dead in alley-lobar pneumonia."

No. 23187: "Diabetes, tuberculosis, or nervous indigestion."

No. 23253: "Consider it tuberculosis."

No. 23300: "Found dead."

No. 23484: "Found crushed."

No. 23512: "Could be diabetes or poison."

No. 23551: "Died suddenly after taking medicine."

No. 23568: "Medicinal poisoning."

No. 23574: "Body entirely burned." 
No. 23577: "Found dead in bath-room."

No. 23605: "Died suddenly."

No. 23670: "Loss of blood."

No. 23686: "Shock."

No. 23687: "Body covered with sores."

No. 23731: "Acute arsenical poisoning-accident."

In none of these cases was an autopsy performed, although one would suppose that in some, if not in all, more precise information is needed not only to determine the exact cause of death, but definitely to exclude foul play.

\section{Cost of Administration}

The apparent cost of administration of the coroner's office appears to be about one-half what it was in 1912. The scattering of items throughout the county work makes it impossible to be exact, but it is safe to assume that the entire cost of administration, including the morgue and numerous miscellaneous items, is between $\$ 10,000$ and $\$ 15,000$ annually. ${ }^{1}$

REPORT OF AUDITOR'S OFFICE OF CUYAHOGA COUNTY ON THE EXPENSE OF THE CORONER'S OFFICE

\begin{tabular}{|c|c|c|c|}
\hline & $\begin{array}{c}\text { September, } \\
1912\end{array}$ & $\begin{array}{c}\text { September, } \\
1919\end{array}$ & $\begin{array}{c}\text { September, } \\
1920\end{array}$ \\
\hline $\begin{array}{l}\text { Coroner's fees } \\
\text { Constable's fees } \\
\text { Witness' fees } \\
\text { Autopsy fees } \\
\text { Miscellaneous }\end{array}$ & $\begin{array}{r}\$ 6,101.75 \\
1,585.30 \\
1,801.90 \\
1,155.00 \\
127.61\end{array}$ & $\begin{array}{c}\$ 4,629.10 \\
\text { i4.40 } \\
1,290.00 \\
\ldots\end{array}$ & $\begin{array}{r}\$ 1,876.82 \\
5.50 \\
12.60 \\
2,760.00 \\
44.55\end{array}$ \\
\hline Totals & $\$ 10,771.56$ & $\$ 5,933.50$ & $\$ 4,699.47$ \\
\hline
\end{tabular}

Even a cursory glance at the foregoing suffices to show that the work of coroner as now performed is far from adequate. It is indeed high time that the facts are faced and an effective arrangement commensurate with modern scientific efficiency be instituted.

This means abolishing the office of coroner.

\section{The Remedy}

During the recent (1921) session of the Ohio Legislature a bill was introduced through the efforts of the present coroner of Cuyahoga County, Dr. A. P. Hammond, which was designed to meet some of the objections

1 The budget for the office of chief medical examiner of New York for the year 1921 is $\$ 127,303$, of which $\$ 120,653$ is for salaries and wages. 
without abolishing the office of coroner. This bill allows the coroner, in counties having a population of 100,000 or more, to appoint an official stenographer, and "in counties where there is maintained a county morgue, the coroner may also appoint necessary assistant custodians of the morgue, in no case to exceed three in number." Above all, in counties having a population of 100,000 or more, "no person shall be eligible to the office of coroner except a licensed physician of good standing in his profession."

The principal objections to this bill are:

1. That the coroner is elected and not appointed. Keeping the office in politics makes it impossible to secure the quality of service required. No competent expert can be induced to subject his work or his professional career to the uncertainties of partisan politics. Continuity of service and freedom from extraneous interference are the sine qua non of scientific efficiency.

2. That the decision whether or not to perform an autopsy rests not with the coroner, but with the prosecuting attorney. This most pernicious custom makes the scientific determination of the cause of death subservient to the requirements of the prosecutor's office and dependent upon the state of his finances, instead of regarding such determination as a complete end in itself, the results to be used in whatever way may be considered proper by the prosecutors or anyone else.

3. That the coroner should be a physician, but not necessarily experienced in pathology. It is amply demonstrated by the history of the coroner's office in Cuyahoga County that securing a physician as coroner does not in itself constitute a sufficient safeguard against unsatisfactory results.

In 1877 the General Court of Massachusetts abolished the coroner and created in his place a medical examiner. ${ }^{1}$ Dr. George Burgess Magrath, medical examiner of Suffolk County, Massachusetts, has kindly furnished the following statement in regard to the Massachusetts law and its functioning:

The Massachusetts Medical Examiner Law was enacted in 1877. It abolished the office of coroner, assigned to physicians appointed by the governor all of the responsibilities involved in the investigation of the cause and manner of deaths supposedly due to injury, and delegated to justices of courts of first instance the magisterial function of fixing the responsibility for a death due to an unlawful act. The only important modification of the original statute is one made a few years ago by an amendment which substituted for the word "violence" the words "act or negligence of another" in that portion of the law governing inquests.

1 The Massachusetts law is appended. 
The statute is not highly specific in its definition of the jurisdiction of a medical examiner, in that it merely provides for his functioning in the case of death of any person "supposed to have come to his death from violence." The interpretation of this statute by the medical examiners of the commonwealth is, however, such as to extend its provisions to include all deaths caused directly or indirectly by traumatism, including traumatic septicemia, deaths caused by the action of chemical substances, of thermal or electrical agencies; deaths following abortions, irrespective of circumstances; deaths from disease resulting from injury or infection relating to occupation; deaths from neglect; sudden deaths of persons not disabled by recognized disease; and the deaths of persons found dead. This interpretation is, of course, necessary in order to make the law of any practical value, and brings within the scope of its operation deaths universally recognized as appropriate for medico-legal inquiry.

The principal advantages of the Massachusetts type of medico-legal inquiry over the coroner system are as follows:

(1) The separation of medical and judicial functions and the delegating of each to appropriate officials.

(2) The giving to the medical investigator the primary and full jurisdiction over the body of the decedent, thereby insuring to him ample opportunity to observe conditions or circumstances tending to show the manner as well as the cause of death. These often include facts susceptible of recognition and proper interpretation by a medical examiner only.

(3) The economy incidental to the use of existing courts which dispenses with the coroner's court and jury.

(4) The placing where it belongs, in the hands of a medical man, the duty of determining promptly the cause of death, whereby crimes against life may be immediately brought to light and the appropriate judicial and police authorities notified thereof; whereby also deaths from injury other than that incidental to the act or negligence of another, as well as deaths from so-called natural causes, may be recognized as such with equal promptness, without unnecessary publicity, and without the use and incidental expense of a court or coroner's jury.

(5) The opportunity existent is an appointive position of selecting therefor physicians qualified by special training and experience.

Dr. Charles Norris, Chief Medical Examiner of New York city, under the recently enacted law of New York ${ }^{1}$ abolishing the coroner and establishing the office of chief medical examiner, has thus summed up his experiences and conclusions: ${ }^{2}$

General dissatisfaction with the work of the coroner of the city of New York

1 Laws of New York, 1915, Chap. 285. "An act to amend the Greater New York Charter and repeal certain sections thereof." (See also: Laws of New York, 1882. Chap. 410.)

2 "The Medical Examiner versus the Coroner," by Charles Norris, M.D., $\mathrm{Na}$ tional Municipal Review, Vol. IX, No. 8, August, 1920. 
resulted in many attempts in the legislature at Albany to abolish this office and to substitute an office to be known as medical examiner, after the fashion of that created many years before in Massachusetts. Finally on April 14, 1915, the office of the coroner was abolished and in its place the office of chief medical examiner was established.

\section{The Coroner's Office Breaks Down}

Unlike the coroner's office, the medical examiner's office was not given quasijudicial powers, but was vested with sufficient authority to administer oaths and take affidavits, proofs, and examinations as to any matter within the jurisdiction of the office. The judicial functions formerly vested in the coroners were, under the medical examiner's act, transferred to the proper legal authorities, namely, the magistrates and the grand jury. Prisoners are now held by the magistrates, and the defendants are indicted by the grand jury upon presentation of the facts by the district attorney from the reports furnished by the medical examiner, the police and witnesses.

The judicial functions of the coroner's office are now more satisfactorily and quickly handled by the legally trained magistrates and by the grand jury under the guidance of the district attorney. In other words, the judicial functions of the coroner's office are redundant and have no proper place.

The correct determination of the cause of death is designated as medical jurisprudence, the science which correlates our medical knowledge to the purpose of the law. Thorough equipment in medicine and surgery must be supplemented by a knowledge of firearms, the effect of bullets on the human body, recognition of powder marks and burns, etc. Familiarity with the biological methods employed in testing suspected blood, semen, and other stains; practical knowledge of botany in the examination of dust and foreign material upon the clothes of suspects and in the examination of the intestinal contents for particles of food, that is, plant seeds and fibers of animal and vegetable origin; an acquaintance with the flora and fauna of waters, namely, diatoms, etc., may be of great assistance in the microscopic examination of the contents of the lungs and stomach of persons supposed to have been drowned; and again, the determination of the freezing-point and the differences in the salt content between the blood of right and left side of the heart may be of use to confirm or negate the diagnosis of drowning. Entomology also may be of considerable assistance in establishing the date of death through the cadaveric flora and fauna.

This incomplete summary of the duties of the pathological expert serves to emphasize the point I wish to make. That the officer whose duty it is to make such examinations which have as their one and single aim the determination of the cause of death and a correct and analytically interpretative analysis of the surrounding circumstances attending, must be a physician by education, technically and practically trained in these branches. No lay or professional man other than a well-trained pathologist as above defined possesses the requisite natural or legal qualifications to discharge properly the duties of such an office. 
The records of the medical examiner's office are open to the public, and daily use of such records is made by representatives of insurance companies, the families or representatives of the deceased, the army and navy authorities (especially during the late war), and the State Industrial Commission. Whereas under the coroners, the chemical examinations, even in poison cases, were not made except here and there, when the services of the pathological chemist of Bellevue Hospital in Manhattan were called upon to aid in a scientific inquiry, the office at the present time is constantly required to furnish evidence of the presence or absence of alcohol and of poisons. We are furnishing constantly to the department of health, the census bureau at Washington, and the various insurance companies, information in order to give them accurate data for purposes of classification, etc. The educational value of our reports is illustrated by the curious fact that the office is now criticized in those instances where chemical examinations are not made.

Without the aid of a properly organized chemical laboratory many certificates of death would be signed improperly. A most noteworthy illustration of this point is the fact that before the attention of the country was called to the so-called epidemics of wood alcohol poisoning, this office had become aware of the iniquitous sale of methylated spirits in place of grain alcohol through the routine chemical examination of cases which had come to autopsy in which the pathological lesions were indefinite.

The difficulty in abolishing a long and well-established office, as was the coroner's, is abundantly illustrated by the discussions which took place before the senate committee on city affairs in 1915. The arguments presented by the representatives of the coroner's system were that the coroners' physicians had surveyed a very large number of cases, that they were competent in view of this fact, that the establishment of a medical examiner's office would entail an extraordinary expenditure of moneys-some claiming that a satisfactory substitute of the system could not be maintained under less than half a million dollars a year. As a mere matter of fact, the medical examiner's office was created with a budget of about $\$ 65,000$ less than the coroner's budget for Greater New York. The favorite arguments of the coroners were that they were the protectors of the rights of the people, that the new system was instituted purely for the benefits of the medical colleges and that the introduction of a new system was merely a scheme to obtain sufficient autopsies for medical purposes. Glaringly false statements were made in the hearing.

\section{The Medical Examiner Faces Perplexing Problems}

One of the most serious tasks that the medical examiner performs is the determination of criminal negligence in accident cases. This consists in the investigation of the circumstances surrounding the deaths in various industrial accidents, the analysis of poisonous fumes in manholes, the deaths resulting from careless cyanide disinfection, either in rooms or in the holds of vessels, deaths resulting from salvarsan poisoning, deaths resulting from structural 
defects in wood from dry rot and in the careless construction of buildings and other structures in general. In fact, the policy of the office is to bring out all the facts, medical, pathologic, or chemical, and to present all such evidence in proper fashion, making direct and trustworthy inferences and at the same time to avoid the danger of looking at facts through the spectacles of theory.

The numerous cases of asphyxiation by illuminant gas which this office handles yearly present a subject of considerable importance to the commonwealth. The duty of the office is not merely to give a correct determination of the cause of death, namely, whether accidental, suicidal, or homicidal, but to report to the proper authorities any negligence or carelessness on the part of the landowner or tenant in connection with the attachments of the gas tubing to the heating and illuminating apparatus or structural defects causing leakage of coal gas from water heaters or furnaces. There have been a number of accidental deaths due to the habit of a few of the keepers of boarding-houses of turning off the gas at stated hours and again turning on the gas in the early morning hours when the tenants are still asleep, the burners being turned on. One of the difficulties we have experienced is that there is no single department which has responsibility to whom such cases can be referred with a certainty they will receive prompt attention and action. The inadvisability of the use of rubber tubing for gas connections was called to the attention of the board of aldermen a few years ago and it is expected that action will be taken to prohibit its use in connections of this kind.

I wish to call attention to the necessity of performing autopsies upon all suspected cases, namely, all those cases in which the diagnosis cannot be made beyond reasonable doubt. Curious illustrations have occurred in this office to indicate how important a matter this is to the community. For instance, we have had two cases within the past several months of supposed criminal abortions in women in their early forties, upon whom criminal abortions have been performed, and who at autopsy were found not pregnant. The department examines cases rejected by the department of health and death certificates signed by apparently reputable physicians have disclosed cases of acute gastroenteritis which turned out to be peritonitis following criminal abortion, and cases of suicide in women supposedly pregnant (one case up to the seventh month, in an elderly married woman), autopsy revealing that there was no pregnancy, pregnancy being feared due to the appearance of the menopause and poison being taken to deliver a supposed fœtus.

\section{Recommendations}

1. The office of coroner should be abolished.

2. A law similar to the New York or Massachusetts law creating a medical examiner should be enacted.

3. The medical examiner should be a physician, expert in pathology and in medico-legal investigations.

4. The Board of County Commissioners should appoint from a civil 
service list a medical examiner, and in counties having more than 100,000 inhabitants should appoint a chief medical examiner.

5. The chief medical examiner should have the power to appoint and to remove such deputies, assistant medical examiners, scientific experts, officers, and employees as may be provided for by law.

6. The medical examiner or his deputy or assistant should take charge of the body of any person who has died from criminal violence, or by a casualty, or by suicide, or suddenly when in apparent health or when unattended by a physician, or in prison, or in any suspicious or unusual manner.

7. If, in the opinion of the medical examiner, an autopsy is necessary, it should be performed by the medical examiner or his deputy or assistants.

8. The medical examiner should be in charge of the morgue.

9. Suitable laboratories, autopsy rooms, record rooms, and vaults, properly equipped for the performance of whatever investigations may be required in the course of the medical examiner's work, should be provided at the morgue.

10. A budget should be drawn up for the office of medical examiner each year, based upon the total amount of work to be done and not upon any proportionate relation to other public expenditures.

\section{Prosecution}

There is no provision for special medical examination in connection with prosecutions. It is left to the discretion of the prosecutor to call in physicians or other specialists to serve as expert witnesses. This is in accordance with the course pursued almost everywhere, and probably is satisfactory, according to present standards. There are certain individual prosecutors who consult and who may even be advised by experts throughout a trial without placing them upon the witness-stand. While this is a little more progressive than the general practice, it has the disadvantage of being partisan.

Prosecutors, in common with others, would benefit if there were available a body of expert opinion which could be invoked, as a routine measure, in all criminal cases.

\section{Adjudication}

\section{Municipal Court}

In the Municipal Court no special provision is made for expert medical or mental examinations. Cases dealt with by this court are in the main minor ones. They do not attract attention, and are passed 
through the court in a more or less routine fashion, on the general assumption that a delinquent requires punishment.

That the Municipal Court should constitute a process of weeding out socially incompetent individuals or serious delinquent types not yet guilty of a major crime is not comprehended. In a community in which public opinion on this subject is more advanced the Municipal Court is regarded as the most important clearing-house and sorting station for keeping the stream of civic life pure.

\section{Common Pleas Court}

The Common Pleas Court, criminal branch, hears cases of insanity under certain conditions. There are three ways in which such cases come before this court:

1. According to Sec. 13577, General Code, the grand jury may, if it finds the accused person insane, report that finding to the Common Pleas Court instead of indicting the person. The court then, as provided by law, impanels a jury to try that fact, whether or not the person is insane. If found insane, he is committed to Lima State Hospital for the criminal insane. The Ihlenfeld case is the first and only case to be dealt with according to the provisions of this section. Judge Baer, who tried the case, says this method saves time and money.

2. After a person has been indicted, and before sentence, his attorney may present to the court a certificate from a reputable physician to the effect that the person accused is insane, whereupon a jury is impaneled to decide the matter. The burden of proof rests on the defense. If threefourths of the jury find the accused insane, he is committed to Lima State Hospital. (Sec. $13608 \mathrm{ff}$.)

3. The defense of insanity may be made at a regular trial. If the person tried upon an indictment for an offense is acquitted on the sole ground that he was insane, he is committed to Lima State Hospital, Sec. 13679. In all cases, if restored to reason, he may be prosecuted for the offense.

These seem to be the only ways in which such cases come before the Common Pleas Court. The number of such cases is small. During 1919 there were but seven cases. No separate or special records are kept; the records of the number of such trials and disposition of cases are found in the general Common Pleas docket. The prosecution can oppose the plea of insanity and call in doctors or other specialists as witnesses. There is no special provision in law for calling in experts or for their compensation in such cases. Judge Levine and Judge Baer are of the opinion that the Common Pleas judge can order examination to be made as to an 
accused person's sanity. No specific powers of that nature are mentioned in statutes.

In Judge Baer's opinion there should be a laboratory to investigate the mental condition of persons indicted, especially in the case of recidivists. Such work he considers belongs to a specialist and not to the judge, who cannot detect such cases when they appear in court.

\section{Probate Court}

There are no medical experts specially attached to the Probate Court to act in lunacy and feeble-minded cases. The law requires that in every case of feeble-mindedness, epilepsy, or insanity two reputable physicians shall be called in as medical witnesses. Technically, these are selected by the probate judge in each case, and serve only for that case. As a matter of practice, of course, physicians appointed to this commission are almost always the same; but this is purely dependent on the judge's choice and judgment. The medical witnesses are paid $\$ 5.00$ for each case in which they testify, or, in other words, $\$ 5.00$ for each certificate. At present the two physicians appointed by the judge are experts in mental diseases, having had experience in State hospitals.

There is no equipment for this work; the court does not control any offices or laboratories, though when it is not possible to arrive at a decision without special observation, the court is able, as a rule, to send the patient for examination to the psychopathic ward of the city hospital, which is the so-called Detention Hospital.

No selection of cases is possible; the examinations are made in those cases which are brought into the Probate Court on a complaint of insanity, epilepsy, or feeble-mindedness. Every complaint made is examined. The original papers in all cases are kept in the office of the court. Certified copies are sent to the hospital or other institution to which the patient is sent for examination and observation or to which he is committed. Reports of work are also made to the Secretary of State.

The examiners perform their work wherever necessary, according to the requirements of the case. They visit patients in their homes and in hospitals, at the State hospital, in jails, or wherever else they may be. The recommendations of the medical examiners are nearly always carried out. The judge acts upon the medical experts' advice also, and has confidence in the examiners whom he selects because they, in his opinion, are careful and conscientious in their work. Since the medical examiners are appointed by the judge, their mutual relations are very close. Apparently no other consideration than their fitness for the work enters into their appointments. 
This system, which is obviously open to many theoretical objections, especially the opportunity it affords for political and other considerations to play an important part, is safeguarded by the fact that the present probate judge is above allowing such factors to influence his judgment. The medical examiners are free from the objection of being interested in the State hospitals, especially since the law requires that no physician officially connected with these may serve as examiner for the Probate Court.

In regard to the relation of medical examiners to commitment of insane persons, there is this to be said: The law which authorized the payment to the medical examiner of a fee for each case committed obviously places a premium on committing individuals; it would seem that the interest of the physician was to commit persons rather than to keep them out of institutions. Any possible tendency in this direction is counteracted, however, by the equally potent restraint of laws concerning malpractice and other legal actions.

Nevertheless, the recompensing of these special witnesses is a bad practice. Physicians are not only open to the influence above mentioned, but personal considerations enter in which have no place in this connection, such as the fact that these fees, which are paid through public funds, are in the nature of a largesse and should, therefore, be distributed among as large a number of physicians as possible. In the eyes of the more unscrupulous it will appear as a downright "graft," which may be connived at only if every one gets his full share. In Cleveland, as in other cities where this system is used, the work is done with little, if any, evidence of bad influences. Nevertheless, from the point of view of efficiency, and above all that of educating public opinion, it should be changed.

The tendency in all matters pertaining to insanity, at least since Charles Reade published Hard Cash, has been to remove all specific incentive in the matter of commitments. This fact, probably more than any other, has resulted in the respect shown for the State hospital and the prejudice in favor of this institution as compared with private institutions for mental cases.

The decision, whether a person should be segregated to a certain extent and deprived of his liberty, should be made on purely objective evidence, and while it is true that the court makes the final decision and examines the records, it is nevertheless upon the evidence submitted by the medical experts that such a decision is made by the court. If, then, medical examiners are swayed, either consciously or unconsciously, by other reasons than those based upon purely objective evidence, the court, 
even if ignorant of this, cannot act in an unbiased way. The result is that medical examiners should be paid either a salary or a fixed fee for every examination they make, regardless of whether commitment is recommended or not. At present they are paid for the certificate issued and not for the examination made.

The same statements which apply to the question of expert witnesses in general apply here. There may be, and probably should be, two kinds of experts available to the courts, the one serving as a public official on salary, for either full or part time, the other physicians who, in addition to the usual medical qualifications, have qualified and been appointed as experts. When a court or other public official or a private individual requires the services of an expert other than the officially salaried expert, he may select one from this qualified list. This system does not force any expert upon either courts or private individuals, nor does it require the poor man to suffer because he cannot afford the expensive specialist. Furthermore, it guarantees that the public official will be non-partisan and that the privately retained expert will at least measure up to the minimum standard requirements.

There is another phase of the relationship between the medical and particularly the mental expert and the Probate Court. In the Probate Court questions of property rights, guardianship, and conservatorship continually arise. While the question of mental disease or mental deficiency may not arise, there may, nevertheless, be important considerations in which the expert knowledge of the qualified psychiatrist would be of considerable value to the court. This refers particularly to that very large field of personality factors which we are just beginning to study scientifically. Every judge of the Probate Court will readily recognize what is referred to here, and probably every judge who has served in the Probate Court has made use of his experts in non-insane and nonfeeble-minded cases, for the purpose of evaluating the personality factors before making a decision.

This important work requires specialization and, furthermore, cannot be done satisfactorily unless experts making the examinations are employed on full time; that is, the experts cannot be expected to be efficient if they are called in only occasionally on such cases-they must be dealing with them as a matter of daily routine.

In the last year 560 cases have been examined by medical commissions for the Probate Court at $\$ 10$ a case, or a total expenditure of $\$ 5,600$ for medical fees alone. This does not include the sheriff fees, witness fees, and other incidentals. 


\section{Recommendations}

1. A chief psychiatrist should be appointed by the judge of the Probate Court from a civil service list.

2. The chief psychiatrist should be empowered to appoint from a civil service list three assistant or deputy psychiatrists, one psychologist, and one assistant psychologist.

3. Suitable salaries should be provided to attract properly.qualified experts.

4. The necessary clerical assistance and office quarters should be provided in the new court-house office building or county jail.

5. The chief psychiatrist should examine and pass upon all cases coming from the Probate Court, the Municipal Court, and the Court of Common Pleas, in which the question of sanity or insanity, epilepsy, or mental deficiency is raised.

6. The chief psychiatrist should cause to be examined, physically and mentally, in so far as possible, all persons coming before the Municipal Court.

7. The chief psychiatrist should present to the courts in writing a statement of the findings and opinion of the psychiatrist in each case examined.

8. In cases of dispute or doubt the court should be able to appoint a special psychiatrist to examine a case.

9. The person to be examined, his counsel, relatives, or friends, should be permitted to be represented by a psychiatrist who should have access to the findings of the chief psychiatrist, and who may be present at and participate in the examination by the chief psychiatrist, but who may not interfere with the conduct of such examinations.

10. The sheriff of Cuyahoga County and the Director of Public Welfare should be able to call upon the psychiatrist to examine any person in their custody and to enter a petition for commitment of any person thus examined who shall be found to be insane, epileptic, or feeble-minded.

11. Whenever, in the opinion of the psychiatrist, any person examined requires more extended study or observation than can be given at the county or city jail, application should be made to the court having jurisdiction, for temporary care at the city psychopathic hospital for a period of ten days, or not more than three months, or until such time as the director of the psychopathic hospital shall depose in writing that the examination or observation has been completed. 


\section{CHAPTER IV}

\section{PREVENTION}

\section{Early Detection of Special Cases}

$\mathbf{I}$

F WE may correctly assume that delinquency in most instances is not merely accidental, but is associated with characteristics and personal peculiarities inherent in the individual, it must follow that any attempt at prevention must include elimination at the source. By this we mean the examination of children of school age and even younger from the point of view of mental and personality characteristics, as manifested especially in behavior. It is by no means a certain or a simple matter to determine, even after careful examination, which children will present major behavior problems later in life. But it is certainly possible to determine which ones are in need of immediate special training and which show present behavior or mental deviations.

A careful study of this kind, followed by intensive training and observation of the physical, mental, and social factors involved, will, if applied to enough children, be comparable to the results obtained in the same circumstances by the methods of physical health training. If these methods now succeed in the Juvenile Courts, where they are applied after delinquency develops, there is every reason to expect even more satisfactory results when applied earlier, before the major problems of delinquency appear. When such a plan has been in operation for a generation, it is not unlikely that the problem of delinquency in the community will have changed so much as to make jails, as we now know them, quite unnecessary. We shall probably always require places of detention, but with a better understanding of the real causes of delinquency and crime and with more effective methods of prevention and treatment it is fair to assume that future detention institutions will differ from the present ones as modern hospitals differ from the ancient pest houses.

Meanwhile the police will continue to pick up and detain a large number of individuals who are a source of trouble and loss to the community and of little profit to themselves. Even in these cases an intelligent attitude requires that suitable studies shall be made of each individual case in order really to solve the problem, instead of depending entirely on forcible detention and segregation and the supposedly curative effects of 
punitive imprisonment. The number of recidivists who pass through our jails is ample evidence against such misplaced confidence.

Even if a thorough examination of each prisoner is not possible, a sorting by simple examinations will identify extreme types of feebleminded or psychopathic individuals. Individuals who are brought to light by these sorting examinations cannot be properly disposed of without treatment, and the treatment which may be given is one of three general types or combinations of these, namely, physical, mental, or social.

Physical treatment is directed against physical disease, on the one hand, and physical handicaps and defects, on the other. It is not necessary to enlarge upon this familiar topic. The main thing to emphasize here is the importance of correcting all physical disabilities, even those of apparently minor significance, in the interest of improving the mental and behavior reactions. Physicians often err in minimizing the effects of minor physical ailments.

For example, in the field of the psychoneuroses, as exemplified by the cases of so-called shell-shock during the war, the slighter the physical injury, the greater the psychic disturbance. In the field of behavior diffculties this is often markedly true. It is obvious, therefore, that physical examination must be performed with subtlety and niceness of observation. Clearly a physician, to be effective in the physical examination of behavior cases, must approach his work from a different angle from his general medical practice. The examination thus performed must then be correlated with the mental and social factors of each case in order that suitable physical treatment may be prescribed.

Mental treatment consists in the main of two kinds: first, education and training of various mental faculties or talents, which are carried out in accordance with established principles of educational training and certain sorts of habit formation; second, treatment by various means of what may be considered pathological mental traits. Psychotherapy, hydrotherapy, mechanotherapy, occupational therapy, and other modern forms of treatment may be applied by trained experts to good effect.

Social treatment is perhaps the most modern and least well defined of all the various forms of treatment. As applied to delinquency, it consists mainly of adjusting environmental conditions to the needs of the individual case. The important point is not merely to change the environment, but to adapt the environment to the needs, temporary or permanent, of an individual more or less incapable of adapting himself. This form of treatment is consequently varied, and includes the adjustment of the individual to living conditions in his particular community, as well as social relief, recreation, or employment. 


\section{Public Information and Education}

One of the most potent influences in prevention is, of course, public education. As in public health, the only effective way to educate the public is by spreading broadcast the knowledge now available to which the public is entitled.

Unfortunately, in this era of advertising, everyone is becoming suspicious of propaganda conducted under the guise of public education. It is, therefore, necessary to force upon the public something more than offhand opinions and prejudices. Ultimate progress depends upon the strict adherence to facts. For example, during recent years considerable propaganda has been adopted to prove that feeble-mindedness is one of the principal causes of criminality. It has been contended that if we detect and segregate the feeble-minded early in life, we can reduce crime by one-third to one-half, if not more. This belief was based upon the finding that in certain institutions from one-fourth to one-third of the institutional population was rated feeble-minded by intelligence tests.

This contention was given a most favorable reception, and for a time promised to induce a more scientific attitude on the part of officials toward the various phenomena of crime, and also to arouse a greater interest in and support of the institutional care of the feeble-minded. Certain officials-police, prosecutors, attorneys, prison authorities, in short, all who were brought in close contact with the criminal population-were reluctant to accept these statements, but their attitude was ascribed to natural conservatism.

More recent work has shown that while figures for the institutions were undoubtedly correct, the interpretation placed upon them was not correct, because it failed to take into account the nature of the population from which the prisoners came. From information now available in regard to the intelligence distribution throughout the United States it appears that the prison populations are probably fairly representative, so far as intelligence goes, of the communities from which they come. It may be true, therefore, that a quarter of the persons in a given institution are feeble-minded, but, in order to reduce crime by 25 per cent. not only would 25 per cent. of the prison population have to be committed to an institution for the feeble-minded, but 25 per cent. of the population from which they came would have to be segregated, which is clearly ridiculous.

This illustrates one of the dangers of the proposed methods, even when applied to a worthy purpose. Nothing could be more desirable than the scientific treatment of criminals and the application of psychological, psychiatric, and other mental methods to criminals and delin- 
quents. But it is a mistake to make the success of such a venture depend upon arousing the public's interest by unwarranted statements. In the business world, where an effect is desired for a short time, such methods may be legitimate, but in the case of treatment of crime, where we are building for generations ahead, they are nothing short of dangerous. The psychology of salesmanship has no place in the sphere of science. The reaction in the public mind of arousing interest on the basis of statements which are only partly true causes a loss of confidence which retards progress more than initial conservatism.

\section{RESEARCH}

Where shall the facts and information be obtained upon which a campaign of public education may be based?

Obviously, in an experimental subject, such as criminology, and one in which science is just beginning to make itself felt, concrete information is extremely scanty. In order to keep pace with the progressive demands of modern community life and the growing public interest, provision must be made for investigation and research into the nature and treatment of delinquency and crime.

Such scientific research requires the same arrangements as any other sort of scientific investigation. In the first place, there must be properly trained and equipped experts. They must have a place in which to work which is officially designated the laboratory, and in which are provided all the necessary paraphernalia for scientific research. This is not the place to enter into detailed statements as to the exact size or arrangement of such laboratories or staff. These depend largely upon the resources which the community makes available for the purpose and the interest which it arouses.

Since scientific research is at best an uncertain matter, a liberal allowance or margin of safety is advisable in order to insure a minimum of return. There are no rules for this work, and there is, as yet, no standard. It would be better, however, for Cleveland not to venture into this field at all unless the start can be made on a scale commensurate not only with the size and importance of the city, but with the size and menace of the problem.

A research laboratory or institution, properly staffed and equipped, could conduct scientific investigations into behavior problems for the police, schools, public health bureaus, courts, jails, correctional and penal institutions, and the numerous public and private social agencies.

In another part of this section of the survey there is a brief account of a psychological analysis of the population of the Cleveland workhouse. 
It will be seen from this analysis that the workhouse has a large number of low-grade feeble-minded men. Reference to the chart will show that the number is out of proportion to the rest of the community. Clearly, here is a problem for mental science-for the student of the pathology of human behavior. We are spending several hundred million dollars in the United States annually in dealing with the end results of criminality and behavior disorders. Probably not $\$ 500,000$ is being spent in a scientific attack upon the causes. ${ }^{1}$

\section{Training of Workers and Experts}

The plan outlined thus far has discussed: (a) The workers for practical daily routine; (b) the research institution and staff, where new knowledge may be sought and gained; and (c) the dissemination of information to train and direct public opinion. There is left one more item to round out the scheme, and that is a provision for the training of workers and experts who are to take their places in the ranks.

Whenever a community has been aroused on the subject of mental problems, and particularly behavior problems, and has finally decided to establish scientific work, the perplexing question presents itself: "Where shall we find the workers?" It must be admitted that the workers available for immediate employment in this field are limited in number. This is, however, not to be wondered at, nor is it an indication that the subject does not appeal to scientific minds.

Rather it is a manifestation of one of the many vicious circles in our social organization. There must be a demand for this work and a realization on the part of the public of its importance great enough to insure a career for the workers. This, in turn, depends upon the attainment of results of a concrete and practical sort, to stimulate public interest. Many who might have been glad to devote their lives to this science have been compelled to seek other fields by a failure to obtain either opportunity or remuneration enough.

In order permanently to break up this vicious circle and to make the scheme outlined here quite clear, we must, therefore, add a provision for the training of workers and experts. This training should be given in the

'It is as well, perhaps, to state here that the term "scientific," as used repeatedly in this report, is not used as applied to the worker in the exact sciences. The scientist referred to here is not a man manipulating test-tubes and galvanometers alone. The investigation of behavior problems requires scientists equipped to deal not only with the methods of exact science, but also those who are capable of devoting themselves to problems of education and social organization. 
main under the auspices of a research laboratory, as we suggested, and in connection with the schools and universities of the community. Such training should be offered, in the first place, to physicians, lawyers, psychologists, psychiatrists, social workers, administrators, and public officials. A flexible curriculum should permit these different classes of professional workers to obtain the training needed to make their particular contact with the problem of delinquency. In order to do this it might be desirable to utilize existing departments of the university, perhaps the medical school. The latter is preferable to the law school, but close correlation between the law school and such work in the medical school is essential.

In addition, special courses should be offered to social workers, parole and probation officers, police officers, teachers, and nurses. Here again the curriculum might be so arranged that police officers, for instance, should receive a brief and intensive training, whereas social workers and probation officers should receive a more extended training. A scheme such as this, furthermore, makes possible part time graduate work or special investigations, just as now a properly qualified student may enter a laboratory for post-graduate study on a special topic.

When an organization of this sort has functioned long enough to produce the first graduates, the community can equip itself in such a way as undoubtedly to reap the benefit in a continually lessened cost of administration of criminal justice; and not the least of the benefits to be expected from such an organization is that other communities, no less anxious to improve their crime statistics than Cleveland, and no better off for staff or special workers, will turn to Cleveland for their personnel.

\section{Recommendations}

1. If possible, a privately supported institute or clinic should be established either independently or, preferably, in connection with Western Reserve University.

2. The object of the institute should be:

(a) Investigation of the nature and treatment of human behavior difficulties.

(b) The training and education of special workers and experts in the field of behavior problems.

3. The institute should have a staff comprehensive enough to include the methods of physical and mental health and the social sciences.

4. The institute shall be equipped with the necessary laboratory space and apparatus and with bed capacity for a limited number of patients. 


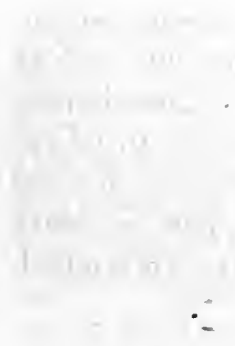

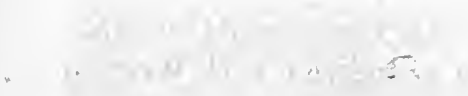




\section{PART VI \\ LEGAL EDUCATION \\ IN CLEVELAND}

BY

ALBERT M. KALES 
5 


\section{LEGAL EDUCATION IN CLEVELAND}

\section{State Requirements and Local Facilities}

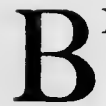

EFORE taking the bar examinations in Ohio one who is not admitted to practice in another State must have studied law for three years and must have had a general education equivalent to a four-year high school course. He need not complete his high school course, or its equivalent, before commencing his legal studies. The applicant who studies in Cleveland may do so under the instruction of any attorney in Cleveland, or in any one of three law schools, viz., the Law School of Western Reserve University, the Cleveland Law School, and the John Marshall Law School.

During the past four years 58 persons who gave Cleveland as their address have been admitted to take the bar examinations upon the certificate of an attorney that the applicant had completed some period of study under his direction. Of these, the greater number are now practising in Cleveland. In some instances the period of study under the attorney was the six-month period required of those who have taken the State bar examinations and failed. In others the period of study was one year, supplementary to a law school course of two years. Probably in few instances was the entire three-year period of study under the direction of the attorney certifying. In a few well-authenticated instances men who have studied for three years at a law school, but have been refused a certificate by the law school, have secured a certificate from an attorney in Cleveland or in some other part of the State and have, on the basis thereof, been permitted to take the bar examinations. In one instance a student who had been refused a certificate by a law school was certified by an attorney outside of Cleveland. The attorney stated that the student had studied law under his direction for three years, when, as a matter of fact, the student had been for three years in attendance at a law school in Cleveland, several hours' ride by rail from the city where the certifying attorney resided and conducted his practice.

In the past four years 66 attorneys of Cleveland have certified that students under their direction have satisfactorily completed some period 
of legal studies as the basis for taking the bar examinations. Of these, three gave such certificates in 1917, 17 in 1918, 25 in 1919 (one certifying to two applicants and one to four), and 22 in 1920 (two certifying each to two applicants and one certifying who had also certified in 1918).

Inquiry among these attorneys as to the course of study pursued under their direction resulted in the following information: In one instance an attempt was made to give a review course of six months for those who failed in the bar examinations. In one instance the attorney conducted an informal school for business men and certified two students who had done sufficient work to warrant, in his judgment, the certification. In one instance the student had taken a correspondence school course and also done bona fide work under the direction of the attorney certifying for three years. But it seems to be the view of many that an attorney is justified in certifying if he has personal knowledge that the student has actually pursued legal studies, and if the attorney has quizzed him at least once in regard to the subjects studied. It is the exception that a definite course is laid out by the attorney and the student pursues it under his immediate personal direction and is quizzed from week to week, or even from month to month.

At least one attempt has been made by a correspondence school to secure for its students the certificate of an attorney that its students have (on the basis of the correspondence school course alone) satisfactorily completed a three-year course of legal study. In this instance the Supreme Court intimated that it would be improper for the attorney to give the certification, and he refused to do so.

The Law School of Western Reserve University has been established since 1892. It now has 609 graduates, of which approximately 280 are practising law in Cleveland. It is at present contributing from 35 to 50 graduates a year, 75 per cent. of whom, it is estimated, remain in Cleveland for the practice of the law.

The Cleveland Law School has been established since 1897, and during that time has been under the direction of Judge Willis Vickery. It has approximately 1,000 graduates, of which about one-third are estimated by Judge Vickery to be in practice, and of these by far the larger portion are engaged in practice in Cleveland. This school for the past two or three years has been graduating yearly between 70 and 80 students, by far the larger portion of whom remain in Cleveland for the practice of the law.

The John Marshall Law School has been established since 1916 and has graduated 35 students, of whom about two-thirds are estimated to be in practice, and of these, all but two are in practice in Cleveland. 
In 1921 it graduated 21 students, by far the larger portion of whom remained in Cleveland to practise.

Of the members of the bar of Cleveland who have acted as prosecutors in the past twenty years in Cleveland, 27 are graduates of the Cleveland Law School, 11 of the Law School of Western Reserve University, none of the John Marshall Law School, and 11 of other law schools, including one from Harvard, five from Michigan, one from Cornell, and two from Ohio State.

In the current lawyers' directory of Cleveland about 1,400 persons are listed. Of these, it may be inferred, 280 are graduates of the Western Reserve Law School, about 300 of the Cleveland Law School, and about 20 of the John Marshall Law School.

\section{The Law Schoor of Western Reserve University}

Students entering this school must have completed a four-year college course in an approved college and have obtained a degree; or they must have satisfactorily completed three years of college work in Adelbert College (the Liberal Arts Department of Western Reserve University), thereby becoming candidates for a degree at Adelbert College after the first year in the Law School.

Of the 154 students now in this school, all but three answer these requirements. The school has admitted three persons as special students. The vote of the faculty is based, in all but one of these cases, upon the fact that the special student has probably had the equivalent of a college course, but in an institution about whose standards exact information is not readily obtainable. The special students are not candidates for a degree.

Four students now in the school were foreign born-two in AustriaHungary, one in Finland, and one in Russia. Three-fourths of the students are engaged in supporting themselves partially by work outside of the school, and 10 per cent. are supporting themselves wholly in this way. The work engaged in by these students occurs for the most part in the heart of the city, about thirty minutes' ride on the street-cars from the university.

The hours devoted to recitations are from $8 \mathrm{~A}$. M. to 12 noon. These hours accommodate the men who earn a livelihood, wholly or in part, while at the same time taking their law course.

\section{Faculty and Curriculum}

Resident teachers, viz., those who give all their time to teaching at the school, receive salaries ranging from $\$ 4,500$ to $\$ 6,000$ a year. Mem- 
bers of the bar in Cleveland who do a slight amount of teaching receive compensation at the rate of five dollars an hour, but this is in practically all cases turned back to the school, so that the services of these men are donated.

Following is a list of the resident teachers with some facts as to the teachers and the courses they conduct:

Archibald Hall Throckmorton: A.B., Roanoke College, 1896; A.M., Princeton University, 1897; LL.B., Washington and Lee University, 1900. Resident professor. Not in active practice. Teaches Constitutional Law, Insurance, Pleading, and Torts. Uses Hall's Cases in Constitutional Law; lectures and Hinton's Cases in Pleading; Wambaugh's Cases in Insurance; lectures and Hepburn's Cases in Torts. Inspection of examination papers in the above courses shows 10 problem questions in each. These questions appear to be in accordance with the standard of questions used by the best law schools.

Walter Thomas Dunmore: A.B., Oberlin College, 1900; A.M., Oberlin College, 1905; LL.B., Western Reserve University, 1904. Resident professor. Not in active practice. Teaches Property, Evidence, and Conflict of Laws. Uses Bigelow's Cases, Volumes I and II, and Gray's Cases in Property, Volumes III and IV; Thayer's Cases in Evidence and Beale's Cases in Confict of Laws. Inspection of examination papers in the above courses shows 10 problem questions in each. These questions appear to be in accordance with the standard of questions used by the best law schools.

Alvin Collins Brightman: A.B., Oberlin College, 1900; LL.B., Western Reserve University, 1909. Resident professor. Not in active practice. Teaches Contracts, Quasi-Contracts, Sales, Partnership, and Damages. Uses Williston's Cases in Contracts; Woodruff's Cases in Quasi-Contracts; Williston's Cases in Sales; Mechem's Cases in Partnership, and Mechem and Gilbert's Cases in Damages. Inspection of examination papers in the above courses shows 10 problem questions in each. These questions appear to be in accordance with the standard of questions used by the best law schools.

Clarence Millard Finfrock: A.B., Ohio Wesleyan University, 1902; A.M., 1907; LL.B., Western Reserve University, 1907. Resident professor. Not in active practice. Teaches Equity Jurisdiction, Trusts, Negotiable Instruments, and Domestic Relations. Uses Woodruff's Cases in Domestic Relations; Smith and Moore's Cases in Bills and Notes; Ames' Cases in Equity Jurisdiction; Scott's Cases in Trusts. An inspection of examination papers in the above courses shows 10 problem questions in each. These questions appear to be in accordance with the standard of questions used by the best law schools.

Alexander Hadden: A.B., Oberlin College, 1873. Practised law until he became Probate Judge in 1905. Teaches Crimes and Criminal Procedure. Uses lectures and Rood's Cases. Examination paper for 1920 shows 5 problem ques- 
tions and 5 questions calling for definitions and conventional distinctions. Examination paper of February, 1921, shows 4 problem questions and the balance calling for definitions and distinctions.

Frank MacMillan Cobb: A.B., Yale University, 1897; LL.B., Western Reserve University, 1899. In active practice. Teaches Public Service Corporations two hours each week for half the year. Uses Wyman's Cases. Specimen examination paper shows 10 problem questions. These questions appear to be in accordance with the standard of questions used in the best law schools.

Richard Inglis: A.B., Harvard University, 1903; LL.B., 1906. Teaches Private Corporations. In active practice. Uses Warren's Cases. Specimen examination paper shows 10 problem questions. These questions appear to be in accordance with the standard of questions used by the best law schools.

Clinton DeWitt: A.B., Adelbert College, 1910; LL.B., Western Reserve University, 1912. In active practice. Teaches Suretyship and Mortgages. Uses DeWitt's Cases in Suretyship; Durfee's Cases in Mortgages. Specimen examination paper shows 10 problem questions. These questions appear to be in accordance with the standard of questions used in the best law schools.

Austin V. Cannon: B.S., Buchtel College, 1892. In practice since 1894. Teaches Bankruptcy. Lectures and selected decisions used. No examination paper submitted.

William Cullen Keough: A.B., Harvard University, 1904; A.M., 1905; LL.B., Western Reserve University, 1909. In practice since 1909. Teaches Municipal Corporations. Uses Beale's Cases. Specimen examination paper shows 10 problem questions. These questions appear to be in accordance with the standard of questions used in the best law schools.

James Cooper Logue: A.B., Adelbert College, 1907; LL.B., Western Reserve University, 1909. In practice since 1909. Teaches Agency. Uses Wambaugh's Cases. Specimen examination paper shows 10 problem questions. These questions appear to be in accordance with the standard of questions used in the best law schools.

John Frederic Oberlin: Gives special lectures on Patents, Trade-mark, and Copyright Law.

Physical characteristics of the school: The school occupies an entire building adjoining the campus of Western Reserve University, with adequate class-rooms, teachers' offices, library, reading-room, and library stacks. The library consists of upward of 15,000 volumes. They include the English and American reports, statutes, and leading text-books. The library reading-room seats 90 . It is open from $8 \mathrm{~A}$. M. to 9.30 P. м., and is used by the students as a place of study.

The school has a special endowment, yielding at the present time 
about $\$ 7,000$ per annum. The policy is to pay out of tuition fees the difference between its endowment income and its overhead expenses (not including the interest on the investment in the land and buildings which it occupies). In fact, it is now operating with an annual deficit of about $\$ 4,000$, which is made up by the trustees of Western Reserve University. The school hopes to eliminate this by an increased special endowment.

\section{The Cleveland Law School}

Without attempting to analyze the published entrance requirements, the fact is that anyone, regardless of his preliminary education, may become a student of law at the school. From the students' registration cards the following facts appear as to the preliminary education upon entering the school of the 419 students now enrolled:

College graduates

Number

Those having some college training, from one semester to three years

Those having apparently a full four-year high school course

Those who have not completed a full four-year high school course, but have had some high school work

Those who have had no high school work at all before entering the law school

Those about whom no information could be obtained from the registration cards

Whenever the registration card contained the general statement that the student had had a preliminary education designated as "high school," it was assumed that he had completed the high school course. The test of a number of such answers by inquiry of the student makes it probable that some who wrote on their cards "high school" had not completed the high school course. Judge Vickery, the dean of the school, made an estimate of those who had not completed a high school course as somewhat more than 94 .

Of the 25 college graduates, one was foreign born, having been born in Hungary. Of the 74 who had some college training, 11 were foreign born-four in Russia, three in Austria-Hungary, one in Germany, one in Croatia, one in Canada, one in Transylvania. Of the 226 who appear to have completed a high school course, 42 were foreign born-15 in Russia, four in Austria-Hungary, three in Hungary, three in Poland, four in Czecho-Slovakia, three in Italy, one in Croatia, one in JugoSlavia, two in Scotland, one in Ireland, one in England, one in Canada, 
one in New South Wales, one in Jamaica, one in Barbados (British West Indies). Of the 47 who had done some high school work, nine were foreign born-three in Russia, two in Italy, two in Austria-Hungary, one in Rumania, one in Hungary. Of the 24 who had received no high school education or its equivalent, eight were foreign born-two in Russia, one in Poland, one in Austria, one in Sicily, one in England, one in Ireland, one in Norway. Of the 23 as to whose preliminary education no information appears on the registration cards, only three gave information as to their place of birth-one native born, one born in Russia, and one in Ireland.

All the students with a few exceptions, not exceeding five, were, upon entering the school, earning their livelihood in regular occupations, such as clerk, salesman, insurance, real estate, accountant, stenographer, and private secretary.

Classes are held from 5 to 7 and 7 to 9 P. M., Mondays, Wednesdays, and Fridays, each of two sections having each two hours of class-room work.

\section{Faculty and Curriculum}

All the teachers are lawyers practising in Cleveland, who perform their duties as teachers in addition to their professional efforts as lawyers. They receive compensation in cash at a rate which causes practising attorneys to seek places on the teaching staff.

Following is a list of the teachers now actually teaching at the school, with some facts concerning the teachers and the courses they give:

Willis Vickery: Boston University Law School, 1884. In active practice twenty-one years; on the Common Pleas Bench ten years, and two and onehalf years on the Circuit Court of Appeals. Gives Contracts, seventy hours, using Clark's text-book; Constitutional Law, twenty-six hours, using Black's text-book; Criminal Law, forty hours, using Clark and Marshall; Partnership, thirty-six hours, using Gilmore; Legal Ethics, ten hours, using lectures. From 10 to 12 per cent. of the entire class fail to receive degrees. Each year three or four men are denied a certificate of satisfactory completion of studies for the bar examiners. This year about five will fail to get such a certificate. Examination paper in Contracts shows about 10 problem questions out of 20 , the rest calling for definitions and distinctions. Examination paper in Constitutional Law shows 10 questions, of which only one appears to be a problem question, the rest calling for discussion of general rules or the doctrine of particular cases. Examination paper in Partnership shows 10 questions, of which three are problem questions, the rest calling for definitions or precise information. Examination paper in Criminal Law shows 12 questions, of which four are problem questions. 
Melville W. Vickery: Graduate of Cleveland Law School. Admitted to the bar in 1914. In active practice. Teaches Domestic Relations, twenty hours, using Schouler's text-book. Covers the course by lectures on the text. About three or four out of a class of 60 failed. Examination paper shows 10 questions, six of which are problem questions and the other four call for definitions.

James Lind: Western Reserve Law School, 1912. In active practice as much as possible since 1912. Teaches Criminal Law, thirty hours, using Clark and Marshall's text-book. Examination paper shows 10 questions, of which five are problem questions and five call for definitions.

William Fish Marsteller: Graduate of University of Michigan Law School. In active practice. Employed by a firm as trial lawyer. Admitted to the bar, 1918. Teaches Contracts, seventy hours, using Clark's text-book; Partnership, thirty-five hours, using Gilmore's text-book; Contracts, one semester, using Huffcutt and Woodruff's Cases; Negotiable Instruments, one semester, using Bunker. No examination paper submitted.

Alfred Clum: Graduate of George Washington University Law School. General practice since 1890. Gives Equity, five weeks, using Merwin's textbook; Evidence, five weeks, using McKelvey. Examination paper shows five questions in Evidence, all of which call for statement of rules and none of which are problem questions. Another examination paper in Evidence shows 10 questions, none of which are problem questions, but all call for statement of rules. Examination paper in Equity shows six questions, three of which appear to be problem questions and the rest call for definitions or information as to particular rules. Another examination paper in Equity shows 10 questions, none of which are problem questions.

L. Q. Rawson: Graduate of Cincinnati Law School. Entire time given to practice. Admitted to bar twenty-nine years. Gives Negotiable Instruments, twenty-six hours, using Bigelow on Bills and Notes; Suretyship, twenty-six hours, using Stearns on Suretyship. Examination paper in Negotiable Instruments shows 10 questions, of which five are problem questions and the rest call for statement of rules or definitions. Examination paper in Suretyship shows 10 questions, of which eight are problem questions and the rest call for definitions.

Howard D. Burnett: Graduate of Y. M. C. A. Law School of Cincinnati. In general practice since 1906. Gives Wills, forty-two hours, using Gardner; Agency, thirty-six hours, using Mechem; Sales and Personal Property, fiftytwo hours, using Benjamin on Sales. Examination paper in Wills shows 10 questions, of which three appear to be problem questions and the rest call for definitions or statement of rules. Another examination paper in Wills shows five questions, of which one appears to be a problem. Examination paper in Agency shows five questions, of which four appear to be problems and one calls for definitions. Examination paper on Sales shows five questions, of which two appear to be problem questions. Another examination paper in Agency shows 
10 questions, of which six appear to be problem questions. Another examination paper in Sales and Personal Property shows 10 questions, of which eight appear to be problem questions and the others call for definitions.

Harry Lewis Beibel: Graduate of Western Reserve Law School. In general practice. Admitted to the bar in 1914. Gives Wills, forty hours, using Gardner; Torts, thirty-eight hours, using Cooley. Examination paper in Wills shows 10 questions, of which five appear to be problems and the rest call for definitions or statement of particular rules. Another examination paper in Wills shows five questions, of which two are problem questions. Examination paper in Torts shows five questions, of which three appear to be problems. Another examination paper in Torts shows 10 questions, of which four appear to be problems.

Samuel H. Silbert: Graduate of Baldwin-Wallace University and Cleveland Law School. In active practice for eight years and six years on the bench. Teaches Bailments, twenty-six hours, using Dobie's text-book; Domestic Relations, twenty hours, using Schouler. Examination paper in Domestic Relations shows 10 questions and contains a mixture of slight problem questions and a test as to definitions and statement of particular rules. Examination paper in Bailments shows 10 questions, each with from two to five subdivisions, calling for a mixture of slight problems and definitions and statement of particular rules.

Arthur E. Rowley: Graduate of University of Michigan and the Chicago College of Law. Admitted to the bar in 1892. In practice since that time. Gives a short course of lectures on Statutory Law.

Physical characteristics of the school: Its rooms are situated on the top floor of a modern office building, within a block of the public square, and have the appearance of being well kept up. It has three classrooms and adequate seating capacity, a general office room, and Judge Vickery's private office. Its library is kept in the office room and consists of the Ohio reports, digests, and statutes, a few text-books and encyclopedias of law. Judge Vickery said he had at one time paid a sum to secure the use, by his students, of the County Law Library which is used by the lawyers and judges of Cleveland, but that since the students did not avail themselves of the privilege he had ceased to provide it.

The school is the private enterprise of Judge Vickery. It is run for private profit, but it is fair to state that while he has sought to make the school a profitable investment, he has also sought to provide as good a legal education for his students as the conditions under which they were taught permitted. He has been insistent upon requiring full time of his teachers. 
The John Marshall Law School

Again, without attempting to analyze the published statement of entrance requirements, the fact is that anyone, regardless of his preliminary education, may become a student of law at this school. The following facts concerning the preliminary education of the students in this school appear from their answers to a questionnaire filled out by the students themselves:

College graduates

Number

17

Those having some college training, from one semester to three years

Those who have completed a four-year high school course 58

Those who have had some high school work only

Those who have had no high school training 36

Those from whom no information was obtained

Of the 17 college graduates, one was foreign born, having been born in Germany. In two instances where the student was native born both parents were foreign born-in one instance they were English and in the other German. Of the 30 who had had some college work, five were foreign born: three in Russia, one in Jugo-Slavia, one in Germany. In five instances where the student was native born both parents were foreign born-three Irish, one Russian, one Holland-Swiss. Of the 58 who had completed the high school course, 17 were foreign born: nine in Russia, two in Poland, two in Hungary, two in Czecho-Slovakia, one in Austria, one in England. In 10 instances where the student was native born both parents were foreign born-five Russian, two German, one Hungarian, one Czecho-Slovakian, one Syrian. Of the 36 who had had some high school training, six were foreign born-three in Russia, one in Austria, one in Ireland, one in Netherlands. In 12 instances where the student was native born both parents were foreign born-four Russian, two German, one Polish, one Austrian, one Italian, one English, one Irish. Of the six who had received no high school education at all, one was foreign born, having been born in Italy. In two instances where the student was native born both parents were foreign born-one German and one Irish.

All the students in the school, with the exception of not to exceed five, were earning their livelihood in regular occupations while pursuing their studies.

Classes are held from 4 to 6 and 7 to 9 P. M. on Mondays, Wednesdays, and Fridays, which provides two hours of class-room work for each of two sections. 


\section{Faculty and Curriculum}

All the teachers in the school except two are lawyers practising at the bar in Cleveland. Their teaching is in addition to their regular duties as practitioners. Their rate of compensation ranges from $\$ 5$ to $\$ 10$ per each double section hour of teaching.

Following is a list of the teachers actually teaching at the school, together with some facts about the teachers and the courses which they give:

Robert Parsons Abbey: Graduate of Cleveland Law School. In active practice eleven years. Teaches Bills and Notes two hours five days a week, running for three months. Uses text-book by Tilden with Brannan as auxiliary. Fails on an average of three men out of 20. No specimen examination paper given.

Cary R. Alburn: A.B., Adelbert College. Attended Western Reserve University Law School and Oxford University, England; B.C.L. (Oxford). In active practice twelve and one-half years. Teaches Private Corporations. Uses Clark's text-book and Wormser's Cases. Average of 7 per cent. of those taking the course fail. None, however, have failed to receive a degree in two years. One was denied a certificate of satisfactory completion of studies. Specimen examination paper submitted shows 10 questions, none of which were problems; many called for definitions and a few for general answers as to extent of liability.

John C. Barkley: Western Reserve University Law School, 1906. In active practice fourteen years. Teaches Bills and Notes twenty-six hours. Course is based upon Ohio Negotiable Instruments Code and Ohio decisions. An average of eight out of 41 students fail to pass the examination. A specimen examination paper shows 12 questions, one-half of which call for definitions and the other one-half are to a considerable extent problem questions.

Kenneth D. Carter: Attended the University of Wisconsin. Graduate of Ohio State University Law School. In active practice full time. Admitted to the bar four years. Teaches Partnership eighteen hours, using Mechem's Elements, second edition, which he completes and thereafter discusses the Ohio cases. Also teaches Constitutional Law twenty hours, using text-book by Black, third edition. Covers about five-sevenths of the text-book, with the Ohio and Federal Constitutions. Has taught the course only one year and has no record of the number of men failed. Specimen examination paper in Partnership shows a series of 10 substantial and rather ambitious problem questions.

Norton McGiffin: Graduate of University of Michigan Law School. In general practice since December, 1912. Has given Suretyship, September 15 to December 1, three hours a week, using Stearns' text-book, second edition, of which he covers all. Also taught Equity three hours a week, September 15 to December 15, using Pomeroy, students' edition, of which he omits Rights and 
Interests of Married Women, Probate Law and Wills, and Mortgages. An average of from 5 to 15 per cent. of his men fail to pass the examination. Specimen examination paper shows in one case 10 ambitious problem questions and in two instances in another, a series of questions calling for definitions with but two problem questions.

Ralph T. Hisey: Western Reserve Law School, 1915. Secretary of the Pyramid Savings Co. Not in active practice. Teaches Personal Property thirty hours, using Childs' Personal Property, of which he covers all. First year as an instructor and presents no specimen examination paper and makes no report as to number of students failed.

C. T. Kirkbride: Graduate of Western Reserve Law School. In practice for fifteen years. Teaches Domestic Relations about twenty hours, using Long, Domestic Relations. Covers entire volume. Fails from 5 to 10 per cent. of men taking examination. Specimen examination paper attached shows six questions calling for definitions and four problem questions.

Dean Lawrence: Graduate of the John Marshall Law School. In practice two years, mostly office work. Teaches Torts forty hours, using text-book by Chapin, all of which is covered. Also teaches Suretyship thirty hours, using Stearns, all of which is covered. An average of from 20 to 30 per cent. of his pupils fail to pass the examination, but none fail to receive a degree and none are denied a certificate of satisfactory completion of studies for bar examination. Specimen examination paper attached shows a series of 20 questions, practically all of which are problems.

Cyrus Locher: Graduate of Western Reserve Law School. In active practice since 1907. Teaches Mortgages twelve hours. Uses no text-book. An average of 5 per cent. of his men fail to pass examination. Gives no specimen examination paper.

Dean B. Meck: Graduate of John Marshall Law School. Assistant to the Director of Law of the National Lamp Works of the General Electric Company. Admitted to the bar five years. Teaches Agency thirty hours, using Huffcutt on Agency, covering the entire volume. An average of about 15 per cent. of the men in his course fail to pass, and about 5 per cent. of these fail to receive a degree. About 10 per cent. fail to receive a certificate of satisfactory completion of studies for the bar examination. Specimen examination paper shows about 20 questions, of which about eight are problem questions and about 12 call for definitions or discussion of general principles.

David C. Meck: Dean of the John Marshall Law School. Graduate of the Cleveland Law School. Not in practice. Admitted to the bar eight years. Teaches Contracts one-half year, using Clark's text-book, of which he covers all, together with Throckmorton's case book and Ohio State reports. Also teaches Bailments and Carriers one-third of year, using Dobie's text-book, of 
which he covers all, together with 60 cases from the Ohio State and Federal reports. Fails to pass on an average of 15 per cent. of his students. Of those taught by him who are candidates for a degree, 5 per cent. fail to receive a degree and the same number are refused a certificate of satistfacory completion of studies for the bar examination. A specimen examination paper shows 24 questions, all of them calling for definitions or the drawing of distinctions.

Edwin E. Miller: Graduate of Western Reserve Law School. In active general practice to the fullest extent. Admitted to the bar twelve years. Gives the course on Evidence thirty-five hours, using Hughes on Evidence, covering every page, including the illustrations in the back of the book. Also teaches Wills forty-three hours, covering all the text of Gardner on Wills. In addition students draw at least four wills and other papers for the Probate Court and go over a series of 40 problems formulated by the instructor. Also teaches Practical Conveyancing thirteen hours. This course is taught with a series of 11 problems. A series of these problems submitted show them to cover many of the practical details relating to Abstracts in Cleveland. Examination of a specimen paper in Evidence shows 20 to 30 questions calling for definitions or statement of particular rules of evidence for the most part; three or four were in the form of problems. A specimen examination paper in Wills shows a series of 10 questions, seven of which are problem questions. In 1920 no one failed to pass the examination in Wills and only one failed in Evidence. In 1921 there were two who failed in Evidence.

Sterling Parks: A.B., University of Michigan, 1888; LL.B., George Washington, 1894. In active practice twenty-seven years. Gives course on Real Estate, three lectures a week, four and one-half months, using Burdick's textbook. Covers practically the entire work. One specimen examination paper shows about 20 questions, practically all definitions. Another paper shows 10 questions, practically all of which are problems. Out of a class of 40 students, five failed to pass the examination given.

James B. Ruhl: Graduate of Ohio Northern Law School. Degrees B.S. M.S., LL.B., LL.M. Active practice in Cleveland since 1891. Teaches Pleading forty hours, using Phillips' text-book and covering all of the text; also Stephen's Common Law Pleading in part and Ohio decisions and statutes. Not yet had a student who did not pass. Specimen examination paper shows eight questions calling for definitions and statement of rules and one question calling for the drafting of papers.

K. T. Siddall: Graduate of Harvard Law School. In active practice eight years. Teaches course on Real Property three hours a week for six months. Uses text-book by Burdick and covers subject as treated by Burdick. None have failed to pass his examinations. Specimen examination paper shows five problem questions out of nine.

J. W. Woods: Graduate of University of Michigan Law School. Very [ 501 ] 
active practice. Admitted to the bar in 1909. Teaches Criminal Law thirty hours, using Clark's text-book, and covers entire text and procedure. Specimen examination paper shows 10 problems.

The following have been instructors at the John Marshall Law School, but are not now teaching:

Howard A. Couse: Graduate of the Yale Law School. In practice since 1894.

John H. Schultz: Graduate of Western Reserve Law School. Admitted to the bar in 1918.

E. J. Hopple: Attended Western Reserve Law School but did not graduate. In active practice sixteen years.

Edward H. Tracy: Graduate of Yale Law School. In practice since 1895. Taught Domestic Relations.

Physical surroundings of the school: Its rooms are situated on the third floor of the old court-house building facing the public square. They consist of three lecture rooms, a library and study room, office of the dean, and law fraternity room. Its library consists of the Ohio reports, United States reports, Cyc., Corpus Juris, Ohio Digest, Federal Digest, Ohio Statutes, and 50 reference text-books. No access to any other library is provided.

The school is a corporation for pecuniary profit. David C. Meck holds the largest amount of stock held by any one individual. Other stockholders are, with a few exceptions, teachers in the school. The school has only graduated one class-that of the year 1920 .

\section{Hours of Teaching in Law Schools in Cleveland}

Table 1 is a comparative study of the number of hours of teaching given to the different subjects at Western Reserve University Law School, Cleveland Law School, and John Marshall Law School, and other well-known law schools throughout the country.

The only subjects offered in the Cleveland Law School and the John Marshall Law School are those prescribed by the bar examiners for admission to the bar. Courses on Bankruptcy, Damages, Insurance, Quasi-Contracts, Conflict of Laws, Municipal Corporations, Mortgages, and Trusts offered at other law schools are not offered at the Cleveland Law School or the John Marshall Law School. These subjects are not in the list of subjects required to be studied to qualify the applicant for taking the Ohio State bar examinations. 


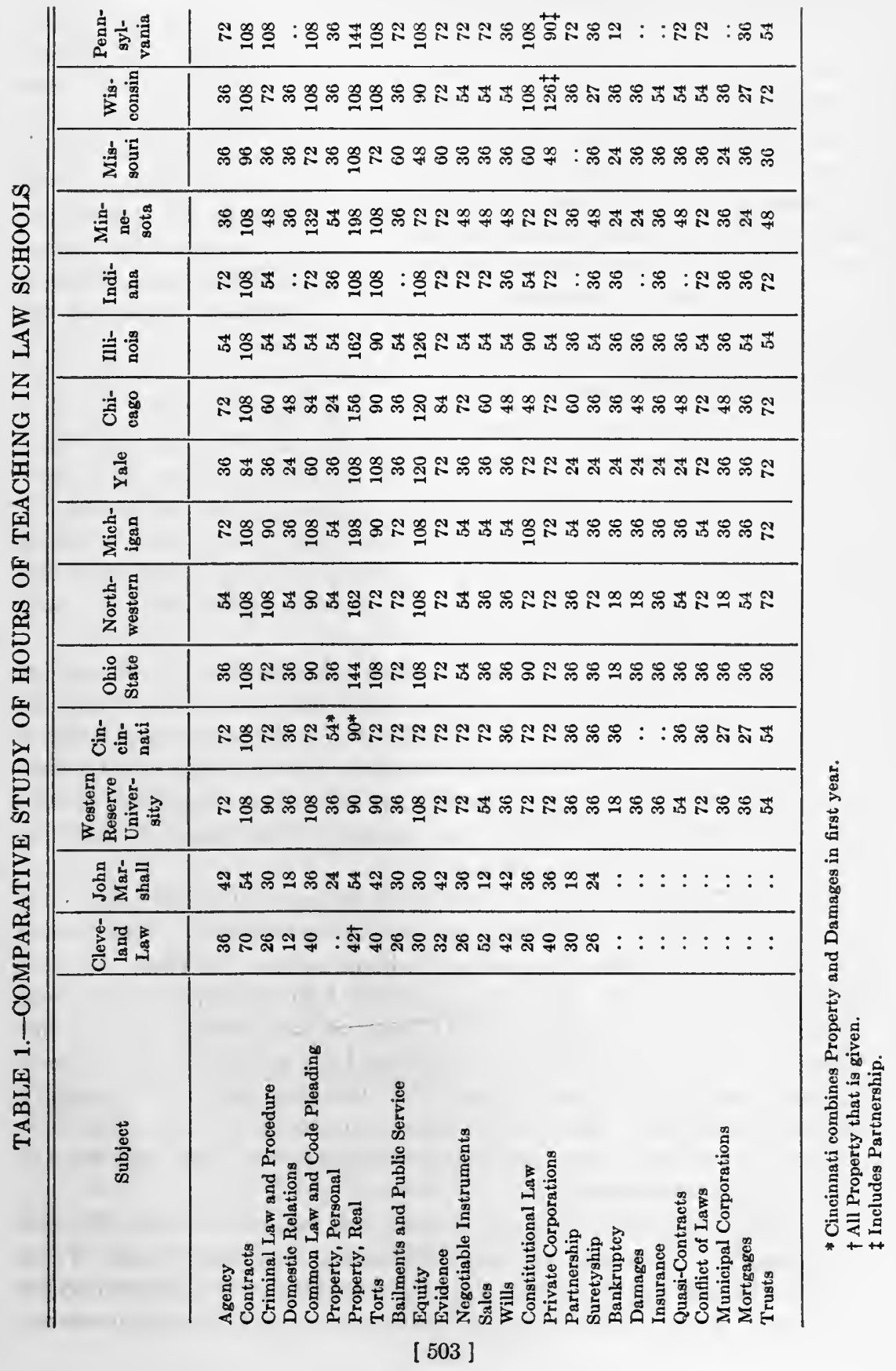


In 1915-16 the Cleveland Law School was the only night law school in Cleveland. It had been in operation about twenty years and had a large body of alumni in Cleveland. Judge Vickery felt that it was strong enough to raise the standard of night-law-school education. He therefore proposed to put into effect a four-year course and to require the completion of this course before giving a certificate enabling students to take the State bar examinations. But a new night law school was started on the basis of providing the student with a certificate after three years of study. A considerable number of students were deflected to the new law school, and the plan for a four-year course was given up.

\section{Night High Schools}

The bar examiners require as a condition of taking examinations that the applicant shall have had four years of high school work in a Class 1 high school, or its equivalent, in addition to the required study of law. It is permissible, however, that the high school and the law course be taken at the same time. In the Cleveland Law School and the John Marshall Law School together at least 141 students have not completed a high school course. Of these, 30 , at least, have had no part of a high school course.

Those who have not completed a high school course, or its equivalent, may do so by attending one of two night high schools, the BaldwinWallace (Night) Preparatory School, affiliated with the Baldwin-Wallace College, and the John Marshall Night High School, affiliated with Ohio Northern University. These night high schools are operated in convenient proximity to the night law schools. Their classes are held on Tuesday and Thursday evenings.

Of the 47 students at the John Marshall Law School who have not had any high school work or who have not completed a high school course, 21 were taking a night high school course. Of these, 15 were taking the night high school course at the John Marshall Night High School. Of the 94 students of the Cleveland Law School who had not completed a high school course or had any high school training, 20 were taking a night high school course at the Baldwin-Wallace Preparatory Night High School. How many other students in the Cleveland Law School were taking night high school work at other night high schools could not be ascertained.

A report upon the night high schools was made under our direction by E. L. Findley, a principal in a Cleveland public high school. From his report it appears that these schools have a competent corps of teachers and give a four-year high school course which meets the requirements 
of the course for Class 1 high schools in Ohio. By adding a summer high school term these schools enable a student to do one and one-half years of high school work in each twelve months. It appears also that the principals of the night high schools, except in rare and special cases, do not permit men who have had less than two years of high school to take the night high school course at the same time they are taking the night law school course.

The John Marshall Night High School has an enrollment of 90, of whom only 15 are taking a night law course. The Baldwin-Wallace has an enrollment of 122 , of whom only 20 are taking a night law course. Both the night high schools accommodate a considerable majority of students who are not taking any law course.

The principal in each school has full discretion in determining what credits he will allow for work done at other schools or in bookkeeping and typewriting, and may admit students to any year of the night high school work on such showing. When students so admitted have graduated from the night high school they receive a certificate that they have completed the equivalent of a four-year high school course. This certificate enables the student, in the case of the Baldwin-Wallace Night Preparatory School, to matriculate at the Baldwin-Wallace College, and in the case of the John Marshall Night High School, to matriculate at Ohio Northern University, and these matriculations enable the student to fulfil the requirements of the bar examiners as to their general education. The principals of the schools in question reported to $\mathrm{Mr}$. Findley that, in this matter of allowing credits to students who had studied in other schools or done work outside of school, they followed the usual practice which obtains in the Ohio public high schools of the first class, and this statement has been accepted as correct without investigation.

\section{Bar Examination Crammers}

There are at least two quiz courses conducted in Cleveland for the purpose of cramming candidates for the bar examinations. Both of these draw from the Cleveland Law School. They are conducted by the following:

Melville W. Vickery (a son of Judge Vickery): Has about 20 students. He charges one dollar an hour and conducts the course three hours a week for about six weeks.

Howard D. Burnett: Received his training in Judge Guswiler's quiz in Cincinnati. He has over 100 students, divided into classes which meet in his office three times a week. He charges one dollar an hour. 


\section{Ohio Bar Examinations}

During the past five years an average of 85 per cent. of all those taking the bar examinations have passed them. We have no data as to what proportion, if any, of those who failed come from law schools in Cleveland. The percentage of failures in the years 1910-1919 of those taking the bar examinations in New York is as follows:

1910

1911

1912

1913

1914

1915

1916

1917

1918

1919
57 per cent.

57 per cent.

48 per cent.

40 per cent.

50 per cent.

41 per cent.

44 per cent.

38 per cent.

44 per cent.

43 per cent.

The percentage of failures in the years 1912-1920 of those taking the bar examinations in Illinois is as follows:

1912

1913

1914

1915

1916

1917

1918

1919

1920
28 per cent.

48 per cent.

35 per cent.

23 per cent.

27 per cent.

37 per cent.

72 per cent.

55 per cent.

58 per cent.

\section{Conclusions}

1. The privilege of qualifying for the bar examinations by presenting a certificate of a member of the bar does not result to any substantial extent in providing an adequate means of legal education. Its principal use appears to be to enable to qualify for the bar examinations those who have not completed a three-year course of legal study in a law school; or who have taken the bar examinations and failed and are required to study for at least six months before taking the bar examinations again; or who have attempted to prepare by means of a correspondence school course, which is not accepted by the State bar examiners as a satisfactory course of legal study; or who have taken a three-year course in a regularly organized law school, but have failed to receive a certificate of satisfactory work from the authorities of such school. 
2. The Cleveland Law School and the John Marshall Law School succeed in giving to their students at least the minimum amount of legal education which will enable them to pass the bar examinations. It is, therefore, proper to conclude that those schools give such legal education as the public authorities having control thereof in Ohio regard as sufficient for admission to the bar.

No effort has been made to reach a conclusion as to the comparative merits of the several law schools or to make a complete analysis of the standard of legal education which each respectively maintains. It is fair, however, to point out that the night law schools of Cleveland give only six hours a week of class-room work for a period not to exceed thirty-six weeks in each year, or six hundred and forty-eight class-room hours in three years. In admittedly first-class law schools the number of class-room hours in a three-year course is, on the same basis of calculation, one thousand and eighty hours. As students in the night law schools are earning their own living in occupations out of school hours, as a large proportion have a very meager preliminary education, and as they receive only six hundred and forty-eight hours of class-room teaching in three years, a good deal of which, as evidenced by the examination questions, has to do with definitions of legal conceptions and conventional distinctions, it is evident that the standard of legal education in the night law schools should be raised. In this conclusion Judge Vickery, the dean of the Cleveland Law School, and Mr. Meck, the dean of the John Marshall Law School, concur.

3. So long as the standard of legal education set by the State board of bar examiners remains what it is, it is futile to make a purely destructive attack upon the existence or standard of education of night law schools run for pecuniary profit. If it were conceivable-which it is not-that such schools should be prohibited, the result would not be to throw the 500 or 600 men who wish to study law into schools with a higher standard, but would be to throw them into the hands of attorneys under whose direction they would study, or purport to study, for the purpose of qualifying themselves to take the State bar examinations.

Nor is it practicable to call upon the night law schools run for profit to adopt a higher standard. It is an economic fact that so long as law schools run for private profit may freely enter the field of legal education, no such school can raise its standard above the minimum which will enable applicants for admission to the bar to pass the bar examinations. If one attempts to do so by requiring a longer period of study or more hours of study a week, it will at once lose patronage to a school which keeps to the minimum standard, or it will call into existence a school 
which will secure students on the basis of the minimum standard. This has already been demonstrated in Cleveland.

The only way to defeat the economic effect of free competition in night law schools run for profit is to organize a night law school, regardless of profit, which in the same time of study and with the same convenient hours for students earning a livelihood, and for a smaller price, will offer a better course and by this means draw students from the present night law schools, or force them to raise their standards. Experience, however, indicates that up to the present time the limit of altruistic effort by law teachers and others interested in higher standards of legal education has been reached.

4. The practical course to pursue in raising the standard of legal education in night law schools run for profit is to raise the standards for admission to the bar. By this means the increased standard must be met by all alike, and one school cannot cut in on another with a lower standard. Such a move would receive the support of proprietors of the present night law schools in Cleveland.

5. In asking for stricter requirements for admission to the bar it must be borne in mind that such requests defeat their own ends if they go too far, for the temper of those in authority is still strong that entrance into the legal profession shall not be more difficult than is necessary to insure the minimum capacity and talent required for the less exacting and important positions in the profession.

6 . The public is entitled to demand at least a bona fide general elementary education equivalent to four years of high school, completed before the student commences his legal studies, so that he is not in the position of earning his own living, attending a night high school and a night school of law all at the same time.

7. The gap between the amount of class-room teaching in admittedly first-class law schools and that given in the night law schools of Cleveland is too wide. The former provide a period of from thirty-two to thirty-six weeks each year, with a minimum of class-room work of ten hours per week. This equals approximately one thousand and eighty class-room hours in the three-year course. The latter, with a maximum of six hours a week for thirty-six weeks each year, give only six hundred and forty-eight hours. This difference should be cut down by requiring of the night schools that they give at least eight hundred and sixty-four class-room hours of instruction. This can be done if the night law school work is continued for thirty-six weeks each year with six class-room hours a week for four years. At the same time the curriculum of the night law schools should be enlarged so as to include at least the greater part 
of the following subjects: Bankruptcy, Damages, Insurance, QuasiContracts, Conflict of Laws, Municipal Corporations, Mortgages and Trusts, and a considerable addition of Real Property.

It should be kept in mind, however, that there is no use in advancing the requirements for study in night law schools if study with an attorney is to be permitted with no guaranty that instruction by him will be maintained at the level required of the night law school, and if the standard of the bar examinations be not also advanced to keep pace with the advanced standard required of the law schools. With bar examinations conducted as at present and the power of students to obtain certificates from attorneys that they studied three years, increased requirements of the law school would be futile. The student would study at a law school long enough to prepare for the bar examinations as at present conducted, and then would seek the certificate of a practising attorney. The net result would be that students taking the night-law-school course would, in fact, spend but three years at the night law school, just as they do at present.

8. The public is entitled to the exercise of visitorial powers by the board of bar examiners, or by committees of the bar acting under their direction, over all law schools and all persons giving instruction in law whose certificates are accepted by the board. The public is equally entitled to the exercise of visitorial powers by the board of bar examiners, or committees of lawyers acting under their direction, over all schools (other than the public high schools) whose certificate that a student has completed the equivalent of a four-year high school course is accepted by the board.

9. The public is entitled to ask for a rigid inquiry into the moral character of applicants to take bar examinations, especially those elements of moral character which, when lacking in a member of the legal profession, are most disastrous to the public administration of justice and to the interests of clients-such elements as his conception of the code of legal ethics and of the oath of attorney which he takes, and his appreciation of the meaning of his oath to support the Constitution and the laws of the State and the United States.

\section{Recommendations}

1. No certificate of an attorney that a student has completed a satisfactory course of study under him should be accepted by the State board of bar examiners unless-(1) The attorney giving the certificate shall have registered with the board before the commencement of such 
course his desire to give a course of legal study, and (2) at the same time outlined the course which he proposes to give and show his means for giving adequate and regular instruction equivalent to that given by schools giving at least six hours a week of class-room instruction for thirty-six weeks during the year. The attorney should submit also to the visitorial powers of the State board of bar examiners or of a committee of lawyers acting under their direction. The student desiring to study under the direction of such attorney should obtain a certificate from him at the completion of each period of study of one year or less, and the attorney's certificate should state the fact to be that he has personally given to the student the course of study as outlined in his application to the bar examiners.

2. It should be required that a four-year high school course, or its equivalent, shall have been completed by the student before he commences his three-year course of legal study, and that where the certificate showing the completion of the four-year high school course is given by the principal of a school run for private profit, such school be subject to visitorial powers by the bar examiners, or by a committee of lawyers acting under their direction, with power in the bar examiners, on cause shown, to refuse to recognize its certificate.

3. The character of the period of legal study should be specified more in detail, both as to the subjects which the law school should offer and the amount of time that must be spent in recitation each week by the student and the number of weeks in each year that classes shall be held. Thus, candidates for the bar examinations should be required to have completed a course of legal study extending over a period equivalent to thirty-six weeks in each year for three years, with a minimum of eight class-room exercises a week of at least fifty minutes each, or eight hundred and sixty-four class-room hours. This would mean that a night law school giving six hours a week for thirty-six weeks each year would complete the required course in four years instead of three.

The standard of the bar examinations should be raised to meet the standard of study involved in the requirement of eight hundred and sixty-four class-room hours of teaching, as against the present requirement of six hundred and forty-eight class-room hours-that is to say, the bar examination questions should cover more subjects and with an increased proportion of problem questions which test the student's power of legal reasoning and grasp of legal principles as distinguished from his mere knowledge of definitions of legal conceptions, conventional distinctions, and fixed rules.

4. A committee of the bar should be appointed by the State bar ex- 
aminers to act under their direction to examine into the moral fitness of all applicants for permission to take the bar examinations; each candidate should come before the committee personally for direct oral examination, and the scrutiny of the candidate's moral character should be broadened so as to include not only his conduct and reputation for honesty, but his conception of the fiduciary relation, his knowledge of legal ethics, and his general training and conduct as throwing light upon his willingness to live up to the oath of attorney. To this committee also might well be turned over the conduct of the written examination of the student on the subject of legal ethics. 


$$
-
$$$$
5
$$ 


\title{
PART VII \\ NEWSPAPERS AND CRIMINAL JUSTICE
}

\author{
BY \\ M. K. WISEHART
}




\title{
NEWSPAPERS AND CRIMINAL JUSTICE
}

\author{
CHAPTER I ${ }^{1}$
}

\section{SUMMARY}

$\mathrm{C}$

LEVELAND, like other large American cities, is a newspaperreading community. The three week-day papers, the Plain Dealer, the Press, and the News, on April 1, 1921, had an aggregate circulation of 484,215 copies. The Sunday Plain Dealer and the Sunday News-Leader (the Sunday edition of the News) have an aggregate circulation of 394,738 . The size of the circulation of week-day editions is well over half the population, and of the Sunday editions is barely half. It need hardly be added that the range of a newspaper's audience largely exceeds its circulation.

In mechanical facilities and journalistic enterprise Cleveland's press is distinctly modern. Its newspapers have excellent equipment for the speedy presentation of news; they have large stafis of reporters and executives incessantly on the alert to excite the interest of readers. In short, all the devices of modern journalism, both material and psychological, find conspicuous illustration in Cleveland.

But there is an added element in any appraisal of Cleveland's press which differentiates this city from other big centers: the field is restricted to three papers-one morning paper (the Plain Dealer) and two afternoon papers (the Press and the News), with the obvious result that the power of the individual paper is greatly enhanced.

The intensification of the "power of the press" exerted in Cleveland clearly furnishes ample justification, if not compelling necessity, for study in any comprehensive survey of the administration of justice. The present report, however, was not undertaken upon any a priori assumption as to the responsibility of newspapers in the administration of criminal justice. It was made because it could not be avoided.

After the survey was under way the investigators charged with the

1 This chapter is contributed by Felix Frankfurter. 
different divisions of the inquiry found themselves, independently, encountering the press as an immediate and persisting factor in their respective problems. The separate investigations of the police, the prosecution, and the criminal courts quickly touched the press as one of the great sensory nerves in the organism of criminal justice. Public officials and private citizens alike, in representative numbers, regarded the newspapers, for weal or woe, as an indispensable factor in the situation.

This wide-spread belief as to the significant share attributable to Cleveland's press for the quality and the results of criminal justice soon found striking confirmations. With a view to eliciting authentic data as to the actual functioning of criminal justice from the profession primarily charged with its administration, a questionnaire was sent to all the members of the Cleveland bar. While no question specifically referred to newspapers, there was one "catch-all" question intended to provoke suggestions deemed by the bar pertinent to the scope of the inquiry. A surprisingly large percentage of the replies volunteered suggestions or comment regarding the effect of newspapers upon the administration of justice. ${ }^{1}$ Doubtless some of these comments were neither sufficiently objective nor duly mindful of the complexity of the problem, but the existence of wide-spread opinion entertained by responsible men of affairs and judgment is in itself a consideration of high importance. Finally, to the universal assumption as to the "power of the press" and to the wide-spread testimony to this fact must be added the volume of actual space given by the newspapers of Cleveland to news of "crime" and its "punishment." When it is noted that the news space given to matters covered under the term "the administration of criminal

${ }^{1}$ The following are typical quotations from the replies referred to in the text:

"Newspapers advertise too much of the trials of the crooks, and also investigations made by the police. A crook by reading the newspapers can know just what is being done."

"Criminal cases ought to be tried on their own merits to a court and jury and not, as is the practice in Cleveland, to try them to the newspapers and grand-stands."

"The chief defect to me seems to be the overwhelming influence of the newspapers. Judges and prosecutors generally seem dominated by fear of the press. Criminal justice will never be fairly or impartially administered so long as the newspapers have the power they now have and use it as ignorantly as they now do."

"One of the main difficulties is the desire of the Cleveland newspapers to print sensational matters. Newspaper men fallaciously state that they print only what the public demands, but it is just as true that they themselves create that public taste by their policies. This the prosecutors and judges know and take advantage of." 
justice" ranges from about 6 per cent. to 28 per cent. of the total news space, the inference is inescapable that the nature of what is printed, or not printed, its quality and underlying standards, above all, the general atmosphere that is hereby generated, must exert a most potent influence upon those who administer justice as well as upon the thought of the community, upon which, in the last analysis, the quality of the administration of justice inevitably rests.

\section{General Point of View}

Granting the pertinence of a study of the press as the chief source of public opinion in its relation to the administration of criminal justice, the manner of such a study-its scope and basis of evaluation-is bound to arouse the greatest diversity of opinion. This is natural enough, for we are here in a pioneer field. No such study as this has, as far as we know, ever been attempted. The material is elusive, little susceptible of quantitative measurement, and without any established standards of judgment. Here, as elsewhere, we are seeking to appraise results. But the appraisal is of influences on the public mind, on official conduct, on the promotion or corruption of civic standards. All these are imponderables. The work of the police, of the prosecution, of the courts, of penal institutions, may, as this survey shows, be largely judged by statistical standards. This is not true of the part the press plays. The sources of opinion-making, and its consequences-the effects of the press, that is-are not demonstrable in figures. The data are largely tendential. All we can do is to be as accurate and objective as is possible for painstaking and disinterested effort. And we must not expect too much from a beginning, from a first step in a new field. Of abuse or glorification of the press there is much; of the application of the scientific method to a study of that complicated process of business and opinionmaking which we call the press there is pitiably little.

In making this report, therefore, we had to go most warily. We did not pretend to deal with the institution of the newspaper in general, nor was it our task to deal with the fundamental inquiry how to foster a more critical mind in the newspaper-reading public. We were concerned with those aspects of the press which are inseparably related to the administration of criminal justice. This limited scope of the study must be constantly kept in mind. Nor did we apply to the problem an ideal conception of a newspaper's functions or assume ideal means for achieving them. We start from that conception of newspapers-their power, their responsibility, their limitations-which editors and publishers themselves profess. Broadly speaking, the only assumptions 
underlying this study are-(1) that the public derives its opinions about "the administration of criminal justice" from the kind, the quality, and the volume of newspaper matter affecting criminal justice; (2) that the influence exerted by public opinion on the system of criminal justice is largely dependent upon the extent of informed opinion in the community; (3) that the whole scheme of criminal justice, particularly under an elective system with short tenures, is pervasively affected not so much by editorial opinion as by the views which are gradually deposited in the minds of the electors through the more vivid and persistent, and therefore more potent, influence of the daily news column; (4) that, with due regard to the practical limitations which confront the press, the newspapers of Cleveland can furnish accurate, sober, wellbalanced, and interesting news of, and comment on, the functioning of criminal justice, and thereby largely contribute toward creating and sustaining the necessary informed public opinion.

\section{Practical Difficulties}

Every fair judgment upon the work of newspapers must be conditioned by an understanding of their problem. The modern daily is in the grip of unavoidable mechanical and social forces. Time is a powerful factor. Particularly is this true of the afternoon papers, with their multiple issues. The compulsion of speed affects judgment as to what is significant, as well as the accuracy or adequacy with which it is conveyed. The conscious necessity of appealing to the public throughout the day, by means of successive issues, necessarily throws the emphasis upon what excites curiosity rather than upon what informs opinion. This element of speed, this momentary timeliness, is partly the slave of the press and partly its master. Undoubtedly the public "wants" an uninterrupted and exciting stream of "news"; but, also undoubtedly, the public has been taught by the press to "want" such "news," and the press continues feverishly to stimulate the "want." Mechanical inventions have had their share in the process. Partly they have stirred newspapers to their present-day methods; partly the inventions themselves were stimulated by newspaper enterprise.

In all this competition has been the most responsible factor. Perhaps no business today discloses fiercer, less restrained competition, than the newspaper business. Since this is, in effect, a struggle for the capture of the public's mind, the arts that are exercised, the interests that are excited or neglected, are bound to have vital reflexes upon that most intimate and extensive aspect of a community's life called criminal justice. So long as competition remains unbridled, so long as ephemeral 
excitement may legitimately control newspaper policy, just so long is temporary excitement bound to influence the tone of the press.

Competition is the severest pressure exerted upon the press, but not the only one. Because of competition, other pressures assert themselves. The range of competition leads newspapers to go beyond the mere reporting of crime and of the efforts of law enforcement, and drives them to scoring "scoops" and "beats." As a result, a personal relation is sought between newspaper men and the officers of the law, with a view to facilitating opportunities for such "scoops." In turn, a play for the favor of newspapers is made by officials whose public or professional life not inconsiderably depends upon advertising. Eager for special opportunities, the reporters play favorites with police officials, judges, and prosecutors. The barriers of impersonalness which should exist between law enforcers and the press are thus broken down. The result is a confusion of standards, and conscious or unconscious partiality and exploitation by the press.

Finally, at the core of any appraisal of the press is the stubborn fact that newspapers are usually not regarded as civic or public undertakings, but as private ventures primarily operated for commercial profit. It is a notorious fact that the public does not pay for its news. It expects the papers to recoup their losses from the expenses of news gathering through advertising. Because of habit or training comparatively few individuals are today ready to pay more than a nominal sum for their daily paper. The axis on which the volume of advertising turns is circulation. Therefore, under present conditions, to live, a newspaper must reach the largest possible number of readers at the smallest possible price.

This low price per copy imposes upon the newspaper, especially under competitive advertising rates, a very rigid ratio of expense to income. The point of diminishing returns in the amount of salary expenditure is very rapidly reached in the small cities, less rapidly but just as certainly in cities of the size of Cleveland, least rapidly in New York. If, for example, all the highest salaried writers of the New York Times or the New York World were engaged by one of the Cleveland newspapers they could not possibly increase the circulation of that paper so as to afford the increased salaries. Most of the Cleveland reporters, at present, are on salaries comparable to the pay of high-school teachers. Only a very much smaller number of higher salaried specialists are employed in the news departments. The publishers rely on low-priced men for the bulk of the news matter. Moreover, the turnover of these reporters is marked. For a number of years places on Cleveland papers, as is true in other cities, have been subject to frequent change. Some 
positions are filled as many as four times a year. As a result, substantial background of knowledge, let alone expertness, for the various assignments is usually wanting.

The effect of all this upon the news of the complex processes of criminal justice is obvious. Without specialized training, in most instances, to begin with, the diversity and the frequence of his shifts usually prevent the reporter from acquiring much obligation toward the reader or the material. Nor can a solid basis of knowledge or a background for discerning judgment be thus built up. Too frequently great versatility in knowledge as well as understanding is expected from poorly paid and poorly equipped men. ${ }^{1}$

\section{Function of Newspapers in Relation to Criminal Justice}

Newspapers undertake to chronicle significant events from day to day. These include crime as well as efforts to prevent and punish crime. The only questions which arise with reference to the recital of actual happenings are as to the quality of the news, that is, the atmosphere, the emphasis, the accuracy of the "story." Moreover, reiteration is here a psychological element of enormous significance. It is by the repetitive process that the mental habit, the community outlook, upon criminal justice is formed. Newspapers realize very acutely that "the emphasis makes the song." Clearly, then, it is through the presentation of "news" that the press exercises its most comprehensive and constant function in relation to criminal justice. But the activity of the press does not end there. The various newspapers of Cleveland have special articles intended for informing public opinion and for creating the knowledge and atmosphere necessary for the improvement of the existing system. By these articles, some of them sober and scientific, newspapers recognize their special responsibility for public opinion as the generator of public justice.

Serious limits circumscribe the function of the press as critic. Newspapers cannot be, and should not be expected to be, agencies for the continuous scientific investigation of the actual operation of criminal justice. That is a burden clearly to be borne by the entire community. The want of a steady stream of such scientific data as a basis of criticism is to be kept in mind when considering the shortcomings of the press.

${ }^{1}$ Of late, scarcity of work has had its effect also upon the newspaper men and has tended somewhat to stabilize newspaper employment. One ventures the belief that the immediate future will see fewer of the defects chargeable to inexperience and rapid turnover of news writers. 
The need, as well as the inability, of newspapers themselves to cope with the problems is thus put by one of Cleveland's editors:

"Some time ago it seemed to me desirable that we should follow every case that reached the police through every step until it was finally disposed of. Such reports, it seemed to me, would show exactly what was going on in the administration of justice. I assigned police reporters to the task. These reporters started in at Central Station, and they were not long in finding that they had undertaken a stupendous task. Then I called in a law firm and asked them to do the work. Representatives of this firm worked a week, and then reported that unless we were prepared to finance a stafi of 10 or 12 men for a year for this particular work there was no use going ahead, as the results would be too slight.

"I am of the opinion that constant reports regarding just what is going on in the administration of justice are necessary and advisable as a check on public officials. From my experience I question if newspapers are qualified to do the task thoroughly and well. I am convinced that if such reports, by way of continuous publicity as a check on public officials, are to appear in daily newspapers, they will have to be prepared by some organization equipped for and experienced in that kind of research."

Newspapers, then, may rightly be charged with the duties, as well as the privileges, of chronicler and critic. More the community should not expect; but in fact, it does. To no small degree newspapers are deemed to be the super-government, or, at least, the supervising authority over all official agencies. All too easily the community looks to its newspapers for the detection of crime and the enforcement of law. Partly, doubtless, the newspapers themselves are responsible for these unreasonable expectations. Unreasonable they are, nevertheless, and even intolerable. Newspapers are neither the government nor the people. They cannot be charged with any of the responsibilities of government, nor should they be allowed to assume them. Neither can the community at large relieve itself of ultimate responsibility for the conditions which this survey of Cleveland's administration of criminal justice has revealed. We must not expect the newspapers to carry the full load of the democratic experiment. Their share is ample.

Criticism of Newspapers in Relation to Administration of Justice

The succeeding pages disclose evidence typical of methods of treatment, by the press of Cleveland, of matters affecting the administration of justice whose evil influence appears beyond controversy. Broadly speaking, these evils operate in two ways: either as effective interference with the orderly and just administration of law, or as the most potent 
molder of the kind of public opinion which is wholly incompatible with civilized standards of criminal justice.

1. Interferences by the press with effective law enforcement take two forms: (a) direct participation by the press in law enforcement, and $(b)$ irresponsible publicity which embarrasses the official detection of wrongdoing or hampers the impartial processes of law in the trial of the accused.

(a) In common with papers throughout the country, the Cleveland newspapers from time to time become not merely the chroniclers of criminal news, but its creators. One probably encounters here a deeprooted tradition. So much of a city's news is police news and so many of the staff of city news reporters came up as police reporters that it is not at all surprising to find the transition easy from reporting to discovering news. An evil it is none the less. Perhaps the greatest struggle in the history of the law is the transference of its enforcement from private to public hands. Peculiarly is this true of the criminal law. The vindication of public wrongs must be left exclusively to its public guardians. No aspect of it, not even the detection of offenders, can be allowed to become a pawn in the game of competitive journalism, no matter how much of high public motive is likewise operating. Such an incident as the Lyons case ${ }^{1}$ presents does not belong to legitimate newspaper enterprise. A newspaper is, after all, a newspaper, not an arresting agency nor a detective bureau. Not the least of the resulting evils is the weakening of official responsibility and the entanglement of officers of the law in journalistic enterprise.

(b) Undoubtedly, there is a kind of unrestrained publicity which seriously interferes with law enforcement, without any compensating public gain. Too frequently there is no further standard of judgment by the newspapers of the propriety of publication except the immediate interest of the news. The bearing of a specific publication upon the vindication of law is all too little heeded. Ordinary newspaper practice (and here again the Cleveland newspapers merely reflect standards of journalism common everywhere) is not such as to prevent the publication of information that would clearly handicap the police pursuit of suspects, nor such as to prevent the disappearance of witnesses essential for the prosecution. It is difficult to determine whether the press has fostered this notion of publicity or responded to it, or whether it is a combination of the interplay of desires for publicity by press and officials. Undoubtedly, both police officials and prosecutors seem to act on the 
assumption that their efforts at law enforcement must be revealed to the public in full detail while those efforts are still in their preparatory and even prophetic stages. On the part of police and prosecutors this sort of publicity is resorted to partly to avoid criticism, partly to secure advertising, and in some instances, doubtless, with the good faith of enlisting public support in the tracking of crime. There may be instances when such public support should properly be enlisted. The occasion must be left to the professional discretion of high-minded, disinterested, and competent law officers. The practice of unlimited publicity is at present certainly not thus circumscribed by exclusive considerations of law enforcement. On the contrary, the abuses of the present practice are well established and generally admitted. The succeeding pages are full of illustrations. The Shelton case, the whiskeyrunning launch incident, the Purpera case, all tell the tale (pp. 529-530).

No less embarrassing to the course of justice is the method of reporting cases that, for some reason or another, particularly arouse public interest. Every lawyer, as well as every newspaperman, knows that "in spite of forms" juries are "extremely likely to be impregnated by the environing atmosphere." To a great extent, newspapers create that atmosphere. The public hostility or sympathy which may be engendered for or against an accused may largely determine the fate of the trial. All too frequently, extraneous factors, such as the attitude of editors and reporters upon crimes of a particular character, influence the nature of their news "reports." Instances are too many in which the public is furnished not a disinterested report but a dramatic interpretation of a trial. The Hupp, the Huettel, the Kaber trials are instances that will readily suggest themselves to readers of Cleveland newspapers. "Human interest" is the excuse; corruption of the community's standards may be the consequence. Instead of a sober summary regarding action taken by police and prosecutor, or of the evidence presented in court, current methods of newspaper writing permit the selection and treatment of newspaper material in a style plainly intended either to condone or to condemn the accused. Moreover, it is a standing accusation against American criminal justice that such journalistic intention is too often successful.

2. A deeper cause for concern is the quality of public opinion resulting from the treatment of individual cases. In the hurly-burly of today yesterday's paper may be dead, but not the influence which it exerted. Whether a newspaper wills it or not, whether its readers are alive to the process, the inescapable fact is that the flavor and substance of daily news reporting is, for good or ill, the most potent builder of 
opinion. What is "played up" or neglected from day to day gradually determines the public's mind as well as the official mind. To a considerable extent during the last fifteen years crime enforcement in Cleveland has oscillated between hysteria and neglect. A striking illustration, as shown by this survey, is the attitude of Cleveland toward the parole system. How large a measure of responsibility for such unhealthy conditions rests with the newspapers is attested by this and other reports of this survey. Pungent overemphasis at one time, systematic sentimentalizing at another, cannot possibly furnish a basis for a responsible and informed public opinion. Nor is it surprising that judges and prosecutors, dependent upon passing public favor, will, consciously and unconsciously, cater to the prevailing mood of the newspapers as the molders and exponents of "public opinion." The exploitation of Judge Stevens' dramatic liquor fines, and the practical neglect by the papers of the judge's quiet remission of the same fines, tells the tale (p. 552).

In the nature of things, we venture to repeat, the effects of abuses and shortcomings to which these pages call attention cannot be proved statistically. We are dealing with the quality of opinion and its consequences, for which no quantitative measurements have as yet been devised. The chief evil of that aspect of the press with which this report is concerned lies, as we see it, in the quality of the news. This report proves that the Cleveland papers exemplify that evil. A low tone, emotionalism, off-emphasis, irrelevance, and neglect are, we submit, the outstanding sources of newspaper shortcomings. These qualities of news matter fashion the mind of the public. The public, in its turn, is stimulated to want this kind of news. No student of opinionmaking will deny that on public questions the newspapers give the dominant content to the public mind. This report essays, for the first time, the task of showing what that content is by significant illustrations. A massive demonstration would simply reprint the treatment of crime matters by the Cleveland press for successive years, for instance, 1914, 1916, 1919, 1920. Space prohibits such extensive proof. We were, therefore, restricted to a comparatively few significant instances illustrative of the way Cleveland newspapers deal with crime matters and its inevitable effect upon the public mind. The whole process and atmosphere are amply illustrated, in the following pages, by the Purpera, Hupp, and Kaber cases. The report also illustrates how the newspapers, and therefore the public, oscillate between hysteria and indifference toward law enforcement. It also illustrates, in the treatment of Judge Stevens' liquor fines, how "stuff" is "played up" and misguides 
the community. All these are accurate and significant illustrations. These things are the heart of the matter. A single instance may illustrate but does not exhaust the evil exerted. And so apologists may explain away every incident which this report sets forth and yet leave untouched the total result which they evidence. We wish to guard against misapprehension due to the perversion of sensitiveness. We do not say the Cleveland papers are signally bad; we do not say that they are worse than the papers of comparable cities-for all we know they may not be as bad. That, we submit, is beside the present point. Here, as in the other studies of Cleveland institutions, we are concerned with Cleveland. It does not advance the cause of truth nor of selfknowledge as the basis of improvement to have the pot call the kettle black. This survey only proves what has long been felt and widely believed. We have singled out no paper for special illustration. All of them are of equal indifference to this survey. They are all illustrative of habits and standards for which no one paper is responsible and which none transcends.

Nor are we unmindful how powerful are the influences which here are subjected to scrutiny. An adequate dissemination of the findings of this survey depends upon them; no less, action upon these findings. But we confidently rely upon the civic mindedness of the press and its fundamental regard for fair play. During the course of the survey the Cleveland newspapers have certainly manifested every desire to help, and have generously recognized their high public responsibility.

\section{ConcLusions}

Admitting all the shortcomings of the press in its relation to criminal justice, we should, nevertheless, be exceedingly cautious of all facile proposals of panaceas. The most significant conclusion revealed by this survey is that the entire system of criminal justice, as actually administered, is largely a reflex of the general community standards. This is peculiarly true of the part the press plays. Here we can least rely upon legislative or structural changes. The freedom of the press involves one of the most vital expressions of the democratic faith. We must not too rudely tamper with one of our great political and constitutional principles, even in an effort to correct some of its abuses in practice. Reform must be looked for in a steady transformation of the standards set by the community for its newspapers and by the press for itself. In the language of the greatest of our judges, "the main remedy . . . for the evils of public opinion is for us to grow more civilized." A full 
realization of the implications behind these few words will furnish a clue to the problem and will fashion the means for its solution.

In seeking more specifically to translate into action the responsibility of the newspapers it is not intended in the slightest to minimize the ultimate responsibility of the public. It may truthfully be said that every community has the press that it deserves. Here we encounter what logicians call mutuality of cause and effect; the press makes "public opinion," and "public opinion" makes the press. As in other aspects of our social life, we are confronted by a vicious circle. Somehow it must be broken. It can be broken only by the insight, the sacrifice, the daring, above all, the will to break it, of some individuals. After all, a responsible press should not measure its standards by the shortcomings of the public. Just as the legal profession has a professional duty, and should have the professional pride to establish and maintain its own high standards, so journalism should be jealous for the high quality and tone of its profession. No profession has deeper and wider responsibility, if responsibility be proportionate to power. The press is keenly alive to the need of lifting the whole level of the legal profession. And rightly so. The press should be no less alive to rigorous self-criticism. Signs of this process are not wholly wanting. This is the shortest road toward giving us a press that will be alert and enterprising, but devoted to the steady growth of reason.

That will necessitate certain self-denials. Just as there has been a steady subjection of business to moral standards and a steady recognition by business that certain things are not to be done, so newspapers must agree to restrict the field of competition in their relation to criminal justice. "Scoops" and "beats" should, by common consent of the profession, be surrendered where impairment for respect of the law, or even its frustration, may be the price. Thus there might well be a common consent not to publish evidence before its actual use in a public trial except with the consent of the kind of prosecutor or presiding judge whom the reports on Prosecution and Criminal Courts envisage as adequate to a modern system of justice. Equally pertinent is it to suggest that newspapers should impose upon themselves a self-denying ordinance not to go out and make evidence. We readily appreciate that the line is not an easy one to draw between news reporting and news making. No one would suggest, for instance, that a newspaper like the New York World should not engage in such an inquiry as its Ku-Klux investigation. Equally true is it that a line must be drawn, and that, however broad the line may be, it is now often overstepped. But, surely where a specific crime has been committed, such as the McGannon case illus- 
trates, the rudimentary function of law enforcement, with all that it implies, must be discharged exclusively by the officers of the law. If the police, prosecuting or judicial machinery breaks down, it is not for the newspapers to bolster it up. The newspapers should be free as critics and not become involved as partisans. Only by paying the cost for governmental neglect, incompetence, or corruption will the public finally and fully realize its own responsibility for the quality of government. It will not do to have the public relieved of its responsibility by having newspapers confuse their important but limited functions. The press should neither be asked nor be allowed to assume the tasks of the government or of its master, the community. To the general community standards and to the press itself, then, we must look for an improvement of the press as the great instrument of opinion. But just as the level of business conduct has been lifted, partly, by pressure from without, like President Roosevelt's preachments, so the press would surely be responsive to the articulate expression of the community's needs and hopes, if firmly and persistently voiced, by even a few of its high-minded, influential citizens.

\section{Recommendations}

The other reports in this survey deal with public agencies of law enforcement. As to these, improvement depends to a considerable extent on the structure and organization of each agency; changes affecting them may be brought about by legislative and administrative action. Newspapers present a different problem. They cannot be coerced by legislation or by structural reform. Improvement must largely come from the recognition of definite standards of public duty by the profession of journalism and the voluntary enforcement of these standards by common consent of the profession. To such voluntary acceptance and action by the press we recommend the following:

1. Adherence to a rule that newspapers are to have no direct participation in the administration of criminal justice.

2. Formulation by the newspapers, in consultation with representatives of the police, prosecution, and courts, of rules of practice governing the publication of evidence before its actual use in public trials so as to avoid possible embarrassment to the official detection of crime or to the impartial processes of law in the trial of cases.

3. Increased effort to make "stories" of criminal trials sober and informative reports of the course of a trial, giving a fair perspective, however brief, of the entire evidence presented in court.

4. Recognition of the fact, as the guiding consideration of newspaper practice toward treatment of "crime" matters, that the administration of criminal justice is most potently influenced by "public opinion," and that the quality and effectiveness of public opinion in its turn largely depend on the quality of the daily news column. 


\section{CHAPTER II}

\section{CHARACTER OF NEWSPAPER REPORTING}

\section{Before Trial}

$\mathbf{R}$

EPORTS of crimes and details of police activity looking toward the detection and arrest of guilty persons constitute a considerable part of the news in Cleveland newspapers. Immediately after a crime is reported to the police the newspapers print details of the crime itself, together with all the available clues. If the crime has sensational features, as is not infrequently the case, these clues are worked up with special care and emphasis, and if possible some indication of persons suspected is given.

I. After the first report of the crime the daily news accounts consist of new developments in the case, in the form of new clues, new suspicions, or reports of impending arrests. These details are printed with great lack of reserve. They are described in a manner calculated to keep alive public interest in the police search, and without seeming to take care lest information be given which might be useful to the culprit seeking to escape. We are not here apportioning blame for the practice. That the abuses are largely in the control of the police and prosecutors hardly admits of doubt. No less true is it that the practice, prevalent throughout the country, is partly prompted by fear of public criticism if "results" are not immediately forthcoming. We are here merely reporting the facts of the evil practice.

On January 4, 1921, the Plain Dealer printed a column and a half article which included the following paragraphs:

\section{DETECTIVES WATCH CAR, TAKE THREE ${ }^{1}$}

Three youths held as suspects in connection with the murder Friday of Wilfred C. Sly and George K. Fanner, officers of the W. W. Sly Manufacturing Co., were arrested at different hours yesterday at a garage where

1 No effort has been made to reproduce the typography of the headlines of the articles reprinted in this report. Headlines are indicated by the use of capital letters. In some instances only part of a headline is reprinted. 
police have been watching an automobile which they believe is the one used by the murderers in their escape.

The arrests were made by the detectives on guard after each of the trio had entered and sought to drive the car out into the street.

At the time this article appeared three other individuals suspected of participation in the crime were at large, one of whom, when arrested later in Los Angeles, confessed and named his confederates. The information on which the quoted statement was based was given by the police to reporters at Central Station shortly after the arrests were made.

Subsequently Samuel Purpera, who confessed his participation in the crime and named his confederate, was arrested in Los Angeles. On March 18 appeared in the Plain Dealer an article two-thirds of a column in length, with the headline, "Purpera Admits Being Tipped OfF," and proceeding as follows:

Confederates of Sam Purpera, under arrest in Los Angeles charged with the murders of Wilfred C. Sly and George K. Fanner, gave him advance information of every action of the Cleveland police.

This was admitted by Purpera in his confession to County Prosecutor Edward C. Stanton and Detective Inspector Charles N. Sterling on Wednesday, when they confronted him with their evidence connecting him with the crime.

Not only was Purpera apprised of the actions of the police here, but he was provided with passports designed to get him safely into Mexico, he admitted in his confession.

Prosecutor Stanton and Inspector Sterling yesterday resumed their questioning of Purpera in his cell in the Los Angeles jail in an effort to force him to reveal further details of the daylight robbery and murders.

In his original confession, Purpera not only admitted his own participation in the murders, but revealed the identity of the others who were with him.

Coincidentally with word of Purpera's arrest, police found that his confederates had received the information before the police and that they had disappeared. Word has been dispatched to police authorities throughout the United States, however. Ocean steamships will be watched to prevent any member of the band from leaving the country.

Even after this clear indication that the fugitives were making use of information which might have come from newspaper publication, the Press printed an article three days later with the headline, "To INDICT Frve," and beneath it this statement:

Police Chief Monday was awaiting word of the search being made in suburbs of Los Angeles for an accomplice of Purpera. 
Numerous instances are available in which matter has been printed giving premature publicity to police activities which might better not have been published at the time. The following cases are typical:

1. From the Press, December 10, 1919:

ARREST NEAR IN POLICE MURDER. COMPANION OF PATROLMAN'S ASSAILANT IS CAPTURED. KHAKI COAT GIVES CLUE. MAN TAKEN IN RAID ON KINSMAN-RD. CONFESSES.

Police late Wednesday were ready to nab the slayer of Patrolman Robert Shelton.

Positive knowledge of the murderer's identity resulted Wednesday from the capture of his "pal" in a spectacular raid upon a Kinsman-rd. house.

\section{From the Plain Dealer, December 12, 1919:}

DETECTIVES LEAVE ON SLAYER'S TRAIL. FOLLOW SWEETHEART OF POLICEMAN'S MURDERER TO DISTANT CITY. MAN AND GIRL HELD AS WITNESSES GIVE TIP IN MYSTERY.

Believing that they are close upon the trail of the man who shot and killed Patrolman Robert Shelton last Sunday morning, Captain of Detectives George Matowitz and Detective William Peters were searching in a city several hundred miles from Cleveland last night.

Detective Peters was sent to identify the man, whom he arrested three years ago on a larceny charge.

Acting upon a tip that the sweetheart of the murderer had left Cleveland to join him, the officers followed her. They expect to find the woman and man together.

From information which police gathered yesterday it was practically established that the murderer left Cleveland Monday evening after the crime. The woman left Cleveland some time Tuesday and police are convinced that before the man left he had made arrangements for her to join him.

The practice of announcing the direction in which the police are pursuing a criminal is common in Cleveland newspapers. Their attitude in this regard is that they have the right to print anything the police make public, and that since every criminal at large knows he is pursued, it does no harm to disclose the direction in which the chase is being conducted.

Instances of the publication of such material are not hard to find. The Plain Dealer, June 13, 1921, in an article about a whisky-running launch which was found in Rocky River, stated: "Lakewood police were watching the craft early today, hoping some member of the crew might return." Two days later the same paper, in an article headed by an 
eight-column streamer reading "Business Men Threatened; Trap LAID," stated: "Two dummy packages resembling money which had been planted at spots in the East End were being watched by city detectives early today as a result of letters demanding from $\$ 8,000$ to $\$ 10,000$.

. These papers were sold by carriers on the Public Square as early as 2 A. M. of the publication date. If the articles were correct in their statements, it is obvious that at the very moment the police were watching for the criminal, the public was being told that the trap was set.

II. When a suspected person has been caught, the case is given somewhat different treatment by the papers. The arrest is often made the occasion for giving again all the details of the case, adding what the prisoner has to say, what his lawyer and his friends have to say, and sometimes even what private citizens think about the need for speedy trial and punishment. If the case is murder, interviews with friends and relatives of the murdered man may appear, expressing more or less certainty of the guilt of the person under arrest. The arraignment of the prisoner in court, or an intimation from the police that the prisoner has expressed fear of death in the electric chair, may be made the occasion for another complete review of the case. The reporters make frequent visits to the offices of the prosecutors and their assistants. Names of witnesses to appear before the grand jury, or to testify in court, and occasionally advance information of the trial of the prosecution, are frequently obtained in this way, and immediately appear in print.

The following extracts illustrate this tendency:

1. From the Plain Dealer, March 17, 1921:

YOUTH TELLS HOW HIS BAND KILLED MEN. PURPERA, HELD IN LOS ANGELES, SAYS SIX ROBBERS OPENED FIRE AFTER SLY PUT UP HIS WEAPON.

Sam Purpera, 17, under arrest in Los Angeles, confessed to County Prosecutor Edward C. Stanton and Detective Inspector Charles N. Sterling late yesterday how he and six others killed Wilfred C. Sly and George K. Fanner in the daylight robbery of Dec. 31.

Dispatches from Los Angeles, quoting police officials, declare Purpera informed Prosecutor Stanton and Inspector Sterling how the automobile containing Sly and Fanner was crowded to the railing of the Nickel Plate bridge at W. 47 th street by the car in which he rode. He then told how Sly and Fanner left their car.

"Sly tumbled to the fact that something was wrong and pulled a gun and pointed it at me," he said, according to Los Angeles police. "We convinced him it was a mistake, and Sly put his gun up. Then all six of us began to shoot up the other car." 
"I did it," he is quoted as having said later. "I suppose I'll go to the chair for this, but there is no use bringing anybody else into it."

Then after some reflection, and apparently in a different frame of mind, he added:

"I don't think they can land me in the chair for this job-I'm too young."

Since his arrest Friday, Purpera had steadfastly maintained his innocence of any connection with the murders.

It was only after Prosecutor Stanton and Inspector Sterling had convinced him, according to Los Angeles police, that they had sufficient evidence to convict him of the charges of first degree murder on which he was indicted that Purpera agreed to talk.

"We had talked this thing over for a long while," he is reported to have said. "On the day of the blowoff, we went out to the bridge in two machines. We stalled until the car with the goods in it came our way, and then the auto I was in drove alongside the other machine as close as we could.

"It was not long until we had 'em huggin' the rail of the bridge and they had to cut their speed. Sly tumbled to the fact that something was wrong and pulled a gun, pointing it straight at me.

"We convinced them that it was a mistake and that our steering gear was out of whack. Sly put up his gun, and all six of us began to shoot up the other car.

"Some of the others got the money and beat it. I never showed for my cut and never got any of the coin."

\section{From the Press, March 25, 1921:}

\section{PRESS MAN INTERVIEWS SLY-FANNER MURDERER}

Accompanying this interview was a "box" containing the following:

\section{SIGNED CONFESSION IN SLY-FANNER MURDER BY SAMUEL PURPERA}

On Dec. 20, 1920, I was in Dreamland Dance Hall. I met ........ and he told me he needed a machine for Dec. 31 . I said, "all right."

At 10 'clock the morning of the crime I met one of the other fellows. I said, "....., I need a machine."

He gave me the key and I said I would fix him up. I then brought the Stearns (belonging to Fred H. Goff) on E. Ninth St., and some fellows jumped on and we went to W. 47 th St. and waited for awhile and then we went down to the Federal Reserve Bank.

We waited for awhile and we followed Sly's machine to W. 46th st.

When we got to the bridge we cut them short. They came out with pointed guns.

When we were thru arguing, I walked away a little and the fellows from the other car came out and started shooting. They jumped on the car again and when we went a few blocks I jumped off. 
One of them had the money and he jumped on the machine......... was at the wheel. Down W. 47th st. to Bridge ave., and we turned west to 65 th st., and then turned north and I jumped off and left them there.

This "confession" was printed in both the Plain Dealer and the News of March 26, 1921. According to the News report of this date, this confession was written by Purpera on a train while he was being brought from Los Angeles by Prosecutor Stanton and Inspector Sterling.

Again the News, on April 14, 1921, printed the affidavits of May E. Neely, Edward J. Allen, and Charles E. Burke, in connection with the trial of Judge McGannon. Doubtless the News in so doing felt it was performing a public service. But these affidavits were the basis of the perjury case against McGannon and of indictments against the three individuals named, all of which at the time of publication remained to be tried.

No special effort is made by the newspapers to protect grand jury proceedings from undue publicity or to maintain sufficient secrecy regarding criminal cases to insure their effective prosecution. In Cleveland as elsewhere the elimination of this particular evil (striking at the very theory of the grand jury) is largely in the control of the prosecutor.

Obviously, this practice of "trial by newspapers" which precedes the judicial trial may have two serious results: first, exposing the prosecution's case, and secondly, creating a definite and wide-spread public opinion as to the merits of the case in anticipation of the trial.

\section{Character of Newspaper Reporting During Trial}

The outstanding characteristic of newspaper reporting of trials is the presence, in abundance, of so-called "human interest" material, the inevitable effect of which is the creation of public sympathy for one or the other side of the case. Newspaper reports of criminal trials are not, as a rule, in any sense summaries of the evidence and arguments presented in court. Yet, surely, such should be their function. Their emphasis is too frequently not upon the essential facts of the case, but upon minor or irrelevant incidents. By the selection of these incidents and the emphasis given them, an atmosphere either of hostility or of sympathy toward the defendant is created. And the outcome of the trial depends, as everyone conversant with trials knows, not a little upon that elusive "atmosphere."

I. A few illustrations follow, all dealing with the Hupp case. On the night of January 10, 1918, Elmer Hupp shot Charles Joyce, a salesman, in Hupp's home. 
1. From the Plain Dealer, March 6, 1918:

Nearly every woman in court was silently weeping as Hupp told of his devotion to his wife and daughter.......... Hupp, nerves almost worn out by distress and anxiety, frequently paused to wipe his eyes. Even the men in the crowded court room were visibly affected by the pathos of the story of his anguish. One woman was completely overcome..........

2. From the Press, February 28, 1918:

\section{WHY HUPP KILLED JOYCE}

Elmer Hupp's position in the social tragedy to be put to analysis by chemistry of law this week, differs radically from that of most men who claim rights under the "unwritten law."

Here was no adherence to an artificial code by which a man shot to avenge an offense against himself and vindicate his own honor.

He says he acted not for revenge but to protect his wife.

Hupp's position was and is now as elemental as the earth from which he won his wealth.

He believed that another man proposed to take his wife from him and he preserved his own position by killing the man.

His point of view seems quite as simple and unaffected as a man who defends his property rights by killing a burglar.

The difference between his position and the man who avenges a wrong already committed is indicated by lack of any show of resentment against his wife and by his own statement:

"My wife is going to stick by me and I am going to protect her."

\section{Ethics Differ from Popular Viewpoint}

Charles L. Joyce, the man who was killed, had been made to see that his visits to the house were resented by Hupp.

Fiction and drama of recent years, reflecting popular ideas, has inclined to a solution of such situations by a decision of the wife-she being permitted to choose between the two.

No such fine-drawn ethics were to be expected from Hupp. Here was a man, without much education, who had won his way by hard work as an oil driller, in rough neighborhoods among rough men.

His simple purpose seemed to be to hold his own wife. That this possession was threatened was indicated sufficiently for him when he found Joyce hiding in the attic on his return to his home in Lakewood.

3. From the Press, March 1, 1918:

HUPP BOUGHT A GUN TO KILL HIMSELF-LAWYER SAYS. SLAYER WEEPS AS DAUGHTER ENTERS COURT. DAVID CALLS HUPP "ONE-WOMAN" MAN. HE PAMPERED WIFE EVEN TO PLANNING SUICIDE TO MAKE HER LIFE A HAPPIER ONE.

"Elmer Hupp was a 'one-woman' man!"

Attorney W. L. David banged his fists down on the trial table Friday afternoon as he opened his speech to the jury with this statement in Hupp's defense.............. 
A jury in the case was sworn Friday noon. Only one unmarried man was on it.............

David immediately began his statement to the jury.

He told how Hupp had pampered his wife and on two occasions had planned suicide because he thought he was standing in the way of his wife's happiness.

"The second of these two occasions was on the day Joyce was shot," David said.

"Hupp bought a revolver to shoot himself. He made one last trip to his home intending only to take a last long look at his wife before he ended it all. He had no thought of entering but he saw his wife with Joyce and he lost control of himself."

It was this loss of control that Hupp's attorneys had pointed out as the "red rage" on which they base their claim of justification for Hupp's deed.

\section{From the Press, March 1, 1918:}

\section{THE RACK OF HIS OWN THOUGHTS TORTURES HUPP}

A keenly sensitive mouth and a broad forehead, deeply lined by long habit of tensely concentrated thought, seem to characterize Elmer Hupp.

The sensitive, cleanly cut mouth, matching mild blue eyes, give an almost boyish look to his face.

This is in spite of the deep lines and rugged outlines which are the work of a long struggle for success and perhaps, also, of the tragedy ...... He seemed like a man who lies on the rack of his own thoughts. One wonders what he is thinking.

\section{From the News, March 2, 1918:}

\section{LOVE TRAGEDY FALLS HEAVIEST ON GIRL. SHE WILL TELL . ALL TO SAVE HER FATHER}

Consuelo- "whose noble purity is sustained amidst temptations and disillusions." A winsome, cream and pink blonde girl sat looking out on a sun-lit world Saturday - autos speeding by, children romping, a bird circling high in the air, emblem of all that is care-free and glad. As she watched, a tear trickled down the little girl's cheek and her lips quivered.

She is living the fate her name, grewsomely tragic in the light of events during the last month, implies.

For little Consuelo Hupp, the most pathetic figure in the love triangle which has sent a man to his grave, which has pointed the finger of shame at her mother and has plunged her father into a fight against spending the rest of his life in the penitentiary, must still show that same constancy symbolized by the name her parents by some strange fancy picked for her........ 


\section{From the News, March 7, 1918:}

HUPP'S FATE RESTS ON GOD'S LAW. SLAYER AND CHILD SOB SIDE BY SIDE. CROWDED COURT ROOM IS "ROOM OF TEARS" AS ATTORNEY FOR DEFENSE PAINTS "ONE-WOMAN" MAN'S VAIN FIGHT FOR HOME OF HAPPINESS. SUNSHINE VERDICT FOR CONSUELO'S SAKE IS DEMANDED IN SUMMING UP ARGUMENTS. THROWS ARMS ABOUT FATHER AND CRIES.

A sweet-faced and winsome fourteen year old girl-Consuelo Huppsobbed convulsively in Judge Kennedy's crowded court-room Thursday while attorneys, who are defending her father, made an impassioned plea to twelve men for a verdict that would put "sunshine in the little girl's heart."

Her arms were about the neck of her father, Elmer Hupp, the "onewoman" man-when the lawyers drew the mantle of charity over any relations between Mrs. Hupp and Charles L. Joyce, friend of the Hupp household and victim of Hupp's "red rage."

"We can't have people ask this little girl 'Where is your Daddy?' and have her answer 'He's in the penitentiary," David cried.

The influence exerted by such persistent news campaigns preceding a trial and continuing during its progress is subtle but sure. Every trial lawyer feels it. The evil is not remedied by the judge cautioning the jury against considerations which might prejudice their judgment of the facts brought out in the trial, or even by such drastic measures as locking the jury up during the progress of a trial. The atmosphere in which the case is tried from day to day will still be charged with an emphasis which it is asking too much of human nature to resist.

II. This style of treatment especially characterizes "unwritten law" cases. Exactly similar tendencies appeared in the news reports of the trial of Mrs. Maria Huettel, charged with second degree murder for shooting her husband just after he had obtained a divorce. The main contention of the defense in this case was that Huettel was shot while struggling to prevent Mrs. Huettel's suicide. Constantly during the trial space was given to lengthy reports of the defendant's fainting, weeping, and hysteria, and the sobbing of her relatives. It should be noted that newspaper treatment of the Huettel case differed slightly from that of the Hupp case in that the Press did not use signed articles by special writers (known sometimes in newspaper language as "sob sisters"), and the Plain Dealer was noticeably conservative in its use of headlines and sensational emphasis.

III. More recently, during the trial of Mrs. Eva Kaber, the Plain Dealer printed in one of its issues (July 14, 1921) a particularly striking [ 536 ] 
example of this style ot news reporting, from which we quote the following:

\section{THUMBS DOWN, IDLE WOMEN GLOAT OVER FIRST MORSEL}

They call for a thrill.

They got it.

The court room where Mrs. Eva Catherine Kaber is on trial for her life was filled to overflowing with idle women spectators yesterday.

They crowded the customary court rules requiring judicial conduct, to the very margin.

They brought their lunch. They came early. They stayed late.

Gladly, eagerly they endured the stuffiness of the old court house, the uncomfortable chairs, the sticky heat which meant frequent powdering of perspiring noses, all for the sake of a sensation.

They were not disappointed.

Whether she is guilty or not, insane or as clear minded as the judge himself, Mrs. Kaber's punishment has already begun. With her fate still being weighed by the hand of justice, certainly her soul must be wracked by the drama in which she is the central figure.

Her mental torture reached a climax yesterday afternoon. In the morning she gave way to hysterics. Shrieking and screaming, she was led from the room. In the afternoon, however, her behavior was different.

\section{Then Buzz Breaks Loose}

She quietly crumpled up in her chair and fell in a faint.

For an instant there was a hush. Then, as she was helped to Judge Maurice Bernon's room immediately adjoining, the buzz began. With court thus summarily recessed, the gallery gloated over its morsel.

With the principals out of the room, the place resembled a movie matinee audience during intermission.

The chatter rose above the noise of the traffic on the streets below. Sticks of chewing gum were brought forth from handbags. Complexions were freshened, and fans, real and improvised, began to keep time with the wagging tongues.

IV. In contrast with the foregoing tendencies, some notice should be given to newspaper reports which have the effect of creating prejudices of a different kind. When actual or alleged "confessions" have been made, newspaper reports of the case, before and during trial, frequently refer to the "confession" and thereby create a presumption of guilt. Confessions, it is well known, do not always prove guilt. A variety of motives and influences other than guilt gives rise to them. They are of equivocal legal value, particularly when the circumstances under which they are given are not clearly defined. Hence the insistence by newspapers on the conclusiveness of a "confession" before such a "confession" has withstood the tests that the law imposes for its validity is unwarranted from any aspect of fairness or justice. 
V. To some extent, judging by the current newspaper practice of presenting "human interest" reports of criminal trials, writers seem to be unable to avoid indicating their own impressions as to the guilt or innocence of the defendant. The following may be noted:

1. From the News, December 16, 1919 (editorial):

\section{QUICK JUSTICE BEST}

The restraining and corrective effects of the penalty the law and the courts will inflict upon the murderer [John Platzky] of Robert Shelton, the latest policeman slain in doing his duty and solely because he was doing it, will be much greater if it comes quickly than it can be if it is long delayed. The time to teach the plain lesson of such a crime is when it is fresh in mind and much talked about.

And in this case the way to swift justice lies wide open. The police have the confessed murderer. Even though he now fights to escape the chair, he has admitted that he killed without warning, by stealth, after thinking over his plight. There seems to be no good reason why he might not be brought to trial, found guilty, sentenced and executed within six or eight weeks.

If that should be done the chill struck into the hearts of potential and prospective murderers would be much more dismaying and paralyzing than any possible punishment which might come after a year or so of delays and doubts. The murderers themselves know all about that. When they want to terrify men subject to bandit extortion, or to strike terror into the breasts of possible informers, they kill quickly. They know too much about the psychology of crime, its perpetrators and its victims, to wait a year or two.

\section{From the News, December 21, 1919:}

PLATZKY, SHERMAN TO GET SPEEDY TRIALS. ENTER PLEAS OF "NOT GUILTY" IN POLICE KILLING CHARGE; CASE SET FOR JANUARY 12.

Quick disposal of the cases against John Platzky, self-confessed slayer of Patrolman Shelton, and his pal, George Sherman, jointly indicted for the murder, was indicated yesterday when the two, with two of their girl companions, were arraigned before Criminal Judge Powell.

\section{From the News, January 13, 1920:}

\section{THE PLATZKY CASE}

John Platzky, confessed slayer of Policeman Robert Shelton, is on trial for his life. The public will be vitally interested in knowing whether the law is strong enough to exact adequate punishment for coldblooded killing of the men who are sworn to uphold the law and protect citizens and their property. Platzky confessed, it will be remembered, that he deliberately shot the officer after his arrest as a burglar. He was out on parole from a previous crime and also admitted a long list of burglaries. 
Will quibbles over forms and legal technicalities avail Platzky?

Will he be able to escape with a reformatory or penitentiary sentence?

Or will he pay the supreme penalty in the death chair? ${ }^{1}$

1 The following editorial, taken from the News, seems to express the point of view of newspapers in regard to publicity given to criminal trials:

From the News, January 19, 1920:

\section{TRIAL PUBLICITY}

Many good citizens deplore the publicity lavished on murderers, robbers, and other criminals when arrested or tried. These thoughtful objectors believe the front page prominence of headline and cut is flattering to the felon, convinces him he is a person of consequence, represents him to the undiscriminating as in some sort a hero, tends to encourage other men to seek a similar notoriety by similar criminal acts.

Not infrequently this view is communicated to newspaper editors with remonstrances against criminal court publicity and requests for its diminution. We would not say this opinion is wholly mistaken. We concede that persons of moderate intelligence are sometimes moved by the news from court-room or jail to make a silly fuss over some worthless scoundrel.

Our own view is that notoriety accorded criminals might encourage others to court some of it for themselves by adopting criminal careers, providing it were favorable notoriety, represent the subject as a hero worthy of admiration. But if publicity pictures the prisoner as a low-lived rogue with whom no person of character could possibly sympathize, we cannot see that honest men will thereby be influenced to take to crime, no matter how large the headlines. On the contrary, we believe such advertising of the consequences of lawbreaking would be most helpful in discouraging crime, if only the machinery of law did its part by providing an impressive penalty for the last chapter. 


\title{
CHAPTER III
}

\section{ACTIVE PARTICIPATION BY NEWSPAPERS IN ADMINISTRATION OF JUSTICE}

\begin{abstract}
CTUAL interference with the machinery of criminal administration is shown by an incident which took place in August, 1917. On August 24 or 25, Leonard Lyons, charged with the murder of John Murphy in a gang feud, was arrested by the Cleveland police. On the morning of August 25 the Leader, a morning paper, ${ }^{1}$ in a prominently displayed article on the front page, printed an exclusive account of the arrest. The headline and paragraphs from the article follow:
\end{abstract}

LYONS, SLAYER, SURRENDERS HERE. COMES IN AFTER DEAL MADE WITH BROTHER. ARRIVES IN AUTOMOBILE, GIVES SELF UP TO DETECTIVE RABSHAW FROM RENDEZVOUS. PROBABLY WILL BE RELEASED ON \$10,000 BAIL TODAY. ENDS FOUR DAYS OF FUTILE EFFORT BY OFFICERS. EVEN CHIEF ROWE AND UNIFORMED MEN USED IN VAIN HUNT-HOW IT WAS DONE.

Leonard Lyons, the man who killed John Murphy in the climax to a gang feud covering two years, surrendered to Chief of Detectives Gideon Rabshaw, Assistant Chief of Detectives Thomas F. Mahoney and Detective Harry Brown shortly after midnight.

The surrender came at the end of a fourth day's vain search for Lyons who escaped in an automobile after he shot his victim in the bar of the Oak Cafe at Vincent Avenue and E. 6th st. last Monday night.

\section{Surrender is "Arranged"}

Arrangements for Lyons to give himself up were made through his brother Frank (Kid) Lyons.

Chief Rabshaw and his men accompanied by Frank Lyons drove in automobiles to an agreed point and met another machine containing the fugitive......

No hint of the fugitive's movements had reached police or detectives prior to the time of Frank Lyons coming as an emissary for his brother and offering his surrender. Chief Rabshaw and his men were guided to the meeting place where Lyons appeared, according to his brother's promise, coming in a machine from his hiding place......

1 The daily Leader soon afterward was sold to the Plain Dealer. 
On the following day the Leader printed the following article:

LYONS FREED ON $\$ 10,000$ BOND A FEW HOURS AFTER THE SURRENDER. POLICE CHAGRINED AT SUDDEN SURRENDER, AS ANNOUNCED IN THE LEADER AFTER FOUR DAYS OF VAIN HUNT.

..... The arrest in Painesville at 2:30 o'clock in the morning as published exclusively in The Leader, was the result of arrangements made by Frank Lyons, brother of the fugitive....

In the party that went to Painesville to the spot appointed for the surrender, were Chief of Detectives Gideon Rabshaw, Assistant Chief of Detectives Mahoney, Detective Harry Brown and two representatives of the Leader......

.Lyons smiled a bit over the apparent discomfiture of Police Chief Rowe, who for the first time since Rabshaw was appointed Chief of Detectives issued orders for his uniformed men to venture into the detective field.

One of the representatives of the Leader accompanied Chief of Detectives Rabshaw and his party on the trip to Painesville. Furthermore, arrangements for the surrender of Leonard Lyons were made in the first instance by Frank or "Kid" Lyons through the Leader's representative. The prisoner was held at the home of a representative of the Leader following his arrest in Painesville, in order, apparently, to delay the hour of his appearance at police headquarters, where, through the formal police record, both morning papers would have had news of his arrest at the same time. The arrest was planned with the chief of detectives, not, as is usual, with the chief of police, and subsequent articles in the News use this fact to reflect discredit upon Chief of Police Rowe, while at the same time commending Chief of Detectives Rabshaw. For several days after the arrest there was much newspaper discussion of the case, including talk of a proposed "investigation" of the police. In this discussion the News and the Plain Dealer adopted widely different points of view, the latter criticizing the police sharply while the News, which was owned by the same company that owned the daily Leader, ridiculed the proposed investigation. The difference will be apparent from the following quoted extracts:

1. From the Plain Dealer, August 26, 1917:

\section{COUNCIL WILL PROBE POLICE IN LYONS' CASE}

Councilmanic and probably grand jury investigation into the failure of city police to arrest Leonard Lyons, accused of the murder of "Roughhouse Johnny" Murphy in a down town cafe, until relatives of the fugitive arranged conditions of his surrender, will be started tomorrow. 
2. On August 28 the Leader printed the following:

COUNCIL VOTES NEW POLICE QUIZ. LYONS ARREST USED BY STOLTE AS ARGUMENT FOR FRESH INQUIRY

The city council, urged oratorically by Councilman Stolte, is going to stage another investigation of the Police Department.

Admission will be free.

Undismayed by the big printing bill piled up as the sole accomplishment of last year's probe, Stolte told the council that the police force: "Ain't working as a unit" citing as a specific example the manner in which Leonard Lyons, slayer of John Murphy, was arrested by detectives last Saturday morning.

3. On August 29 the Plain Dealer printed an article containing interviews with various judges on faults in the administration of justice, and this statement regarding the proposed investigation: "The entire decent element of the city is swinging into line to prevent the police investigation developing into a "whitewash." "

4. On August 29 the News carried the following statement: "Not a single police investigation was proposed yesterday. The entire day passed without heavy firing or disorder on the police 'front.' "'

5. The Plain Dealer of August 27, 1917, carried these paragraphs:

POLICE KNEW OF CHANGE IN LYONS' CHARGE. PROSECUTOR

SAYS HE TOLD DETECTIVES BEFORE ARREST, ALLEGA-

TION WOULD BE SOFTENED. REPORT SAYS RABSHAW'S

MEN ASKED FOR SUCH HELP AFTER FAILURE TO FIND FUGITIVE.

Chief of Detectives Rabshaw made the arrangement with Frank "Kid" Lyons for the delivery of his brother after Prosecutor Lind had announced his intention of reducing it. It was also stated last night that Chief Rabshaw sent a detective to Prosecutor Lind and asked him to alter the charge....

And while police defended their policy of dickering with gangsters, Cleveland had its third murder within six weeks to climax a week-end wave of crime which included burglary, vicious assaults on hold-up victims, confidence trickery, automobile thefts, operation of "speakeasies" and bootlegging.

6. On August 27 the Leader printed an article under the headline, “Lyons Makes Exit Until Case is Ready," without mentioning any investigation into the matter of the reduction of the charge against Lyons from first- to second-degree murder. The article contained the following statement: "Chief Assistant County Prosecutor Babka commended Rabshaw in making the deal with Lyons' relatives." No mention was made by the Leader of the fact that the original charge was changed from first- to second-degree murder by agreement between the relatives of Lyons and Rabshaw without the knowledge of the chief of police. The fact may, of course, have been unknown to the Leader, but 
in view of the close association of members of the staff of the Leader with this case, such a supposition seems doubtful.'

Judged casually, this entire story matter might be regarded as of slight moment-little more than a tempest in a tea-pot. The incident is significant, however, because the fact that a newspaper has been able to obtain "exclusive" news in this way is apt to have far-reaching results. It may affect the policy of the criticism from the newspapers not getting the news, as well as determine the subsequent attitude of the favored newspaper toward individuals who have assisted it in making a "scoop." It is not without some significance, for instance, that at various times after the arrest of Lyons and the Leader's exclusive news article, there appeared in the News, of which the Leader's representative in the Lyons case subsequently became city editor, articles about Chief Rabshaw of a very laudatory nature. The effect upon police morale of "boosting" a police official as against his chief need not be labored. The evil becomes still more demoralizing when the "boost" is connected with favors shown to one newspaper in a highly competitive press.

It is well known among newspaper men, members of the police department, and various officials of Cleveland that when Chief of Police Rowe retired in December, 1917, the influence of the News was given to the support of the candidacy of Captain Rowlands, now inspector, to succeed him. Chief Smith was also a candidate to succeed Rowe. Interest taken by the News in the appointment of Rowlands was of such a nature that Rowlands was frequently called "the News' candidate."

Whether the attitude of the News toward Chief Smith is influenced in any way by the fact that the editors of the News preferred a rival candidate or is due to some other cause cannot, of course, be determined here. What does seem clear is that the News has followed a policy of extreme criticism and special hostility toward the chief of police. Yet the report on Police Administration in this survey makes it abundantly clear that the fundamental causes for dissatisfaction with Cleveland's police are attributable to the system.

By calling attention to this situation we do not mean to imply that newspapers should not urge candidates for public office. But we do suggest the need of drawing a line between merely enlightening the public as to the merits or disqualifications of candidates and, on the other hand, actually becoming selectors of candidates. A newspaper should hold itself free to deal with the office and should not compromise itself for this task by selecting the office holder. Particularly is this true of a nonpolitical, technical city service like the police department.

${ }^{1}$ An opportunity was given by the Foundation to a representative of the News to insert in this report a statement of the considerations which in his opinion justified the procedure in the Lyons case. 


\section{NEWSPAPER CAMPAIGNS}

\section{"Crime Waves"}

$\mathbf{I}$

$\mathrm{N}$ RECENT years, since the war, much newspaper publicity has been given to the existence and frequency of periods when crimes of violence of all sorts seem to be on the increase. The phrase "crime wave" was invented, and soon the idea became fixed in popular belief that periodic outbreaks of crime were occurring, more or less referable to the unsettling influences of the war. But the undiscriminating and unchecked use made of the theory of "crime waves" appears from a systematic study of the files of Cleveland papers. And the excitation of the public mind to such an emotional conception of "crime waves" is clearly not an effective way of educating the public to understanding and action.

On the other hand, it must be remembered that recently a succession of dramatic crimes in Cleveland stirred an already effervescent public feeling. The McGannon scandal, the Sly-Fanner murders, the Kaber case, the Parma school teachers' mystery, formed an unusual combination to tempt the newspapers to exert their arts. They were doubtlessly influenced by the conviction that they must resort to the explosives of sensationalism to arouse public opinion and official action.

Let us compare the actual number of felonies for a given period with the newspaper prominence crime news was given in that period. Let us take the month of January, 1919, in which, according to the newspapers, a "crime wave" got under way. Table 1 shows the number of felonies by weeks, exclusive of automobiles driven away, and the number of inches of news space given the administration of justice, including crime news, by the three dailies.

It will be seen that while the amount of space given the accounts of crime and news of the administration of justice responded to an increase in the amount of crime, yet the response was out of all proportion to the actual increase in crime. Whereas 345 felonies were reported the first two weeks and 363 the last two weeks of the month, the amount of space given the administration of justice, including erime news, the first half 
of the month was 925 inches and the second half 6,642 inches. The first half of the month the newspapers were saying nothing about a "crime wave," the second half the readers were vehemently told that a crime wave was sweeping the city.

TABLE 1.-NUMBER OF FELONIES, BY WEEKS, COMPARED TO NEWS SPACE 1

\begin{tabular}{|c|c|c|c|c|}
\hline \multirow{2}{*}{ Week beginning } & \multirow[b]{2}{*}{ Felonies } & \multicolumn{3}{|c|}{ Inches of news space } \\
\hline & & $\begin{array}{c}\text { News and } \\
\text { News-Leader }\end{array}$ & Press & $\begin{array}{c}\text { Plain Dealer, } \\
\text { daily and } \\
\text { Sunday }\end{array}$ \\
\hline $\begin{array}{lr}\text { January } & 1 \\
\text { January } & 8 \\
\text { January } 15 \\
\text { January } 22\end{array}$ & $\begin{array}{l}153 \\
192 \\
203 \\
160\end{array}$ & $\begin{array}{r}59 \\
200 \\
1304 \\
765\end{array}$ & $\begin{array}{r}51 \\
236 \\
1123 \\
813\end{array}$ & $\begin{array}{r}107 \\
272 \\
1451 \\
1098\end{array}$ \\
\hline
\end{tabular}

${ }^{1}$ Space occupied by headlines is not included in the figures.

Space devoted to news of actual crimes did not, of course, increase to so great an extent. A count of the inches devoted to crime news in one of the dailies for January gives the following figures: week of January 1, 49 inches; week of January 8, 144 inches; week of January 15, 246 inches; week of January 22, 196 inches. Incidentally, the paper publishing the most news of the "crime wave" gave, in the week of January 15,28 per cent. of its news space to news of crime and the administration of justice.

"Crime wave" treatment by the newspapers is significant because of the quality of the news matter. The kind of "news" and the way it is treated, it cannot be too often repeated, makes the public mind and, therefore, the public's attitude toward criminal justice. A few of the outstanding tendencies of newspaper treatment of crime and the administration of criminal justice, during a "crime wave," may thus be summarized:

1. An unusual amount of space and special headline emphasis are given to crimes indiscriminately, whether great or small. News treatment of such a period tends to create and sustain interest in the "crime wave" as a daily feature or news "serial." There is little or no attempt to give dependable statistics of the actual increase in crime, and still less to analyze causes and underlying conditions.

2. A tendency to stimulate the belief that all crimes committed at such a time are part of some special phenomenon that constitutes a "crime wave" and can be cured by some quick panaceas. 
3. A tendency to demand summary action and quickly reportable "results" on the part of police, prosecutors, and judges.

This last tendency is, from the point of view of the effective administration of criminal justice, the most serious result of "crime waves" as they are treated by the newspapers. Spurts of activity in any department of the machinery provided for law enforcement are sure to lead to congestion, inefficiency, and ultimate demoralization. Reform does not come that way. Moreover, where the community is whipped up to demand "results" of its system of criminal justice, officials responsive to popular whims, as this survey discloses them to be, will, at least unconsciously, care more to satisfy popular demands than to be observant of the tried processes of law.

One of the ablest judges of the Common Pleas Court has thus indicated some of the effects of newspaper agitation over "crime waves":

"During the January, 1921, term of court out of the first sixteen criminal cases tried before me, there were twelve acquittals. This might be taken to indicate that the jury system is at fault, but other elements must be considered. The fact is that these cases came to court as a result of indictments returned the preceding fall when the newspapers were laying stress upon the amount of crime in Cleveland. In my opinion, there was not sufficient evidence in eleven of these cases to warrant indictment, and I question if they would have been returned but for the agitation at the time. Two factors must therefore be considered-the injustice that may be done to individuals at a time of public excitement during a so-called 'crime wave' and the fact that the time of the court is needlessly consumed by cases that should not come to trial."

A former member of the prosecutor's office, who is now a judge of the Common Pleas Court, brings similar testimony:

"I was in the prosecutor's office and my work was largely in the grand jury room during one of the recent crime waves that received much newspaper prominence. During this particular term of court to which I refer, I believe that we returned more indictments than were ever before returned during one term of court in Cleveland. A grand jury will, in normal times, return some indictments that ought not to be returned, but I was satisfied that of all the indictments returned during this particular session at least one-sixth of them were unwarranted. Half of this one-sixth, I believe, were returned owing to abnormal conditions,-chiefly as a result of the prevailing newspaper agitation of the time."

\section{BaIl Bond Exposure}

During January and February, 1919, there occurred what was known as "the bail bond exposé." The story is told in the reports on Prosecution and Courts in this survey. It became known that a number of per- 
sons suspected or actually arrested and charged with crimes had been previously under arrest and released on bail. Special newspaper attention was given to the fact that bail was fixed by judges on the recommendation of the prosecutor, and in view of this power of fixing bail by recommendation the prosecutor was urged to demand higher bail. It was also said that conditions affecting bail bonds were so lax that many persons on bail were eluding justice, while their bondsmen were not suffering any financial loss as a result of the default.

Agitation following on these disclosures had two results almost immediately: first, the prosecutor was led to declare that he would recommend higher bail, which he did, and to ask writs of capias and forfeiture of bonds in numerous cases. Then it was discovered that many of the defendants whose bonds had been forfeited were only waiting to be notified of the date of their trials, and in many cases the courts were obliged to set aside the forfeiture. Undoubtedly abuses and laxity as to bail bonds had grown up, and the newspapers' campaign directed attention to dangerous tendencies. But these "campaigns" become indiscriminate in their attack. Too often the baby is thrown out with the bath water.

Let the newspapers themselves indicate some of the results.

1. From the News, January 20, 1919:

With the several investigations under way, and with bonds being forfeited by Prosecutor Doerfler at a rate unprecedented in Cuyahoga County history, County Jail Monday was filled to overflowing with criminals of every degree.

Sheriff Hanratty said that 350 men and women were already in the jail and that more were expected during the day as those sought on capiases were rounded up.

2. From the News, January 23, 1919:

NO EMPTY CELLS IN JAIL AS ROBBERY CASES CLOG COURTS

The civil branch of the Common Pleas court was called on Thursday to assist in hearing criminal trials as the result of the sudden increase in the activity of prosecuting officials and the rush of "cases," owing to forfeiture of bonds, surrender of hunted offenders and unprecedented number of arrests.

The effect of these newspaper "drives" and the tendency to regard mere numbers of indictments as evidence of efficient administration in fact result, as this survey amply discloses, in great inefficiency and may well involve grave injustice. A judge of the Common Pleas Court has declared that the effect on grand juries of "publicity" of this kind is to 
cause many indictments to be returned in which judges have to direct acquittal because of insufficient or ill-considered evidence.

\section{Parole Abuse}

Much criticism of the administration of the parole law has appeared recently in Cleveland newspapers. Undoubtedly there have been abuses due to various causes as set forth in the report on Correctional and Penal Treatment. But many erroneous conceptions have been lodged in the public mind by unwarranted statements. Thus, sweeping assertions have been made as to the number of paroled men who have committed crime while on parole, supported by the most meager statistics. The whole parole system has consequently been jeopardized through the reckless or careless instillation of erroneous ideas or "facts" into the reading public's mind.

1. From the Plain Dealer, April 24, 1921 (editorial):

\section{"PAROLED"}

Throughout the record of the men implicated or suspected of implication in the Sprosty murder appears time after time one all-significant word.

"Paroled."

"Bobbie" Hunt, who is charged by his "pals" with having fired the shot that killed the patrolman, was sent to the reformatory in 1918 and paroled.

William Murphy, alias Conton, member of the gang that shot Sprosty, was paroled from the reformatory in 1918 and again in 1920.

Martin Dwyer, companion of Murphy and other criminal escapades, was paroled from the reformatory and is now there serving a sentence as a parole violator.

So runs the story of criminal activities. Most bandit gangs are made up in large part of paroled men-men who have been turned loose on the public by some board given more to sentimentalism and leniency than to justice.

If the parole abuse were curbed the keystone of the arch of banditry would fall.

2. From the Press, April 26, 1921:

\section{CRIMES ARE PLANNED AT WORKHOUSE}

Cleveland's crime wave continues to rise.

The toll of pillage and murder increases. Gangsters scoff at law and courts. And peaceful citizens shudder.

Since the first of the year, in the months of January, February, March and 25 days of April, 317 robberies have been listed and 13 murders......

Nearly every crime horror has its parole angle. It has become second nature for detectives, city editors, police reporters and others who are thrown in pursuit of criminals to look for the "past." The criminal is not cured. Free on parole, from Warrensville, or Mansfield, or Columbus 
Penitentiary, or having served his sentence, he gets back again on the job of loot and death.

3. From the Press, January 4, 1921:

PETTY CRIMINALS BECOME MURDERERS WHEN PAROLES AND EASY BAIL FREE THEM AND RESULT IN CONTEMPT FOR LAW. INSTANCES SHOW HOW MEN STARTED IN CRIME BY PETTY THEFTS AND NOW ARE BEHIND BARS FOR LIFE.

This article contained summaries of eight cases of individuals who had committed serious crimes while out on bail or on parole.

It is the practice of Cleveland newspapers to give prominence to the circumstances of a crime committed by a prisoner on parole. We quote an example from the News, April 6, 1921:

\section{HOW ALLEGED SLAYER CONVICTED AS ROBBER WAS LEFT FREE TO KILL}

Here is an example of the way young criminals are allowed their freedom, under the present bond system, to continue their crimes providing the youth identified as the slayer of Robert L. Fischer is proven guilty.

This youth, twenty years old, was arrested July 27,1920 , for complicity in the robbery of a jewelry store the afternoon of July 26 .

He was bound over to the grand jury the following day in $\$ 10,000$ bail. Bond was furnished immediately and he was free until February 26, when a jury found him guilty of robbery.

Motion for a new trial was overruled by Judge Powell on February 28 and he was sentenced to the penitentiary. Execution of the sentence was suspended to March 15, pending the filing of a petition in error.

A petition was filed in appellate court March 15 and a new bond of $\$ 15,000$ was fixed. This, too, was furnished at once and the youth, still at large, is not now being sought for murder.

The case of this youthful murder suspect parallels that of Frank Motto, now awaiting trial for first degree murder in connection with the double killing of Wilfred C. Sly and George K. Fanner, during a payroll holdup on New Year's eve. Motto is said to have played a part in the tragedy while free in $\$ 10,000$ bail pending a decision of the appellate court on an auto theft case of which Motto was convicted.

What notice or comment has appeared in the newspapers at the time action was taken by prosecutors, judges, or parole board members? Has the publicity attending the course of action of these officials been such as to check abuses of parole, suspended sentence, and bail bond system?

An examination of the columns of Cleveland newspapers indicates that from 1917 until late in 1920 careful observation of the action taken by officials and intelligent appraisal of parole cases has not been a matter 
of common practice. By way of caution it should be remembered that these were partly war years, with their war preoccupations. As indications of the extent of the neglect or indifference during this period of time, the following important cases are cited, together with a report of the newspaper treatment the matter received on the day or on the day after the action was taken.

Charles Calabreese convicted of burglary and larceny January 25, 1917. Sentenced to reformatory and paroled.

Andrew Kebort indicted for robbery February 8, 1918. Pleaded guilty March 11,1918 . Nothing further done until June 9, 1919, when he was sentenced to the Ohio State Reformatory and sentence suspended, the sentence being a mere formality to clean up the record.

Adam Diefenbach, convicted November 5,1920 , on charge of rape and sentenced to Ohio State Penitentiary. On November 12, motion for new trial granted. On this date Diefenbach pleaded guilty to assault and battery and was sentenced to thirty days.

Warren Smith, arrested July 22, 1920, charge manslaughter. Discharged, September 30, 1920.

Julius Pettianto, convicted of auto stealing, March 22, 1920. Writ of error, dismissed by court of appeals for want of prosecution, November 22, 1920. Pettianto meanwhile disappeared and is still at large.

Ethel Martine, indicted December 19, 1919, charge of larceny. - On May 11, 1920 , bond was forfeited and capias was issued. Defendant disappeared and is still at large.

Louis Ettkin, grocer, found guilty of violating liquor law by Judge Silbert, November 23,1920 . Fined $\$ 200$ and costs. Fine changed same day to $\$ 100$ and costs. Motion in mitigation. Bond forfeiture. Again set aside. On February 21, 1921, motion in mitigation allowed and $\$ 75$ of fine suspended. Fine of $\$ 25$ paid on February 21. At least seven continuances.
No mention of Calabreese in newspapers of this or the following date.

No Cleveland newspaper contains mention of sentence and suspension in issues of June 9 or June 10, 1919. When Kebort was arrested for murder some time in July or August of the same year, all newspapers noted the fact that his previous sentence had been suspended.

No Cleveland newspaper mentioned the case on November 12 or 19.

No mention in any newspaper of September 30 or October 1.

No mention in any newspaper of the discharge for want of prosecution, in issues of November 22 or 23, 1920. The aspects of the case are alluded to in the Plain Dealer in January, 1921.

No mention in any newspaper of May 11 or 12 of this forfeiture.

Of this extraordinary procedure, no mention occurred in the Plain Dealer of February 22, nor in the Press and News of February 21 and 22 . 
Frank Lyons, Sr., indicted on charge of receiving stolen property, November 14, 1916. Nolle prosequi April 10, 1919.

Frank Lyons, Sr., Frank Lyons, Jr., and Leonard Lyons indicted on charge of manslaughter December 22, 1911. First defendant pleaded guilty to assault and battery May 4, 1912, was fined $\$ 50$ and was sentenced to 90 days; 90 days suspended. Second nol. pros. same date. Third pleaded guilty and was sentenced to one year.
No mention in Plain Dealer, April 11 nor Press and News of A pril 10 and 11.

The case was mentioned in two-inch article in the Press on May 4. It was covered in Plain Dealer by a four-inch article on the sixth page of the issue of May 5. No mention in the News of May 4 nor Leader of May 5.

\section{Campaigns to Reform the Courts}

All the Cleveland newspapers devote considerable space to the disposition of cases made by the various judges, chiefly those of the Municipal Court, though frequently members of the Common Pleas Bench receive attention. Most of this news deals with the routine work of the courts, such as reports of the amount of bail fixed, sentences and decisions rendered, but not infrequently the action of a judge may be featured daily for a considerable period of time. At such times interviews with photographs and sketches are included.

The news treatment of the traffic situation in July, 1916, may serve as an example of the manner in which the work of individual judges receives special but wholly erroneous emphasis. The effects of this practice, and the susceptibility of judges to evoke it, have been set forth in the report on courts in this survey. Frequent accounts of court proceedings in traffic cases appeared in all Cleveland newspapers of this period, though the Plain Dealer appears to have given much less attention to it than the Press and News.

1. The News of July 12,1916 , contained a three-column cut of Judge Frank C. Phillips. The headline of the article read: "ABandon Hope, All Ye Who Enter Here. Hits Nemesis of Speed Ban." The opening paragraphs of the article read as follows:

When an autoist, who unfortunately has been caught speeding or violating any one of the many auto laws, steps to the bench of the Police Court and finds himself looking into these eyes he instinctively reaches for his pocket-book.

This picture is that of Judge F. C. Phillips and he has the names of the auto law violators. Many face him but few escape his judicial wrath.....

Since Phillips' ascent to the police court bench, July 3rd, the city has grown $\$ 1,700$ richer by reason of fines imposed on motorists. 
2. The News, September 21, 1916:

\begin{abstract}
DYER GETS 45 DAYS. MUST SERVE 20 OF THEM. BARRED FROM DRIVING FOR 3 MONTHS. IS SENTENCED TO JAIL.

Police Judge Phillips sentenced J. Milton Dyer, architect who drew the plans for the City Hall and Warrensville Farm Buildings, to 45 days in the County Jail and ordered him to pay a fine of $\$ 50$ and costs on a charge of driving an auto, September 15th, while he was intoxicated.
\end{abstract}

With this article there appeared a three-column picture of DyerJudge Phillips, and a jail door. The article contained a list of men sen, tenced to jail by Judge Phillips for traffic violations.

3. From the Plain Dealer, July 9, 1916:

\title{
SPEEDERS, LISTEN, TROUBLE BREWS. CARELESS AUTOMO- BILE DRIVERS FACE REAL PUNISHMENT HEREAFTER. THIRD OFFENSE AUTOISTS ARE GOING TO JAIL, WARNS CITY JUDGE.
}

Speeders, listen!

Municipal Judge Frank A. Phillips warns that all third-offenders speeders arraigned before him will be sent to jail. Common Pleas Judge P. L. A. Leighley contends the statute providing jail sentences for speeders is valid.

During January, 1921, the heavy penalties meted out to liquor violators became the subject of special news treatment. Reports of these fines and sentences were important news because of the unusual penalties fixed by the courts.

4. From the Press, January 3, 1921:

WHAT CITIZENS SAY. FOLLOWING ARE SOME INTERVIEWS WITH CLEVELANDERS ON THE SUBJECT "WHAT CAN BE DONE TO MAKE CLEVELAND SAFE."

Judge F. L. Stevens, on his first day in Criminal Court: "I am going to strike at the root of the evil, that is, the liquor traffic. I am going to hit that hard, and keep hitting it as long as it exists. These bandits are filled with liquor which makes them want to shoot and kill."

\section{From the Press, January 4, 1921:}

\section{FINES GOING UP. POLICE JUDGE AIDING IN CRIME CRUSADE.}

Nine hundred cases continued from preceding term of court are now before City Judge Howells and Stevens. The 900 cases include 94 liquor cases and these will be heard by Judge Stevens.

"I will say that it is a good thing for the city that they have been placed 
on my docket," Stevens said Tuesday. "I am informed that some attorneys for defendants are very sorry that the cases are to come before me."

Stevens Tuesday imposed the third fine in two days of $\$ 1,000$ and costs in liquor cases. .....

Stevens said that in all cases where proprietors of stores were caught selling liquor continually he would give a $\$ 1,000$ fine.

6. From the Press, January 7, 1921:

NO COURT DELAY. THAT IS THE AIM OF JUDGE IN REFUSING CONTINUANCE. HOWELLS SPEEDS JUSTICE. STEVENS GETS LETTER THREATENING HIS LIFE.

Judge George A. Howells refused requests for continuances by lawyers in City Court Friday. This was a method to speed justice......

Judge F. L. Stevens read in court a letter threatening his life because of his severe fines against traffic violators and against liquor law violators who had been fined from $\$ 1,000$ to $\$ 3,000$.

"Threats to kill me if such sentences are imposed in future will have no effect on the administration of justice," Judge Stevens said.

7. In the Press of January 10, 1921, appeared a first-page editorial with a page-wide headline reading as follows:

"WHAT SHALL I DO?" ASKS POLICE JUDGE STEVENS-IF YOU KNOW PLEASE TELL HIM.

Judge F. L. Stevens of Municipal Court wants advice. He has been imposing fines of from $\$ 1,000$ to $\$ 3,000$ on liquor law violators. If they are unable to pay, they are sent to Warrensville Workhouse where they earn $\$ .42$ a day to apply on their fines.

"At this rate of pay they would have to serve anywhere from 7 to 21 years," said Stevens. "That would be obviously unjust but I shall continue to impose a heavy fine."

What Stevens wants is a system which would enable liquor law violators to pay their fines without spending a large part of their lives in the Workhouse. He called on fifteen members of Cleveland organizations to evolve such a system and also invited suggestions from citizens generally. If you have any, Stevens wants them.

8. From the Press, January 24, 1921:

DEEP MYSTERY, IT'S JUDGE STEVENS RELIEF FOR DRY VIOLATORS. HOW TO GET 'EM OUT OF JAIL? "WE DON'T KNOW" REPLY MOST OF COMMITTEE MEMBERS.

The solution to Judge Stevens' dilemma is yet to be found. Stevens asked citizens to tell him what to do with liquor law violators who can't pay their fines. Serving out a $\$ 3,000$ fine in the Workhouse at the rate of 43 cents a day would take 21 years. "What's to be done?" Stevens asks.

(The article continued with quotations from citizens who had been asked by Judge Stevens to serve "on a committee to aid him.") 


\title{
9. On January 19, the News printed the following:
}

\begin{abstract}
STEVENS TAKES STING OUT OF \$1,000 FINES. WON'T KEEP DELINQUENTS IN WORKHOUSE TOO LONG.

The sting was missing in Judge Stevens' daily $\$ 1,000$ fine for liquor violation in Police Court Wednesday, following an address by the judge Tuesday night before the Dry Maintenance League.

Stevens told dry advocates he would assess heavy fines and send culprits to the workhouse when they could not pay up and there would remain until the judge thought "they had had enough" and then he would suspend the rest of the sentence.
\end{abstract}

Both the Press and News gave much less attention to the final outcome of Judge Stevens' procedure than to the court's dramatic pronouncements. Yet effective results as contrasted with paper results, or dramatic gestures, are the only results that matter. The futility of Judge Stevens' "played-up" activity is conclusively dealt with in the reports on Courts and Prosecution. The record shows that 60 persons given extreme penalties in January were unable to pay their fines on April 20. Of these, 24 returned to court and had their fines suspended. Twenty-four were paroled by the parole board. Seven paid their fines, one died, and four were still serving time in the Workhouse. On the first Sunday in April the Leader-News did carry a prominently displayed article indicating the futility of the Court's procedure. The headline of the article was: "Records Show Few Serve Rum Sentences. Many Fined $\$ 1,000$ Escape Lightly in End." The opening paragraphs read as follows:

Fines of $\$ 3,000, \$ 2,000$, and $\$ 1,000$ for liquor violations mean little, court records show. Eighty-two persons have been sentenced for these amounts by one judge in police court since January 1. Only five persons have paid the full penalty.

The total of fines imposed in these amounts upon the eighty-two persons has been $\$ 88,000$. Including the five who paid the full amount, the total collected was $\$ 12,500 \ldots \ldots$.

The quotations illustrate a tendency of newspapers in general to distribute emphasis irresponsibly, having regard neither for the proportions of the event discussed nor for the building up of an effective public opinion, formed, as opinion is, upon the intake of the news column. It is this trait which causes lawyers and judges of Cleveland to say that the newspapers are always emphasizing non-essentials in regards to judges. Subservience to the popular response to sensation and excitement is the only constant element. The effect is sometimes mere sensationalism, but it may be much more serious. Such irresponsibility leaves the news- 
papers free to exploit the individual judge for political ends, in fact, to make or unmake judges; and this opportunity, as the report on the Courts indicates, they have not left unexercised.

Judges themselves are not unconscious of the political importance of frequent newspaper mention, however factitious, though there is great difference among them in seeking publicity or trying to avoid it. The following statement made by a judge of the municipal bench is illuminating:

"I have told newspaper men that, if something is going on in the city, and if somebody says something for which he doesn't want to be quoted, they can quote me as saying it. I have given them this permission, but I don't know that they have ever used it."

When the judge was asked on what grounds he had seen fit to issue such an unusual sanction, he said: "It doesn't matter what they say. It's all constructive."

A judge of the Court of Common Pleas, who is regarded as one of the able men of that court, thus summed up the situation: "You can't get on the bench without advertising; you can't stay on without furnishing copy." 


$$
\text { - }
$$$$
5
$$ 


\section{PART VIII}

\section{CRIMINAL JUSTICE IN THE AMERICAN CITY-A SUMMARY}

BY

ROSCOE POUND 


$$
\text { - }
$$

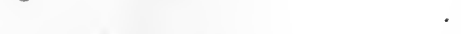




\section{CRIMINAL JUSTICE IN THE AMERICAN CITY-A SUMMARY}

\section{CHAPTER I \\ THE NATURE OF THE PROBLEM \\ Men, Machinery, and Environment}

$\mathrm{P}$ RIMITIVE man interprets all things in terms of benevolent or malevolent powers whom he must placate and to whose caprices he is subjected. His laws are gifts or revelations of the gods. The need for obeying them is to avoid the wrath of the gods, which will fall indiscriminately upon the community which harbors those who do not walk in the divinely dictated path. He seeks to understand things in terms of personalities, with wants and desires and wills like his own. This interpretation of the occurrences of nature in terms of personality is closely connected with a primitive instinct to hurt somebody or be avenged on something when things go wrong or one is crossed in his purposes or meets with some injury. The fundamental instinct of pugnacity reacts at once to such situations. In the Mosaic Law, if an ox gored a man, the ox must be surrendered for vengeance. In Athens, when a man was killed by the falling of a branch from a tree, the kinsmen of the dead man solemnly chopped down the tree. At Rome, if a domestic animal did any injury, the owner must surrender the animal to the vengeance of the injured person or pay a penalty for standing between the latter and his vengeance. When Huckleberry Finn's father stumbled over the barrel, he promptly kicked it in response to the same instinct. So when things go wrong in the conduct of government or in the administration of justice, the instinct of pugnacity is aroused and the public cries out for some one to be hurt. The general assumption is that legal and political miscarriages resolve themselves into a matter of good men and bad men, and that the task is a simple one of discovery and elimination of the bad.

In truth, the matter is much more complicated than the bad-man interpretation of social and political difficulties assumes. Formerly men sought to understand history by means of a great-man interpretation. History was the record of the actions of great men and of the effects of 
those actions upon social life. Just now there is a certain tendency to revive this interpretation, and we need not ignore the rôle of great men while insisting that much else needs to be taken into account in order to understand history. In the same way we need not ignore the importance of good men in public life in insisting that much beside individual character needs to be considered in order to understand the shortcomings of legal administration. For good men, if we get them, must work in the social and political and legal environment, and with the legal and administrative tools of the time and place. Often the best of men are the victims of bad or inadequate machinery which impedes their earnest efforts to do right, and may even constrain them to do what they would not do freely. Easy-going men of the best intentions become caught in the machinery and unconsciously become part of it. Moreover, bad men, who commonly make their livelihood by their wits, are unceasingly vigilant to take advantage of the opportunities which outworn or inadequate machinery affords. Where the good are impeded by the instruments with which they must work, the easy-going give up the effort to do things in the face of the impediments and let the machinery take its own course. Thus the well-intentioned drift. It may be that the illintentioned secretly give direction to the drift; but quite as likely the drift is to their profit because they are watchful to make it so. We may not expect that any political or legal machinery may be conceived which will eliminate wholly these opportunities for the ill-intentioned to warp the administration of justice to their desires. Yet some machinery increases them both in number and in possibilities, and it must be our study to devise political and legal apparatus which will reduce them to a minimum in both respects.

Along with the bad-man interpretation there commonly goes a faith in legal and political machinery in and of itself : a belief that when anything goes wrong we should appeal at once to the legislature to put a law upon the statute book in order to meet the special case, and that if this law is but abstractly just and reasonable, it will in some way enforce itself and set things to rights. We must enact the one perfect law for each special situation and put out of office the one bad man who perverts its operation. Then all will go well of itself. This faith in legal and political machinery is inherited and deep rooted. Our Puritan forbears abhorred subordination of one man's will to another's, and sought rather a "consociation" in which men should be "with one another, not over one another." They conceived of laws as guides to the conscience of the upright man, and believed that if laws were inherently just and reasonable, they would appeal to his conscience as such, and secure obedience 
by their own moral weight. This mode of political thought, well suited to the needs of a small group of God-fearing men founding a commonwealth in a new world, is ill suited to the needs of the enormous groups of men of all sorts and conditions who jostle each other in the city of today. There, law must be more than a guide to conscience. There, men will not take time to consider how the intrinsic right and justice of the law appeal to their consciences, but in the rush and turmoil of a busy, crowded life, will consider offhand how far the law may be made an instrument of achieving their desires. There, good laws will not enforce themselves, and the problem of enforcement becomes no less urgent than the problem of providing just laws. The administrative element in justice, the work of adjusting the application of law to individual cases with an eye to their unique features, becomes increasingly important as we become more crowded and division of labor becomes more minute, and individual wants and desires and claims come in contact or conflict at more points. In this administrative element of justice men count for more than machinery. And yet even here men must work with machinery. The output is a joint product of man and of machine, and it often happens that what the man does is dictated by the capacity or the exigencies of the machine quite as much as that what the machine does is dictated by the will of the man.

Not the least significant discoveries of modern psychology are the extent to which what we have called free will is a product, not a cause, and the extent to which what we take to be reasons for actions are but rationalizings of what we desire to do and do on different grounds. In the administration of justice there are many subtle forces at work of which we are but partially conscious. Tradition, education, physical surroundings, race, class and professional solidarity, and economic, political, and social influence of all sorts and degrees make up a complex environment in which men endeavor to reach certain results by means of legal machinery. No discussion simply in terms of men or of legal and political machinery, or of both, ignoring this complex environment, will serve. At whatever cost in loss of dramatic interest or satisfying simplicity of plan, we must insist on plurality of causes and plurality and relativity of remedies.

Both the bad-man interpretation and the faith in legislation and new laws as remedies illustrate a common mode of thinking which seeks to explain everything by some one cause and to cure every ill by some one sovereign remedy. It is not hard for an ordinary person to toss up one ball so as to keep it in motion continually. With practice one may learn to keep two going at once. But only a skilful juggler can so handle three 
or more at once. In the same way the ordinary man may think of one cause or one remedy at a time, but finds difficulty in bearing two in mind at once and leaves consideration of larger numbers to the expert. All branches of knowledge, theoretical and practical, have had to contend with this difficulty of holding all the factors of problems in mind at once. In all ages men have sought to avoid this difficulty by searching for some solving word or phrase or some ultimate idea or some universal cure-all, whereby to escape the hard task of thinking of many things in one connection. The several sciences have struggled with the desire for a simplification that covers up difficulties instead of overcoming them and the assumption of one cause for each phenomenon and one remedy for each ill. Neither the science of law nor the science of politics has escaped this struggle to master complex facts by giving them a fictitious appearance of simplicity. Nor has the quest for the simple and easy been more successful in these sciences than elsewhere. There was no easy royal road to learning, and there is no simple and easy popular road to an understanding of law and government and mastery of the difficult problems which each presents. The citizen who seeks such understanding must expect to study hard and think critically and to keep many things in mind at once while framing his judgments. He must expect those judgments to be largely tentative and relative to time, place, and circumstances. Much as he might like to rest in some formula and to believe in the efficacy of some one specific applied once for all, he will find such hope as futile as the quest for the philosopher's stone or the fountain of youth or the one cure for all bodily ills in which men formerly engaged in a like hope of achieving an easy simplicity. At the very outset we must give up the search for a single explanation of the inadequacy to its purposes of punitive justice in action, and hence must give up the search for any single simple remedy.

We may say that the three chief factors in the administration of justice are-(1) the men by whom it is administered; (2) the machinery of legal and political institutions by means of which they administer justice; and (3) the environment in which they do so. One who surveys the workings of a legal system with these three things in mind will not go far wrong. Yet his picture will not be complete nor wholly accurate. He must take account also of certain practical limitations and practical difficulties inherent in the legal ordering of human relations, at least by any legal institutions thus far devised. The purposes of law, as we know them, and the very nature of legal institutions as we have received and fashioned them, involve certain obstacles to our doing everything which we should like to do by means thereof, and even to our doing well many 
things which we have been trying to do thereby for generations. These practical limitations on effective legal action explain much that, on a superficial view, is ascribed to bad men or bad legal machinery. Hence a fourth factor must be added, namely, (4) the bounds within which the law may function effectively as a practical system.

\section{The Function of Law}

We look to the physical and biological sciences to augment the means of satisfying human wants and to teach us to conserve those means. We look to the social sciences to teach us how we may apply those means to the purpose of satisfying human wants with a minimum of friction and waste. Thus we may think of the legal order as a piece of social engineering; as a human attempt to conserve values and eliminate friction and preclude waste in the process of satisfying human wants. That part of the whole process of social engineering which has to do with the ordering of human relations and of human conduct through applying to men the force of politically organized society is the domain of law.

To illustrate the function of law we may consider the common case where large numbers of persons seek admission to a baseball game or seek to buy tickets at a theater. If each individual is left to himself, and in his desire to get to the ticket window first and procure the best seat pushes and shoves his individual way thereto as his strength and disposition dictate, it is not unlikely that few will be served in any reasonable time. When all seek to be served at once, no one may be served. In the endeavor of each to secure his individual desire in a crowd of fellow-men seeking likewise to secure their individual desires, he and they are sure to lose much of what they seek through the friction of a disorderly scramble, the waste of time and temper in trials of individual strength and persistence, and the inability to do business at the window in the push and shove of an unregulated crowd after they get there. On the other hand, if the crowd is "lined up," is ordered, and is required or persuaded to pursue an orderly course to the window and await each his turn, friction is done away with, time is conserved, waste of effort is eliminated, and each may secure freely and with comparative speed what he seeks to the extent that there are accommodations available. If there are not enough for all, yet all are satisfied so far as may be with a minimum of waste. The task of the law is similar. It is one of making the goods of existence go as far as possible in the satisfaction of human wants by preventing friction in the use of them and waste in the enjoyment of them, so that where each may not have everything that he wants or all that he claims, he may at least have all that is reasonably possible. 
In this process of adjusting and ordering human relations and ordering human conduct in order to eliminate friction and waste, the legal order deals, on the one hand, with controversies between individuals. Where their claims or wants or desires overlap, it seeks to harmonize and reconcile those claims or wants or desires by a system of rules and principles administered in tribunals. On the other hand, it has to deal with certain acts or courses of conduct which run counter to the interests involved in the existence and functioning of civilized society. Civilized society rests upon the general security, including the general safety, the general health, peace, and good order, and the security of the economic order. It is maintained through social institutions, domestic, religious and political. It involves a moral life and hence calls for protection of the general morals. In a crowded world it presupposes conservation of social resources. It is a society of individual human beings, and hence its proper functioning presupposes the moral and social life of each individual therein according to its standards. These social interests, as they may be called, namely, the general security, the security of social institutions, the general morals, the conservation of social resources, and the individual moral or social life, are threatened by the anti-social acts or anti-social conduct or even anti-social mode of life of particular individuals. To restrain these persons, to deter others who might follow their example, to correct such anti-social mode of life as far as possible, and to give effect to these social interests, the law imposes a system of duties upon all persons in society, enforced through administrative and police supervision, through prosecution and through penal treatment. The part of the legal system that defines these duties and prescribes how they shall be enforced by means of prosecutions and penal treatment is the criminal law.

It is important to bear in mind that the law is only one of many regulative agencies whereby human conduct is ordered for the securing of social interests. The household, religious organizations, fraternal organizations, social, professional, and trade organizations may operate also, through their internal discipline, to order the conduct of their members and to restrain them from anti-social conduct. In the past these organizations, whereby the force of the opinions of one's fellow-members may be brought to bear upon him, have played a large part in maintaining civilized society. When the law seems to break down in whole or in part we may well inquire, among other things, how far it is supported or is interfered with by some or all of these organizations, and how far they also or some of them must bear the blame. Obviously the number and vitality of these organizations in any society and the manner in which 
and ends for which they are conducted are important items in the environment of the administration of justice.

To think of the legal order functionally, in terms of engineering, is especially important in such a survey as the present. Here we are not concerned with legal rules in their abstract nature, but in their concrete workings. We are not seeking to know what the law is. We seek to know what the legal system does and how what it does measures up to the requirements of the ends for which it is done. Hence the purpose of the law must be before us as a critique of its achievements in action, not some criterion drawn from the law itself. When the growth of a city makes the old mechanical structures, set up by the engineers of the past, inadequate to the wants or needs of the present, and calls for newer and larger and better structures of mechanical engineering, we do not judge the old structures by their conformity to some ideal plan, conceived before they were built, but by their results in action. We do not abuse the men who devised nor those who, for the time being, are operating the old structures. We set out to plan and build new and better structures. No less science, no less preliminary study, no less thorough preparation, no less intelligently directed effort, is required when the growth of a city calls for new structures in the way of social engineering. In each case the question is one of achieving certain practical ends in view of the means at hand, the structures of the past, the ingenuity of the engineers, the limitations of science, and the strength or feebleness of the public desire that those ends be met. In each case, also, the preliminary survey must take account, in the first instance, of the difficulties to be overcome.

\section{Difficulties Involved in the Administration of Justice}

Difficulties in the administration of justice, with which we must reckon in order to appraise intelligently the workings of any particular legal or judicial organization, are partly in the very subject matter. That is, they are wider than time and place and inhere in all attempts to order human conduct and human relations by the force of politically organized society-at least through any legal or administrative machinery which thus far the wit of man has been able to devise. Also they are partly in the times in which justice is administering. That is, they are wider than the place which we may be investigating and are involved in the general condition of legal science in the civilized world, in a particular time, the ideas as to the purpose of law entertained'generally in that time, and the general attitude of the time toward law and government. Again, they are partly in the system that has come down to us from a past in which it was constructed under and to cope with different conditions 
and hence is ill-adapted to the social, economic, and political environment in which it must operate. Finally they may be partly in purely local conditions. Accordingly, I shall consider these difficulties under four heads: (1) Inherent difficulties; (2) general difficulties; (3) American difficulties; (4) local difficulties. 


\section{CHAPTER II}

\section{INHERENT DIFFICULTIES}

\section{Dissatisfaction with the Administration of Justice}

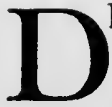

ISSATISFACTION with the administration of justice is as old as law. As long as there have been laws and lawyers conscientious men have believed that laws were but arbitrary technicalities, and that the attempt to govern the relations of men in accordance with them resulted largely in injustice. From the beginning others have asserted that, so far as laws were good, they were perverted in their application, and that the actual administration of justice was unequal or inefficient or corrupt. In the first stage of legal development one of the Greek Seven Sages said that "laws are like spiders' webs, wherein small flies are caught, while the great break through." In the history of Anglo-American law discontent has an ancient and unbroken pedigree from Anglo-Saxon times to the present. The Anglo-Saxon law books are full of complaint that the king's peace is not well kept, that justice is not done equally, and that great men do not readily submit to the law which is appropriate to them. Later the Mirror of Justices contains a list of 155 abuses in legal administration. Still later Wyclif complains that lawyers try causes "by subtlety and cavilations of law," and not by the gospel, "as if the gospel were not so good as pagan's law." In the reign of Henry VIII it was complained that good laws were obstructed in their operation by interpretations in the courts in which "everyone that can color reason maketh a stop to the best law that is beforetime devised." James I sent for the judges on complaint of the Archbishop of Canterbury, and argued to them that "the law was founded upon reason and that he and others had reason as well as the judges." In the eighteenth century there was complaint that the bench was occupied by "legal monks," utterly ignorant of human nature and of the affairs of men. After the Revolution the administration of justice in America was the subject of bitter attacks. Many judges were impeached, not for any crimes or misdemeanors, but because the whole administration of justice was suspected or objected to. The movement for an elective bench which swept over the United States about the middle of the last century 
grew out of these attacks. In England in the first half of the nineteenth century attacks on the courts were hardly less bitter, as the reader of Dickens may readily verify. In our own time the agitation for recall of judges and recall of judicial decisions was strong less than a decade ago. We must not allow this perennial and perhaps inevitable discontent with all law to blind us to serious and well-founded complaints as to the actual operation of the legal system today. But it may give us a needed warning that some discontent is unavoidable, that we may not hope to obviate all grounds of complaint, and that we must begin by taking account of the inherent difficulties, because of which a certain amount of dissatisfaction must always be discounted.

\section{Inherent Difficulties in All Justice According to Law}

\section{The Mechanical Operation of Legal Rules}

To a certain extent legal rules must operate mechanically and the most important and most constant cause of dissatisfaction with all law in all times grows out of this circumstance. A proper balance between strict rule and magisterial discretion is one of the most difficult problems of the science of law. Throughout the history of law men have turned from an extreme of the one to an extreme of the other and then back again, without being able to attain a satisfactory administration of justice through either. Sometimes, as in the strict law of the late medieval courts in England, or as in the maturity of American law in the last half of the nineteenth century, men put their faith in strict confinement of the magistrate by minute and detailed rules or by a mechanical process of application of law through logical deduction from fixed principles. By way of reaction at other times men pin their faith in a wide magisterial power to fit justice to the facts of the particular case through judicial discretion, as in the administrative tribunals of sixteenth- and seventeenth-century England, the executive and legislative justice of the American colonies, and the executive boards and commissions which are setting up in this country today on every hand. But these reactions are followed by new periods of fixed rules. Thus experience seems to show that the mechanical action of law may be tempered but may not be obviated.

We seek to administer justice according to law. That is, we seek just results by means of a machinery of legal rules. But a certain sacrifice of justice is involved in the very attainment of it through rules, which yet are, on the whole, the best and most certain method of attaining it which we have discovered. Legal rules are general rules. In order to 
make them general we must eliminate what by and large are the immaterial elements of particular controversies. This would be of no consequence if all cases were alike, or if it were possible to foresee or to reckon precisely the degree in which actual cases approach or depart from the types which the law defines. In practice they approximate to these types in endless gradations, the one often shading into the next, so that in difficult cases choice of the proper type is not easy and often gives rise to judicial disagreement. As a result, when the law eliminates what are taken to be immaterial factors in order to frame a general rule, it can never avoid entirely elimination of factors which may have an important bearing upon some particular controversy.

There are three ways of meeting this difficulty: One is to provide a judicial or magisterial dispensing power, or even a series of devices for introducing discretion into the administration of justice. In American administration of criminal justice today there is a long series of such devices, one imposed upon the other. There is the discretion of the police as to who and what shall be brought before the tribunals. There are wide and substantially uncontrolled powers in prosecuting attorneys to ignore offenses or offenders, to dismiss proceedings in their earlier stages, to present them to grand juries in such a way that no indictment follows, to decline to prosecute after indictment, or to agree to accept a plea of guilty of a lesser offense. There is the power of the grand jury to ignore the charge. There is the power of the trial jury to exercise a dispensing power through a general verdict of not guilty. Next comes judicial discretion as to sentence or suspension of sentence or mitigation of sentence. Finally there is administrative parole or probation, and in the last resort executive pardon. All these involve uncertainty-opportunity for perversion of the device intended to meet exceptional cases into a means of enabling the typical offender to escape, and a sometimes intolerable scope for the personal equation of the official.

A second way of meeting this difficulty is to eliminate all discretion and seek to meet exceptional cases by an elaborate series of legal exceptions and qualifications and detailed provisos. But human foresight has not proved equal to foreseeing all the varieties of exception for which provision must be made, and the attempt to cover everything by special provisions makes the legal system cumbrous and unworkable.

Hence the law usually ends by adopting a third method of compromising between wide discretion and over-minute law making. But in order to reach a middle ground between rule and discretion some sacrifice of flexibility of application to individual cases is necessary. And this sacrifice cannot go far without a danger of occasional injustice. Moreover, 
the slightest sacrifice, necessary as it is, makes legal rules appear arbitrary and brings the application of them more or less into conflict with the moral ideas of individual citizens. Whenever, in a complex and crowded society containing heterogeneous elements, groups and classes and interests have conflicting ideas of justice, this cause of dissatisfaction is likely to become acute. The individual citizen looks only at single cases, and measures them by his individual sense of right and wrong. The courts must look at cases by types or classes and must measure them by what is necessarily to some extent an artificial standard. If discretion is given the judge, his exercise of it may reflect the view of the element of society from which he comes or with which he associates. If his hands are tied by law, he may be forced to apply the ethical ideas of the past as formulated in common law and legislation. In either event there are many chances that judicial standards and the ethical standards of individual critics will diverge. Herein lies a fruitful cause of popular dissatisfaction with the administration of justice.

\section{Difference in Rate of Progress Between Law and Public Opinion}

In seeking to maintain the interests of civilized society through public administration of justice we risk a certain sacrifice of those interests through corruption or the personal prejudices of magistrates or individual incompetency of those to whom administration is committed. To make this risk as small as possible, to preclude corruption, restrain personal prejudices, and minimize the scope of incompetency, the law formulates the moral ideas of the community in rules and requires the tribunals to apply those rules. So far as they are formulations of public opinion, legal rules cannot exist until public opinion has become fixed and settled, and cannot well change until public opinion has definitely changed. It follows that law is likely to lag somewhat behind public opinion whenever the latter is active and growing.

Many devices have been resorted to in order to make the law more immediately sensitive and responsive to public opinion. Some of these are frequent and copious legislation upon legal subjects, deprofessionalizing the practice of law by opening it to all, regardless of education and special training, putting of the courts into politics through making judges elective for short terms, conferring wide powers upon juries at the expense of courts, setting up of administrative tribunals with large jurisdiction, to be exercised in a non-technical fashion, and recall of judges or of judicial decisions. The first four of these expedients were tried in the fore part of the last century, and many jurisdictions carried some or even all of them to extremes. The last three have been urged in the present 
century, and a tendency to commit enforcement of law to administrative agencies and tribunals has gone far. But none of them has succeeded in its purpose, and many of them in action have subjected the administration of justice not to public opinion, but to influences destructive of the interests which law seeks to maintain. We must recognize that this difficulty in justice according to law may be minimized, but not wholly obviated. We must make a practical compromise. Experience has shown that public opinion must affect the administration of justice through the rules by which justice is administered rather than through direct pressure upon those who apply them. Interference with the uniform and scientific application of them, when actual controversies arise, introduces elements of uncertainty, caprice, and deference to aggressive interests which defeat the general security. But if public opinion affects tribunals through the rules by which they decide, as these rules, once established, stand till abrogated or altered, it follows that the law will not respond quickly to new conditions. It will not change until ill effects are felt-often not until they are felt acutely. The economic or political or moral change must come first. While it is coming and until it is so definite and complete as to affect the law and formulate itself therein, divergence between law and a growing public opinion is likely to be acute and to create much dissatisfaction. We must pay this price for the certainty and uniformity demanded by the general security. It should be said, however, that consciousness of this inherent difficulty easily leads lawyers to neglect the importance of reducing this difference in rate of growth between law and public opinion so far as possible.

\section{Popular Underestimation of the Difficulties in Administering Justice}

Much popular dissatisfaction with justice according to law arises from a popular assumption that the administration of justice is an easy task to which anyone is competent. If the task of law may be described in terms of social engineering, laws may be compared to the formulas of engineers. They sum up the experience of many courts with many cases and enable the magistrate to apply that experience without being aware of it. In the same way the formula enables the engineer to utilize the accumulated experience of past builders even though he could not of himself work out a step in its evolution. The lay public are no more competent to construct and apply the one formula than the other. Each requires special knowledge and special preparation. But the notion that any one is competent to understand what justice requires in the intricate controversies and complicated relations of a modern urban community leads to all manner of obstacles to proper standards of training for the 
bar, to low standards of qualification for judicial office, and to impatience of scientific methods and a high measure of technical skill. This notion was especially strong in pioneer America, and its influence may be seen in extravagant powers of juries, lay judges of probate, and legislative or judicial attacks upon the authority of precedents in most of the States of the South and West. In criminal law it is usually manifest in legislation committing the fixing of penalties to trial juries, not perceiving that the trier, in order to determine the facts fairly, ought not to know certain things without which, on the other hand, the penalty cannot be fixed intelligently. Popular judgments are reached by labeling acts according to certain obvious characteristics. A judge, on the other hand, must examine carefully into all the details of the act, the conditions, internal and external, under which it was done, its motive and its consequences. Hence his judgment may well differ from that of the man in the street, although they apply the same moral standard. The man in the street is likely to regard this disagreement as proof of defects in the administration of justice. Yet courts do not sit to register his judgment on such data as he has but to do what the sober judgment of the community would dictate upon the basis of all the facts.

It is not generally realized how much the public is interested in maintaining the highest scientific standards in the administration of justice. It is the most certain protection against corruption, prejudice, class feeling, and incompetence. Publicity is important, but it is impossible to invoke public indignation in every case, nor is it always evoked in the right cases. Our main reliance must be put in the training of bench and bar, whereby the judges form habits of seeking and applying principles when called upon to act, and the lawyers are able to subject their decisions to expert criticism. The latter is especially important. The daily criticism of trained minds, the knowledge that nothing which does not conform to the principles and received doctrines of scientific law will escape notice, will do more than any other agency for the every-day purity and efficiency of courts of justice. But as things are today the best trained element of the bar more and more does its chief work out of court, and wholly avoids criminal cases. Thus in our large cities the most effective check upon the administration of justice becomes inoperative, and this special difficulty is added to the inherent difficulty involved in public reluctance to admit the necessity of scientific justice and the training of bench and bar which it presupposes. 


\section{Popular Impatience of Restraint}

Law involves restraint and regulation with the sheriff and his posse or the police force in the background to enforce it. As a society becomes more complex, as it carries further the division of labor, as it becomes more crowded and more diversified in race and in habits of life and thought, the amount of restraint and regulation must increaseenormously. But however necessary and salutary this restraint, men have never been reconciled to it entirely; and most American communities are still so close to the frontier that pioneer hostility toward discipline, good order, and obedience is still often a latent instinct in the better class of citizens. The very fact that the restraint of the legal order is in some sort a compromise between the individual and his fellows makes the individual, who must abate some partof his activities in the interest of his fellows, more or less restive. In a time of absolute democratic theories this restiveness may be acute. The feeling that each individual, as an organ of the sovereign democracy, is above the law which he helps to make, fosters disrespect for legal methods and legal institutions and a spirit of resistance to them. Thus the administration of justice according to law is made more difficult. Whether the law is enforced or is not enforced, dissatisfaction will result.

Popular impatience of restraint is aggravated in the United States by political and legal theories of "natural law." As a political doctrine, they lead individuals to put into action a conviction that conformity to the dictates of the individual conscience is a test of the validity of a law. Accordingly, jurors will disregard statutes in perfect good faith, as in the Sunday-closing prosecutions in Chicago in 1908. In the same spirit a well-known preacher wrote not long since that a prime cause of lawlessness was enactment of legislation at variance with the law of nature. In the same spirit a sincere and, as he believed, a law-abiding labor leader declared in a Labor Day address that he would not obey mandates of the courts which deprived him of his natural "rights." In the same spirit the business man may regard evasion of statutes which interfere with his carrying on business as he chooses as something entirely legitimate. In the same spirit public officials in recent addresses have commended administrative violation of the legal rights of certain obnoxious persons, and one of the law officers of the federal government has publicly approved of mob violence toward such persons. Such examples at the top of the social scale do not make for respect for law at the bottom. 


\section{Inherent Limitations on Effective Legal Action}

There are certain limitations inherent in the administration of justice through legal machinery - at least, through any of which we have knowledge-which prevent the law from securing all interests which ethical considerations or social ideals indicate as proper or even desirable to be secured. Five such limitations are of much importance in connection with the criminal law. These are: (1) Difficulties involved in ascertainment of the facts to which legal rules are to be applied, so that, especially in certain types of case, it is difficult to discover the offender or there is danger of convicting the innocent; (2) the intangibleness of certain duties which morally are of much moment but legally defy enforcement, as, for instance, many duties involved in the family relation to which courts of domestic relations or juvenile courts seek to give effect; (3) the subtlety of certain modes of inflicting injury and of modes of infringing important interests which the legal order would be glad to secure effectively if it might; (4) the inapplicability of the legal machinery of rule and sanction to many human relations and to some serious wrongs, and (5) the necessity of relying upon individuals to set the law in motion.

Three of the limitations just enumerated call for some notice. Intrigue may seriously disturb the peace of a household. The subtle methods by which grievous wrongs may be done in this way have been the theme of playwright and novelist for generations. One court, indeed, has tried the experiment of enjoining a defendant from flirting with a plaintiff's wife. But the futility of legal interference in such cases is obvious and is generally recognized. In no other cases is self-redress so persistently resorted to nor so commonly approved by the public. Again, many cases are too small for the ponderous machinery of prosecution and yet may involve undoubted and serious wrongs to individuals. How to deal with the small annoyances and neighborhood quarrels and petty depredations and small-scale predatory activities which irritate the mass of an urban population but do not seem to involve enough to justify the expensive process of the law is by no means the least of the problems of the legal order in the modern city. Here as elsewhere we must make a practical compromise, and whatever the compromise, many will needs be dissatisfied. Finally, law will not enforce itself. We must in some way stimulate individuals to go to the trouble of vindicating it; and yet we must not suffer them to use it as a means of extortion or of gratifying spite. Our rules must obtain in action, not merely lie dormant in the books. But if they are to obtain in action, the authority which prescribes them must be so backed by social-psychological power as to be in a position to give them effect as motives for action in spite of countervailing 
individual motives. Hence the notorious futility of two sorts of lawmaking which are very common: (1) Lawmaking which has nothing behind it but the sovereign imperative, in which the mere words "be it enacted" are relied upon to accomplish the end sought, and (2) lawmaking which is intended to "educate"-to set up an ideal of what men ought to do rather than a rule of what they shall do. To a large extent law depends for its enforcement upon the extent to which it can identify social interests with individual interests, and can give rise to or rely upon individual desire to enforce its rules. In criminal law the desire of the offender to escape and the desire of his friends and relatives that he escape, are strong and active. Unless the desires of other individuals may be enlisted in the service of the law, administrative machinery is likely to fall into an easy-going routine, readily manipulated in the interest of offenders, and the law in the books to become wholly academic, while something quite different obtains in action.

Few appreciate the far-reaching operation of the foregoing limitations upon legal action. There is constant pressure upon the law to "do something," whether it may do anything worth while or not. In periods of expansion the tendency to call upon law to do more than it is adapted to do is especially strong. The result is sure to be failure and the failure affects the whole legal order injuriously.

\section{Inherent Difficulties in All Criminal Justice}

\section{Public Desire for Vengeance}

Historically, one of the origins of criminal law is in summary community self-help, in offhand public vengeance by a more or less orderly mob. Regulation of this public vengeance, giving rise to a sort of orderly lynch law, is one of the earliest forms of criminal law. The spirit which gave rise to this institution of summary mob self-help in primitive society is still active. It has its roots in a deep-seated instinct, and must be reckoned with in all administration of criminal justice. Moralists and sociologists no longer regard revenge or satisfaction of a desire for vengeance as a legitimate end of penal treatment. But jurists are not agreed. Many insist upon the retributive theory in one form or another, and Anglo-American lawyers commonly regard satisfaction of public desire for vengeance as both a legitimate and a practically necessary end. This disagreement is reflected in all our criminal legislation. Statutes enacted at different times proceed upon different theories. Indeed, the usual course is that adherents of one theory of penal treatment will procure one measure, and adherents of a different theory another, from law- 
makers who have no theory of their own. For nothing is done with so little of scientific or orderly method as the legislative making of laws.

Administration is necessarily affected by the fundamental conflict with respect to aims and purposes which pervades our penal legislation. But apart from this, the conflicting theories are also at work in administration. One magistrate paroles freely; another may condemn the system of parole. One executive pardons freely, another not at all. One jury is stern and as like as not acts upon the revenge theory; another jury is soft-hearted. One judge is systematically severe and holds that crime must inevitably be followed by retribution; another is systematically lenient, and many others have no system or policy whatever. Thus the fact that we are not all agreed, nor are we ourselves agreed in all our moods, infects both legislation and administration with uncertainty, inconsistency, and in consequence inefficiency. All attempts to better this situation must reckon with a deep-seated popular desire for vengeance in crimes appealing to the emotions, or in times when crimes against the general security are numerous. Lawyers know well that the average client is apt to be eager to begin a criminal prosecution. He is not satisfied to sue civilly and obtain compensation for an injury. He insists upon something that will hurt the wrongdoer, and is willing to pay liberally to that end. It has taken a long time to eliminate the revenge element from the civil side of the law. Indeed, traces still remain there. On the criminal side this element is still vigorous. The general security requires us to repress self-help, especially mob or mass self-help. Also we must strive to meet the demands of the moral sentiment of the community. These considerations constrain us to keep many things in the criminal law which are purely retributive, and thus serve to preserve a condition of fundamental conflict between different parts of the system. Undoubtedly the law and its administration should reflect the sober views of the community, not its views when momentarily inflamed. But the sober views of the average citizen are by no means so advanced on this subject as to make a wholly scientific system possible.

\section{A Condition of Internal Opposition in Criminal Law Due to Historical Causes}

As has been said, criminal law exists to maintain social interests as such; but the social interest in the general security and the social interest in the individual life continually come into conflict, and in criminal law, as everywhere else in law, the problem is one of compromise; of balancing conflicting interests and of securing as much as may be with the least sacrifice of other interests. The most insistent and fundamental of 
social interests are involved in criminal law. Civilized society presupposes peace and good order, security of social institutions, security of the general morals, and conservation and intelligent use of social resources. But it demands no less that free individual initiative which is the basis of economic progress, that freedom of criticism without which political progress is impossible, and that free mental activity which is a prerequisite of cultural progress. Above all it demands that the individual be able to live a moral and social life as a human being. These claims, which may be put broadly as a social interest in the individual life, continually trench upon the interest in the security of social institutions, and often, in appearance at least, run counter to the paramount interest in the general security. Compromise of such claims for the purpose of securing as much as we may is peculiarly difficult. For historical reasons this difficulty has taken the form of a condition of internal opposition in criminal law which has always impaired its efficiency. As a result there has been a continual movement back and forth between an extreme solicitude for the general security, leading to a minimum of regard for the individual accused and reliance upon summary, unhampered, arbitrary, administrative punitive justice, and at the other extreme excessive solicitude for the social interest in the individual life, leading to a minimum of regard for the general security and security of social institutions and reliance upon strictly regulated judicial punitive justice, hampered at all points by checks and balances and technical obstacles. In England the medieval legal checks upon punitive justice were followed by the rise of the Star Chamber and other forms of executive criminal administration. This was followed by the exaggerated legalism of a common-law prosecution. The latter, carried to an extreme in nineteenth-century America, is being followed hard today by the rise of administrative justice through boards and commissions. The over-technical tenderness for the offender in our criminal law of the last century is giving way to carelessness of violation of the constitutional rights of accused persons and callousness as to administrative methods of dealing with criminals, real or supposed, in the supposed interest of efficient enforcement of penal laws. It happens that within the present century Cleveland has seen both sentimental tenderness toward accused persons and Draconian judicial severity in action. In this contrast, familiar to the citizens of Cleveland, may be seen a picture in miniature of what has always gone on in the history of criminal law.

Criminal law has its origin, historically, in legal regulation of certain crude forms of social control. Thus it has two sides from the beginning. On the one hand, it is made up of prohibitions addressed to the individual 
in order to secure social interests. On the other hand, it is made up of limitations upon the enforcement of these prohibitions in order to secure the social interest in the individual life. In Anglo-American criminal law, as a result of the contests between courts and king in seventeenthcentury England, the accused came to be thought of not as an offender pursued by the justice of society, but as a presumably innocent person pursued by the potentially oppressive power of the king. The common law, declared in bills of rights, came to be thought of as standing between the individual and the state, and as protecting the individual from oppression by the agents of the state. No efficient administration of criminal law in a large urban population is possible under the reign of such a theory. But we have abandoned it in places only. Despite an obvious reaction, it still determines many features of American criminal prosecution. Moreover, we must not forget that it is but a historical form of one of the two elements of which criminal law is made up.

\section{The Close Connection of Criminal Law and Administration with Politics}

Criminal law has a much closer connection with politics than the civil side of the law, and this operates to its disadvantage, particularly in respect of administration. There is relatively little danger of oppression through civil litigation. On the other hand, there has been constant fear of oppression through the criminal law. In history drastic enforcement of severe penal laws has been employed notoriously to keep a people or a class in subjection. Not only is one class suspicious of attempts by another to force its ideas upon the community under penalty of prosecution, but the power of a majority or even a plurality to visit with punishment practices which a strong minority consider in no way objectionable is liable to abuse. Whether rightly or wrongly used, this power puts a strain upon criminal law and administration. Also criminal prosecutions are possible weapons of offense and defense in class and industrial conflicts. Hence suspicion arises that one side or the other may get an advantage through abuse of the prosecuting machinery, giving rise to political struggles to get control of that machinery. Thus considerations of efficient securing of social interests are pushed into the background, and the atmosphere in which prosecutions are conducted becomes political. In practice the result is, when the public conscience is active or public indignation is roused, to be spectacular at the expense of efficiency. When the public conscience is sluggish and public attention is focused elsewhere, the temptation is to be lax for fear of offending dominant or militant political groups. 


\section{The Inherent Unreliability of Evidence in Criminal Cases}

Inherent unreliability of evidence upon which tribunals must proceed affects all departments of judicial administration of justice. But in criminal law, where passions are aroused, where the consequences are so serious, where unscrupulous persons are so apt to be arrayed on one side or the other, the difficulties growing out of the necessity of relying upon human testimony are grave. Psychologists have demonstrated abundantly the extent to which errors of observation and unsuspected suggestion affect the testimony of the most conscientious. Undoubtedly there is much practical psychology and trained intuition behind the common-law rules of evidence; but they are based largely on the psychology of the jury rather than on that of the witness. The problem of lying witnesses, defective observation, and suggestion, as affecting proof in criminal cases, has yet to be studied scientifically by American lawyers. The maxims and presumptions in which we express our practical experience in these connections are too much of the rule-of-thumb type, and are apt to be merely pieces to move in the procedural game between prosecutor and accused.

Moreover, in the administration of criminal law the inherent unreliability of oral evidence of witnesses is aggravated by three circumstances. On the one hand there is the bad influence of police esprit de corps. The unfortunate convictions of Beck and Edalji in England, which will long remain classical examples of convictions of the innocent in modern times, were clearly traceable to determination of the police to convict innocent men whom they had erroneously assumed to be guilty. The testimony of experienced trial lawyers who have written memoirs or reminiscences is uniform to the effect that the testimony upon which prosecutor, must chiefly rely is apt to be so colored and warped as to be subject. grave doubt. Serjeant Ballantine, whose long experience in pros ing and defending entitled him to speak with authority, says that" de corps, antipathy toward the criminal classes, the habit of tes? that it ceases to be regarded as a serious matter, and the $t$. which besets police officers to communicate opinions or theo" press, thus "pledging themselves to views which it is damas sagacity to retract," so operate as to cause serious and even riages of justice. The student of criminology may verify $t ! 1$ by study of American criminal trials. Yet from the nes such testimony is the best available.

In some part police esprit de corps is counteracter habitual defenders of criminals and activity of frienc's accused. But these are often more available and $\mathbf{r} \pi$. 
service of the guilty than of the innocent. Getting witnesses out of the way or silencing them or modifying their testimony by importunity, social pressure, intimidation, appeals to race solidarity, or sympathy are thoroughly familiar matters to the observer of criminal justice in action, and the memoirs and reminiscences of criminal trial lawyers show that nothing new in these respects has been devised in the modern American city. Caleb Quirk, Esq., of Alibi House, in the early part of the last century, would be quite at home in any of our cities today.

We are dealing here with an inherent difficulty. Yet much may be done to mitigate it which we are not doing. (1) If scientific methods of criminal investigation were employed at the very beginning and the preparation of the general run of criminal cases in the prosecutor's office were as thorough and systematic as the preparation of the civil cases, for example, of a public service company, the opportunities for subornation that have made the alibi notorious and the opportunity for suppression of evidence would be much lessened. (2) If the administration of oaths and the formalities of reception of evidence in all stages of a criminal proceeding and before all tribunals were such as to impress those who take part with the seriousness of what is going on, some part of the notorious perjury which attends the administration of justice might be precluded. (3) A better organized and better trained and better disciplined bar might eliminate the type of practitioner that promotes subornation and grows rich on systematic and scientific suppression of evidence and silencing of witnesses. It is noteworthy that incorporation of the lower branch of the legal profession in England had the effect of driving out a low type of solicitor which still thrives in large numbers rith us. - But for the most part we must hope that study of the psylogy of testimony will reveal better methods of ascertaining facts in nal prosecutions than those which are now available. Until such ds come we must reckon with unreliability of evidence as a for: inherent difficulty.

Vider Scope for Administrative Discretion Required in Criminal Law

red with the adjustment of civil relations, criminal law inh greater scope for discretion. Much that may be done 1 matters of property and contract, and hence with asproper influences are excluded by the perfection of the be done by the individual judgment of judges or public e dealing with human conduct, and hence is open to all nces that may be brought to bear upon the individual 
human being. It is one of the difficult problems of all law to maintain a due proportion between detailed rules and judicial or administrative discretion. In criminal law the dangers involved in such discretion are obvious. The power which it involves is large and is peculiarly liable to abuse. Moreover, the consequences of abuse are serious, involving life and liberty, where on the civil side of the law the effects extend rather to property. But there are two circumstances in criminal law that require a wide discretion on the part of prosecutors and magistrates: (1) In the administration of criminal law the moral or ethical element plays a large part, and purely moral or ethical matters do not lend themselves to strict rules. (2) As we now think, penal treatment is to fit the criminal rather than punishment to fit the crime. Hence whether there shall be a prosecution and what shall be done to and with the convicted offender after prosecution must be left largely to the discretion of someone. Even when we sought to make the punishment fit the crime the impossibility of a mathematically constructed system of penalties became manifest, and sentence, within wide limits, was a matter for the discretion of the trial judge. In those days notorious inequalities in sentences bore constant witness to the liability of unfettered discretion to abuse, even in the best of hands. In England, review of sentences by the Court of Criminal Appeal is relied upon to meet this particular danger. In the United States the tendency is to entrust the nature and duration of penal treatment to some administrative board. But whichever course is taken the beginning and continuation as well as the details of the ultimate result of a criminal prosecution must be left largely to the discretion of someone, with all which that may imply.

\section{Inherent Inadequacy of Penal Methods}

On the civil side of the law the modes of enforcement have become very efficacious. If $A$ dispossesses $B$ of land, the sheriff may put $A$ out and $\mathrm{B}$ back in possession. If $\mathrm{A}$ dispossesses $\mathrm{B}$ of a chattel, the sheriff may take it from $A$ and give it back to $B$. If $A$ does not convey to $B$ as he promised, an officer of the court may make a deed to which the law gives the effect of the promised conveyance. If $\mathrm{A}$ does not pay a debt he owes B, the sheriff may sell A's goods and pay B out of the proceeds. No such thoroughgoing remedies are available in criminal law. To guard against further harm from a particular offender, and to guard against others who might repeat the offense, society relies upon fear as a deterrent. It attempts to create a wide-spread fear of punishment and to bring this fear home to the particular offender. Preventive justice, in such matters as are dealt with by the criminal law, must be confined 
within narrow limits, since it involves undue interference with the freedom of action of individuals. Accordingly, in the great mass of cases the criminal law can only step in after an offense has been committed. But the system of protecting society by creating a general fear of punishment encounters two inherent difficulties: (1) Experience has shown that fear is never a complete deterrent. The venturesome will believe they can escape. The fearless will be indifferent whether they escape. The crafty will believe they can evade, and enough will succeed to encourage others. (2) Threats of punishment are often likely to defeat themselves. The zeal of lawmakers frequently imposes penalties to which juries will not agree that offenders should be subjected. It sometimes defines acts as criminal for which juries will not agree to see men punished. Thus we get so-called dead-letter laws, which weaken the authority of law and destroy the efficacy of fear as a deterrent. Sometimes, indeed, it has happened that courts did not have sympathy with over-severe laws or extreme penalties and warped the law to prevent conviction. Our criminal procedure still suffers from the astuteness of judges in the past to avoid convictions at a time when all felonies were punishable with death. However efficient the administration of criminal law, it will be necessary to make some allowance for this inherent difficulty.

\section{The Tendency to Put Too Great a Burden on the Criminal Law}

It is a great disadvantage to the criminal law that it is so interesting in action to the layman. Criminal law is the type of law which figures chiefly in the morning papers; hence when the layman thinks of law, he is almost certain to think of criminal law. Moreover, because of a wellknown human instinct, the layman's short and simple cure for all ills is to hurt somebody. Hence every lay lawmaker turns instinctively to the criminal law when he comes to provide a sanction for his new measure, and every new statute adds one more to the mass of prescribed penalties for which a criminal prosecution may be invoked. It is impossible for any legal machinery to do all which our voluminous penal legislation expects of it. Serious study of how to make our huge annual output of legislation effective for its purpose without prosecutions and giving up the naive faith that finds expression in the common phrase, "there ought to be a law against it," as an article in the legislative creed, would do much for the efficiency of criminal law. 


\section{GENERAL DIFFICULTIES}

\section{Prevalence of Dissatisfaction with Criminal Law and Its Administration}

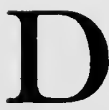

ISSATISFACTION with criminal law and its administration is neither a local nor an American phenomenon. It was world wide at the beginning of the second decade of the present century. For the past seven years other matters have occupied men's thoughts. But there are signs already that agitation for improvement is breaking out again or will soon break out again in many lands. In Italy a commission is now at work upon a new criminal code and promises a thoroughgoing reform, especially in procedure. Certain causes operating throughout the civilized world, and affecting all administration of criminal justice in the present generation, must be taken into account in any critical appraisal of the workings of the criminal law in a particular locality.

\section{New Demands Upon Law}

Law, it has been said, "is but the skeleton of social order." It must be "clothed upon with the flesh and blood of morality." In a time of unrest and doubt as to the very foundations of belief and of conduct, when absolute theories of morals and supernatural sanctions have much less hold upon the mass of the people than when our institutions were formative, and as a consequence conscience and individual responsibility are relaxed, law is strained to do double duty, and much more is expected of it than in a time when morals as a regulating agency were more efficacious. In an era of secularization in which the law is looked to for much that was formerly conceived as in the domain of the church and the home, in an urban, industrial society in which, for example, truancy and incorrigibility of children may be matters for a court rather than for household discipline, we must expect that the legal administration of justice will be affected sensibly.

\section{The Problem of Enforcement}

In the present century new demands upon law and new social conditions involved in our urban, industrial civilization have made enforce- 
ment of law a conspicuous problem in legal science. In a simpler, more homogeneous, less crowded society it was assumed that the enforcing machinery and the efficiency of its operation were not matters of concern to the lawyer. He might think of law as the declared will of the State. In that event he would say that his business was to know and interpret and apply the declaration of the State's will. If the precepts in which that will was declared were not enforced, the trouble lay, not in the law, but in the supineness or incompetency or corruption of the executive officials whose duty it was to execute the law. Or he might think of law as a body of principles of justice, discovered by human experience of conduct and decision, and only formulated by legislator or court or jurist. In that event, if they were not enforced, he was inclined to say that it was because they ought not to be enforced; because they were not sound or accurate formulations of the principles revealed by history and tested by experience. Or, again, he might think of law as a formulation of moral or ethical principles, deriving their real authority from their inherent justice. In that case he was likely to think that they would largely enforce themselves because of their appeal to the conscience of the individual. Nor was this wholly untrue at a time when the program of law was relatively simple and the reasons behind the relatively few laws were apparent on the surface to almost any thoughtful man. But when the area of legal interference becomes greatly enlarged, as it must be in the complex urban industrial society of today; when law has an ambitious program of interposing in almost every field of human activity and regulating human conduct in all its forms and relations, the reasons behind the multitude of legal precepts contained in our voluminous criminal codes and administrative regulations are not readily apparent, and often may well be disputed by those who are able to perceive them. The lawyer, trained in ideas which were appropriate to the simple legal program of the past, is likely to assume today that enforcement of the law is nothing of which he need think. Accordingly, when in the endeavor to secure newly pressing interests ambitious but inexpert reformers turn to penal legislation and add new sections to the overburdened penal code, or the public become alarmed in a time of reconstruction and unrest and threaten an orgy of drastic penal legislation, the lawyer whose habit has been to study the justice of rules, rather than the enforcement of them, is in no position to give effective assistance. Much of popular distrust of the legal profession is due to this change in the conditions to which legal theories are to be applied, while the theories still obtain. 


\section{The Demand for Concrete Justice}

In the nineteenth century, with a simple program of preserving the general security in a primarily rural agricultural society, we were wont to think of justice in terms of the abstract claims of abstract human beings. Today emphasis is put rather upon concrete justice in the individual case. We are not so ready to admit, as an excuse for failure of justice in particular cases, that "John Doe must suffer for the commonwealth's sake." It is felt that abstractly just rules do not justify results that fall short of justice, and that injury to John Doe may be avoided if we bestir ourselves to find more effective legal and administrative devices. Hence today legal proceedings are judged by their results in action, not by their conformity to some abstract, ideal scheme. Features of the administration of justice which were regarded patiently in the middle of the nineteenth century are spoken of now with impatience in a community in which conservation of time and effort has become important, and men have learned from modern business and industrial engineering to think in terms of results. The lawyer has been trained to think of the general or average result reached in a type or class of cases, and the demand of the present century for results in individual cases conflicts with his traditional ideas. Adjustment of legal thinking and judicial methods to this demand for concrete justice - to a large extent a legitimate demand in the conditions of today-must go forward slowly in the nature of things, and will long contribute to an unsatisfactory administration of law in certain types of case in which the demand is particularly insistent and the legal tradition is specially averse thereto.

\section{The Demand for Individualization}

One of the most insistent demands of today is for individualization of criminal justice-for a criminal justice that will not turn recidivists through the mill of justice periodically at regular intervals, nor, on the other hand, divert the youthful occasional offender into a habitual criminal by treating the crime, in his person, rather than the criminal. The nineteenth century was hostile to individualization and to administrative discretion, which is the chief agency of individualization, seeking to reduce the whole administration of justice to abstractly just, formal, rigid rules, mechanically administered. This was true the world over. It was specially true, and true to an exaggerated degree, in America, because of the political ideas of the Puritan, who believed men should be "with one another, not over one another," of politico-legal ideas that grew out of contests between courts and crown in seventeenth-century England, of experience of the American colonists with executive and legislative jus- 
tice, and of pioneer jealousy of administrative and governmental action. The result was to impose shackles of detailed rules and rigid procedure upon every sort of judicial, administrative, and governmental activity. In practice there was a general policy of "can't." No agency of government was to be allowed to do anything beyond a necessary minimum. Hence we got rigid, detailed procedure and hard and fast schemes of penal treatment, lest prosecutor or court or prison authorities do something spontaneously in view of the exigencies of a particular case-we got a procedure governed by a code, rather than by rule and custom of the court, as at common law; we got in some states a police discipline shackled by checks that deprived it of all real efficacy, and we got in many states constitutional obstacles to legislation in the form of detailed requirements as to the generality of laws, as to what should appear in legislative journals, and as to title and repeal. It should be emphasized that this spirit, which hampers effective criminal justice so seriously, has no necessary connection with an economic policy of laissez faire. Whatever the policy of a society may be as to interference with or regulation of men's general activities or economic activities or business relations, it is no part of a laissez faire policy to leave individual criminal activity as free as possible to follow its own course. The spirit of hampering judicial and administrative agencies was due rather to faith in abstract rules and in machinery as inherently efficacious, and to lack of faith in official action as such for any purpose, than to any economic policy. Without regulating many things, the law may yet set out to deal effectively with what it does attempt to regulate or to prevent.

\section{Changed Ideas as to the End of Criminal Law}

\section{The Passing of the Retributive Theory}

Our traditional criminal law thinks of the offender as a free moral agent who, having before him the choice whether to do right or wrong, intentionally chose to do wrong. In the nineteenth century we believed that justice consisted in imposing upon this wilful wrongdoer a penalty exactly corresponding to his crime. It was not a question of treatment of this offender, but of the exact retribution appropriate to this crime. We know today that the matter is much more complicated than this simple theory assumes. We know that criminals must be classified as well as crimes. We know that the old analysis of act and intent can stand only as an artificial legal analysis and that the mental element in crime presents a series of difficult problems. We recognize that in order to deal with crime in an intelligent and practical manner we must give up the 
retributive theory. But this means that we must largely make over our whole criminal law, which was rebuilt around that theory in the last two centuries, and that work is going on slowly all over the world. The condition of criminal law calls for continuous intelligent bringing to bear upon the problem of securing social interests by law and upon the detailed applications of that problem-for the bringing to bear upon them of every resource of legal and social and medical science. We shall achieve lasting results neither by some analytical scheme or rigid system worked out logically in libraries on the sole basis of books and law reports, as some lawyers seem to hope, nor by abandoning the experience of the past, preserved in the law reports, and turning exclusively to administrative, non-legal, expert agencies, which is the hope of many laymen. Pending this making over of criminal law we must expect that many features of the administration of criminal justice will remain unsatisfactory.

\section{Increased Regard for Human Personality}

Today we feel that when the law confers or exercises a power of control the legal order should safeguard the human existence of the person controlled. Thus the old-time sea law, with its absolute power of the master over the sailor, described in action by Dana in Two Years Before the Mast, the old-time ignominious punishments that treated the human offender like a brute, that did not save his human dignity-all such things have been disappearing as we come to take account of the social interest in the individual human life and to weigh that interest against the social interest in the general security on which the last century insisted so exclusively. This feeling for the human dignity, the human life, of the offender is somewhat different from the feeling for abstract individual liberty and consequent system of checks upon prosecution and safeguards of accused persons and loopholes for escape which developed in Anglo-American criminal law for historical reasons from the seventeenth to the nineteenth century. Until it crystallizes in well-settled and wellunderstood legal and administrative policies, until proper compromises between the interest in the individual human life and the general security, security of social institutions, and general morals are worked out at many points, there is likely to be vacillation, uncertainty, and inefficiency in the administration of criminal justice. This will be true especially at the two extremes of a prosecution-the beginning in police discretion when an offense has been committed, and the end in penal treatment of the convicted offender. Cleveland has seen in somewhat acute form a phenomenon that is to be seen in criminal justice throughout the 
world, and is merely an incident of changing ideas as to what we are doing through the criminal law and why we are doing it. The effect in unsettling the administration of criminal law is unfortunate. Discontent with the results of some of the newer methods of penal treatment is not unlikely to lead to temporary reaction to older methods, which will but aggravate the difficulty. Partly these newer methods and their results have been misunderstood and misrepresented. Partly results which are justly objected to are due to the inevitable crude fumblings involved in all application of new methods. Naturally the public is impatient. But we can no more return to the old methods than we can return to horsecars or ox-teams or flails or sickles. We must go forward scientifically and not vacillate between extreme experiments along new lines and reactionary reversions to methods that belong wholly to the past.

\section{New Developments in Psychology and Psychopathology}

Medical science has all but undergone a rebirth within a generation. Within a generation psychology has risen to a practical science of the first importance, with far-reaching applications on every side. Psychopathology has overturned much that the criminal law of the past had built upon. Indeed, the fundamental theory of our orthodox criminal law has gone down before modern psychology and psychopathology. The results are only beginning to be felt. One result is a just dissatisfaction on the part of the medical profession with what they observe in judicial administration of justice and legal treatment of criminals. In prevention, in criminal investigation as a preliminary to prosecution, in the trial of issues of fact and in penal treatment we have much to learn from the physician and.psychologist and psychopathologist. But during the period of transition in which we are learning it and are learning how to use it there will be much experimenting and some fumbling and much dissatisfaction.

\section{The Present Condition of Criminal Law}

As a result of the several causes suggested above, the criminal law of today, throughout the world, is made up more or less of successive strata of rules, institutions, traditional modes of thought, and legislative provisions representing different and inconsistent ideas of the end of criminal law, the purpose of penal treatment, and the nature of crime. This is true especially in Anglo-American criminal law. With us all stages of development and all theories and all manner of combinations of them are represented in rules and doctrines which the courts are called upon to administer. Indeed, all or many of them may be represented in 
legislative acts bearing the same date. The result is that our criminal law is not internally consistent, much less homogeneous and well organized. Even if the administrative machinery were all that it should be and the personnel of administration were all that it should be, the condition of criminal law of itself would impede satisfactory administration.

Unfortunately, criminal law never attained the systematic perfection that marks the civil side of the law in Roman law, and is beginning to be found on the civil side of Anglo-American law. Until the criminal law is studied as zealously and scientifically and is regarded by teachers, students, lawyers, and judges as being as worthy of their best and most intelligent efforts as is the civil side of the law, the administration of criminal justice will continue to fall short of public expectation. 
CHAPTER IV

\section{AMERICAN DIFFICULTIES}

\section{Conditions for Which American Criminal Law and Procedure Were Shaped}

$\mathrm{T}$

10 UNDERSTAND the administration of criminal justice in American cities today we must first perceive the problems of administration of justice in a homogeneous, pioneer, primarily agricultural community of the first half of the nineteenth century, and the difficulties involved in meeting those problems with the legal institutions and legal doctrines inherited or received from seventeenth-century England. We must then perceive the problems of administration of justice in a modern heterogeneous, urban, industrial community and the difficulties involved in meeting those problems with the legal and judicial machinery inherited or received from England and adapted and given new and fixed shape for pioneer rural America.

Professor Sumner called attention to the importance of an understanding of frontier or pioneer conditions in the study of American politics. "Some of our worst political abuses," he said, "come from transferring to our now large and crowded cities maxims and usages which were convenient and harmless in backwoods country towns." This is no less true of our most serious legal abuses. It must be remembered that our judicial organization and the great body of our legal institutions and common law are the work of the last quarter of the eighteenth century and the first half of the nineteenth century. For practical purposes American legal and judicial history begins after the Revolution. In colonial America the administration of justice was at first executive and legislative. American law reports begin at the end of the eighteenth century. The America for which seventeenth-century English legal institutions and eighteenth-century English law were received and made over was not at all the America in which those institutions and that law must function today. Our great cities and the social and legal problems to which they give rise are of the last half of the nineteenth century. Many are of the last quarter of that century. Our largest city now contains in 326 square miles a larger and infinitely more diversified popula- 
tion than the whole 13 States when the federal judicial organization which has served so generally as a model was adopted. The last State of the Union was opened to settlement by the white man within a generation. Except perhaps in the narrow fringe of original settlements along the Atlantic coast, rural conditions prevailed everywhere within the memory of those now living, and in any part of the country one need do little more than scratch the surface in order to come upon the pioneer. Thus our law and our legal institutions got the stamp of the pioneer while they were formative.

Our Anglo-American judicial and prosecuting organization, criminal law and criminal procedure, as they grew up and took shape in the fore part of the last century, presuppose a homogeneous people, jealous of its rights, zealous to keep order, and in sympathy with institutions of government which it understands and in which it believes-a people which, in all matters of moment, will conform to the precepts of law when they are ascertained and made known, which may be relied upon to set the machinery of the law in motion of its own initiative when wrong has been done, and to enforce the law intelligently and steadfastly in the jury-box. In other words, they presuppose an American farming community of the first half of the nineteenth century. We are employing them to do justice in a heterogeneous, diversified, crowded city population, containing elements used to being trodden on by those in authority, ignorant of our institutions, at least in all but form, with good reason suspicious of government as they have known it, and hence often imbued with distrust of all government, loth to invoke legal machinery, of which they think in terms of the social conditions in another part of the world, and inclined to think of a jury trial as some sort of man hunt, not knowing the nature of the proceedings that have gone before nor appreciating the manifold guarantees by which at common law an accused person is assured every facility for a full defense.

The Administration of Criminal Justice in the First Half of the Nineteenth Centurx

\section{The Criminals and Conditions of Crime}

At the outset we must notice the different type of criminal and different conditions of crime for which our formative institutions were shaped. The occasional criminal, the criminal of passion, and the mentally defective, were the chief concern of the criminal law, and its task was to restrain them in a homogeneous community under pioneer or rural conditions, in a society little diversified economically and for the most 
part restrained already by deep religious conviction and strict moral training. So far as it was necessary to deal with vice it was the rough, virile vice of a vigorous stock that lived out-of-doors. Organized professional criminality on a large scale, operating over the whole country, was unknown. The occasional band of robbers or of cattle thieves could be dealt with by a sheriff and a posse. Commercialized vice on a large scale, extending its operations over many localities, was unknown. Large cities with a diversified, shifting industrial population, with extreme divergencies of economic condition, with rapid and easy communications with other like centers, with a population moving back and forth daily in swarms to a business center and crowding a great volume of business into a few hours, did not afford opportunities for specialized professional crime. Such conditions have come upon us slowly in some parts of the country, but with extreme rapidity in others, as in Cleveland. In either event they have come upon an administrative and judicial machinery made for rural communities and simply added to or patched from time to time to meet special emergencies. The professional criminal and his advisers have learned readily to use this machinery and to make devices intended to temper the application of criminal law to the occasional offender a means of escape for the habitual offender. Experience has shown this in all our cities. But the "Mortality Tables" in the report on Prosecution" and the examples of the facility with which old offenders take advantage of the series of mitigating agencies, set forth in Chapter II of the report on Criminal Courts, tell the story eloquently.

\section{Administrative Machinery}

We inherited from England a medieval system of sheriffs, coroners, and constables, devised originally for a rural society and easily adapted to pioneer rural conditions. The town marshal was a constable with no civil functions and some added powers and duties. He went out of office with every political change. He kept order and did an occasional bit of detection in the event of a sensational crime. A police force, as we now know it, is an institution of the nineteenth century, and, unhappily, our police organization and administration have been affected to no small extent by ideas derived from the older, pre-urban régime. What is particularly noticeable about the nineteenth-century Anglo-American administrative system is its lack of organization, decentralized responsibility, and abundant facilities for obstruction in comparison with means for effective achievement of results. As a rule, none of these officials was

${ }^{1} \mathrm{Pp} .91,93$, and 95.

[ 592 ] 
answerable to any one but the electorate. He coöperated with other officials or thwarted them as his fancy or the exigencies of politics might dictate. Each locality had its own administrative officer, acting on his own judgment, and responsible to no superior, and the execution or nonexecution of laws therein was its own affair.

This decentralization, division of power, and hampering of administration was part of the system of checks and balances to which we pinned our faith in the last century. It has been said that our institutions were the work of men who believed in original sin and were unwilling to leave open any door for the intrinsically sinful official which they could possibly close. To this Puritan jealousy of administration we added a pioneer jealousy of administration. "The unthinking sons of the sagebrush," says Owen Wister, "ill tolerate anything which stands for discipline, good order, and obedience; and the man who lets another command him they despise." Such has always been the spirit of the pioneer, and institutions shaped by that spirit are well adapted to a pioneer society. But in a crowded urban society, in holding down the potentially sinful administrative official we give the actually sinful professional criminal his opportunity, and in insuring a latitude of free individual self-assertion beyond what they require for the upright, we give a dangerous scope to the corrupt. The local conditions of cities demand centralization and organization of administrative agencies, coördination of responsibility with power, and reliance upon personality rather than upon checks and balances as emphatically as a pioneer, rural community demands decentralization, division of power, independent magistracies, and checks upon administration.

\section{English Criminal Law at the Revolution}

When, at the end of the eighteenth century and in the early nineteenth century, we began to build an American criminal law with received English materials, the memory of the contests between courts and crown in seventeenth-century England, of the abuse of prosecutions by Stuart kings, and of the extent to which criminal law might be used as an agency of religious persecution and political subjection, was still fresh. Hence a hundred years ago the problem seemed to be how to hold down the administration of punitive justice and protect the individual from oppression under the guise thereof, rather than how to make criminal law an effective agency for securing social interests. English criminal law had grown out of royal regulations of summary local self-redress and had been developed by judicial experience to meet violent crimes in an age of force and violence. Later the necessities of more civilized times 
had led to the development in the court of Star Chamber of what is now the common law as to misdemeanors. Thus one part of the English law of crimes as we found it at the Revolution was harsh and brutal, as befitted a law made to put down murder by violence, robbery, rape, and cattle-stealing in a rough and ready community. The legislation in New York at the end of the eighteenth century which abolished the death penalty for felonies other than murder, and the English legislation of the legislative reform movement in the fore part of the nineteenth century, was chiefly concerned in doing away with the brutalities of the old law as to felonies. Another part of the English law of crimes at the Revolution seemed to involve dangerous magisterial discretion, as might have been expected of a body of law made in the council of Tudor and Stuart kings in an age of absolute government and extreme theories of royal prerogative. Puritan jealousy of subordination and administration, pioneer selfreliance, and inherited fear of political oppression by governmental agencies, since the colonists had had experience of the close connection of law with politics, were decisive of our shaping of this body of criminal law at the time when it was formative. In particular these things had three important results:

(1) They led nineteenth-century American law to exaggerate the complicated, expensive, and time-consuming machinery of a commonlaw prosecution, lest some safeguard of individual liberty be overlooked. It is only thus that we may understand the many steps set forth in Chapter III of the report upon the Criminal Courts.

(2) They led to curtailings of the power of the judge to control the trial and hold the jury to its province, and to conferring of excessive power upon juries. These had their origin in colonial America, before true courts and judicial justice had developed, when juries were a needed check upon the executive justice of royal governors. They were added to through the need of checks upon royal judges. They were carried still further during the hostility to courts and lawyers and English legal institutions that prevailed immediately after the Revolution. Finally, they got their fullest development in frontier communities in the nineteenth century.

(3) Both had the result of enfeebling the administration of criminal law. But these enfeeblings did not work much evil in a time when crime was relatively rare and abnormal; when the community did not require the swift-moving punitive justice adjusted to the task of enforcing a voluminous criminal code against a multitude of offenders which we demand today. How they affect the enforcement of law today is shown strikingly in Table 2 of the report on Criminal Courts, and Tables 1, 2, 
and 3 in the report on Prosecution. Unfortunately, when the conditions that call for a more effective criminal justice became acute, we had ceased to take the same interest in criminal law that had been taken early in the nineteenth century, when the leaders of the legal profession achieved their most conspicuous triumphs in criminal cases, and in consequence there has been no such systematic expert consideration of how to give efficacy to criminal justice in the present as was devoted to the work of enfeebling it in the past.

\section{English Criminal Procedure at the Revolution}

As the substantive criminal law had been brutal in the spirit of a substitute for lynch law, so English criminal procedure had been brutal and unfair to the accused. The trial methods of seventeenth-century prosecutors and the conduct of seventeenth-century trial judges, imitated by some royal judges in eighteenth-century America, led to stringent provisions in our bills of rights for the protection of accused persons and for securing them a fair trial. Except in political prosecutions, criminal prosecutions in the English polity were privately conducted. Also there was no review of convictions except for error on the face of the formal record and no granting of new trials to the convicted. Both of these conditions were changed in American law. A local public prosecutor was set up in each locality. The practice of review of administrative convictions before colonial legislatures and granting of new trials by colonial legislatures after judicial judgments made us familiar with review of criminal proceedings and led to a system of criminal appellate procedure. But the local prosecutor, the model whereof is the federal district attorney of the Judiciary Act of 1789, while suggested by the French procureur $d u$ roi, was not made part of an organized administrative system, but instead was given complete independence as a sort of attorney general in petto. In the federal system a certain control is had through the federal department of justice. In the States there is no such power. The local prosecutor and the attorney general may coöperate or may ignore each other or may clash as their dispositions or their politics lead them. The wide powers of local prosecutors, the lack of control over them, and the extent to which they may determine the whole course of law enforcement, without leaving a tangible record of what they have done and what they have undone, are beginning to attract attention.

No officer in our large cities has so much real power with so little ostensible power. The easiest path to improper influence upon criminal justice is through the office of the public prosecutor, and there is much evidence that professional defenders of professional criminals and pro- 
fessional extortioners from occasional offenders in more than one American city understand this thoroughly. In a rural pioneer community with a small local bar, a small criminal docket, and only occasional terms of court, the public prosecutor had relatively little power. Grand juries had ample time to deliberate and did their work critically. What the public prosecutor did or failed to do was evident to and subject to criticism by alert and expert critics actively engaged in the courts. In the modern city, with congested criminal dockets, a crowded bar, the leaders of which seldom or never go into the criminal courts, and continuous sessions of court almost throughout the year, he is watched only by alert and expert professional defenders who often know the game of criminal justice better than he does. There is no effective check upon him. The series of mitigating agencies which were introduced into our criminal justice under different conditions offer abundant opportunity to cover up his tracks, and the pressure of judicial business makes the common-law check of judicial approval, when required, a perfunctory ceremony. The chief pressure upon him is political, and this sort of pressure is easily exerted by politician-criminal-law practitioners as a means of defeating enforcement of the law. No feature of our administration of criminal justice calls for thoroughgoing study so urgently as the public prosecutor. Mr. Bettman's pioneer study of a prosecutor's office in action in an urban community should be pondered by every thoughtful lawyer.

Review of convictions and granting of new trials by appellate courts were called for especially in America because of the need for judicial finding and shaping of the law which we were receiving from England and adapting to our conditions. When James Kent went upon the bench in New York in $\mathbf{1 7 9 1}$ he tells us that there were no State law reports and nobody knew what was the law. Later there was need of judicial interpretation of the criminal codes which became common in the United States after the model of the French penal code of 1810 . But this institution had the effect of enfeebling the administration of criminal law in that settlement of the law was then more important than punishment of the individual offender. Thus, in the second half of the nineteenth century, when the law had become settled, new trials were granted constantly on academic legal points although no doubt of guilt could exist. There has been a marked change in this respect in the past two decades. Yet the function of finding the law for a pioneer community whose criminal law is formative, as the real function of a criminal appellate tribunal rather than reviewing guilt or innocence of the accused, has impressed its spirit upon our whole system of review of convictions. How much it still affects our administration of justice may be seen by 
comparing the reported decisions of an American supreme court with those of the English Court of Criminal Appeal.

It will have been noted that all three of our American innovations upon seventeenth-century English criminal procedure were in the direction of mitigation and afforded additional incidental opportunities for the guilty to escape. Accordingly, as English criminal justice is notoriously more feeble than criminal justice upon the Continent, American criminal justice is more feeble than English. What this means to the habitual offender is suggested by the statistics in Chapter I of the report on Police Administration.

\section{The System of Courts at the Revolution}

English judicial organization at the time of the Revolution was too arbitrary and involved to be taken as a model to be followed in detail in this country. Yet by eliminating the more obvious anomalies, a general outline could be perceived which was the model of our system of courts. For the purposes of criminal justice, beginning at the bottom, this was: (1) Local peace magistrates and local inferior courts with jurisdiction to examine and bind over for felonies and a petty jurisdiction over misdemeanors, subject to appeal to and retrial in the court of general jurisdiction; (2) a central court of general jurisdiction at law and over crimes, with provision for local trial of causes at circuit; (3) a supreme court of review. The defect in that scheme that appealed to the formative period of judicial organization was not its lack of unity, the multiplicity of courts or the double appeals, but its over-centralization for the needs of a sparsely settled community that sought to bring justice to every man. In a community of long distances in a time of slow communication and expensive travel central courts entailed intolerable expense upon litigants. Judicial organizations were devised with a view to bringing justice to every man's door. But the model was English at a time when English judicial organization was at its worst. For in the eighteenth century the English had not yet overhauled their system of courts. It had grown up by successive creation or evolution of new courts when new types of work arose or old tribunals ceased to function efficiently, so that some 74 courts existed, 17 of which did the work now done in England by three. Thus we took an archaic system for our model, and the circumstances of the time in which our courts were organized tended to foster a policy of multiplication. As a result, we go on creating new courts at a time when the conditions of our large cities call for unification.

A contributing factor in this decentralized judicial organization was the need of judicial ascertainment of the law in a new community already 
adverted to. We had to devise a body of substantive criminal law in a time of rapid expansion. For more than a century the main energies of our judicial system were devoted to the working out of a consistent, logical, minutely precise body of precedents. To us the important part of the system was not the trial judge who tried and sentenced the accused, but the judge of the appellate court who availed himself of the occasion given by the prosecution to develop the law. We judged the judicial system rather by the written opinions filed in its highest court than by the efficient functioning of its prosecuting machinery. Our eyes were fixed upon the task of providing rules. It is no wonder that our failure to devote equal attention to application and enforcement of rules too often allowed the machinery designed to give effect to the rules to defeat the purposes of law in their actual operation. If one reads the report upon the courts in Cleveland with this historical background in mind, he will understand many things. The rise of special problems, such as those which come before juvenile courts and our urban courts of domestic relations, the great increase in police regulations, especially of traffic regulations since the advent of the automobile, the increased opportunities for professional crime and consequent large-scale organization of criminal enterprises, the presence in our cities of large groups of aliens, as well as of citizens of foreign birth and no little race solidarity, the resulting colonies in our cities of large numbers of persons not trained in the ideas which our legal polity presupposes, and the complex economic organization, with its incidental results of recurring times of unemployment and continual inflow and outflow of laborers-all these things affect court organization as well as police and prosecutor. They call for strong peace magistrates, well organized and provided with ample facilities. They call for a single court of criminal jurisdiction, in which the steps in a prosecution may be reduced to a minimum - a court well organized and continually in session. All this is very far from the system we inherited from the nineteenth century.

\section{The Bench at the Revolution and in the Nineteenth Century}

As has been said, the administration of justice in colonial America was at first executive and legislative, rather than judicial. Legislative new trials persisted until the end of the eighteenth century, legislative appellate jurisdiction until the middle of the nineteenth century, and legislative divorces until the last quarter of the nineteenth century. Judicial justice was only just establishing itself at the time of the Revolution, and came to its own in the last decades of the eighteenth century and the beginning of the nineteenth. In the colonies the courts were 
manned by laymen, with the occasional exception of the chief justice, and in some of the colonies the royal chief justices did not so conduct themselves as to inspire confidence in lawyers as judicial magistrates. At the time of the Revolution it was beginning to be thought advisable to have judges learned in the law. But many of the States relied upon judges without legal training until well into the nineteenth century. Thus, two of the three justices in New Hampshire after the Revolution were laymen, and the Chief Justice of Rhode Island from 1819 to 1826 was a farmer.

Three factors brought about a wholly different attitude toward the bench from that which has obtained in England since 1688. Here, as in so many cases in American legal and political institutions, we derive from seventeenth-century rather than from eighteenth-century England. The politics-ridden bench of the Stuarts rather than the independent judiciary of modern England was the original model. The federal constitution and the federal judiciary act of 1789 set a better model and, on the whole, the federal courts have kept to the best traditions of a common-law bench. Also the appointive State courts, with permanent tenure, at the end of the eighteenth century and in the first half of the nineteenth century, were manned by judges of the highest type, who made that period a classical one in the history of Anglo-American law. But the hostility to courts and lawyers due to economic causes after the Revolution, and the radical democratic movement of the next generation, with its leveling tendencies, its tendency to carry out abstract political theory to its logical conclusions, and its cult of incompetency, which is so often a by-product of democracy, combined to work a gradual change. Hostility to Federalist judges, some of whom, it must be admitted, followed the example of political judges in England too closely, had much to do with the first experiments with an elective bench. Thus a complete change took place in the mode of choice and tenure of judges which became general after 1850 .

In rural pioneer America the elective short-term judge did not work badly, although it is significant that the great names which are the ornaments of American judicial history belong, with scarcely an exception, to the era of appointed judges with permanent tenure. Today judges in rural jurisdictions chosen at the polls and for relatively short terms are, on the whole, reasonably satisfactory. But the elected short term bench has not achieved what its adherents expected of it, and has achieved some other things which have a bad influence upon the administration of justice.

It may be shown from the debates in constitutional conventions by [599] 
which elective judges were provided for that the advocates of that system expected to put the judges into the closest touch with the people, to make them responsive to public opinion, to subject them to the pressure of popular criticism and to liberalize the administration of justice. English law, which we were receiving and making over, was looked upon with suspicion by a large part of the community and it was thought that a permanent judiciary was over-technical. This feeling had some justification in the obstinacy with which some strong judges adhered to English rules and practices simply as such, and in the impossibility of administering justice in the nineteenth century by the formal, involved, artificial common-law procedure of the eighteenth century. But what the new system of choosing judges actually did was to subject the bench to professional political pressure, to make judges responsive to political considerations rather than to public opinion, and, in the long run, to insure at most a mediocre bench which has proved more narrowly technical and, on the whole, less liberal in practice than appointed judges with permanent tenure in the few jurisdictions which retained that system. On the other hand, the judges elected for short terms soon lost effective control over the administration of justice, and common-law traditions of legal proceeding became seriously impaired. Lack of control over the trial bar on the part of judges who cannot afford to antagonize and cannot insist upon expedition and high ethical forensic standards of conduct without imperiling their positions is a chief cause of the unnecessary continuances and postponements, the difficulties in obtaining juries, the wranglings of counsel and the ill treatment of witnesses which have cast discredit upon American criminal trials. It is significant that these things are almost unknown in jurisdictions in which judicial tenure is permanent and secure.

Moreover, the putting of the bench into politics and the modes of thought of the pioneer resulted in breaking down the common-law standards of decorum and of judicial propriety. How far this decadence of dignity and decorum may go is strikingly illustrated in the report on Criminal Courts. The habitual presence of the higher type of lawyer in the civil courts has prevented such things as are of common occurrence in inferior criminal tribunals. But the judicial Barnum and even the judicial mountebank are well-known characters in most American jurisdictions today, and they are fostered by a system under which, in the large city, a magistrate must keep in the public eye in order to hold his place. Even more serious is the careless, slip-shod despatch of business which develops in courts conducted without regard for decorum-a method which lends itself to such things as are described in Chapter III 
of the report on Prosecution, and Chapter $\mathrm{V}$ of the report on Criminal Courts. The nadir is reached when campaign funds for judges are raised by subscription from those who practise or have litigation before them.

That the public should see and feel that justice is done is scarcely less important than the actual doing of justice. Order, decorum, and judicial dignity, in fact, promote the despatch of business. More than this, they promote respect for law and confidence in the work of the courts. No one should wonder at the prevalence of perjury in courts so conducted as to make the administration of oaths and the giving of testimony perfunctory acts, done offhand in the midst of Babel. No one should wonder at the lack of public confidence in the administration of justice by courts which appear to be conducted by whispered confidential communications with politicians and criminal-law practitioners of doubtful repute, rather than by solemn public proceedings in open court. All these things are natural results of putting the bench into politics under the conditions of the modern city. One of the chief items in any program of improvement must be to free the court-rooms of our lower tribunals from the atmosphere of crudity and coarseness given them by the "Jefferson Brick" era of American politics, confirmed in them by the pioneer, and accentuated by the press of work, mixed population, and crowd of lowgrade lawyers in the large city.

\section{The Bar At and After the Revolution}

At the Revolution the bar was hardly more than beginning in this country. The colonies had little need of lawyers until after the middle of the eighteenth century. With the rise of judicial justice administered by courts in place of executive justice and legislative justice which prevailed during the greater part of the colonial period, a tendency to go to England for legal education began to appear, and there were a few good lawyers in more than one colony at the Revolution. After the Revolution law and lawyers were in much disfavor; the law, because it could not escape the odium of its English origin in the period of bitter feelings after the war, lawyers, because they alone seemed to thrive in the economic disorganization and disturbed conditions that followed peace. These circumstances and the radical democratic notions of the Jeffersonian era determined our professional organization.

In England, as now, the legal profession was organized in two branches. The upper branch, barristers or counselors, were alone eligible for judicial office and had exclusive exercise of the function of advocacy. This branch was well organized in societies coming down from the Middle Ages, had high professional traditions, professional discipline, control of 
admission to its ranks, and a decayed system of legal education which, nevertheless, was capable of being modernized and made effective. The lower branch, attorneys, solicitors, did the work of client-caretaking and acted as agents for their clients in litigation. Although some American jurisdictions made a distinction between counselors and attorneys, it soon came to little in practice, and "attorney and counselor" became the American rule. But the attorney furnished the model rather than the counselor. The profession was not organized in any real sense. As in the case of attorneys and solicitors in England, each court had its roll of practitioners, there was no professional discipline, the power of the courts to remove from the roll was exercised in flagrant cases only, and the training was wholly by apprenticeship. Thus the bar was largely deprofessionalized. In rural circuits the close daily contact of a small bar, each well known to his fellows, served to maintain traditional professional standards. But with the obsolescence of the practice of going circuit and the rise of large urban bars, containing numbers who are wholly unknown to their fellow practitioners, it ceased to be possible to keep up traditional standards in this way. Gradually also a differentiation took place and three well-defined groups became set off from the main body of the bar, namely, a well-educated, well-trained stratum at the top, an uneducated, untrained, or ill-trained stratum at the bottom, and a small group of none too scrupulous politician-lawyers. The practice of criminal law came to be almost exclusively the domain of the two last.

Readers of English fiction of the fore part of the last century will remember the condition of the lower branch of the profession in England at that time as there portrayed. 'Sampson Brass, Dodson \& Fogg, and Quirk, Gammon \& Snap are types that we recognize perfectly today. In England incorporation of the lower branch of the profession, with the consequent introduction of discipline, professional feeling, and requirements of education and professional training, have effected a reform. We have moved more slowly. In the last quarter of the nineteenth century the rise of bar associations was the beginning of better things. These associations have done much for professional organization, professional ethics, and professional discipline. But they are voluntary organizations, and it has happened in some cities, and may happen anywhere, that the lower strata of the bar, seeing the advantages of voluntary organization, have formed organizations and exercised a sinister influence upon the administration of justice.

Three stages may be perceived in the development of the American bar. The first stage is marked by the leadership of the trial lawyer. The great achievements of the bar were in the forum, and the most conspicu- 
ous success was success before juries in the trial of criminal cases. The bench and the legislature were recruited from the trial bar. The law was largely fashioned to be a body of rules for use in the trial of causes. This stage lasted until the Civil War and still persists in some rural communities. In a second stage leadership passed to the railroad lawyer. The proof of professional success was to represent a railroad company. The leaders of the bar were permanently employed as defenders in civil causes and their energies, their ingenuity, and their learning were exercised in defeating or thwarting those who sought relief against public service companies in the courts. But where the bench was elective, because of popular suspicion of those companies, judges and legislators were seldom chosen from these leaders. Hence criminal law became the almost exclusive field of the lower stratum of the bar, and the recognized leaders in ability and learning ceased to be the official leaders as judges, prosecutors, and lawmakers. Today leadership seems to have passed to the client-caretaker. The office of a leader of the bar is a huge business organization. Its function is to advise, to organize, to reorganize, and direct busines enterprises, to point out dangers and mark safe channels and chart reefs for the business adventurer, and in our older communities to act, as one might say, as a steward for the absentee owners of our industries. The actual administration of justice in the courts interests him only as it discloses reefs or bars or currents to be avoided by the pilot of business men. Thus the leaders of the bar in the cities are coming to be divorced not only from the administration of criminal justice, but from the whole work of the courts, and the most effective check upon judicial administration of justice is ceasing to be operative.

It may be conceded that the economic causes which have turned the energies of the ablest and best trained in the profession into client-caretaking are inexorable, and that we may not hope to divert the leaders to less remunerative work and work of less magnitude with respect to the economic interests involved. But it does not follow that those who practise chiefly in the courts, and especially those who do the bulk of the work in criminal cases, should be uneducated, ill trained, and undisciplined.

Corporate organization of the bar, as at common law, and as both branches of the legal profession are now organized in England, and proper educational standards, both preliminary and professional, are items of the first moment in any plan for improving the administration of justice in our large cities. In such cities there must be many lawyers of foreign birth or foreign parentage. To confine the practice of law to any group, racial or linguistic or economic, would be to exclude other groups from 
their just share in making, interpreting, and applying the law, and thus to deprive them of their just share in a polity which is primarily legal. But it is vital that these lawyers should know the spirit of our polity; and that is the spirit of our common law. The mere rule-of-thumb training in local law and procedure or in meager generalities of definition and abstract principle which most of them now get in night law schools gives no adequate conception of our law nor of our legal institutions. However good their intentions, they cannot use the machinery of a commonlaw prosecution intelligently with such training, and it is no wonder that our legal system functions badly in their hands. Chapter III of the report on Prosecution, disclosing methods at variance not only with justice, but with the whole spirit of our institutions, should be read with these things in mind.

\section{Penal Treatment at the End of the Eighteenth Century}

Modern criminal science begins in the second half of the eighteenth century, after the classical treatise of Beccaria on crimes and punishments. But the movement for a rational and humane penal treatment which that treatise began did not affect our law till the end of the eighteenth century, when legislation began to provide imprisonment rather than death as a punishment for all but a few felonies. Thus our penal treatment was grafted on a system that proceeded on radically different ideas. The jail system, inherited from England, did not work badly in small country county-seats in the fore part of the nineteenth century, but became intolerable in the large city of the present century. The American Prison Congress was not organized till 1870, and the American Institute of Criminal Law and Criminology not until 1910. In other words, our system of penal treatment, experimental in its inception and grafted on a bad system, has had not much more than a century in which to develop, has been studied scientifically for not much more than a generation, and before it was much more than worked out for the conditions of agricultural America has had to be applied, as well as we might, to the predominantly urban America of today. These facts explain much.

The Problems of Criminal Justice in the American City of Today

\section{Reshaping of the Substantive Criminal Law}

From the foregoing discussion it will have been seen that before our criminal justice may function satisfactorily the chaotic, internally inconsistent, to a large extent anachronistic, condition of our substantive 
criminal law must be taken in hand. Both the report on Prosecution and the report on the Criminal Courts bring out the relative disproportion in the time devoted to civil as compared with criminal litigation. It is not that the former receives too much judicial attention, but that we have acquired a habit of neglecting the latter. This is true no less of the substance of the law. We have made great strides in the civil side of the law in a generation. Much has been done in civil procedure in the last two decades. But criminal law has stood still, and with a few notable exceptions in one or two localities criminal procedure remains what it was fifty years ago. Thus the neglect of the criminal law by the leaders of the bar, reflected in neglect of it in our law schools, bears fruit in a backward condition which is full of advantage to the law breaker and to those who make their livelihood by representing him. What we have to do is nothing less than to reshape the substantive criminal law so as to maintain the general security and the security of social institutions, and at the same time maintain the social interest in the human life of every individual, under the circumstances of the modern city; and we must do this upon the basis of traditional rules and principles in which the latter was chiefly regarded, and yet were warped in their application by those who regarded only the former.

This is too large a subject for the city. As things are it calls for nothing less than a ministry of justice, at least in each of our larger States; for our so-called departments of justice are but offices for legal advice to State officers, for representation of the State in its civil litigation, and for advocacy in the courts of review in criminal causes. In the federal government the Department of Justice is more. There it is a well-organized prosecuting bureau. But nowhere is it organized to study the functioning of our legal institutions, the application and enforcement of law, the cases in which and reasons for which it fails to do justice or to do complete justice, the new situations which arise continually and the means of meeting them, what legislation achieves its purpose and what not and why, and thus to give expert and intelligent guidance to those who frame and those who administer our laws. In the rural, agricultural society of the past, the judiciary committees of the two houses of the legislature could do efficiently so much of this as was needed. Today, even if our crowded legislative sessions allowed the time, no legislative committee is competent to the highly specialized work required. In consequence, commissions are provided from time to time to study particular subjects. But their work is not coördinated, there is no continuity in what they do nor in what successive legislatures do, and the whole process is wasteful, expensive and ineffective. A 
ministry of justice in the foregoing sense was proposed by Jeremy Bentham during the English legislative reform movement of the last century. It was approved by the Conference of Bar Association Delegates at the meeting of the American Bar Association in 1917. It was recommended in 1918 by a Parliamentary Commission headed by Lord Haldane as one of the chief items in a plan for reconstruction of the British administrative system. ${ }^{1}$ It deserves to be kept in mind by American lawyers as one of the things to be provided in the inevitable reconstruction of our administrative system in a country in which the center of gravity has definitely shifted to the city.

\section{Organization of the Administration of Justice}

It is no less urgent, and more immediately practicable, to organize the administration of justice as a whole and in all its branches, to prune the accumulation of checks and mitigating agencies which discourage prosecuting witnesses and afford opportunity of escape to the guilty without profiting the innocent (see, for example, the manner in which preliminary examinations are conducted in the Municipal Court, as disclosed in the report on Prosecution), to coördinate responsibility and power, putting both in a few conspicuous officials charged with authority to supervise and direct and plan and enforce their policies, and with responsibility for the due functioning of criminal justice, and to correlate the judicial and administrative agencies, so that, instead of acting independently, and sometimes in conflict, they will operate with one known policy in all things and will not be able to shift responsibility from one to the other or let it fall down between them, as in the Raleigh prosecution. Only in this way is it possible to insure an efficient machine to dispose of the great volume of prosecution required in the modern city and enforce the great mass of police regulation demanded by the conditions of urban life.

Specifically, three points are to be urged:

\section{(i) Unification of Courts}

The system of courts should be unified. An administrative head should be provided with large powers of organizing judicial business, of systematizing the assignment of cases to judges and judges to types of work, of applying the judicial force where the exigencies of the work demand, and of applying it upon that work to the best advantage. Thus, in place of rotation of judges dictated by political exigencies, the personnel of the bench would be employed systematically and intelligently, as

'See Judge Cardozo's "Ministry of Justice," 35 Harv. L. Rev. 113. 
the size and importance of the work demand. Also he should have power, in connection with a council of judges, to initiate and determine policies so that the unseemly spectacle of two judges of coördinate jurisdiction applying the same law in two wholly different ways in two adjoining rooms shall come to an end, and he should be responsible for the due functioning of the judicial system in all these respects.

\section{(ii) Organization of the Prosecuting System}

The prosecuting system should be unified. The administrative head of the system should have full power to control and responsibility for the acts of his subordinates. He should be required to keep proper records of all that goes on in the course of a prosecution from the beginning, with recorded reasons for his action in types of proceeding where the law, made for simpler conditions, now requires what has become a perfunctory approval by the court. He should be a part of an organized general prosecuting system of the State, not a wholly independent functionary. Note, for example, in the report on Prosecution the extent to which the public prosecutor may, if he chooses, neglect to assist the court of review with proper briefs or arguments. No publicity attends his neglect of that duty, and he has it in his power to present the State's side of a criminal appeal or not, wholly as he likes. In the same way he may coöperate with or operate independently or even thwart the police, and they are in a like position with respect to him. Criminal investigation and preparation of causes for trial have reached a high degree of development. But our prosecuting system is not adapted to the one, and except in sensational cases, its methods with respect to the other are usually crude in comparison with those employed in civil litigation. If nothing else were to be considered, the mere waste of energy involved in an unorganized prosecuting system ought not to be tolerated in view of the volume of criminal business in the courts of a modern city. To no small extent the effectiveness of English criminal justice is due to the centralized administrative supervision exercised by the Director of Public Prosecutions. His vigilant scrutiny of what is done and what is not done by local prosecuting agencies has no parallel in our State prosecuting organization.

\section{(iii) Organization of Administrative Agencies}

All administrative agencies, including the work now done in connection with the administration of justice by sheriffs, coroners, clerks, bailiffs, and probation officers, should be unified and organized under a responsible head, put in proper relation to the head of the judicial system, so as to eliminate friction and insure uniform policies in judicial and 
administrative action. This administrative head should have the power to determine the details of organization as circumstances require, to systematize and supervise, to initiate and enforce policies, and to set up such technical and expert adjuncts to the court as the business before it may require. He should be responsible for the proper functioning of this part of the administration of justice. He could easily save enough by proper organization and improved administrative methods to justify his position on that score alone. If for no other reasons, organization of the administrative agencies of our judicial system is demanded by considerations of expense. The cost of administering criminal justice in the modern city by methods devised for wholly different conditions precludes doing many things as they should be done, while wasting money in doing other things that need not be done, or in doing them in clumsy and expensive fashion. The enormous sums of money which we spend each year in the judicial administration of justice and its administrative incidents must eventually invite scrutiny of the mode in which those sums are employed. Through the fault of no person, but because of the system made for other times and different conditions, they are not employed to the best advantage. Nor can they be so long as city and county administration of justice go on parallel and independent in the same urban area, overlapping in many things, duplicating machinery unnecessarily, and without effective correlation of activities. Other functions of government are requiring and will continue to require increased expenditures and exacting taxation. Every source of expense that competes with them must justify itself by economy and efficiency. Here as elsewhere these things are not to be had through a decentralized congeries of independent functionaries, but by organization, system, supervision, and concentrated responsible authority.

\section{Adequate Provision for Petty Prosecutions}

Comparison of the facilities provided for and time spent upon small civil causes as compared with small criminal causes calls for serious reflection. The statistics on this head in the report on Prosecution and the report on Criminal Courts may be duplicated in almost any metropolitan area, and are a reproach to American administration of justice. It is at this point that the administration of criminal justice touches immediately the greatest number of people. It is at this point that the great mass of an urban population, whose experience of law is too likely to have been only an experience of arbitrary discretion of police officers and offhand action of magistrates, tempered by political influence, might be taught the spirit of our institutions and made to feel that the law was a 
living force for securing their interests. Such extra-legal proceedings as those by summons in the municipal prosecutor's office, proceedings with no warrant in law and hence no legal safeguards that may easily degenerate into violation of constitutional rights under color of legal authority, should give way to a proper administrative organization whereby the courts in our large cities could function legally as bureaus of justice. The legal profession as a whole has little interest in petty prosecutions. But for the very reason that these proceedings are in consequence withdrawn from the field of active scrutiny by the bulk of the profession our bar associations should be zealous to see that adequate provision is made for them. Few of the leaders of the profession are aware of the actual situation, and when the facts are stated publicly, some of the best, most public-spirited, and most respected members of the bar are not unlikely to assume that such things cannot be true and to denounce those who reveal them as agitators or muck-rakers.

\section{Preventive Methods}

Preventive justice is no less important than preventive medicine. If we think of the legal order in terms of social engineering, it must be evident that sanitary engineering is not the least important feature. Prevention at the source rather than penal treatment afterward must be a large item in dealing with crime. Cleveland is well awake to this, and has well-organized institutions for social work. But no survey would be complete that did not emphasize the importance of correlating these institutions and agencies with police, prosecution, judicial organization, and agencies of penal treatment. There ought to be no possibility of misunderstanding, friction, or cross-purposes. And this requires that the administrative agencies connected with the administration of justice be unified and organized under a responsible head.

\section{Justice in Family Relations}

Conditions of crowded urban life, periodical unemployment, shifting of labor from city to city, and economic pressure threaten the security of the social institutions of marriage and the family and call for special consideration in organizing the courts of our large cities. Administration of justice in relations of family life is difficult for two reasons: one is that it involves questions on the borderline between law and morals, where, from its very nature, law is least efficacious; the other is that proper judicial adjustment of controversies involving those relations calls for wide discretion and yet they involve matters more tender than any that can come before tribunals. Such questions must be dealt with 
as a whole, not piecemeal, partly in criminal prosecutions, partly in juvenile courts, partly in petty proceedings before magistrates, and partly in courts having jurisdiction to appoint guardians. They must be dealt with by strong judges with large experience and trained intuitions. Anything less is a denial of justice to the mass of the population which cannot afford protracted legal proceedings in many courts. Anything less is a menace to the most fundamental of social institutions. To achieve these things the courts and administrative agencies connected therewith must be unified so that causes may be disposed of as a whole, without repeated partial threshings over of the same straw in separate proceedings, and so that causes that call for strong judges may receive the treatment they deserve without regard to the sums of money involved.

\section{Unshackling of Administration}

Above all, effective administration of criminal justice in the modern American city calls for an unshackling of administration from the bonds imposed when men who had little experience of popular government and much experience of royal government sought to make rules do the whole work of the legal order. The principle involved in the constitutional separation of powers is really no more than the principle involved in all specialization. Certain things which involve special training or special competency or special attention are done better by those who devote thereto their whole time or their whole attention for the time being. Hence if the officers of a court may best gather and study statistics of judicial administration to the end that such administration be improved; if they may best conduct psychological laboratories or psychopathological examinations or laboratories for the study of criminals, there is really nothing in the nature of a court to prevent. There is no reason why the courts in metropolitan areas may not be so organized as to permit these things, although they are not needed or are less needed in rural areas and hence are not provided for therein. The nineteenth-century political idea of uniformity over geographic areas, thinking in feudal terms of soil rather than of human beings peopling the soil, is not applicable to States of today in which populations greater than those in whole States when this idea took root in our State constitutions are compressed within a few square miles of municipal jurisdiction. A unification of administrative agencies with power to adapt administration to the peculiar needs of particular localities must supersede rigid uniformity over areas laid out according to the exigencies of the map. Regulation of public utilities, factory inspection, tenement house inspection, building laws, and a score of things of the sort have accustomed us to administrative boards 
and commissions with wide powers to organize their business and large administrative discretion. There are no such checks upon these boards and commissions as are operative in the case of courts. And yet, for historical reasons, we are loth to confer upon judicial administrative agencies the latitude which we freely concede to newly created executive agencies. Undoubtedly one of the tasks of American law today is to work out an adequate system of administrative law. But there is no reason to suppose that judicial administration is not as adequate to this task as executive administration.

\section{State ANd City}

For the larger part of what it needs in the way of machinery to cope with crime the city must depend upon action by the State legislature or even amendments of the State constitution. The State may do anything not prohibited by the federal constitution. The State legislature may do anything not prohibited by federal and State constitutions. The city may do only what the State empowers it to do. Hence in order to adapt the institutions devised for rural conditions of the past to the rapidly changing urban conditions of today, it must first induce action by those who live under quite different conditions, to whom the methods and agencies developed for rural communities of the last century seem entirely adequate. When there are several large cities in a State, each with its own problems, and a large agricultural population with preponderant political power, proper provision for the special needs of criminal justice in the city becomes a matter of much difficulty. Here again a unified judicial organization for the whole State and organization of the administrative agencies of justice for the whole State, under a head responsible for insuring an adequate functioning of the legal system in each locality, and clothed with power to make the proper adjustments to that end, may bring about the right compromises between urban and rural needs from time to time as occasion requires, and preserve the balance as changes take place, without disturbance of the fundamental organization. 


\section{CHAPTER V}

\section{LOCAL AND TEMPORARY DIFFICULTIES}

\section{Exceptionally Rapid Growth}

$\mathbf{F}$ EATURES of the administration of criminal justice which may be found in large cities throughout the country and difficulties which operate in all American cities to a greater or less degree are exaggerated in Cleveland because of exceptionally rapid growth in population and rapid industrial expansion. A city which has increased in population so rapidly and in so large a proportion within the past decade may not expect that its legal institutions will keep pace with such expansion.

\section{Instability of the Industrial Population}

Another factor of importance is the mobile population due to the rapidity of industrial expansion in recent years. In May, 1920, there were 127,285 children in the public schools of Cleveland. Between June, 1920, and April, 1921, 40,300 children in the public schools changed their residence. Of these, 5,063 moved out of the city. The figures at hand indicate that a little more than 63,000 , or more than 40 per cent. of the whole number of children in the public schools, moved during the past year. In some instances the same child moved twice or oftener during that time. These figures show a high degree of mobility among the relatively stable part of the industrial population represented by children in the schools. Data from the census of 1920 as to the mobility of the population of Cleveland are not yet available and will not be published for some time to come. The census of 1910 showed that 52.8 per cent. of the population was born in Ohio, 11.9 per cent. in other States, and 35 per cent. in foreign countries. Since that time the city population has increased nearly a quarter of a million.

Some studies made during the war indicate that the moral implications of an increasingly migratory laboring population call for serious consideration. Our institutions presuppose a stable, home-owning, taxpaying population, of which each individual has and feels a personal interest in its legal and political institutions and bears his share in the 
conduct of them. Irregularity and discontinuity of employment and consequent migration from city to eity, or back and forth between city and country, preclude the sort of society for which our institutions were shaped. That these things must make for crime and for the bad functioning of criminal justice in a large urban population is self-evident, and is shown abundantly by the facts disclosed by this survey. A survey of the industrial situation with reference to these things would no doubt disclose much that might be used with effect in preventing crime.

\section{Post-War Conditions}

Finally, a temporary difficulty of some moment is to be seen in the conditions following the war. Legal history shows us that crime has always increased notably for a time after a long or hard war. In this country the increase of crime after the Revolution and after the Civil War was marked. In England it was especially notable after the Napoleonic wars. It is well marked in Europe today. The economic and social conditions which contribute to this phenomenon are especially pronounced in the large city. Moreover, the circumstances of the late war, during which laborers were highly paid and all members of the family were employed, leading to habits and modes of life which do not readily readjust, coöperate with the habits of rough and ready action and callousness toward life and limb and property, which every war has developed for a time. Thus the conditions arose which came to be known as "crime waves." These things belong to a social and economic survey rather than to a survey of criminal justice. Yet we must take account of them in any appraisal of the functioning of criminal justice during the past three years.

Thus far I have considered the difficulties involved in the administration of criminal justice in an American city of today, seeking to connect the conditions found in Cleveland with those that exist to some degree in all our cities, and have considered the ultimate remedies. This is a necessary background. It shows also that remedying many of the clear evils involved must be a slow process, and that the remedies immediately available may not be expected to achieve permanent results. Yet they may improve the administration of criminal justice in Cleveland a great deal. These immediate measures of improvement will be considered in the following pages. 


\section{CHAPTER VI}

\section{POLICE}

$T \mathrm{~N}$ reading Mr. Fosdick's study of police administration in Cleveland one must be struck with the relation of the points which he brings out to those which are disclosed in the studies of courts, of prosecutors, and of penal treatment. In each case the primary difficulties arise from "transient administration," suitable enough in a rural community of the nineteenth century, and from trying to meet the needs of an urban community of today by merely adding numbers to the administrative force or by adding further incoördinated administrative agencies to a system which was devised originally for a small town.

Seven points in connection with the report upon police, most of which will recur in one form or another in each of the other reports, deserve to be noted. These are: (1) The transition from rural to urban and thence to metropolitan conditions has been met not by intelligent reconstruction, but by patching and addition of numbers; (2) lack of continuity in administration; (3) rigidity of organization, making adjustment to the exigencies of rapid growth and exceptional diversity of population impossible; (4) a tendency to perfunctory routine growing out of the foregoing circumstances; (5) division of power and diffused, ill-defined responsibility, making it difficult to hold any one to account for unsatisfactory results; (6) an assumption of versatility on the part of the officials and subordinates, whereby they are expected to do specialized work offhand in a system of frequent rotation without any adequate provision for the specialization involved in the large undertaking of enforcing the criminal law in a modern city; (7) want of provision for intelligent study of the functioning of administrative machinery, either by those who operate it or by others.

(1) As growth in population takes place the staple resource of our lawmakers has been to provide more offices, more officials to each office, and more administrative machinery of the same sort as that already existing. Hence no student of American legal and political institutions need be surprised to learn from Mr. Fosdick's report that Cleveland's police force of 1921 is little more than the police department of 1866 magnified. We shall not appreciate what this means if we say merely 
that the population now is more than eight times what it was before. For the difference between the Cleveland of that day and the Cleveland of today is one of kind, not merely one of degree. The change has been treated as if it were but one of degree. A few examples discussed in the report on police will bring this out.

Thus it appears that the patrol force is distributed and managed exactly as it was thirty years ago, and the patrol routine is determined by a tradition coming down from a time when demands upon and conditions of the patrol service were wholly different. The complete change in these demands and conditions in recent years has brought little change in the method of distribution of the patrol force or in the supervision of its operations. Again, we are told that the radical change in the population of Cleveland and the consequences thereof for police administration have brought about nothing new in the detective service except new faces and a few meager records. In Cleveland, as everywhere else, it has been assumed that given a certain number of officers, administrative machinery would somehow run of its own motion. Nor will it do to say that money is lacking or has been lacking to do more. A system of patching and of adding more men to an organization made for different circumstances consumes money in doing needless things. See, for instance, the reports on 16 cases of burglary in January, 1921, set out in Chapter VIII of Mr. Fosdick's report. Such expenditure of time and money in perfunctory routine is worse than useless. A system that allows such things to go on indefinitely without scrutiny and with provision of more of the same sort as a staple remedial device cannot be expected to leave money available for needed facilities in a metropolitan community.

(2) "Transient administration," as Mr. Fosdick well puts it, "is fatal to success in any complex technical enterprise." The public business is the only sort of business in which it is tolerated in the United States of today. Every part of the administration of criminal justice suffers from it. It is one of the legacies of pioneer America. It results in almost complete want of continuity in administration, leading to want of settled policy, conflict of policy between successive incumbents, and waste of time and effort by each incumbent in learning what ought to be a known body of organized experience handed down from official to official, continually added to and continually adapted by trained intelligence to the newer conditions as they arise. But such things are impossible unless the head of the police is a permanent official, chosen without regard to politics or to geography. The pioneer notion of short tenure and selection from among the voters of a politico-geographical area is out of place in the city of today. 
(3) Rigid organization applied to the entire force regardless of the differences in the types of work appropriate to the different branches of police service and regardless of the shiftings of population, changes in the character of localities, and rise of new sorts of crime and instruments of wrongdoing, is an obstacle to police efficiency, just as rigidity of organization impedes efficiency of the courts and, indeed, of all the administrative agencies of criminal justice. A striking example may be seen in the organization of patrolling. The city is divided into precincts, which are in effect so many separate police departments with their own records, their own hierarchy of rank, their own complement of men, and an organized system of commanding and of supervising officers. The occasion of this precinct organization is to be found in old-time conditions of transportation and of the attempt to solve the problem of police distribution in view of those conditions. When policemen had to go on foot or on horseback to their posts and to the station where they reported, it was necessary to set up substations where they could meet and report and from which they could be sent out. Motor cycles and motor cars have obviated the conditions for which the organization grew up. But the hard and fast geographical lines and precinct organization remain and are unaffected by continual changes in the character of the several districts and in the problem they present to police administration. $\mathrm{Mr}$. Fosdick's recommendations in this respect deserve thorough consideration, not only in themselves, but because the condition of rigid organization on which he comments is not confined to the police but pervades the whole administration of criminal justice.

(4) Lack of continuity, rigid organization, and division of responsibility result in administrative lethargy. Officials become caught, as it were, in the cogs of the machinery and cease to bestir themselves to effect results or to take advantage of the opportunities of their positions. They easily fall into a perfunctory routine and work in a rut, laborious and conscientious it may be, but without intelligence or constructive policy. The poor work of the detective bureau shown in Chapter VIII of the report on Police Administration, the poor development of crime prevention shown in Chapter IX, the circumstance that Cleveland was the only city of over half a million population at the date of this survey which was without policewomen, the want of adequate provision for use of motors in patrolling and in police work generally, as set forth in Chapter VII, and the stereotyped, unelastic work of the civil service commission set forth in Chapter IV, will be found paralleled by a like failure to rise to the opportunities of administration disclosed in the report on prosecution. These things are not to be attributed to the de- 
ficiencies of persons holding office for the time being. They are deep seated in our administrative system. The development of police training schools in Cleveland, a notable administrative achievement, shows that, in spite of the system, individual ingenuity and capacity will do things. Yet by their very contrast such achievements serve to emphasize the condition of drift which must go with lack of continuous policy, rigid organization, and divided or undefined or non-located responsibility.

(5) Division of power, diffused, ill-defined, and non-located responsibility, are obstacles to efficient working of the administration of criminal justice in every department. In police administration in Cleveland we find a conspicuous example in the undefined line between the authority of the chief of police and the authority of the director of public safety, (discussed in Chapter III of Mr. Fosdick's report), the curious situation in which the chief of police is responsible to the mayor for incompetency, but to the director of public safety for the conduct of his work, the falling down of responsibility for discipline between the chief and the director, and the system of two officials with much power to check and thwart each other, but with little power of assured initiative and with indefinite responsibility. Another example may be seen in the divided power with respect to discipline, discussed in Chapter IV. Still another may be seen in the lack of coördination between the civil service commission and the police department, also discussed in Chapter IV. Such things are characteristic of all American administration and have come down to us from pioneer conditions, where division of power had an important function and operated to meet real needs of society. Mr. Fosdick's recommendation that power be concentrated in a single responsible expert administrative head of the police force is in line with what must be done in every department of the administration of criminal justice if it is to be effective for its purpose.

(6) Police administration suffers especially from what Kipling calls the American idea of versatility - the idea that any man can do anything. A general in the Civil War tells us that for a time the notion prevailed in the North that 1,000 men, plus 1,000 horses, plus 1,000 sabres, would make a cavalry regiment. It was no matter that the men knew nothing about the care of horses. There was a lively faith that they would be able to put up their horses in some sort of peripatetic livery stable at the end of the day's march. In the same way we assume that 100 men, plus 100 uniforms, plus 100 clubs, will make 100 policemen. As Mr. Fosdick points out, most policemen are recruited from occupations whose character is as far removed as can be from the character of the work which they are to do. Naturally, there is a large turnover of police 
personnel which is incompatible with effective work. This pioneer idea of succession in public employ, of continual rotation, and that there is no need of careful development of specialists for special tasks stands in the way of effective criminal justice in the modern city in every connection. Examples in police administration in Cleveland are to be seen in the work of the detective bureau, as set forth in Chapter VIII, and the want of adequate provision for prevention of crime, as set forth in Chapter IX. One need not have made a special study of police to perceive the cogency of Mr. Fosdick's argument as to the need of specialization in both connections. His recommendations on these points should be noted particularly.

(7) Finally here, as everywhere else, in our administration of criminal justice, there is no provision and there are no facilities for intelligent study of the functioning of the machinery by those who operate it or are responsible for its operation. There was no need for such study in the rural or small urban community of the nineteenth century. The things that had to be done were simple and were within the comprehension of the average intelligent citizen. It is otherwise with the questions which come up in police administration today. Such matters as those to which Mr. Fosdick calls attention-organization of the patrol service, the use of motors in police work, recruiting and organization of the detective force, organization of the clerical work of the police department, and special service in crime prevention-must be studied constantly in the light of metropolitan conditions exactly as similar problems of organization and management are studied in a modern business establishment. To take one more instance, set forth in Chapter $\mathrm{X}$ of the report on police, the detailing. of detectives and sergeants of police to do clerical work is an outgrowth of the simpler conditions of the past, when there was little of such work to be done and the policemen could easily do it themselves. Today such a system involves waste of money and waste of administrative power. But there is no one person who is responsible for studying such conditions or has power to deal with them effectively. Hence there is no pressure upon any one comparable to the competition in business which compels the business man to be a vigilant student of the functioning of his plant or to go to the wall.

All the recommendations in the report on police depend upon the one pivotal point of entrusting complete authority to and concentrating full responsibility in a single directing head with permanent tenure, making police service an independent department, as is now done in the majority of the large cities of the United States. The details are in Chapter III of Mr. Fosdick's report, and it would not be useful to repeat them. But 
the central idea of "a direct line of responsibility running from a single head down through the whole organization," and of avoiding all "short circuits of responsibility," is one which cannot be urged too strongly. Overhauling of the whole administrative machinery of criminal justice with this idea before us is the remedy to which every part of the survey unmistakably points. 


\section{CHAPTER VII}

\section{PROSECUTION}

7 WO significant facts are the starting-point from which we must begin in considering the prosecuting system in Cleveland today. The county prosecutor's office was created and its functions were defined more than one hundred years ago, and its traditions and methods had been definitely shaped at the time of the Civil War. The municipal prosecutor's office was created in 1854, and its traditions and methods are still those of the old-time police court prosecutor. It is impressive to compare the one county prosecutor of 1863 , when the population of Cleveland was 58,000, when there were 60 indictments and 1,600 arrests in a year, and when the criminal code contained 249 sections, with the eight (one prosecutor and seven assistants) county prosecutors of today, working in a county population of 940,000 , with 2,700 indictments and 27,000 arrests each year, and enforeing a criminal code of 1,053 sections. That indictments are 45 times as many, arrests about 17 times as many, and crimes defined by statute four times as many, as in 1863 are impressive facts. But to put it thus is to divert attention from the most significant fact. What we have to deal with is not merely an enormous increase in population, in the number of indictments, in the number of arrests and in the number of legislatively defined crimes. It is a radical change in the conditions and character of crimes and in the environment of prosecutions. The multiplication of the number of prosecutors by eight and of the payroll of the office by 24 , which has gone along with the growth in population and in the volume of criminal prosecution, might well have sufficed if there had been a simple question of multiplication. That easy resource has proved unequal to a situation which is not the situation of 1863 multiplied by eight, or by 12 , or by 24 , but a wholly new one to which the methods and the machinery of 1863 are not adapted.

In connection with the report on Police Administration I suggested seven points of general significance which related the difficulties in police administration in Cleveland today with those found in other departments of criminal justice. It will be worth while to note these identical points as they are brought out no less clearly in the report on prosecution. 
(1) Transition from rural to urban and thence to metropolitan conditions has not been met by intelligent reconstruction, but simply by addition of more men and expenditure of more money. Take the municipal prosecutor: the methods of his office are still the methods of the date of its origin-before the Civil War. There is no system or organization whatever, as, indeed, there did not need to be in the simple conditions of that time. Old-time casual methods of indiscriminate lumping of all sorts of cases on one docket, the want of any intelligent segregation of the work, and the consequent disorder and delay which wear out witnesses and lead many lawyers to avoid practice on the criminal side of the municipal court, were proper enough in the police court of a city of 58,000 inhabitants with a municipal code of 100 standing ordinances. ${ }^{1}$

It was well enough then to have no system of segregating cases, to have no system of keeping affidavits, ${ }^{2}$ to have no records or file or docket, but rely wholly on the court docket for such information as could not be held in the prosecutor's memory, ${ }^{3}$ to have no stenographic record of the testimony on preliminary examinations ${ }^{4}$ and to make no systematic preparation of the cases prosecuted. ${ }^{5}$ The whole process disclosed is that of the old-time country law office with relatively few cases to be tried at periodical terms with intervals between them where pencil memoranda on the back of a few files will eke out memory and suffice for all purposes. To conduct such an office efficiently/under the conditions of today there must be system and organization and intelligent segregation of cases, as well as numerous assistants. So long as the latter is the sole expedient relied upon to cope with the difficulties of the office it is no wonder that complaint is made of insufficient time to handle the great volume of work effectively. Nor is it strange that perjury is rife and prosecution ineffective when there is no stenographic report of the testimony in preliminary examinations. Under such circumstances the testimony at the trial may vary from that at the preliminary examination without any check, and there is not sufficient material available for preparation on the part of the trial prosecutor. Nor is any indubitable proof at hand upon which to prosecute for perjury. If one compares this practice, suitable enough in the Cleveland of fifty years ago, with the English practice, ${ }^{6}$ he may perceive another reason for the ineffectiveness

1 The municipal prosecutor's office was created in 1854. The Revised Ordinances of Cleveland of 1855 contained 109 standing ordinances.

2 Report on Prosecution, p. 120.
'Ibid., p. 122.
Ibid., p. 118.
5 Ibid., pp. 138-139.
- Ibid., pp. 201-202. 
of the criminal justice here as compared with English cities of greater population.

In the county prosecutor's office, except for a good system of records and provision of a managing clerk in June of the present year, little has been done beyond adding a corps of assistants to differentiate the office from a country prosecutor's office of today or from the office as it was in Cleveland sixty years ago. The result is what Mr. Bettman happily terms "a system of serial unpreparedness," inevitable when a prosecutor in a city of 800,000 inhabitants and a calendar of over 2,700 indictments each year uses methods coming down from a time when 60 indictments were a year's work and the single prosecutor could rely on his own memory. This seems to have been aggravated by a practice of so arranging the work of the assistants that the trial prosecutor shall not know in advance what case he is to try. ${ }^{2}$ This practice, which obviously makes prosecution feeble and inefficient, seems to have been thought necessary to prevent improper influences from being brought to bear upon an assistant who is known to be in charge of a case. ${ }^{3}$ Thus the absence of organization and of responsible administrative control compels resort to devices that merely add to the existing ineffectiveness.

(2) Want of continuity in administration is a cause of ineffectiveness in prosecution no less than in the work of the police. Thus, in Mr. Bettman's report ${ }^{4}$ we find that in January, 1921, 12 of the first 16 cases tried before one of the judges in the criminal branch of the Court of Common Pleas resulted in acquittals. This is too large a percentage of failure to be accounted for even by the want of systematic preparation for trial which has prevailed in all prosecution in Cleveland and is a legacy of the past. The opinion of the trial judge $\mathrm{f}^{5}$ that the entire change in personnel involved in a change of administration was a considerable factor in this unfortunate result seems entirely warranted. If the reader will note the complete turnover in the personnel of the force on January $1,1921,6$ he cannot but see that even if there had been proper organization and systematic methods of preparation, it would not have been easy to enter at once upon the trial of 16 cases and to give proper attention immediately to more than 800 indictments. If there are reasons for periodical election of the prosecuting attorney,--which is at least debatable,--some degree of permanent organization in the office is clearly required. When there were but 60 indictments each year, a new prosecutor could come into office on January 1 and pick up in a few days the relatively few

1 Report on Prosecution, p. 172.

Ibid., p. 174.
- Ibid., p. 174.

2 Ibid., p. 175.

- Ibid., p. 165.
Ibid., p. 163. 
threads that would enable the work of the office to go forward effectively. Under the conditions of today this is impossible.

(3) Rigidity of organization is another factor in the ineffectiveness of prosecution, as in the ineffectiveness of police administration. Both the county prosecutor's office and the municipal prosecutor's office are laid out along hard and fast lines of three grades of assistants at fixed, graded salaries. In practice these assistants are largely independent functionaries, acting on their own responsibility. ${ }^{1}$ In the case of the municipal prosecutor, the assistants are appointed by the director of law, the same as their chief. In the case of the county prosecutor, the assistants are appointed by the prosecuting attorney, but there seems to be a tradition or habit of independent action. ${ }^{2}$ In effect the positions of assistant prosecutor have been treated as so many political jobs to be handed out, and the assistants have been set up as graded, more or less coördinate prosecutors, instead of an organized staff of subordinates. There is much excuse, therefore, for the incumbents who have not exerted themselves to introduce system and organization and improve methods needed to cope with the business with which the prosecutors' offices are now confronted. Struggling with a huge volume of work, and hampered by rigid lines imposed by law or by traditions of independent action on the part of assistants, who are coördinate rather than subordinate, it is no wonder that prosecutors in Cleveland have shown little initiative in adapting their offices to the work to be done and have not risen to the few opportunities that have been left open to them. The same situation of independent and unsupervised action of assistants is to be seen in many cities. Everywhere it produces the same results. It was much in evidence in the recent proceedings against a prosecuting attorney in metropolitan Boston.

(4) Naturally, as we have seen already in police administration, the conditions just discussed, coupled with division of power and diffused, ill-defined responsibility, have given rise to a tendency to make of prosecution a perfunctory routine-a tendency which is destructive of efficiency. In the municipal prosecutor's office this is strikingly manifest in the purely negative rôle of the prosecutor in trials in the municipal court, ${ }^{3}$ in the perfunctory preparation of cases, ${ }^{4}$ in the perfunctory drawing of affidavits which often results ultimately in throwing out the case before the grand jury or nolle prosequi because the offense charged does not correspond to facts provable, ${ }^{5}$ in the perfunctory acquiescence in

1 Report on Prosecution, p. 119.

2 Ibid., p. 163.

Ibid., p. 114.

' Ibid., pp. 138-139.

Ibid., p. 139. 
suspension or mitigation of sentence, ${ }^{1}$ in the former laxity as to enforcement of bail bonds, ${ }^{2}$ and in the perfunctory attention or lack of attention to the execution of sentences. ${ }^{3}$ When we remember that admittedly there is much more than enough work for the whole force of the prosecutor's office to do, the perfunctory presence of an assistant in court in cases in which there is really nothing for him to $\mathrm{do}^{4}$ is a conspicuous example of how a routine may develop which involves waste of power, precludes efficiency, and prevents realizing of the possibilities which exist even in an outworn system. ${ }^{5}$

In the county prosecutor's office there are many examples of the same tendency, such as perfunctory preparation of cases which, under the circumstances of today, amounts to no preparation, ${ }^{6}$ perfunctory observance merging into non-observance of the rule as to reasons for nolles, ${ }^{7}$ the former laxity in watching bail proceedings ${ }^{8}$ laxity in the requirements of statute with respect to mitigation of sentence, ${ }^{9}$ laxity as to the rule requiring that the court be furnished with a list of known criminals against whom prosecutions are pending, ${ }^{10}$ perfunctory examination of trial jurors, ${ }^{11}$ and laxity in following cases to the appellate court. ${ }^{12}$ This tendency to make important features of prosecution into a mere perfunctorily followed ritual is destructive of efficiency and explains much in the "Mortality Tables" in Mr. Bettman's report. ${ }^{13}$

(5) More fundamental and more serious is the division of power and diffused, ill-defined responsibility, which we have seen already in police administration. This is especially clear in the office of the municipal prosecutor, and its results are manifest in Chapter II of the report on Prosecution. In the first place the municipal prosecutor has no real control of his own office. His assistants are appointed by the director of law. But the latter devotes his attention almost exclusively to civil litigation of the city. Hence the assistant prosecutors are substantially without executive control or supervision, and each pursues his own policy or lack of policy, his own interpretation of the law, and his own methods. ${ }^{14}$ With no real records to act as a check, in that, in contrast with the practice in civil cases, the records and files do not show who acted in any particular case, ${ }^{15}$ responsibility for the wide powers of "no papering" and nolle prosequi falls down between the prosecutor, the assistants, and the
1 Report on Prosecution, pp. 140, 141.
Ibid., p. 155.
Ibid., pp. 152-154.
Ibid., p. 197.
Ibid., p. 204.
- Ibid., p. 170.
7 Ibid., p. 181.
8 Ibid., p. 184.
- Ibid., p. 182.
${ }^{10}$ Ibid., p. 175.
11 Ibid., p. 162.
12 Ibid., p. 187.
${ }^{13}$ Ibid., pp. 91-95.
14 Ibid., p. 119.
15 Ibid., p. 131. 
court. ${ }^{1}$ The opportunities for sinister influence upon the administration of justice in the lax practice of "no papering" are apparent. ${ }^{2}$ No doubt, with the small calendars of sixty years ago, reliance upon memory served well enough. Today, when the number of State cases "no papered" in the municipal court is about one-third of the whole criminal calendar of 1863 , it is evident that the proceeding needs a check. But nobody is responsible for providing an effective one. A like situation is disclosed in the matter of accepting pleas of lesser offense, ${ }^{3}$ and in the power of so presenting or failing to present a case to the grand jury as to result in the grand jury failing to bring in an indictment. ${ }^{4}$ A result is to be seen on pages 238 to 240 of the report on the Criminal Courts. A system under which, in ten years, the same person can be before the courts from 10 to 18 times, largely on charges of robbery, burglary, and larceny, which make it clear that he is a habitual or professional offender, and can escape at least half of the time by discharge on preliminary examination, no bill, nolle, plea to lesser offense, or suspended sentence, with no records showing who is responsible, is nothing short of an inducement to professional crime. Much has been said heretofore about the lack of proper preparation in criminal prosecutions, which is in startling contrast with the careful preparation of civil litigation in the offices of those who practise in civil cases. It is to be noted that some of the most serious features of this habitual unpreparedness on the part of the prosecution flow from divided responsibility. ${ }^{5}$ Mr. Bettman's suggestion ${ }^{6}$ that all State cases be put in exclusive charge of the county prosecutor from the outset is the beginning of any effective improvement of prosecution in Cleveland.

(6) Another legacy from pioneer or rural conditions which seriously impairs efficacy of prosecution is the assumption of versatility on the part of the prosecutor's assistants, which is involved in a system of choosing them on the basis of politics or of allotment among the different racial groups, and then throwing the work of the municipal prosecutor's office at them as chance dictates, with no distribution or specialization, presuming that they may all rotate from one sort of work to another with satisfactory results. In the old days of small calendars, a small penal code and a small body of standing ordinances, this assumption of versatility on the part of the prosecuting officer was sound enough, for no great versatility was involved. When, instead of one prosecutor to 60 cases, there comes to be one to 318 , it is another story.
1 Report on Prosecution, pp. 143-146.
2 Ibid., p. 144.
${ }^{3}$ Ibid., p. 149.
"Ibid., p. 179.
5 Ibid., p. 208.
${ }^{6}$ Ibid., p. 209. 
(7) Again, in prosecution, as in police administration, it is no one's business to study the functioning of the system, nor are there adequate facilities open to those who are in some measure definitely responsible for the initiation of better methods, whereby they may be able to rise to that responsibility effectively. Such matters as modernizing the system of beginning every petty prosecution with arrest, ${ }^{1}$ or provision of stenographic report of testimony at preliminary examinations, ${ }^{2}$ with which all students of English prosecution are familiar, are left in the condition in which they were seventy-five years ago because no one is definitely charged with the responsibility of keeping the methods of prosecution abreast of the requirements of the time and of the best which experience elsewhere has developed, and in large part the crude system of records and the absence of any proper system of statistics of criminal justice do not enable the average prosecutor, however well intentioned, to form any adequate conception of how his office is, in fact, functioning.

Results of the foregoing defects in the prosecuting machinery in promoting perjury and subornation of perjury, ${ }^{3}$ in creating suspicion of the whole administration of criminal justice on the part of those who witness its operation, ${ }^{4}$ in affording opportunities for favoritism or corruption or abuse or extortion, ${ }^{5}$ and especially in affording opportunities to the professional defender of accused persons, ${ }^{6}$ are abundantly shown both in $\mathrm{Mr}$. Bettman's report and in Chapter III of the /report on the Criminal Courts. One cannot insist too strongly that the remedy is not more prosecutors or more patchwork tinkering along the lines of the past, but rather organization, permanence of tenure, unity and continuity of policy, and concentration of responsibility with commensurate power. Along with these must go a cutting off of the unnecessary steps in prosecution and a pruning away of the excess of mitigating agencies which have accumulated in the course of Anglo-American legal history. ${ }^{7}$

1 Report on Prosecution, p. 202.

Ibid., p. 113.

Ibid., pp. 207-208.

' See report on Criminal Courts, Chapter III.
Ibid., pp. 116, 203.

Ibid., p. 208. 


\section{CHAPTER VIII}

\section{CRIMINAL COURTS}

RIMINAL courts in Cleveland show other phases of the picture at which we have been looking in surveying police and prosecution. Here again the pivotal point is that institutions originally devised for rural or small-town conditions are failing to function effectively under metropolitan conditions. Here again a change in the character of the community in which criminal justice has to be administered has been treated as if no more were involved than an increase of population in the same sort of environment. Accordingly, multiplication of judges and patchwork adaptation have been the chief means by which to meet a situation that calls for thorough reorganization. But there is much excuse for the present state of the criminal courts in Cleveland, in that organization of courts is something of State concern, governed largely by constitutional provisions, and it is by no means easy to educate the State at large to the needs of modern cities when existing institutions are working well enough in the average locality, where the conditions for which they were framed still exist. Moreover, when growth takes place so rapidly and the character of a community changes within a generation it is not to be expected that the bar will appreciate at once the significance of growth and change in relation to judicial organization and administration. The natural and desirable conservatism of lawyers will lead them to seek to get along as well as may be with the institutions and legal machinery at hand. It will be convenient to consider certain facts as to the present functioning of the criminal courts in Cleveland under the same heads already made use of in connection with police and prosecution.

(1) On the criminal side there has been little reconstruction since the days when the system of courts was devised for a pioneer community. The Municipal Court on its criminal side is still, in its traditions, its methods, its modes of doing business, its records, and its whole atmosphere, a police court of a small town of the middle of the last century. One notable improvement, namely, the doing away with two trials on the merits in petty prosecutions by reviewing proceedings in the Municipal Court on misdemeanors within its jurisdiction only for 
errors of law, stands out conspicuously. For the rest, there are simply more judges and more prosecutors. The Court of Common Pleas still operates on the system, appropriate to the past, of periodical terms of court with intervals between them. It is true that in Cleveland, as in all large cities where the system of terms is kept up, the intervals between the terms tend to disappear and there tends to be, in fact, a continuous sitting, except for a long vacation during the hot weather. But the organization of the business of the court with reference to terms still justifies in appearance the practice of preliminary examination and binding over to another tribunal which grew up to meet the exigencies of a time when the intervals between the terms were longer and the courts were sitting intermittently. Between these terms it was necessary for magistrates to conduct preliminary inquiries, bind over accused persons, and take the other necessary intermediate steps which could not be taken in the court when not in session. Again, the procedure of prosecution, good enough when there were 60 indictments a year, becomes impossible when there are 2,700 a year. The 14 steps in a prosecution set forth in the report on the Criminal Courts ${ }^{1}$ have tended to increase rather than diminish in the endeavor to adjust this machinery to the exigencies of criminal justice in a large city.

Tinkering instead of intelligent reconstruction, and addition of new devices instead of simplification, have resulted in a cumbrous process which affords many opportunities to the habitual offender and opposes few checks to his doubtful activities. ${ }^{2}$

On the criminal side of the Municipal Court persistence of police court organization and traditions and methods is particularly unfortunate. The personnel of the bench appears to suffer in particular from that tradition. For if a tribunal is commonly known as a "police court," that fact is bound to affect the action of the public in determining what type of judge should sit therein. But, as is true in so many localities in America today, it suffers especially from the subjection of judges to pressure and the imposition upon them of a need of keeping in the public eye which is involved in the system of primary elections. As is well said in the report on courts, ${ }^{3}$ this attempt to "adapt the democracy of the town meeting to a great cosmopolitan population" has disappointed the expectations of its authors. The real significance of this failure is that the primary system attempted to deal with new situations by tinkering old machinery; it took the elective bench, an institution of

${ }^{1}$ The Criminal Courts, p. 235.

${ }^{2}$ See Diagram 2, report on the Criminal Courts.

${ }^{3}$ Ibid., p. 260. 
the middle of the nineteenth century, for granted, and proposed to insure that more citizens participated actively in the election. Everyone could and probably did know the character and qualifications of the few conspicuous lawyers who were candidates for judicial office in the judicial district or of the rising young lawyers who sought election as police magistrate of the small town of 1850 . Under the circumstances of that time the greater the number of citizens that voted, the more intelligent the choice was likely to be. Today, when the average citizen of Cleveland can know the lawyers and judges only from what he chances to read in the newspapers or as he chances to meet them in the course of litigation or in social activities, it is often true that the greater the number of citizens who vote, the more unintelligent the choice.

Again, the physical conditions and decorum of the tribunal are those of the old-time police court of a small town. ${ }^{1}$ There is no segregation of cases, for this was not needed in the old-time police court. ${ }^{2}$ The inadequate system of records is inherited from the police court and was good enough for the police court of a small town. ${ }^{3}$ The scanty attention to cases which is so unfortunate a feature of the administration of criminal justice in the Municipal Court belongs to the days when the police magistrate knew the town drunkard, as did all his neighbors, and could dispose of the case of Huck Finn's father offhand, with the assurance of one who knew. Today the method persists, but the personal knowledge on the part of the court and of the community which assured that justice would be done is no more. Without this check it results in opportunities for questionable influences in the case of real offenders, danger of irreparable injury to the occasional offender, who is not able to command such influences, and in consequence a general suspicion of the whole process which must affect the attitude of the public toward the administration of justice, no matter how unfounded. Such things as the shifting of cases from one judge to another, with no effective check upon the manner in and the reasons for which it is done, grow naturally out of the multiplication of judges, making the court not an organized entity, with systematized business methods, controlled by a responsible head on an intelligently determined policy, but a congeries of coördinate tribunals, each proceeding as if it had before it its own small volume of business, as if it had the intimate personal knowledge of the men and things before it, and was subject to the check of general knowledge of those men and things by the whole community which obtained in the large town or small city of the middle of the last century.

${ }^{1}$ Report on the Criminal Courts, pp. 278, 279.

2 Ibid., p. 280.

3 Ibid., pp. 292, 293.

4 Ibid., p. 282.

[629] 
To a less degree the same phenomenon may be noted on the criminal side of the Court of Common Pleas. Increase of work has led to more judges of coördinate authority. ${ }^{1}$ There is no executive head. The judges are free to have conflicting policies or to fluctuate in their policies. ${ }^{2}$ Judicial approval in the case of nolle prosequi, which was effective in the days of 60 indictments in a year, and may well be a real check in a rural community or a small city, decays into an empty form. ${ }^{3}$ The supreme court of Massachusetts has recently pointed out that the court must rely on the prosecutor in such matters under the urban conditions of today, and yet the only check on the prosecutor is the scrutiny of the court. The parole system, administered in a large city in courts so organized, leads inevitably "to paroling in the dark." 4 It is assumed, as was true enough in the old days of small calendars in rural communities, that everyone knows or can know all about the offender. When the administration of justice goes on such an assumption in a city of 800,000 persons, the situation discussed on page 325 of the report on Courts is inevitable.

(2) Bad effects of lack of continuity in administration are equally evident. If some rotation of judges is necessary, there is the more reason why the courts should be so organized that the rotation shall not involve fluctuation in policy, divergence in interpretation of the law on matters where such divergence is easily preventable, fumbling methods while the judge for the time being is acquiring experience of a new class of work, and pressure to put off cases or shift them so as to get them before a judge whose policies or methods are believed or suspected to be favorable to or lenient toward the particular accused or one of his type. Such things not only impair efficiency - they weaken respect for courts and for the law. The judicial council, recommended by Mr. Smith, ${ }^{5}$ would go far as a remedy. But the ultimate cure is in unification and thorough organization of the court under responsible administrative leadership.

(3) Organization of courts is defective not only in that there are two courts largely dealing with the same cases where one court could deal with all much better, and because those two courts are made up of coördinate judges, with no responsible directing agency, but even more in that the lines are rigidly laid down by law and do not admit of the judges in the large city doing much to meet the special problems that confront city courts, even if they had encouragement to do so. It has been noted that the mode of choice and tenure of judges are the same for rural and for

1 Report on the Criminal Courts, pp. 299, 300.

Ibid., p. 303.

Ibid., p. $328 . \quad$ Ibid., p. 326.

Ibid., p. 369. 
metropolitan courts, although the environment that makes them work well enough in the one case insures that they will work quite differently in the other case. No less serious is the inability to use the personnel of the court to the best advantage under a system constructed for times when one judge in each local district could dispose of the relatively small calendars. When business increased, more judges were added. But when the number increases to a certain point waste of judicial power comes to be likely, and this waste is a serious thing when business has grown so as to tax the energies of the bench. Moreover, provision of a probation department ${ }^{1}$ and of a bureau of information, ${ }^{2}$ required by urban though not by rural administration of criminal justice, and many things of the sort, ought to be within the powers of the judges when and where they are needed, and ought not to be determined with reference to the whole State by detailed provisions of general laws, as if the conditions of city and country were invariably the same, or as if things not needed in the latter should, therefore, be denied to the former.

(4) Tendency to perfunctory routine appears no less clearly in a judicial administration than in police and in prosecution, and it is the product of the same general causes. In the Municipal Court the casual routine of preliminary examination and perfunctory practice as to binding over, ${ }^{3}$ the perfunctory methods whereby a robber (afterward convicted) is released on bail, while his victim is in jail one hundred and six days to insure his attendance as a witness at the trial, ${ }^{4}$ the laxity as to postponements and continuances, with its inevitable results in wearing out prosecuting witnesses and enfeebling the administration of criminal justice, ${ }^{5}$ and the perversion of the motion in mitigation of sentences ${ }^{6}$ are examples of what must happen in a large city until the courts are unified and given a modern organization, and until responsibility and power are definitely located and are concentrated. Similar phenomena are to be seen on the criminal side of the Court of Common Pleas. Laxity in the "passing" of cases, with resulting enfeebling prosecution, ${ }^{7}$ the condition of judicial helplessness in the matter of nolles, although 20 per cent. of felony cases are disposed of by nolle prosequi, ${ }^{8}$ judicial helplessness in the matter of parole, ${ }^{9}$ where responsibility falls down between the court and prosecutor, and the "blanket nolle,"10 with all its possibilities and opportunities for those who habitually represent accused persons, ${ }^{11}$ exist be-

1 Report on the Criminal Courts, pp. 329, 330.

2 Ibid., p. 331.

3 Report on Prosecution, p. 116. Report on the Criminal Courts, p. 314.
I Ibid., pp. 282-284.
- Ibid., pp. 285, 286.
I Ibid., p. 304.
B Ibid., p. 322.
- Ibid., pp. 325, 327.
${ }^{10}$ Ibid., p. 329 .
"I Ibid., pp. 322, 328. 
cause the attempt to apply the methods and organization of the middle of the last century, with no continuity in administration, with a rigid organization of coördinated judges and no defined and concentrated responsibility, has of necessity made vital steps in the course of criminal justice a mere ritual under the pressure of a great mass of cases to be disposed of without possibility of personal knowledge of the parties or of the circumstances by court or prosecutor.

(5) Some ill effects of division of power and diffused and ill-defined responsibility have been noted already. But this point calls for special emphasis here, no less than in police administration and prosecution. The Raleigh case ${ }^{1}$ is not important because it was a farce. When we have said that, we have said no more than is obvious to everyone. The important thing is to know that no one in particular can be held responsible for its being a farce. Again, the situation disclosed in Table 16 of the report on the Criminal Courts, and discussed on the same page of that report, is not merely serious in itself, but quite as much so because no one in particular is responsible. The wide variation in the policies of coördinate judges, shown on pages 305 to 309 , is a serious thing. It is quite as serious that it is no one's business to do away with it. Again, the hopelessly defective system of records in criminal cases in the Municipal Court, disclosed in the report on Prosecution, ${ }^{2}$ with its result in the absence of any real check on the activities of hangers-on of the police court, is not merely bad in itself, but even worse in disclosing what may happen in the administration of justice in a large city when it is left to direct itself and no one is responsible for making and keeping it what it should be.

(6) Closely connected with the foregoing point is the want of provision for intelligent study of the judicial system in action and want of any system of judicial statistics. There are admirable models here in the English system of judicial statistics and in the statistics published by the Municipal Court of Chicago. But all improvement in this respect depends ultimately on provision of an executive head, with undivided power and undivided responsibility.

When one considers the matters just discussed in connection with what we have seen of the same sort in police administration and in prosecution, it is easy to see why, without anyone in particular being responsible, and even with conscientious, hard-working men in many of the official positions involved, the system is "worked for weak spots" by those who know how; ${ }^{3}$ to see why, without anyone in particular being

1 Report on the Criminal Courts, p. 262.

2 Report on Prosecution, pp. 120-132.

${ }^{3}$ Report on the Criminal Courts, pp. 238-241. 
to blame, 23 per cent. only of those who are prosecuted are found or plead guilty ${ }^{1}$ to see why it is that the slacker agencies of justice tend to acquire the business at the expense of the stricter ${ }^{2}$-in short, to see how and why the whole system lends itself to manipulation. ${ }^{3}$

It is not necessary to repeat the recommendations in the report on courts, but four of them call for special consideration.

One immediately practicable improvement is to eliminate unnecessary steps in prosecution. In State cases all the steps in the Municipal Court and the grand jury ought to be dispensed with, reserving the grand jury for those occasional situations where a special inquiry is necessary for some particular reason. The grand jury has been done away with in many jurisdictions, and the matter is no longer one of conjecture or experiment. Only good results have followed from eliminating it as an every-day agency. Moreover, the conditions of large cities make such demands in the way of jury service that if the grand jury is done away with as a regular feature of prosecution, pressure upon the petit jury system is to that extent relieved. A practice which operates successfully in 18 States need not be feared by the most conservative, and relief of prosecution from the burden of two preliminary investigations must strengthen the administration of criminal justice.

Another important measure would be to curtail the use of jurors in civil cases. We ask too much of busy citizens in our large cities when under the conditions of business and of employment today we ask them to serve upon juries and use juries habitually for every sort of legal business. If, as in England, the civil jury was reserved for those cases to which civil juries are best adapted-assault and battery, malicious prosecution, slander and libel, breach of promise, and the like, where a certain moral element comes into play-and commercial causes and causes involving property were habitually tried by the court, it might be possible to secure better juries in criminal cases. The situation disclosed in Chapter XI of the report on the Criminal Courts compels us to reflect whether we really achieve anything by our endeavor to preserve the jury system exactly as it was one hundred years ago, and operate it as an every-day agency of justice in a large city.

The civil jury is enormously expensive. Do we succeed in doing enough by means of this time-consuming and expensive agency to make up for the injury that we do to the effectiveness of the criminal jury, which we must preserve? Sooner or later this question must be answered. If we go on as we have been going, we may succeed only in breaking

${ }^{1}$ Report on the Criminal Courts, p. 242.

2 Ibid., p. 242.

Ibid., p. 244. 
down the institution of the jury as anything more than a perfunctory adjunct to judicial justice. Something of the sort has actually happened in the case of the grand jury in more than one community.

Mr. Smith recommends the institution of a "public defender," and his recommendation deserves careful consideration. For myself, I am skeptical. It seems to me that the public defender is called for chiefly because of bad organization of prosecution, bad conditions in the prosecutors' offices, and a tendency to perfunctory routine there and in the courts. In other words, lack of modern organization in prosecution and in courts calls for a remedy, and, as usual, the remedy is sought in adding another functionary instead of in dealing with the difficulty at its source. Unless prosecution and courts are given an organization suitable to the needs of the large city, I suspect that after the novelty wears off the defender's office will begin to show the same phenomena as those shown by the prosecutor's office throughout the country. If prosecution and courts are properly organized, I suspect that no further official need be provided.

Most of all, however, the bar and the public need to reconsider the whole question of mode of choice and tenure of judges. What an independent bench appointed for life can do for a situation not unlike the one we have been studying in Cleveland is shown strikingly in the recent removal of a district attorney in a district including part of metropolitan Boston. Political considerations that would have been a strong deterrent in the courts of most States did not suggest themselves to anyone, and the court proceeded with a thoroughness and decision in marked contrast to the helplessness and indecision and tendency to evade responsibility which are usually manifest in American State courts when habitual or entrenched abuses are to be dealt with. Only one who has practised under an elective short term judiciary and then seen an appointed judiciary with life tenure in action can appreciate the difference. The advertising judge, the spectacular judge, the judicial "good fellow," the judge who caters to groups and organizations and identifies himself with racial and religious or trade organizations, is simply unknown where the common-law tradition of an independent bench still obtains. Nowhere is such a bench so much needed as in the large city of today. The recommendations on page 276 of the report on the Criminal Courts ought to be pondered carefully by all who seek better things in the administration of criminal justice.

1 Report on the Criminal Courts, pp. 310-312, 368. 


\section{CHAPTER IX}

\section{THE BAR}

$T$ HREE checks upon those who take part in the administration of justice are relied upon in our polity to insure that the wide powers which the law confines to judges and prosecutors are properly used. These are: (1) Professional training, traditional modes of thought, and habits of decision with reference to principles on the part of the judge; (2) the scrutiny of all proceedings by the bar; and (3) the records which show fully what has been done, by whom and upon what facts. In the case of the judge, his training in law is relied on to impel him to conform his every action to certain known standards. Professional habit leads him in every case to seek such standards before acting and to refer his action thereto. Again, every decision which he renders is, in the theory of our institutions, subject to criticism by a learned profession, to whose opinion the judge, as a member of the profession, should be keenly sensitive. Moreover, every decision and the case on which it is based are supposed to appear in full in public records. In the case of the prosecutor, our polity relies on the scrutiny of his acts by the judge, on criticism of his conduct of his office by the bar, and on the records of the courts which are supposed to set forth all that is done in the course of prosecution and the case in which and papers upon which it was done. No doubt, as in the case of all officials, public opinion informed by the press is also relied upon. But in the nature of things this check can have only a general operation and may not be relied upon with respect to the details of every-day conduct of the administration of justice. So much that goes on in courts is of necessity technical in character and intelligible in its true setting only to experts that the press and public opinion must be ultimate rather than ordinary agencies for holding the administration of justice to the right course.

It has been seen that in the case of the criminal side of the Municipal Court and the office of the municipal prosecutor the records are such as not only to afford no real check, but actually to cover up the facts and to baffle the investigator. When added to this, instead of scrutiny of what goes on by the entire bar, as in the old-time magistrate's court, where law- 
yers were few, were intimately associated, were primarily engaged in trial work, and all knew what was going on in all the tribunals, a group of professional criminal lawyers practise criminal cases and the bulk of the bar know little more of what goes on in criminal justice than the public at large, it is apparent that the checks upon which the theory of our institutions relies are ineffective and it may not be expected that the system will operate as it should. Relying in theory upon the professional feeling of the bar and the scrutiny of official action and criticism thereof by the bar, which were effective regulating agencies under different conditions, we in fact subject prosecution to the sagacious scrutiny of professional defenders of accused persons, who study the weak points in the system and learn how to take advantage of them. In theory the lawyer is an officer of the court, assisting the criminal court to do justice by seeing that the case of the accused is fully and properly presented. Instead, we are not unlikely to find an astute, experienced player of a politico-procedural game, whereby the course of criminal justice is systematically obstructed or perverted. How the numerous steps in a prosecution-the division of responsibility between two prosecutors, the imperfect records of the Municipal Court, and want of continuity or consistent policy in administration-lend themselves to his activities is shown in the report on the Criminal Courts. ${ }^{1}$ The disclosures in the recent case in which a district attorney in metropolitan Boston was removed by the supreme court of Massachusetts showed a similar situation there. No projects for improvement will achieve much unless they take account of the relation of the education, organization, and discipline of the bar to the several difficulties with which criminal justice must contend.

Want of education, want of organization, want of discipline of those who are habitually most active in defending accused persons in our large cities, are conspicuous and significant facts. But they are especially significant when looked at in connection with what we have discovered already with regard to police prosecution and courts. So looked at it becomes evident that the present-day condition of that part of the bar which practices in criminal cases in our large cities is only a phase of a general situation, which has grown up in the transition from a pioneer rural society to an industrial urban society.

For one thing, no intelligent reconstruction of the profession has come with the profound change in environment. Two important steps forward have been taken. Bar associations have been organized and admission to the bar has been committed to the supreme court and conditioned upon an

${ }^{1}$ Report on the Criminal Courts, pp. 284, 285. 
examination conducted under the auspices of that court, instead of being left to the local courts. Each of these steps has great possibilities and each has already achieved something. But neither has done all that might have been done nor may either, as things are, do all that needs to be done. Except for these two steps-chiefly important in their possibilities-education, organization, and discipline of the bar are the same in the metropolitan and cosmopolitan city of today as in the homogeneous small-town or rural community of the past. For example, in 1860 training by way of apprenticeship in a lawyer's office might well have been an ideal mode of preparation. Daily contact with an upright and experienced lawyer introduced the student to the very spirit of Anglo-American law, and the highest professional conceptions as handed down in the common-law traditions. Today lawyers with whom such daily contact would be profitable are too busy to look at students, and their offices are so crowded with business that no effective study of the old type is possible therein. We have the testimony of a committee of the American Bar Association, headed by Elihu Root, in a report approved by that association at its last meeting, that study in the office of a practising lawyer under the conditions that obtain in our cities today can be no real legal education. Mr. Kales' report on Legal Education in Cleveland shows that in this community certificates of study under a practising attorney are used chiefly in order to enable persons who have prepared in some other way and have not qualified in that way to bring themselves within the purview of the rules. In cities this mode of training has ceased to be more than perfunctory, and permission to qualify in this way is an invitation to evade such standards as there are. Again, organization and discipline in a bar of over 1,400 members are very different things from what they were in a bar of some 60 members. Yet the methods are essentially the same for the heterogeneous membership of 1,400 in the metropolitan city as for the homogeneous bar of 50 or 75 in the large town of the past.

Here, also, the tendency to develop a perfunctory routine is evident, and it has operated to deprive the improved method of admission to the bar of much of its potential efficacy. Thus the general attitude of lawyers in the matter of certificates of study under their direction, their willingness to make such certificates, even where there has been no pretense of actual study in their offices or under their supervision and their disposition to treat such certificates as formalities, are in part a survival of ideas from pioneer times and in part a result of lack of any conscious responsibility for the condition of the profession. Likewise the laxity of bar examiners is attributable to the same causes. Both of these phe- 
nomena are of general occurrence throughout the country. When everyone at the local bar knew the candidates and knew in whose offices they had been studying, what their antecedents were and what they had been doing, certificates and examinations might well be thought matters of form and disregarded in the same spirit in which the pioneers discarded the pomp and ceremony of court etiquette and even the more important items of dignity and decorum. Survival of that spirit in the bar of a cosmopolitan city serves to recruit the ranks of the police court lawyers, well known in all our large cities. Lack of interest in professional education on the part of the bar is a serious factor in the ineffectiveness of criminal justice. Where large numbers of persons of foreign birth or foreign ancestry come to the bar-as they should do, for every element in our population should bear its part in the administration of our democratic and legal polity-there is peculiar need that they have the best education which we may afford them. Yet, as a rule, those who most need it have the least. Whereas they need to learn the whole spirit of our institutions, they are likely to get no more than a superficial course in the practical details of what goes on in the courts. The need of such persons for general education, for professional education, and for personal contact for a sufficient period with lawyers who know the traditions and spirit of Anglo-American law and of the legal profession as our legal institutions presuppose it, is peculiarly great. Yet none of these things is possible when a person of foreign birth works eight hours a day for an employer and at the same time attends a night high school and a night law school. If we put the period of employment at eight hours and the period required for high school study and study of law at the minimum of six hours each, it means that, if justice is done to all three, the student is putting in twenty hours of work each day for six days in each week. Under the circumstances which obtain in Cleveland, where the night law schools and the night high schools alternate in instruction, each giving three nights a week, if we put the minimum of time spent in recitation and in study at six hours for each during the three days respectively devoted to high school study and to law study, the result is that the student would devote fourteen hours of each twenty-four for six days of each week to his work. One need not say that this is not and cannot be done. When such things are attempted or pretended, we may not expect that the students will understand a system of law and of legal and political institutions wholly different from that in which they or their parents and associates were brought up. Such students need more contact with lawyers of high ideals than the ordinary student for that same reason. But none is possible in any effective way in a three-year night course of 
three nights a week when the student is at the same time working all day for an employer and pursuing a high school course on alternate nights. More than 40 students are known to have been preparing for the bar in this way in Cleveland last year.

It is not controversial that the standard of the night law schools in Cleveland is in important respects below the standard of such schools in other cities of the size of Cleveland, and very much below what it ought to be. The night schools in Cleveland require of the student six hundred and forty-eight class-room hours as against one thousand and eighty, the minimum in the day schools. Note what this means in the one matter of criminal law and procedure. One of the Cleveland night schools gives twenty-six class-room hours to this subject; the other gives thirty. On the other hand, not to go outside of Ohio, the three admittedly first-class schools, Cincinnati, Ohio State, and Western Reserve, give to that subject seventy-two, seventy-two, and ninety hours respectively. Yet it is more than likely that the student with one-third of the legal training will be the one who will practise in the criminal courts. With one exception the night schools in Cleveland teach only the subjects required for the bar examination. They have inadequate library facilities and their students have no time to use libraries if such facilities were at hand. But this means that they have no time to read the books that every lawyer ought to read if he is to form an adequate conception of his duties and of the system of administering justice of which he is to be a part. For few have time to read such books after admission. These things are not the fault of those in charge of the night schools. They arise from a practical situation in which standards are governed not by what ought to be required, but by low requirements for admission to the bar, loosely administered, and by competition for students.

It is noteworthy that 85 per cent. of those who apply for examination pass the Ohio bar examination, whereas in New York 42 per cent. pass (on an average for the past ten years) and in Illinois 62 per cent. (on an average for the past nine years). The night schools in New York and in Chicago require more hours of attendance and are in no wise inferior to those in Cleveland. There is no reason to suppose that the difference between Ohio and the States named is due to any cause other than a relatively low standard in the examinations. Some philanthropist might endow a night law school which could then run without regard to competition, and could take for its object to give the best possible legal education for students who must attend at night, rather than merely to prepare for bar examinations. Unless this is done, the only practicable remedy is to raise the standards for admission and thus enable the night 
schools to exact a reasonable education. Mr. Kales' recommendations as to improved standards for admission are conservative and immediately practicable, and even this minimum ought to result in marked improvement in the quality of those who are admitted to the bar. Special attention should be called to Mr. Kales' recommendation of exercise of visitorial powers by the bar examiners or a committee of lawyers under their direction. If the work of visiting the law schools is done thoroughly and intelligently, the resulting understanding of each other's aims and methods by law schools and bar examiners will produce good results.

Education must be followed by organization and discipline. The subject of organization is complicated by the difference in conditions between city and country, and the notion that one hard and fast scheme must be made to serve both. The possibilities of corporate organization have been shown abundantly in the experience of incorporation of the lower branch of the profession in England. Bar associations may do much. Yet membership in them is voluntary, and the officers and committees of these associations are busy men, whose primary responsibilities are to their clients and who can give but a residue of their energies to professional discipline. What they can do after the event is shown by the vigorous action of the Boston Bar Association in presenting charges against a district attorney and seeking his removal, and in proceeding for disbarment of practitioners in the criminal courts whose activities have become notorious. But there ought to be professional agencies for dealing with such things before they become notorious, and before their notoriety breeds disrespect for law and for the courts. The plan of the American Judicature Society for corporate organization of the bar deserves to be studied and pondered by all lawyers who have the good of the profession and the improvement of the administration of justice at heart.

It is easy to say that the bar has a large responsibility, both to improve itself and to improve the whole administration of criminal justice. When one looks beneath the surface, however, he soon sees that there is no bar to hold responsible in any real sense. There are 1,400 lawyers. But 1,400 lawyers of all sorts, of the most diverse antecedents and the most divergent interests, practising in a city of 800,000 inhabitants drawn from every part of the earth, do not constitute a bar except in name. Nor can those lawyers who, by their standing in the profession are in a position to lead, be held responsible. The legislature has control of standards of education and admission. The courts have control of discipline. In each case, as things are, political considerations and the timidity that goes with short tenure and choice by primary election pre- 
clude decisive action and result in occasional spasmodic efforts, with long intervals of apathy. The real responsibility upon the leaders of the profession is one of perceiving the situation, of studying what has been done elsewhere to meet like situations, and of intelligently considering the projects which have been proposed in order to make the bar an organized, self-governing, responsible entity, instead of a mere collective name for 1,400 money-getters, each following his own interests. When it is deemed a sufficient answer to a proposal for incorporation of the bar to say that "lawyers are as honest as other people," the lawyer is inviting the unintelligent and destructive application of the legislative steam roller by the layman, which always comes eventually when he refuses to put his house in order intelligently on his own motion. 


\section{CHAPTER $\mathrm{X}$}

\section{PENAL TREATMENT AND CORRECTIONAL INSTITUTIONS}

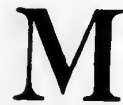

ANY aspects of correctional institutions in Cleveland make a bad impression on one who has studied the subject of penal treatment and has formed some scientific conception of what such institutions should be in order to achieve what is demanded of them in the sight of today. But here again one cannot but see that rapid growth and persistence of ideas and methods appropriate to conditions only outgrown yesterday, as it were, are chiefly responsible. As one reads Mr. Lewis' report he soon recognizes certain common points that run through the conduct of all the institutions examined.

(1) There is no proper segregation of the inmates. At the city jail there is no grading or segregation except according to sex, and with respect to whether or not the case of the accused has been disposed of judicially. At the Warrensville workhouse the prisoners are habitually thrown together, more or less indiscriminately. At the county jail prisoners "mingle indiscriminately" during the exercise periods. At the Detention Home there are no adequate means of segregation. In other words, nothing adequate is done in these institutions to prevent them from operating as seminaries or breeding-places of more crime. All this belongs to the old-time town lock-up and old-time county jail, and is a survival from the conditions of the past. As is true in most localities, the city jail shows this most noticeably. The careless and indifferent handling of prisoners in that institution is something with which the student of our penal methods becomes but too familiar. What can happen in such institutions to innocent persons is unhappily illustrated by the two extreme cases in Chapter I of Mr. Lewis' report. It is humiliating to think that such things are far too common in cities of twentieth-century America, and nothing could point more eloquently to the need of responsible and effective administrative supervision and of unified administrative organization, which alone can assure such supervision-a need which is apparent on every hand in the administration of criminal justice in large cities.

(2) Again, records are almost invariably inadequate for the requirements of today. In the city jail the only record is a jailer's docket, 
containing the name of the prisoner and the charge. The Warrensville workhouse has no proper records, and reliance is had on memory rather than on records, with unfortunate results for the system of parole. The records of the county jail are inadequate. There are no proper records in the Girls' Home at Warrensville. The same reliance on memory is to be seen in connection with parole, and probation work also is handicapped by crude and unsatisfactory records. Here again we have a survival from the time when no records were needed such as we must have in order to deal effectively with the crowd of delinquents who pass in and out of the correctional institutions of today.

(3) Lack of administrative system is general. It begins at the top, in the failure to develop any machinery to permit the Director of Public Welfare to exercise adequate control over the different divisions which are supposed to be subject to his authority. A mere paper federation of divisions and bureaus with no administrative cohesion and functioning only as an agency of suggestion to the chiefs of divisions and superintendents cannot be expected to accomplish results of moment. Examples of this lack of administrative organization and system in particular institutions are to be seen in the Warrensville workhouse, where each officer is a power unto himself, and in the Girls' Home at Warrensville. They are to be seen especially in the crude and undeveloped system of parole, where the results are serious. Results of lack of organized administrative control and definitely located responsibility may be seen in the absence of any modern system of receiving prisoners and eliminating vermin at the Warrensville workhouse, in the lack of a modern system of identification at that institution, and in the idleness and demoralization there. They are to be seen also in the inadequate training of guards at the county jail and in the lack of suitable employment or directed recreation at the Detention Home. Most of all, and most unfortunate in its consequences, want of organization of administrative agencies is making nugatory and injuring public confidence in the most promising of American discoveries in penal treatment. There has been much just complaint as to parole and probation in Cleveland. But who is to be held responsible for the utterly inadequate staff of parole officers, overwhelmed with work and unable to give proper time to probation? Who are responsible for the utterly inadequate clerical facilities for this work? Instead of dealing with this matter at the root by modern administrative organization, the legislature enacts a statute which is a distinct step backward, with the result that what ought to be done by modern methods by a thoroughly organized and responsibly supervised system of probation, is left to executive clemency, which 
ought to be reserved for occasional and exceptional cases. The discussion in Chapter IV of Mr. Lewis' report should be read and pondered. But here, as elsewhere, the pivotal point is thorough organization of the administrative agencies of criminal justice, so that such matters may be studied intelligently before mischief occurs, and someone may be held distinctly responsible if mischief is not prevented.

How completely the administrative and the judicial are interlocked in criminal justice is illustrated in the case of probation. The judges, finding that they cannot rely on the inadequate staff of State parole officers to make the painstaking investigations which the probation system demands, attempt to do the work of individualization themselves. But they have no means of doing it intelligently, and the consequent fluctuation and vacillation in the disposition of cases injure respect for the courts. The courts are forced to attempt work that belongs to a correctional system after the tribunal is through with the accused; but they have more than enough to do in their own province, and the results are necessarily unfortunate. Organization of all the administrative agencies of justice is imperatively required in order to make this essential part of criminal justice function as it should. While this organization of administrative agencies is coming, Mr. Lewis' recommendations will do much to improve correctional measures and to pave the way for better things.

A much brighter picture is presented by the Juvenile Court. Here again the court is handicapped by too small a staff for a tribunal handling over 4,200 cases a year. Here also legacies of the past are to be seen in a tendency to trust too much to memory of details, in inadequate records, in some waste of administrative power, and in some lack of coördination with other agencies. But these are of minor importance. It is evident that the central difficulty is that, because of rapid growth of population and of special conditions making for juvenile delinquency, the volume of work has increased far beyond existing facilities for dealing with it properly. The court itself, with an ampler budget and a larger staff, is equal to making the needed improvements on its own initiative. 


\section{CHAPTER XI}

\section{THE UTILIZING OF MEDICAL SCIENCE}

$\mathrm{T}$

YHERE is much reason for the backwardness of criminal justice in taking advantage of the enormous strides made by medical

science in the last generation. Things have moved so rapidly that, even if the courts had not been struggling with a steadily increasing volume of business and the continual need of new adaptations to conditions of transition from a rural to an urban society, it would not have been easy to keep up with the march of knowledge and the rise of new methods in medicine, in psychology, and in psychopathology. But the judicial system has not been so organized as to be able to take advantage of these things in any systematic or effective way in any event. All the phenomena that we have observed in connection with police and prosecution and courts and penal treatment stand out in this connection also.

(1) There has been no intelligent reconstruction of the medical side of criminal justice, but only patching and tinkering and addition of more officials, without giving them organization or responsible supervision or coördinating their activities. Each court and each administrative agency which has seen the need of better expert medical assistance has gone about the matter in its own way to do what it could with the means at hand. Thus all that has been done has been done in an unrelated fashion, with resultant overlapping, with important gaps unattended to, and consequent ineffectiveness. In some part this is due to a survival of the old-time notion of punishing the vicious willed. Practically no use is made of medical, and especially of mental, treatment in dealing with adult offenders, except in the occasional obvious case. The old attitude of faith in the efficacy of strict discipline and rigorous punitive methods makes us slow to realize the need of individualization, the need of intelligent study of the person we are dealing with, in all cases of correctional treatment under the circumstances of today. This has come to be recognized in connection with juvenile courts. But it is needed in all cases in order to make the work of the courts and of administrative officials after conviction intelligent and effective. It cannot be said too emphatically that this is not a matter of sentimentality or of mushy humanitarianism. It is a practical matter of saving the expense in- 
volved in bungling efforts to deal with pathological cases by methods devised for the wilful wrongdoer and of insuring effective handling of criminals instead of futile attempts to deal with crime. Experience where courts and psychopathic hospitals have worked together intelligently has demonstrated that an actual saving of expense is possible if such agencies are properly organized in relation to court and the prosecution, are used in the initial stages of a prosecution, and are employed systematically and as a settled policy. Prevention is especially a matter for medical science, and preventive justice is the weakest side of our system. Examination of children before delinquency develops, instead of afterward, intelligent disposition of socially incompetent and delinquent types when they first appear in petty cases in the Municipal Court, before they commit major crimes, and investigation of the mental condition of all those prosecuted in the Court of Common Pleas before indictment, or, at least, before sentence, are things for which adequate provision ought to be made and might be made almost immediately. Nor is addition of an expert here and one there, the setting up of a bureau or laboratory here and another there, the real remedy. Proper utilization of medical science in the administration of criminal justice is a part of the whole problem of organization of courts and organization of the administrative agencies of justice.

(2) Lack of continuity in administration operates also to prevent thoroughgoing employment of the results of modern medical science anywhere in the course of criminal justice. In general, Dr. Adler's study shows that officials to whom these things are committed are ill equipped for constructive work, and the occasional exception makes the rule more marked. Cleveland is fortunate at present in a coroner who is doing well under antiquated conditions, and gives an example of the best that we may expect from conscientious officers under a bad system. But he is elected for a two-year term, and the public cares little about who is chosen or how he conducts his office. A change might occur at any time which would alter the whole character of the office. Moreover, even when administered as well as it can be, and, indeed, better than the people have reason to expect, it falls far short of what ought to be and could be done with a proper administrative organization. Dr. Adler's recommendation that the office of coroner be abolished and an office of medical examiner created, as in New York and in Massachusetts, is justified by the experience of those two States, and should be followed. In a city as large as Cleveland it is unsafe to entrust the work that now devolves upon the coroner in connection with criminal investigation in homicide cases to anyone but a highly trained and exceptionally compe- 
tent pathologist and medicolegal expert. In the general run of things no such person will be secured for an elective short-term office, open to anyone who happens to be a physician.

(3) Rigidity of organization is noticeable here as elsewhere. The police, the coroner, the prosecutors, the Probate Court, the Juvenile Court, and the criminal side of the Court of Common Pleas have each their own way of securing and using medical expert assistance.

(4) Also a consequence is seen in a tendency to perfunctory routine. This is illustrated strikingly in the coroner's records. Perfunctory entries taken from the records and set forth in Dr. Adler's report show that the existence of records is wasteful, and, indeed, investigation by the coroner is wasteful if the records are so kept and if the records truly reflect the actual investigations had.

(5) Division of power and authority and consequent diffused, illdefined responsibility, both for effective work and for utilizing the results of medical science, are in evidence everywhere. The police department has a police surgeon, but his position is inadequately provided for. He has too many men to examine and his equipment is insufficient. The staff of the coroner is appointed by the county commissioners, and their tenure is subject to the pleasure of those officials. The coroner has no power over them. He is responsible to the people at the next election. His assistants are responsible to the county commissioners. It is no wonder that the work of the office, even under a good incumbent, is often perfunctory. Again, a special constable is attached to the coroner's office who has large discretion as to what witnesses to subpoena at an inquest. It appears that selection of witnesses usually depends on his judgment. These are large powers in cases where homicide is suspected, and go with little responsibility. Jurisdiction over lunacy and feeblemindedness is in the Probate Court, which has no special experts, no equipment for such cases, and is in no position to make any selection of cases or to coördinate its work in such matters in any way with the administration of criminal justice. The defective delinquent may come before the Municipal Court for violation of a city ordinance or before the Court of Common Pleas for a felony, or before the Probate Court to be adjudged a lunatic, and each tribunal will look at his case from its own special angle. This is wasteful as well as ineffective. In the end a system of examination and observation of all cases at the outset would save money as well as insure intelligent handling of the case, as has been demonstrated wherever it has been tried.

(6) Nowhere is the pioneer assumption of versatility so out of place as in the relation of medical science to the administration of criminal 
justice. The days have gone by when one physician is like another in such matters. Physicians no longer take all medical knowledge for their province. Only responsible and systematic organization of the administrative agencies of justice, with secure tenure for the expert subordinates, can insure the sort of medical assistance which the administration of justice in criminal cases now calls for at every step. To merely prescribe that this or that independent elective functionary or assistant appointed for a term be a physician assures nothing.

(7) Nowhere, also, is provision for constant intelligent study of the system of criminal justice and the possibilities of making it effective more called for than in the present connection. The importance of prevention of crime, rather than of punitive methods afterward, the whole problem of dealing with criminal behavior at its source, the importance of mental hygiene, the question of mental-health stations for juvenile cases - these things and many others will press for consideration by a responsible administrative head of a properly organized system of criminal justice in the modern city. They will be urged in medical associations and discussed in scientific periodicals. But the discussions will bear no fruit until it becomes someone's business to be vigilant in seeing to it that the best means that are at hand are intelligently sought for and intelligently made use of in the administration of public business, even as in the conduct of private business. 
CHAPTER XII

\section{GENERAL CONCLUSIONS}

$\mathrm{C}$ ERTAIN immediate improvements are practicable. The details will be found in the several reports, where they are discussed at length and reasons are given. I shall do no more than sum up what seem to me the salient points.

(1) Mr. Fosdick's recommendations for separation of the police from the department of public safety; for a director of police, a single, civilian, administrative head with undivided authority and responsibility, charged with laying down policies and devising programs of police work and with seeing to it that his policies and programs are carried out by his subordinates; for committing the subject of promotions and discipline to the director of police, making use of the civil service tests as minimum qualification standards; for a board of promotion; for the use of motor equipment in regular patrol work, the establishment of patrol booths, consolidation of police precincts, and reorganization of patrol beats; for giving the director of police power to recruit detectives from outside the police force by original appointments where it seems advisable; for a special service division and for a secretarial division, show the way to put this part of the legal treatment of crime upon a modern and effective basis by means which are no longer experimental, but have proved their efficacy in the experience of other cities.

(2) In the municipal prosecutor's office, provision of a managing clerk, systematic organization of the work and coördination with the other agencies of criminal justice in Cleveland, and, above all, control of the assistants and subordinates, and consequent responsibility for what they do and what they fail to do; in the county prosecutor's office, control of the assistants, firmer and more intelligent organization of the business, systematic modern methods of criminal investigation and preparation of cases, and, above all, continuous and systematic coördination of the work of that office with that of the police, municipal prosecutor, the administrative agencies of the courts and the courts themselves, together with the laying out of policies and organized supervision to see that they are carried out-all these things are immediately feasible improvements which will accomplish much. The further step of turning 
over the whole course of a State prosecution from the beginning to the county prosecutor should come next.

(3) In the Municipal Court systematic, intelligent segregation of business upon the trial calendars, orderly handling of the cause list, with an established policy as to transferring cases from one session to another, a proper system of records, better methods with respect to order and decorum, stenographic records of testimony in binding over cases and in misdemeanors in which habitual, professional crime or commercial vice is involved, and better methods in the despatch of trial business, insuring sufficient attention to each case to assure a just and intelligent disposition of it; on the criminal side of the Court of Common Pleas, abolition of terms of court, provision of a permanent executive head to guide the administrative work, give continuity and uniformity to policies, and insure more intelligent and systematic use of the personnel of the court in the disposition of its business and provision of an adequate probation department, with modern facilities - these are measures of immediate improvement which are not in any wise speculative, for which we may vouch experience in other jurisdictions. The next step should be a unified court, to be secured by transferring of criminal business to one court.

(4) In criminal procedure, beginning of prosecutions by summons rather than arrest in case of minor offenses, abolition of the grand jury, simplification of the bail system, ${ }^{1}$ regulation, if not abolition, of the "no-papers" practice,-which is not known to common law nor to legislation,-provision for requiring written statement of reasons for "no papers," nolles, and acceptance of pleas of lesser offense, participation of the prosecutor in proceedings in mitigation of sentence, and a clear policy with respect to new trials, are feasible improvements about which, in the light of experience elsewhere, there can be no real controversy.

(5) With respect to the bar, abolition of admission to take bar examinations on certificate of study under a practising attorney, requirement of at least a four-year high school course, to be completed before beginning the study of law, as a necessary preliminary education; requirement of a minimum of class-room hours per week in all law schools, day or night, so as to insure that the time devoted to study in night law schools is at least approximately that required in standard day schools, and visitorial supervision of law schools and of private schools giving preliminary education to law students by the bar examiners or 
under their auspices-this is a minimum program, less than that adopted by a six to one vote at the last meeting of the American Bar Association, and one to which the present proprietors of night law schools in Cleveland entirely agree. Ultimately, the bar should urge the standards recommended by the American Bar Association. For the rest, the Bar Association may and should bestir itself to rid the profession of an element active in criminal cases which brings the profession and the law into disrespect. This is a difficult and thankless task, and demands much sacrifice on the part of the busy, high-minded, public-spirited leaders of the bar. But it is the only resource until corporate organization of the profession provides a continuous agency for enforcing discipline and insuring adherence to proper standards, acting on its own motion, and responsible for maintaining the conduct of the profession at a high level.

(6) More adequate facilities should be provided for the juvenile court.

(7) The opportunities of the office of Director of Public Welfare should be emphasized, facilities should be given that officer for rising to those opportunities, and the public should then demand that he do so.

(8) A statute on the lines of the New York Indeterminate Sentence and Parole Law should replace the present statute in Ohio, which is a typical product of hasty legislative striking in the dark at evils that are attracting public notice for the moment.

(9) The office of coroner should be abolished and a medical examiner provided, following experience of the wisdom of this change in New York and Massachusetts.

But these immediate measures of relief will not insure a continuously efficient functioning of criminal justice as something permanent, going on automatically after the excitement of the moment has gone down. Perhaps nothing will do so entirely. So far as these things can be insured, we must look to unification of police administration, with undivided authority and responsibility under a director with permanent tenure, dependent only on results; to unification of the prosecuting agencies, with permanent tenure and undivided authority and responsibility; to unification of the courts and organization of judicial business under a responsible administrative head; to unification and organization of the administrative agencies of criminal justice under a responsible administrative head with secure tenure; to the incorporation of the bar, with provision for responsible disciplinary agencies; to adequate provision for legal education, and, above all, to the taking of the bench out of politics and restoring the common-law independence of the judiciary, 
preferably by returning to the system of judges appointed for life or good behavior, or, at least, by some of the alternative plans proposed in the report on courts. These things must come slowly. The bar should be thinking of them and studying them, for in the end the convictions of the bar in these matters will be decisive. In the formative period of our institutions faith in the efficacy of intelligent effort enabled Americans to make over the institutions of mediæval England, as they came to us in the Colonial period, into a modern, workable system for pioneer rural communities in a new world and in a wholly changed environment. Relatively, our task today is the easier. Our judicial organization is much better as a foundation on which to build than that which was left to us by the Colonies, or than the eighteenth-century English organization which was the only other model. Our law is better organized, more accessible, and much more complete than that on which Marshall and Kent and Story labored. The bar is better taught and in far better public esteem than it was at the close of the eighteenth century. If American lawyers of today have to face public suspicion, legislative indifference to the demands of legal justice because of the more pressing exigencies of politics, and the constant pressure of the advocates of specious nostrums for the cure of all ills of the body-politic, the lawyers of the end of the eighteenth century and beginning of the nineteenth century had to face these same obstacles, and to face them with much less effective weapons than those available to the lawyer of today. The advantage which they had was a juristic optimism involved in their faith that law was reason, and hence reason law, and their belief that by sheer efforts of reason they could achieve a perfect system. A like faith in the efficacy of effort, and a like 'determination on the part of the present generation of lawyers to devote their energy and ingenuity to making over the institutions of rural America for the predominantly urban America of today, will achieve no less and will make the first half of the twentieth century a classic period in American law no less truly than was the first half of the nineteenth century. 


\section{APPENDICES}





\title{
APPENDIX I \\ THE HISTORY OF THE SURVEY
}

\author{
By Raymond Moley \\ Director of the Cleveland Foundation
}

\section{$\Pi$} HIS survey of criminal justice in Cleveland was authorized by action of the Cleveland Foundation Committee on January 4, 1921. Field work was started on February 1 and was completed in June. The reports were written and revised during the summer months of 1921 and were with one exception given to the public in September and October. A total of thirty-five staff workers were employed for various periods of time during the progress of the work. ${ }^{1}$

\section{The Cleveland Foundation and Its Work}

The Cleveland Foundation, which conducted this survey of eriminal justice, was founded in 1914. The plan for this, the first of the community trusts, was formulated by F. H. Goff, and brought into existence by formal resolution of the board of directors of the Cleveland Trust Company. It provides a means for the distribution of bequests left by men and women interested in the social welfare of the city of Cleveland. During the early years of its existence its limited funds have been used for comprehensive studies of the life and institutions of the community. Two major surveys have been conducted by the Foundation, one on public education in 1915 and 1916 and one on recreation completed in 1919. In addition to these the Foundation has conducted and published the results of several minor pieces of research such as the Cleveland Year Book, an annual publication, and a Directory of Community Activities.

The Cleveland Foundation is governed by a committee, three of the five members of which are chosen by the United States District Judge, the Probate Judge, and the Mayor of Cleveland. Two are appointed by the Cleveland Trust Company, the trustee of the funds of the Foundation. Thus a majority of the governing board are chosen by public officials and represent the public.

${ }^{1} \mathrm{~A}$ list of the members of the staff will be found on pages 662,663 . 


\section{The Origins of the Survey}

The first demands for a survey of criminal justice came from the welfare agencies of the city. In 1919 the Welfare Federation had a committee on delinquency, headed by Judge Carl D. Friebolin. This committee was prevented by limited funds and inadequate equipment from carrying on effective work but it clearly demonstrated the need for more information. In December, 1919, the secretary of this committee, Professor C. E. Gehlke, of Western Reserve University, proposed to the foundation that it undertake a survey of the whole problem of delinquency, both adult and juvenile. At that time there was prepared by Dr. Gehlke an outline for a survey of the administration of Criminal Justice in Cleveland. From this first formulation the plan grew until it was decided to undertake the work which was subsequently carried through along lines laid down by the directors of the survey and their associates.

A survey of such a subject and upon so comprehensive a scale cannot lightly be undertaken in any city at any time. Unless it has a reasonable assurance of the support of a very considerable body of public sentiment, a study penetrating so far into a field invested with intangible and subtle influences cannot hope to succeed. Conditions were probably as unsatisfactory in 1920 as in 1921, but the public did not so profoundly realize it. So the Foundation waited for a year for such a sentiment to appear.

On November 10, 1921, Mayor W. S. Fitzgerald addressed a letter to the Foundation asking that there be considered "a general survey of vice and crime conditions . . . to be conducted without bias of any kind and with the sole purpose of developing the facts"

A week later the Cleveland Bar Association, through its executive committee, adopted a resolution requesting the Cleveland Foundation "to conduct a survey of the administration of justice in Cleveland with particular reference to the treatment of the offender, such a study to be the basis of constructive measures to improve the machinery for the administration of the law." It was resolved further that "the precise scope of the survey and the selection of its personnel be left entirely within the discretion of the Foundation Committee." With this resolution the Bar Association pledged "hearty coöperation not only in making the survey but in bringing about the adoption of the constructive measures therein recommended."

These requests were followed by formal requests of the same general character from the Chamber of Commerce, the League of Women Voters, the Federation of Women's Clubs, the Welfare Federation and a number of individuals and other organizations. 


\section{The Advisory Committee}

A survey should be a coöperative enterprise in which the community seeks to study itself. In this task the experts who perform the technical research and the organization that sponsors it do little more than to lead the way. The community, through its group associations, must grow into harmony with the purposes of the study; it must feel its own responsibility for its own institutions, and through representative persons should be constantly informed of progress and plans. Moreover, those who are engaged in the study need constant advice and guidance from persons representing the diversified opinions of the city. To serve as an instrument of contact between the survey workers and the public, and to provide a source of practical advice, an advisory committee was formed which represented in its personnel a wide variety of interest and opinion. This advisory committee was made up of fortyfour individuals invited to serve by the Foundation Committee.

This committee held meetings during the progress of the survey to hear and discuss reports of progress. After the completion of the reports subcommittees were formed from the membership of the advisory committee to read and discuss the reports. During the months of June and July no less than 25 meetings were held, in which these subcommittees went over each report in great detail with the authors. As a result of these conferences, each report was considerably altered by the author in the light of the suggestions made by the committees.

The chairman of the advisory committee was Mr. Amos Burt Thompson, whose active interest in the survey was an invaluable service to the members of the staff and to the Foundation Committee.

The members of the advisory committee were:

Amos Burt Thompson, Chairman

Mrs. A. M. Allyn

A. D. Baldwin

George Bellamy

A. A. Benesch

Dr. R. H. Bishop, Jr.

Morris Black

Alva Bradley

Rev. Dan F. Bradley

Starr Cadwallader

Harold T. Clark

W. L. David

Dean W. T. Dunmore

John D. Fackler

Mrs. E. H. Fishman

Judge Carl D. Friebolin

David E. Green
Isador Grossman

Judge F. A. Henry

Dr. Charles S. Howe

Paul Howland

Elton Hoyt, II

Dr. P. A. Jacobs

Dr. H. T. Karsner

W. G. Lee

Rev. Alexander McGaffin

Frank S. McGowan

Miss Ida McKean

H. H. McKeehan

Sylvester V. McMahon

Mrs. Walter H. Merriam

M. P. Mooney

Rev. Francis T. Moran

Mrs. Frank Muhlhauser 
W. M. Pattison

F. A. Quail

F. W. Ramsey

Dr. Henry Sanford

A. A. Stearns

Mrs. Katherine Stebbins

Judge F. E. Stevens
Dr. C. W. Stone

Judge John J. Sullivan

M. L. Thomsen

Miss Grace Treat

Miss Alice S. Tyler

Peter Witt

Rabbi Louis Wolsey

\section{The Foundation Committee and Its Staff}

The Foundation Committee maintains a permanent office staff consisting of the director of the Foundation, a publicity and editorial director, and office assistants. In conducting a survey of this kind a definite coöperative plan is followed by which this permanent local staff facilitates the work through making available to the survey directors and specialists their knowledge of people, newspapers, locations, organizations, and governmental agencies within the city, and by acting as the direct representatives of the Foundation in relations with the public.

In accordance with this policy the permanent Foundation staff in this survey took no actual part in the investigation. Their responsibility consisted of determining with the approval of the committee the methods and the time of presenting the results of the survey to the public. This included the arranging of public meetings, writing and releasing press material, organizing committees and arranging for the publication of the reports.

\section{Conferences with Public Officials}

After each report had been subjected to the committee conferences above described, it was revised by its author and directors of the survey, and submitted to the public official charged by the law with responsibility for the institution surveyed. For example, the report on Police Administration was submitted to the chief of police, that part of the Prosecution report dealing with the city prosecutors to the city director of law and the chief police prosecutor, the section on the Juvenile Court and the Detention Home to the judge of the juvenile court. Each report was gone over in detail in this way, every objection or criticism by a public official of a fact in the report was submitted to the author of the report for consideration. This procedure, which has been followed in all of the Cleveland Foundation surveys, makes it possible in most cases to attain substantial agreement between surveyors and surveyed upon all questions of fact. Matters involving opinion or inference drawn from facts are made upon the responsibility of the author of the report and the directors of the survey and they alone should finally determine the contents of a 
report. The only report not thus submitted was that on the Criminal Courts. This one covered the work of two courts, in which a total of 23 judges share almost concurrent authority. The practical difficulty of conference with so many officials influenced the committee to decide not to follow the usual procedure in dealing with this report, a decision in which the presiding judge of the Common Pleas Court concurred.

These conferences with public officials were most important to the success of the survey. Every report gained very materially from the frank criticism which it received in this way. Every public official participated with an honest desire to coöperate in any movement which promised to raise the standard of the administration of the criminal law and restore it to its former place in public esteem. Scores of alterations were made in the reports as a result of the conferences with the advisory committee and with officials. After this searching process of revision had been completed, the individual reports were published in paper-bound volumes of from 30 to 140 pages.

\section{Carrying the Community}

A survey such as this becomes an effective instrument of social progress only when the results of the scientific investigation are carried over into the public thought and action by building up within the community an informed public opinion on the subject that has been studied. Two major processes are involved in the social survey. One is the conduct of the investigation, and the other is the education of the public. The two processes are carried forward simultaneously, but the investigation in the lead in point of time. In the present case, long and continuous effort has been devoted to bringing the results of the survey to the interest and attention of the public.

The reports were given to the public at intervals of a few days during September and October, 1921. Three luncheon meetings were held under the auspices of the Foundation for the presentation of the reports by Messrs. Fosdick, Bettman, and Smith. Dean Pound addressed a public meeting under the joint auspices of the Bar Association and the Foundation, while Dr. Adler addressed the Academy of Medicine. Meetings of this sort form an admirable means of focusing public attention upon reports. Just as the address of Dr. Adler to the Academy of Medicine and that of Dean Pound to the Bar Association brought forcefully to the most interested groups the contents of two major reports, an attempt was made to bring together the specific persons in the community whose interest would most largely influence certain other phases of the process of law enforcement. For example, practically all of the prosecutors and 
assistant prosecutors attended Mr. Bettman's meeting, while Mr. Fosdick's audience included the Chief of Police, his inspectors, and many members of the force. These luncheon meetings were attended by an average of from 400 to 500 persons.

The newspaper support which the survey received was a very important factor in its success. The public spirit of all three of the daily papers was shown in the fact that many columns of space were invariably given to all of the reports by all of the papers. This in spite of the fact that from the standpoint of "news" value reports of this kind are long and technical. The newspaper summaries were made by the newspapers themselves and were in the main accurately and intelligently made. Editorial comment, cartoons, and other special forms of emphasis very greatly added to the public influence of the survey.

Copies of the separate reports were placed on sale at the meetings and at the bookstores. Members of the Foundation staff have augmented the educational campaign with over 50 addresses during the year before groups representing all elements of city life. To reinforce and render more permanent the effect of the survey upon public opinion addresses and study courses upon the survey will continue throughout the present winter. Moreover, a 32-page summary of the material contained in this volume is being prepared and will be issued in a large edition for free distribution. The Survey Graphic for November, 1921, featured an account of the survey prepared by Mr. John W. Love of the Foundation staff.

\section{The Cleveland Association for Criminal Justice}

The Cleveland Bar Association, in its resolution requesting the Foundation to make the survey, pledged itself not only to coöperate in the making of the survey, but to aid "in bringing about the adoption of the constructive measures therein recommended." In line with this pledge the Bar Association, after the survey reports had been given to the public, selected a committee "to take up with the Cleveland Foundation . . the matter of establishing an organization for the promotion of efficient administration of criminal justice." The chairman of this committee was Homer H. McKeehan.

As a result of a number of conferences of not only representatives of the Bar Association and the Foundation, but a number of other civic bodies, there was formed in December, 1921, the Cleveland Association for Criminal Justice.

This organization is an association of the great civic organizations of 
the city. The number of charter members is 13 , including the following organizations:

The Cleveland Bar Association
The Cleveland Automobile Club
The Cleveland Chamber of Commerce
The Cleveland Advertising Club
The Cleveland Academy of Medicine
The Cleveland Real Estate Board
The Civic League of Cleveland
The League of Women Voters
The Women's City Club
The Cleveland Builders' Exchange
The Cuyahoga County Council of the American Legion
The Cleveland Chamber of Industry
The Industrial Association of Cleveland

Under the articles of the association each of these organizations elects two members of the board of directors, with an additional 12 selected at large. This board of directors chooses an executive committee and the officers of the organization. As has been mentioned, the members of the association are organizations, not persons. There is, however, provision for the enlistment of smaller civic organizations, such as church clubs, as auxiliary members and for interested individuals as associate members.

Some idea of the scope of activities of the organization may be gained from the names of the standing committees:

$\begin{array}{ll}\text { Police } & \text { Prosecutions } \\ \text { Juries } & \text { Courts } \\ \text { Probation, Parole, Punishment and } & \text { Medical Relations } \\ \text { Institutions } & \text { Public Office Administration } \\ \text { Finance } & \text { Legislation } \\ & \text { Publicity }\end{array}$

In general the functions of the association will be as follows:

1. To exercise a constant surveillance upon the processes of justice, to the end that the public may be constantly informed as to conditions, both good and bad, which exist in the field of criminal justice.

2. To assist those in authority to make improvements where desirable in the organization and operation of the agencies of criminal justice.

The association has assured itself of financial support and plans to continue for an indefinite period of not less than five years. As operating director, the association has selected Mr. Charles DeWoody, who took office January 1, 1922. 
There has thus been created an agency, backed by the aggregate power of the most important civic organizations (including over 50,000 individual members), to represent the all-important public interest in the processes by which life and property are protected in a great city.

\section{Cost of the Survey}

The total cost of the survey was $\$ 38,394.78$. The amounts expended on each of the main portions of the work are shown in the following cost accounting. This amount does not include the cost of printing which will be repaid in part through the sale of printed reports or the expenses of the permanent staff of the Foundation.

Distribution of Costs Among Principal Divisions of Work

Police Administration

$\$ 7,893.15$

Prosecution

Criminal Courts

Correctional and Penal Treatment

$9,257.38$

Medical Science and Criminal Justice

$10,996.89$

Legal Education in Cleveland $5,065.97$

$1,222.17$

Newspapers and Criminal Justice

Total

$\frac{3,175.98}{\$ 38,394.78}$

\section{Principal Purposes for Which Funds Were Spent}

Salaries

Traveling and living expenses of staff

Clerical assistants

$\$ 19,918.32$

Rent and miscellaneous office expenses

$8,608.30$

Publicity

$5,316.46$

Miscellaneous 


\section{STAFF OF THE SURVEY}

\section{DIRECTORS}

Roscoe Pound, Dean of Harvard University Law School.

Felix Frankfurter, Byrne professor of administrative law, Harvard University Law School.

\section{DIRECTORS' STAFF}

C. E. GeHLKE, statistical director for the Cleveland Foundation.

R. S. Judge, Pittsburgh, formerly special agent, Bureau of Investigation, Department of Justice, Washington.

Harry S. Richards, business statistician, Federal Reserve Bank, Cleveland; formerly with the Bureau of the Census, Washington.

H. B. Flinkers, of the Foundation Staff.

Charles B. Ryan, municipal accountant with the Municipal Research Bureau of Cleveland.

JoHN W. Love, editorial director for the Cleveland Foundation.

Helen Chew, of the Foundation Staff.

Hazel Zimmerman, of the Foundation Staff.

L. J. WoLF.

\section{CLERICAL STAFF}

Elizabeth Cummer, Alice G. Harrison, Mrs. Mary Hoefer, Doré Landad, Orville P. Moon, Paul Keodgh, Rodney S. Sutton.

\section{SPECIAL DIVISIONS OF INQUIRY}

\section{Court Organization and Administration}

Regrnald Heber Smith, author of Justice and the Poor, prepared for the Carnegie Corporation, 1919; member of Hale and Dorr, Boston law firm.

Herbert B. Ehrmann, associated with Hale and Dorr, Boston.

\section{Police}

RAYMond Fosdick, director; author of American Police Systems, and an authority on police administration; formerly Under-Secretary-General of the League of Nations. 


\section{Prosecution}

Alfred Betrman, director; formerly city solicitor of Cincinnati, and special assistant to the United States Attorney General; member of the Cincinnati law firm of Moulinier, Bettman and Hunt.

Howard F. Burns, formerly of White, Johnson, Cannon and Spieth, Cleveland law firm.

\section{Penal and Correctional Treatment}

BURDETTE G. LEwIs, director; state commissioner of institutions and agencies in New Jersey; author of The Offender, 1917.

Calvin Derrick, superintendent of the New Jersey State Home for Boys, Jamesburg, N. J.

Edgar A. Doll, director of education and classification, Department of Institutions of New Jersey.

\section{Psychiatry and Medical Relations}

Dr. Herman M. Adeer, director; state criminologist of Illinois.

E. K. Wickman, psychologist on the staff of Dr. Adler in Chicago.

Maurice R. Davie, assistant professor of sociology, Yale University.

\section{Legal Endcation}

Albert M. Kales, Chicago, member of the law firm of Fisher, Boyden, Kales and Bell, formerly professor of law at Harvard University.

William B. Dawson, with Stanley and Horwitz, Cleveland law firm.

\section{Newspapers and Criminal Justice}

M. K. Wisenart, American Magazine, New York, formerly on the Washington staff of the New York Eventing Sun. 


\title{
APPENDIX II
}

\section{THE STATISTICAL MATERIAL AND METHODS OF THE SURVEY}

\author{
By C. E. Gehlke \\ Statistical Director for the Cleveland Foundation
}

T

$\mathrm{HE}$ statistical material used in the survey was of two main classes. The first consisted of the official case records of individual offenders passing through the courts and the penal institutions of the city. The second was in the main composed of data taken from official reports and summaries made by the various agencies themselves. It contained also a small number of case histories, treated more individually and intensively than were those in the first class.

The latter class of material was statistically analyzed by the individual investigators incidentally to the development of their several studies. It appears in the report practically in the forms chosen by them. The function of the statistical division of the staff was to tabulate and summarize the material of the first class. Its task was conceived of primarily as that of analyzing in every practicable way the thousands of case histories which were abstracted from the official records. These analyses were submitted to the various investigators with the aim of furnishing the necessary basis of statistical fact upon which to estimate the efficiency of the courts and other penal agencies that were studied. The tables as they appear in print represent the selection by the investigators of only those summaries of which the sharp limitation of space did not forbid the inclusion. A large proportion of the statistics submitted to them were carried out in a detail that could not be included without unduly expanding the reports. Furthermore, with few exceptions, the basic tables are given without percentages, an omission also necessitated by reason of this condensation.

The material of this first class consists of the following groups of cases:

1. In the Common Pleas Court, 3,236 cases; these were all the cases which appeared in that court first in 1919, plus about 100 in January, 1920. These latter cases were included by mistake, but their inclusion was not discovered until much of the tabulation had been done. They were left 
in principally because they were in all respects apparently homogeneous with the others. The 3,236 cases did not include those misdemeanor cases which came as an appeal from the decision of a lower court, nor those which were brought into the court at the first instance, but which were sent to a lower court because they involved misdemeanors, not felonies.

The facts about these cases were brought down to the date of March $1,1921$.

2. In the Common Pleas Court, 640 cases; these were all the cases begun in the months of January, February, and March of 1921, subject to the same omissions as indicated for the preceding class.

3. Preliminary examinations for felonies made in the Municipal Court during 1919 and 1920, 685 cases.

4. Violations of the ordinances of the city of Cleveland arraigned in the Municipal Court in 1919 and 1920, 1,832 cases.

5. Violations of statutes of the State of Ohio defining misdemeanors, arraigned in the Municipal Court in 1919 and 1920, 1,953 cases.

6. Prisoners in the workhouse whose sentences were terminated during the months of January, February, March, July, August, and September, 1920, 1,322 cases. This material was used exclusively in the report on Correctional and Penal Treatment.

With respect to groups 3,4 , and 5 , a word of explanation is necessary. Cases in the Municipal Court are filed when completed. A number of cases of the same charge are often filed under the same number (see p. 130, report on Prosecution, and p. 293, report on the Criminal Courts). The instructions to the clerical assistants abstracting data from these files were to take every tenth case by number in the files. This procedure produced a slight disproportion of some kinds of cases. It resulted also in a discrepancy between the number of records abstracted, and one-tenth the number of total persons involved. This was accentuated by the fact that "bond forfeited" cases are filed periodically as they accumulate in a separate temporary file. In order to ascertain whether these discrepancies affected the conclusions respecting proportions of various kinds of dispositions for the whole group, the following procedure was undertaken.

The number of cases of each charge was multiplied by the percentages of dispositions of each kind. These products for all charges were summed by dispositions. It was then found that these sums agreed almost exactly with the figures obtained by multiplying the total number of cases for the two years by the percentage of each kind of disposition derived from our selected cases. This method was adapted from the familiar one used in "correcting" the death-rate of a population.

Since importance was attached not to the relative number of cases of 
each charge, but only to the proportions of each kind of disposition for the given charge, this discrepancy of totals is insignificant for the purposes of the survey.

The schedules in which the case histories were abstracted from the records are shown below. There were two for each case in groups 1 and 2, one schedule covering the history in the Municipal and the other in the Common Pleas Court. The Municipal Court schedules were two-one for examinations in felony cases and one for misdemeanor cases. In the latter a difference in color differentiated city and State cases. There was one form of schedule for the cases of prisoners in the workhouse. Each schedule was 5 by 8 inches.

After a preliminary hand sort and count it was determined to use mechanical tabulation. Through the courtesy of the Board of Education the mechanical tabulating machinery of its accounting department was put at the service of the survey at the hours in which it was not used in its regular work. The generous assistance of the operators of this machinery was the second factor which made the use of this machinery possible.

Thanks are also due to Colonel Leonard P. Ayres, Vice-President of the Cleveland Trust Company. The statistical director is indebted to him both for his most valuable counsel and for his very generous assistance in the designing and execution of many of the diagrams of this book. The director's greatest obligation is to Harmen B. Flinkers, his chief assistant, upon whose intelligent devotion to the work of tabulation and analysis he learned to depend with complete confidence.

\section{Schedules of Data}

1. Schedule of data covering Municipal Court history of felony cases begun in the Common Pleas Court during the year 1919, and the first three months of 1921. (Criminal Courts and Prosecution reports.)

C. P. Docket Name Charge. M. Ct. No.

Date of offence

Date of affidavit

Date of arrest

Date bound over.

Date of transcript.
Judge.

To what term.

Amount of bail

Date-if given

Bondsman

Own recognizance 
2. Schedule of data covering history of felony cases in Common Pleas Court begun in that court during the year 1919 and the first three months of 1921. (Criminal Courts and Prosecution reports.)

Docket. Name. Record

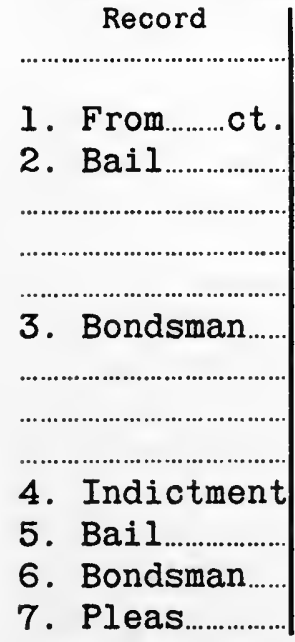

Date|Substance|

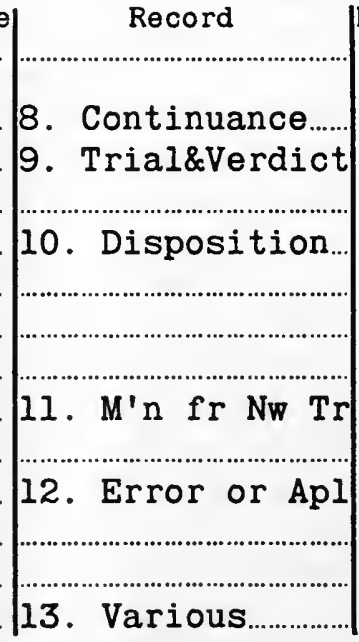

Charge.

Date|Substance

Judges $5 \ldots \ldots \ldots \ldots . . . . . .110,11$ C. Pr. D's Atty. Municipal Ct. No.

Appt .

3. Schedule of data covering history of misdemeanor cases in Municipal Court, 1919 and 1920. (Criminal Courts and Prosecution reports.)

Docket.........Name

Charge Class

Offence

Pleas.

Affidavit.

Jury claim

Arrest.

Disposition.

Bail

Bondsman.

Own recognizance Judge

Motion for nw. tr.

Motion in miti.

Appeal or error.

Continuances 
4. Schedule of data covering preliminary hearings of felony cases in the Municipal Court, 1919 and 1920. (Criminal Courts and Prosecution reports.)

Docket..........Name

Charge Class

Offence

Examination

Affidavit

Exam. waived

Arrest.

Disposition.

Bail

Continuances

Bondsman

Own recognizance

Various

Judge.

5. Schedule of data respecting prisoners in the Workhouse, whose terms ended during January, February, March, July, August, and September, 1920. (Tables 3-7, Correctional and Penal Treatment report.) Name Nationality......................

Residence.

$$
\text { city }
$$

state

country

Name of Court Name of Offence

Sentence

Date received at Workhouse

day month year

Date released

$$
\text { day }
$$

month

year

Released by Released

Returned

Court order...... on parole......by court order

day month year

If returned for violation of parole

day month year [ 669 ] 


\section{APPENDIX III}

\section{THE NORWOOD BILL}

$\infty$

ENATE Bill No. 8, of the Eighty-fourth General Assembly Regular Session, 1921, of Ohio Legislature, introduced by Senator Norwood, and which became a law without the Governor's approval:

\section{A BiLl}

To amend section 2166 of the General Code, relative to indeterminate sentence to the Ohio Penitentiary.

Be It Enacted by the General Assembly of the State of Ohio:

Section 1. That section 2166 of the General Code be amended to read as follows:

Sec. 2166. Courts imposing sentences to the Ohio penitentiary for felonies, except treason, and murder in the first degree, shall make them general, - . . but they shall fix within the limits prescribed by law, a minimum period of duration of such sentences. All terms of imprisonment of persons in the Ohio penitentiary may be terminated by the Ohio board of clemency, as authorized by this chapter, but no such terms shall exceed the maximum . . . term provided by law for the felony of which the prisoner was convicted, nor be less than the minimum term fixed by the court for such felony. If a prisoner is sentenced for two or more separate felonies, his term of imprisonment may equal, but shall not exceed, the aggregate of the maximum terms of all the felonies for which he was sentenced and, for the purposes of this chapter he shall be held to be serving one continuous term of imprisonment. If through oversight or otherwise, a sentence to the Ohio penitentiary should be for a definite term, it shall not thereby become void, but the person so sentenced shall be subject to the liabilities of this chapter and receive the benefits thereof, as if he had not been sentenced in the manner required by this section.

Section 2. That said original section 2166 of the General Code and all laws or parts of laws inconsistent with this act be, and the same are hereby repealed. 


\section{APPENDIX IV}

\section{PARDONS IN OHIO}

\section{A STUDY OF THE PARDONING POWER AS EXERCISED BY THE GOVERNORS OF OHIO, APPLYING TO THE STATE PENITENTIARY}

EDitor's Note-Most of the data for this report were gathered by Kosciusko Kitchen, of Logan, and C. J. Mueller, of Middletown, law students at Western Reserve University, who were interested in this phase of the Ohio penal system. The material was submitted to the Ohio Institute for Public Efficiency, Columbus, Ohio, which is responsible for the form of the report and the recommendations. The recommendations were written by R. E. Miles, director of the Institute.

The data gathered relate only to pardons and commutations granted to inmates of the Ohio Penitentiary. As these constitute, however, over two-thirds of all pardons granted by the several governors, it is felt that the conclusions drawn may be considered substantiated.

General data were gathered for the period July 1, 1899, to June 30, 1921, and detailed analysis of the records from January 11, 1915, to January 10, 1921. The latter period comprises the last three executive terms, previous to which time the records lack sufficient accuracy to make detailed study worth while.

\section{What is a Pardon?}

According to official records, there are eight recognized ways in which a prisoner at the Ohio Penitentiary may receive his liberty. These eight ways are as follows:

Expiration of sentence
Parole
Full pardon
Conditional pardon
Commutation of sentence
Conditional commutation of sentence
Conditional release
Final release

Without stopping to discuss here how many of these classifications might be considered superfluous, a pardon is distinguished from the other methods of release in the fact that it effects a restoration of the rights and privileges of citizenship which are forfeited by conviction of a felony. Among these are the rights to be an elector or juror, or to hold an office of honor, trust, or profit. ${ }^{1}$ 
Where a general pardon has been granted, it obliterates the record of conviction, and offenses committed within its terms cannot be reconsidered for the purpose of sentencing one under the habitual criminal act. 1

A commutation differs from a general pardon in that, while shortening the sentence, it does not obliterate the record of conviction. General rights of citizenship are restored.

"The main reasons for investing the chief executives of modern nations with the wide discretion which they exercise in this regard are to prevent injustice because of the fallibility of human laws, which sometimes work injustice in individual cases, although they may be salutary on the whole; the possibility that a person may be unjustly accused and convicted, which may not be discovered until long afterward; to make it possible for the supreme authority to release persons convicted and sentenced under harsh and oppressive laws, especially political offenders convicted in a time of great public excitement and discord; to enable the chief executive to reward in this manner repentance and good conduct in prison, where he is satisfied that a thorough reform has been effected, and justice satisfied. . . . The necessity for the exercise of this power on the ground last named is greatly lessened by statutes allowing a graduated commutation of a term of imprisonment as a reward for repentance and good conduct in prison." 2

Another ground sometimes urged for the use of a pardon or commutation is the "occasional necessity of obtaining evidence from one wrongdoer to secure the conviction and punishment of another. In certain forms of crime, such as bribery and conspiracy, in which more than one person must be concerned, the precise facts usually lie in the knowledge of the guilty parties only, and it is often very difficult, sometimes quite impossible, to secure adequate proof against any, unless one of them can be induced to testify."3

\section{The Governor's Powers}

Under the provisions of the Ohio constitution, adopted in 1851, almost unlimited pardoning powers are conferred upon the Governor. Article III, Section 11, of the constitution says:

He [the Governor| shall have power, after conviction, to grant reprieves, commutations and pardons, for all crimes and offenses, except treason and cases of impeachment, upon such conditions as he may think proper; subject, however,

${ }^{1}$ State v. Williams, 7 O.N.P. 562, 5 O.D.(N.P.) 545.

2 New International Encyclopedia.

3 Charles J. Bonaparte, in Yale Law Journal, vol. 19, 1909-10, pp. 603-8. 
to such regulations, as to the manner of applying for pardons, as may be prescribed by law.

$\mathrm{He}$ shall communicate to the general assembly, at every regular session each case of reprieve, commutation, or pardon granted, stating the name and crime of the convict, the sentence, its date, and the date of the commutation, pardon, or reprieve, with his reason therefor.

The regular procedure for dealing with pardons, found in Sections 93-101 of the General Code, may be summarized as follows:

Notice of application furnished to prosecuting attorney of proper county and published in newspaper, except in capital cases.

Prosecuting attorney reports certain information to board of pardons.

Board of pardons presents recommendation to governor.

Governor grants or rejects application.

Any or all of the foregoing provisions, however, may be dispensed with by the governor in case of apparent imminent danger of death or on recommendation of the warden and director of public welfare, with reason stated therefor.

\section{Organization for Handling Pardons}

It was not until 1888 that Ohio recognized the practical need of an organized personnel to review applications for, and the data bearing upon, pardon cases. A Board of Pardons, consisting of four members, was created, which functioned until 1917, when it was abolished and its duties and powers transferred to the Board of Clemency.

Four years prior to the establishment of the Board of Pardons, however, a Board of Managers had been created to supervise the parole system. This board was abolished in 1911, and its functions were transferred to the Board of Administration, established in that year. From 1911 until 1917 the parole system was administered by the Board of Administration.

During the three decades that followed the creation of the two organized personnels to administer the pardon and parole systems, respectively, no effort was made, apparently, to combine the work and avoid the duplication and overlapping of information and effort. In 1917, however, the Board of Clemency came into existence. It consisted of two members of opposite political faith, appointed by the governor from different appellate judicial districts. It was charged with the administration of pardons and paroles so far as they related to "penal" institutions ( $i$. e., the penitentiary and the two reformatories).

On July 1, 1921, the reorganization code abolished the Board of 44 [673] 
Clemency and transferred its powers and duties to the Department of Public Welfare, to be exercised within the department by a Board of Pardon and Parole, consisting of the Superintendent of Pardon and Parole and two other persons within the department designated by the Director of Public Welfare. This, with the addition of field officers attached to the individual institutions, constitutes the present machinery for administering pardons and paroles.

It will be recalled that under the reorganization code now governing State departments, each director of a department is appointed by the governor, by and with the advice and consent of the Senate, and holds his office during the pleasure of the governor. Under the same law, the Superintendent of Pardon and Parole is appointed by the director of the department of public welfare and holds his office during the pleasure of the director. Under present conditions, therefore, the maximum term of which any assurance can be afforded to the members of the Board of Pardon and Parole is two years, and at any time within that period they are subject to immediate removal at the pleasure of the director, who in turn is subject to the same possibility by action of the governor. Such an arrangement can hardly fail to create great difficulty in securing experienced and qualified persons, and in addition makes it very likely that frequent changes in personnel will take place. Under such circumstances the effort to build up and maintain higher standards cannot but be seriously handicapped.

At present the functions imposed upon the Board of Pardon and Parole are limited to passing judgment upon the applications which come before it. It is not responsible for supervision of pardoned or paroled prisoners to see that conditions attached to the pardon or parole are properly enforced. It has no field staff to provide it with information as to the home, industrial, and community conditions into which a pardoned or paroled prisoner will return. Without such a staff, and also without adequate records, it is entirely unreasonable to expect the board to perform its duties effectively. The natural effect, furthermore, of depriving the board of all responsibility for enforcement of conditions attached to pardons and paroles is to make the board more liberal, or even lax, in granting releases. A board whose members were not conscientious might easily allow its policy to degenerate into a "turn-'emloose" process, with serious results to the public.

\section{How the Pardoning Power Has Been Exercised}

An analysis of available official records was made to obtain whatever information might be afforded by them. For what they may be worth, 
the results are given in the following statements of fact, the interpretation of which, unless stated, is left to the reader.

\section{Number Granted}

During the period from July 1, 1899, to June 30, 1921, 837 pardons and commutations were granted by the governors, an average of 38 a year. ${ }^{1}$ The number of pardons and commutations granted each year, together with the average daily population of the Ohio penitentiary, are given in Table 1. The number granted in the last eight years, according to the table, slightly exceeds the number granted in the preceding fourteen years. The average number granted during the first fourteen years was 29 , or 1.8 per cent. of the average annual population of the penitentiary; the average number granted during the last eight years was 54 , or 2.9 per cent. of the average annual population of the penitentiary.

TABLE 1.-AVERAGE DAILY POPULATION OF THE OHIO PENITENTIARY AND NUMBER OF RELEASES THEREFROM BY EXECUTIVE PARDON OR COMMUTATION BY FISCAL YEARS ENDING JUNE 30, 1900, TO 1921 INCLUSIVE ${ }^{2}$

\begin{tabular}{c|c|c|c|c|c}
\hline \hline Year & $\begin{array}{c}\text { Average } \\
\text { daily } \\
\text { population }\end{array}$ & $\begin{array}{c}\text { Released by } \\
\text { executive } \\
\text { action }\end{array}$ & Year & $\begin{array}{c}\text { Average } \\
\text { daily } \\
\text { population }\end{array}$ & $\begin{array}{c}\text { Released by } \\
\text { executive } \\
\text { action }\end{array}$ \\
\hline 1900 & 1,831 & 28 & 1911 & 1,594 & 32 \\
1901 & 1,681 & 26 & 1912 & 1,586 & 22 \\
1902 & 1,689 & 23 & 1913 & 1,628 & 41 \\
1903 & 1,557 & 29 & 1914 & 1,628 & 75 \\
1904 & 1,554 & 24 & 1915 & 1,781 & 46 \\
1905 & 1,591 & 29 & 1916 & 1,884 & 60 \\
1906 & 1,608 & 36 & 1917 & 1,845 & 70 \\
1907 & 1,565 & 20 & 1918 & 2,000 & 63 \\
1908 & 1,612 & 35 & 1919 & 1,881 & 37 \\
1909 & 1,661 & 42 & 1920 & 1,984 & 47 \\
1910 & 1,634 & 20 & 1921 & 2,037 & 32 \\
\hline
\end{tabular}

Attention is drawn to the fluctuation shown in Diagram 1 in the number of pardons and commutations granted from year to year. The highest number in any one year was 75, in 1914; the lowest was 20, in

"The word "year," as used in these statements, means "twelve months ending June 30."

2 This table was compiled from State records which are available only for the fiscal year ending June 30. Figures given will, therefore, not agree with the figures given in other tables which cover the twelve months beginning with the second Monday of January, when the governor takes office. 
1907. For the three successive years, 1912, 1913, 1914, the numbers ran respectively $22,41,75$. A satisfactory explanation of such variation is not evident.

Nearly two-thirds of the cases of executive action are pardons, the remainder being commutations. From January 11, 1915, to January 10, 1921, 258 pardons and 135 commutations were granted by the respective governors. Of the total of 393,240 were conditional and 153 unconditional.

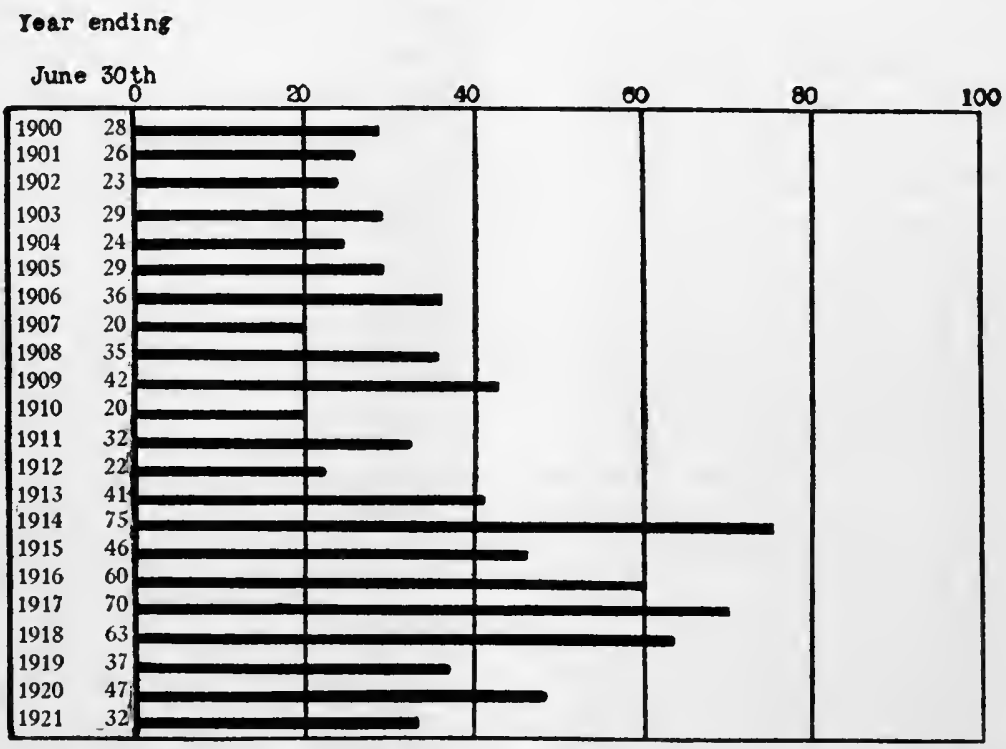

Diagram 1.-Comparison of Numbers of Releases Granted from Year to Year.

\section{Offenses Pardoned}

Of the 393 pardons and commutations granted in the last six years, 158 were granted to persons who had been convicted of murder, manslaughter, assault, shooting or cutting to kill, or maiming. For firstdegree murder there were 31 , and for second-degree murder, 89 . Of the same 393,160 were to persons who had been convicted of offenses against property, and 24 were for sexual crimes.

During the ten years 1900 to 1909 inclusive, 93 commitments for first-degree murder were received at the Ohio penitentiary, of which 41 were terminated by pardon, commutation, or parole before November 15, 1921. During the same period 118 second-degree commitments were received, of which 94 were terminated by pardon, commutation, or parole before November 15, 1921. Of the total 211, 135, or 64 per 
cent., were released before November 15,1921 , on which date only nine of the 211 remained in the penitentiary.

Table 2 is the distribution of releases in the last six years by types of offense and by kinds of official action taken.

TABLE 2.-NUMBER OF OFFICIAL ACTIONS TAKEN, JANUARY 11, 1915, TO JANUARY 10, 1921, CLASSIFIED BY PRINCIPAL OFFENSES AND KIND OF ACTION

\begin{tabular}{|c|c|c|c|c|c|}
\hline \multirow{3}{*}{ Offense of which convicted } & \multirow{3}{*}{$\begin{array}{l}\text { Num- } \\
\text { ber of } \\
\text { official } \\
\text { actions }\end{array}$} & \multicolumn{4}{|c|}{ Kind of action } \\
\hline & & \multicolumn{2}{|c|}{ Unconditional } & \multicolumn{2}{|c|}{ Conditional } \\
\hline & & $\begin{array}{l}\text { Par- } \\
\text { dons }\end{array}$ & $\begin{array}{l}\text { Com- } \\
\text { muta- } \\
\text { tions }\end{array}$ & $\begin{array}{l}\text { Par- } \\
\text { dons }\end{array}$ & $\begin{array}{l}\text { Com- } \\
\text { muta- } \\
\text { tions }\end{array}$ \\
\hline $\begin{array}{l}\text { Abandoning legitimate child } \\
\text { Arson } \\
\text { Assault to kill } \\
\text { Assault to rape } \\
\text { Auto stealing } \\
\text { Burglary } \\
\text { Burglary of inhabited dwellings } \\
\text { Burglary and larceny } \\
\text { Burglary and larceny and habitual crim- } \\
\text { inal } \\
\text { Burning property to prejudice insurer } \\
\text { Carrying concealed weapons } \\
\text { Cutting to kill } \\
\text { Cutting to wound } \\
\text { Embezzlement } \\
\text { Embezzlement of public money } \\
\text { Forgery } \\
\text { Incest } \\
\text { Larceny } \\
\text { Maiming } \\
\text { Manslaughter } \\
\text { Murder-first degree } \\
\text { Murder-second degree } \\
\text { Non-support } \\
\text { Obtaining money under false pretenses } \\
\text { Operating motor vehicle without owner's } \\
\text { consent } \\
\text { Perjury } \\
\text { Pocketpicking } \\
\text { Rape } \\
\text { Receiving stolen property } \\
\text { Robbery } \\
\text { Shooting to kill } \\
\text { Uttering and publishing forged instrument } \\
\text { Miscellaneous }\end{array}$ & $\begin{array}{r}3 \\
2 \\
6 \\
3 \\
4 \\
12 \\
26 \\
25 \\
\\
2 \\
2 \\
5 \\
5 \\
2 \\
16 \\
2 \\
16 \\
2 \\
25 \\
2 \\
13 \\
31 \\
89 \\
12 \\
4 \\
3 \\
3 \\
2 \\
7 \\
19 \\
6 \\
10 \\
12 \\
2 \\
23\end{array}$ & $\begin{array}{r}1 \\
\ddot{2} \\
\ddot{7} \\
1 \\
5 \\
1 \\
9 \\
\ddot{9} \\
5 \\
23 \\
\ddot{1} \\
1 \\
1 \\
\ddot{1} \\
3 \\
1 \\
3 \\
2 \\
\text { i0 }\end{array}$ & 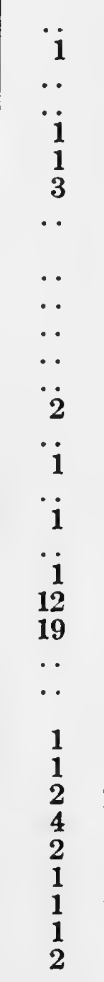 & $\begin{array}{r}2 \\
\ddot{3} \\
1 \\
3 \\
3 \\
11 \\
11 \\
1 \\
1 \\
1 \\
2 \\
2 \\
1 \\
6 \\
1 \\
7 \\
10 \\
1 \\
10 \\
6 \\
36 \\
10 \\
3 \\
1 \\
1 \\
2 \\
7 \\
3 \\
3 \\
7 \\
1 \\
6\end{array}$ & 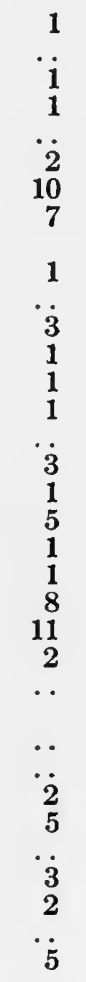 \\
\hline \multirow[t]{2}{*}{ Totals } & 393 & 96 & 57 & 162 & 78 \\
\hline & & \multicolumn{2}{|c|}{153} & \multicolumn{2}{|c|}{240} \\
\hline
\end{tabular}




\section{Time Served}

Table 3 classifies releases for six years by sentences and time served. This table shows that:

1. The 384 individuals who received the 393 pardons and commutations during the six-year period intensively studied served an average of 3 years, 4 months, and 26 days each. The longest time of 23 years, 8 months, and 6 days was served by a prisoner sentenced to life; the shortest time of 16 days was served upon a one to three-year sentence.

TABLE 3.-RELEASES, JANUARY 11, 1915, TO JANUARY 10, 1921, CLASSIFIED BY SENTENCES AND AVERAGE TIME SERVED ${ }^{1}$

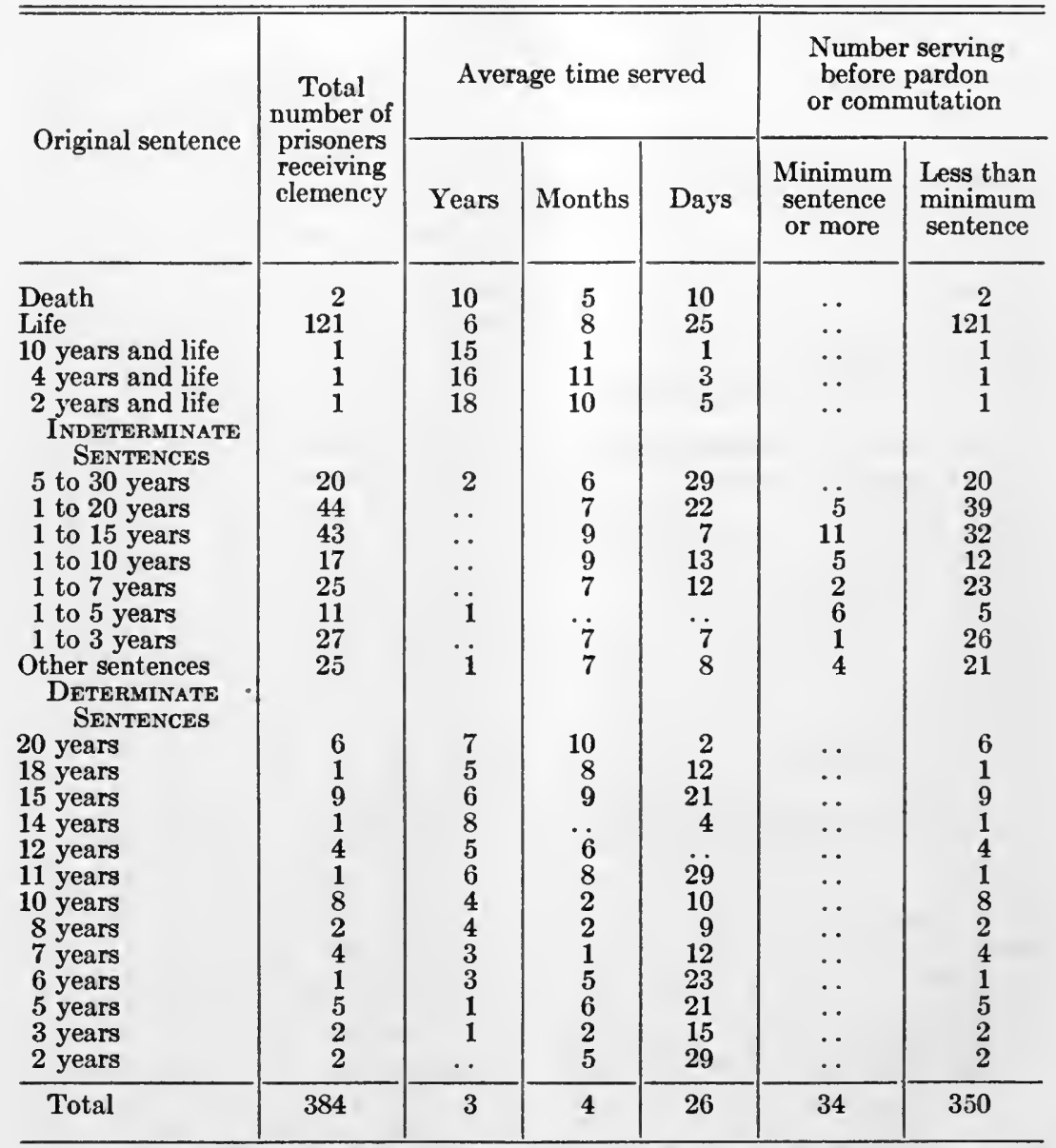

${ }^{1}$ During this period the governor granted 393 pardons and commutations, but nine prisoners received clemency two different times. 
2. The average time actually served by 121 persons sentenced to life imprisonment was 6 years, 8 months, and 25 days.

3. Of the total 384,350 served less than the minimum sentence. Frequently the time served was less than half the minimum sentence.

An analysis of the disposition of first- and second-degree murderers received at the penitentiary in the ten-year period 1900-1909 inclusive is given in Table 4 . Of the 93 first-degree murderers received in that time, four served less than five years, 19 between 5 and 10 years, 15 between 10 and 15 years, and three between 15 and 20 years, a total of 41 released. Of the 118 second-degree murderers similarly received, 17 served less than 5 years, 38 between 5 and 10 years, 39 between 10 and 15 years, a total of 94 released.

TABLE 4.-DISPOSITION OF FIRST AND SECOND-DEGREE MURDERERS COMMITTED DURING TEN YEARS, JANUARY 1, 1900, TO DECEMBER 31, 1909. COMPILED AS OF NOVEMBER 15, 1921

\begin{tabular}{|c|c|c|c|}
\hline & $\begin{array}{l}\text { First-degree } \\
\text { murder }\end{array}$ & $\begin{array}{l}\text { Second-degree } \\
\text { murder }\end{array}$ & Total \\
\hline $\begin{array}{l}\text { Electrocuted } \\
\text { Died } \\
\text { Escaped; not returned } \\
\text { Transferred } \\
\text { Pardon or commutation } \\
\text { Less than } 5 \text { years } \\
5 \text { to } 10 \text { years } \\
10 \text { to } 15 \text { years } \\
15 \text { to } 20 \text { years } \\
\text { Paroled } \\
\text { Less than } 5 \text { years } \\
5 \text { to } 10 \text { years } \\
10 \text { to } 15 \text { years } \\
\text { Still in prison } \\
10 \text { to } 15 \text { years } \\
15 \text { to } 20 \text { years }\end{array}$ & $\begin{array}{c}26 \\
12 \\
4 \\
4 \\
39 \\
(4) \\
(17) \\
(15) \\
(3) \\
2 \\
(2) \\
\cdots \\
(6 \\
6) \\
\cdots\end{array}$ & $\begin{array}{c}5 \\
4 \\
12 \\
47 \\
(12) \\
(29) \\
(6) \\
\dot{4} 7 \\
(5) \\
(9) \\
(33) \\
3 \\
(2) \\
(1)\end{array}$ & $\begin{array}{r}26 \\
17 \\
8 \\
16 \\
86 \\
(16) \\
(46) \\
(21) \\
(3) \\
49 \\
(5) \\
(11) \\
(33) \\
9 \\
(8) \\
(1)\end{array}$ \\
\hline Totals & 93 & 118 & 211 \\
\hline
\end{tabular}

Reasons Assigned for Release

According to official records reasons assigned for release were the following:

Recommended by Boards of Pardon and Clemency

Recommended by trial judge, prosecuting attorney, and Clemency Board

Recommended by prison officials Recommended by citizens

Imminent danger of death

In honor of a holiday

Long term and good prison record
Evidence of reform

155

Sentence too severe

Comparative justice, partners in crime receiving light sentences 3

Doubt of guilt

To leave State

Lack of mental responsibility

48 Temporarily insane at time of

41

28 commission of the crime

Total 
It is observed that in the majority of cases, comprising 218, recommended by the Board of Pardons or Board of Clemency, judges, prison officials, and citizens, no real and valid reason for release is stated. Among these are found 16 convicted of first-degree murder, 40 convicted of second-degree murder, 9 convicted of manslaughter, and 9 of shooting or cutting to kill.

Presumably the recommendations were based on reasons which seemed proper and adequate, and should, therefore, have been definitely stated. If the present practice is pursued, however, it affords possibilities of concealing pardons of a doubtful nature from public notice.

Inquiry revealed that in a number of cases the recommendations of the Board of Clemency were based on a belief that even the minimum sentence imposed was excessive. To the extent that the board's belief on this point was well founded, such criticism as might be suggested would apply rather to the minimum sentences imposed by existing laws than to the acts of pardon. It may be remarked that the result of the Norwood law, enacted by the last Assembly, authorizing judges to impose a minimum sentence in excess of that fixed by statute, will doubtless be to increase the number of cases seeking executive pardon or commutation.

The 41 pardons issued "in honor of a holiday" would seem to be largely sentimental, no valid reason being stated. The list of holidays thus signalized during the six-year period is as follows: New Year's, Washington's Birthday, Memorial Day, Independence Day, Labor Day, Jewish New Year, Emancipation Day, Columbus Day, Thanksgiving Day, Christmas Day, Greek Independence Day.

It is related that on one occasion a pardon "in honor of "St. Patrick's Day was awarded to a prisoner who seemed to possess a good Irish name, but who too late proved to be a Scotchman.

"Lack of mental responsibility," assigned in three cases, would seem to be an admirable reason why release should not be granted. Is a person convicted of "assault to kill" to be turned loose on the community because of a mental.irresponsibility which increases the probability of another offense?

Release "to leave the State," if other States pursue the same process, is only a futile attempt at getting rid of undesirables by dumping them in our neighbors' yards.

\section{Previous Record of Applicants}

The previous record of applicants has not in all cases received sufficient attention in the exercise of the pardoning power. This may safely 
be taken for granted when the offender is again found delinquent within a short time. One illustration is given.

\section{Prisoner's Number 49,820}

Received July 7, 1915, for burglary and larceny; sentence, 1 to 15 years.

Previous record:

One term at Ohio State Reformatory at Mansfield.

No. 30848 Ohio Penitentiary for horse stealing, June 27, 1898, to May 4, 1899.

No. 3565 Michigan Reformatory for receiving stolen property, June 6, 1900, to April 7, 1901.

No. 34318 Ohio Penitentiary for horse stealing, July 16, 1902, to May 3, 1906.

A31772 Auburn Prison, New York, for burglary and larceny, October 24, 1911, to October 23, 1913, when placed on parole, discharged from parole October 27, 1914.

Conditional pardon granted December 20,1916, after serving one year, five months, and thirteen days.

Returned to penitentiary May 27, 1919, for shooting to kill, sentence one to twenty years.

Prisoner's Numbers: 40,033 Determinate; 45,642 Indeterminate

October 11, 1910, admitted to the Ohio penitentiary upon conviction of robbery; sentence, fifteen years; operating an automobile without owner's consent, sentence, from one to five years.

February 17, 1912, paroled.

May 2, 1912, arrested and held for investigation by Columbus police.

May 7, 1912, returned to penitentiary.

April 15, 1913, parole restored.

November 17, 1913, arrested for taking an automobile without leave, by Columbus police. Bound over on $\$ 1,000$ bond.

December 23, 1913, returned to penitentiary.

June 8,1917 , conditional pardon, for which he was to abstain from the use of intoxicating liquors, stay out of saloons, attend church regularly, and report for two years as if on parole. Verbal understanding that he was to remain out of the State.

September 1, 1920, arrested by Columbus police for petty larceny, after being out of State since June, 1917. Released subject to call of prosecutor.

September 7, 1920, arrested for grand larceny by Columbus police. Case dismissed.

October 31, 1920, arrested for petty larceny by Columbus police. Bond forfeited.

November 1, 1920, arrested for carrying concealed weapons by Columbus police. Bound over on a $\$ 500$ bond. 
May 18, 1921, arrested by Columbus police for being drunk. Bond forfeited. June 14, 1921, arrested for illegal possession of liquor by Columbus police. Fined $\$ 100$ and costs.

October 4, 1921, arrested by Columbus police in connection with the burglary of an inhabited dwelling. Bound over to grand jury.

General: While intoxicated, he visited the penitentiary and threatened the warden for opposing a pardon and recommending his return.

The Bertillon department of the Columbus police force is now endeavoring to secure information from the Bertillon clearing-houses at Fort Leavenworth, Kansas, Washington, D. C., and Mansfield, Ohio.

The Columbus police docket shows a long record extending back to 1909 . A brother was killed recently by a member of the Columbus police force, when caught driving a wagonload of stolen goods away. Two other brothers have police records almost equally discouraging.

Twenty-six pardons and commutations were granted to prisoners convicted of burglary of an inhabited dwelling, 10 of whom had served one previous term; one, two previous terms. Two of these were convicted of burglary; three for robbery; one for receiving stolen goods; and six, the nature of whose previous offenses was not shown upon the records.

Twenty-five pardons and commutations were issued to prisoners convicted of burglary and larceny, nine of whom were "repeaters." Seven of these were serving their second term; one, his third term; and one, his fifth term. The offenses for which they were previously convicted were: burglary, burglary and larceny, horse stealing, robbery, receiving stolen goods, perjury, larceny, and cutting to wound.

Seven pardoned were sentenced for pocketpicking, three of whom had served a total of 10 previous terms; five for larceny, two for pocketpicking, and three for offenses not shown.

The history of "repeaters" is not complete because prison records do not always show former records served. From information available, however, it was ascertained that in 393 cases 67 were "repeaters," 46 having served one previous term; 13 , two terms; 5 , three terms; 2 , four terms; and 1, five terms. Undoubtedly, a careful analysis of the records of the Bertillon department would show a larger percentage of "repeaters" to whom pardons and commutations have been granted.

\section{Enforcement}

No argument should be necessary that when a pardon or commutation is issued conditional upon compliance with certain requirements, these requirements should be enforced. In the case of pardons, however, the statutes governing the enforcement procedure furnishes an 
excellent example of "passing the buck." The procedure is about as follows:

The field officer reports to the warden, who reports to the director of public welfare, who reports to the governor, who notifies the prosecuting attorney, who files any information with the probate judge, who issues a warrant to the sheriff to pursue, arrest, and bring the offender into court for examination.

What wonder that cases like the following are the result?

\section{Prisoner's Number, 49,418}

Received February 21, 1915; sentenced, one to three years for carrying concealed weapons.

Released February 19, 1916, by commutation of sentence to one year, January 24, 1916, on condition that he abstain from liquor, stay away from places where liquor was sold, report as if on parole for two years.

Field officer reported on June 20, 1916: " $\mathrm{E}-$ has been drunk continually since his conditional pardon. He is a gambler, bootlegger, and habitual drunkard. Lies around houses of ill-fame all the time. The people are disgusted with his conduct. He is delinquent on three reports. Memorandum furnished me says that he must report for two years. Now, if this doesn't mean anything, why burden our records with it or waste time looking up his kind of cases? Things of this kind bring us into bad odor with general public. Reported on this case before March 3, 1916. E-claims he has a full pardon and refers every one to his attorney. Actually I would not know how to proceed if I caught him committing murder."

$\mathrm{E}$ — has not made a report since his release and violates the condition of his release with impunity.

He was convicted of robbery and returned to Ohio Penitentiary May 7,1917, to serve one to fifteen years. At the time of the trial the prosecuting attorney stated that "E_— was guilty of every crime in the catalog. Arrested a hundred times, a gambler, robber, bootlegger, etc. Proud of it. Should be kept in for life and then would not pay for meanness."

The trial judge said at time of trial: "The former offense he committed was a robbery, but he pointed a gun at the victim, and so I sent him up for carrying concealed weapons. Recommend he be kept for maximum time."

$\mathrm{E}$ — was given a second conditional release October 22, 1918.

$$
\text { Prisoner's Number, 49,061 }
$$

Received December 22, 1920, for check to defraud; sentence, one to three years.

Released January 8,1921 , by conditional pardon after serving only sixteen days of his sentence. Under the conditions of his pardon he was to abstain from intoxicating liquors and report as if on parole for three years, paying back the money obtained on bad checks. 
Field agent reported on June 25, 1921: "Wrecked borrowed car, found dead drunk a couple of times. Father says he acted much like he did years ago when sent to Toledo Asylum for dipsomania."

No action to date as a violator.

\section{Conclusions and Recommendations}

The principal conclusions may be summarized as follows:

1. The pardoning power has, in our judgment, been more extensively resorted to than should be necessary. In part this seems to have been due to a view that the minimum sentence in certain cases was too long. The fluctuation in number of pardons in different years apparently indicates an absence of recognized policy.

2. Many pardons have been granted even for the most serious offenses. During the past six years pardons and commutations were granted to 31 persons convicted of murder in the first degree, and to 89 convicted of murder in the second degree. Of the 211 committed for first- or second-degree murder during the ten years 1900-1909, 135, or 64 per cent., were released before November 15, 1921, on which date only nine of the 211 remained in the penitentiary. In view of the fact that in Ohio intent to kill is an essential element of murder in either degree, question may be raised whether an average of 20 persons per year convicted of first- or second-degree murder should receive pardons or commutations.

3. The time served by those receiving pardons and commutations was generally short in comparison with the sentence imposed. For example, the average time actually served by the 121 persons sentenced to life imprisonment and receiving pardons or commutations during the past six years, was six years, eight months, and twenty-five days. Of the 211 first- and second-degree murderers committed during the ten years 1900-1909, 135 were released in less than twenty years, 132 in less than fifteen years, 78 in less than ten years, and 21 in less than five years.

4. In a number of cases the reason stated for granting the pardon or commutation was inadequate or improper; e.g., "in honor of a holiday" (such as Greek Independence Day, Jewish New Year's, etc.), and "lack of mental responsibility."

5. In some cases the information available was either insufficient to warrant action or directly pointed to a refusal.

6. Enforcement of conditions attached to pardons and commutations has not been sufficiently strict.

As a result of these conditions, the public is justified in feeling that its security has not been properly considered in the exercise of the 
pardoning power. In order that the public safety may be more effectually guarded, the following recommendations are offered:

1. Pardons should be granted only in cases where adequate evidence indicates that injustice has been done, and in order at least partially to remedy that injustice; or in rare cases to reward an extraordinary deed of heroism or fidelity. In all other cases where executive action is deemed to be necessary, it should be in the form of a commutation.

2. Commutations should be granted only where adequate evidence indicates that the minimum sentence was unduly long and that the interests of society as well as of the individual will be promoted; in other words, only in order to enable the Board of Parole to act in necessary cases where the law now prevents their acting. The sentimental practice of granting holiday commutations, with little or no apparent other reason, should be discontinued.

3. Conditions attached to a pardon or commutation should be strictly enforced. The statute should be at once amended so that there may be no doubt as to the power of the State's field officers to take summary action with violators of parole conditions.

4. The parole system should be thoroughly reorganized.

The Board of Pardon and Parole should not hold office at the pleasure of the director of public welfare as is now the case. The effect of this arrangement is to render the appointment of qualified and experienced persons much less likely, and to make them much more susceptible to political or other pressure while in office. A statutory amendment would be needed to effect this change.

The Board of Pardon and Parole should not be limited to a mere "turn-'em-loose" function. If the Board has no responsibility for seeing that its decisions are justified and the conditions of parole imposed by it are enforced, its action can hardly fail to become more perfunctory. The Board should be charged with the enforcement of the parole system as well as its quasi-judicial aspect.

In order to perform this duty, the field officers now attached to the several institutions should be transferred to the Superintendent of Pardon and Parole and should be increased in number. This would also lead to greater economy, as there is at present a duplication of traveling over the same territory.

An adequate record system should at once be installed and maintained to afford the requisite information, without which official action is mere guesswork.

Before release physical and mental examinations should be given 
and investigations made of the home, industrial, and community condition to which the paroled prisoner would return.

Many of the foregoing recommendations can be effected without legislation. The governor can inaugurate a more guarded use of his constitutional pardoning powers; can establish a suitable distinction between pardons and commutations; can direct a stricter enforcement of conditions; and can bring about a more efficient and economical administration of the parole system. If he believes these changes desirable, there need, therefore, be no delay in proceeding to inaugurate them. 


\title{
APPENDIX V
}

\section{REPORT OF INTELLIGENCE SURVEY OF THE CLEVELAND POLICE DEPARTMENT}

\author{
By E. K. WICKMAN \\ Psychologist, Division of the Criminologist, Illinois
}

\begin{abstract}
SURVEY of the intelligence of the personnel of the Division of Police of Cleveland was made in connection with the survey of the 1 administration of justice conducted by the Cleveland Foundation. Mental ratings on 979 officers, detectives, and patrolmen were secured by the use of the army Alpha Intelligence Examination.
\end{abstract}

The survey was made with the coopperation of the Chief of Police, Frank W. Smith, who ordered the men of his department assembled for the examination and who lent his coöperation and influence to their effective administration and completion. The examinations were not compulsory for the men, with the exception of those in the training school. Orders by the Chief of Police were issued for all men who were on active duty during the three days of the survey to report for the examination, but the actual examination was taken voluntarily. There were, however, no men in the department who declined to submit to the tests.

The 979 men who were examined compose over 90 per cent. of the entire department, and the men who were not rated were not actually available for the examination during the three days of the survey. The general orders for the assembling of the men called for one-half of one of the four platoons for each group examination. The examinations were made on the salary time of the men, and the groups were assembled at 1 , 2 , and 3 o'clock in the afternoons, and at 7.30 and 10 o'clock in the evenings. The 979 men include officers (captains, lieutenants, and sergeants), detectives, men of the vice bureau, the traffic, mounted, emergency, and regular patrolmen, and the members of the training school.

The intelligence examination used was the army Alpha examination, the scale employed for literates in the examination of officers and recruits in the United States army. The army procedure in the administration of the examination was adhered to in all respects. The groups varied in size from 10 to $90 \mathrm{men}$. With the exception of the captains and detec- 
tives, the groups were assembled in the training school class-room of the Eighth Precinct Police Station. All five forms of the Alpha examination were employed, so as to avoid possible coaching.

The papers were later scored by special clerks, and intelligence ratings were assigned to all the men on the basis of the army letter rating scale, as given on page 66 , footnote 1 .

The distribution of intelligence ratings for the officers, detectives, and various divisions of the patrolmen is shown in Tables 4 and 5 , page 68, and in Diagram 1, below.

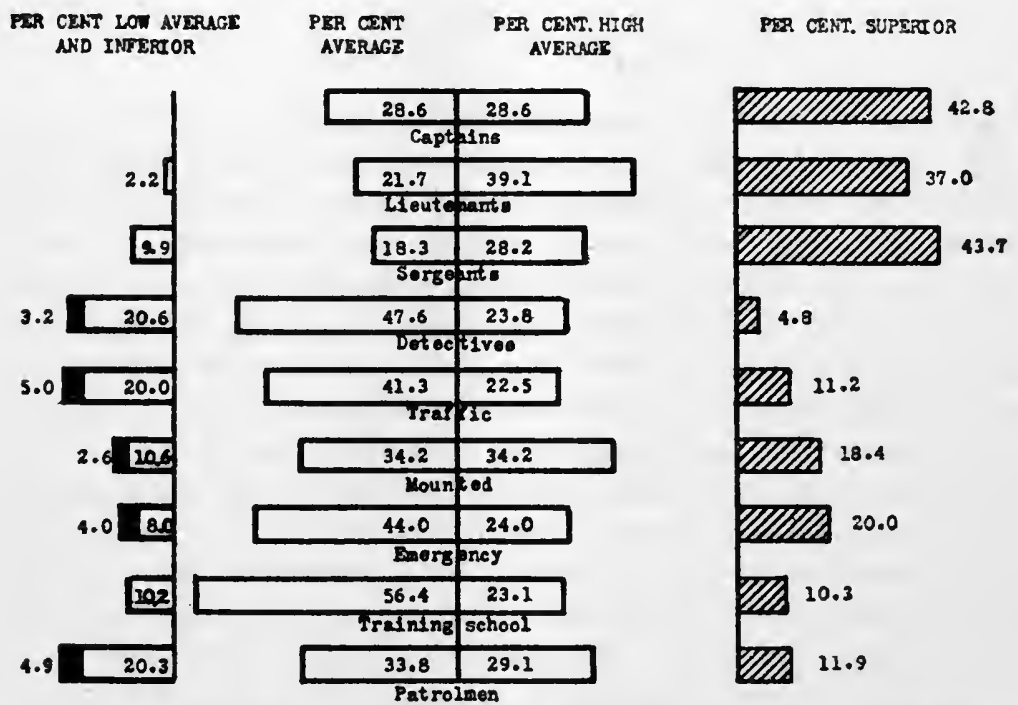

Diagram 1.--Intelligence ratings of divisions of Cleveland police department.

About 40 per cent. of the officers of the department rate in the superior grades of intelligence. These ratings were secured by about 13.5 per cent. of the draft army. Another 32 per cent. of the officers are of high average intelligence; about 20 per cent. are average, while 6 per cent. are low average. There are no representatives among the officers in the inferior grades of intelligence.

Of the patrolmen, there are 12 per cent. in the superior grades, 28 per cent. are high average, while the greatest percentage (34) are average. There is a heavier percentage of patrolmen in the low average group than in the superior groups, and about 3 per cent. are definitely in the inferior grades of intelligence. Of the various divisions of the patrolmen, the emergency and mounted police have the higher intelligence distributions. 
The detectives, a group of 63 men, rate lowest in the entire department. There are less than 5 per cent. in the superior grades, and about 23 per cent. are high average, while 70 per cent. are either average, low average, or inferior.

A further comparison of these divisions of police is shown in Table 3, page 67 , and in Diagrams 2 and 3, by comparing their median scores and the range of scores of the high, middle, and low third of each division. The median scores of the officers varies between 95 and 98 . These are high scores in the high average grade of intelligence. The patrolmen have a median of 67 , which falls in the average grade of intelligence, while the detectives are the lowest of the divisions, with a median of 59 .

At present the detectives are ranking, as far as salary is concerned, with the lieutenants, but a comparison of these two groups shows that the lieutenants have 37 per cent. of representatives in the superior grades of intelligence, as opposed to 4.8 per cent. of the detectives, and only 23.9 per cent. in the average and low average grades, as compared with 71.4 per cent. of the detectives. The lieutenants' median falls at 95 , while the detectives' is 59. Furthermore, the low third of the lieutenants has a higher range of scores than the middle third of the detectives.

When compared with the results obtained from the recent draft army, there is, of course, a very small percentage (3.6 per cent.) of men in the police department who rate in the inferior grades of intelligence in which the lowest 25 per cent. of the men in the draft army were classified. The men of the police department group themselves closely about the average grade of intelligence, and the medians of the patrolmen are about identical with the medians of the draft army. With the exception of the officers, there is a smaller percentage of representatives in the police department in the superior grades of intelligence than were found in the draft army. The detectives have no representatives in the very superior grade of intelligence, a classification secured by 4.5 per cent. of the draft army, and only three individuals of the detectives have superior intelligence, as opposed to 9 per cent. of the draft. As a whole, however, the police department ranks somewhat higher than the majority of the men of the draft. This is evident in its somewhat larger percentage of representatives of high average intelligence.

Table 4, page 68, shows a distribution of intelligence ratings of patrolmen according to the date of entry into the police department. There is very little difference in the ratings of the first year groups, who entered between 1895-1919. There is a slight decrease with length of service, much of which may be attributed to the deterioration of in- 


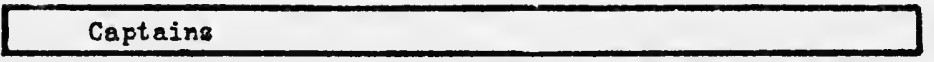

\begin{tabular}{|c|}
\hline Lieut enants \\
\hline Sergeants \\
\hline
\end{tabular}

\begin{tabular}{|c|c|}
\hline Detectives & 59 \\
\hline Vice squad & 61 \\
\hline Traffic police & 67 \\
\hline Uounted police & 67 \\
\hline Emergency police & 63 \\
\hline Patrolmen & 63 \\
\hline Training school \\
\hline
\end{tabular}

\section{8}

Diagram 2.-Median scores, Cleveland police department.
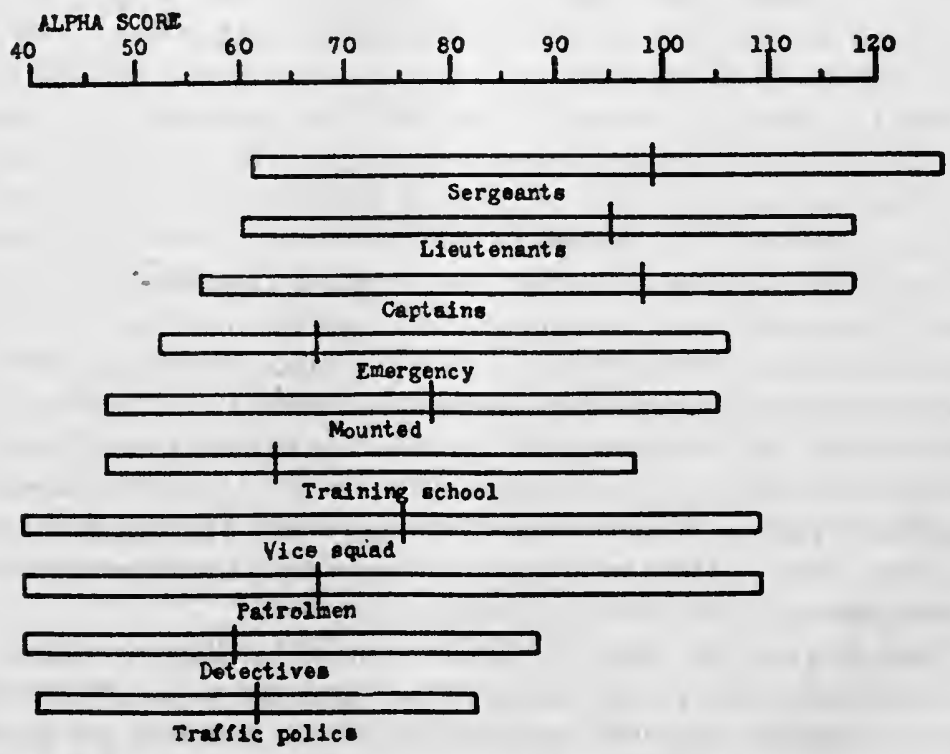

Diagram 3.-Range of scores between first and third quartiles of Cleveland police department. (The median scores are indicated by the cross lines.) 


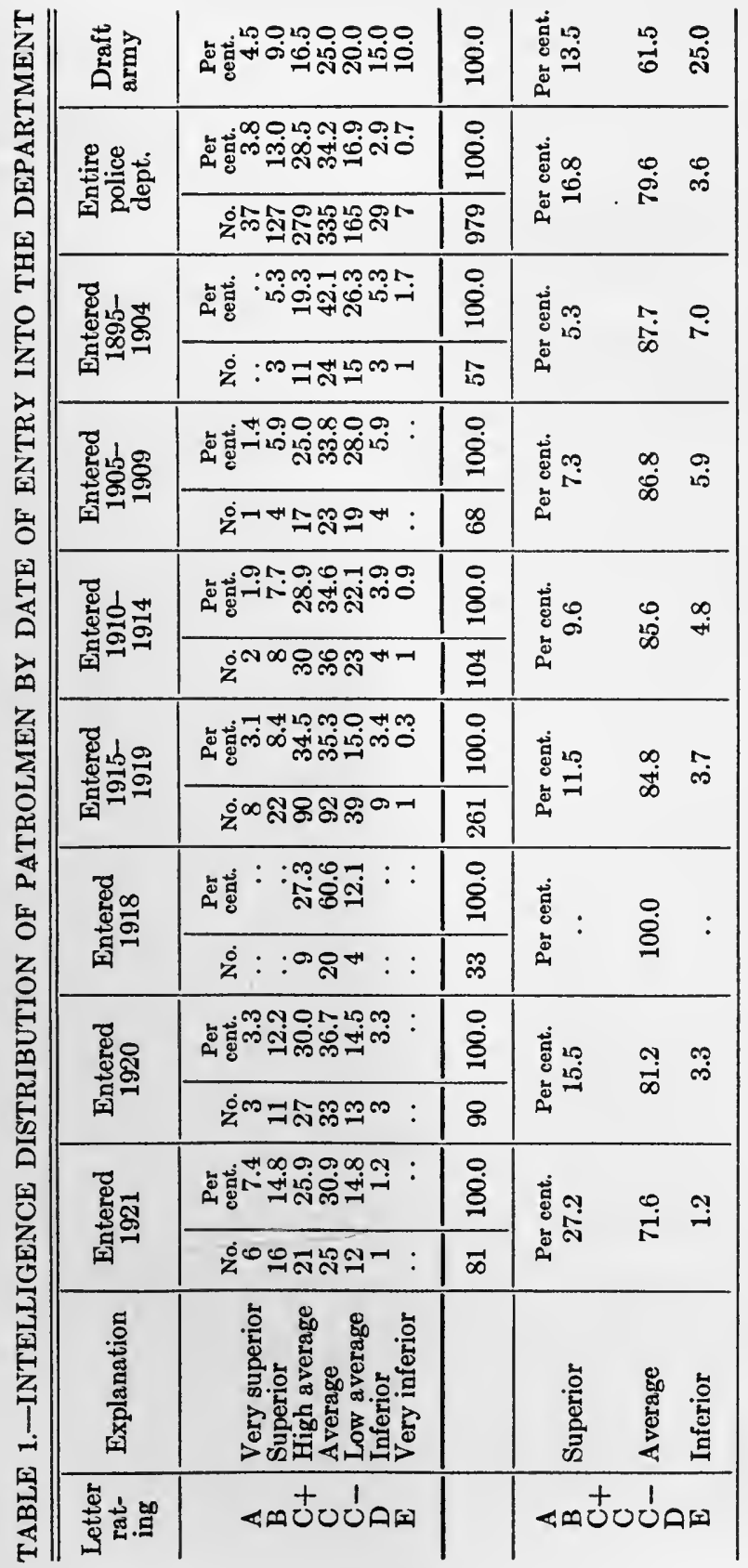


creasing age. The table also shows that the men who entered during the present year, 1921, have a considerably higher percentage of men of superior intelligence. The war year, 1918, produced no men either of superior or of inferior intelligence. All of the entrants in that year rate in the average classes of intelligence. 


\title{
APPENDIX VI
}

\section{INTELLIGENCE SURVEY OF THE CLEVELAND WORKHOUSE}

\author{
By E. K. WICKMAN \\ Paychologist, Division of the Criminologist, Illinois
}

N INTELLIGENCE survey of the workhouse of Cleveland, Ohio,
was made in connection with the survey of the Administration of
Justice, to illustrate some of the results which may be obtained by mental studies. The population of this institution was about 450 men, of whom about one-fifth were examined by the use of the Army Alpha Intelligence Examination. This one-fifth was chosen by assembling the men in single file and selecting every fifth man in line for examination. To this group were added all of the men who were at the workhouse on federal charges, and also the group of men called "long termers." One hundred and twenty-six men were thus assembled for the examination; of these, 32 were illiterate and were unable to take the examination, insofar as they claimed to be unable to read and write, and one other man was unable to take the examination because of poor vision.

Records were thus secured on 93 of the men, of whom 44 (47 per cent.) were native-born whites, 32 (34 per cent.) were negroes, and 13 (14 per cent.) were foreign born. Four men did not indicate birth or race.

The distribution of intelligence ratings as secured by the army Alpha examination is given in Table 5 .

The literate native-born white group who took the examination fall mostly in the average grades of intelligence, but about 15 per cent. of them are inferior. The army statisties show about 14 per cent. inferior in this group of native-born whites. There are, however, only about 4 per cent. in the superior groups, as opposed to 15 per cent. in the army.

Of the negroes, 61 per cent. fall in the inferior groups of intelligence as opposed to 43 per cent. in the army.

The average rating for the white prisoners fall in the " $\mathrm{C}$ " or average group of intelligence, as it also did in the army, while the average for the negro prisoners falls in the "D" or inferior group, while the army average was "C-" or low average group. 
TABLE 1.-DISTRIBUTION OF INTELLIGENCE RATINGS IN THE WORKHOUSE

\begin{tabular}{|c|c|c|c|c|c|c|c|c|c|c|}
\hline & \multicolumn{2}{|c|}{$\begin{array}{c}\text { Native } \\
\text { born } \\
\text { white }\end{array}$} & $\begin{array}{c}\text { Foreign } \\
\text { born }\end{array}$ & \multicolumn{2}{|c|}{$\underset{\text { whites }}{\text { All }}$} & \multicolumn{2}{|c|}{ Negroes } & $\begin{array}{c}\begin{array}{c}\text { Race } \\
\text { unknown }\end{array} \\
\text { No. }\end{array}$ & \multicolumn{2}{|c|}{ Total } \\
\hline $\begin{array}{l}\mathbf{A} \\
\mathbf{B} \\
\mathbf{C}+ \\
\mathbf{C} \\
\mathbf{C}- \\
\mathbf{D}- \\
\mathbf{E}\end{array}$ & $\begin{array}{r}\text { No. } \\
\because 2 \\
2 \\
16 \\
13 \\
6 \\
2 \\
5\end{array}$ & $\begin{array}{r}\begin{array}{r}\text { Per } \\
\text { cent. }\end{array} \\
\dot{4} . \dot{5} \\
36.4 \\
29.6 \\
13.6 \\
4.5 \\
11.4\end{array}$ & $\begin{array}{c}\text { No. } \\
\ddot{1} \\
\ddot{1} \\
3 \\
4 \\
4\end{array}$ & \begin{tabular}{r} 
No. \\
\hdashline 3 \\
16 \\
14 \\
9 \\
6 \\
9
\end{tabular} & $\begin{array}{r}\begin{array}{c}\text { Per } \\
\text { cent. }\end{array} \\
\therefore . \dot{3} \\
28.0 \\
24.5 \\
15.8 \\
10.5 \\
15.8\end{array}$ & $\begin{array}{c}\text { No. } \\
\ldots \\
\ldots \\
\ddot{2} \\
7 \\
9 \\
14\end{array}$ & 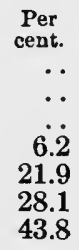 & $\begin{array}{c}\text { No. } \\
\ldots \\
\ldots \\
\ldots \\
\ldots \\
\cdots \\
4\end{array}$ & $\begin{array}{r}\text { No. } \\
\ddot{3} \\
16 \\
16 \\
16 \\
15 \\
27\end{array}$ & $\begin{array}{r}\begin{array}{r}\text { Per } \\
\text { cent. }\end{array} \\
\ldots . \dot{2} \\
17.2 \\
17.2 \\
17.2 \\
16.2 \\
29.0\end{array}$ \\
\hline Total & 44 & 100.0 & 13 & 57 & 99.9 & 32 & 100.0 & 4 & 93 & 100.0 \\
\hline
\end{tabular}

Per cent.

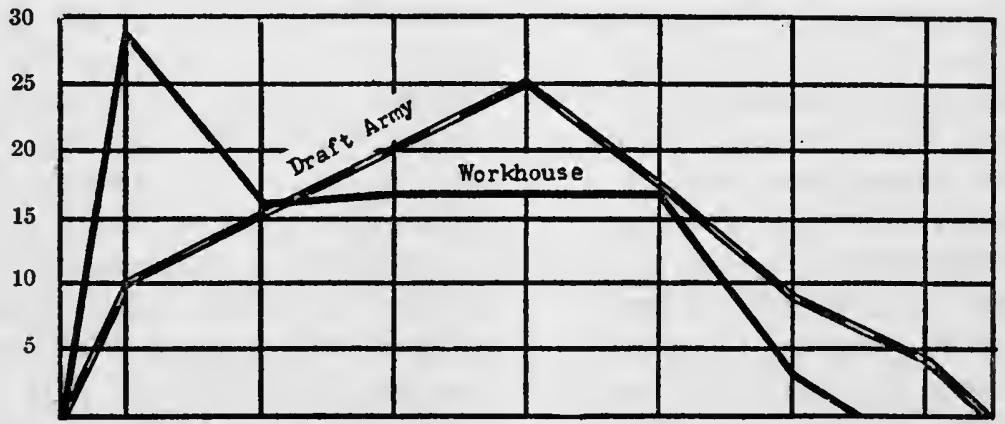

Diagram 1.-Comparison of intelligence distributions of Cleveland Workhouse and United States Draft Army.

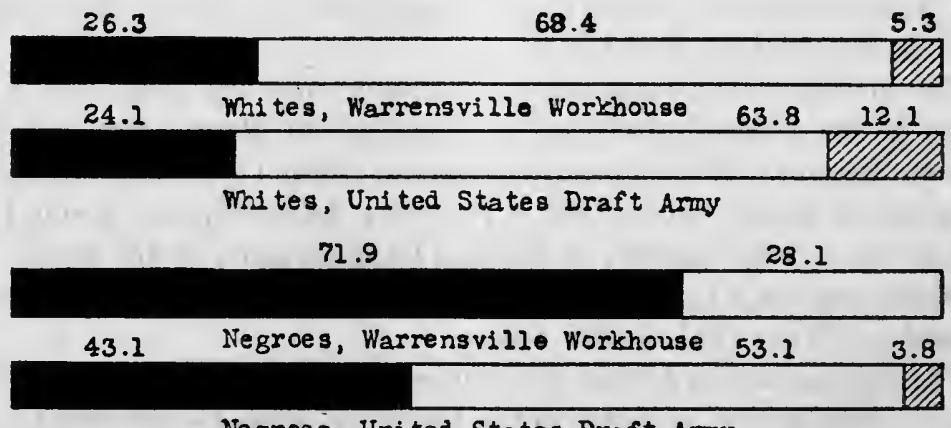

Negroes, United States Draft Army

Diagram 2.-Comparison of intelligence ratings, Warrensville Workhouse with United States Draft Army. 
Diagram 1 shows the distribution of intelligence ratings of the Cleveland workhouse with the United States draft army. In Diagram 2 the same distribution is shown for whites and negroes separately.

These results would undoubtedly be lowered if ratings of the illiterate men were included, so that it may safely be said that the intelligence of these men at the Cleveland workhouse is somewhat below the draft army intelligence. 


\section{APPENDIX VII}

\section{TEXT OF THE MASSACHUSETTS MEDICAL EXAMINER LAW}

\section{The Commonwealth of Massachusetts \\ General Laws, Chapter 38 \\ Medical Examiners}

Section 1. The governor, with the advice and consent of the council, shall appoint for terms of seven years able and discreet men, learned in the science of medicine, as medical examiners in and for their respective counties, and as associate medical examiners in and for their respective districts in counties divided into districts, otherwise in and for their respective counties, in number as follows:

Two examiners and two associate examiners in Suffolk county, and one examiner and one associate examiner in Nantucket county and in each of the following districts:

Barnstable county, district one, comprising Harwich, Dennis, Yarmouth, Brewster, Chatham, Orleans and Eastham; district two, Barnstable, Bourne, Sandwich, Mashpee and Falmouth; and district three, Provincetown, Truro and Wellfleet.

Berkshire county, district one, comprising North Adams, Williamstown, Clarksburg, Adams, Florida, Savoy, New Ashford and Cheshire; district two, Pittsfield, Lanesborough, Windsor, Dalton, Hinsdale, Peru and Hancock; district three, Richmond, Lenox, Washington, Becket, Lee, Stockbridge, Tyringham and Otis; and district four, West Stockbridge, Alford, Great Barrington, Monterey, Sandisfield, New Marlborough, Sheffield, Egremont and Mount Washington.

Bristol county, district one, comprising Attleboro, North Attleborough, Seekonk, Norton, Mansfield and Rehoboth; district two, Taunton, Raynham, Easton, Berkley, and Dighton; district three, Fall River, Somerset, Swansea, Freetown and Westport; and district four, New Bedford, Dartmouth, Fairhaven and Acushnet.

Dukes county, district one, comprising Edgartown and Oak Bluffs; district two, Tisbury, West Tisbury and Gosnold; and district three, Chilmark and Gay Head.

Essex county, district one, comprising Gloucester and Rockport; district 
two, Ipswich, Rowley, Hamilton and Essex; district three, Newburyport, Newbury, West Newbury, Amesbury and Salisbury; district four, Haverhill and Merrimac; district five, Lawrence, Methuen, Andover and North Andover; district six, Georgetown, Boxford, Topsfield and Groveland; district seven, Beverly, Wenham and Manchester; district eight, Peabody, Danvers, Middleton and Lynnfield; district nine, Lynn, Saugus, Nahant and Swampscott; and district ten, Salem and Marblehead.

Franklin county, the northern district, comprising Orange, Warwick, New Salem and Wendell; the eastern district, Bernardston, Erving, Gill, Greenfield, Leverett, Montague, Northfield, Shutesbury and Sunderland; and the western district, Ashfield, Buckland, Charlemont, Colrain, Conway, Deerfield, Hawley, Heath, Leyden, Monroe, Rowe, Shelburne and Whately.

Hampden county, district one, comprising Brimfield, Holland, Palmer, Monson and Wales; district two, Springfield, Agawam, East Longmeadow, Longmeadow, West Springfield, Wilbraham and Hampden; district three, Holyoke; district four, Blandford, Chester, Granville, Montgomery, Russell, Southwick, Tolland and Westfield; and district five, Chicopee and Ludlow.

Hampshire county, district one, comprising Northampton, Chesterfield, Cummington, Goshen, Hatfield, Plainfield and Williamsburg; district two, Easthampton, Huntington, Middlefield, Southampton, Westhampton and Worthington; district three, Amherst, Granby, Hadley, Pelham and South Hadley; and district four, Belchertown, Enfield, Greenwich, Prescott and Ware.

Middlesex county, district one, comprising Cambridge, Belmont and Arlington; district two, Malden, Somerville, Everett and Medford; district three, Melrose, Stoneham, Wakefield, Wilmington, Reading and North Reading; district four, Woburn, Winchester, Lexington and Burlington; district five, Lowell, Dracut, Tewksbury, Billerica, Chelmsford and Tyngsborough; district six, Concord, Carlisle, Bedford, Lincoln, Littleton, Acton and Boxborough; district seven, Newton, Waltham, Watertown and Weston; district eight, Framingham, Wayland, Natick, Sherborn, Holliston, Hopkinton and Ashland; district nine, Marlborough, Hudson, Maynard, Stow and Sudbury; district ten, Ayer, Groton, Westford, Dunstable, Pepperell, Shirley, Townsend and Ashby.

Norfolk county, district one, comprising Dedham, Needham, Wellesley, Westwood, Norwood and Dover; district two, Cohasset; district three, Quincy, Milton and Randolph; district four, Weymouth, Braintree and Holbrook; district five, Avon, Stoughton, Canton, Walpole and Sharon; district six, Franklin, Foxborough and Wrentham; district seven, Medway, Medfield, Millis, Norfolk and Bellingham; and district eight, Brookline.

Plymouth county, district one, comprising Brockton, West Bridgewater, East Bridgewater, Bridgewater and Whitman; district two, Abington, Rockland, Hanover, Hanson, Norwell and Pembroke; district three, Plymouth, Halifax, Kingston, Plympton and Duxbury; district four, Middleborough, Wareham, Mattapoisett, Carver, Rochester, Lakeville and Marion; and district five, Hingham, Hull, Scituate and Marshfield. 
Worcester county, district one, comprising Athol, Dana, Petersham, Phillipston and Royalston; district two, Gardner, Templeton and Winchendon; district three, Fitchburg, Ashburnham, Leominster, Lunenburg, Princeton and Westminster; district four, Berlin, Bolton, Boylston, Clinton, Harvard, Lancaster and Sterling; district five, Grafton, Northborough, Southborough and Westborough; district six, Hopedale, Mendon, Milford and Upton; district seven, Blackstone, Douglas, Millville, Northbridge and Uxbridge; district eight, Charlton, Dudley, Oxford, Southbridge, Sturbridge and Webster; district nine, Brookfield, East Brookfield, North Brookfield, Spencer, Warren and West Brookfield; district ten, Barre, Hubbardston, Hardwick, New Braintree, Oakham and Rutland; and district eleven, Worcester, Auburn, Holden, Leicester, Millbury, Paxton, Shrewsbury, Sutton and West Boylston.

Secrion 2. The associate medical examiners for Suffolk county shall, at the request of either of its medical examiners, perform the duties and have the powers of medical examiners. Each medical examiner shall in each year be entitled to two months' service in the aggregate from the associates. Associate examiners in the other counties shall, in the absence of the medical examiners or in case of their inability to act, perform in their respective districts all the duties of medical examiners.

Sectron 3. Each examiner and associate examiner, before entering upon his duties, shall be sworn and give bond for the faithful performance thereof, in the sum of five thousand dollars, to the county treasurer, with sureties by him approved. Failure for three months after appointment to give such bond shall render his appointment void. A surety or his executors or administrators may be discharged from further liability thereon in the manner provided in section six of chapter thirty-seven.

Section 4. Upon breach of the condition of such bond to the injury of any person, the principal may be removed from office and action brought thereon in like manner as upon the bond of a sheriff.

Section 5. In Suffolk county each medical examiner shall receive from the county a salary of five thousand dollars, and each associate medical examiner a salary of eight hundred and thirty-three dollars; but if either associate serves in any year more than two months, he shall for such additional service be paid at the same rate, and the amount so paid shall be deducted from the salary of the medical examiner at whose request he so serves. The medical examiners for said county shall be provided with rooms suitably furnished for the performance of their duties, the rent, furnishing and office equipment of which shall be paid for by said county upon approval of the mayor of Boston. Each of said medical examiners may, in the name of the county, contract such bills for clerical service, postage, stationery, printing, telephone, traveling, and for such other incidental expenses as may in his opinion be necessary for the proper performance of his duty, to an amount not exceeding six thousand dollars in any one year; and each associate may so contract bills for the said purposes 
to an amount not exceeding one thousand dollars in any one year; and all such bills shall be paid by said county, upon a certificate by the contracting examiner that they were necessarily incurred in the performance of his duty, and upon the approval of the auditor of Boston, as provided in section nineteen, and of the mayor. Medical examiners and associate medical examiners in other counties shall receive fees as follows: For a view without an autopsy, seven dollars; for a view and an autopsy, thirty dollars; and for travel, ten cents a mile to and from the place of view.

Section 6. Medical examiners shall make examination upon the view of the dead bodies of only such persons as are supposed to have died by violence. If a medical examiner has notice that there is within his county the body of such a person, he shall forthwith go to the place where the body lies and take charge of the same; and if, on view thereof and personal inquiry into the cause and manner of death, he considers a further examination necessary, he shall, upon written authorization of the district attorney, mayor or selectmen of the district, city or town where the body lies, make an autopsy in the presence of two or more discreet persons, whose attendance he may compel by subpona. Before making such autopsy he shall call the attention of the witnesses to the appearance and position of the body. He shall then and there carefully record every fact and circumstance tending to show the condition of the body and the cause and manner of death, with the names and addresses of said witnesses, which record he shall subscribe. If a medical examiner or an associate examiner considers it necessary to have a physician present as a witness at an autopsy, such physician shall receive a fee of five dollars. Other witnesses, except officers named in section fifty of chapter two hundred and sixty-two, shall be allowed two dollars each. A clerk may be employed to reduce to writing the results of a medical examination or autopsy, and shall receive two dollars a day.

The medical examiner may, if he considers it necessary, employ a chemist to aid in the examination of the body or of substances supposed to have caused or contributed to the death, and he shall receive such compensation as the examiner certifies to be just and reasonable.

Section 7. He shall forthwith file with the district attorney for his district a report of each autopsy and view and of his personal inquiries, with a certificate that, in his judgment, the manner and cause of death could not be ascertained by view and inquiry and that an autopsy was necessary. The district attorney, if he concurs, shall so certify to the commissioners of the county where the same was held, or in Suffolk county, to the auditor of Boston. If upon such view, personal inquiry or autopsy, the medical examiner is of opinion that the death may have been caused by the act or negligence of another, he shall at once notify the district attorney and a justice of a district court or trial justice within whose jurisdiction the body was found, if the place where found and the place of the said act or negligence are within the same county, or if the latter place is unknown; otherwise, the district attorney and such a justice 
within whose district or jurisdiction the said act or negligence occurred. $\mathrm{He}$ shall also file with the district attorney thus notified, and with the justice or in his court, an attested copy of the record of the autopsy made as provided in the preceding section. He shall in all cases certify to the town clerk or registrar in the place where the deceased died his name and residence, if known; otherwise a description as full as may be, with the cause and manner of death.

Section 8. The court or trial justice shall thereupon hold an inquest, from which all persons not required by law to attend may be excluded. The district attorney, or any person designated by him, may attend the inquest and examine the witnesses, who may be kept separate, so that they cannot converse with each other until they have been examined. Within sixty days after any case of death by accident upon a railroad, electric railroad, street. railway or railroad for private use an inquest shall be held, and the court or justice shall give seasonable notice of the time and place thereof to the department of public utilities. Within a like period after any case of death in which a motor vehicle is involved, an inquest shall be held, and the court or justice shall give seasonable notice of the time and place thereof to the department of public works. The attorney general or the district attorney may, notwithstanding the medical examiner's report that a death was not caused by the act. or negligence of another, direct an inquest to be held, and likewise in case of death by any casualty.

Section 9. If it appears that the place where the supposed act or negligence occurred and the place where the body was found are both without the limits of the judicial district of the court or the jurisdiction of the trial justice notified by the medical examiner under section seven, the court or justice shall nevertheless proceed with the inquest and have continuous and exclusive jurisdiction thereof if either place is within the commonwealth and within fifty rods of the boundary line of such district or jurisdiction, unless a prior and like notice shall have been issued by a medical examiner in another county in accordance with said section.

Section 10. A district court about to hold an inquest may appoint an officer qualified to serve criminal process to investigate the case and to summon the witnesses, and may allow him additional compensation therefor, payable in like manner as the fees of officers in criminal cases.

Section 11. If a magistrate believes that an inquest to be held by him relates to the accidental death of a passenger or employee upon a railroad or electric railroad or a traveler upon a public or private way at a railroad crossing, or to an accidental death connected with the operation of a street railway or of a railroad for private use, he shall cause a verbatim report of the evidence to be made and sworn to by the person making it; and the report and the bill for services, after examination and written approval by the magistrate, shall be forwarded to the department of public utilities within thirty days after the date of the inquest, and, when made, a copy of the magistrate's report on the 
inquest. The bill, when approved by said department, shall be forwarded to the state auditor and paid by the commonwealth, assessed on the person owning or operating such railroad or railway, and shall be collected in the same manner as taxes upon corporations. The magistrate may in his discretion refuse fees to witnesses in the employ of the person upon whose railroad or railway the accident occurred.

Section 12. The magistrate shall report in writing when, where and by what means the person met his death, his name, if known, and all material circumstances attending his death, and the name, if known, of any person whose unlawful act or negligence appears to have contributed thereto. He shall file his report in the superior court for the county where the inquest is held.

Section 13. If a person charged by the report with the commission of a crime is at large, the magistrate shall forthwith issue process for his arrest, returnable before any court or magistrate having jurisdiction. If he finds that murder, manslaughter or an assault has been committed, he may bind over, for appearance in said court, as in criminal cases, such witnesses as he considers necessary, or as the district attorney may designate.

Section 14. No embalming fluid, or any substitute therefor, shall be injected into the body of any person supposed to have met his death by violence, until a permit, signed by the medical examiner, has first been obtained.

Secrion 15. After an autopsy or a view or examination without an autopsy, the medical examiner shall deliver the body, upon application, to the husband or wife, to the next of kin, or to any friend of the deceased, who shall have priority in the order named. If the body is unidentified or unclaimed for fortyeight hours after the view thereof, the medical examiner shall deliver it to the overseers of the poor of the town where found, who shall bury it in accordance with section seventeen of chapter one hundred and seventeen.

Section 16. Medical examiners and associate examiners within their respective districts shall, on application and payment or tender of seven dollars, view the body and make personal inquiry concerning the death of any person whose body is intended for cremation, and shall authorize such cremation only when of opinion that no further examination or judicial inquiry concerning such death is necessary.

Section 17. The medical examiner may allow reasonable compensation, payable by the county in the manner provided in section nineteen, for services rendered in bringing to land a human body found in any of the harbors, rivers or waters of the commonwealth, but this provision shall not entitle any person to compensation for services rendered in searching for a dead body.

Section 18. The medical examiner shall take charge of any money or other personal property of the deceased found on or near the body, and deliver it to the person entitled to its custody or possession, or, if not claimed within 
sixty days, to a public administrator. For fraudulent neglect or refusal so to deliver such property within three days after demand, a medical examiner or an associate medical examiner shall be punished by a fine of not more than five hundred dollars or by imprisonment for not more than two years.

Section 19. Every medical examiner shall return an account of the expenses of each view or autopsy, including his fees, to the commissioners of the county where held, or in Suffolk county to the auditor of Boston, and shall annex to his return the written authorization of the autopsy. The commissioners or auditor shall audit the same, and certify to the county treasurer what items therein are just and reasonable, and he shall pay the same to the person entitled thereto. No auditing officer shall certify any fee for an autopsy until he has received from the district attorney the certificate required by section seven.

Secrion 20. Every medical examiner and associate examiner shall annually, on or before March first, transmit to the state secretary certified copies of the records of all deaths by him investigated during the preceding year, and within sixty days after the expiration of his term shall make like returns for so much of the year as he held office. For a refusal or neglect so to do, he shall forfeit not less than ten nor more than fifty dollars.

Section 21. Each medical examiner and associate examiner, including those in Suffolk county, shall receive from the commonwealth twenty cents for each of the first twenty deaths recorded and returned by him in any year, as provided in the preceding section, and ten cents for each additional death so recorded and returned, as certified by the state secretary.

Section 22. The state secretary shall, at the expense of the commonwealth, prepare and furnish to the medical examiners blank record books and blank forms for returns, and shall cause the returns for each year to be bound together in one volume with indexes; and shall prepare therefrom such tables as will render them of utility, and shall make annual report thereof to the general court in connection with the report required by section twenty-one of chapter forty-six. 


\title{
APPENDIX VIII
}

\section{TEXT OF THE NEW YORK MEDICAL EXAMINER LAW}

\author{
LAWS OF NEW YoRK, 1915
}

\section{Chap. 284}

\begin{abstract}
N ACT to amend the Greater New York Charter, and repeal certain sections thereof and of chapter four hundred and ten of the Laws of eighteen hundred and eighty-two, in relation to the abolition of the office of Coroner and the establishment of the office of the chief medical examiner. Became a law April 14, 1915, with the approval of the Governor. Passes, three-fifths being present.
\end{abstract}

\section{Accepted by the City}

The People of the State of New York, represented in Senate and Assembly, do enact as follows:

Section 1. The office of coroner in the City of New York shall be abolished on January first, nineteen hundred and eighteen, and after this section takes effect, a vacancy occurring in such an office in any borough shall not be filled unless by reason of the occurrence thereof, there shall be no coroner in office in such borough, in which case the vacancy in such borough last occurring shall be filled for a term to expire on January first, nineteen hundred and eighteen. If, by reason of the provisions of this section, the number of coroners in a borough be reduced, the remaining coroner or coroners in such borough shall have the powers and perform the duties conferred or imposed by law on the board of coroners in such borough.

2. Title four of chapter twenty-three, sections fifteen hundred and seventy and fifteen hundred and seventy-one of the Greater New York charter, as reenacted by chapter four hundred and sixty-six of the laws of nineteen hundred and one is hereby repealed, and in its place is inserted a new title to be numbered four and to read as follows:

\section{TITLE IV \\ Chief Medical Examiner}

Section 1570. Organization of office; officers and employees.

1571. Violent and suspicious deaths; procedure.

1571a. Autopsies; findings.

1571b. Report of deaths; removal of body.

1571c. Records.

1571d. Oaths and affidavits. 


\section{Organization of Office; Officers and Employees}

1570. There is hereby established the office of Chief Medical Examiner of the City of New York. The head of the office shall be called the "chief medical examiner." He shall be appointed by the mayor from the classified service and be a doctor of medicine, and a skilled pathologist and microscopist.

The mayor may remove such officer upon stating in writing his reasons therefor, to be filed in the office of the municipal civil service commission and served upon such officer, and allowing him an opportunity of making a public explanation. The chief medical examiner may appoint and remove such deputies, assistant medical examiners, scientific experts, officers and employees as may be provided for pursuant to law. Such deputy medical examiners and assistant medical examiners, as may be appointed, shall possess qualifications similar to those required in the appointment of the chief medical examiner. The office shall be kept open every day in the year, including Sundays and holidays, with a clerk in constant attendance at all times during the day and night.

\section{Violent and Suspicious Deaths; Procedure}

1571. When, in the city of New York, any person shall die from criminal violence, or by a casualty, or by suicide, or suddenly when in apparent health, or when unattended by a physician, or in prison, or in any suspicious or unusual manner, the officer in charge of the station house in the police precinct in which such person died shall immediately notify the office of the chief medical examiner of the known facts, concerning the time, place, manner and circumstances of such death. Immediately upon receipt of such notification the chief medical examiner, or a deputy or assistant medical examiner, shall go to the dead body, and take charge of the same. Such examiner shall fully investigate the essential facts concerning the circumstances of the death, taking the names and address of as many witnesses thereto as it may be practical to obtain, and before leaving the premises, shall reduce all such facts to writing and file the same in his office. The police officer so detailed, shall, in the absence of the next of kin of deceased person, take possession of all property of value found on such person, make an exact inventory thereof on his report, and deliver such property to the police department, which shall surrender the same to the person entitled to its custody or possession. Such examiner shall take possession of any portable objects, which, in his opinion, may be useful in establishing the cause of death, and deliver them to the police department.

Nothing in this section contained shall effect the powers and duties of a public administrator as now provided by law.

\section{Autopsies; Findings}

1571a. If the cause of such death shall be established beyond a reasonable doubt, the medical examiner in charge shall so report to his office. If, however, in the opinion of such medical examiner, an autopsy is necessary, the same shall 
be performed by a medical examiner. A detailed description of the findings written during the progress of such autopsy and the conclusions drawn therefrom shall thereupon be filed in his office.

\section{Report of Deaths; Removal of Body}

1571b. It shall be the duty of any citizen who may become aware of the death of any such person to report such death forthwith to the office of the chief medical examiner and the police officer, who shall forthwith notify the officer in charge of the station house in the police precinct in which such person died. Any person who shall wilfully neglect or refuse to report such death or who, without written order from a medical examiner, shall wilfully touch, remove or disturb the body of any such person, or wilfully touch, remove or disturb the clothing, or any article upon or near such body, shall be guilty of a misdemeanor.

\section{Records}

1571c. It shall be the duty of the office of medical examiner to keep full and complete records. Such records shall be kept in the office, properly indexed, stating the name, if known, of every such person, the place where the body was found, the date of death. The record of each case shall be attached to the original report of the medical examiner and the detailed findings of the autopsy, if any. The office shall promptly deliver to the appropriate district attorney copies of all records relating to every death as to which there is, in the judgment of the medical examiner in charge, any indication of criminality. All other records shall be open to public inspection as provided in section fifteen hundred and forty-five. The appropriate district attorney and the police commissioner of the city may require, from such officer, such further records and such daily information as they may deem necessary.

\section{Oaths and Affidavits}

1571d. The chief medical examiner and all deputy or assistant medical examiners may administer oaths and take affidavits, proofs and examinations as to any matter within the jurisdiction of the office.

3. Section eleven hundred and-seventy-nine of such charter is hereby amended to read as follows:

\section{Bureaus}

1179. There shall be two bureaus in the department of health. The chief officer of one bureau shall be called the sanitary superintendent, who at the time of his appointment shall have been, for at least ten years, a practicing physician, and for three years a resident of the City of New York, and he shall be the chief executive officer of said department. The chief officer of the second bureau shall be called the registrar of records, and in said bureau shall be re- 
corded, without fees, every birth, marriage and death, which shall occur in the City of New York.

4. Section twelve hundred and three of such charter is hereby amended to read as follows:

\section{Chief Medical Examiner's Returns}

1203. The department of health, may, from time to time, make rules and regulations fixing the time of rendering, and defining the form of returns and reports to be made to said department by the office of the chief medical examiner of the city of New York, in all cases of death which shall be investigated by it, and the office of the chief medical examiner is hereby required to conform to such rules and regulations.

5. Section twelve hundred and thirty-eight of such charter is hereby amended to read as follows:

\section{Deaths to be Reported}

1238. It shall be the duty of the next of kin of any person deceased, and of each person being with such deceased person at his or her death, to file report in writing, with the department of health, within five days after such death, stating the age, color, nativity, last occupation and cause of death of such deceased person, and the borough and street the place of such person's death and last residence. Physicians who have attended deceased persons in their last illness shall, in the certificate of the deceased of such persons, specify, as near as the same can be ascertained, the name and surname, age, occupation, term of residence in said city, place of nativity, condition of life whether single or married, widow or widower, colored, last place of residence and the cause of death of such deceased persons, and the medical examiners of the city shall, in their certificates, conform to the requirements of this section.

6. Such charter is hereby amended by inserting therein a new section to be numbered fifteen hundred and eighty-five, and to read as follows:

\section{County Clerks to Exercise Certain Statutory Powers and Duties of Coroners}

1585a. In the city of New York the powers imposed and the duties conferred upon coroners by the provisions of the title three of chapter two of the code of civil procedure shall be exercised and performed by the county clerk of the appropriate county, and said county clerk shall, in the exercise and performance thereof, be subject to the same liabilities and responsibilities as are prescribed in such title in the case of coroners.

7. Sections seventeen hundred and sixty-six to seventeen hundred and seventy-nine, both inclusive, of chapter four hundred and ten of the laws of eighteen hundred and eighty-two, entitled "An Act to consolidate into one act and to declare the special and local laws affecting public interests in the city of New York," and all acts amending such sections are hereby repealed. 
8. The officers and the employees now exercising the powers and duties which by this act are abolished, or are conferred or imposed upon the office of chief medical examiner including coroner's physicians, shall be transferred to the office of chief medical examiner. Service in the office, board or body from which transferred shall count for all purposes as service in the office of the chicf medical examiner.

9. All funds, property, records, books, papers and documents within the jurisdiction or control of any such coroner or such board of coroners, shall, on demand, be transferred and delivered to the office of the chief medical examiner. The board of estimate and apportionment shall transfer to the office of the chief medical examiner all unexpended appropriations made by the city to enable any coroner, or board of coroners, to exercise any of the powers and duties which by this act are abolished or are conferred or imposed upon such office of chief medical examiner.

10. Section one of this act shall take effect immediately. The remainder of the act shall take effect January first, nineteen hundred and eighteen. 


\title{
APPENDIX IX
}

\section{BIBLIOGRAPHY}

\author{
Comprled by Edward B. Adams
}

Librarian of the Harvard Law School

\begin{abstract}
TOLERABLY complete bibliography of the general subjects involved in these reports on criminal justice in Cleveland would require a large volume. This is obviously not the place for it.
\end{abstract} The following list, therefore, which contains only material in English, modern and readily accessible, is intended as merely suggestive.

\section{Pouce}

Anderson, Sir Robert. The Lighter Side of My Official Life. London, 1910.

Cahalane, Cornelius F. Police Practice and Procedure. New York, 1915.

Costello, A. E. Our Police Protectors. New York, 1885.

Eldridge, B. P., and Watts, W. B. Our Rival, the Rascal. Boston, 1897.

Fosdick, Raymond B. American Police Systems. New York, 1920.

European Police Systems. New York, 1915.

The Passing of the Bertillon System of Identification. 6 Jour. Crim. Law and Criminology, 363.

Fuld, Leonard F. Police Administration. New York, 1909.

Graper, Elmer D. American Police Administration. New York, 1921.

Gross, Hans. Criminal Investigation. Translated from the German by Adam and Adam. Calcutta, New York, 1907.

Henry, Sir Edward R. Classification and Uses of Finger Prints. Third edition. London, 1905.

Lansdowne, Andrew. A Life's Reminiscences of Scotland Yard. London, 1890.

Lee, Capt. W. L. M. A History of Police in England. London, 1901.

McAdoo, Commissioner William. Guarding a Great City. New York, 1906.

MacNaghten, Sir Melville. Days of My Years. London, 1914.

New York City. Report of Special Committee of Board of Aldermen appointed to investigate the Police Department. (Curran report) 1912.

Police Reports. See the periodical reports of the police departments of a few states, and of all the larger cities.

Ray, P. O. Metropolitan and State Police. 11 Jour. Crim. Law and Criminology, $453-67$.

Savage, Edward H. Chronological Record of the Boston Watch and Police from 1631 to 1865, together with the Recollections of a Boston Police Officer or Boston by Daylight and Gaslight. Second edition. Boston, 1865.

Smith, Lieutenant Colonel Sir Henry. From Constable to Commissioner. London, 1910.

United States Census. Report on American Police Departments. Washington, 1915. 
Vincent, C. E. Howard. A Police Code. Fifteenth edition. London, 1912.

Vollmer, August. Practical Method for Selecting Policemen. 11 Jour. Crim. Law and Criminology, 571-81.

and Schneider, Albert. School for Police as Planned at Berkeley. 7 Jour. Crim. Law and Criminology, 877-898.

Walling, George W. Recollections of a New York Chief of Police. New York, 1888. Wilder, H. H., and Wentworth, B. Personal Identification. Boston, 1918.

Woods, Arthur. Crime Prevention. Princeton University Press, 1918.

- Policeman and Public. Yale University Press, 1919.

\section{Criminal Courts and Procedure}

Alexander, G. Glover. The Administration of Justice in Criminal Matters (in England and Wales). Cambridge (England), new edition, 1915.

American Bar Association Reports and Journal. Especially, since 1908, the Reports of the Special Committee to Suggest Remedies and Formulate Proposed Laws to Prevent Delay and Unnecessary Cost in Litigation and of similar committees.

American Institute of Criminal Law and Criminology. Criminal Procedure in England. Washington, Government Printing Office, 1914.

American Judicature Society. Bulletins and, since 1917, Journal. Chicago, 1914-. Ballantine, Sergeant. Some Experiences of a Barrister's Life. 2 vols. London, 1882. Barrows, Samuel J. Children's Courts in the United States. Washington, 1904.

Cobb, W. B. Court of Prevention: the Municipal Term Court of the City of New York. 11 Jour. Crim. Law and Criminology, 47-59, May, 1920.

Edwards, George J., Jr. The Grand Jury. Philadelphia, 1906.

Eliot, Thomas D. The Juvenile Court and the Community. New York, 1914.

Flexner, Bernard, and Baldwin, R. N. Juvenile Courts and Probation. New York, 1914.

Gamon, H. R. P. The London Police Court, Today and Tomorrow. London, 1907. Goldman, Mayer C. The Public Defender. Second edition, New York, 1919.

Hall, James P. The Selection, Tenure and Retirement of Judges. (Address before the Ohio State Bar Association, 1915.) Bulletin X, American Judicature Society.

Harley, H. Business Management for the Courts as Exemplified by the Municipal Court of Chicago. 5 Va. L. Rev., 1-26, October, 1917.

Detroit's New Model Criminal Court. 11 Jour. Crim. Law and Criminology, 398-412, November, 1920 .

- Justice or Litigation. 6 Va. L. Rev., 143-155, December, 1919.

Judicial Statistics, England and Wales. Published annually in London by the Home Office.

Justice through Simplified Legal Procedure. By many hands. Annals of Am. Acad. of Pol. and Soc. Science, September, 1917.

Kales, Albert M. A Comparative Study of the English and the Cook County Judicial Establishments. 4 Ill. Law Rev., 303.

Methods of Selecting and Retiring Judges. Bulletin VI, American Judicature Society, 29.

- Reorganization of the Circuit and Superior Courts of Cook County. 7 Ill. Law Rev., 218, 291.

Leaming, Thomas. A Philadelphia Lawyer in the London Courts. New York, 1911.

Levy, J. H. The Necessity for Criminal Appeal, as illustrated by the Maybrick case. New York, 1902.

MacChesney, N. W. Efficient Administration of Justice. 15 Ill. Law Rev., 14-23, May, 1920.

Mack, Julian W. The Juvenile Court. Address before the Minnesota State Bar Association, 1907. 
Massachusetts Judicature Commission. Second and Final Report, 1921.

Massachusetts Law Quarterly. 1915-.

Moley, Raymond. The Municipal Court of Cleveland. National Municipal Review, vol. 5 , No. 3 .

Münsterburg, Hugo. On the Witness Stand. New York, 1909.

Municipal and Juvenile Courts. See periodical reports of the Municipal, Juvenile, or similar courts of the larger cities, especially Boston, Chicago, Cleveland, New York, and Philadelphia.

National Economic League. Eliot, Charles W., and others. Preliminary report on Efficiency in the Administration of Justice, 1914.

Olson, Harry. Efficiency in the Administration of Criminal Justice. New York State Bar Association. Reports, 1917.

- Municipal Court of Chicago-its Organization and Administration. Cent. L. J., 92: 81-91, February 4, 1921.

Parmelee, Maurice. The Principles of Anthropology and Sociology in their Relations to Criminal Procedure. New York, 1912.

Pound, Roscoe. Administration of Justice in the Modern City. 26 Harvard Law Rev., 302 (1913).

Bibliography of Procedural Reform, Including Organization of Courts. $11 \mathrm{Ill}$. Law Rev., 451 (1917). Reprinted, with a short supplement, in 5 Mass. Law Quar., 332, May, 1920.

Causes of Popular Dissatisfaction with the Administration of Justice. 29 Am. Bar Assn. Reps., 395 (1906).

The Future of the Criminal Law. 21 Columbia Law Rev., 1-16 (January, 1921).

Inherent and Acquired Difficulties in the Administration of Criminal Justice. Proceedings Pol. Science Association, 1907, p. 222.

- Justice According to Law. Columbia Law Rev., vols. 13 and 14, 1913-14.

Law in Books and Law in Action. (Address before the Maryland State Bar Association, July, 1909.)

Limits of Effective Legal Action. (Address before the Pennsylvania Bar Association, June, 1916.)

- Organization of Courts. (Address before the Law Association of Philadelphia, January 31, 1913.) Bulletin VI, American Judicature Society.

Social Problems and the Courts. (Address before the National Conference of Charities and Correction, June, 1912.) 18 Am. Jour. Sociology, 331.

Purcell, Edmund D. Forty Years at the Criminal Bar. London, 1916.

Ransom, W. L. Organization of the Courts for the Better Administration of Justice. 2 Cornell L. Q., 186-201, 261-282.

Reform of the Criminal Law and Procedure. Annals of Am. Acad. of Pol. and Soc. Science, July, 1911.

Riddell, W. R. Administration of Justice. Illinois State Bar Association (1914), 353.

Robinson, Louis N. History and Organization of Criminal Statistics in the United States. Boston, 1911.

Scoville, Samuel, Jr. The Evolution of our Criminal Procedure. Annals of the Am. Acad. of Pol. and Soc. Science, March, 1914.

Selection and Retirement of Judges. Bulletin IVA, American Judicature Society (1915).

Smith, Reginald H. Denial of Justice. A Study of Our Existing Administration of Justice as it Affects Poor Citizens and Immigrants. 3 Journal American Judicature Society, 112-126, December, 1919.

- Justice and the Poor. New York, 1919.

Storey, Moorefield. Reform of Legal Procedure. Yale University Press, 1911.

Thompson, J. J. Machinery of Justice; a Study of Courts. 11 Ill. Law Rev., 406418, January, 1917. 
Train, Arthur. Courts, Criminals and the Camorra. New York, 1912.

The Prisoner at the Bar. Second edition, New York, 1908.

- True Stories of Crime from the District Attorney's Office. New York, 1908.

Whitlock, Brand. Enforcement of Laws in Cities. Indianapolis, 1910.

Wigmore, J. H. Wanted-A Chief Judicial Superintendent. 1 Journal American Judicature Society, 7-9, June, 1917.

Williams, Montagu. Leaves of a Life. 2 vols. London, 1890.

Later Leaves. London, 1891.

Winslow, J. B. Legal Education and Court Reform. 3 Journal American Judicature Society, 69-74, October, 1919.

\section{Penal Treatment}

Abbott, Edwin M. The Indeterminate Sentence, Release on Parole and Pardon. 6 Jour. Crim. Law and Criminology, 73.

American Prison Association, Proceedings of the Annual Congresses. 1874-.

Bacon, Corinne, compiler. Prison Reform. White Plains, N. Y., 1917.

Barrows, Samuel J. The Indeterminate Sentence and the Parole Law. Washington, 1898.

Prison Systems of the United States. Washington, 1900.

Reformatory Systems in the United States. Washington, 1900.

Berkman, Alexander. Prison Memoirs of an Anarchist. New York, 1912.

Boies, Henry M. The Science of Penology. New York, 1901.

Brockway, Zebulon R. Fifty Years of Prison Service. New York, 1912.

The Reformatory System in the United States. 1900.

Butler, A. W. Ten Years of the Indeterminate Sentence. Indianapolis, 1917.

Carpenter, Edward. Prisons, Police, and Punishment. London, 1905.

Cassidy, Michael J. Prisons and Convicts. 1897.

Chicago, Report of the Civil Service Commission. Prison Labor and Management; House of Correction. 1914.

Chute, Charles L. State Supervision of Probation. Albany, 1918.

Conti, Ugo. Comments on the American Prison System. Jour. Crim. Law and Ćriminology, July, 1911.

Cook, A. Our Prison System. London, 1914.

DeLacy, W. T. Treatment of Criminals by Probation. 1906.

Du Cane, Edmund F. The Punishment and Prevention of Crime. London, 1885.

Folks, Homer. Developments of Ten Years in New York's Probation Service. Albany, 1917.

Fornaro, Carlo de. A Modern Purgatory. New York, 1917.

George, W. R. The George Junior Republic: Its History and Ideals. New_York, 1911.

Gordon, Charles. The Old Bailey and Newgate. London, 1902.

Goring, Charles. The English Convict, a Statistical Study. London, 1913.

Griffiths, Arthur. Chronicles of Newgate. 2 vols. London, 1884.

Henderson, Charles R., ed. Correction and Prevention: Four volumes prepared for the eighth international prison congress. New York, 1910.

Henderson, Charles R. Modern Prison Systems. Washington, 1903.

Hopkins, Tighe. Wards of the State. Boston, 1913.

Horsley, J. W. Prisons and Prisoners. New York, 1899.

Illinois-Department of Public Welfare. Rules and Laws controlling the division of Pardons and Paroles. 1919.

Ives, George. A History of Penal Methods. London, 1914. 
Jaffray, Julia K. The Prison and the Prisoner, a Symposium. Boston, 1917. Journal of Delinquency. Whittier State School, Whittier, California, 1916-.

Leeson, Cecil. The Probation System. London, 1914.

Lewis, Burdette G. The Offender. Second edition. New York, 1921.

Lowrie, D. My Life in Prison. New York, 1912.

Martyn, F. A Holiday in Goal. London, 1911.

Massachusetts Commission on Probation. Probation Manual. Boston, 1916.

Miner, Maude E. Probation Work in the Magistrates' Courts of New York City. New York, 1909.

Murphy, Patrick C. Behind Gray Walls. 1920.

Nalder, Frank F. The American State Reformatory. University of California Press, Berkeley, 1920.

National Probation Association. Annual Report and Proceedings of Annual Conference, 1909-.

New York City Department of Correction. Annual reports. By Commissioner Katharine B. Davis.

New York State Probation Commission. Manual for Probation Officers in New York State. Second edition. Albany, 1918.

- Methods of Supervising Persons on Probation. Albany, 1918.

Nitsche, Paul, and Wilmanns, Karl. The History of the Prison Psychoses. New York, 1912.

Oppenheimer, Heinrich. The Rationale of Punishment. London, 1913.

Osborne, T. M. Society and Prisons. New Haven, 1916.

Within Prison Walls. New York, 1914.

Pardon and Parole. See periodical reports of boards in sundry states, e. g., Minnesota and Missouri.

Potts, Charles S. Crime and the Treatment of Criminals. 1910.

Prison Association of New York. Annual Reports.

Prison Labor in Governors' Messages, 1912-13. New York.

Prison Reform, Commission on . . . of the State of New York. Preliminary report. New York, 1914.

Prison Reports. See the periodical reports of the State Prisons or Reformatories in most of the States.

Queen, Stuart A. The Passing of the County Jail. Menasha, Wis., 1920.

Quinton, R. F. The Modern Prison Curriculum. London, 1912.

Saleilles, R. The Individualization of Punishment. Translated from the French by Rachel S. Jastrow. Boston, 1911.

Scott, Wellington. Seventeen Years in the Underworld. Boston, 1916.

Smithers, William W. Executive Clemency in Pennsylvania. Philadelphia, 1909.

Spalding, W. F.; Follett, M.D., et al. The Indeterminate Sentence and the Parole Law. Washington, Government Printing Office, 1899.

State or City Probation Commissions or Bureaus. See their periodical reports in many States, and the reports of the bureaus attached to courts in the larger cities, e. g., the annual reports of the Probation Bureau of the New York City Magistrates' Courts.

Tarde, G. Penal Philosophy. Translated from the French by Rapalje Howell. Boston, 1912.

Taylor, W. L. The Man Behind the Bars. New York, 1914.

United States Census. Prisoners and Delinquents, 1910. Washington, 1913.

United States: Congress: House. Hearings before the Committee on the Probation System for Federal Prisoners, May 13, 1916. Washington, 1916.

- Report of the Committee on the Judiciary on the Probation System in United States Courts. 1917. 
Public Health Service. Correctional Methods and Reformation of Juvenile

Delinquents, by W. L. Treadway. Washington, 1910.

Convict Labor for Road Work by Pennypacker, Fairbank and Draper. Washington, 1916.

Whiteway, A. R. Recent Object Lessons in Penal Science. London, 1898-1902.

Whitin, E. Stagg. Penal Servitude. New York, 1912.

Wines, Frederick H. Punishment and Reformation. New edition by Winthrop D.

Lane. New York, 1919.

\section{General, Medical Relations, and Miscellaneous}

Adam, Hargrave L. The Story of Crime from the Cradle to the Grave. London, 1908.

Addams, Jane. The Spirit of Youth and the City Streets. New York, 1909.

American Institute of Criminal Law and Criminology, Journal. Chicago, 1910-

- Proceedings of the First National Conference on Criminal Law and Criminology. Chicago, 1910.

Anderson, Sir Robert. Criminals and Crime. London, 1907.

Aschaffenburg, Gustav. Crime and Its Repression. Translated from the German by Adalbert Albrecht. Boston, 1913.

Bar, Carl Ludwig von. History of Continental Criminal Law. Translated from the German. Boston, 1916.

Breckinridge, Sophonisba B., and Abbott, Edith. The Delinquent Child and the Home. 1912.

Cook, William G. H. Insanity and Mental Deficiency in Relation to Legal Responsibility. London, 1921.

Culbert, Hugh E. Medical Men and the Law. Philadelphia, 1913.

Currier, Albert H. The Present Day Problem of Crime. Boston, 1912.

Davis, Katharine B., Fernald, Mabel Ruth, and others. A Study of Women Delinquents in New York City. New York, 1920.

Devon, James. The Criminal and the Community. New York, 1912.

Draehms, A. The Criminal. New York, 1900.

Dugdale, Richard L. The Jukes. Fourth edition. New York, 1910.

Ellis, Havelock. The Criminal. Fourth edition. London, 1913.

The Task of Social Hygiene. London, 1913.

Esmein, Adhémar. A History of Continental Criminal Procedure. Translated from the French by John Simpson. Boston, 1913.

Estabrook, Arthur H. The Jukes in 1915. Washington, 1916.

Fenton, Frances. The Influence of Newspaper Presentations upon the Growth of Crime. Thesis. University of Chicago Press, 1911.

Ferrero, Gina Lombroso. Criminal Man According to the Classification of Cesare Lombroso. New York, 1911.

Ferri, Enrico. Criminal Sociology. Translated by Kelly and Lisle. Boston, 1917.

Garofalo, R. Criminology. Translated by Robert W. Miller. Boston, 1914.

Glueck, Bernard. Forensic Psychiatry. Boston, 1916.

Goddard, Henry H. The Criminal Imbecile. New York, 1915.

The Kallikak Family. New York, 1916.

Griffith, Griffith J. Crime and Criminals. Los Angeles, 1910.

Gross, Hans. Criminal Psychology. Translated from fourth German edition by Dr. Horace M. Kallen. Boston, 1911.

Hall, Arthur C. Crime in its Relations to Social Progress. (Columbia University Studies, XV.) New York, 1902. 
Healy, William. The Individual Delinquent. Boston, 1915.

Mental Conflicts and Misconduct. Boston, 1917.

and Fernald, Grace M. Tests for Practical Mental Classification. Princeton, 1911.

Henderson, Charles R. The Cause and Cure of Crime. Chicago, 1914.

—Dependent, Defective and Delinquent Classes. Second edition, Boston, 1901.

Holmes, Thomas. Known to the Police. New York, 1908.

Kellor, Frances A. Experimental Sociology. Delinquents. New York, 1901.

Kennedy, James H., and Day, Wilson M. Bench and Bar of Cleveland. Cleveland, 1889.

Lehman, Frederick W. The Law and the Newspaper. University of Missouri Bulletin, Dèc., 1917.

Lombroso, Cesare. Crime, Its Causes and Remedies. Translated by Rev. Henry P. Horton. Boston, 1912.

McConnell, Ray M. Criminal Responsibility and Social Constraint. New York, 1912.

McDonald, Arthur. Criminology. New York, 1893.

Juvenile Crime and Reformation. Washington, 1903.

Mercier, Charles. Crime and Criminals. London, 1919.

Mitchell, C. Ainsworth. Science and the Criminal. Boston, 1911.

Modern Criminal Science Series. Published under the auspices of the American Institute of Criminal Law and Criminology. 1911-.

Morrison, William D. Crime and Its Causes. London, 1891.

Juvenile Offenders. London, 1896.

Mosby, Thomas S. Causes and Cures of Crime. St. Louis, 1913.

Olson, Harry. Disease and Crime. Chicago, 1916.

Parmelee, Maurice. Criminology. New York, 1918.

- Personality and Conduct. New York, 1918.

Payer, Harry. Articles on Cleveland Justice. Published in the Cleveland Press, February 3-7, 1921.

Pelham, C. The Chronicles of Crime. 2 vols. London, 1891.

Pike, Luke O. A History of Crime in England. 2 vols. London, 1873-76.

Quinton, R. F. Crime and Criminals, 1876-1910. New York, 1910.

Quiros, C. Bernaldo de. Modern Theories of Criminality. Translated from the Spanish. Boston, 1911.

Reed, Alfred Z. Training for the Public Profession of Law. Carnegie Foundation, New York, 1921.

Russell, Charles E. B., and Rigby, L. M. The Making of the Criminal. New York, 1906.

Rylands, Louis G. Crime, Its Causes and Remedy. London, 1889.

Stephen, Sir James F. A History of the Criminal Law of England. 3 vols. London, 1883.

Travis, Thomas. The Young Malefactor. Third edition. New York, 1912. 


\section{INDEX}


$\therefore$ 


\section{INDEX}

Abbey, Robert Parsons, of John Marshall Law School, 499

Abernethy, A. V., secretary of the Bar Association, 268

Abortions, supposed criminal, 473

Acceptances of plea of lesser offensepractice in county court, 180 practice in municipal court, 149 recommendations as to practice, 208 statistics, 95, 140

Addams, Judge George S., of juvenile court, $266,392,393,398,445,446$

Administration of criminal justicepurpose of, 12 standards of, 192

Admission to bar, state requirements for, 489

Adolescence, 449

Advertising Club, 223

Advertising, judges', 269, 271

Age of police appointees, 26

Agencies, child welfare, 450 juvenile behavior, 442

Alburn, Cary R., of John Marshall Law School, 499

Allen, Judge Florence, 266, 303

American Judicature Society, Bulletin IV-A, Chicago, note, 273

Animal Protective League, 223

Appeals, 235

results of in court of appeals, 318 police, 10, 49

to civil service commission by police, 49

Appellate cases-

county prosecutor's work in, 187

municipal prosecutor's work in, with statistics, 139

Appendices-

bibliography, 707

history of survey, 655

intelligence survey of workhouse, 692

Norwood bill, 669

pardons in Ohio, 670

report of intelligence survey of police department, 686

statistical material and methods of the survey, 664
Appendices-

text of Massachusetts medical examiner law, 695

text of New York medical examiner law, 702

Appointees, age of police, 26

Arrests, 241

Assignment commissionercreation of, 315

duties of, 315

Assignments, rank of police not affected by, 11

Associated Charities clearing house, 392, 397

Attorneys, certification for bar examinations, 489

Automobile-

as preventive of crime, 59

police recovery squad, 9

thefts of, 3

use of for patrol, 59

Autopsy, 460, 464, 468

in Massachusetts medical examiner's office, 472

fees, 464

ordered by prosecutor, 465

records, 466

room, 466

Ayres, Leonard P., 393

Babcock, Judge, 266

Baer, Judge George P., 266, 271, 272

on laboratory for mental investigation, 476

Bail bonds-

common pleas court, evils of, 313

enforcement by county prosecutors, 184

enforcement by municipal prosecutors, 154

excessive number of bonds required, 154

forfeitures, 290

municipal court, 290

pending error, 320

recommendations as to enforcement, 212

recommendations as to reduction in number, 212 
Bail bonds-

statistics of enforcement by county prosecutor, 185

statistics of enforcement by municipal prosecutor, 155

Bail bond commissioner, established, 291

Bail jumping, possibilities of, 235

Baker, Newton D., appointment of prosecutors, footnote, 272

Baldwin Wallace Preparatory school, night high school, 504

Baltimore, municipal court, 447

Bar and Bar Association, Cleveland, 229 dislikes criminal practice, 233

duties and opportunities, 219

education, organization and responsibility of, 636

influence in selection of judges, 265

past activities in regard to administration of justice, 216

prestige of criminal law practice, 218

Bar Association v. Sleeper, instance of perjury, 361

Bar examinations-

certification by attorneys, 489

crammers, 505

state requirements, 489

statistics of Ohio compared with

New York and Illinois, 506

Barkley, John C., of John Marshall Law School, 499

Barry, Professor Charles S., Binet tests in Detroit, 394

Baskin, R. A., prosecutor, footnote, 165

Bedford Hills penitentiary, 447

Beebe, Judge William B., 271

Behavior-

cases, 481

criminal, 443

difficulties of interpretation, 443, $452,456,484,485$

juvenile in courts, 445

juvenile in schools, 443

scientific investigation of problems of, 483

Bell, Oscar C., chief municipal prosecutor, 134,145

Bench-

effects of election laws, 254

importance of, 251

personnel of, 251

Bench and Bar of Cleveland, Kennedy and

Day, quoted, footnote, 288

Bench parole-

after new trial granted, 336

loose operation of, 324 use of, 242

Bentham, Jeremy, Rationale of Judicial Evidence, 212

Berkeley, Cal., 20, 72

Bernon, Judge Maurice, 267, 303

Bernstein, Judge A. E., 271
Bibliography, 707

Bicycles, use of by police, 58

Binet, Alfred, tests, 448

Birmingham, England, 17

Bixby, H. D., 394

Blanket nolleby Judge Kennedy, 305, 328 recommendations as to, 329

Blossom, Dudley S., director of public welfare, 423

Board of county commissioners appoint medical examiner, 473

Board of health of Cleveland, 465

Board of promotion for police, recommended, 42

Boldiszar, Frank E., prosecutor in Mazzeo case, 454

Bondsmen, professionalin common pleas court, 313

in municipal court, 287,290

Boston, 20, 22, 41, 44, 53

municipal court of, 447

municipal court, probation staff, footnote, 330

Bounpane, Blase, prosecutor in Mazzeo case, 163

Boylan bill, constitutes Cuyahoga County separate district, 317

Boys' Farm-

commitments to, 407

discipline, 408

history of, 406

intelligence tests, 407

paroles and discharges, 408

recommendations, 409

Boys' School, 403, 442

mental clinic recommended, 406

mental examinations, 404

printing department, 404

recommendations, 405

staff of, 445

woodworking department, 404

Bribery of judges, 260

Brightman, A. C., of Western Reserve University, 492

Budget, preparation of police, 14

Buffalo, crime comparisons with, 3

Bureau of criminal identification, division of police, 238,289

Bureau of information, police, 80

Bureau of Investigation, United States district attorney's office, 191

Bureau of Juvenile Research, Columbus, $398,443,445,419$

Bureau of Municipal Research, 223

Burglary, comparative statistics, 3

Burnett, H. D., of Cleveland Law School, 496

quiz classes, 505

Burns, William J., superintendent of workhouse, 381

Busher, J. J., bail bond commissioner, 291 
Caffey, Francis C., 190

Cahalane, inspector of New York police training school quoted, 27

Callaghan, Mrs. Antoinette, probation officer, 288, 330, 417, 418

Callahan, detective, 69

Campaign funds, solicitation of by judges, 273

Cannon, Austin V., of Western Reserve University, 493

Cantillon, James D., 292

Carter, Kenneth D., of John Marshall Law School, 499

Central bureau of information, recommended, 331

Chamber of commerce, 372 plan of jail building, 431

Chapman, Judge, 266

Chicago-

coalition judicial ticket, footnote, 260

juvenile officers, 79

municipal court of, 447

Chief of detectives, on promotion, 43

Chief of police, 13, 18, 51

authority of, 14

how appointed, 10

leadership of, 7

responsible to mayor, 15

Child welfare agencies, 450

Cincinnati, juvenile court, 391

City chemist, 465

City immigration bureau, 375

City infirmary, Warrensville, 376

Civic League, 372 influence in selection of judges, 265

Civil and criminal administration compared-

place where justice administered, 213

record and filing system, 132

time devoted to trials, 114

Civil service, 10, 22, 34

as source of police recruits, 33

examinations for police, 11

recommendations in prosecutors office, 214

Civil service commission, 32,51

appeals to, 49

police recruiting by, 24

power of review, 15

Civil service examinations, police, 21

Civil service governs promotions of police, 36

Clerk of courtscommon pleas, 314

delay in handling appeal cases, 319

election of, 315

Cleveland. See Community-

Cleveland Law School, 489

equipment, 497

faculty and curriculum, 495
Cleveland Law School, history of, 490

private enterprise of Judge Vickery, 497

requirements for admission, 494

statistics of enrollment, 490

Cleveland recreation survey, 384

Cline, John A., blanket nolle, footnote 329

Clinics-

at Fairview Hospital, 445, 454

behavior observation, 443

diagnostic, 454

public venereal, 454

Clum, Alfred, of Cleveland Law School, 496

Cobb, Frank M., of Western Reserve University, 493

Collister, Judge, 266

Commitments to Boys' Farm, no information with, 395

Common Pleas Court-

clerk's office, 314

election of clerk, 315

geographic jurisdiction of, 231

history of, 297

insanity cases in, 475

jurisdiction of, 86, 231, 297

lack of executive head, 299

laxity in passing cases, 303

personnel, 252, 299

physical surroundings, 297

power to review misdemeanors, 231

professional bondsmen in, 313

recommendations, general, 316

recommendations as to jurisdiction

in misdemeanor cases, 247

salary of judges, 297

suspended sentences, 182

system of records, 314,261

terms of, 298

volume of work, 299

Community, the -

"easy town," 324

general conditions, 222

present facilities for improving administration of justice, 225

recommendations as to improving administration of justice, 225

Concord penitentiary, 347

Consumers' League, 223

Continuances, effect of, 284, 285

Coroner, 461

compensation, 461

cost of, 468

court and jury, 470

crime detection by, 457

deputy coroner, 458

duties of, 458,465

election and tenure, 461

equipment, 466

history of, 458 
Coroner. office of, $466,469,478$

personnel of office, 462

recommendations, 468

records of, 467

relations to police, 463

report of Municipal Association of Cleveland, 457

staff, appointment by county commissioners, 461

Corrigan, assistant prosecutor, note of, 336

Costs, police, comparison with Detroit, 58

Counsel, assigned, policy of, 310

County commissioners appoint staff of coroner, 461

County morgue, 466,469

County prosecutor-

does not participate in early preparation of cases, 138

history of office, 159

methods and practices, 161

physical surroundings of office, 164 salaries, 169

Court, Common Pleas. See Common Pleas Court.

Court, Municipal. See Municipal Court.

Court of appeals-

history of, 317

organization of, 317

power to review misdemeanor jurisdiction of Municipal court, 231

recommendations, 320

speed in handling cases, 318

statistics, 319

Couse, Howard A., of John Marshall Law School, 502

Cousin, Victor, quoted, 192

Cowles, detective, 69

Cox, Governor, 259

Crime-

detection of, 454,464

detection of, by coroner, 457

general problem of, 3,439

preponderance of, in American cities, 3

research, 483

sources of, 443

statistics, 3

treatment of, 443

Crime, prevention of, $8,19,21,55,59,75$, 485,490

education of public, 482

need of, 77

Crime waves, 85, 230, 241 and paroling, 324

Crime and criminals, influence evoked by arrest, 233

Criminal courtsbuilding, proposed, 461 in practice, 233

increasing severity of, 242
Criminal courts

organization of, 231

problem of, 229,628

system inadequate, 229

Criminal identification, 11

Criminal investigation, superintendent of, 11

Criminal jurisdiction-

constitutional provisions, 248

elimination of unnecessary steps, 246

Criminal lawyer-

disposition of cases, 244

professional, 233

Criminal procedure, civic responsibility in, 371

Criminal prosecutions-

chances to escape, 238

simplification of, 346

too complex, 234

Criminality, criminology, and crime, 482

Cull, Judge Dan B., 271, 305

bench parole after new trial granted, 336

letter to American Legion, quoted, 327

Dance Hall inspection bureau, department of police, 77

David, William L., special prosecutor in perjury case, 337

Davis, Governor Harry L., did not sign Norwood bill, 426

Dayton, O., Moraine Park Private School, 406

Defectives, 451, 455

Deibel, Harry L., of Cleveland Law School, 497

Delinquency, $439,480,483$ diagnosis of, 442

Delinquency and Spare Time, by Henry W. Thurston, 389

Demotion, police, 45

Dempsey, Judge John P., appointment of, 268

Denby, Edwin, as head of probation work in Detroit, footnote, 331

Department of education, co-operation with Juvenile Court, 393, 445

Department of health, city, 440, 442, 452

Department of police, organization of, recommendations, 18

Department of psychology and placement in schools, 405

Department of public safety, organization of, 10

Department of public welfare, 375 recommendations, 377

Department of Reference and Research, 393

Dependency, 439

Detective bureau, 16, 55, 64, 
Detective bureau, organization of, 64

personnel, 64

promotion in, 40

recommendations, 71

records, 69

reports, 8

Detective service, 7

Detectives, 25

appointment of, recommendations, 71

intelligence tests, 66

personnel, 66

promotion, recommendations, 73

salaries of, 65

supervision of, 70

Detention home, 400, 442, 445

equipment, 400

personnel, 401

recommendations, 403

Detroit, 22, 57, 59, 61, 77, 81, 394

crime comparisons with, 3

municipal court, 447

police costs, 58

unified court of, 248

use of summons in, 291

Detroit criminal court, weakness of, 309

DeWitt, Clinton, of Western Reserve

University, 493

Direct primary law, 254

Director of police, 18

appointment of detectives, 71

recommendations for tenure, 20

recommendations on promotion, 42 selection of, 21

Director of public safety, 7, 13, 28

appointed by, 10

chief of police responsible to, 15

decision not final, 49

promotions in police department, 36

Director of public welfare-

charter provisions, 375

control over institutions of city, 376

parole power, 422

Discharge for want of prosecution, 235

Discipline, Boys' School, 408

Discipline, police, 14, 52 disciplinary record, 37 recommendations, 53

Diseasetrial board, 53

contagious, 440

mental, 454

venereal, 455

Dismissalpolice, $22,28,45$

Disrespect for law, 357

Division of charities and correction, 375

Doerfler, Samuel, prosecutor, 217

action on assigned counsel, 310

Draft army, 450, 490

Drug addiction, 456
Dry Maintenance League, 223

Dunmore, W. T., of Western Reserve University, 492

Dustin, Virgil A., jury commissioner, 344

Eisenhauer, John A., superintendent of Boys' Farm, 407

Eldredge, Albert C., assistant superintendent of schools, 393

Election laws-

changes of, 253, 254

history of, as to judges, 253

Elections-

of judges, recommendations, 273, 365

religious appeal in, 35

Elmira reformatory, 447

Ence, William H., jury bailiff, 345

England, 3, 20, 31

Epilepsy, 486, 489

Estep, Judge, 267

Ettkin, Louis, case of, footnote, 285

Examinations-

police, 31,36

preliminary in felonies, 445

promotional, for police, 38

Execution docket, principal record of municipal court, 293

Fairview hospital clinic, 453, 464

Federal criminal administration, general results, 188

Feeblemindedness, 441, 446, 451, 476, 482

Felonies-

history of procedure in, 247

preliminary examination in municipal court, 231

Felony arrests, disposition of, 236

Fernald, Dr. Guy, 450

Findley, E. L., report on night high schools, 504

Finfrock, C. M., of Western Reserve University, 492

Fire division, 16

Foran, Judge Martin, parole experience, 327

Ford, Judge, 266, 272

France, 20

Friebolin, Judge Carl D., 266

Funds, police, inadequate, 9

Gafney, Thomas, 345

Girls' Farm, 409

equipment, 409

recommendations, 411

records of, 410

Glasgow, age limit, police, 28 
Glasgow, crime comparisons with, 3

Gorrell bill, approved, 419

Gott, Judge F. B., 266

against unions, footnote, 264

Grand jury, 231, 465, 471

action in felony cases, 231

composition, 175

present function, 91, 175, 210

recommendations as to abolition of, 210

Green, city councilman, 104, 106

Group plan commission, plans for new jail, 432

Hadden, Judge Alexander, 492

Hall, Dean James Parker, 364

Hammond, Dr. A. P., coroner, 462, 468

Harwood, Sergeant, 33

Haserodt, E. B., clerk of courts, 314

Health department, 420

Health survey, Cleveland, 439, 443

Healy, Dr. William, 450

Henry, Peter J., clerk municipal court, 292

Hisey, Ralph T., of the Cleveland Law School, 500

Hopple, E. J., of John Marshall Law School, 502

Hospitals, 442, 445, 454, 476, 479

Howells, Judge George A., 271, 279

liquor law violations, 281

refuses lawyers to defend prostitutes, 287

Hudson Boys' Farm, 392

Huettel case, 523

Huge, Lieutenant, 33

Humane Society, Cleveland, 223, 445

Hupp case, 523, 533

Hydrotherapy, 481

Illinois, 447

Indianapolis, 77

Indigent defendant, representation of, 312

Information bureau, police, 11

Ingersol, Judge Alvin, 317

Inglis, Richard, of Western Reserve University, 493

Inquests, 458, 465, 466

Insanity, 441, 448, 476, 479

Institutions-

correctional, 443

penal, 443

reformatory, 450

Intelligence tests, Boys' Farm, 407

Intervals between stages of casesstatistics, 170

summer accumulation, 172

Intoxication in police force, 48
Jail, city, 377

detention of prisoners, 378

equipment of, 378

recommendations, 380

sanitary conditions, 377

Jail, county, 386, 479, 483

equipment, 387

proposed, 431, 434

recommendations, 388

sanitary conditions, 386

Jalos, L. M., jury bailiff, 349

John Marshall Law School, 489

equipment, 502

faculty and curriculum, 499

history of, 490

requirements for admission, 498

statistics of enrollment, 490

student body, 498

John Marshall night high school, 504

Johnson, Tom I.., 323

Joint committee on judiciary, recommended, 277

Judges-

assignment of Common Pleas, 309

attendance in Court of Common

Pleas, 303

career of municipal, 256

depend on prosecutors in nolles, 328

follow public clamor in imposing sentence and in paroling, 323

legal career of Common Pleas, 255

peculiarities in dispositions of cases of common pleas, 305

probate, 446,477

rotation of, 303

Judiciary, joint committee on, recommended, 277

Juries. See Jury.

Jurors-

occupations of, 349

reasons for failure to qualify, 345

Jury-

general dissatisfaction with, 340

haven of the unemployed, 352

history of, 340

method of selection, 341,344

recommendations, 353

Jury commissioners, 344

Jury system, weaknesses of, 343

Juvenile court, $389,439,444,465,480$

administrative shortcomings, 395

co-operation with department of education, 446

jurisdiction of, 397

mental examinations recommended, 398

personnel, 390

procedure, 396

psychiatrist recommended, 398

recommendations as to budget, 398

recommendations, general, 398

records of, 390 
Juvenile court should not be included in new jail building, 434

work of probation department, 396

Juvenile police officers, recommended, 78

Kaber case, 523, 536

Kansas City, 59

Kaps, Charles L., footnote, 300

Kebort, Andrew, case of, shows evils of parole system, 327

Keeler, Judge, 266

Kennedy, Judge Thomas M., 266, 272, 305

blanket nolle, 305, 328

Kennel, Archie J., assignment commissioner, 315

jury commissioner, 344

Keough, William C., of Western Reserve University, 493

Keough, Judge, 267, 271

Kirkbride, C. T., of John Marshall Law School, 500

Koestle, George-

detective, footnote, 150

superintendent of bureau of criminal identification, 241

Kohler, Fred, "golden rule," 118, 323

Kramer, Judge Samuel E., 266, 271

Kreisberg, prosecutor, 104, 108, 149

Labor, influence of, organized in courts, 264

Labor unions, 372

Laboratories, research, methods of, 448 , 456,483

Larceny, comparative statistics, 3

Law School of Western Reserve University, 489

equipment, 493

faculty and curriculum, 491

faculty salaries, 491

history of, 490

requirements for admission, 491

statistics of enrollment, 490

student body, 491

Law schools, 490

courses offered, 502

faculty, 491, 495, 499

four-year course in night schools recommended, 510

hours of work required, 502

requirements for admission, 491 , 494,498

student body, 491, 494, 498

Lawes, Major Lewis, superintendent of New York City Reformatory, 383

Lawrence, Dean, of John Marshall Law School, 500

Legal aid society, 296

Legal education in Cleveland, conclusions, 506
Leighley, Judge P. L. A., presiding, 272

Leland Stanford University, 450

Levine, Judge Manuel, 266, 271, 475 pleas of guilty, 305

Lewis, Burdette G., The Offender, quoted, 192

Lewis, Tom, chief probation officer, 395, 398

Lind, James, of the Cleveland Law School, 496

Liquor law violationsas treated by Judge Stevens, 281 motion in mitigation in, 285 study of cases, 283

Liverpool, 17, 35 age limits of police, 28 crime comparisons with, 3

Locher, Cyrus, of John Marshall Law School, 500

Logue, James C., of Western Reserve University, 493

London, 22, 35, 77 age limits of police, 28

crime comparisons with, 3 intoxication in police force, 49 promotions, police, 44 selection of police recruits, 31

Los Angeles, 58, 77, 79

Louisville, Ky., 60

Luckey, Dr. Bertha L., director of school psychological clinic, 445, 393

Luthringer v. State, footnote, 317

Lyons case as handled by newspapers 522

as treated by News, 540

Magrath, Dr. George Burgess, 469

Malingering by police, 453,456

Manchester, age limit for police, 28

Marlow, Miss Laura A., superintendent of Detention Home, 401

Marsteller, William Fish, of Cleveland Law School, 496

Massachusetts medical examiner law, 695

Mayor-

appoints chief of police, 10

appoints director of public safety, 10 removal of police chief, 13

McGannon, Judge William H., 271

as executive head of municipal court, 300

in Kagy case, 216, 527

resignation of, 268

McGannon trial, perjury in, 337

MeGiffin, Norton, of John Marshall Law School, 499

Mechanotherapy, 481

Meck, David C., dean of John Marshall Law School, 500

Meck, Dean B., of John Marshall Law School, 500 
Medical advisers, for probation staff, recommended, 367

Medical science, defective utilization by law, 646

Mental clinic, at Boys' School recommended, 406

Mental examinations-

Boys' School, 404

in municipal court, 474

nature of, 448

Mental health, division of, 444

Mental health officers, 455,457

Mental health stations, 442

Metlicka, James, probation officer, 330 , 417,418

Michigan, 447

Miller, Edwin E., of John Marshall Law School, 501

Miller, parole officer, 423

Milwaukee, 20

Misdemeanor jurisdiction, transferred to Common Pleas Court recommended, 247

Misdemeanors, 231

Mitigation of sentencespractice in municipal court, 150 recommendations as to practice, 208 statistics in municipal court, 91, 141

Moraine Park Private School, Dayton, O., 406

Morgan, Judge R. M., defeated by labor, footnote, 264

Morgue, county, 469 equipment of, 466

Motion in mitigationabolition of recommended, 296 evils of, 285

Motions for new trials. See Trials.

Motor equipment for police, $9,58,60$

Motorized patrol, 59

Moylan, Judge David, 271

Munich, 19

Municipal association of Cleveland, report on coroner's office, 457

Municipal Bulletin, quoted on juries, 341

Municipal courtaverage number of days between arrest and disposition, 283

bail bond forfeitures, 290

clerk of, 292

criminal division, 231

decorum in, 279

evils in motion of mitigation, 285

geographic jurisdiction of, 231

importance of, 87

jurisdiction of, 86

methods and practices, 97, 113

no special provision for mental and

physical examinations, 474

origin of, 278

personnel, 252

physical surroundings, 97,278
Municipal court-

police court ring, 286

preliminary examination in felony cases, 231

probation records crude, 417

probation work in, 417

recommendations as to methods and practices, 198

recommendations for segregated docket, 199

recommendations, general, 295

reviewable by Common Pleas Court, 231

reviewable by Court of Appeals, 231

rule 3 , continuances, 282

scant attention to individual cases, 282

separate sessions recommended, 280 shifting cases, 280

suspended sentences, 150

system of records, $286,293,295,393$

unclassified docket, 110

volume of work, 279

Municipal prosecutor-

history of office, 117

hours of work, 156

importance of, 87

jurisdiction of, 86

methods and practices in court, $9 \mathrm{~S}$, 114

not best advisers of courts, 323

physical surroundings of office, 118

preparation of cases, 138

private practice, 156

record of, 119, 132, 137

relation to coroner, 465

salaries, 134

summons, use of, in neighborhood quarrels, 291

Murders, comparative statistics, 3

Murphy, Frank J., clerk civil branch of Common Pleas Court, 300

Neely, Miss May, witness in McGannon case, 337

Neff, Judge William B., 266

New York, 34, 47, 59, 61, 77

training mounted police, 27

voluntary defenders' committee, 368

New York City Reformatory, 383

New York medical examiner law, 702

New York police training school, 27

New York World, 526

News, Cleveland-

Hupp case, 535

Lyons' case, 540

Newspaper reporting-

before trials, 528

during trials, 533

Newspapersactive participation in criminal investigations, 540 
Newspapers-

advertising judges, use of by, 273

as source of public opinion, 517

character of, 524

circulation of, 515

crime waves, 544

equipment, 515

importance of, in administration of justice, 520

interference in criminal cases, 519

law enforcement, 519

recommendations, 527

relation to public officials, 519

Night high schools, statistics of attendance, 504

No billed cases, 235

practice concerning, 95, 179

recommendations as to practice, 207 statistics, 95

No papers, 234

practice in municipal court and municipal prosecutors' office, 143 , 145

recommendations as to practice, 207 statistics in municipal court, 91

Nolan, Frank, case of paroling, 325

Nolle prosequi, 235, 322

faults of, 328

liquor law violations, 284

practice in Common Pleas Court, 180 practice in municipal court, 144 recommend that be in writing, 328 recommendations as to practice, 207

Non-partisan judiciary act, 254

Norris, Dr. Charles, 470

Norwood bill, 669 provisions and criticisms of, 426 repeal urged, 428

Novario, prosecutor, 100, 104, 147

Oberlin, John F., of Western Reserve University, 493

Occupational therapy, 481

Offenders, adult, mental and medical treatment, 447

Ohio indeterminate sentence law, 428

Ohio laws, election of judges, 253

Ohio legislature, 468

Ohio Motorist, footnote, 239

O'Malley, Dr., police surgeon, 452

O'Meara, Commissioner Stephen, 20 quoted, 41

Order number 73, 15

Organization of criminal courts, 231 too complex, 234 recommendations, 366

Pardons, 235, 422 recommendations, 430 report on Ohio, 670 statistics, $\mathbf{4 2 8}$
Paris, age limits, of police, 28

Parks, Sterling, of John Marshall Law School, 501

Parole, 235, 422 bench, $242,324,336$

Boys' Farm, 408

faults of, 326

system inadequate, 423

treatment by newspapers, 548

Pathology, mental, 452, 469

Patrol-

beats, determination of, 56

booths, 61

force, turnover, 28

history of, 55

methods of, 59

patrol service, 63

problems of, 55

Pearce, Judge Berkeley, 271

Pearson, Judge Alvin J., 266, 305

Penal and correctional treatment, difficulties of, 643

Pensions-

police, 28

police surgeon, 453

Perjury, 337

laxness in punishing, 338

recommendations, 339

Personnel-

and politics in courts, 362

changes due to election laws in bench, 254

Common Pleas Court, effect of rotation of judges, 304

conducting criminal procedure, 234

coroner's office, 462

county prosecutor's office, 165

municipal prosecutor's office, 132

of bench, 251

of courts, general summary, 356 362,364

police, distribution by types of work, 11

police, selection and training, 24

police department, 7, 12, 19, 58

police turnover, 28

woman's probation department, 418

Phillips, Judge F. C., 266, 272, 305

Phillips, Judge G. L., 267

Physical conditions-

county prosecutor's office, 164

municipal court, 97

municipal prosecutor's office, 118

recommendations as to place where

criminal justice administered, 213

Physicians, district, 452, 454, 465, 477

Pickell, Frank G., assistant superintendent of schools, 393,403

Plain Dealer, Clevelandletter of Judge Cull, 327

Lyons' case, 541

Sly-Fanner case, 528, 531 
Pleas of guilty of lesser offense, 322

Police blotter, 288

Police court. See Municipal Court.

"Police court," means of advertising by judges, 271

"Police court ring," 286

Police-

administration, 454

appointments, $22,28,31$

army alpha test, 67,686

chief of, 486

crime detection by, 452

discipline of, 14

distribution of personnel by types of work, 11

equipment of, $8,12,13$

increase in numbers, 58

intelligence survey, 686

malingering, 453, 456

motor equipment for, 60

number needed, 57

occupations of police recruits, 24

organization of, $6,10,20$

personnel,selection and training of, 24

problem of, 615

promotions, 14

recommendations as to police surgeon and mental health officer, 457

relation to coroner, 463

seniority, 37

sources of, $7,24,33$

special service division, 75

suspension, $10,45,48$

traffic, 11,40

turnover, 28

Police department-

bureau of criminal identification, 238,289

history of, 6

organization.of, 6

present conditions, 6

secretarial division, 81

statistics of, 6

vice bureau, 8,40

welfare officers, unit of, recommended, 78

Police headquarters, proposed, 431

Police record of four major crimes, Detroit court, 249

Police training school, 34

Police women, 77

Politicians, importance of, in relations to courts, 261

Politics, 19

Powell, Judge Homer G., 266, 272

bench parole after new trial granted, 336

handling of McGannon case, 338

Precinct stations-

distribution of, 62

history of, 62
Precinct stations-

recommendations, 63

reports, 8

Preparation of cases-

absence of, in early stages of case, 79,162

county prosecutor's office, 169,175

county prosecutor does not participate in early stages, 138

detection and investigation by municipal prosecutor, 138

municipal prosecutor's office, 138

recommendations as to methods, 208,210

Press, Cleveland, 1, 259, 262

on parole, 548

Purpera case, 529, 532

Raleigh case, 212

Prestige of criminal law practice-

how to improve it, 220

importance of criminal practice, 193

The Cleveland Bar, 134, 218

Prevention of crime. See Crime Prevention.

Printing department, Boys' School; 404

Prison, prisoners, 447, 453, 455, 482

Probate court, no medical experts attached to, 476

Probate court, recommendations for chief psychiatrist, 479

Probation, 460, 464, 478, 412

crude records in municipal court, 417

Gorrell Bill, 419

in municipal court, 417

juvenile, 396

medical advisers, recommended, 367 statistics, 413

volume of, in state, 412

Probation department, adequate, recommended, 329, 330

Probation staff, adequate, recommended, 367

Promotion, police, 10, 36

by director of public safety, 36 recommendations, 42

Prosecution, problem of, 621

Prosecutors. See County and Municipal Prosecutors.

Prostitutes, police court ring, 287

Psychiatrist -

for Juvenile Court, 399

none on staff of courts, 445

recommendations for, 479

Psychiatry, 446, 451, 457, 479

Psychologist, appointment recommended, 479

Psychoneuroses, 483

Psychotherapy, 481

Public defenderrecommended, 368

skepticism as to, 635

Public safety, director of, 7 
Public safety, department of, 9, 16

Publicity and self-advertisement of judges, 268, 273

Punishment as crime preventive, 481

Purpera case, 523, 524 newspaper story, 529

Raleigh, Tim, case of, 262

Rawson, L. Q., of Cleveland Law School, 496

Recidivists, 233

Recommendationsapplicants for admission to bar, 509 blanket nolles, 329

Boys' Farm, 409

Boys' School, 405

chief psychiatrist for probate court, 479

city jail, 380

committee appointed by bar to examine moral fitness of candidates for bar, 510

Common Pleas Court, 316

completion of four years high school before admission to law school, 510

coroner's office, 468

county jail, 388

court of appeals, 320

department of public welfare, 377

detention home, 403

election of judges, 273

four-year course in night law schools, 510

Girls' Farm, 411

juries, 353

juvenile behavior in schools, 505

juvenile court, 398

legal education in Cleveland, 506

mental and physical examinations, 446

mental health officer, 448

motions for new trial, 336

municipal court, 295

no certificate of an attorney be accepted by bar examiners, 509

organization of night law school without profit, 508

pardons and paroles, 430

patrol service, 63

placing misdemeanor jurisdiction in common pleas court, 247

police discipline, 53

police promotions, 42

police records, 82

probation, 420

proposed jail plans, 434

public safety, 16

rigid inquiry into moral character of applicants for admission to bar, 509
Recommendations-

selection of judges, 276

to raise standard set by bar examiners, 507

workhouse, 385

Record bureau, police, 11

Records-

autopsy, 466

Common Pleas Court, system of, 314

coroners, 467

county offices, 164

court, inadequate, 261

detective bureau, 69

Girls' Farm, 401

municipal court, antiquated system, 286, 292, 393

municipal court, importance of, 295

municipal prosecutor's office, 119, 132,137

no papers and nolles in municipal prosecutor's office, 145,149

nolles and acceptance of lesser pleas in county prosecutor's office, 181 nolles, 123,207

police, $8,12,81$

police disciplinary, 47

police surgeon, 453

probation in municipal court, 417

recommendations, 204, 446

sifting of cases in municipal prosecutor's office, 121, 205

Recruiting -

detectives, 71

police force, 24

Religious appeal in elections, 263

Reserve squadrons, 59

Resignations, police department, 28

Retail Merchants' Board, 223

Robbery, comparative statistics, 3

Robinson, Gibson H., 345

Rogues gallery, 289

Roosevelt, Theodore, autobiography, quoted, 42

Rosenberg, prosecutor, 106

Rowley, Arthur E., of Cleveland Law School, 497

Ruhl, James B., of John Marshall Law School, 501

Runner, police court, 287

Russick, prosecutor, 101, 104

St. Louis, 59, 77, 81 crime comparisons with, 3 size of police department, 58

Safety Council, 223

Salariescause of police turnover, 30 county prosecutor's office, 169 municipal prosecutor's office, 134 recommendations as to prosecutors, 314 
Salmon, Dr. T. W., 443

Samman, M. L., prosecutor, 147

San Francisco, 5

Sanders, Judge Fielder, 267, 271

Sanity, 452, 479

Sawicki, Judge Joseph, 271

School psychological clinic, 393

Schultz, John H., of John Marshall Law School, 502

Schwan, Judge, 266

Scotland, 3, 20

Seattle, 59

Secretarial division, police department, 55,81

organization of, 81

personnel, 81

recommendations, 82

Selzer, Judge Charles L., 271

has witness chair removed, 280

Seniority, police, 37

Sentences, severity of, 242

Shell shock, 481

Shelton case, 523

Sheriff, duties in case of sudden death, 466

Siddal, K. T., of John Marshall Law School, 501

Signal system, 9

Silbert, Judge Samuel, of Cleveland Law School, 497

and Raleigh case, 262

Simon, Dr. Theodore, test, 448

Sing Sing prison, 447

Sly-Fanner case, newspaper report of, 528

Smith, Chief Frank W., 12, 34

Special service division, police, 75

Spinello, Rosario, number 9211 in Court of Appeals, 319

Stanton, E. C., as city prosecutor, 119, 181

State department of public welfare, 419

Stevens, Judge F. E., 266, 305

bench parole after new trial granted, 336

Stevens, Judge F. L., 279

handling liquor law violations, 281, 524

Strimple, Judge, 266

Stuttgart, 19

Subnormality, determination of, 449

Sullivan, John J., president of Bar Association, 268

Summons-

absence of use in criminal cases, 118, 202

recommendations as to use of, 118 , 202

use of, by prosecutor in neighborhood quarrels, 291

Surgeon, police, 11

Suspects, examination of, 453
Suspended sentence, 235, 322

and criminal political lawyer, 245

classified by counsel, 212

faults of, 328

practice in Common Pleas Court, 182

practice in Municipal Court, 150

recommendations, 208

Suspension, police, $10,45,48$

Switzerland, 20

Taylor and Boggis Foundry v. Iron Molders' Union, 264

Terrell, Judge Virgil J., 271

Thiesen, Dr. W. W., director of school department of reference and research, 393

Thomas, Warden, Ohio penitentiary, 425

Throckmorton, A. H., of Western Reserve University, 492

Thurston, Henry W., Delinquency and Spare Time, 389

Toledo, crime in, 4

Tracy, Edward H., of John Marshall Law School, 502

Traffic-

division of police, 11,40

regulation of, 7,11

Train, Arthur C., The Prisoner at the Bar, quoted, 199

Training of personnel, police department, 24,27

Training school, police, 34

as personnel service division, 35

Travelers' Aid Society, 77

Trial board, recommendations, 53

Trials, new, 235

frequency of motion for, 332

motions for, 332

recommendations, 336 results of, 333

Trials, police, $10,14,47$

Turnover in patrol force, 28 causes of, 30

\section{Undertakers, 463}

Unified court, recommended, 366

Uniformed patrol force, 11, 55

United States Army Alpha tests, 66

University of Michigan, 394

Vagrancy, significance of, 456

Veterinary, surgeon, police department, 11

Vice bureau-

crime prevention, 75

reports, $8,40,79$

Vice cases, 454

Vice squad, 11, 25

Vickery, Judge Willis, dean of Cleveland Law School, 236, 317, 495 
Vickery, Melville W., of Cleveland Law School, 496 quiz class, 505

Vollmer, August, quoted, 77

Voluntary defender, recommended, 312, 316

Wales, 3

Walters, Miss Claire E., psychologist, 445,393 gives mental examinations at Boys' School, 404

Washburn, Judge, 317

Welfare Federation, 79, 445 child welfare bureau recommended, 397

Welfare officers, unit of, recommended, 78

Westchester County, N. Y., penitentiary and workhouse, plan of, 433

Western Reserve University Medical School, 420

Whipple, Professor, 459

White Plains, N. Y., 433

Wilcox, Miss Marion, 390

Women police, 25

Women's Association for Justice, 223
Women's bureau, police department, 77

Women's probation department, 288, 417 personnel, 418

Women's Protective Association, 77, 223, 454 work of, 418

Woods, Arthur, quoted, 34, 45, 47, 78

Woods, J. W., of John Marshall Law School, 501

Woodworking department of Boys' School, 404 workhouse, 383

Workhouse, Warrensville, 380, 483, 495 administration of, 381 broom shop, 383 equipment, 380 escapes from, 384 intelligence survey, 692 no punishment records, 382 personnel, 381 reception of prisoners, 382 recommendations, 385 releases, 424 woodworking plant, 383

Yerkes, Professor Robert M., 450 
UNIVERSITY OF CALIFORNIA LIBRARY Los Angeles

This book is DUE on the last date stamped below.

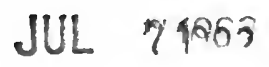

41585 


\section{PUBLICATIONS OF THE CLEVELAND FOUNDATION}

\section{CRIMINAL JUSTICE IN CLEVELAND}

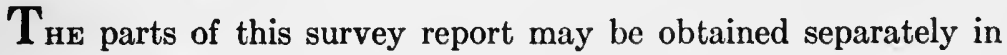
paper covers at the following prices:

Police Administration, by Raymond B. Fosdick. $\$ 1$.

Prosecution, by Alfred Bettman and Howard F. Burns. $\$ 1$.

The Criminal Courts, by Reginald Heber Smith and Herbert B. Ehrmann. \$1. Correctional and Penal Treatment, by Burdette G. Lewis. 50 cents.

Medical Science and Criminal Justice, by Dr. Herman M. Adler. 50 cents. Legal Education in Cleveland, by Albert M. Kales. 25 cents.

Criminal Justice in the American City, by Roscoe Pound. $\$ 1$.

In ordering, give the names of the separates desired, not the part numbers.

\section{THE RECREATION SURVEY}

A study of the causes and effects of the spare-time activities of Cleveland, made under the general direction of Rowland Haynes, formerly director of the New York Community Service, now director of the Welfare Federation of Cleveland. Published in separate volumes.

Delinquency and Spare Time, by Henry W. Thurston.

A study of typical cases of juvenile delinquency which show the relation between spare-time activities and a gradual drifting into delinquency.

School Work and Spare Time, by J. G. Bonser.

School progress depends upon interests better revealed by a child's sparetime activities than by any other influence either inside or outside the home.

Wholesome Citizens and Spare Time, by J. L. Gillin.

The volume shows the factors which formed wholesome recreation habits in childhood.

The Sphere of Private Agencies, by L. E. Bowman and others.

A study of the sphere of usefulness of those agencies in the field or recreation which are supported by private funds, such as churches, clubs, etc.

Commercial Recreation, by Charlotte Rumbold and Raymond Moley. A study of Cleveland's profit-making recreational enterprises, the motion picture theater, the dance hall, etc., with recommendations for licensing and control.

Public Provision for Recreation, by Rowland Haynes and S. P. Davies. Recreation supported by public funds is essentially large scale recreation, whose greatest requirement is adequate and well-trained leadership.

A Community Recreation Program, by Rowland Haynes and C. K. Matson. A community recreation program for Cleveland for today and tomorrow.

Bound in cloth at 50 cents per volume, $\$ 3.50$ for the set 


\section{THE EDUCATION SURVEY}

A study of the public schools of Cleveland, made under the general direction of Col. Leonard P. Ayres, formerly director, division of education, Russell Sage Foundation. Published in separate volumes.

Child Accounting in the Public Schools, by Leonard P. Ayres. 35 cents.

Educational Extension, by Clarence Arthur Perry. 35 cents.

Education through Recreation, by George E. Johnson. 35 cents.

Financing the Public Schools, by Earle Clark. 35 cents.

Health Work in the Public Schools, by Leonard P. Ayres and May Ayres. 35 cents.

Household Arts and School Lunches, by Alice C. Boughton. 35 cents.

Measuring the Work of the Public Schools, by Charles Hubbard Judd. 75 cents.

Overcrowded Schools and the Platoon Plan, by Shattuck O. Hartwell. 35 cents.

School Buildings and Equipment, by Leonard P. Ayres and May Ayres. 35 cents.

Schools and Classes for Exceptional Children, by David Mitchell. 35 cents. School Organization and Administration, by Leonard P. Ayres. 35 cents.

The Public Library and the Public Schools, by Leonard P. Ayres and Adele McKinnie. 35 cents.

The School and the Immigrant, by Herbert Adolphus Miller. 35 cents.

The Teaching Staff, by Walter A. Jessup. 35 cents.

What the Schools Teach and Might Teach, by Franklin Bobbitt. 35 cents.

The Cleveland School Survey (summary volume), by Leonard P. Ayres. 75 cents.

Boys and Girls in Commercial Work, by Bertha M. Stevens. 35 cents.

Department Store Occupations, by Iris Prouty O'Leary. 35 cents.

Dressmaking and Millinery, by Edna Bryner. 35 cents.

Railroad and Street Transportation, by Ralph D. Flemming. 35 cents.

The Building Trades, by Frank L. Shaw. 35 cents.

The Garment Trades, by Edna Bryner. 35 cents.

The Metal Trades, by R. R. Lutz. 35 cents.

The Printing Trades, by Frank L. Shaw. 35 cents.

Wage Earning and Education (summary volume), by R. R. Lutz. 75 cents.

The Cleveland Yearbooks - civic histories published annually beginning with 1921. Cloth, $\$ 1.00$.

Directory of Community Activities, guide book to social and civic agencies of Cleveland. Cloth, $\$ 1.00$.

\section{THE CLEVELAND FOUNDATION}

1202 Swethand Building

Cleveland, Ohio 


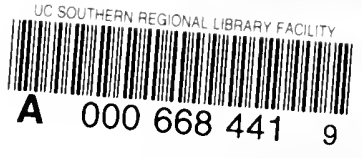


